\title{
Waste Isolation Pilot Plant Annual Site Environmental Report for 2006
}

September 2007

United States Department of Energy

Carlsbad Field Office

Carlsbad, New Mexico

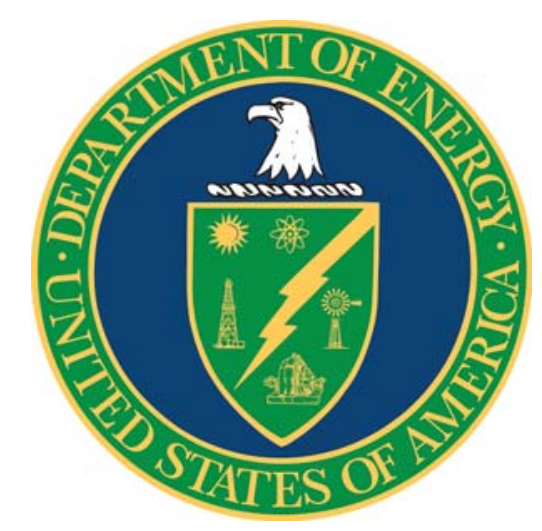



This document has been submitted as required to:

Office of Scientific and Technical Information

P.O. Box 62

Oak Ridge, TN 37831

Prices available from (865) 576-1188

Additional information about this document may be obtained by calling (800) 336-9477. Copies may be obtained by contacting the National Technical Information Service, U.S. Department of Commerce, 5285 Port Royal Road, Springfield, VA 22161

Processing and final preparation of this report was performed by the Waste Isolation Pilot Plant Management and Operating Contractor for the U.S. Department of Energy under Contract No. DE-AC29-01AL66444. 
Waste Isolation Pilot Plant Annual Site Environmental Report for 2006

DOE/WIPP-07-2225

This page intentionally left blank 


\section{TABLE OF CONTENTS}

EXECUTIVE SUMMARY $\ldots \ldots \ldots \ldots \ldots \ldots \ldots \ldots \ldots \ldots \ldots \ldots \ldots \ldots$

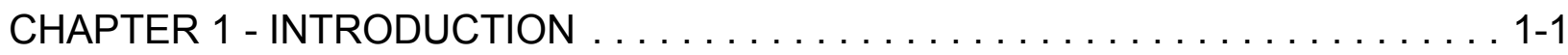

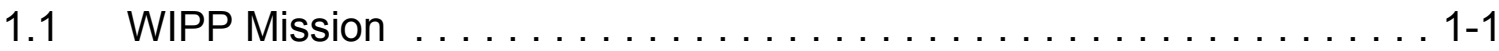

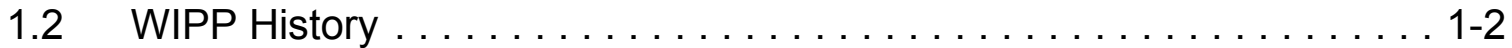

1.3 Site Description . . . . . . . . . . . . . . . . . . . . . 1-3

1.3.1 WIPP Property Areas . . . . . . . . . . . . .

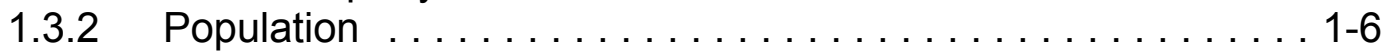

1.4 WIPP Environmental Stewardship . . . . . . . . . . . . . . . 1-6

1.4.1 Environmental Monitoring Plan . . . . . . . . . . . 1-6

1.4.2 WIPP Environmental Monitoring Program and Surveillance

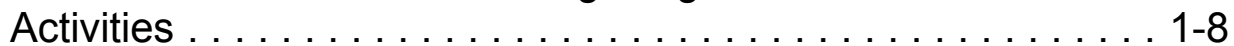

1.5 Environmental Performance . . . . . . . . . . . . . . . . . . 1-8

1.6 Organization of This Annual Site Environmental Report . . . . . . . . 1-9

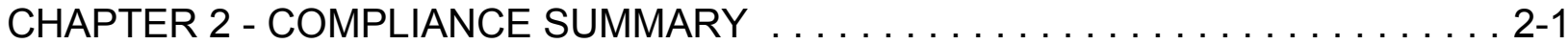

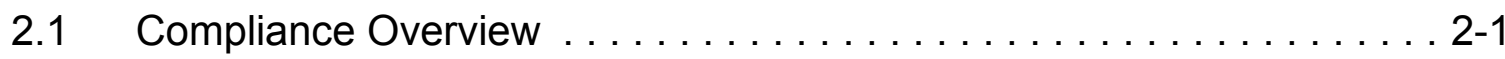

2.2 Compliance Status . . . . . . . . . . . . . . .

2.2.1 Comprehensive Environmental Response, Compensation, and Liability Act . . . . . . . . . . . . . . . . . 2-1

2.2.2 Resource Conservation and Recovery Act . . . . . . . . . 2-2

2.2.3 National Environmental Policy Act . . . . . . . . . . . . 2-6

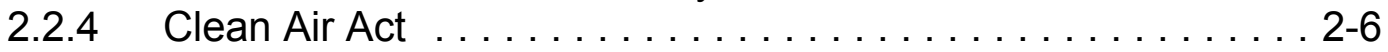

2.2 .5 Clean Water Act . . . . . . . . . . . . . . . . . . 2-7

2.2.6 New Mexico Water Quality Act $\ldots \ldots \ldots \ldots \ldots \ldots \ldots \ldots .2-7$

2.2.7 Safe Drinking Water Act . . . . . . . . . . . . . . . 2-9

2.2.8 National Historic Preservation Act . . . . . . . . . . . . 2-9

2.2 .9 Toxic Substances Control Act . . . . . . . . . . . . . . 2-9

2.2.10 Federal Insecticide, Fungicide, and Rodenticide Act . . . . . 2 2-10

2.2.11 Endangered Species Act . . . . . . . . . . . . . . 2-10

2.2.12 Migratory Bird Treaty Act $\ldots \ldots \ldots \ldots \ldots \ldots \ldots \ldots .2-11$

2.2.13 Federal Land Policy and Management Act . . . . . . . . 2-11

2.2.14 Federal Facilities Compliance Act . . . . . . . . . . . . 2-12

2.2.15 Atomic Energy Act . . . . . . . . . . . . . . . . . . . 2 2-12

2.2.16 DOE Orders . . . . . . . . . . . . . . . . . . 2-15

2.2.17 Executive Orders ...................... 2-17

2.3 Other Significant Accomplishments and Ongoing Compliance Activities

CHAPTER 3 - ENVIRONMENTAL MANAGEMENT SYSTEM $\ldots \ldots \ldots \ldots \ldots \ldots$ 3-1

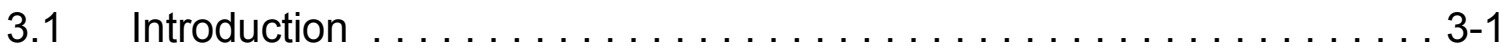

3.2 WIPP EMS Elements $\ldots \ldots \ldots \ldots \ldots \ldots \ldots \ldots \ldots \ldots \ldots \ldots .1$

3.2.1 Policy . . . . . . . . . . . . . . .

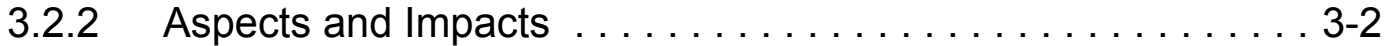

3.2.3 Legal and other Requirements . . . . . . . . . . . . 3-3 
3.2.4 Objectives and Targets $\ldots \ldots \ldots \ldots \ldots \ldots \ldots \ldots \ldots .3$

3.2.5 Environmental Management Program $\ldots \ldots \ldots \ldots \ldots \ldots .4$

3.2.6 Structure and Responsibility . . . . . . . . . . . . . 3-5

3.2.7 Training, Awareness, and Competency . . . . . . . . . 3-5

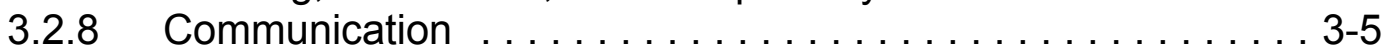

3.2 .9 EMS Documentation $\ldots \ldots \ldots \ldots \ldots \ldots \ldots \ldots \ldots . .6 \ldots$

3.2.10 Document Control and Records . . . . . . . . . . . . 3-6

3.2.11 Operating Control . . . . . . . . . . . . . . . . . . 3-6

3.2.12 Emergency Preparedness and Response ........... 3-7

3.2.13 Measuring and Monitoring (Environmental Performance Measurement) . . . . . . . . . . . . . . . . . . .

3.2.14 Corrective and Preventive Action . . . . . . . . . . . . . 3-13

3.2 .15 EMS Audit . . . . . . . . . . . . . . . . . . 3-13

3.2.16 Management Review ................... 3-14

3.2.17 Status of EMS Implementation $\ldots \ldots \ldots \ldots \ldots \ldots \ldots$ 3-15

CHAPTER 4 - ENVIRONMENTAL RADIOLOGICAL PROGRAM INFORMATION . 4-1

$4.1 \quad$ Effluent Monitoring $\ldots \ldots \ldots \ldots \ldots \ldots \ldots \ldots \ldots \ldots \ldots \ldots \ldots \ldots$

4.1.1 Sample Collection . . . . . . . . . . . . . . . . 4-4

4.1.2 Sample Preparation . . . . . . . . . . . . . . . . 4-5

4.1.3 Determination of Individual Radionuclides . . . . . . . . 4 4-5

4.1.4 Results and Discussion . . . . . . . . . . . . . . . . 4-5

4.2 Airborne Particulates . . . . . . . . . . . . . . . . . . . . . . . . . 4-7

4.2.1 Sample Collection . . . . . . . . . . . . . . . 4-7

4.2.2 Sample Preparation . . . . . . . . . . . . . . . . 4

4.2.3 Determination of Individual Radionuclides . . . . . . . . . 4-9

4.2.4 Results and Discussion . . . . . . . . . . . . . . . . . 4-9

4.3 Groundwater . . . . . . . . . . . . . . . . . . . . . . . 4-10

4.3.1 Sample Collection . . . . . . . . . . . . . . 4-10

4.3.2 Sample Preparation . . . . . . . . . . . . . . . 4-11

4.3.3 Determination of Individual Radionuclides . . . . . . . . . . 4-11

4.3.4 Results and Discussion . . . . . . . . . . . . . . . . 4-11

4.4 Surface Water . . . . . . . . . . . . . . . . . . . . 4-15

4.4.1 Sample Collection . . . . . . . . . . . . . . 4-15

4.4.2 Sample Preparation . . . . . . . . . . . . . . . 4-16

4.4.3 Determination of Individual Radionuclides . . . . . . . . . . 4-16

4.4.4 Results and Discussion . . . . . . . . . . . . . . . 4-17

4.5 Sediments . . . . . . . . . . . . . . . . . . . . . . 4-20

4.5.1 Sample Collection $\ldots \ldots \ldots \ldots \ldots \ldots \ldots \ldots \ldots \ldots .4 .20$

4.5.2 Sample Preparation . . . . . . . . . . . . . . . 4-20

4.5.3 Determination of Individual Radionuclides . . . . . . . . . 4-20

4.5.4 Results and Discussion . . . . . . . . . . . . . . . 4-21

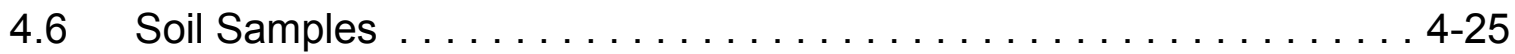

4.6.1 Sample Collection . . . . . . . . . . . . . . 4-25

4.6.2 Sample Preparation . . . . . . . . . . . . . . . . 46

4.6.3 Determination of Individual Radionuclides . . . . . . . . . 4-26

4.6.4 Results and Discussion . . . . . . . . . . . . . . . . 4-27 
$4.7 \quad$ Biota $\ldots \ldots \ldots \ldots \ldots \ldots \ldots \ldots \ldots \ldots \ldots \ldots \ldots \ldots \ldots .4 .31$

4.7.1 Sample Collection . . . . . . . . . . . . . . 4-31

4.7.2 Sample Preparation ...................... 4-31

4.7.3 Results and Discussion ................... 4-32

4.8 Potential Dose from WIPP Operations $\ldots \ldots \ldots \ldots \ldots \ldots \ldots \ldots 4-35$

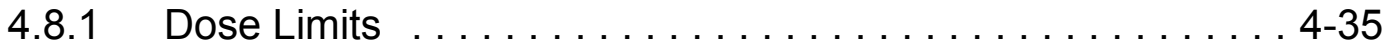

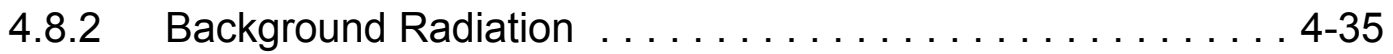

4.8.3 Dose from Air Emissions . . . . . . . . . . . . . . . 4-36

4.8.4 Total Potential Dose from WIPP Operations . . . . . . . . 4 4-37

4.8.5 Dose to Nonhuman Biota . . . . . . . . . . . . . . . . . . . . 4-39

4.8.6 Release of Property Containing Residual Radioactive Material . . . . . . . . . . . . . . . . . . . . . . . 4-41

4.9 Radiological Program Conclusions . . . . . . . . . . . . . . 4-41

CHAPTER 5 - ENVIRONMENTAL NONRADIOLOGICAL PROGRAM

INFORMATION ........................ 5-1

5.1 Principal Functions of Nonradiological Sampling . . . . . . . . . 5-1

5.2 Land Management Programs . . . . . . . . . . . . . . . . . 5-1

$5.2 .1 \quad$ Land Use Requests . . . . . . . . . . . . . . . . .

5.2.2 Wildlife Population Monitoring $\ldots \ldots \ldots \ldots \ldots \ldots \ldots \ldots .5-2$

5.2 .3 Reclamation of Disturbed Lands . . . . . . . . . . . . 5-2

5.2 .4 Oil and Gas Surveillance . . . . . . . . . . . . . . . . 5-3

5.3 Meteorological Monitoring . . . . . . . . . . . . . . . . 5-3

$5.3 .1 \quad$ Climatic Data . . . . . . . . . . . . . . . . . . . 5-4

5.3.2 Wind Direction and Wind Speed $\ldots \ldots \ldots \ldots \ldots \ldots \ldots .5-7$

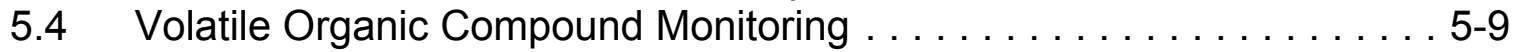

5.5 Seismic Activity . . . . . . . . . . . . . . . . . . . . 5-12

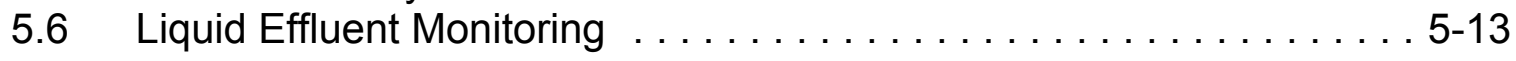

CHAPTER 6 - SITE HYDROLOGY, GROUNDWATER MONITORING, AND

PUBLIC DRINKING WATER PROTECTION . . . . . . . . . . 6-1

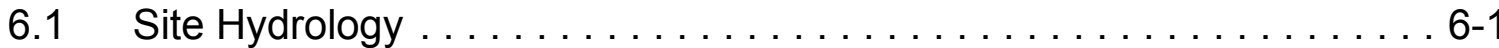

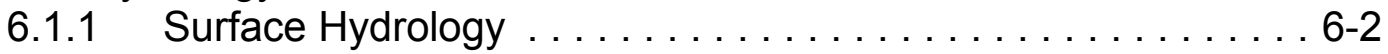

6.1 .2 Subsurface Hydrology $\ldots \ldots \ldots \ldots \ldots \ldots \ldots \ldots \ldots .6 .2$

6.2 Groundwater Monitoring $\ldots \ldots \ldots \ldots \ldots \ldots \ldots \ldots \ldots \ldots \ldots 6.5$

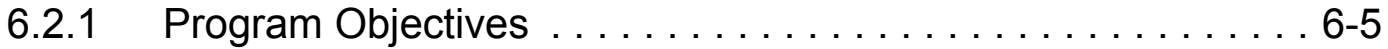

6.2.2 Summary of 2006 Activities . . . . . . . . . . . . . 6-5

6.2.3 Groundwater Quality Sampling $\ldots \ldots \ldots \ldots \ldots \ldots \ldots 6.7$

6.2.4 Evaluation of Groundwater Quality $\ldots \ldots \ldots \ldots \ldots \ldots .6 .10$

6.2.5 Groundwater Level Surveillance . . . . . . . . . . . . 6-11

6.2.6 Pressure Density Surveys . . . . . . . . . . . . . 6-23

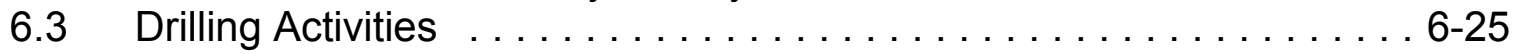

6.4 Hydraulic Testing and Other Water Quality Sampling . . . . . . . . 6-26

6.5 Well Maintenance .......................... 6-26 
6.6 Shallow Subsurface Water Monitoring Program . . . . . . . . . 6-29

6.6.1 Shallow Subsurface Water Quality Sampling . . . . . . . . . 6-32

6.6.2 Shallow Subsurface Water Level Surveillance . . . . . . . . . . 6-32

6.7 Public Drinking Water Protection . . . . . . . . . . . . . . . . . . . . 6-34

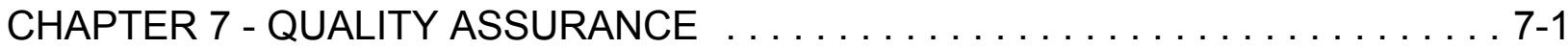

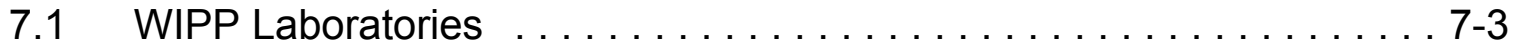

7.1.1 Completeness . . . . . . . . . . . . . . . . . . 7-3

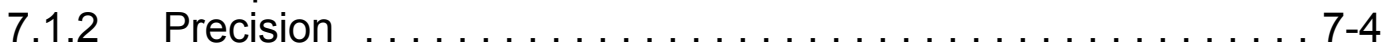

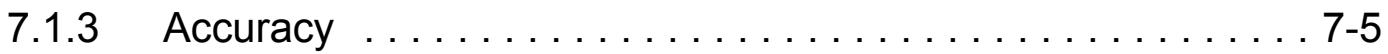

7.1 .4 Comparability . . . . . . . . . . . . .

7.1.5 Representativeness . . . . . . . . . . . . . . . . . 7-6

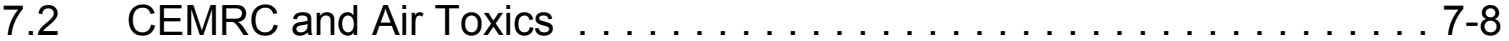

7.2.1 Completeness . . . . . . . . . . . . . . . . . 7-8

7.2.2 Precision . . . . . . . . . . . . . . . . . . . . . 7-8

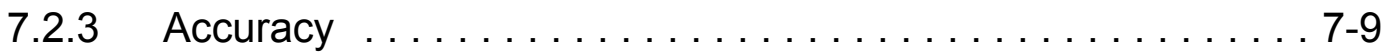

7.2 .4 Comparability . . . . . . . . . . . . . . . . . . . 7-10

7.2.5 Representativeness . . . . . . . . . . . . . . . . 7-10

7.3 TraceAnalysis, Inc. . . . . . . . . . . . . . . . . . . . 7-10

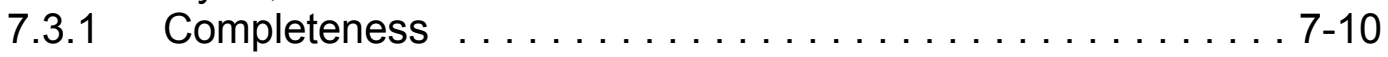

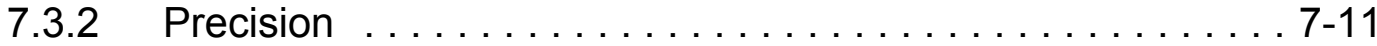

7.3.3 Accuracy .......................... 7.11

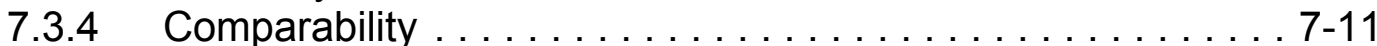

7.3.5 Representativeness . . . . . . . . . . . . . . 7-11

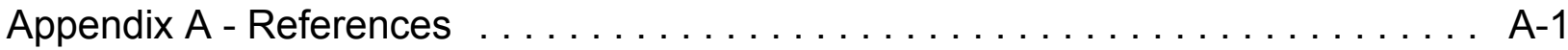

Appendix B - Active Environmental Permits $\ldots \ldots \ldots \ldots \ldots \ldots \ldots \ldots$ B-1

Appendix C - Location Codes ......................... C-1

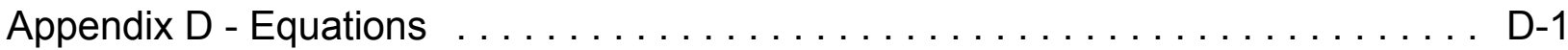

Appendix E - Time Trend Plots for Detectable Constituents in Groundwater ..... E-1

Appendix F - Groundwater Data Tables $\ldots \ldots \ldots \ldots \ldots \ldots \ldots \ldots \ldots \ldots$ F-1

Appendix G - Air Sampling Data: Concentrations of Radionuclides . . . . . . . . . G-1

Appendix $\mathrm{H}$ - Comparison of Detected Radionuclides to the Radiological Baseline . $\mathrm{H}-1$ 


\section{LIST OF TABLES}

Table 1 DOE EMS Implementation Indicator Status $\ldots \ldots \ldots \ldots \ldots \ldots$ xix

Table $1.1 \quad$ Environmental Monitoring Sampling $\ldots \ldots \ldots \ldots \ldots \ldots \ldots \ldots \ldots$

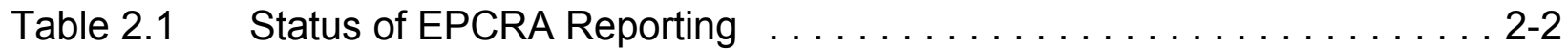

Table 2.2 Permit Modification Notifications Submitted in $2006 \ldots . . . \ldots$. . . . . 2-4

Table 2.3 Materials Recycled at WIPP $\ldots \ldots \ldots \ldots \ldots \ldots \ldots \ldots \ldots \ldots .2-20$

Table 3.1 EMS Effectiveness in Environmental Performance . . . . . . . . . 3-15

Table 4.1 Activity (Bq) of Quarterly Composite Air Samples from the WIPP Effluent Monitoring Stations A, B, and C for $2006 \ldots \ldots \ldots \ldots \ldots$. . . . . .

Table 4.2 Minimum, Maximum, and Average Radionuclide Concentrations $\left(\mathrm{Bq} / \mathrm{m}^{3}\right)$ in Air Filter Composites from Stations Surrounding the WIPP Site

Table 4.3 Radionuclide Concentrations (Bq/L) in Groundwater from Wells at the WIPP Site $\ldots \ldots \ldots \ldots \ldots \ldots \ldots \ldots \ldots \ldots \ldots \ldots \ldots \ldots \ldots .12$

Table 4.4 Results of Duplicate Groundwater Sample Analysis for Sampling Round 22

Table 4.5 Results of Duplicate Groundwater Sample Analysis for Sampling Round 23

Table 4.6 Uranium Concentrations $(\mathrm{Bq} / \mathrm{L})$ in Surface Water Near the WIPP Site

Table 4.7 Americium and Plutonium Concentrations $(\mathrm{Bq} / \mathrm{L})$ in Surface Water Near the WIPP Site

Table 4.8 Selected Radionuclide Concentrations $(\mathrm{Bq} / \mathrm{L})$ in Surface Water Near the WIPP Site . . . . . . . . . . . . . . . . . . . . 4-18

Table 4.9 Results of Duplicate Surface Water Sample Analysis . . . . . . . . 4-20

Table 4.10 Uranium Concentrations $(\mathrm{Bq} / \mathrm{g})$ in Sediment Near the WIPP Site . . . 4-22

Table 4.11 Americium and Plutonium Concentrations (Bq/g) in Sediment Near the WIPP Site 
Table 4.12 Selected Radionuclide Concentrations (Bq/g) in Sediment Near the WIPP Site . . . . . . . . . . . . . . . . . . . 4-24

Table 4.13 Results of Duplicate Sediment Sampling Analysis . . . . . . . . . . 4-25

Table 4.14 Uranium Concentrations $(\mathrm{Bq} / \mathrm{g})$ in Soil Near the WIPP Site . . . . . 4-27

Table 4.15 Americium and Plutonium Concentrations $(\mathrm{Bq} / \mathrm{g})$ in Soil Near the WIPP Site . . . . . . . . . . . . . . . .

Table 4.16 Selected Radionuclide Concentrations $(\mathrm{Bq} / \mathrm{g})$ in Soil Near the WIPP Site

Table 4.17 Results of Duplicate Soil Sampling Analysis in Soil Near the WIPP Site

Table 4.18 Radionuclide Concentrations (Bq/g Wet Mass) in Vegetation Near the WIPP Site . . . . . . . . . . . . . . . . . . . . 4-33

Table 4.19 Results of Duplicate Vegetation Sample Analysis . . . . . . . . . . 4-34

Table 4.20 Radionuclide Concentrations (Bq/g Wet Mass) in Deer, Quail, Rabbit, and Fish Near the WIPP Site.

Table 4.21 Annual Estimated Average Radiation Dose Received by a Member of the Population of the United States from Naturally Occurring Radiation Sources

Table 4.22 WIPP Radiological Dose and Release Summary 4-38

Table 4.23 General Screening Results for Potential Radiation Dose to Nonhuman Biota from Radionuclide Concentrations in Surface Water $(\mathrm{Bq} / \mathrm{L})$, Sediment $(\mathrm{Bq} / \mathrm{g})$, and Soil $(\mathrm{Bq} / \mathrm{g})$ Near the WIPP Site in 2006

Table 4.24 Comparison of Dose to the Whole Body to EPA Limit of $25 \mathrm{mrem} /$ year per 40 CFR $\S 191.03(\mathrm{~b})$

Table 4.25 Comparison of Dose to the Critical Organ to EPA Limit of $75 \mathrm{mrem} /$ year per 40 CFR §191.03(b)

Table 4.26 Comparison of EDEs to EPA Limit of $10 \mathrm{mrem} / \mathrm{year}$ per 40 CFR $\S 61.92$

Table 5.1 Concentrations of Concern for Volatile Organic Compounds, from Attachment $\mathrm{N}$ of the HWFP (No. NM4890139088-TSDF) . . . . . . 5-10 
Table 5.2 Repository Air VOC MRLs $\ldots \ldots \ldots \ldots \ldots \ldots \ldots \ldots \ldots \ldots .4 .11$

Table 5.3 Disposal Room VOC MRLs . . . . . . . . . . . . . . . . 5-12

Table 5.4 Sewage Lagoon and H-19 Semiannual Analytical Results for January 1 through June $30,2006 \ldots \ldots \ldots \ldots \ldots \ldots \ldots$. . . . . . . . . .

Table 5.5 Sewage Lagoon and H-19 Semiannual Analytical Results for

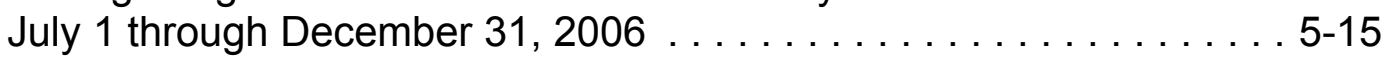

Table 5.6 Infiltration Control Evaporation Ponds Annual Analytical Results for January 1 through December 31, 2006 . . . . . . . . . . 5-16

Table 6.1 Summary of 2006 DOE WIPP Region Groundwater Monitoring Program ..................

Table 6.2 Analytical Parameters for Which Groundwater Was Analyzed . . . . . 6-9

Table 6.3 Water Level Elevations for the November 2006 Potentiometric Surface, Culebra Hydraulic Unit . . . . . . . . . . . . 6-17

Table 6.4 Pressure Density Survey for $2006 \ldots \ldots \ldots \ldots \ldots \ldots \ldots .6 .23$

Table 6.5 Monitoring Well Elevations $\ldots \ldots \ldots \ldots \ldots \ldots \ldots \ldots \ldots .6 \ldots \ldots \ldots$

Table 6.6 2006 Shallow Subsurface Water Quality Sampling Results . . . . . 6-32

Table $7.1 \quad$ NRIP for WIPP Laboratories, $2006 \ldots \ldots \ldots \ldots \ldots$. . . . . . . . . . . .

Table 7.2 Mixed Analyte Performance Evaluation Review for WIPP Laboratories, 2006 . . . . . . . . . . . . . . . . . . . . 7-7 
Waste Isolation Pilot Plant Annual Site Environmental Report for 2006

DOE/WIPP-07-2225

This page intentionally left blank 


\section{LIST OF FIGURES}

Figure 1 Site Environmental Goals Scorecard ................ xv

Figure 2 WIPP Environmental Management System $\ldots \ldots \ldots \ldots \ldots \ldots$ xvi

Figure $3 \quad$ EMS Effectiveness Indicators $\ldots \ldots \ldots \ldots \ldots \ldots \ldots \ldots \ldots \ldots$ xviii

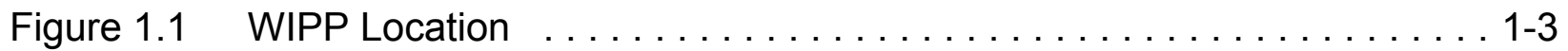

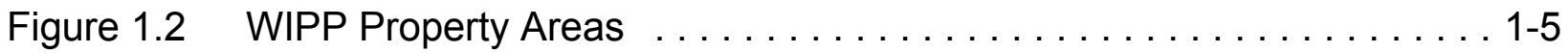

Figure 2.1 Waste Disposed Compared to Waste Recycled . . . . . . . . . . . 2-22

Figure 3.1 Site Environmental Goals Scorecard . . . . . . . . . . . . . . 3-4

Figure 3.2 FY 2006 Recycled Versus Disposed Materials . . . . . . . . . . . 3-8

Figure $3.3 \quad$ Yearly Water Usage at WIPP $\ldots \ldots \ldots \ldots \ldots \ldots \ldots \ldots \ldots \ldots \ldots \ldots \ldots$

Figure 3.4 WIPP Carbon Emissions - Estimated $\ldots \ldots \ldots \ldots \ldots \ldots \ldots \ldots$ 3-10

Figure 3.5 EMS Effectiveness Indicators $\ldots \ldots \ldots \ldots \ldots \ldots \ldots \ldots \ldots . . \ldots \ldots \ldots$

Figure 3.6 Consolidation and Replacement of Environmental Executive Orders .................... 3-14

Figure 4.1 Air Sampling Locations On and Near the WIPP Facility $\ldots \ldots \ldots \ldots$ 4-8

Figure 4.2 Routine Surface Water Sampling Locations $\ldots \ldots \ldots \ldots \ldots \ldots$ 4-16

Figure 4.3 Sediment Sampling Sites $\ldots \ldots \ldots \ldots \ldots \ldots \ldots \ldots \ldots \ldots \ldots .4 .20$

Figure 4.4 Routine Soil and Vegetation Sampling Areas . . . . . . . . . . . 4-26

Figure 4.5 Dose to the Whole Body for the Hypothetical Maximally Exposed Individual at the WIPP Fence Line $\ldots \ldots \ldots \ldots \ldots \ldots \ldots \ldots .4-42$

Figure 4.6 Dose to the Critical Organ for Hypothetical Maximally Exposed Individual at the WIPP Fence Line . . . . . . . . . . . 4-43

Figure 4.7 WIPP EDE to the Off-Site MEI $\ldots \ldots \ldots \ldots \ldots \ldots \ldots \ldots .44$

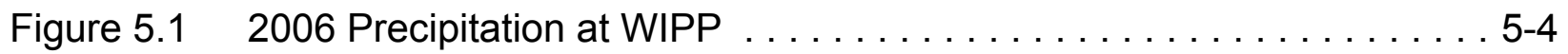

Figure 5.2 WIPP High Temperatures for $2006 \ldots \ldots \ldots \ldots \ldots \ldots \ldots \ldots$ 5-5 


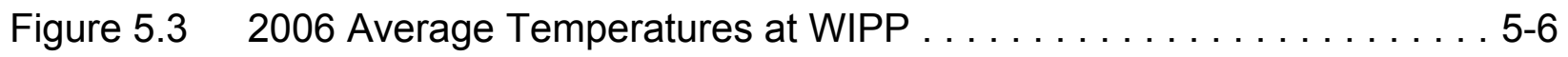

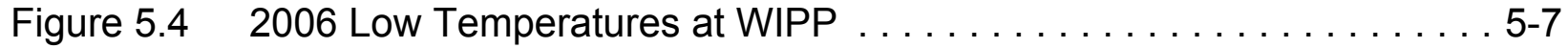

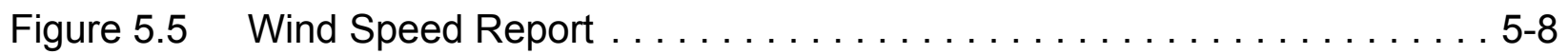

Figure 5.6 Typical Disposal Room VOC Sampling Locations . . . . . . . . . . . . 5-9

Figure 5.7 WIPP Seismograph Station Locations $\ldots \ldots \ldots \ldots \ldots \ldots \ldots \ldots$ 5-13

Figure $6.1 \quad$ WIPP Stratigraphy $\ldots \ldots \ldots \ldots \ldots \ldots \ldots \ldots \ldots \ldots .6 \ldots \ldots \ldots \ldots$

Figure 6.2 Groundwater Level Surveillance Wells $\ldots \ldots \ldots \ldots \ldots \ldots \ldots \ldots 6$ 6.7

Figure 6.3 Water Quality Sampling Program Wells $\ldots \ldots \ldots \ldots \ldots \ldots \ldots 6$ 6-8

Figure 6.4 Hydrograph of WQSP-1 $\ldots \ldots \ldots \ldots \ldots \ldots \ldots \ldots \ldots \ldots \ldots 6$ 6-13

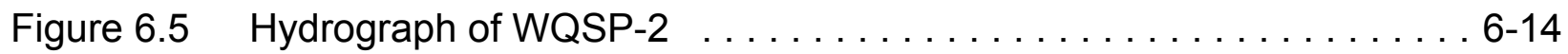

Figure 6.6 Hydrograph of WQSP-3 $\ldots \ldots \ldots \ldots \ldots \ldots \ldots \ldots \ldots \ldots \ldots 6$ 6-14

Figure $6.7 \quad$ Hydrograph of WQSP-4 $\ldots \ldots \ldots \ldots \ldots \ldots \ldots \ldots \ldots \ldots \ldots 6$ 6-15

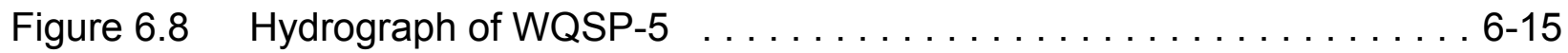

Figure 6.9 Hydrograph of WQSP-6 $\ldots \ldots \ldots \ldots \ldots \ldots \ldots \ldots \ldots \ldots \ldots 6$ 6-16

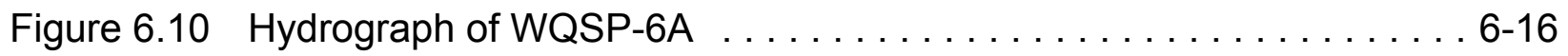

Figure 6.11 Culebra Potentionmetric Surface Map . . . . . . . . . . . . . 6-21

Figure 6.12 Locations of SSW Wells (Piezometers PZ-1 through 12; Wells C-2811, C-2505, C-2506, and C-2507 . . . . . . . . 6-31

Figure 6.13 Contour Plot of SSW Potentiometric Surface in the Santa Rosa Formation ....................... 6-33 


\section{EXECUTIVE SUMMARY}

\section{Purpose}

The purpose of the Waste Isolation Pilot Plant Annual Site Environmental Report for 2006 (ASER) is to provide information required by U.S. Department of Energy (DOE) Order 231.1A, Environment, Safety, and Health Reporting. Specifically, the ASER presents summary environmental data that:

- $\quad$ Characterize site environmental management performance.

- $\quad$ Summarize environmental occurrences and responses reported during the calendar year.

- $\quad$ Confirm compliance with environmental standards and requirements.

- $\quad$ Highlight significant facility programs and efforts.

The DOE Carlsbad Field Office (CBFO) and Washington TRU Solutions LLC (WTS) maintain and preserve the environmental resources at the WIPP site. DOE Order 231.1A; DOE Order 450.1, Environmental Protection Program; and DOE Order 5400.5, Radiation Protection of the Public and Environment, require that the affected environment at and near DOE facilities be monitored to ensure the safety and health of the public and the environment.

This report was prepared in accordance with DOE Order 231.1A. This order requires that DOE facilities submit an ASER to the DOE Headquarters Office of the Assistant Secretary for Environment, Safety, and Health. The WIPP Hazardous Waste Facility Permit (HWFP) (No. NM4890139088-TSDF [treatment, storage, and disposal facility]) further requires that the ASER be provided to the New Mexico Environment Department (NMED).

\section{Major Site Programs}

\section{Mission}

The mission of WIPP is to safely and permanently dispose of transuranic (TRU) radioactive waste generated by the production of nuclear weapons and other activities related to the national defense of the United States. In 2006, 10,398 cubic meters $\left(\mathrm{m}^{3}\right)$ of TRU waste were disposed of at the WIPP facility. From the first receipt of waste in March 1999 through the end of $2006,44,687 \mathrm{~m}^{3}$ of TRU waste had been disposed of at the WIPP facility.

\section{Monitoring and Surveillance}

It is the policy of the DOE to conduct its operations at the WIPP facility in compliance with applicable environmental laws and regulations, and to protect human health and 
the environment. This is accomplished through a management system consisting of radiological and nonradiological environmental monitoring and surveillance and a rigorous assessment of compliance with applicable environmental regulations. As part of this management system, the DOE collects data needed to detect and quantify potential impacts that WIPP facility operations may have on the surrounding environment. The Waste Isolation Pilot Plant Environmental Monitoring Plan (DOE/WIPP 99-2194) (WIPP Environmental Monitory Plan) outlines major environmental monitoring and surveillance activities at the WIPP facility and the WIPP facility quality assurance/quality control (QA/QC) program as it relates to environmental monitoring.

WIPP employees conduct both effluent (i.e., point source monitoring at release points such as the exhaust shaft, to detect radionuclides and to quantify dose rates) along with traditional pathway and receptor monitoring in the broader environment. Monitoring results are also used to ensure that WIPP facility operations comply with DOE and other applicable federal and state standards and requirements. The WIPP environmental monitoring program is designed to monitor pathways that radionuclides and other contaminants could take to reach the environment surrounding the WIPP facility. Pathways monitored include air, groundwater, surface water, soils, sediments, vegetation, and game animals. The goal of this monitoring is to determine if the local ecosystem has been, or is being, impacted by WIPP facility operations and, if so, to evaluate the geographic extent and the effects on the environment.

The Waste Isolation Pilot Plant Land Management Plan (DOE/WIPP 93-004) (LMP) was created in compliance with the WIPP Land Withdrawal Act of 1992 (LWA) (Public Law [Pub. L.] 102-579, as amended by Pub. L. 104-201, National Defense Authorization Act for Fiscal Year 1997). This plan identifies resource values, promotes multiple-use management, and identifies long-term goals for the management of WIPP project lands. The LMP includes a land reclamation program that addresses both the short-term and long-term effects of WIPP facility operations. WIPP personnel also conduct surveillance in the region surrounding the site to protect the WIPP facility from trespass.

In this report, the WIPP facility environmental monitoring and surveillance programs are grouped as follows:

Environmental Radiological Programs

- $\quad$ Effluent

- $\quad$ Airborne particulates

- Groundwater

- $\quad$ Surface water

- Sediments

- Soil

- Biota 
Environmental Nonradiological Programs

- $\quad$ Land management

- Meteorology

- $\quad$ Volatile organic compounds

- $\quad$ Seismic activity

- $\quad$ Liquid effluent

Groundwater Protection Programs

- Groundwater quality

- Groundwater levels

- $\quad$ Pressure density surveys

- $\quad$ Shallow subsurface water quality

- $\quad$ Shallow subsurface water levels

In 2006, the results of each of these monitoring and surveillance programs, observations, and analytical data, demonstrated that (1) compliance with applicable environmental requirements was achieved and (2) the operations at the WIPP facility have not had a negative impact on human health or the environment.

\section{Environmental Compliance}

The WIPP facility is required to comply with applicable federal and state laws and DOE orders. In order to accomplish and document compliance with certain requirements, the following submittals, required on a routine basis, were prepared in 2006:

New Mexico Submittals

A. Hazardous Waste Facility Permit

- 2005 Annual Site Environmental Report

- Confirmatory VOC and Mine Ventilation Rate Monitoring Report

- $\quad$ Quarterly Solid Waste Management Unit (SWMU) Activities

Progress Reports

- Waste Minimization Statement

- WIPP Groundwater Detection Monitoring Semiannual Groundwater Monitoring Reports

- Geotechnical Analysis Report

- Monthly Water Level Report 
B. Discharge Permit (DP-831)

- $\quad$ Semiannual Discharge Monitoring Reports

C. Superfund Amendments and Reauthorization Act of 1986

- $\quad$ Emergency and Hazardous Chemical Inventory Report

- $\quad$ Toxic Chemical Release Inventory Report

- 2006 Annual Polychlorinated Biphenyls Report

\section{Environmental Protection Agency Submittals}

- Delaware Basin Monitoring Annual Report

- WIPP Subsidence Monument Leveling Survey

- 2006 Annual Change Report

- Toxic Chemical Release Inventory Report

Other correspondence, regulatory submittals, monitoring reports, and the results of the U.S. Environmental Protection Agency (EPA) Annual Inspection, as well as other inspections, are described in Chapters 2 and 3 of this report.

In 2006, the WIPP facility received one administrative notice of violation, relative to compliance with the HWFP, which is discussed in detail in Section 2.2.2.

\section{Key Initiatives}

\section{Pollution Prevention}

WIPP personnel focused on two primary areas for pollution prevention (P2) improvements in 2006. These were integrating P2 into the project through the Environmental Management System (EMS) and maintaining employee awareness of P2.

Implementing goals, objectives and targets is a key EMS element for improving P2 performance. For 2006, WIPP personnel set eight environmental goals with each of these being specifically related to P2. Seven of the goals were intended to improve P2 performance in selected areas. One goal focused on maintaining the excellent performance of the WIPP facility in the area of environmental reportable releases. The goals contribute to accomplishing DOE programmatic goals and were completed as noted in Figure 1. 
Waste Isolation Pilot Plant Annual Site Environmental Report for 2006 DOE/WIPP-07-2225

\begin{tabular}{|c|c|c|}
\hline \multicolumn{3}{|c|}{$\begin{array}{c}\text { Figure } 1 \text { - Site Environmental Goals Scorecard } \\
\text { WIPP FY } 2006 \text { Performance }\end{array}$} \\
\hline DOE Goal Category & Goal & Status \\
\hline \multirow[t]{3}{*}{ Waste Prevention } & $\begin{array}{l}\text { 1. No increase in the WIPP site's } \\
\text { sanitary (household) waste } \\
\text { generation rate per employee. }\end{array}$ & $\begin{array}{l}\text { Achieved. Each WIPP site employee } \\
\text { generated . } 2 \text { metric tons of waste during } \\
\text { FY } 2005 \text { and FY } 2006 \text {. }\end{array}$ \\
\hline & $\begin{array}{l}\text { 2. Each department will evaluate at } \\
\text { least one waste stream, and identify } \\
\text { and begin implementing a plan for } \\
\text { its reduction. }\end{array}$ & $\begin{array}{l}\text { Achieved } 71 \text { Percent. Five of seven } \\
\text { departments completed this goal. }\end{array}$ \\
\hline & $\begin{array}{l}\text { 3. Reduce paper and paper-based } \\
\text { office goods consumption. }\end{array}$ & $\begin{array}{l}\text { Achieved. Each employee used an average } \\
\text { of } 2 \text { pounds or } 235 \text { sheets less paper in } \\
\text { FY } 2006 \text { versus FY } 2005 \text {. }\end{array}$ \\
\hline \multirow[t]{3}{*}{$\begin{array}{l}\text { Environmentally } \\
\text { Preferred Purchasing }\end{array}$} & $\begin{array}{l}\text { 4. Evaluate use of bio-based diesel } \\
\text { fuel. }\end{array}$ & $\begin{array}{l}\text { Achieved. As a result of the evaluation, a } \\
\text { FY } 2007 \text { goal is proposed for conducting a } \\
\text { test of biodiesel in the WIPP site commuting } \\
\text { buses. }\end{array}$ \\
\hline & $\begin{array}{l}\text { 5. Partner with site janitorial service to } \\
\text { identify and use cost effective, fit for } \\
\text { purpose, environmentally preferred } \\
\text { cleaning supplies at the WIPP site. } \\
\end{array}$ & $\begin{array}{l}\text { Achieved. Janitorial environmentally } \\
\text { preferred products were identified, and it was } \\
\text { agreed that testing would deferred to } \\
\text { FY } 2007 \text {. }\end{array}$ \\
\hline & $\begin{array}{l}\text { 6. Add legal and ledger size paper to } \\
\text { current paper purchase contract for } \\
\text { routine stocking (assures recycled } \\
\text { content standard met). }\end{array}$ & $\begin{array}{l}\text { Achieved. Research was conducted that } \\
\text { determined that the purchase of legal and } \\
\text { ledger sized paper from local office supplier } \\
\text { meets the EPA recycled content standard. }\end{array}$ \\
\hline $\begin{array}{l}\text { Environmental } \\
\text { Stewardship (water, } \\
\text { energy, and fuel } \\
\text { efficiency, resource } \\
\text { conservation) }\end{array}$ & $\begin{array}{l}\text { 7. Evaluate fresh water usage to } \\
\text { understand water usage profile and } \\
\text { determine if there are areas for } \\
\text { improved efficiency. }\end{array}$ & $\begin{array}{l}\text { Achieved. The evaluation concluded that the } \\
\text { primary areas for future improvements in } \\
\text { water usage are in personal use areas rather } \\
\text { than through industrial use. }\end{array}$ \\
\hline $\begin{array}{l}\text { Recycling of Solid } \\
\text { Wastes }\end{array}$ & $\begin{array}{l}\text { 8. Increase ratio of materials recycled } \\
\text { to the total quantity of sanitary waste } \\
\text { generated to } 65 \text { percent, a } 5 \text { percent } \\
\text { increase compared to FY } 2005 \text {. }\end{array}$ & $\begin{array}{l}\text { Not Achieved. This was a stretch goal for } \\
\text { the WIPP site with WIPP achieving a } \\
54 \text { percent recycling rate. On a volume basis, } \\
\text { WIPP recycled } 33 \text { metric tons of materials } \\
\text { ( } 22 \text { percent) more than in FY } 2005 \text { with } \\
\text { increases in quantities of paper, computer } \\
\text { equipment, scrap metal. }\end{array}$ \\
\hline
\end{tabular}

Individual and departmental support and participation in P2 was the theme for 2006 awareness efforts. To emphasize the message, articles in the TRU News (the WIPP facility bi-weekly internal newsletter) recognized P2 accomplishments of individuals and organizations that participated in them. Articles in the Pollution Prevention News, posted each month, focused on $\mathrm{P} 2$ at home in the areas of use and recycling of rechargeable batteries, water conservation, energy efficiency for air conditioning and lighting, and recycling of used engine oil. The WIPP 2006 Earth Day celebration focused on energy conservation through the use of compact fluorescent light bulbs. In addition two of the eight WIPP environmental goals were only achievable with broad engagement of the departments and individuals. One was the goal for each department to evaluate and begin to implement a plan for reducing one of their department's waste streams. The majority of the departments achieved their goal in 2006. Finally, focus continues on the recycling program, providing a visible, constant focal point for 
individual participation in the $\mathrm{P} 2$ program. The quantity of recycled materials was increased by 33.1 metric tons or 22 percent compared to 2005 .

\section{Environmental Management System}

The WIPP EMS continued to be in compliance with DOE Order 450.1 throughout 2006 after initially declaring compliance in October 2005 . The DOE order required site EMSs to be integrated with the Integrated Safety Management System (ISMS) by December 2005. These systems are described in the Waste Isolation Pilot Plant Environmental Management System Description (DOE/WIPP 05-3318) and the Integrated Safety Management System Description (DOE/CBFO 98-2276). Both of these documents describe how the EMS is integrated into the ISMS.

Compliance with the order and system effectiveness was confirmed through the completion of the CBFO Annual Review of the WIPP Integrated Safety Management System of September 2006 and the WIPP Environmental Management System Annual Report for Fiscal Year 2006 (DOE/WIPP-07-3333).

The EMS conforms to the guiding principles of the International Organization for Standardization (ISO) 14001, Environmental Management Systems - Specification with Guidance for Use (ISO, 2004), incorporating the continuous improvement cycle (Plan, Do, Check, and Adjust) and the ISO elements as shown in Figure 2. 


\section{WIPP Environmental Management System (EMS)}

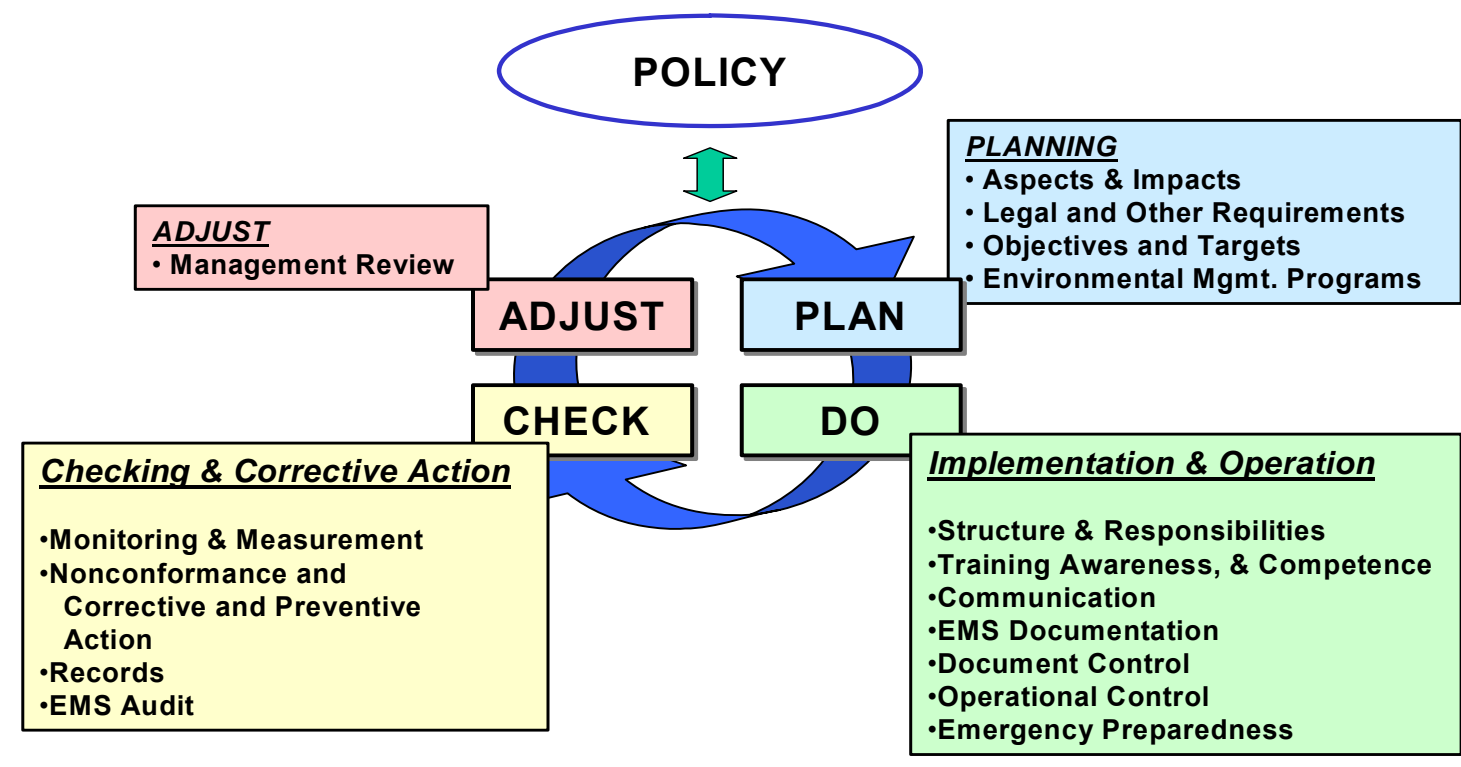

Figure 2 - WIPP Environmental Management System

The EMS is also well integrated into overall site operations and management processes. Examples of this integration with basic business processes are:

- $\quad$ EMS objective and target setting is integrated with the WIPP programmatic planning process.

- $\quad$ EMS awareness training is integrated with the project's overall training program.

- Environmental responsibilities are defined and operational control is maintained through integration with conduct of operations and conduct of maintenance programs and procedures.

- $\quad$ Emergency preparedness and response are fully integrated with the overall emergency planning process and managing of emergencies includes appropriate handling of safety, environmental, and operational considerations.

- Monitoring of environmental compliance and EMS is conducted through the WIPP assessment processes. These include the quality assurance and management assessment programs, the environmental assessment program and externally managed compliance and system assessments. 


\section{EMS Effectiveness}

Indicators were used for determining the EMS effectiveness in operating the project in alignment with its three major environmental policy commitments (i.e., environmental stewardship, compliance with legal and internal requirements, and continual improvement in environmental performance.) These indicators were the basis for the determination by WIPP management that the EMS continues to be suitable and effective for meeting the WIPP environmental policy. Figure 3 summarizes the indicators.

\begin{tabular}{|l|c|c|}
\hline \multicolumn{3}{|c|}{ Figure 3 - EMS Effectiveness Indicators } \\
Environmental Stewardship, Compliance, Continual Improvement \\
\hline \multicolumn{1}{|c|}{ Performance Indicator } & FY 2006 & FY 2005 \\
\hline $\begin{array}{l}\text { Aspects and impacts - business milestones related to } \\
\text { significant aspects and impacts management }\end{array}$ & $\begin{array}{c}77 \% \\
(217 \text { of } 283)\end{array}$ & $\begin{array}{c}78 \% \\
(265 \text { of 338) }\end{array}$ \\
\hline $\begin{array}{l}\text { Revisions to significant aspects and impacts (does not include } \\
\text { administrative revisions.) }\end{array}$ & 2 & 0 \\
\hline Environmental goals accomplished & $\begin{array}{c}83 \% \\
(6.7 \text { of } 8)\end{array}$ & $\begin{array}{c}78 \% \\
(7 \text { of } 9)\end{array}$ \\
\hline Reportable unauthorized contaminant releases & 0 & 0 \\
\hline External agency compliance findings/violations & 1 & 0 \\
\hline $\begin{array}{l}\text { Evaluations (number and percentage of total) that review topics } \\
\text { supporting environmental compliance and/or performance. }\end{array}$ & $250 / 76 \%$ & $275 / 72 \%$ \\
\hline Corrective action process - percent of issues self-discovered & $\begin{array}{c}62 \% \\
(88 \text { of } 142)\end{array}$ & NA* \\
\hline Recommendations implemented from EMS annual report & 5.5 of 6.0 & 8 of 9 \\
\hline
\end{tabular}

* Not available

Data generated from implementation of the WIPP environmental monitoring program are also indicators of environmental stewardship. The monitoring data demonstrate that there has been no adverse impact to human health or the environment from WIPP facility operations.

Measures for EMS integration with ISMS and system implementation were those established by the DOE to measure implementation progress and performance. In 2006, the DOE updated their requirements for annually reporting the status of each site's EMS Implementation. The new requirements include both a scorecard for implementation of key EMS elements and rankings to reflect the EMS effectiveness in achieving environmental performance improvement.

The EMS scorecard data define EMS implementation status in terms of four implementation stages. These implementation stages include, Stage 1 - the EMS element is not implemented; Stage 2 - system needs are identified but not implemented; Stage 3 - the system is implemented; and Stage 4 - the system is implemented and is resulting in continuous improvement. The status of EMS implementation is summarized in Table 1. 
Waste Isolation Pilot Plant Annual Site Environmental Report for 2006 DOE/WIPP-07-2225

\begin{tabular}{|c|l|c|}
\hline \multicolumn{1}{|c|}{ Table 1 - DOE EMS Implementation Indicator Status } \\
\hline \multicolumn{1}{|c|}{ Implementation Indicator } & $\begin{array}{c}\text { Implementation } \\
\text { Stage }\end{array}$ \\
\hline 1 & Environmental Aspects and Impacts & 4 \\
\hline 2 & Objectives, Goals and Targets & 4 \\
\hline 3 & Operational Controls & 4 \\
\hline 4 & Environmental Awareness and Training & 4 \\
\hline 5 & EMS Incorporation into Contracts & 3 \\
\hline 6 & EMS Audits & 4 \\
\hline 7 & Management Review & 4 \\
\hline
\end{tabular}

The WIPP rankings relative to environmental performance improvements also demonstrated the EMS to be successful. The DOE required sites to use a five-point ranking scale relative to multiple performance criteria. The scale ranged from one as rating the EMS as "having no effect" to five as rating the EMS as "having a significant effect." Table 2 summarizes the effectiveness rankings for the WIPP EMS.

\section{Table 2 - EMS Effectiveness in Environmental Performance}

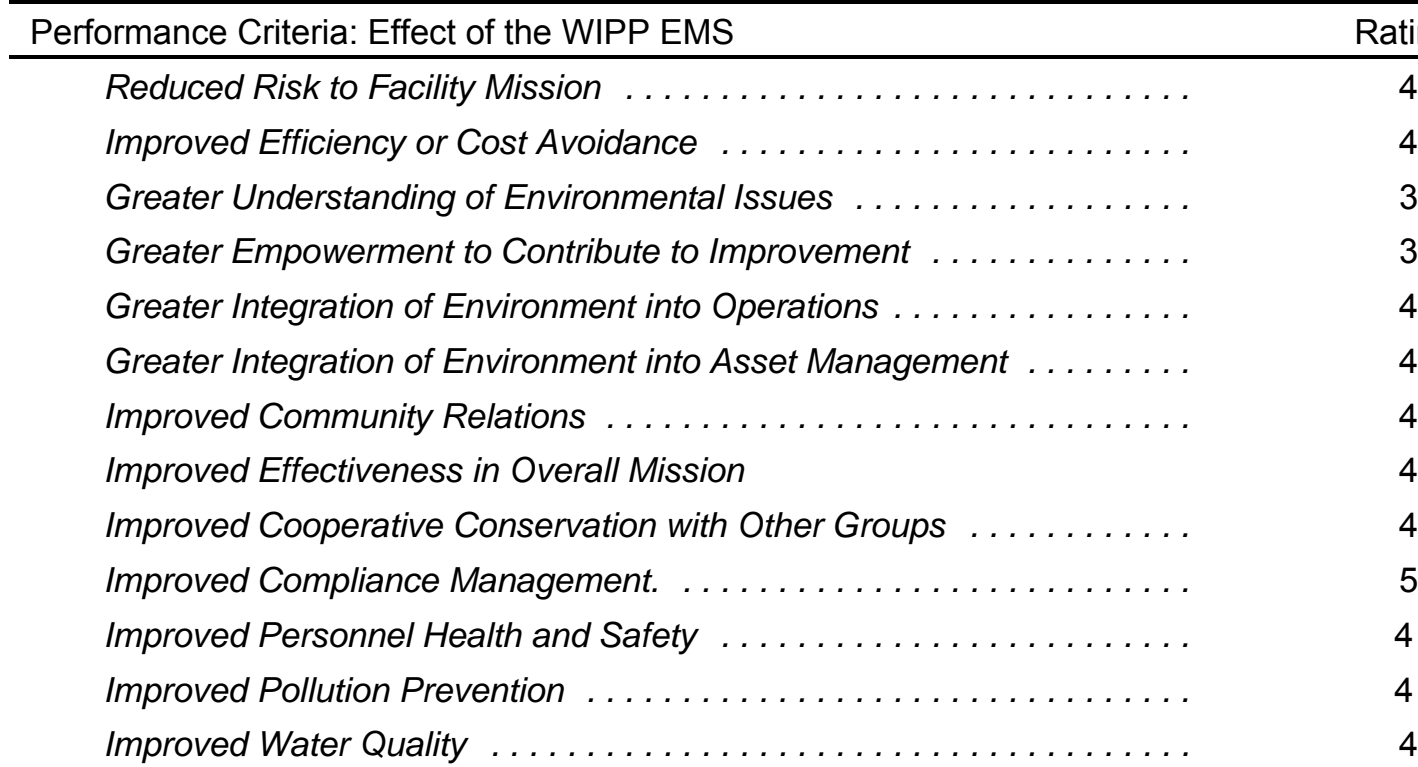

Improved Air Quality

Does Not Apply

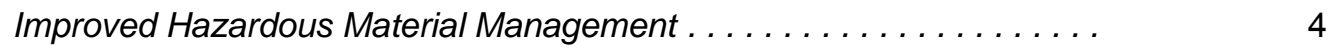

Improved Hazardous Waste Management . . . . . . . . . ...... 4

Improved Solid Waste Management . . . . . . . . ............. 4

Improved Conservation of Natural Resources ............... 5

Improved Facility Energy Conservation .................. 4

Improved Vehicle Fuel Conservation ................... 2

Improved Water Conservation $\ldots \ldots \ldots \ldots \ldots \ldots \ldots \ldots \ldots \ldots \ldots$

Reduced Number of Permits Needed to Operate ............. Does Not Apply 


\title{
Summary of Releases and Radiological Doses to the Public
}

\author{
Doses to the Public and the Environment
}

The radiation dose to members of the public from WIPP facility operations has been calculated from WIPP facility effluent monitoring results and demonstrates compliance with federal regulations.

\section{Dose Limits}

The regulatory limit for the WIPP facility is established in Title 40 Code of Federal Regulations (CFR) Part 191, Subpart A, "Environmental Standards for Management and Storage." The referenced standard requires that the combined annual dose equivalent to any member of the public in the general environment resulting from discharges of radioactive material and direct radiation from such management and storage shall not exceed 25 millirem (mrem) ("rem" is roentgen equivalent man) to the whole body and 75 mrem to any critical organ. In addition, in a 1995 Memorandum of Understanding between the EPA and the DOE, the DOE agreed that the WIPP facility would comply with 40 CFR Part 61, Subpart H, "National Emission Standards for Emissions of Radionuclides Other Than Radon from Department of Energy Facilities," hereafter referred to as the NESHAP (National Emissions Standards for Hazardous Air Pollutants). The NESHAP standard requires that the emissions of radionuclides to the ambient air from Department of Energy facilities shall not exceed those amounts that would cause any member of the public to receive in any year an effective dose equivalent (EDE) of 10 mrem per year.

\section{Background Radiation}

There are several sources of naturally occurring radiation: cosmic and cosmogenic radiation (from outer space and the earth's atmosphere), terrestrial radiation (from the earth's crust), and internal radiation (naturally occurring radioactive material in our bodies). In addition to natural radioactivity, small amounts of radioactivity from aboveground nuclear weapons tests and from the 1986 Chernobyl nuclear accident are present in the environment. A potential source of radiation in the environment near and at the WIPP site is the result of Project Gnome. Under Project Gnome, a nuclear device was detonated in bedded salt on December 10, 1961, approximately 9 kilometers (km) (5.4 miles [mi]) from the WIPP site. The Project Gnome shot vented into the atmosphere; therefore, environmental samples taken at the WIPP site may contain residual contamination from this occurrence. Together, natural radiation and residual fallout are called "background" radiation. Exposure to radioactivity from weapons testing fallout is quite small compared to natural radioactivity and continually gets smaller as radionuclides decay. The average annual dose received by a member of the public from naturally occurring radionuclides is approximately 3 millisieverts (mSv) (300 mrem) (NCRP [National Council on Radiation Protection and Measurements], 1987a). Site-specific background gamma measurements on the surface, conducted by Sandia National Laboratories, showed average dose rate of $7.65 \mathrm{microR} / \mathrm{hour}$ (Minnema and Brewer, 1983) which would equate to the background gamma radiation 
dose of $0.67 \mathrm{mSv}$ (67.0 mrem) per year. A comprehensive radiological baseline study before WIPP facility disposal operations began was also documented in Statistical Summary of the Radiological Baseline Program for the Waste Isolation Pilot Plant (DOE/WIPP 92-037), which provides the basis for environmental background comparison after WIPP facility disposal operations commenced.

\section{Dose from Air Emissions}

WIPP personnel have identified air emissions as the major pathway of concern for radionuclide transport during the receipt and emplacement of waste at the WIPP facility. To determine the radiation dose received by members of the public from WIPP facility operations, WIPP personnel used the emission monitoring and test procedure for DOE facilities (40 CFR §61.93, "Emission Monitoring and Test Procedure"), which requires the use of the EPA-approved CAP88-PC to calculate the EDE to members of the public. CAP88-PC dose calculations are based on the assumption that exposed people remain at home during the entire year and all vegetables, milk, and meat consumed are home produced. Thus, this dose calculation is a maximum dose that encompasses dose from inhalation, plume submersion, deposition, and ingestion of air-emitted radionuclides.

\section{$\underline{\text { Total Dose from WIPP Facility Operations }}$}

The dose to an individual from the ingestion of WIPP facility-related radionuclides transported in water is nonexistent because drinking water for communities near the WIPP site comes from groundwater sources that are too far away to be affected by WIPP facility operations.

Game animals sampled during 2006 were deer, quail, fish, and rabbit. The only radionuclides detected were not different from baseline levels. By extrapolation, no dose from WIPP facility-related radionuclides has been received by any individual from this pathway (e.g., the ingestion of meat from game animals) during 2006.

Based on the results of the WIPP effluent monitoring program, concentrations of radionuclides in air emissions did not exceed regulatory dose limits set by 40 CFR Part 191, Subpart A, or by 40 CFR Part 61, Subpart H. The results indicate that the hypothetical maximally exposed individual (MEI) who resides year-round at the fence line, 300 meters $(\mathrm{m})$ from the exhaust shaft, receives a dose that is less than 8.16E-07 mSv (8.16E-05 mrem) per year for the whole body, and is less than $1.30 \mathrm{E}-05 \mathrm{mSv}(1.30 \mathrm{E}-03 \mathrm{mrem})$ per year for the critical organ. These values are in compliance with the Subpart A requirements specified in 40 CFR §191.03(b). For NESHAP (40 CFR §61.92) standards, the EDE potentially received by the MEI residing $7.5 \mathrm{~km}$ (4.66 miles) west-northwest of WIPP was calculated to be less than $3.93 \mathrm{E}-08 \mathrm{mSv}$ (3.93E-06 mrem) per year whole body. This value is in compliance with the 40 CFR $\S 61.92$ requirements.

Chapter 4 of this report presents figures and tables that provide the EDE values from calendar years (CY) 1999 through 2006. Note that these EDE values are below the EPA limit specified in 40 CFR Part 191, Subpart A, and 40 CFR Part 61, Subpart H. 


\section{Dose to Nonhuman Biota}

Dose limits that cause no deleterious effects on populations of aquatic and terrestrial organisms have been suggested by the NCRP and the International Atomic Energy Agency. These absorbed dose limits are:

- Aquatic Animals $10 \mathrm{mGy} / \mathrm{d}$ (milli gray/day), (1 rad [radiation absorbed dose]/d)

- Terrestrial Plants $10 \mathrm{mGy} / \mathrm{d}(1 \mathrm{rad} / \mathrm{d})$

- Terrestrial Animals $1 \mathrm{mGy} / \mathrm{d}(0.1 \mathrm{rad} / \mathrm{d})$

The DOE requires discussion of radiation doses to nonhuman biota in the ASER using the DOE Technical Standard, DOE-STD-1153-2002, A Graded Approach for Evaluating Radiation Doses to Aquatic and Terrestrial Biota. This standard requires an initial screening phase using conservative assumptions.

This guidance was used to screen radionuclide concentrations observed around the WIPP site during 2006. The screening results indicate that radiation in the environment surrounding the WIPP site does not have a deleterious effect on populations of plants and animals.

Release of Property Containing Residual Radioactive Material

There was no release of radiologically contaminated materials or property in 2006 . 


\section{ACRONYMS, ABBREVIATIONS, AND UNITS OF MEASURE}

$\begin{array}{ll}\text { amsl } & \text { above mean sea level } \\ \text { ANOVA } & \text { Analysis of Variance } \\ \text { ANSI } & \text { American National Standards Institute } \\ \text { ASER } & \text { Annual Site Environmental Report } \\ \text { ASME } & \text { American Society of Mechanical Engineers } \\ \text { ASTM } & \text { American Society for Testing and Materials } \\ & \\ \text { BCG } & \text { biota concentration guide } \\ \text { BLM } & \text { U.S. Department of the Interior, Bureau of Land Management } \\ \text { Bq } & \text { becquerel(s) } \\ \text { CAO } & \text { Carlsbad Area Office (now Carlsbad Field Office) } \\ \text { CAP88 } & \text { computer code for calculating both dose and risk from radionuclide } \\ \text { CBFO } & \text { emissions } \\ \text { CERCLA } & \text { Carlsbad Field Office } \\ \text { CEMRC } & \text { Act } \\ \text { CFR } & \text { Carlsbad Environmentive Environmental Response, Compensation, and Liability } \\ \text { CH } & \text { Code of Federal Regulations } \\ \text { Ci } & \text { contact-handled } \\ \text { cm } & \text { curie(s) } \\ \text { CY } & \text { centimeter(s) } \\ \text { calendar year } & \\ \text { DOE } & \text { day } \\ \text { DP } & \text { U.S. Department of Energy } \\ \text { EDE } & \text { discharge permit (DP-831) } \\ \text { EH } & \text { effective dose equivalent } \\ \text { EIS } & \text { DOE Department of Environment, Safety, and Health } \\ \text { EMS } & \text { Environmental Impact Statement } \\ \text { EO } & \text { Environmental Management System } \\ \text { EPA } & \text { Executive Order } \\ \text { EPCRA } & \text { U.S. Environmental Protection Agency } \\ \text { ft } & \text { Emergency Planning and Community Right-to-Know Act } \\ \text { ft } & \text { foot/feet } \\ \text { FFCA } & \text { cubic feet } \\ \text { FIFRA } & \text { Federal Facilities Compliance Act } \\ \text { FLPMA } & \text { Federal Insecticide, Fungicide, and Rodenticide Act } \\ \text { FY } & \text { Federal Land Policy and Management Act } \\ & \text { fiscal year } \\ & \\ & \end{array}$




\begin{tabular}{|c|c|}
\hline $\begin{array}{l}\text { g } \\
\text { Gy }\end{array}$ & $\begin{array}{l}\text { gram(s) } \\
\text { gray }\end{array}$ \\
\hline HEPA & high-efficiency particulate air (filter) \\
\hline HWFP & Hazardous Waste Facility Permit \\
\hline in. & $\operatorname{inch}(e s)$ \\
\hline ISMS & Integrated Safety Management System \\
\hline ISO & International Organization for Standardization \\
\hline $\mathrm{kg}$ & kilogram(s) \\
\hline $\mathrm{km}$ & kilometer(s) \\
\hline $\mathrm{km}^{2}$ & square kilometers \\
\hline $\mathrm{L}$ & liter(s) \\
\hline LCS & laboratory control sample \\
\hline LCSD & laboratory control sample duplicate \\
\hline LMP & Land Management Plan \\
\hline LWA & Land Withdrawal Act \\
\hline $\mathrm{m}$ & meter(s) \\
\hline $\mathrm{m}^{3}$ & cubic meters \\
\hline MCD & maximum concentration detected \\
\hline MDC & minimum detectable concentration \\
\hline MEI & maximally exposed individual \\
\hline MAPEP & Mixed Analyte Performance Evaluation Program \\
\hline $\mathrm{mg} / \mathrm{L}$ & milligrams per liter \\
\hline $\mathrm{MgO}$ & magnesium oxide \\
\hline mGy & milli gray \\
\hline $\mathrm{mi}$ & mile(s) \\
\hline $\mathrm{mi}^{2}$ & square miles \\
\hline $\mathrm{ml}$ & milliliter(s) \\
\hline mrem & millirem(s) \\
\hline MRL & method reporting limit \\
\hline $\mathrm{mSv}$ & millisievert(s) \\
\hline N/A & not applicable \\
\hline NAD & North American Datum \\
\hline NCRP & National Council for Radiation Protection and Measurements \\
\hline NEPA & National Environmental Policy Act \\
\hline NESHAP & National Emission Standards for Hazardous Air Pollutants \\
\hline NIST & National Institute of Standards and Technology \\
\hline NMAC & New Mexico Administrative Code \\
\hline NMED & New Mexico Environment Department \\
\hline NMIMT & New Mexico Institute of Mining and Technology \\
\hline NMSA & New Mexico Statutes Annotated \\
\hline NQA & Nuclear Quality Assurance \\
\hline
\end{tabular}




\begin{tabular}{|c|c|}
\hline $\begin{array}{l}\text { NR } \\
\text { NRIP }\end{array}$ & $\begin{array}{l}\text { not reported } \\
\text { National Institute of Standards and Technology Radiochemistry } \\
\text { Intercomparison Program }\end{array}$ \\
\hline $\mathrm{Oz}$ & ounce(s) \\
\hline P2 & pollution prevention \\
\hline PCB & polychlorinated biphenyl \\
\hline PIP & production injection packer \\
\hline ppbv & parts per billion by volume \\
\hline PPOA & Pollution Prevention Opportunity Assessment \\
\hline Pub. L. & Public Law \\
\hline QA & quality assurance \\
\hline QC & quality control \\
\hline $\mathrm{rad}$ & radiation absorbed dose \\
\hline RCRA & Resource Conservation and Recovery Act \\
\hline rem & roentgen equivalent man \\
\hline RER & relative error ratio \\
\hline $\mathrm{RH}$ & remote-handled \\
\hline RPD & relative percent difference \\
\hline $\begin{array}{l}\text { SARA } \\
\text { SD }\end{array}$ & $\begin{array}{l}\text { Superfund Amendments and Reauthorization Act } \\
\text { standard deviation }\end{array}$ \\
\hline SEIS-II & Second Supplemental Environmental Impact Statement \\
\hline SERC & State Emergency Response Commission \\
\hline SNL & Sandia National Laboratories \\
\hline SSW & shallow subsurface water \\
\hline SU & standard unit \\
\hline SWMU & solid waste management unit \\
\hline TDS & total dissolved solids \\
\hline TOX & total organic halogens \\
\hline TPU & total propagated uncertainty \\
\hline TRU & transuranic (waste) \\
\hline TSCA & Toxic Substances Control Act \\
\hline TSDF & treatment, storage, and disposal facility \\
\hline U.S. & United States \\
\hline U.S.C. & United States Code \\
\hline USFWS & U.S. Fish and Wildlife Service \\
\hline UST & underground storage tank \\
\hline UTLV & upper tolerance limit value \\
\hline VOC & volatile organic compound \\
\hline
\end{tabular}


Waste Isolation Pilot Plant Annual Site Environmental Report for 2006 DOE/WIPP-07-2225

WIPP

WQSP

WTS

$\mathrm{yr}$

year

$\sigma$

${ }^{\circ} \mathrm{C}$

${ }^{\circ} \mathrm{F}$

$\mathrm{M}$

$\mu \mathrm{Ci}$

$\mu \mathrm{g}$

$\mu$ mhos

$\%$

[RN]
Waste Isolation Pilot Plant

WIPP Groundwater Quality Sampling Program

Washington TRU Solutions LLC

\section{Symbols}

sigma

degrees Celsius

degrees Fahrenheit

molar

microCurie(s)

microgram(s)

micromhos

percent

radionuclide concentration 


\section{CHAPTER 1 - INTRODUCTION}

The purpose of this report is to provide information needed by the U.S. Department of Energy (DOE) to assess Waste Isolation Pilot Plant (WIPP) environmental performance and to make WIPP environmental information available to stakeholders and members of the public. This report has been prepared in accordance with DOE Order 231.1A, Environment, Safety, and Health Reporting. This report documents the WIPP environmental monitoring and results for calendar year (CY) 2006.

The WIPP facility is authorized by the DOE National Security and Military Applications of Nuclear Energy Authorization Act of 1980 (Public Law [Pub. L.] 96-164). After more than twenty years of scientific study and public input, the WIPP facility received its first shipment of waste on March 26, 1999.

Located in southeastern New Mexico, the WIPP facility is the nation's first underground repository permitted to safely and permanently dispose of transuranic (TRU) radioactive and mixed waste generated through defense activities and programs. TRU waste is defined in the WIPP Land Withdrawal Act of 1992 (LWA) (Pub. L. 102-579) as radioactive waste containing more than 100 nanocuries $(3,700$ becquerels $[\mathrm{Bq}])$ of alpha-emitting TRU isotopes per gram of waste, with half-lives greater than twenty years except for high-level waste, waste that has been determined not to require the degree of isolation required by the disposal regulations, and waste the U.S. Nuclear Regulatory Commission has approved for disposal. Most TRU waste is contaminated industrial trash, such as rags and old tools; sludges from solidified liquids; glass; metal; and other materials. The waste must also meet the criteria in Transuranic Waste Acceptance Criteria for the Waste Isolation Pilot Plant (DOE/WIPP-02-3122).

TRU waste is disposed of 655 meters $(\mathrm{m})(2,150$ feet [ft]) below the surface in excavated disposal rooms in the Salado Formation, which is a thick sequence of Permian Age evaporite beds. At the conclusion of the WIPP disposal phase, seals will be placed in the shafts. One of the main attributes of salt, as a rock formation in which to isolate radioactive waste, is the ability of the salt to creep, that is, to deform continuously over time. Excavations into which the waste-filled drums are placed will close eventually and the surrounding salt will flow around the drums and seal them within the Salado Formation. A detailed description of the WIPP geology and hydrology may be found in Chapter 2 of Title 40 CFR Part 191 Subparts B and C Compliance Recertification Application 2004 (DOE/WIPP-04-3231).

\subsection{WIPP Mission}

Current TRU waste storage facilities at locations across the United States were never intended to provide permanent disposal. The WIPP mission is to provide for the safe, permanent, and environmentally sound disposal of TRU radioactive waste left from research, development, and production of nuclear weapons. Over the planned 35-year operational lifetime, the WIPP facility is expected to receive approximately 37,000 shipments of waste from locations across the United States. 


\subsection{WIPP History}

Government officials and scientists initiated the WIPP site selection process in the 1950s. At that time, the National Academy of Sciences initiated an evaluation of stable geological formations to contain radioactive wastes for thousands of years. In 1955, after extensive study, salt deposits were recommended as a promising medium for the disposal of radioactive waste.

Salt deposits were selected as the host for the planned disposal of nuclear waste for several reasons. Most deposits of salt are found in stable geological areas with very little earthquake activity, assuring the stability of a waste repository. Salt deposits also demonstrate the absence of water that could move waste to the surface. Water, if it had been or were present, would have dissolved the salt beds. In addition, salt is relatively easy to mine. Finally, rock salt heals its own fractures because it is relatively plastic. This means salt formations will slowly and progressively move in to fill mined areas and will safely seal radioactive waste from the biosphere.

Government scientists searched for an appropriate site for the disposal of radioactive waste throughout the 1960s, and finally tested the area of southeastern New Mexico in the early 1970s. Salt formations at the WIPP site were deposited in thick beds during the evaporation of the Permian Sea. These geologic formations consist mainly of sodium chloride, the same substance as table salt. However, the salt is not granular, but in the form of solid rock. The main salt formation is approximately $610 \mathrm{~m}(2,000 \mathrm{ft})$ thick, and begins $259 \mathrm{~m}$ ( $850 \mathrm{ft}$ ) below the earth's surface. Formed during the Permian Age, the large expanses of uninterrupted salt beds provide a geologic environment that is stable.

In 1979, Congress authorized the construction of WIPP, and the DOE constructed the facility during the 1980s. In late 1993, the DOE created the Carlsbad Area Office (CAO), subsequently redesignated as the Carlsbad Field Office (CBFO) to lead the TRU waste disposal effort. The CBFO coordinates the TRU program at waste-generating sites and national laboratories.

In 1999, WIPP received its first waste shipment. On March 25, the first waste bound for WIPP departed Los Alamos National Laboratory in New Mexico; it arrived at the WIPP facility the following morning, and the first wastes were placed underground later that day. On April 27, the first out-of-state shipment arrived at the WIPP site from the Idaho National Engineering and Environmental Laboratory. Later in the year, on October 27, the Secretary of the New Mexico Environment Department (NMED) issued the WIPP Hazardous Waste Facility Permit (HWFP) (No. NM4890139088-TSDF [treatment, storage, and disposal facility]), which allows contact-handled $(\mathrm{CH})$ TRU mixed waste to be managed, stored, and disposed of at the WIPP facility. Mixed waste is waste contaminated by both hazardous and radioactive substances. $\mathrm{CH}$ mixed waste is TRU mixed waste with a surface dose rate less than 200 millirem (mrem) per hour. The surface dose rate is the measurable amount of radioactivity from neutrons and gamma rays at the external surface of the container. 
On October 16, 2006, the Secretary of the NMED issued a revised HWFP allowing the WIPP facility to receive remote-handled $(\mathrm{RH})$ TRU mixed waste. The revised HWFP became effective one month later. RH TRU waste allowable at the WIPP facility has a surface dose rate greater than or equal to 200 mrem per hour and up to 1,000 rem per hour. No RH TRU waste was received at the WIPP facility in 2006.

\subsection{Site Description}

Located in Eddy County in the Chihuahuan Desert of southeastern New Mexico (Figure 1.1), the WIPP site encompasses 41.4 square kilometers $\left(\mathrm{km}^{2}\right)$, or 16 square miles $\left(\mathrm{mi}^{2}\right)$. This part of New Mexico is relatively flat and is sparsely inhabited, with little surface water. The site is $42 \mathrm{~km}$ (26 mi) east of Carlsbad in a region known as Los Medaños (the Dunes).

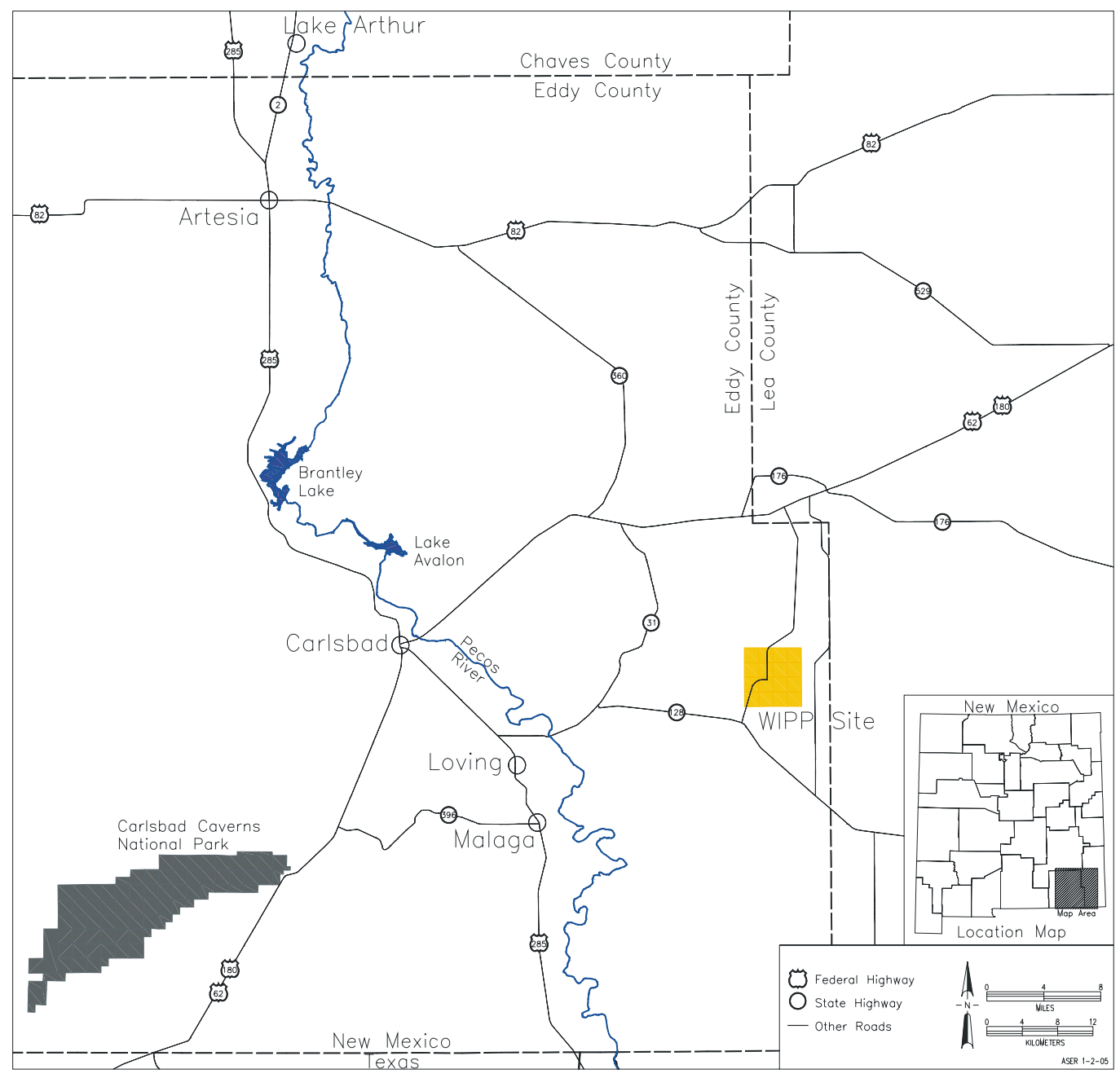

Figure 1.1 - WIPP Location

The WIPP LWA was signed into law on October 30,1992, transferring the administration of federal land from the U.S. Department of the Interior to the DOE. With 
the exception of facilities within the boundaries of the posted $1.2 \mathrm{~km}^{2}\left(0.463 \mathrm{mi}^{2}\right)$ Exclusive Use Area, the surface land uses remain largely unchanged from pre-1992 uses, and are managed in accordance with accepted practices for multiple land use. However, mining and drilling for purposes other than those which support WIPP are prohibited within the WIPP site, with the exception of two mineral leases. The WIPP site boundary extends a minimum of $1.6 \mathrm{~km}(1 \mathrm{mi})$ beyond any of the WIPP underground developments.

The majority of the lands in the immediate vicinity of WIPP are managed by the U.S. Department of the Interior Bureau of Land Management (BLM). Land uses in the surrounding area include livestock grazing; potash mining; oil and gas exploration and production; and recreational activities such as hunting, camping, hiking, and bird watching. The region is home to diverse populations of animals and plants.

\subsubsection{WIPP Property Areas}

Four property areas are defined within the WIPP boundary (Figure 1.2).

\section{Property Protection Area}

The interior core of the facility encompasses $0.129 \mathrm{~km}^{2}\left(0.05 \mathrm{mi}^{2}\right)$ (35 acres) surrounded by a chain link fence. This area is under tight security and uniformed security personnel are on duty 24 hours a day.

\section{Exclusive Use Area}

The Exclusive Use Area is comprised of $1.2 \mathrm{~km}^{2}$ (297 acres). It is surrounded by a five-strand barbed wire fence and is restricted exclusively for the use of the DOE and its contractors and subcontractors in support of the project. This area is marked by the DOE warning (e.g., "no trespassing") signs and is patrolled by WIPP security personnel to prevent unauthorized activities or uses.

\section{Off-Limits Area}

The Off-Limits Area is an area where unauthorized entry and introduction of weapons and/or dangerous materials are prohibited. The Off-Limits Area includes $5.7 \mathrm{~km}^{2}$ $\left(2.2 \mathrm{mi}^{2}\right)(1,421$ acres$)$. Pertinent prohibitions are posted at consistent intervals along the perimeter. Grazing and public thoroughfare will continue in this area unless these activities present a threat to the security, safety, or environmental quality of the WIPP site. This sector is patrolled by WIPP security personnel to prevent unauthorized activities or use.

\section{WIPP Land Withdrawal Area}

The WIPP site boundary delineates the perimeter of the $41.4 \mathrm{~km}^{2}\left(16 \mathrm{mi}^{2}\right)$ $(10,240$ acres) WIPP Land Withdrawal Area. This tract includes properties outlying the Property Protection Area, the Exclusive Use Area, and the Off-Limits Area. 


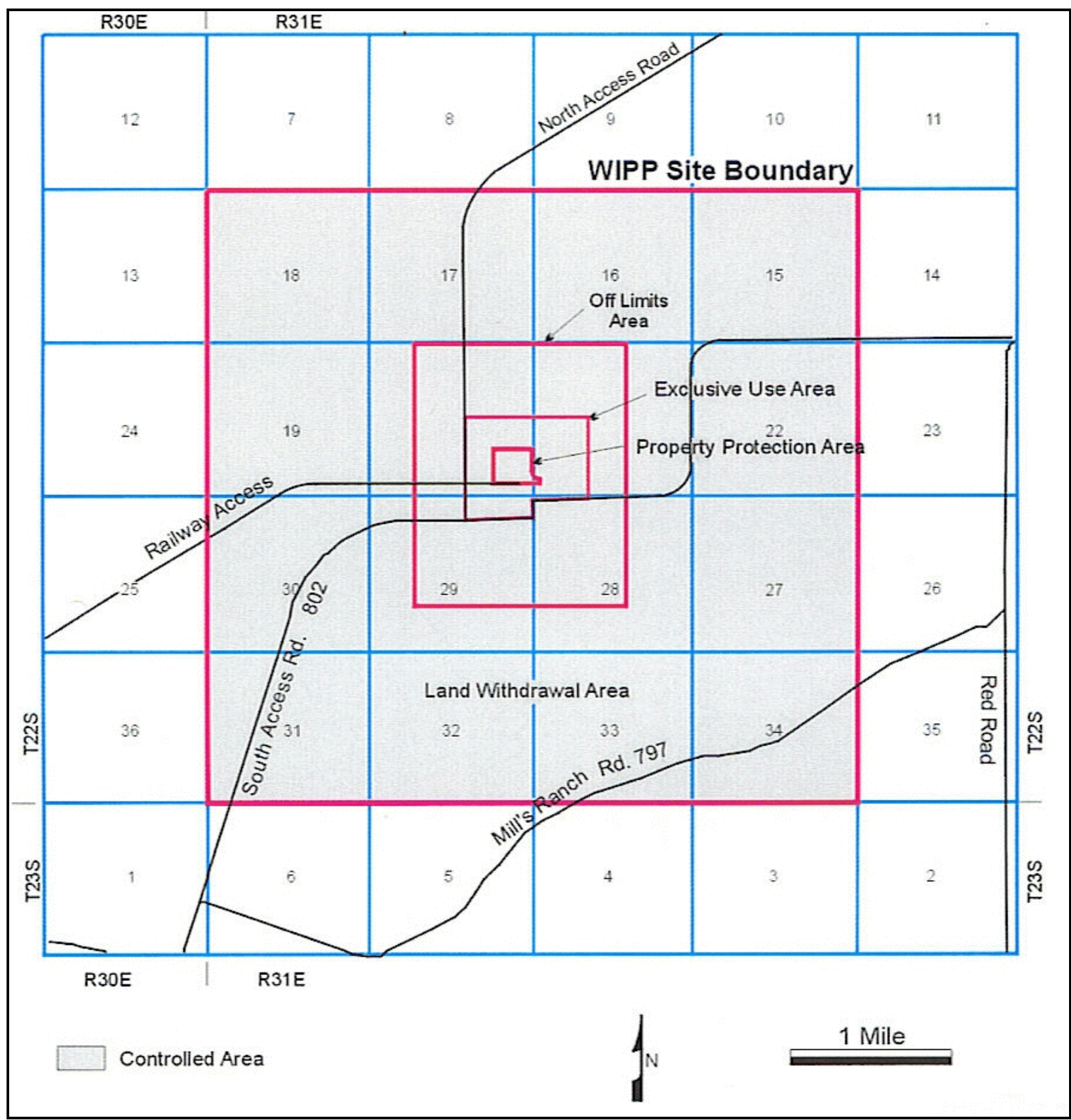

Figure 1.2 - WIPP Property Areas 
Special Management Areas

Certain properties used in the operation of WIPP (e.g., reclamation sites, well pads, roads) are, or may be, identified as Special Management Areas in accordance with the Waste Isolation Pilot Plant Land Management Plan (LMP) (DOE/WIPP 93-004), which is described further in Section 5.2. A Special Management Area designation is made due to values, resources, and/or circumstances that meet criteria for protection and management under special management designations. Unique resources of value that are in danger of being lost or damaged, areas where ongoing construction is occurring, fragile plant and/or animal communities, sites of archaeological significance, locations containing safety hazards, or sectors that may receive an unanticipated elevated security status would be suitable for designation as a Special Management Area. In 2006, there were no areas designated as Special Management Areas.

\subsubsection{Population}

There are 25 residents living within $16 \mathrm{~km}(10 \mathrm{mi})$ of the WIPP site (source: DOE/WIPP 93-004). The population within $16 \mathrm{~km}$ (10 mi) of WIPP is associated with ranching, oil and gas exploration/production, and potash mining. There are two nearby ranch residences, Smith Ranch and Mills Ranch.

The majority of the local population within $80.5 \mathrm{~km}(50 \mathrm{mi})$ of WIPP is concentrated in and around the communities of Carlsbad, Hobbs, Eunice, Loving, Jal, Lovington, and Artesia, New Mexico. The estimated population within this radius is 100,944 (source: 2000 census data). The nearest community is the village of Loving (estimated population 1,326), $29 \mathrm{~km}(18 \mathrm{mi})$ west-southwest of the WIPP site. The nearest major populated area is Carlsbad, $42 \mathrm{~km}(26 \mathrm{mi})$ west of the WIPP site. The estimated population of Carlsbad is 25,625 .

\subsection{WIPP Environmental Stewardship}

The DOE policy is to conduct its operations in compliance with applicable environmental laws and regulations, and to safeguard the integrity of the southeastern New Mexico environment. The DOE conducts effluent monitoring, environmental surveillance, land management, and assessments to verify that these objectives are met. Environmental monitoring includes collecting and analyzing environmental samples from various media and evaluating whether WIPP activities have caused any adverse environmental impacts.

\subsubsection{Environmental Monitoring Plan}

The WIPP Environmental Monitoring Plan (DOE/WIPP-2194) outlines the program for monitoring the environment at the WIPP site, including the major environmental monitoring and surveillance activities at the WIPP facility. The plan also discusses the WIPP quality assurance/quality control (QA/QC) program as it relates to environmental monitoring. The purpose of the plan is to specify how the effect of WIPP facility operations on the local ecosystem is to be determined. Effluent and environmental 
monitoring provide data necessary to demonstrate compliance with applicable environmental protection regulations. The frequency of 2006 sampling is provided in Table 1.1.

Table 1.1 - Environmental Monitoring Sampling ${ }^{1}$

\begin{tabular}{|c|c|c|c|}
\hline Program & Type of Sample & $\begin{array}{l}\text { Number of } \\
\text { Sampling } \\
\text { Locations }\end{array}$ & Sampling Frequency \\
\hline \multirow[t]{11}{*}{ Radiological } & Airborne effluent & 3 & Periodic/Confirmatory \\
\hline & Airborne particulate & 7 & Weekly \\
\hline & $\begin{array}{l}\text { Sewage treatment system } \\
(\mathrm{DP}-831)^{2}\end{array}$ & 3 & Semiannual \\
\hline & $\mathrm{H}-19(\mathrm{DP}-831)^{2}$ & 1 & Semiannual \\
\hline & Liquid effluent & 1 (WHB sump) & If needed \\
\hline & \multicolumn{3}{|l|}{ Biotic } \\
\hline & $\begin{array}{ll}\text { - } & \text { Quail } \\
\text { - } & \text { Rabbits } \\
\text { - } & \text { Beef/Deer } \\
\text { - } & \text { Fish } \\
\text { - } & \text { Vegetation }\end{array}$ & $\begin{array}{l}\text { WIPP vicinity } \\
\text { WIPP vicinity } \\
\text { WIPP vicinity } \\
3 \\
6\end{array}$ & $\begin{array}{l}\text { Annual } \\
\text { As available } \\
\text { As available } \\
\text { Annual } \\
\text { Annual }\end{array}$ \\
\hline & Soil & 6 & Annual \\
\hline & Surface water & Maximum of 14 & Annual \\
\hline & Sediment & $\begin{array}{l}\text { Maximum of 12; } 13 \text { if } \\
\text { sediment is present } \\
\text { at sewage lagoon } \\
\text { outfall }\end{array}$ & Annual \\
\hline & Groundwater & 7 & Semiannual \\
\hline \multirow[t]{6}{*}{ Nonradiological } & Meteorology & 1 & Continuous \\
\hline & \multicolumn{3}{|c|}{ Volatile Organic Compounds (VOCs) } \\
\hline & $\begin{array}{l}\text { - VOCs - Repository } \\
\text { - VOCs - Disposal Room }\end{array}$ & $\begin{array}{l}2 \\
\text { \# of active panel } \\
\text { disposal rooms }\end{array}$ & $\begin{array}{l}\text { Semiweekly } \\
\text { Biweekly }\end{array}$ \\
\hline & Groundwater & 7 & Semiannual \\
\hline & Shallow Subsurface Water & Maximum of 10 & Semiannual \\
\hline & Infiltration controls (DP-831) & 5 & $\begin{array}{l}\text { Annually after a storm } \\
\text { event }\end{array}$ \\
\hline
\end{tabular}

1 The number of certain types of samples taken can be driven by site conditions. For example, during dry periods there may be no surface water or sediment to sample at certain locations. Likewise, the number of samples for biota will also vary. For example, the number of rabbit available as samples of opportunity will vary as will fishing conditions that are affected by weather and algae levels in the water.

2 Includes a nonradiological program component.

The plan describes the monitoring of naturally occurring and specific anthropogenic (human-made) radionuclides. The geographic scope of radiological sampling is based on projections of potential release pathways from the waste disposed of at the WIPP 
facility. The plan also describes monitoring of VOCs, groundwater chemistry, and other nonradiological environmental parameters, and collection of meteorological data.

\subsubsection{WIPP Environmental Monitoring Program and Surveillance Activities}

WIPP employees monitor air, surface water, groundwater, sediments, soils, and biota (e.g., vegetation, select mammals, quail, and fish). Environmental monitoring activities are performed in accordance with procedures that govern how samples are to be taken, preserved, and transferred. Procedures also direct the verification and validation of environmental sampling data.

The atmospheric pathway, which can lead to the inhalation of radionuclides, has been determined to be the most likely exposure pathway to the public from WIPP. Therefore, airborne particulate sampling for alpha-emitting radionuclides is emphasized. Air sampling results are used to trend environmental radiological levels and determine if there has been a deviation from established baseline concentrations. The geographic scope of radiological sampling is based on projections of potential release pathways and nearby populations for the types of radionuclides in WIPP wastes, and includes Carlsbad, New Mexico, and nearby ranches.

Nonradiological environmental monitoring activities at the WIPP site consist of sampling and analyses designed to detect and quantify impacts of construction and operational activities, and verify compliance with applicable requirements. Ecological monitoring focuses on nonradiological effects of WIPP facility operations, such as impacts to wildlife habitat.

\subsection{Environmental Performance}

DOE Order 450.1, Environmental Protection Program, describes the DOE commitment to environmental protection and pledges to implement sound stewardship practices that are protective of the air, water, land, and other natural and cultural resources. The provisions of DOE Order 450.1 are implemented by the WIPP environmental policy and Environmental Management System (EMS).

In 2006, WIPP maintained compliance with applicable environmental laws, regulations, and permit conditions, except as noted in Section 2.2.2. Furthermore, analyses of the WIPP environmental monitoring data have demonstrated that WIPP operations have not had an adverse impact on the environment. Implementation of the WIPP Environmental Monitoring Plan fulfills the environmental monitoring requirements of DOE Order 450.1. Detailed information on WIPP programs are contained in the remaining chapters. 


\subsection{Organization of This Annual Site Environmental Report}

This Annual Site Environmental Report (ASER) is organized as follows:

- Chapter 2 is the Compliance Summary.

- $\quad$ Chapter 3 presents the WIPP Environmental Management System.

- $\quad$ Chapter 4 presents the WIPP Environmental Radiological Protection Program and Dose Assessment.

- $\quad$ Chapter 5 presents the WIPP Environmental Nonradiological Program information and results.

- $\quad$ Chapter 6 presents the WIPP Groundwater Protection Program and results.

- $\quad$ Chapter 7 contains information on Quality Assurance and results. 
Waste Isolation Pilot Plant Annual Site Environmental Report for 2006

DOE/WIPP-07-2225

This page intentionally left blank 


\section{CHAPTER 2 - COMPLIANCE SUMMARY}

The WIPP facility is required to comply with applicable federal and state statutes, and the applicable regulations promulgated pursuant to these statutes, DOE orders, and Executive Orders (EOs). Regulatory requirements are incorporated into facility plans and implementing procedures. The primary method for maintaining compliance with environmental requirements is through the use of engineered controls and written procedures, routine training of facility personnel, ongoing self-assessments, and personnel accountability.

\subsection{Compliance Overview}

In 2006, WIPP maintained compliance with applicable federal and state environmental statutes and regulations, applicable DOE orders, and EOs, excepting an administrative notice of violation discussed in Section 2.2.2. The following sections list the environmental statutes/regulations applicable to WIPP, and describe significant accomplishments and ongoing compliance activities. A detailed breakdown of WIPP compliance with environmental laws is available in the Waste Isolation Pilot Plant Biennial Environmental Compliance Report (DOE/WIPP 06-2171).

\subsection{Compliance Status}

A summary of WIPP compliance with major environmental regulations is presented below. A list of active WIPP environmental permits appears in Appendix B.

\subsubsection{Comprehensive Environmental Response, Compensation, and Liability Act}

The Comprehensive Environmental Response, Compensation, and Liability Act (CERCLA) (42 U.S.C. \$§9601, et seq.), or Superfund, establishes a comprehensive federal strategy for responding to, and establishing liability for, releases of hazardous substances from a facility to the environment. Any spills of hazardous substances that exceed a reportable quantity must be reported to the National Response Center under the provisions of CERCLA and Title 40 Code of Federal Regulations (CFR) Part 302, "Designation, Reportable Quantities, and Notification." Hazardous substance cleanup procedures are specified in 40 CFR Part 300, "National Oil and Hazardous Substances Pollution Contingency Plan." There were no reportable releases at WIPP in 2006, and no release sites have been identified at the WIPP site that would require cleanup under the provisions of CERCLA.

\section{Superfund Amendments and Reauthorization Act of 1986}

The WIPP facility is required by the Superfund Amendments and Reauthorization Act of 1986 (SARA) Title III (42 U.S.C. \$11101) (also known as the Emergency Planning and Community Right-to-Know Act [EPCRA], which is implemented by 40 CFR Parts 302-313) to submit (1) a list of hazardous chemicals present at the facility in excess of 10,000 pounds for which a Material Safety Data Sheet is required, (2) an 
Emergency and Hazardous Chemical Inventory Form (Tier II Form), which identifies the inventory of hazardous chemicals present during the preceding year, and (3) notification to the State Emergency Response Commission (SERC) and the Local Emergency Planning Committee of any accidental releases of hazardous chemicals in excess of reportable quantities. The list of hazardous chemicals and the Tier II Form are also submitted to the regional fire departments.

Title 40 CFR Part 313, "Toxics Release Inventory," identifies requirements for facilities to submit a toxic chemical release report to the U.S. Environmental Protection Agency (EPA) and the resident state if toxic chemicals are used at the facility in excess of established threshold amounts.

The list of chemicals provides external emergency responders with information they may need when responding to a hazardous chemical emergency at WIPP. The Tier II Form, due on March 1 of each year, provides information to the public about hazardous chemicals above threshold planning quantities that a facility has on-site at any time during the year. The Tier II Form is submitted annually to each fire department with which the CBFO maintains a memorandum of understanding and to the Local Emergency Planning Committee and the SERC. The list of chemicals is a one-time notification unless new chemicals in excess of 10,000 pounds, or new information on existing chemicals, is received. The last notification was made in 1999. The Toxic Chemical Release Report was submitted to the EPA and to the SERC prior to the July 1, 2006, reporting deadline. Table 2.1 presents the 2006 EPCRA reporting status. A response of "yes" indicates that the report was required and submitted.

Table 2.1 - Status of EPCRA Reporting

\begin{tabular}{|l|l|c|}
\hline $\begin{array}{c}\text { EPCRA Regulations - } \\
\text { 40 CFR Parts }\end{array}$ & \multicolumn{1}{|c|}{ Description of Reporting } & Status \\
\hline $302-303$ & Planning Notification & Further Notification Not Required \\
\hline 304 & $\begin{array}{l}\text { Extremely Hazardous Substance } \\
\text { Release Notification }\end{array}$ & Not Required \\
\hline $311-312$ & $\begin{array}{l}\text { Material Safety Data Sheet/Chemical } \\
\text { Inventory (Tier II Form) }\end{array}$ & Yes \\
\hline 313 & Toxics Release Inventory Reporting & Yes \\
\hline
\end{tabular}

Accidental Releases of Reportable Quantities of Hazardous Substances

During 2006, there were no releases of hazardous substances exceeding the reportable quantity limits.

\subsubsection{Resource Conservation and Recovery Act}

The Resource Conservation and Recovery Act (RCRA) (42 U.S.C. §§6901, et seq.) was enacted in 1976. Implementing regulations were promulgated in May 1980. This body of regulations ensures that hazardous waste is managed and disposed of in a way that protects human health and the environment. The Hazardous and Solid Waste 
Amendments of 1984 prohibit land disposal of hazardous waste unless treatment standards are met or specific exemptions apply. The amendments also emphasize waste minimization.

The NMED is authorized by the EPA to implement the hazardous waste program in New Mexico pursuant to the New Mexico Hazardous Waste Act (New Mexico Statutes Annotated [NMSA] §§74-4-1, et seq., 1978). The technical standards for hazardous waste treatment, storage, and disposal facilities in New Mexico are outlined in 20.4.1.500 New Mexico Administrative Code (NMAC), which adopts, by reference, 40 CFR Part 264, "Standards for Owners and Operators of Hazardous Waste Treatment, Storage, and Disposal Facilities." The hazardous waste management permitting program is administered through 20.4.1.900 NMAC, which adopts, by reference, 40 CFR Part 270, "EPA Administered Permit Programs: The Hazardous Waste Permit Program.")

\section{Hazardous Waste Facility Permit}

The NMED issued the WIPP HWFP on October 27, 1999, and it became effective November 26, 1999. The HWFP authorized WIPP to receive, store, and dispose of $\mathrm{CH}$ TRU mixed waste. The NMED modified the HWFP on October 16, 2006, to also allow receipt, storage, and disposal of RH TRU mixed waste. Two storage units (the parking area container storage unit and the Waste Handling Building container storage unit) are permitted for storage of TRU mixed waste. Seven underground hazardous waste disposal units are currently permitted for the disposal of $\mathrm{CH}$ and $\mathrm{RH} T R U$ mixed waste.

The NMED conducted a compliance evaluation inspection at the WIPP facility on January 24, 2006. On July 19, 2006, the NMED issued the WIPP permittees a notice of violation because the permittees failed to provide a copy of the current RCRA Contingency Plan to the Secretary of the NMED as required by the HWFP. In the same letter, the NMED noted that the deficiency had been adequately addressed and no further action would be required.

During the 2006 reporting period, extensive efforts were taken to ensure that the WIPP site could manage RH TRU mixed waste in compliance with federal, state, and local regulations and DOE orders. Contractor-led and DOE-led operational readiness reviews were conducted with full-scale demonstration activities from waste receipt through emplacement. The reviews included thorough evaluations that activities were conducted in accordance with the HWFP, EPA certification, and nuclear safety documents. The final DOE Operational Readiness Review was concluded December 13, 2006, with the issuance of a report recommending authorization to begin $\mathrm{RH}$ waste operations at WIPP with the provision of completing a few prestart findings. Prestart items are identified changes or corrections that must be made prior to receiving the first shipment of RH TRU waste.

In 2006, five HWFP modifications were submitted to the NMED in accordance with 20.4.1.900 NMAC. These modifications were all considered Class 1 notifications. The 
Class 1 changes were generally editorial corrections/updates to information in the HWFP and clarifications regarding inconsistent language. No Class 2 or Class 3 changes were submitted in 2006 . Table 2.2 provides details on the modification notices.

Table 2.2 - Permit Modification Notifications Submitted in 2006

\begin{tabular}{|c|c|c|}
\hline Class & Description & Date Submitted \\
\hline Class 1 & Notification to update the RCRA Contingency Plan & March 29, 2006 \\
\hline Class 1 & $\begin{array}{l}\text { Notification change in Uniform Hazardous Waste Manifest Requirements } \\
\text { to conform to new EPA and Hazardous Materials Transportation Act Rule }\end{array}$ & August 31, 2006 \\
\hline Class 1 & $\begin{array}{l}\text { Notification to revise HWFP to correct references, inconsistencies, and } \\
\text { figures }\end{array}$ & October 17,2006 \\
\hline Class 1 & Notification to update the RCRA Contingency Plan & October 17,2006 \\
\hline Class 1 & $\begin{array}{l}\text { Notification to correct inconsistency regarding radiological surveys, } \\
\text { correct inconsistencies regarding waste confirmation, correct procedure } \\
\text { numbers for inspections, correct equation reference, correct how RH } \\
\text { TRU mixed waste will be managed if equipment malfunctions, clarify } \\
\text { requirements for TRU mixed waste handlers, and revise section } \\
\text { numbers. }\end{array}$ & $\begin{array}{l}\text { November 30, } \\
2006\end{array}$ \\
\hline
\end{tabular}

\section{Underground Storage Tanks}

Title 40 CFR Part 280, "Technical Standards and Corrective Action Requirements for Owners and Operators of Underground Storage Tanks (UST)," addresses USTs containing petroleum products or hazardous chemicals. Requirements for UST management pertain to the design, construction, installation, and operation of USTs, as well as notification and corrective action requirements in the event of a release and actions required for out-of-service USTs. The NMED has been authorized by the EPA to regulate USTs, and implements the EPA program through 20.5 NMAC, "Petroleum Storage Tanks." WIPP maintains two USTs registered with the NMED.

The NMED conducted an inspection of the USTs on February 8, 2006. The tanks were determined to be maintained in compliance with the applicable regulations. The inspector did note a broken spill bucket drain valve which was promptly repaired. The inspector conducted a follow-up inspection on March 8, 2006, and noted that the valve had been repaired.

\section{Hazardous Waste Generator Compliance}

Nonradioactive hazardous waste is currently generated through routine facility operations, and is managed in satellite accumulation areas and a "less-than-90-day" accumulation area on the surface. A second, less-than-90-day accumulation area was established in the underground during this reporting period to collect water that originates in the exhaust shaft that has occasionally exhibited the hazardous characteristic of toxicity for lead. The new area was necessary due to changes in the manner in which the water is collected. Rather than removing the water from a sump into drums that can be stored in the surface hazardous waste accumulation area, 
automated pumps in interception boreholes are now used to collect the water in 500-gallon polyethylene containers.

Hazardous waste generated at the WIPP facility is accumulated, characterized, packaged, labeled, and manifested to off-site treatment, storage, and disposal facilities in accordance with the requirements codified in 20.4.1.300 NMAC, which adopts, by reference, 40 CFR Part 262, "Standards Applicable to Generators of Hazardous Waste."

\section{WIPP Solid Waste Management Units and Areas of Concern}

A No Further Action Report and Petition was submitted to the NMED in October 2002 for the purpose of removing the 15 solid waste management units (SWMUs) and eight Areas of Concern from the requirement for further remediation. Between the time of submittal through the end of this reporting period, informal discussions have been held between the DOE and the NMED regarding the status of this petition, and the DOE has submitted quarterly progress reports. The DOE anticipates that there will be a SWMU classification change during 2007 with a formal NMED approval of the No Further Action Report and Petition, and the processing of a Class 3 HWFP modification request to remove the aforementioned SWMUs and Areas of Concern from regulation under the HWFP.

\section{Program Deliverables and Schedule}

WIPP is in compliance with the HWFP conditions related to reporting as noted below:

$\bullet$ The annual Waste Minimization Certification Statement was completed and placed in the operating record as of November 2006 and was transmitted to the NMED.

- $\quad$ HWFP Module IV, Section F, Maintenance and Monitoring, requires annual reports evaluating the geomechanical monitoring program and describing the implementation and results (data and analysis) of the confirmatory VOC monitoring and the mine ventilation rate monitoring. The WIPP facility continued to comply with these requirements by preparation and submission of annual reports in October 2006, representing July 1, 2005, through June 30,2006 , results.

HWFP Module V, Section V.J.2.a, requires reports of the analytical results for semiannual detection monitoring program (DMP) well samples and duplicates as well as results of the statistical analysis of the samples from which the determination was made that there is or is no statistically significant evidence of contamination. These reports for Sampling Rounds 21 and 22 were submitted to the NMED in 2006. 


\subsubsection{National Environmental Policy Act}

The National Environmental Policy Act (NEPA) (42 U.S.C. $\S \$ 4321$, et seq.) requires the federal government to use all practicable means to consider potential environmental impacts of proposed projects as part of the decision-making process. The NEPA also dictates that the public shall be allowed to review and comment on proposed projects that have the potential to significantly affect the environment.

NEPA requirements are detailed in the Council on Environmental Quality regulations in 40 CFR Parts 1500-1508. The DOE codified its requirements for implementing the council's regulations in 10 CFR Part 1021, "National Environmental Policy Act Implementing Procedures." Title 10 CFR §1021.331 requires that, following completion of each environmental impact statement (EIS) and its associated Record of Decision, the DOE prepare a mitigation action plan that addresses mitigation commitments expressed in the Record of Decision. The first WIPP mitigation action plan was prepared in 1991. Additionally, the CBFO tracks the performance of mitigation commitments in the WIPP annual mitigation report. This report is issued in July of each year.

Day-to-day operational compliance with the NEPA at the WIPP facility is achieved through implementation of a NEPA compliance plan and procedure. Forty-five projects were reviewed and approved by the CBFO NEPA Compliance Officer through the NEPA screening and approval process in 2006 . These projects were primarily equipment upgrades at the WIPP site. These approvals were in addition to routine activities which have been predetermined to be bounded by existing NEPA documentation and which do not require additional evaluation by the CBFO NEPA Compliance Officer. There were no new major NEPA documents prepared in support of WIPP in 2006.

\subsubsection{Clean Air Act}

The Clean Air Act (42 U.S.C. $\S \S 7401$, et seq.) provides for the preservation, protection, and enhancement of air quality. Both the state of New Mexico and the EPA have authority for regulating compliance with portions of the Clean Air Act. Radiological effluent monitoring in compliance with EPA requirements is discussed in Section 2.2.15.

The Clean Air Act established National Ambient Air Quality Standards for six "criteria" pollutants: sulfur oxides, particulate matter, carbon monoxide, ozone, nitrogen dioxide, and lead. The initial 1993 WIPP air emissions inventory was developed as a baseline document to calculate maximum potential hourly and annual emissions of both hazardous and criteria pollutants. Based on the current air emissions inventory, WIPP operations do not exceed the 10-ton-per-year emission limit for any individual hazardous air pollutant or the 25-ton-per-year limit for any combination of hazardous air pollutant emissions, or the 10-ton-per-year emission limit for criteria pollutants except for total suspended particulate matter and particulate matter less than 10 microns in diameter. Particulate matter is produced from fugitive sources related to the management of salt tailings extracted from the underground. Consultation with the NMED Air Quality Bureau resulted in a March 2006 determination that a permit is not 
required for fugitive emissions of particulate matter that result from WIPP operations. Proposed facility modifications are reviewed to determine if they will create new air emission sources and require permit applications.

Based on the initial 1993 air emissions inventory, the WIPP site is not required to obtain Clean Air Act permits. WIPP was required to obtain a New Mexico Air Quality Control Regulation 702, Operating Permit (recodified in 2001 as 20.2.72 NMAC, "Construction Permits") for two backup diesel generators at the site in 1993. There have been no activities or modifications to the operating conditions of the diesel generators that would require reporting under the conditions of the permit in 2006.

\subsubsection{Clean Water Act}

The Clean Water Act (33 U.S.C. §§1251, et seq.) establishes provisions for the issuance of permits for discharges into waters of the United States. The regulation defining the scope of the permitting process is contained in 40 CFR $\S 122.1(\mathrm{~b})$, "Scope of the NPDES Permit Requirement," which states that "The NPDES program requires permits for the discharge of 'pollutants' from any 'point source' into 'waters of the United States."

The WIPP facility does not have any discharges into waters of the United States and is not subject to regulation under the National Pollutant Discharge Elimination System (NPDES) program. All waste waters generated at WIPP are either disposed of off-site or managed in on-site, lined evaporation ponds.

\subsubsection{New Mexico Water Quality Act}

The New Mexico Water Quality Act (\$§74-6-1, et seq., NMSA 1978) created the New Mexico Water Quality Control Commission and tasked the commission with the development of regulations to protect New Mexico ground and surface water. New Mexico water quality regulations for ground and surface water protection are contained in 20.6.2 NMAC, "Ground and Surface Water Protection." The WIPP facility does not have any discharges to surface water but does have a discharge permit for discharges that could impact groundwater.

The WIPP facility was issued a discharge permit (DP-831) from the NMED Ground Water Quality Bureau for the operation of the WIPP sewage treatment facility in January 1992. The permit was renewed and modified to include the $\mathrm{H}-19$ Evaporation Pond in July 1997. The H-19 Evaporation Pond is used for the treatment of wastewater generated during groundwater monitoring activities, water removed from sumps in the underground, and condensation from the mine ventilation system's duct work. This permit was last renewed in April 2003.

A discharge permit modification was issued on December 22, 2003, which incorporated subsurface discharges from the salt tailings pile where mined salt from the underground 
facilities are stored at the WIPP site. The permit modification incorporated the following storm water management activities into DP-831:

- $\quad$ Covering the existing salt pile with a 60-mil, high-density polyethylene liner covered with two feet of soil and seeded to establish native vegetation

- $\quad$ Constructing a new salt storage area (Salt Storage Extension) upon a 60-mil HDPE liner that drains storm water runoff to a double-lined pond with leak detection for evaporation.

- $\quad$ Lining three other ponds with synthetic liners to collect and evaporate storm water runoff, minimizing infiltration to the subsurface.

At the request of the Ground Water Quality Bureau in September 2004, a permit modification application was submitted to the Ground Water Quality Bureau on March 4, 2005, which included:

- $\quad$ An evaluation of all options for the ultimate disposition of salt piles.

- A more comprehensive closure plan addressing the final disposition of all active and inactive salt piles.

- $\quad$ A description of the SWMUs outlined in the RCRA Facility Assessment and the HWFP.

On August 5, 2005, the Ground Water Quality Bureau requested additional information regarding the permit application which was provided on September 12, 2005. The revised permit was issued on December 29,2006 . The revised permit requires the submittal of a plan and schedule to install three new groundwater monitoring wells in the vicinity of the site and preliminary design validation salt pile within 90 days of the issuance of the permit. The revised permit also requires the submittal of proposed plan to estimate the seepage of subsurface shallow water into the exhaust shaft within 60 days of permit issuance.

During this reporting period, the liners in two of seven sewage treatment lagoons were replaced (one settling pond and one polishing pond). The WIPP facility has committed to replacing or repairing the liners in the seven sewage lagoons over a period of five years.

Two semiannual discharge monitoring reports were submitted to the NMED for the 2006 reporting period to demonstrate compliance with the inspection, monitoring, and reporting requirements identified in DP-831. The monitoring results are presented in Section 5.6. 


\subsubsection{Safe Drinking Water Act}

The Safe Drinking Water Act (42 U.S.C. §§300f, et seq.) provides the regulatory strategy for protecting public water supply systems and underground sources of drinking water. New Mexico's drinking water regulations are contained in 20.7.10 NMAC, "Drinking Water," which adopts, by reference, 40 CFR Part 141, "National Primary Drinking Water Regulations," and 40 CFR Part 143, "National Secondary Drinking Water Regulations." Water is supplied to the WIPP site by the city of Carlsbad; however, the WIPP facility is classified as a nontransient, noncommunity water system subject to the New Mexico drinking water regulations.

The WIPP facility qualifies for a reduced monitoring schedule under 40 CFR $\S 141.86(d)(4)$, and is required to sample for lead and copper every three years. Drinking water was last sampled in August 2005. All samples were below action levels as specified by New Mexico monitoring requirements for lead and copper in tap water. The next lead and copper samples will be collected between June and September 2008.

Bacterial samples were collected and residual chlorine levels were tested monthly throughout 2006. Chlorine levels were reported to the NMED monthly. All bacteriological analytical results were below the Safe Drinking Water Act regulatory limits.

\subsubsection{National Historic Preservation Act}

The National Historic Preservation Act (16 U.S.C. $\S \S 470$, et seq.) was enacted to protect the nation's cultural resources and establish the National Register of Historic Places. No archaeological investigations were required to support WIPP operations in 2006.

\subsubsection{Toxic Substances Control Act}

The Toxic Substances Control Act (TSCA) (15 U.S.C. $\S \S 2601$, et seq.) was enacted to provide information about all chemicals and to control the production of new chemicals that might present an unreasonable risk of injury to health or the environment. The TSCA authorizes the EPA to require testing of old and new chemical substances. The TSCA also provides the EPA authority to regulate the manufacturing, processing, import, use, and disposal of chemicals.

Polychlorinated biphenyls (PCBs) are one of the compounds regulated by the TSCA. The PCB storage and disposal regulations are listed in the applicable subparts of 40 CFR Part 761, "Polychlorinated Biphenyls (PCBs) Manufacturing, Processing, Distribution in Commerce, and Use Prohibitions." On May 15, 2003, EPA Region VI approved the disposal of waste containing PCBs at the WIPP facility. The WIPP site began receiving PCB-contaminated waste on February 5, 2005. The required PCB annual report, containing information on PCB waste received and disposed of at the WIPP facility in 2005, was submitted to EPA Region VI on June 30, 2006. 
On April 6, 2006, the DOE requested a modification to its conditions of approval for the purpose of disposing RH TRU waste containing PCBs. The EPA Region VI granted this request on November 15, 2006.

\subsubsection{Federal Insecticide, Fungicide, and Rodenticide Act}

The Federal Insecticide, Fungicide, and Rodenticide Act (FIFRA) (7 U.S.C. §§136, et seq.) authorizes the EPA to regulate the registration, certification, use, storage, disposal, transportation, and recall of pesticides. FIFRA authorizes the EPA to establish regulations and procedures regarding the disposal or storage of packages and containers of pesticides and the disposal or storage of excess amounts of such pesticides. The FIFRA regulations are found in 40 CFR Parts 150-189.

All applications of restricted-use pesticides at the WIPP a facility are conducted by commercial pesticide contractors who are required to meet federal and state standards. These contractors store and dispose of pesticides off-site. General-use pesticides are stored according to label instructions. Used, empty cans are discarded by WIPP personnel into satellite accumulation area containers and managed as hazardous waste.

\subsubsection{Endangered Species Act}

The Endangered Species Act (16 U.S.C. §§1531, et seq.) was enacted in 1973 to prevent the extinction of certain species of animals and plants. This act provides strong measures to help alleviate the loss of species and their habitats, and places restrictions on activities that may affect endangered and threatened animals and plants to help ensure their continued survival. With limited exceptions, this act prohibits activities that could impact protected species, unless a permit is granted from the U.S. Fish and Wildlife Service (USFWS). A biological assessment and "formal consultation," followed by the issuance of a "biological opinion" by the USFWS, may be required for any species that is determined to be in potential jeopardy.

To ensure that WIPP environmental protection programs are current in their consideration of sensitive and protected species, a threatened and endangered species survey was conducted from August to November 1996. No threatened or endangered species were found within the WIPP LWA boundaries during the 1996 survey. The DOE has determined that activities associated with the operation of WIPP will have no impact on any threatened or endangered species. Considerations pertaining to protected species are implemented in accordance with the LMP during the deliberation and administration of projects conducted on WIPP lands.

Although there are no known species of plants or animals at the WIPP site that are protected by the Endangered Species Act, the Lesser Prairie Chicken, which is a candidate for listing under the act, does have favorable habitat within the WIPP LWA and other surrounding areas impacted by WIPP operational activities (e.g., drilling boreholes). Therefore, WIPP employees have instituted measures, in consultation with the BLM, to protect the Lesser Prairie Chicken and its habitat. Thus, adherence to 
established BLM time periods during which off-site field activities may not be performed during the Lesser Prairie Chicken's breeding season are in effect for the WIPP site. In 2006, there were no instances associated with WIPP operational activities that had any implications associated with the act.

\subsubsection{Migratory Bird Treaty Act}

The Migratory Bird Treaty Act (16 U.S.C. $\$ \S 703$, et seq.) is intended to protect birds that have common migratory flyways between the United States, Canada, Mexico, Japan, and Russia. The act makes it unlawful "at any time, by any means or in any manner, to pursue, hunt, take, capture, kill, or attempt to take, capture, or kill . . . any migratory bird, any part, nest, or eggs of any such bird" unless specifically authorized by the Secretary of the Interior by direction or through regulations permitting and governing these actions.

Under the Migratory Bird Treaty Act, the CBFO is required to consult annually with the USFWS with respect to impacts on migratory game birds and crows resulting from the hunting activities permitted on WIPP lands. Hunting privileges for the public within the WIPP land withdrawal area are subject to regulations implementing the Migratory Bird Treaty Act (50 CFR Part 20, "Migratory Bird Hunting"), which regulate the harvest of migratory birds by specifying the mode of harvest, hunting seasons, and possession limits.

In 2006, one nest of roadrunner eggs was transferred to a licensed wildlife rehabilitation clinic after consultation and approval by the USFWS. The eggs successfully hatched, but the fledglings did not survive. There were no other incidences at WIPP in 2006 that required interaction with the USFWS related to migratory birds.

\subsubsection{Federal Land Policy and Management Act}

The objective of the Federal Land Policy and Management Act (FLPMA) (43 U.S.C. $\S \S 1701$, et seq.) is to ensure that:

... public lands be managed in a manner that will protect the quality of scientific, scenic, historical, ecological, environmental, air and atmospheric, water resource, and archeological values; that, where appropriate, will preserve and protect certain public lands in their natural condition; that will provide food and habitat for fish and wildlife and domestic animals; and that will provide for outdoor recreation and human occupancy and use.

Title II under the FLPMA, Land Use Planning; Land Acquisition and Disposition, directs the Secretary of the Interior to prepare and maintain an inventory of all public lands and to develop and maintain, with public involvement, land-use plans regardless of whether subject public lands have been classified as withdrawn, set aside, or otherwise designated. The DOE developed, and operates in accordance with, the WIPP LMP, which is described in further detail in Section 5.2. 
Under Title V, Rights-of-Way, the Secretary of the Interior is authorized to grant, issue, or renew rights-of-way over, upon, under, or through public lands. To date, several right-of-way reservations and land-use permits have been granted to the DOE.

Examples of right-of-way permits include those obtained for a water pipeline, an access road, a caliche borrow pit, and a sampling station. Each "facility" (road, pipeline, railroad, etc.) is maintained and operated in accordance with the stipulations provided in the respective right-of-way reservation. Areas that are the subject of a right-of-way reservation are reclaimed and revegetated consistent with the terms of the right-of-way. A list of WIPP active environmental permits, including rights-of-way, is in Appendix B of this report.

\subsubsection{Federal Facilities Compliance Act}

The Federal Facilities Compliance Act (FFCA) of 1992 (42 U.S.C. §§6912, 6939c, and 6961) amended Section 6001 of the Solid Waste Disposal Act and was designed to bring federal facilities (including those under the DOE) into full compliance with RCRA. The FFCA waives the government's sovereign immunity, allowing fines and penalties to be imposed for RCRA violations at DOE facilities. In addition, the FFCA requires that the DOE facilities provide comprehensive data to the EPA and state regulatory agencies on mixed waste inventories, treatment capacities, and treatment plans for each site. The FFCA ensures that the public will be informed of waste treatment options and encourages active public participation in the decisions affecting federal facilities. The FFCA does not require disposal plans. Furthermore, the waste that is designated by the Secretary of Energy for disposal at WIPP is exempted from the land disposal restriction treatment requirements found in 42 U.S.C. $\$ 6924(\mathrm{~m})$, "Treatment Standards for Wastes Subject to Land Disposal," pursuant to Section 9 of the WIPP LWA.

\subsubsection{Atomic Energy Act}

The Atomic Energy Act of 1954, as amended (42 U.S.C. §§2011, et seq.), initiated a national program for research, development, and use of atomic energy for both national defense and domestic civilian purposes. The authority of the EPA to establish generally applicable standards for the protection of the public and the environment from radiation is derived from the Atomic Energy Act, as amended; the Nuclear Waste Policy Act of 1982 (42 U.S.C. $\S \S 10101$, et seq.); the Reorganization Plan of 1970, and the WIPP LWA. Under the WIPP LWA, Congress required the DOE to submit a compliance certification application to demonstrate WIPP compliance with the EPA radioactive waste disposal standards. Congress also required that the EPA certify the DOE's compliance before operations could commence.

The DOE demonstrated compliance with the EPA final disposal regulations in accordance with the criteria of 40 CFR Part 194, "Criteria for the Certification and Recertification of the WIPP's Compliance with the 40 CFR Part 191 Disposal Regulations," with the submittal of a compliance certification application to the EPA in October 1996. The EPA certified WIPP as a TRU waste disposal facility on May 18, 1998. Section 8 of the LWA requires the EPA, subsequent to the initial certification, to conduct periodic recertifications of compliance beginning five years after the initial 
receipt of TRU waste for disposal (March 26, 1999) and at five-year intervals thereafter until the end of the decommissioning phase.

The DOE submitted a compliance recertification application to the EPA on March 26, 2004 (Title 40 CFR Part 191 Subparts B and C Compliance Recertification Application 2004, DOE/WIPP-04-3231). The EPA informed the DOE that its application was complete on September 29, 2005. This Notification of Completeness of the Department of Energy's Compliance Recertification Application for the Waste Isolation Pilot Plant was reported in the Federal Register (FR) on October 20, 2005 (70 FR 61107-61111, 2005). The EPA recertification decision for WIPP was reported April 10, 2006 (71 FR 18010-18021, 2006).

The requirements of 40 CFR Part 194 also allow the EPA to oversee protection of human health and the environment from radiation in accordance with 40 CFR 191, Subpart A, "Environmental Standards for Management and Storage." These standards set the operational requirements limiting annual radiation doses to members of the public from the management and storage operations at disposal facilities operated by the DOE and not regulated by either the U.S. Nuclear Regulatory Commission or agreement states. The annual dose equivalent to any member of the public in the general environment resulting from discharges of radioactive material and direct radiation from management and storage may not exceed $25 \mathrm{mrem}$ to the whole body and 75 mrem to any other critical organ. Compliance with 40 CFR Part 191, Subpart A, is established by radiological monitoring and sampling of the air pathway. To assess releases along the air pathway, WIPP employees implement a biota sampling program and an off-site radiological air monitoring program. The results of monitoring and dose calculations have confirmed that there have been no releases of radionuclides that may adversely impact the public. WIPP personnel have conducted periodic confirmatory monitoring since receipt of waste began in March 1999. Results of the monitoring program demonstrate compliance with the dose limits discussed above and are addressed in further detail in Chapter 4.

WIPP is subject to EPA inspections in accordance with 40 CFR §194.21, "Inspections." The EPA conducted the following audits and inspections at the WIPP site in 2006.

- $\quad$ May 9-11, 2006, the EPA inspected a DOE audit of the Washington TRU Solutions (WTS) QA program for WIPP. The audit showed that the CBFO QA program continues to be properly maintained for the Nuclear Quality Assurance (NQA) organizational element evaluated. The EPA did not identify any findings of nonconformance or concerns as a result of the audit (EPA, 2006a).

June 6-8, 2006, the EPA conducted an audit of the QA program of the Los Alamos National Laboratory Carlsbad Office because they maintain the TRU waste inventory estimates for the DOE. The EPA did not identify any nonconformances in the Los Alamos National Laboratory Carlsbad Office QA program compliance with NQA standards (EPA, 2006b). 
June 20-22, 2006, the EPA conducted their Annual Monitoring Inspection of 40 CFR 191, Subpart A, "Monitoring Programs and Waste Emplacement Process," and there were no findings or concerns (EPA, 2006c).

The WIPP-specific criteria also established reporting requirements for the DOE. The criterion of 40 CFR $\$ 194.4$, "Conditions of Compliance Certification," provides requirements and schedules for reporting planned and unplanned changes that are significant or nonsignificant to the certification/recertification. This section also addresses reporting requirements for a release or expected release and the required reporting schedules. In 2006, the DOE did not submit any reports on significant planned or unplanned changes to the EPA nor did they report any releases or expected releases. In November 2006, the DOE submitted The Annual Change Report - 20052006, DOE/WIPP 06-3317, documenting nonsignificant changes to the certification that occurred between July 1, 2005, and June 30, 2006.

Notifications, nonsignificant changes, and relevant reports issued in 2006 included:

$\bullet$ The EPA approved the DOE to begin characterizing retrievably-stored $\mathrm{RH}$, debris waste by Idaho National Laboratory, Central Characterization Project (EPA, 2006d).

- $\quad$ Minor changes and improvements were made in performance assessment software and hardware.

- $\quad$ The DOE requested that the EPA reduce the amount of magnesium oxide required to be emplaced in the repository on April 10, 2006 (DOE, 2006a).

- $\quad$ The EPA recertified that the WIPP facility continues to comply with the Environmental Standards for the Management and Disposal of Spent Nuclear Fuel, High-Level and Transuranic (TRU) Radioactive Waste set forth in Subparts B and C of 40 CFR Part 191, "Environmental Standards for Disposal," and "Environmental Standards for Ground-Water Protection," respectively (71 FR 18010-18021, 2006).

- $\quad$ On February 27, 2006, the DOE notified the EPA of a new waste container known as the Standard Large Box (SLB2) to transport contact handled waste (DOE, 2006b).

- Issuance of the Geotechnical Analysis Report for July 2004 - June 2005, DOE/WIPP 06-3177, in April 2006. 
- Issuance of the Delaware Basin Monitoring Annual Report, DOE/WIPP 06-2308, in September 2006.

- Issuance of the Waste Isolation Pilot Plant 2005 Site Environmental Report, DOE/WIPP 06-2225, in September 2006.

- $\quad$ Issuance of the Waste Isolation Pilot Plant Biennial Environmental Compliance Report, DOE/WIPP 06-2171, in October 2006.

- $\quad$ Issuance of the WIPP Subsidence Monument Leveling Survey 2005, DOE/WIPP 07-2293, on December 2006.

- The following new Culebra Member monitoring wells were drilled: SNL-10, SNL-16, SNL-18, SNL-19, and SNL-17A.

- $\quad$ The following monitoring wells were plugged and abandoned: WIPP-26, WIPP-27, P-17, and DOE-1.

\subsubsection{DOE Orders}

The DOE uses a system of orders, notices, directives, and policies to implement its programs under the Atomic Energy Act and to ensure compliance with the requirements of the Atomic Energy Act. An assessment process is in place to assure compliance with environmental, safety, and health-related orders.

\subsubsection{DOE Order 231.1A, Environment, Safety and Health Reporting}

This order specifies collection and reporting of information on environment, safety, and health that are required by law or regulation, or that are essential for evaluating DOE operations and identifying opportunities for improvement needed for planning purposes within the DOE. The order specifies the reports that must be filed, the persons or organizations responsible for filing the reports, the recipients of the reports, the format in which the reports must be prepared, and the schedule for filing the reports. This order is implemented at WIPP through the Annual NEPA Planning Summary, Environmental Monitoring Plan, the ASER, the Hazardous and Universal Waste Management Plan, the HWFP Reporting and Notifications Compliance Plan, the Radiation Safety Manual, the dosimetry program, the fire protection program, and WIPP procedures.

\subsubsection{DOE Order 414.1C, Quality Assurance}

This order provides DOE policy, sets forth principles, and assigns responsibilities for establishing, implementing, and maintaining programs, plans, and actions to ensure quality achievement in DOE programs. This order is implemented through the WIPP QA program documents. 


\subsubsection{DOE Order 435.1, Radioactive Waste Management}

The objective of this order is to ensure that all DOE radioactive waste, including TRU waste that is disposed at the WIPP site, is managed in a manner that is protective of workers and the public. In the event that a conflict exists between any requirements of this order and the WIPP LWA regarding their application to WIPP, the requirements of the WIPP LWA prevail. The WIPP facility implements the requirements of this order through the Waste Acceptance Criteria and procedures governing the management and disposal of site-generated radioactive waste.

\subsubsection{DOE Order 450.1, Environmental Protection Program}

This order requires that DOE sites implement sound stewardship practices that are protective of the air, water, land, natural and cultural resources, and cost effectively meet or exceed compliance requirements. It required that this be accomplished by implementing an EMS that is part of the site Integrated Safety Management System (ISMS) by December 31, 2005. The WIPP facility has operated using an EMS that is in alignment with the International Organization for Standards (ISO) 14001 EMS Standard (Environmental Management Systems - Specification with Guidance for Use) since 1997 and was certified to the standard in 1998. After this order was issued, the existing EMS was evaluated and actions were taken to assure integration into the site ISMS and to verify implementation. In October 2005, the WIPP facility self-declared compliance with the order's requirements as a result of this work. The WIPP facility has maintained compliance with the order's requirements as confirmed through the Annual Review of the WIPP Integrated Safety Management System, September, 2006. Chapter 3 provides the detailed discussion of the WIPP EMS and its implementation.

\subsubsection{DOE Order 451.1B, National Environmental Policy Act Compliance Program}

This order establishes DOE requirements and responsibilities for implementing the NEPA, the Council on Environmental Quality Regulations Implementing the Procedural Provisions of NEPA (40 CFR Parts 1500-1508), and the DOE NEPA implementing procedures (10 CFR Part 1021). This order is implemented at WIPP through compliance plans and a screening procedure. These tools are used to evaluate environmental impacts associated with proposed activities and to determine if additional analyses are required.

\subsubsection{DOE Order 5400.5, Radiation Protection of the Public and the Environment}

This order, along with portions of DOE Order 231.1A, establishes standards and requirements for operations of the DOE and its contractors with respect to protecting members of the public and the environment against undue risk from radiation. Activities and analyses describing compliance with the applicable requirements of the order are contained in DOE/WIPP 95-2065, Waste Isolated Pilot Plant Contact Handled (CH) Documented Safety Analysis. Monitoring activities to document compliance with the 
order are described in the WIPP ALARA (as low as reasonably achievable) program manual, the WIPP Environmental Monitoring Plan, the records management program, and the radiation safety manual.

\subsubsection{Executive Orders}

EOs are legally binding orders given by the President, acting as the head of the Executive Branch, to Federal Administrative Agencies. EOs are generally used to direct federal agencies and officials in their execution of congressionally established laws or policies. Compliance with the EOs in this section is accomplished through the WIPP programs, plans, and procedures that comply with the EO's implementing DOE order. Compliance is confirmed through the WIPP assessment process.

\subsubsection{Executive Order 13101, Greening the Government Through Waste Prevention, Recycling, and Federal Acquisition}

This EO requires that federal agencies incorporate waste prevention and recycling into operations, establish goals for solid waste prevention and recycling, develop and implement affirmative procurement programs, purchase environmentally preferable products/materials, and track purchases of EPA-designated recycle content items. Programs for pollution prevention (P2) and affirmative procurement (purchase of environmentally preferable products) is also mandated by the RCRA. The DOE adopted and implemented the Environmentally Preferable Products Program in response to these requirements. This program requires all DOE sites to develop and institute P2 and affirmative procurement plans.

The WIPP facility has integrated these requirements into its operations through implementation of the Waste Isolation Pilot Plant Pollution Prevention Program Plan (WP 02-EC.11) and Waste Isolation Pilot Plant Affirmative Procurement Plan (WP 02-EC.07). The WIPP P2 program facilitates integration of P2 into operations through five mechanisms. These mechanisms and WIPP progress in these areas are summarized in the following paragraphs.

First, WIPP employees use annual goals to maintain organizational focus and direct P2 action. WIPP employees established eight environmental goals for FY 2006. The goals are discussed in Section 3.2.4. A detailed description of progress toward meeting these goals is included in Figure 3.1.

The second mechanism is to maintain employee awareness of P2. In 2006, actions to increase employee awareness included:

- $\quad$ Monthly P2 News articles were published as well as periodic articles in the TRU News.

- $\quad$ P2 was the focus of the Earth Day celebration. 
- $\quad \mathrm{P} 2$ information was updated in the General Employee Training courses in preparation for employees 2006 basic and/or refresher training.

- $\quad$ The P2 website was kept up to date in an easy to use format and included practical tools and information for personnel.

P2 Opportunity Assessments (PPOAs) are the third mechanism used to integrate P2 into WIPP operations. These assessments are used to evaluate potential opportunities for improving various facets of P2 performance-based goals (recycling, affirmative procurement, waste minimization, and waste prevention). Seven PPOAs were completed and were implemented in accordance with assessment recommendations. These are summarized below:

PPOA 06-001: Use of Biodiesel for Mining Equipment

The use of a maximum blend of 20 percent biodiesel/ 80 percent petrodiesel could be used in the mining equipment and would result in greenhouse gas emission reduction. Given advances in commercial availability of pre-blended biodiesel, there is potential for decreases in fuel inefficiencies and nitrous oxide emission increases that have been historically associated with use of biodiesel. Use of biodiesel requires identifying and addressing needs of site for assuring continuous operation of equipment, for establishing the supply source for biodiesel and performing planning and implementation for testing of the fuel.

\section{PPOA 06-002: Well Pad Reclamation}

The traditional method for reclamation of well pads was analyzed and as a result, was modified and used successfully during 2006. Benefits from the modification include eliminating materials being sent for off-site management and disposal, minimizing and in most cases eliminating use of new resources, reducing the amount of fuel associated with vehicle emissions incurred from hauling materials and more cost effective restoration of Lesser Prairie Chicken habitat areas. Using the revised method also resulted in overall savings of $\$ 50,000$ for the year and, for future well pads reclaimed will yield future savings of approximately $\$ 16,000$ per well pad.

PPOA 06-003 Wash Bay Water - Eliminating or Reducing RCRA Waste

This assessment was continued from FY 2005 and focused on eliminating or reducing the quantity of hazardous wastewater generated as a result of routine, but infrequent, washing of mining equipment. The FY 2006 focus was on determining if materials containing cadmium could be isolated from materials not containing cadmium as equipment is washed. Materials from areas expected to contain cadmium were sampled and analyzed. Results did not 


\begin{abstract}
definitively identify cadmium sources and indicated segregation of materials is not feasible.

PPOA 06-004: Construction of Access Road to Water Quality Sampling Program (WQSP) Well \#3

Planning and assessment of construction options for the required access road to this well was performed by WIPP operations and environmental groups. This assessment resulted in disturbance of land and wildlife being minimized for construction of the road, using reclaimed materials rather than new materials, and savings in material expense and fuel use and its associated emissions.

PPOA 06-005 Waste Minimization and Reuse of Sandblasting Material

WIPP maintenance personnel identified that sandblasting materials from a preventive maintenance event on the site water supply tanks were reusable as replacement for sand that would normally be purchased to fill traffic markers for stability. After confirming the material was nonhazardous, nine tons of sand was reused, eliminating the need to send it to the landfill.

PPOA 06-006 Paper Reduction

$\mathrm{RH}$ Waste Operations evaluated the process for completing the $\mathrm{RH}$ Line Management Assessment and found an opportunity to streamline the reviews and reduce paper usage. This PPOA resulted in the use of an electronic versus paper review process for the over 300 affidavits that had to be reviewed by a team of up to ten people. As a result, over forty reams of paper were not required to be purchased and then recycled or disposed. In addition, the equipment necessary to conduct paperless meetings is now available for use in site conference/meeting rooms.

PPOA 06-007 Environmentally Preferred Products for Janitorial Service

Existing cleaning products used by the janitorial service were inventoried and alternative, more environmentally friendly products were researched. The conclusion was that there were several products available that would potentially meet necessary cost, availability and performance criteria. Testing of selected products will begin in the next annual reporting period.
\end{abstract}

The fourth mechanism used to integrate $\mathrm{P} 2$ is maintaining a strong recycling program. The WIPP recycling program continued to be healthy in 2006. Table 2.3 identifies the volumes recycled at WIPP for FY 2004 through FY 2006. 
Waste Isolation Pilot Plant Annual Site Environmental Report for 2006 DOE/WIPP-07-2225

\begin{tabular}{|c|c|c|c|}
\hline $\begin{array}{l}\text { Recycled Material } \\
\text { (metric tons) }\end{array}$ & FY 2004 & FY 2005 & FY 2006 \\
\hline \multicolumn{4}{|l|}{ Paper Products: } \\
\hline Office and Mixed Paper & 0.1 & 15.5 & 19.3 \\
\hline Cardboard & 4.7 & 5.5 & 4.6 \\
\hline \multicolumn{4}{|l|}{ Scrap Metals: } \\
\hline Aluminum cans & 0.3 & 0.3 & 0.1 \\
\hline Scrap Metal - Miscellaneous & 100.4 & 81.3 & 98.8 \\
\hline \multicolumn{4}{|l|}{ Other Items } \\
\hline Ethylene glycol & 4.5 & 4.9 & 0.3 \\
\hline Oil & 5.8 & 3.9 & 5.1 \\
\hline Toner cartridges & 0 & 0.5 & 0.5 \\
\hline Wet batteries & 12.1 & 13.4 & 21.7 \\
\hline $\begin{array}{l}\text { Fluorescent bulbs/high-pressure } \\
\text { sodium bulbs }\end{array}$ & 0.3 & 0.2 & 0.3 \\
\hline Wood & 0 & 3.2 & 0 \\
\hline Silver & 0 & 0 & 0 \\
\hline Plastic & 0 & 0.4 & 1.0 \\
\hline Computer equipment & 3.9 & 4.3 & 18.0 \\
\hline Other Recycled Items & 0 & 12.8 & 9.6 \\
\hline Total Recycled & 132.1 & 146.2 & 179.3 \\
\hline
\end{tabular}

The fifth mechanism for integrating P2 is to continually improve the site's program for acquiring environmentally preferable products, which include recycled content, biobased, and energy-efficient products. While the program structure is provided in the WIPP Affirmative Procurement Plan (WP 02-EC.07), the consideration and purchase of cost-effective environmentally preferable products is achieved through imbedding the program requirements into acquisition procedures and training for requisitioners and credit card purchasers, and integrating requirements into contracts.

For FY 2006, 100 percent of purchases of standard copy paper, toner cartridges, and commercial sanitary tissue products met EPA recycled content requirements as a result of including the requirements in the contract terms. Cement and concrete used for the project also met EPA requirements. In addition, the computer standards at the WIPP facility specify equipment that is energy star compliant with a requirement for purchasers to request approval when purchasing computers that are not specified in the standard.

Site environmental compliance and procurement personnel continue to improve the ability to quantify purchases of other environmentally preferable products, such as office supplies, equipment, or other materials. The improvement will result in vendors and/or 
contractors providing routine reports of environmentally preferable products purchased and used for the project. This improvement will be implemented during FY 2007.

\subsubsection{Executive Order 13123, Greening the Government Through Efficient Energy Management}

This EO recognizes that the federal government is the nation's largest energy consumer. Consequently, federal government agencies are required to significantly improve energy management at federal facilities in order to save taxpayer dollars and reduce emissions that contribute to air pollution and global climate change. Federal government agencies are expected to adopt energy efficiency in building design, construction, and operation. Federal government agencies are expected to promote energy efficiency, water conservation, and the use of renewable energy products, and help foster markets for emerging technologies. DOE Order 430.2A, Departmental Energy and Utilities Management, established requirements for each DOE site that directs agencies operations to meet or exceed the expectations in the EO.

The WIPP facility meets the requirements of this order through implementation of an energy management plan and provides semiannual progress reports to the DOE. The energy management plan addresses actions and progress in the seventeen energy efficiency leadership goals established in the DOE order. Section 3.2.13 summarizes the progress in this area.

\subsubsection{Executive Order 13148, Greening the Government Through Leadership in Environmental Management}

This EO requires development of EMSs, environmental compliance audit programs, reporting under EPCRA, reduction of toxic releases and off-site transfers of toxic chemicals, reduction of the use of toxic chemicals, hazardous substances, and pollutants, and generation of hazardous and radioactive waste, reductions in ozonedepleting substances, and environmentally and economically beneficial landscaping.

Compliance is maintained with this order and is more fully described in within this chapter and Chapter 3.

\subsection{Other Significant Accomplishments and Ongoing Compliance Activities}

\section{Environmental Performance}

WIPP employees monitor routine performance in the areas of material recycling and waste disposal as well as water and energy resource usage as reported in Section 3.2.13. Of note is success in reducing water usage, energy use performance, and recycling. WIPP employees place a strong emphasis on recycling and now recycle a larger quantity of materials than has been disposed for four of the last five years. This is significant in that it has been achieved while total materials generated increased, as expected, since waste emplacement rates have been steadily increasing over the past 
five years. Figure 2.1 illustrates the comparison of wastes disposed to wastes recycled over this five-year period.

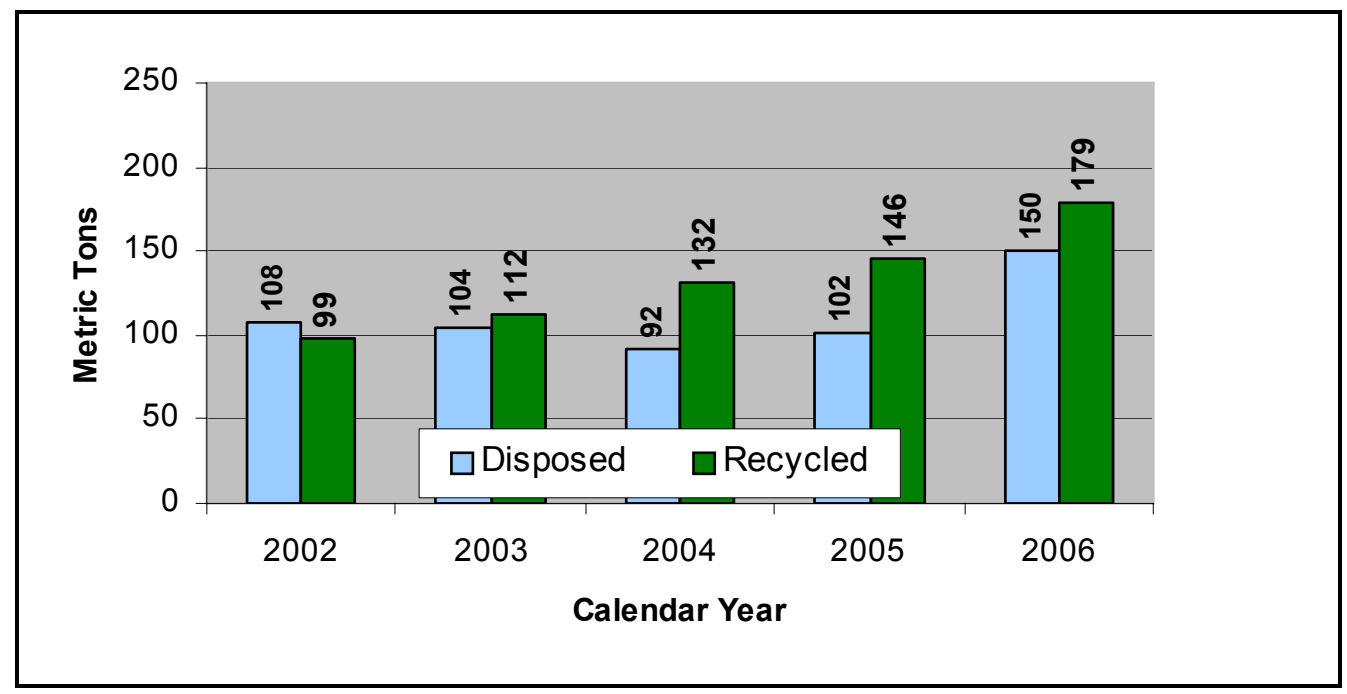

Figure 2.1 - Waste Disposed Compared to Waste Recycled

\section{Environmental Compliance Assessments}

Assessments (evaluations) of activities at the WIPP facility are routinely performed to evaluate that processes are in place to comply with applicable environmental regulatory requirements. This is accomplished through a multi-tiered evaluation system. Evaluations are performed by the WTS Quality Assurance Department, other WTS departments, the CBFO, and its technical contractor, and state and federal agencies. Chapter 3 provides an overview of the WIPP Integrated Evaluation Plan, as well as the system for assuring preventive and corrective actions (Issues Management Program) are accomplished. A review of the evaluation plan and the Issues Management Program demonstrates continuing excellent compliance performance based on a proactive system for preventing compliance issues.

Specific assessments, focused solely on environmental compliance, include those performed in accordance with the Environmental Assessment Plan (WP 02-EC.13). There were four assessments performed under the Environmental Assessment Plan during 2006. These assessments are summarized in the following paragraphs.

From January 20 through February 9, 2006, an assessment was conducted to evaluate compliance with requirements for well water (brines) discharged at WIPP pursuant to DP-831 or disposed of at an approved external disposal facility. This assessment resulted in the determination that requirements are adequately flowed down into work procedures and effectively implemented with the exception of one finding. This finding was related to assuring internally required records were complete relative to off-site disposal of water. The findings corrective action was completed in 2006. 
The next assessment focused on compliance with the HWFP requirements for equipment inspections and was conducted from August 1-8, 2006. The assessment resulted in no findings, one issue that was corrected during the assessment and two exemplary practices. The item corrected during the assessment was the update of two procedures to clearly state specific procedural contents designated in the HWFP. Overall, this assessment confirmed WIPP compliance with requirements.

The third assessment's scope was to evaluate the adequacy of the process for assuring RCRA operating records are properly identified, appropriate retention times set and records are stored as required in the HWFP. This assessment was conducted from September 20 through October 5, 2006. Two findings were identified in this assessment that were related to inconsistent implementation of the Records Management Program given the program's broad definition of the operating record. Although inconsistent implementation was identified, there was no evidence of noncompliance with the HWFP. There were three WIPP Forms issued to address these two findings with the corrective actions for two of the three complete. The corrective action for the third WIPP Form is in progress with programmatic changes and training having been completed. The remaining action for this issue is scheduled for completion as each department undergoes its annual records review.

The final assessment was conducted from November 6-9, 2006. The scope included compliance with the final HWFP as modified for acceptance of RH TRU waste. The purpose of the assessment was to provide independent assurance that the site had adequately flowed down the RH TRU waste requirements in the modified HWFP into plans, programs, and/or procedures. The assessment confirmed that requirements are adequately flowed down and could be implemented effectively. There were three issues that were closed during the assessment. These resulted in the update of a procedure and an item being added to the formal commitment tracking system to assure Parking Surge Capacity is used as approved in the HWFP and annually reported to the NMED. Another item was included in the formal commitment tracking system to establish a mechanism for assuring the maximum permitted amount of RH TRU mixed waste processed is not exceeded.

\section{DOE Audits/Assessments}

There were four audits, assessments, or surveillance audits conducted by the CBFO during FY 2006 focused solely on environmental compliance. There was one corrective action request completed, which resulted in the implementing procedure for DP-831 to add dissolved concentrations for selenium and chromium to the analysis of samples from the infiltration ponds rather than only the total concentration.

\section{Environmentally Beneficial Landscaping Practices}

At WIPP, the most routine opportunity for applying sound reclamation practices involves reclamation of areas such as groundwater monitoring well pads and closure of site roads. The 2006 activities incorporated environmentally beneficial landscaping and waste prevention practices as described in the PPOA summary for well pad 
reclamation. In addition, no new areas that required landscaping were constructed or modified.

\section{Ozone Depleting Substances}

Internal procedures control the acquisition of chemicals and hazardous materials including ozone depleting substances. In addition, procedures include periodic checks for the presence of ozone-depleting substances. The WIPP facility did not have ozonedepleting substances on-site during 2006. 


\section{CHAPTER 3 - ENVIRONMENTAL MANAGEMENT SYSTEM}

\subsection{Introduction}

EMSs are widely recognized by both government and industry as effective mechanisms for achieving an organization's policy commitments for environmental performance. An EMS is based on using the continuous improvement cycle for environmental performance. The cycle begins with planning, the foundation that establishes the organizational commitments to environmental performance via policy. This is followed by implementing the plan and monitoring the organization's environmental performance as it executes the plan. Finally, management reviews environmental performance and the effectiveness of the system, identifying desired improvements. These improvements then initiate the next continuous improvement cycle. This chapter is based on the annual review of the WIPP EMS, which is conducted on a fiscal year basis.

EO 13148 requires that federal agencies implement an EMS. Further, the DOE issued DOE Order 450.1, which requires that DOE sites implement an EMS that is integrated with their ISMS by December 31, 2005. This order established the DOE intent that these EMSs enable sound environmental stewardship practices that are protective of air, water, land, and other natural and cultural resources affected by DOE operations. The order also set the expectation that the systems would enable meeting compliance requirements in a cost-effective manner. The WIPP EMS is in compliance with the order's requirements.

WIPP employees had recognized the value of managing potential environmental impacts and compliance responsibilities prior to issuance of the executive and DOE orders listed above. The EMS was developed and implemented in 1997, and was certified as having met the ISO 14001 EMS standard in 1998. WIPP continued to be ISO-certified until 2003 when the decision was made to maintain the EMS in alignment with the principles of the ISO standard without continuing the formal certification process.

The WIPP policy establishes protection of workers, the public, and the environment as the highest priority in carrying out its mission. The WIPP EMS strengthens compliance with legal requirements, $\mathrm{P} 2$, and continual improvement, as well as assuring that environmental accountability is integrated in the decision-making process.

\subsection{WIPP EMS Elements}

\subsubsection{Policy}

WTS, as management and operating contractor for the WIPP facility, had a strong environmental policy in place prior to the time the EMS was first implemented. When the EMS was integrated into the ISMS (FY 2005), the environmental policy was reviewed and updated to be a policy jointly issued by the CBFO and WTS (CBFO/WTS Environmental Policy Statement, DOE/WIPP-04-3310). It continues to be affirmed 
through issuance of the policy by the current WTS General Manager and CBFO Manager.

Senior management has committed WIPP to achieve and maintain high standards of environmental quality and to provide a safe and healthful workplace for employees while achieving its mission. The environmental policy provides the foundation for the EMS, and identifies the EMS as the mechanism to meet WIPP commitments to:

- $\quad$ Comply with requirements applicable to WIPP.

- $\quad$ Be good environmental stewards (by working with stakeholders, correcting incidents, minimizing harm to environmental resources and using safe, responsible and cost-effective P2 measures).

- Seek continual improvement in environmental performance.

\subsubsection{Aspects and Impacts}

Since the EMS was first implemented, activities, aspects, and impacts for WIPP have remained relatively constant as a result of the stability of the WIPP mission. However, small changes, or upgrades, have been made over time for clarification purposes. The following aspects have been identified as having potentially significant impacts.

- $\quad$ Safe management of TRU wastes

Potential impact: decreased exposure of people and environment both at WIPP and generator sites

- $\quad$ Potential release of pollutants from managing TRU and TRU mixed wastes, hazardous materials, site-generated hazardous and nonhazardous wastes, solid waste management units, and the wastewater treatment system

Potential impact: Contamination of soil, water, air, or biota

- Use of electricity

Potential impact: Loss of use of natural resources

- $\quad$ Storm water runoff

Potential impact: Contamination of soil, water, or biota

- $\quad$ Land management

Potential impact: Compromised stewardship of wildlife, fauna, habitat, and/or historically or culturally significant sites 
Aspects and impacts are reviewed several times during the course of each year. These include environmental reviews of proposed projects, and a more formal, holistic review performed in preparation for the annual EMS review by senior managers. Significance is determined by considering both environmental and business factors such as the probability of occurrence, the scale and severity of the potential impact, associated regulatory and legal requirements and issues, concerns of interested parties, and public and stakeholder opinions.

\subsubsection{Legal and other Requirements}

Environmental requirements are identified as they are issued as draft and proposed, and in final rules and orders. Identification is accomplished through monthly review of the environmentally related notices in the Federal Register and to the New Mexico Administrative Code, and new and proposed changes to existing DOE orders. Subject matter experts are consulted to confirm applicability and assess potential impacts. Needed changes are then initiated to plans, procedures, and training to institutionalize compliance with the new or revised requirements. Environmental requirements and compliance status are summarized for WIPP and are available to the public in the Waste Isolation Pilot Plant Biennial Environmental Compliance Report (DOE/WIPP 06-2171) and Chapter 2 of this report.

\subsubsection{Objectives and Targets}

Setting objectives and targets for addressing the impacts associated with significant aspects is a cornerstone in the planning process of an EMS. At WIPP, this is carried out by managers' review of the significant aspects and impacts during the annual fiscal year programmatic planning process. New or revised WIPP objectives and targets are developed with milestones in the context of the aspects and impacts. Approved objectives and targets are then incorporated into the Complex-Wide Integration Tool, where progress is tracked throughout the year. For FY 2006, 77 percent of WIPP milestones were linked to managing potentially significant environmental aspects.

Sitewide environmental goals (objectives) related to P2 are also set each fiscal year. Eight goals were jointly established by the CBFO and WTS for FY 2006. These goals directly supported four of the five DOE department-level performance-based goals for P2 and sustainable environmental stewardship, as noted in Figure 3.1. Waste prevention goals were focused on each department reducing one of their waste streams and reducing paper and paper-based office consumption in order to not increase household waste generated per person at the WIPP site. As reported in previous ASERs, the WIPP facility has significantly reduced hazardous waste generated on average 90 percent per year compared to 1995. Therefore, it was appropriate to turn the focus to household waste, albeit this is a much more challenging area to effect, particularly in a period of increased activity. Environmentally preferred purchasing focused on biodiesel use, identifying and using more environmentally friendly preferred cleaning products and assuring legal and letter-sized paper are purchased with the minimum recycled content through office supply vendors. The environmental stewardship goal focused on evaluating fresh water usage for further opportunities for 


\section{Waste Isolation Pilot Plant Annual Site Environmental Report for 2006 DOE/WIPP-07-2225}

improvement. A goal was also set for improving the recycling rate. WIPP fully achieved six of the eight and partially achieved another of the goals for FY 2006 as discussed in Section 3.2.13 and demonstrated in Figure 3.1.

\begin{tabular}{|c|c|c|}
\hline \multicolumn{3}{|c|}{$\begin{array}{l}\text { Figure } 3.1 \text { - Site Environmental Goals Scorecard } \\
\text { WIPP FY } 2006 \text { Performance }\end{array}$} \\
\hline DOE Goal Category & Goal & Status \\
\hline \multirow[t]{3}{*}{ Waste Prevention } & $\begin{array}{l}\text { 1. No increase in the WIPP site's } \\
\text { sanitary (household) waste } \\
\text { generation rate per employee. }\end{array}$ & $\begin{array}{l}\text { Achieved. Each WIPP site employee } \\
\text { generated } .2 \text { metric tons of waste during } \\
\text { FY } 2005 \text { and FY } 2006 .\end{array}$ \\
\hline & $\begin{array}{l}\text { 2. Each department will evaluate at } \\
\text { least one waste stream, and identify } \\
\text { and begin implementing a plan for } \\
\text { its reduction. }\end{array}$ & $\begin{array}{l}\text { Achieved } 71 \text { Percent. Five of seven } \\
\text { departments completed this goal. }\end{array}$ \\
\hline & $\begin{array}{l}\text { 3. Reduce paper and paper-based } \\
\text { office goods consumption. }\end{array}$ & $\begin{array}{l}\text { Achieved. Each employee used an average } \\
\text { of } 2 \text { pounds or } 235 \text { sheets less paper in } \\
\text { FY } 2006 \text { versus FY } 2005 \text {. }\end{array}$ \\
\hline \multirow[t]{3}{*}{$\begin{array}{l}\text { Environmentally } \\
\text { Preferred Purchasing }\end{array}$} & $\begin{array}{l}\text { 4. Evaluate use of bio-based diesel } \\
\text { fuel. }\end{array}$ & $\begin{array}{l}\text { Achieved. As a result of the evaluation, a } \\
\text { FY } 2007 \text { goal is proposed for conducting a } \\
\text { test of biodiesel in the WIPP site commuting } \\
\text { buses. }\end{array}$ \\
\hline & $\begin{array}{l}\text { 5. Partner with site janitorial service to } \\
\text { identify and use cost effective, fit for } \\
\text { purpose, environmentally preferred } \\
\text { cleaning supplies at the WIPP site. }\end{array}$ & $\begin{array}{l}\text { Achieved. Janitorial environmentally } \\
\text { preferred products were identified, and it was } \\
\text { agreed that testing would be deferred to } \\
\text { FY } 2007 \text {. }\end{array}$ \\
\hline & $\begin{array}{l}\text { 6. Add legal and ledger size paper to } \\
\text { current paper purchase contract for } \\
\text { routine stocking (assures recycled } \\
\text { content standard met). }\end{array}$ & $\begin{array}{l}\text { Achieved. Research was conducted that } \\
\text { determined that the purchase of legal and } \\
\text { ledger sized paper from local office supplier } \\
\text { meets the EPA recycled content standard. }\end{array}$ \\
\hline $\begin{array}{l}\text { Environmental } \\
\text { Stewardship (water, } \\
\text { energy, and fuel } \\
\text { efficiency, resource } \\
\text { conservation) }\end{array}$ & $\begin{array}{l}\text { 7. Evaluate fresh water usage to } \\
\text { understand water usage profile and } \\
\text { determine if there are areas for } \\
\text { improved efficiency. }\end{array}$ & $\begin{array}{l}\text { Achieved. The evaluation concluded that the } \\
\text { primary areas for future improvements in } \\
\text { water usage are in personal use areas rather } \\
\text { than through industrial use. }\end{array}$ \\
\hline $\begin{array}{l}\text { Recycling of Solid } \\
\text { Wastes }\end{array}$ & $\begin{array}{l}\text { 8. Increase ratio of materials recycled } \\
\text { to the total quantity of sanitary waste } \\
\text { generated to } 65 \text { percent, a } 5 \text { percent } \\
\text { increase compared to FY } 2005 \text {. }\end{array}$ & $\begin{array}{l}\text { Not Achieved. This was a stretch goal for } \\
\text { the WIPP site with WIPP achieving a } \\
54 \text { percent recycling rate. On a volume basis, } \\
\text { WIPP recycled } 33 \text { metric tons of materials } \\
\text { ( } 22 \text { percent) more than in FY } 2005 \text { with } \\
\text { increases in quantities of paper, computer } \\
\text { equipment, and scrap metal. }\end{array}$ \\
\hline
\end{tabular}

\subsubsection{Environmental Management Program}

The next planning step is to identify resource needs and assure that they are obtained. At WIPP, this has been integrated into the business process for developing current and out-year programs along with their associated project milestones. In addition, the WIPP P2 Committee (the Green Team) assists organizations in planning for and achieving P2 goals.

Programs, procedures, and training modules have been developed and are implemented as necessary to meet compliance requirements. Programs, procedures 
and training include those for natural resources protection, $\mathrm{P} 2$, affirmative procurement, waste management, management of mined materials (i.e., salt), and environmental monitoring. Provision of resources for implementation of these plans is accomplished through the normal business budget setting process.

\subsubsection{Structure and Responsibility}

Management's role is to provide the resources essential to implement and control the EMS. These resources include training, funding, human resources, specialized skills and technology. To help facilitate this at WIPP, management has designated EMS Coordinators in both the CBFO and WTS organizations. The coordinators are responsible for maintaining the EMS in accordance with the principles of ISO 14001 and for monitoring and reporting on the effectiveness of the system to management.

EMS responsibilities shared by all employees are included in the General Employee Training module. This training module is reviewed and updated each year. Updates assure that responsibilities for protection of the environment and minimizing any potentially significant impacts are current and meet changing environmental stewardship, compliance, and continual improvement needs.

Specific roles and responsibilities related to compliance issues are integrated into the work procedures necessary to carry out the project. For example, a training module provides the knowledge necessary for employees to be qualified as hazardous waste workers. This, in turn, enables personnel to understand their responsibilities and how to manage this significant aspect so that any negative impacts from hazardous waste management tasks are prevented or mitigated.

\subsubsection{Training, Awareness, and Competency}

Awareness and initial training on the EMS is included in the General Employee Training as discussed in Section 3.2.6. Employees are trained for conformance with the programs and procedures as applicable to their job scope.

The WIPP training program is comprehensive, mature, and based on the DOE methodology for job scope and needs analysis and program design. Specific training and qualification standards have been set for personnel whose work has the potential to result in significant environmental impact. The standards include those for waste handling, waste management (including TRU, TRU mixed, hazardous and other wastes), mining, and maintenance. The frequency of training required for qualification for specific jobs is established and WTS Technical Training initiates and carries out training based on the defined frequency.

\subsubsection{Communication}

Internal communication related to the EMS, including compliance and P2, is accomplished via multiple mechanisms. The primary way WIPP communicates requirements and expectations is through the programs, plans, and procedures that 
integrate environmental requirements into daily work processes. Other methods include meetings, employee performance reviews, internal newsletters, the WIPP Intranet, and awareness posters, signs and banners. A key communication tool is the Pollution Prevention News which began to be published monthly during FY 2006 and focuses on environmental awareness. The WIPP Plan of the Day meeting is also a key communication tool that allows operating and support staff to understand each day's work plan and the interactions necessary to execute the plan in a safe, environmentally sound manner.

Communication with the public occurs as WIPP invites review and input on draft NEPA documents. The process for implementing the NEPA also assures that information is provided to the public related to significant environmental activities. A toll-free information line is maintained and made available to the public for inquiries regarding any topic or issue. Additionally, documents such as this report and the Biennial Environmental Compliance Report, reports submitted to regulatory agencies, and selected information contained in the WIPP Waste Information System are available to the public.

\subsubsection{EMS Documentation}

The WIPP EMS is documented through the Waste Isolation Pilot Plant Environmental Management System Description (DOE/WIPP 05-3318). The programs, procedures, and reports that implement each EMS element are documented in a WIPP EMS Map organized according to the ISO 14001 standard's framework. This document is reviewed annually during the preparation of the EMS Annual Report for needed improvements. The EMS document is updated, as needed, after the management's annual review of the system.

\subsubsection{Document Control and Records}

WIPP has a mature system for document management as established through its records management program and procedure writer's guide. WIPP personnel maintain an electronic document control system to manage development, review, approval and revision of documents. This enables systematic review and input by affected organizations with documentation for each step of the review and approval process.

\subsubsection{Operating Control}

The EMS Aspects and Impacts Table identifies the organizations that are associated with managing WIPP activities so that potential impacts are mitigated. WIPP has three core programs that implement actions to minimize risk by assuring that the integrity (design, operation and maintenance) of facilities and assets is maintained. The documents implementing these programs are Engineering Conduct of Operations (WP 09), Conduct of Operations (WP 10-2), and Maintenance Operations Instruction Manual (WP 04-CO), with their supporting procedures and work instructions. 
Implementation of the Engineering Conduct of Operations assures that requirements for design, physical configuration, and documentation of structures, systems, and components are met and that personnel are properly trained and qualified and understand their related responsibilities.

Conduct of Operations establishes expectations for operating practices, control activities, communications, control of equipment, operations turnover and operations procedures. Operating procedures are fundamental to this program and are developed, reviewed, approved and required to be followed to ensure the facility is operated within its design basis.

The WIPP Maintenance Operations Instruction Manual provides the program structure for conducting maintenance at the WIPP site so that equipment integrity is maintained. It assures that position responsibilities and requirements for the preventive maintenance program are defined. Implementation assures personnel are trained appropriately, responsibilities are understood and the preventive maintenance program is effective.

\subsubsection{Emergency Preparedness and Response}

WIPP emergency preparedness and response capabilities are maintained through planning, training, drills, drill analysis and implementing improvement actions. Extensive planning is evidenced by the overarching emergency management program and sub-tier plans for managing the transfer of information during and after an event (e.g., mine rescue, fires and responding to incidents/accidents associated with transportation of TRU waste from the generator sites to WIPP). Planning and implementation involves the many organizations and individuals that would play a part in responding to an incident including the communications, operations, environmental compliance and safety departments. Supporting these plans are numerous procedures for handling specific types of emergencies identified through the Waste Isolation Pilot Plant Contact-Handled Waste Handling Emergency Planning Hazards Assessment (DOE/WIPP-02-3286), and the Waste Isolation Pilot Plant Remote-Handled Waste Handling Emergency Planning Hazards Assessment (DOE/WIPP-05-3331). These encompass mine rescue, surface and underground fires, hazardous material spill response, and severe weather, as well as security and medical emergencies. Ancillary procedures related to event recovery, categorization of operational incidents and reporting occurrences are also in place.

Training and practicing response skills are a high priority at WIPP. The WIPP training program for the various facets of emergency management consists of twenty self-study or classroom training courses provided to key personnel. Over the course of FY 2006, there were over 500 participants in emergency preparedness and response training courses.

Emergency Management conducts drills and exercises according to an annual drill and exercise plan. Members of the emergency response organization are required to participate in a minimum of one drill each year to demonstrate proficiency in their assigned role. A full-participation exercise is conducted each year to test integrated 
capabilities. Performance during the exercises is critiqued by an independent group and any findings are addressed and managed through the commitment tracking system.

\subsubsection{Measuring and Monitoring (Environmental Performance Measurement)}

Environmental performance is monitored to assure that the WIPP carries out its mission in alignment with its environmental policy to comply with all requirements, be a good environmental steward and continually improve environmental performance. Analysis of data in these arenas becomes the basis for determining the effectiveness of the EMS in achieving policy commitments.

\section{Monitoring Environmental Performance}

Initial implementation of the Waste Isolation Pilot Plant Environmental Monitoring Plan (DOE/WIPP 99-2194) during the planning and preoperational phases of the project established the WIPP baseline environmental conditions. Continuing implementation monitors for environmental effects during the site operations phase. The plan directs the programs for monitoring of radiological and nonradiological effects and land management, as well as providing the criteria and methods for data analysis and QA. Data from the radiological, nonradiological and land management monitoring programs for 2006 indicate that there has been no impact to human health or the environment from WIPP facility operations. Detailed analysis and summaries of the monitoring results are included in Chapters 4 through 6.

WIPP personnel monitor the environmental performance areas of material recycling versus disposal and water and energy resource usage. The percentage of materials recycled versus the total amount of materials generated averaged 57 percent over the last three fiscal years (2004 - 2006) with FY 2006 being slightly lower than FY 2005 due to panel closure and clean up activities increasing the amount of non-recyclable wastes. Each column in Figure 3.2 represents the total materials generated for disposal or recycle from WIPP operations. The two different colors within each column represent the amount of materials recycled (green) versus disposed (blue). 


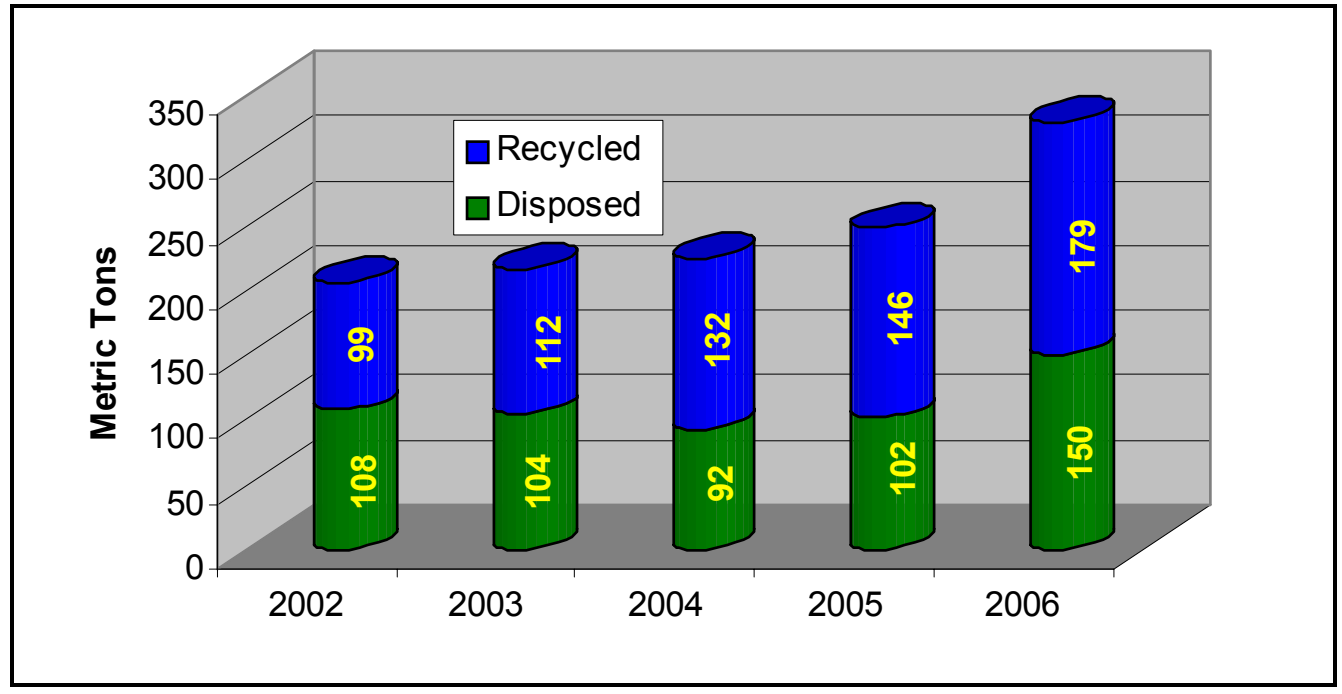

Figure 3.2 - FY 2006 Recycled Versus Disposed Materials

WIPP employees continue to reduce the use of fresh water, with the most significant decrease occurring between FY 2003 and FY 2004 as illustrated in Figure 3.3. This decrease was achieved as a result of process changes for maintenance of sewage lagoon ponds. Smaller, but steady declines have been achieved from FY 2004 through FY 2006. These result from implementing remaining water use reduction opportunities in the personal versus process use areas.

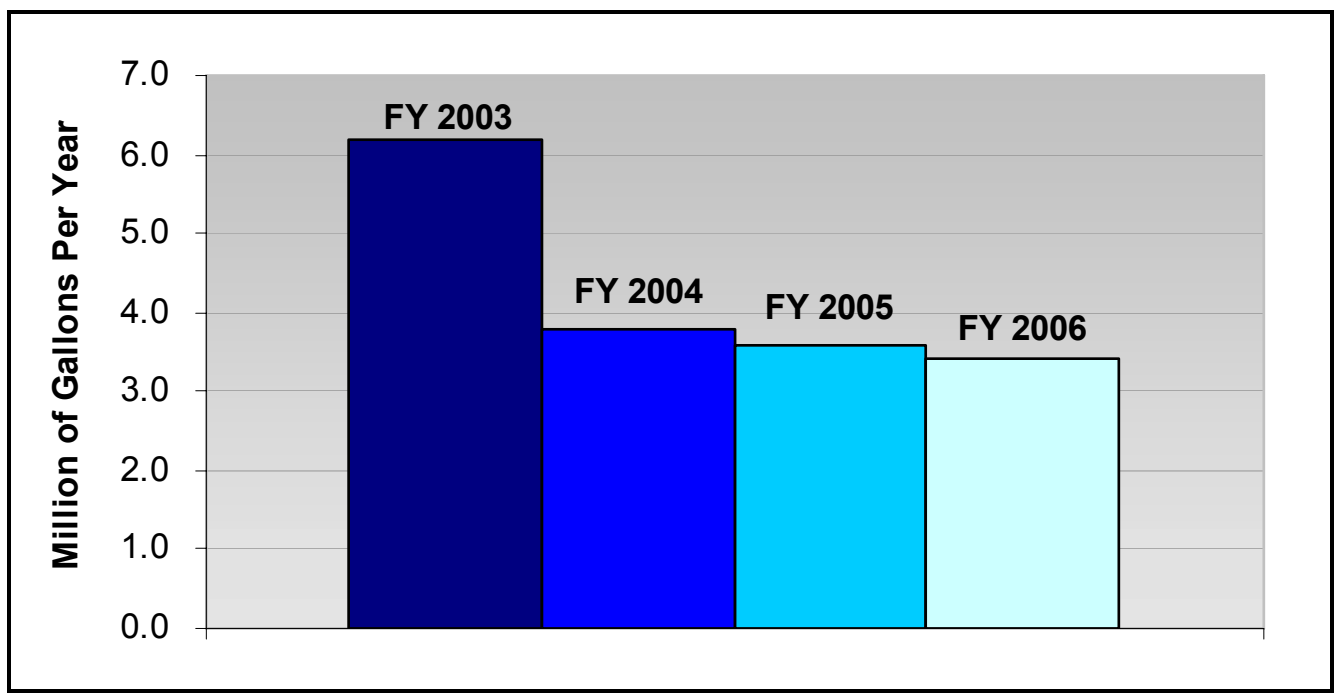

Figure 3.3 - Yearly Water Usage at WIPP

In the area of energy usage, the WIPP Energy Management Plan (updated semiannually) provides an overall picture of energy efficiency efforts and accomplishments. The WIPP site has experienced expected increases in energy use as waste emplacement activities and associated mining activities have increased. However, as a result of implementing prudent conservation practices, increases have 
been limited and carbon emissions associated with energy use at the WIPP site (Figure 3.4) have remained fairly consistent over the past five years. Also contributing to limiting carbon emissions was the WIPP facility's continuing to supply 7 percent of its site energy needs from wind energy.

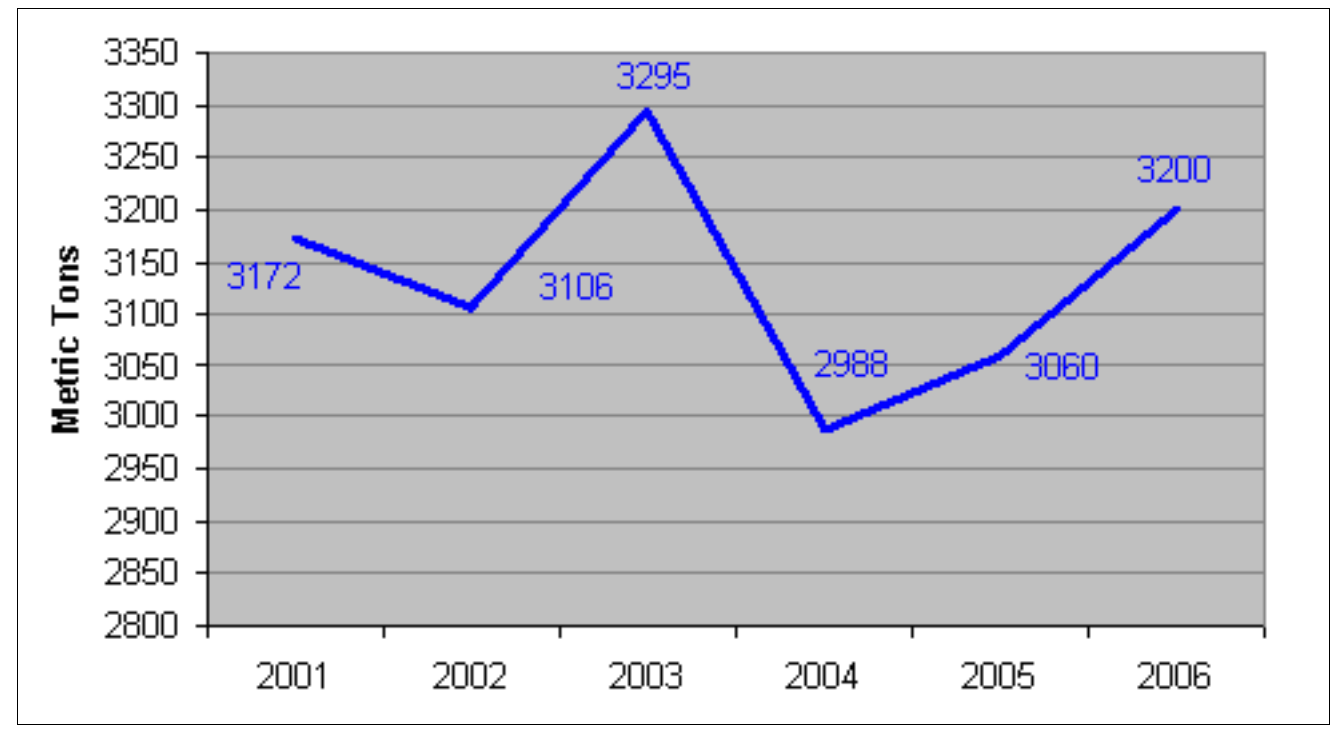

Figure 3.4 - WIPP Carbon Emissions - Estimated

\section{Monitoring for Compliance}

Compliance with requirements for WIPP are monitored through a multi-tiered evaluation system. Monitoring is conducted through the inspections, assessments, surveillances, and audits whose scope includes facets of compliance. These are performed by different organizations and include those performed internally (self-assessments) and those performed by external entities (independent). Internal assessments are performed by various WTS departments and Washington Regulatory and Environmental Services. External assessments are performed by the CBFO QA Department and the Carlsbad Technical Assistance Contractor, DOE Headquarters, the NMED, and the EPA.

Results for FY 2006 demonstrate that the WIPP evaluation system is comprehensive and effective. As summarized in the WTS Integrated Evaluation Plan, Fiscal Year 2006 Performance Results, and reported in the WIPP Environmental Management System Annual Report for FY 2006 (DOE-07-3333), there were 250 evaluations in FY 2006 and 275 in FY 2005 that incorporated varying levels of environmental compliance or performance checks. This equates to over 70 percent of all evaluations performed over the last two years and is indicative of the high level of performance checking that is performed and integrated into the overall operation of the WIPP facility. The evaluations examine implementation of WIPP policies, programs, procedures, and controls that assure compliance. Findings identified through these evaluations are incorporated into the WIPP issues management program and corrective action is tracked through completion. 


\section{Monitoring for Continual Improvement}

The progress toward continual improvement in environmental performance is demonstrated by:

- $\quad$ Recommendations from the prior year's EMS Annual Report having been implemented. Five of six recommendations from the 2005 EMS annual management review were implemented with partial implementation of the sixth during FY 2006. The remaining portions of the sixth will be implemented in FY 2007.

- $\quad$ P2 goals being reviewed and revised. Seven environmental goals were set for FY 2007 including six new goals and the continuation of the FY 2006 partially completed goal. The goals were linked to DOE Order 450.1 goal areas of incorporating environmental stewardship in program planning and operational design, environmentally preferred purchasing, waste prevention and recycling.

- $\quad$ Identification of improvement opportunities. Opportunities are identified through observations/recommendations identified in evaluations as well as identification of issues through personnel's observation of ongoing work activities and planning new or reviewing past work. There were 142 issues/improvement opportunities submitted with improvement/corrective actions managed in this process during FY 2006.

\section{Monitoring EMS Effectiveness}

In addition to the extensive, ongoing, monitoring that is performed as a result of the monitoring plan, indicators are also used to provide a summary of system effectiveness for the annual management review of the EMS. There are eight EMS effectiveness indicators that were used for FY 2006 and summarized in Figure 3.5.

\begin{tabular}{|l|c|c|}
\hline \multicolumn{3}{|c|}{ Figure 3.5 - EMS Effectiveness Indicators } \\
\multicolumn{1}{|c|}{ Environmental Stewardship, Compliance, Continual Improvement } \\
\hline $\begin{array}{l}\text { Pspects and impacts - business milestones related to } \\
\text { significant aspects and impacts management }\end{array}$ & FY 2006 & FY 2005 \\
\hline $\begin{array}{l}\text { Revisions to significant aspects and impacts (does not include } \\
\text { administrative revisions) }\end{array}$ & $\begin{array}{c}77 \% \\
(217 \text { of } 283)\end{array}$ & $\begin{array}{c}78 \% \\
(265 \text { of 338) }\end{array}$ \\
\hline Environmental goals accomplished & 2 & 0 \\
\hline Reportable unauthorized contaminant releases & $\begin{array}{c}83 \% \\
(6.7 \text { of } 8)\end{array}$ & $\begin{array}{c}78 \% \\
(7 \text { of 9) }\end{array}$ \\
\hline External agency compliance findings/violations & 0 & 0 \\
\hline $\begin{array}{l}\text { Evaluations (number and percentage of total) that review topics } \\
\text { supporting environmental compliance and/or performance. }\end{array}$ & $\begin{array}{l}250 / 76 \% \\
0\end{array}$ \\
\hline Corrective action process - percent of issues self-discovered & $\begin{array}{c}62 \% \\
(88 \text { of } 142)\end{array}$ & Not Available \\
\hline Recommendations implemented from annual EMS report & 5.5 of 6.0 & 8 of 9 \\
\hline
\end{tabular}


Indicator 1. This indicator demonstrates the depth of integration of environmental stewardship into the daily course of activities at WIPP, with 77 percent of business milestones being related to managing a significant environmental impact in FY 2006 and 78 percent in FY 2005. This demonstrates that management of significant aspects and impacts is well integrated into operation of the project.

Indicator 2. The second provides a snapshot of modifications or improvements made to assure that aspects continue to reflect the areas where environmental impacts could occur within the scope of the WIPP mission. Two changes were made in FY 2006 to significant aspects. The first change is recognizing that the receipt of PCB waste with TRU radionuclide content augments the basis for identifying Management of TRU and TRU mixed waste as potentially significant. The second change strengthens the recognition that WIPP use of electricity generated from carbon based fuels is potentially significant.

Indicator 3. This indicator demonstrates WIPP has integrated P2 into the EMS and is actively working to minimize its environmental footprint through resource conservation and waste minimization. As noted in Section 3.2.4, WIPP fully achieved six of the eight FY 2006 goals. Of the two remaining goals, one was partially completed (71 percent) and one was not achieved. The goal that was partially achieved, for all departments to identify and plan for reduction of one waste stream, was carried forward for completion into FY 2007. Progress continues to be communicated to the organization on a quarterly basis through the P2 website and posting with other business performance measures on the operations conference room performance measures board.

Of note in FY 2006 goals accomplished, WIPP maintained the household waste generation rate per person at the same level as in FY 2005. In addition, each employee used less paper compared to the prior year. Resource reduction efforts focused on using less paper as it represents one of the largest quantities of resources used to conduct the WIPP mission. These two accomplishments are significant in light of the increased work load, much of which was related to preparations for acceptance of RH TRU waste. Contributing to the accomplishment of these two goals was the active participation by five WIPP departments in identifying a waste stream from their activities and initiating a plan for its reduction. An excellent example of this was $\mathrm{RH}$ Waste Operations setting up and using an electronic (versus paper) review process for the over 300 line management affidavits that were completed in preparation for acceptance of RH TRU waste.

The goal related to increasing the WIPP recycling rate was considered a stretch goal and although the percentage target for materials recycled compared to the total material generated was not achieved due to activity levels at the site, WIPP employees were able to increase the total quantity of paper, computer equipment, and scrap metal recycled. The WIPP facility will continue to maintain a strong recycling program but will not establish a specific percentage for this area.

Indicator 4. WIPP had zero reportable, unauthorized contaminant releases in FY 2006 as has been the case for at least the prior six years. 
Indicator 5. This system indicator demonstrates the WIPP compliance performance and includes any findings, issues, and notices of violation from any external agency including the NMED, the EPA, and the U.S. Nuclear Regulatory Commission. During FY 2006, the WIPP facility received one administrative notice of violation from the NMED that was promptly corrected such that compliance will be sustained. Section 2.2.2 provides more detail regarding this instance.

Indicator 6. This indicator demonstrates the WIPP system for checking environmental performance and compliance continues to be healthy with over 70 percent of all evaluations performed over the last two years containing varying levels of environmental checks.

Indicator 7. This indicator illustrates that the WIPP corrective and preventive action process is thorough, with WIPP having self-discovered 62 percent of the total issues identified and corrected. Issues self-discovered are those issues which WIPP departments identify versus issues that are identified from an assessment, surveillance, or audit external to the department.

Indicator 8. With 5.5 of the 6 system improvements recommended for implementation in FY 2006 fully completed and the remaining portion of final improvement carried forward into FY 2007 for completion, WIPP continues to be effective in its continual improvement process.

\subsubsection{Corrective and Preventive Action}

WIPP employees have institutionalized a thorough process for managing corrective and preventive action through the issues management program. The Issues Management Committee reviews and verifies concerns, and requires appropriate corrective/ preventive action plans be developed and implemented. Completion of action plans is tracked through the commitment tracking system and monitored by the Issues Management Committee through closure. Issues that are managed through this process include environmental issues that may be raised by employees or identified through evaluations, as well as actions identified through the WIPP incident investigation process. The WIPP focus on identification of and response to issues before they become compliance issues or diminish the WIPP environmental performance is demonstrated by only one of the 142 issues being related to an external agency issue (see Section 2.2.2).

\subsubsection{EMS Audit}

An ISMS assessment is performed each year that evaluates integration of EMS into the ISMS and implementation of the EMS. The FY 2006 ISMS review confirmed that the EMS is effectively integrated into the WIPP ISMS and implemented. Recommendations for improvement from the review have been implemented and incorporated into the EMS. 


\subsubsection{Management Review}

CBFO and WTS EMS Coordinators prepare an EMS annual report to management, which is the basis for senior management's review of the effectiveness of the system and managers directing system improvements for the upcoming fiscal year. The annual report is based on analyzing the environmental performance indicator data described in the measuring and monitoring element in this report. The conclusion reached in the FY 2006 annual report is that the EMS remains suitable and effective for achieving policy, and the policy continues to reflect the organization's commitment to environmental performance.

The FY 2006 review also recommended enhancements to four areas, which are listed below. Actions to address these areas will be completed by the end of CY 2007.

1. Perform a preliminary gap analysis of the WIPP environmental policy, EMS, and performance compared to the recently issued EO 13423, Strengthening Federal Environmental, Energy, and Transportation Management, and its associated instructions.

During FY 2006, the Office of the Federal Environmental Executive, at the direction of the President, began work with all federal departments to combine a number of existing Greening the Government EOs into a single order as shown in Figure 3.6. The gap analysis will position WIPP to quickly address new requirements relative to its operations.

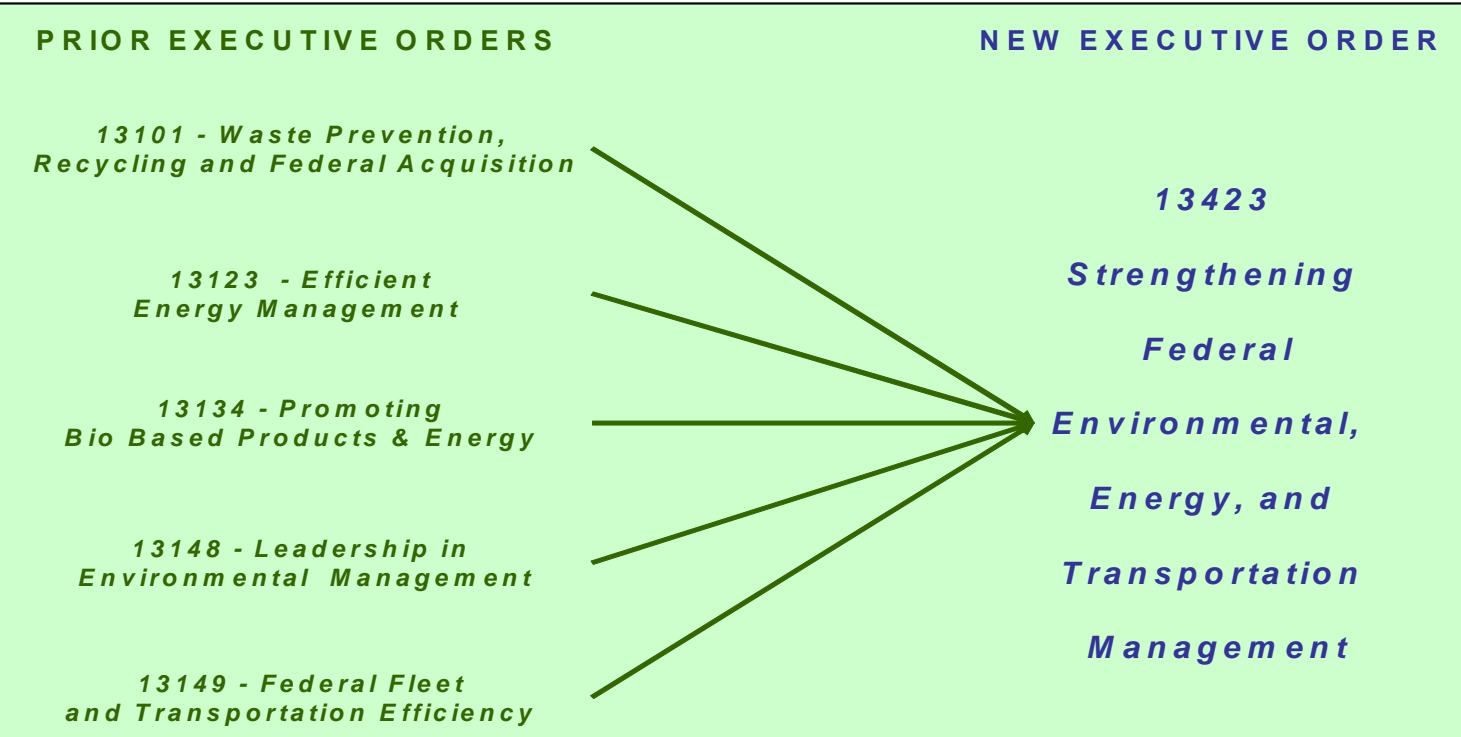

Figure 3.6 - Consolidation and Replacement of Environmental Executive Orders

2. Review EMS description and environmental policy documents and identify and prepare any appropriate updates (including those identified from item 1). 


\section{Waste Isolation Pilot Plant Annual Site Environmental Report for 2006 DOE/WIPP-07-2225}

3. Evaluate and incorporate, based on the evaluation results, the ability to identify and monitor environmentally related issues in the issues management program database currently being developed through QA.

4. Retire the WTS P2 policy statement, which is redundant to the CBFO/WTS Environmental Policy Statement to provide clarity of focus for the organization.

\subsubsection{Status of EMS Implementation}

The DOE requires each of its sites to report on the status of implementation of the EMS. Beginning with FY 2006, this EMS Annual Report included an EMS scorecard and data for determining EMS effectiveness, and sharing experiences.

EMS scorecard data define EMS status in terms of four implementation stages for the multiple categories. Overall, the WIPP scorecard shows that it has a mature EMS with each of these categories being well into the continuous improvement stage.

EMS effectiveness data provided a summary of the results of implementing the system in relation to 22 programmatic and performance criteria. Rankings for each criteria use a five-point scale ranging from one (not at all) to five (a great deal) and also allow for items that "do not apply" to a site. A review of the rankings associated with these criteria indicate that the EMS has been effective in enabling the WIPP facility to complete its mission and to improve its environmental performance. Table 3.1 provides the detailed rankings for this portion of the EMS implementation status.

\begin{tabular}{|c|c|}
\hline Performance Criteria: Effect of the WIPP EMS & Rating \\
\hline Reduced Risk to Facility Mission & 4 \\
\hline Improved Efficiency or Cost Avoidance & 4 \\
\hline Greater Understanding of Environmental Issues & 3 \\
\hline Greater Empowerment to Contribute to Improvement & 3 \\
\hline Greater Integration of Environment into Operations & 4 \\
\hline Greater Integration of Environment into Asset Management & 4 \\
\hline Improved Community Relations & 4 \\
\hline Improved Effectiveness in Overall Mission & 4 \\
\hline Improved Cooperative Conservation with Other Groups & 4 \\
\hline Improved Compliance Management. . & 5 \\
\hline Improved Personnel Health and Safety & 4 \\
\hline Improved Pollution Prevention & 4 \\
\hline Improved Water Quality . . & 4 \\
\hline
\end{tabular}


Waste Isolation Pilot Plant Annual Site Environmental Report for 2006 DOE/WIPP-07-2225

\begin{tabular}{l}
\hline Table 3.1 - EMS Effectiveness in Environmental Performance \\
\hline Performance Criteria: Effect of the WIPP EMS
\end{tabular}

EMS experiences highlight benefits, successes, and best practices for the WIPP EMS, along with challenges associated with implementing and maintaining the system. Benefits of the WIPP EMS is that the system provided the framework for improving the integration of P2 into daily operations, for successfully planning and implementing controls that reduce risk for managing storm water runoff of salt constituents, and for assuring environmental compliance and performance were addressed in operating procedures that were developed and implemented for accepting and disposing of RH TRU waste in FY 2007.

A best practice for the EMS is that it effectively integrates environmental prevention and corrective actions into the WIPP issues management process, as discussed in monitoring and corrective action sections. This provides an excellent example of the seamless integration of the EMS into fundamental operational processes. However, maintaining implementation of the EMS is not without challenges. An ongoing challenge for the WIPP is associated directly with the high level of integration into the daily operations of the project. The challenge is maintaining EMS awareness with a mature system that has been in place since 1997 and that is so well integrated into the operations. The challenge is being addressed by consistently refreshing General Employee Training to reflect the EMS and simplify over 24 aspects and potential impacts into terms which are basic to employees job functions and responsibilities.

As confirmed through this information and the data discussed in Section 3.2.13, used in preparation of the EMS Annual Report, the WIPP EMS continues to be suitable and effective for achieving the project's environmental policy. 


\section{CHAPTER 4 - ENVIRONMENTAL RADIOLOGICAL PROGRAM INFORMATION}

DOE Order 450.1 states that the DOE must "conduct environmental monitoring, as appropriate, to support the site's ISMS, to detect, characterize, and respond to releases from DOE activities; assess impacts; estimate dispersal patterns in the environment; characterize the pathways of exposures and doses to members of the public; characterize the exposures and doses to individuals, to the population; and evaluate the potential impacts to the biota in the vicinity of the DOE activity."

Radionuclides present in the environment, whether naturally occurring or human-made, contribute to radiation doses to humans. Therefore, environmental monitoring around nuclear facilities is imperative to characterize radiological baseline conditions, identify any releases, and determine their effects, should they occur.

WIPP personnel monitor air, groundwater, surface water, soils, sediments and biota to characterize the radiological environment around the WIPP facility. This monitoring is carried out in accordance with the WIPP Environmental Monitoring Plan. The radiological monitoring portion of this plan meets the requirements contained in DOE/EH-00173T, Environmental Regulatory Guide for Radiological Effluent Monitoring.

The purpose of WIPP Effluent Monitoring Program is to determine whether radionuclides are being released from WIPP operations, including the underground TRU waste disposal areas and the Waste Handling Building. The WIPP Effluent Monitoring Program requires monitoring to quantify releases of radioactivity from activities carried out at the WIPP facility into the environment, and to assure that releases do not cause exposures in excess of regulatory limits. The regulatory limits for the WIPP Effluent Monitoring Program can be found in 40 CFR Part 191, Subpart A. The referenced standard specifies that the combined annual dose equivalent to any member of the public in the general environment resulting from discharges of radioactive material and direct radiation from such management and storage shall not exceed $25 \mathrm{mrem}$ to the whole body and 75 mrem to any critical organ. In addition, in a 1995 Memorandum of Understanding between the EPA and the DOE, the DOE agreed that the WIPP facility would comply with 40 CFR Part 61, "National Emissions Standards for Hazardous Air Pollutants" (NESHAP), Subpart H, "National Emissions Standards for Hazardous Air Pollutants Other than Radon from Department of Energy Facilities." The NESHAP standard (40 CFR §61.92) states that the emissions of radionuclides to the ambient air from DOE facilities shall not exceed those amounts which would cause any member of the public to receive in any year an effective dose equivalent (EDE) of $10 \mathrm{mrem}$ per year.

The radiological environment near WIPP includes natural radioactivity, global fallout and, potentially, radioactive contamination remaining from Project Gnome. Under Project Gnome, a nuclear device was detonated underground in bedded salt on December 10, 1961. The test site for Project Gnome is located $9 \mathrm{~km}(5.4 \mathrm{mi})$ southwest of the WIPP site. The Project Gnome shot vented into the atmosphere. Therefore, environmental samples in the vicinity of the WIPP site may contain small amounts of 
fission products from fallout and residual contamination from Project Gnome in addition to natural radioactivity.

Natural background radiation, global fallout, and remaining radioactive contamination from Project Gnome together comprise the radiological baseline for WIPP. A report entitled Statistical Summary of the Radiological Baseline Program for the Waste Isolation Pilot Plant (DOE/WIPP 92-037) summarizes the radiological baseline data obtained at and near the WIPP site during the period from 1985 through 1989, prior to the time that WIPP became operational. Radioisotope concentrations in environmental media sampled under the current ongoing monitoring are compared with this baseline to gain information regarding annual fluctuations. Appendix $\mathrm{H}$ presents figures which compare the highest concentrations of radionuclides detected from the WIPP Environmental Monitoring Program to the baseline data.

Environmental media sampled include airborne particulates, soil, surface water, groundwater, sediments and animal and vegetable biota. These samples are analyzed for ten radionuclides, including natural uranium $\left({ }^{234} \mathrm{U},{ }^{235} \mathrm{U}\right.$, and $\left.{ }^{238} \mathrm{U}\right) ;{ }^{40} \mathrm{~K}$; actinides expected to be present in the waste $\left({ }^{238} \mathrm{Pu},{ }^{239+240} \mathrm{Pu}\right.$, and $\left.{ }^{241} \mathrm{Am}\right)$, and major fission products $\left({ }^{137} \mathrm{Cs},{ }^{60} \mathrm{Co}\right.$, and $\left.{ }^{90} \mathrm{Sr}\right)$. Environmental levels of these radionuclides can provide corroborating information on which to base conclusions regarding releases from WIPP facility operations.

Radionuclides are considered "detected" in a sample if the measured concentration or activity is greater than the total propagated uncertainty (TPU) at the 2 sigma level, and greater than the minimum detectable concentration (MDC). This methodology was patterned after that described in Hanford Decision Level for Alpha Spectrometry Bioassay Analyses Based on the Sample-Specific Total Propagated Uncertainty (MacLellan, 1999). The MDC was determined by the analytical laboratories based on the natural background radiation, the analytical technique, and inherent characteristics of the analytical equipment. The MDC represents the minimum concentration of a radionuclide detectable in a given sample using the given equipment and techniques with a specific statistical confidence (usually 95 percent). TPU is an estimate of the uncertainty in the measurement due to all sources, including counting error, measurement error, chemical recovery error, detector efficiency, randomness of radioactive decay and any other sources of uncertainty.

Measurements of radioactivity are actually probabilities due to the random nature of the disintegration process. A sample is decaying as it is being measured, so no finite value can be assigned. Instead, the ranges of possible activities are reported by incorporating the total propagated uncertainties of the method. For radionuclides determined by gamma spectrometry $\left({ }^{137} \mathrm{Cs},{ }^{60} \mathrm{Co}\right.$, and $\left.{ }^{40} \mathrm{~K}\right)$, an additional factor considered in the determination of detectability is the confidence level with which the peak or peaks associated with the particular radionuclide can be identified by the gamma spectrometry software. In accordance with the Statement of Work for the laboratory analyses, gamma spectroscopy samples with confidence levels less than 90 percent are not considered "detects," regardless of their magnitudes compared to the MDC and TPU. Sample results are also normalized with the instrument background and/or the method 
blank. If either of those measurements have greater activity ranges than the actual sample, it is possible to get negative values on one end of the reported range of activities. Additional information on the equations used is in Appendix D.

The WIPP Laboratories perform these analyses for all radiological samples. The WIPP Laboratories use highly sensitive radiochemical analysis and detection techniques that result in very low detection limits. This allows detection of radionuclides at levels far below those of environmental and human health concern. The MDCs attained by the WIPP Laboratories are below the recommended MDCs specified in American National Standards Institute (ANSI) Standard N13.30, Performance Criteria for Radiobioassay.

Comparisons of radionuclide concentrations were made between years and locations using the statistical procedure, ANOVA (Analysis of Variance) for those data sets containing sufficient "detects" to make such comparisons statistically meaningful. When this or other statistical tests were used, the p-value was reported. The $p$-value is the probability under the null hypothesis of observing a value as unlikely or more unlikely than the value of the test statistic. In many cases, scientists have accepted a value of $p<0.05$ as indicative of a difference between samples. However, interpretation of $p$ requires some judgment on the part of the reader and individual readers may choose to defend higher or lower values of $p$ as their cutoff value. For this report, $p<0.05$ was used.

\section{Effluent Monitoring}

The WIPP Effluent Monitoring Program has three effluent air monitoring stations. These monitoring stations are known as Effluent Monitoring Stations A, B, and C. Each station employs one or more fixed air samplers, collecting particulate from the effluent air stream using a Versapor ${ }^{\circledR}$ filter. Instruments at Station A sample the unfiltered underground exhaust air. Samples collected at Station B represent the underground exhaust air after HEPA (high-efficiency particulate air) filtration and, sometimes, nonfiltered air during ventilation fan maintenance. Samples collected at Station C represent the air from the Waste Handling Building after HEPA filtration. For each sampling event, chain-of-custody forms are initiated to track and maintain an accurate written record of filter sample handling and treatment from the time of sample collection through laboratory procedures to disposal. Filter samples from all three effluent air monitoring stations are typically analyzed for ${ }^{238} \mathrm{Pu},{ }^{239+240} \mathrm{Pu},{ }^{241} \mathrm{Am}$, and ${ }^{90} \mathrm{Sr}$.

Only waste that conforms with DOE/WIPP 02-3122 was accepted for placement in the WIPP facility during CY 2006. Administrative controls prohibit the waste containers from being opened once they are accepted at the WIPP facility. In October 2006, the NMED issued a revised HWFP for the WIPP facility, specifying the final regulatory conditions for RH TRU waste management and disposal at the WIPP facility.

The 2007 Annual Periodic Confirmatory Measurement Compliance Report, as required by 40 CFR Part 61, Subpart H (NESHAP), will provide the details on the RH TRU and TRU mixed waste receipt and emplacement, as well as the ongoing $\mathrm{CH}$ TRU waste process activities. The 2007 report will include analysis of both $\mathrm{CH}$ and $\mathrm{RH}$ 
radionuclides, and updates of both existing and newly created $\mathrm{RH} T R U$ operating procedures. This expanded report will satisfy the established MOU between the EPA, and the DOE (April 5, 1995) regarding the application of the provisions of NESHAP standard. The CAP88-PC dose assessment computer model will continue to be used to estimate the dose(s) and to calculate the EDEs to members of the public.

\section{Environmental Monitoring}

The purpose of radiological environmental monitoring is to measure radionuclides in the ambient environmental media. This allows for a comparison of sample data to results from previous years and to baseline data, to determine what, if any, impact WIPP is having on the surrounding environment (see Appendix $\mathrm{H}$ for comparison graphs). Radiological monitoring at the WIPP site includes sampling and analysis of air, groundwater, surface water, sediment, soil and biota for ten radionuclides. For each sampling event, chain-of-custody forms are initiated to track and maintain an accurate written record of sample handling and treatment from the time of sample collection through delivery to the laboratory. Internal chain of custody forms are used by the laboratory to track and maintain custody while samples are being analyzed.

The radionuclides analyzed are ${ }^{238} \mathrm{Pu},{ }^{239+240} \mathrm{Pu},{ }^{241} \mathrm{Am},{ }^{234} \mathrm{U},{ }^{235} \mathrm{U},{ }^{238} \mathrm{U},{ }^{137} \mathrm{Cs},{ }^{60} \mathrm{Co},{ }^{40} \mathrm{~K}$, and ${ }^{90} \mathrm{Sr}$. Isotopes of plutonium and americium were analyzed because they are the most significant alpha-emitting radionuclides among the constituents of TRU wastes received at the WIPP site. Uranium isotopes were analyzed because they are prominent alpha-emitting radionuclides in the natural environment.

Strontium-90, ${ }^{60} \mathrm{Co}$, and ${ }^{137} \mathrm{Cs}$ are analyzed to demonstrate the ability to quantify these beta and gamma-emitting contaminants should they appear in the TRU waste stream. Potassium-40, a natural gamma-emitting radionuclide which is ubiquitous in the earth's crust, was also monitored.

\subsection{Effluent Monitoring}

\subsubsection{Sample Collection}

Stations $A, B$, and $C$ are monitored with one or more fixed air samplers. The volume of air sampled at each station varies depending on the sampling location and configuration. Each system is designed to provide a representative sample using a $3.0 \mu \mathrm{m}, 47-\mathrm{mm}$ diameter Versapor ${ }^{\circledR}$ membrane filter.

Daily (24-hours) filter samples are collected from Station A from the unfiltered underground exhaust stream. Each day at Station A, approximately $81 \mathrm{~m}^{3}(2,867$ cubic feet $\left[\mathrm{ft}^{3}\right]$ ) of air is filtered through the Versapor $^{\circledR}$ filter.

Weekly (24 hours/seven days per week) filter samples are collected at Stations B and $\mathrm{C}$. Station B represents the underground exhaust air after HEPA filtration and, sometimes, nonfiltered air during maintenance. Each week at Station B, approximately $569 \mathrm{~m}^{3}\left(20,093 \mathrm{ft}^{3}\right)$ of air is filtered through the Versapor ${ }^{\circledR}$ filter. Weekly filter samples 
are also collected at Station C, which represents the air from the Waste Handling Building after HEPA filtration. Each week at Station C, approximately $121 \mathrm{~m}^{3}\left(4,288 \mathrm{ft}^{3}\right)$ of air is filtered through the Versapor ${ }^{\circledR}$ filter. Based on the indicated sampling periods, these air volumes are within \pm 10 percent of the volume derived using the flow rate set point of $0.057 \mathrm{~m}^{3} / \mathrm{min}\left(2 \mathrm{ft}^{3} / \mathrm{min}\right)$ for Stations $A$ and $B$. The air volume for Station $C$ is within \pm 10 percent of the volume derived using the flow rate required for isokinetic sampling conditions and the indicated sampling period. The sample flow rate for Station $\mathrm{C}$ varies according to the exhaust air flow in the Waste Handling Building in order to maintain isokinetic sampling conditions.

The filter samples are composited each quarter for Stations B and C. Because of the large number of samples from Station A, these samples were composited monthly. All filter samples were analyzed radiochemically for ${ }^{241} \mathrm{Am},{ }^{238} \mathrm{Pu},{ }^{239+240} \mathrm{Pu}$, and ${ }^{90} \mathrm{Sr}$.

\subsubsection{Sample Preparation}

Monthly and quarterly filter samples are composited. The composites are transferred into a Pyrex beaker, spiked with appropriate tracers $\left({ }^{243} \mathrm{Am}\right.$ and $\left.{ }^{242} \mathrm{Pu}\right)$, and heated in a Muffle furnace at $250^{\circ} \mathrm{C}\left(482^{\circ} \mathrm{F}\right)$ for two hours, followed by two hours at $375^{\circ} \mathrm{C}\left(707^{\circ} \mathrm{F}\right)$ and six hours at $525^{\circ} \mathrm{C}\left(977^{\circ} \mathrm{F}\right)$.

The ash is cooled, transferred quantitatively into a Teflon beaker by rinsing with concentrated nitric acid, and heated with concentrated hydrofluoric acid until completely dissolved. Hydrofluoric acid is removed by evaporating to dryness.

Approximately 25 milliliters ( $\mathrm{mL}$ ) (0.845 fluid ounce [oz]) of concentrated nitric acid and one gram ( $0.0353 \mathrm{oz}$ ) of boric acid are added, heated, and finally evaporated to dryness. The residue is dissolved in $8 \mathrm{M}$ (molar) nitric acid for gamma spectrometry and determinations of ${ }^{90} \mathrm{Sr}$ and alpha-emitting radionuclides.

\subsubsection{Determination of Individual Radionuclides}

Gamma-emitting radionuclides are measured in the air filters by gamma spectrometry. Strontium-90 and alpha-emitting radionuclides are determined by sequential separation and counting. Strontium-90 is counted with a gas proportional counter. Determination of actinides involves co-precipitation, ion exchange separation, and alpha spectrometry.

\subsubsection{Results and Discussion}

Out of 20 total composite samples, none had detectable radioactivity (Table 4.1). In all cases, either the 2 sigma TPU or the MDC was found to be greater than the estimated values. In cases when the 2 sigma TPU values were greater than the MDC, the 2 sigma TPU values were used as input nuclide data in the CAP88-PC computer model to calculate the EDEs to members of the public (see Section 4.8). These include the 2 sigma TPU values from the following composite air samples: Station $A,{ }^{241} \mathrm{Am}$, during the month of December 2006; Station A, ${ }^{238} \mathrm{Pu}$, during the months of February, June, October and December 2006; Station A, ${ }^{239+240} \mathrm{Pu}$, during the months of February, May, 
July, and November 2006; Station B, ${ }^{241} \mathrm{Am}$, during the third quarter of 2006, and ${ }^{239+240} \mathrm{Pu}$, during the fourth quarter of 2006 ; Station $\mathrm{C},{ }^{239+240} \mathrm{Pu}$, during the first quarter of 2006, and ${ }^{241} \mathrm{Am}$, during the third and fourth quarters of 2006; and all results of ${ }^{90} \mathrm{Sr}$ from Stations $A, B$, and $C$. In all other cases, the MDC values were used as nuclide data in the CAP88-PC computer model (see Section 4.8).

Sampling was routinely performed in the underground using fixed air samplers and continuous air monitors. Evaluation of the filter sample results indicate that there were no detectable releases that exceeded 25 mrem to the whole body and 75 mrem to any critical organ in accordance with the provisions of 40 CFR $\$ 191.03(b)$, from the WIPP facility. In addition, there were no detectable releases that exceeded the 10 mrem per year limit, as specified in 40 CFR $\S 61.92$, and the 0.1 mrem per year limit for periodic confirmatory sampling required by 40 CFR $§ 61.93(b)(4)(i)$, from the WIPP facility.

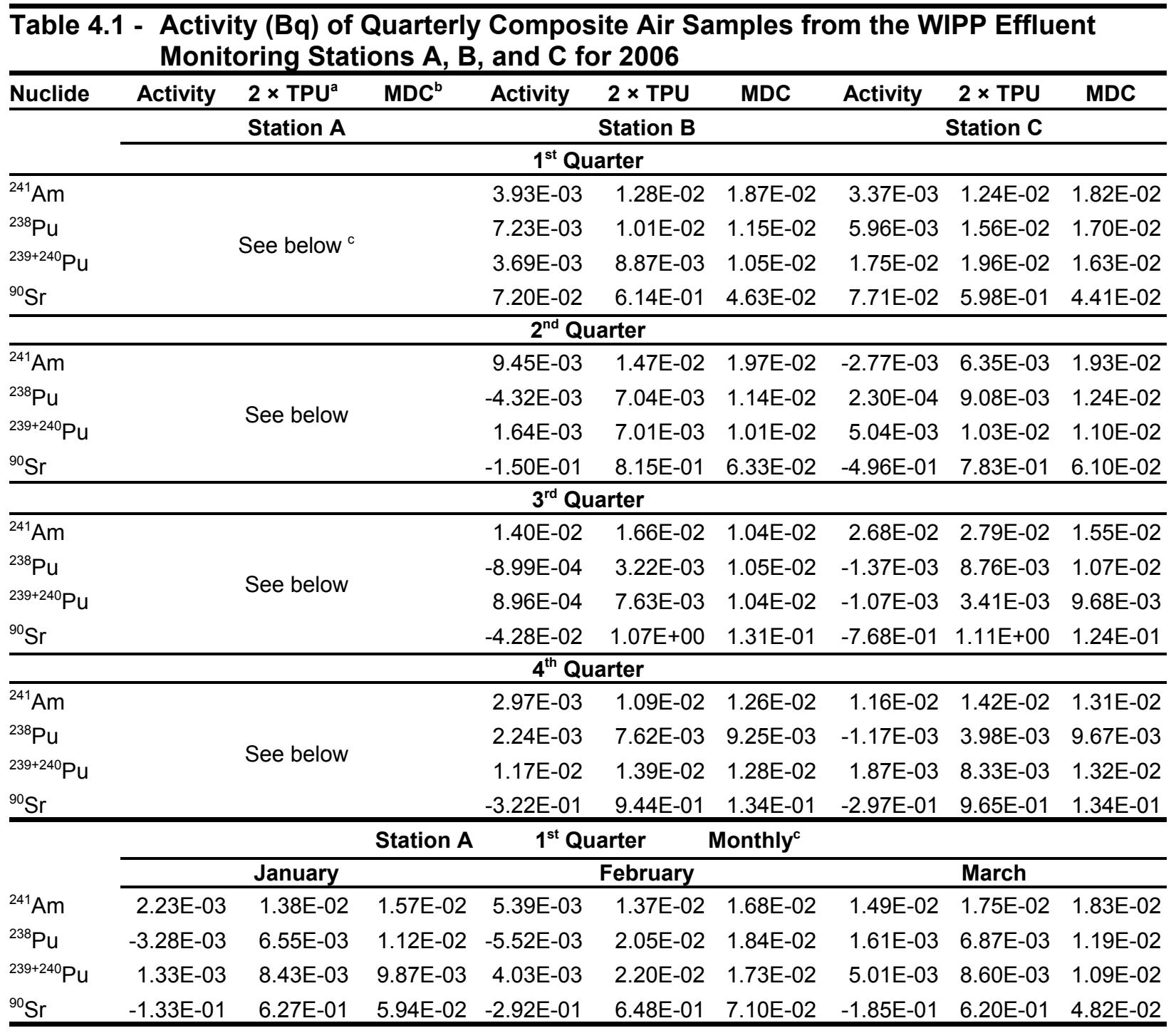


Waste Isolation Pilot Plant Annual Site Environmental Report for 2006 DOE/WIPP-07-2225

\begin{tabular}{|c|c|c|c|c|c|c|c|c|c|}
\hline \multirow[t]{3}{*}{ Nuclide } & Activity & $2 \times \mathrm{TPU}^{\mathrm{a}}$ & MDC $^{b}$ & Activity & $2 \times$ TPU & MDC & Activity & $2 \times$ TPU & MDC \\
\hline & & & Station A & \multicolumn{2}{|c|}{$2^{\text {nd }}$ Quarter } & Monthly & & & \\
\hline & & April & & & May & & \multicolumn{3}{|c|}{ June } \\
\hline${ }^{241} \mathrm{Am}$ & 6.90E-03 & 1.38E-02 & 1.79E-02 & 8.05E-03 & 1.42E-02 & 1.78E-02 & 1.04E-02 & 1.42E-02 & 1.83E-02 \\
\hline${ }^{238} \mathrm{Pu}$ & $-3.64 \mathrm{E}-03$ & $7.40 \mathrm{E}-03$ & 1.46E-02 & $-1.19 \mathrm{E}-04$ & $9.78 \mathrm{E}-03$ & 1.12E-02 & 4.44E-03 & 1.17E-02 & 1.14E-02 \\
\hline${ }^{239+240} \mathrm{Pu}$ & $-1.21 \mathrm{E}-03$ & $4.26 \mathrm{E}-03$ & 1.36E-02 & 1.24E-02 & 1.44E-02 & $1.21 \mathrm{E}-02$ & $6.04 \mathrm{E}-03$ & 1.07E-02 & $1.24 \mathrm{E}-02$ \\
\hline \multirow[t]{3}{*}{${ }^{90} \mathrm{Sr}$} & $2.90 \mathrm{E}-01$ & 5.96E-01 & 4.30E-02 & $2.89 \mathrm{E}-01$ & 5.81E-01 & $6.12 \mathrm{E}-02$ & $-3.74 \mathrm{E}-01$ & 5.91E-01 & $6.90 \mathrm{E}-02$ \\
\hline & \multirow{2}{*}{\multicolumn{3}{|c|}{ Station A }} & \multicolumn{2}{|c|}{$3^{\text {rd }}$ Quarter } & Monthly & & & \\
\hline & & & & & August & & \multicolumn{3}{|c|}{ September } \\
\hline${ }^{241} \mathrm{Am}$ & $6.84 \mathrm{E}-03$ & 1.34E-02 & $2.09 \mathrm{E}-02$ & 1.15E-02 & 1.47E-02 & $1.83 \mathrm{E}-02$ & $-3.19 \mathrm{E}-03$ & 9.34E-03 & 1.96E-02 \\
\hline${ }^{238} \mathrm{Pu}$ & $-2.67 \mathrm{E}-03$ & 6.00E-03 & $1.29 \mathrm{E}-02$ & $-1.78 \mathrm{E}-03$ & 4.93E-03 & 1.16E-02 & 9.19E-05 & 7.43E-03 & 1.03E-02 \\
\hline${ }^{239+240} \mathrm{Pu}$ & 1.31E-02 & $1.42 \mathrm{E}-02$ & 1.15E-02 & $3.55 \mathrm{E}-03$ & $6.96 \mathrm{E}-03$ & 1.13E-02 & $-1.40 \mathrm{E}-03$ & $3.81 \mathrm{E}-03$ & $9.32 \mathrm{E}-03$ \\
\hline \multirow[t]{3}{*}{${ }^{90} \mathrm{Sr}$} & $-1.81 \mathrm{E}-01$ & 7.77E-01 & $5.99 \mathrm{E}-02$ & $6.35 \mathrm{E}-02$ & $1.47 \mathrm{E}+00$ & 1.42E-01 & $-3.41 \mathrm{E}-01$ & $1.10 \mathrm{E}+00$ & $1.21 \mathrm{E}-01$ \\
\hline & \multicolumn{3}{|r|}{ Station A } & \multicolumn{2}{|c|}{$4^{\text {th }}$ Quarter } & Monthly & & & \\
\hline & & October & & & November & & \multicolumn{3}{|c|}{ December } \\
\hline${ }^{241} \mathrm{Am}$ & $2.01 \mathrm{E}-03$ & $1.00 \mathrm{E}-02$ & $1.56 \mathrm{E}-02$ & $3.16 \mathrm{E}-03$ & $1.55 \mathrm{E}-02$ & $1.75 \mathrm{E}-02$ & 1.71E-02 & 1.81E-02 & $1.51 \mathrm{E}-02$ \\
\hline${ }^{238} \mathrm{Pu}$ & $9.59 \mathrm{E}-03$ & 1.68E-02 & $9.77 \mathrm{E}-03$ & $-1.93 \mathrm{E}-03$ & $5.27 \mathrm{E}-03$ & 1.11E-02 & 7.69E-03 & 1.17E-02 & 8.94E-03 \\
\hline${ }^{239+240} \mathrm{Pu}$ & 1.78E-03 & 7.61E-03 & 1.14E-02 & 9.77E-03 & $1.34 \mathrm{E}-02$ & 1.31E-02 & $-1.05 \mathrm{E}-03$ & 3.57E-03 & 1.19E-02 \\
\hline${ }^{90} \mathrm{Sr}$ & $5.90 \mathrm{E}-01$ & $1.31 \mathrm{E}+00$ & $1.39 \mathrm{E}-01$ & $5.17 \mathrm{E}-02$ & $1.17 E+00$ & $1.42 \mathrm{E}-01$ & 1.41E-01 & $1.02 E+00$ & $1.31 \mathrm{E}-01$ \\
\hline
\end{tabular}

\subsection{Airborne Particulates}

\subsubsection{Sample Collection}

Weekly airborne particulate samples are collected from seven locations around WIPP (Figure 4.1) using low-volume air samplers. Locations were selected based on the prevailing wind direction. Location codes are shown in Appendix C. Each week at each sampling location, approximately $600 \mathrm{~m}^{3}\left(21,187 \mathrm{ft}^{3}\right)$ of air is filtered through a 4.7-centimeter $(\mathrm{cm})$ (1.85-inch [in.]) diameter glass microfiber filter using a low-volume continuous air sampler. 


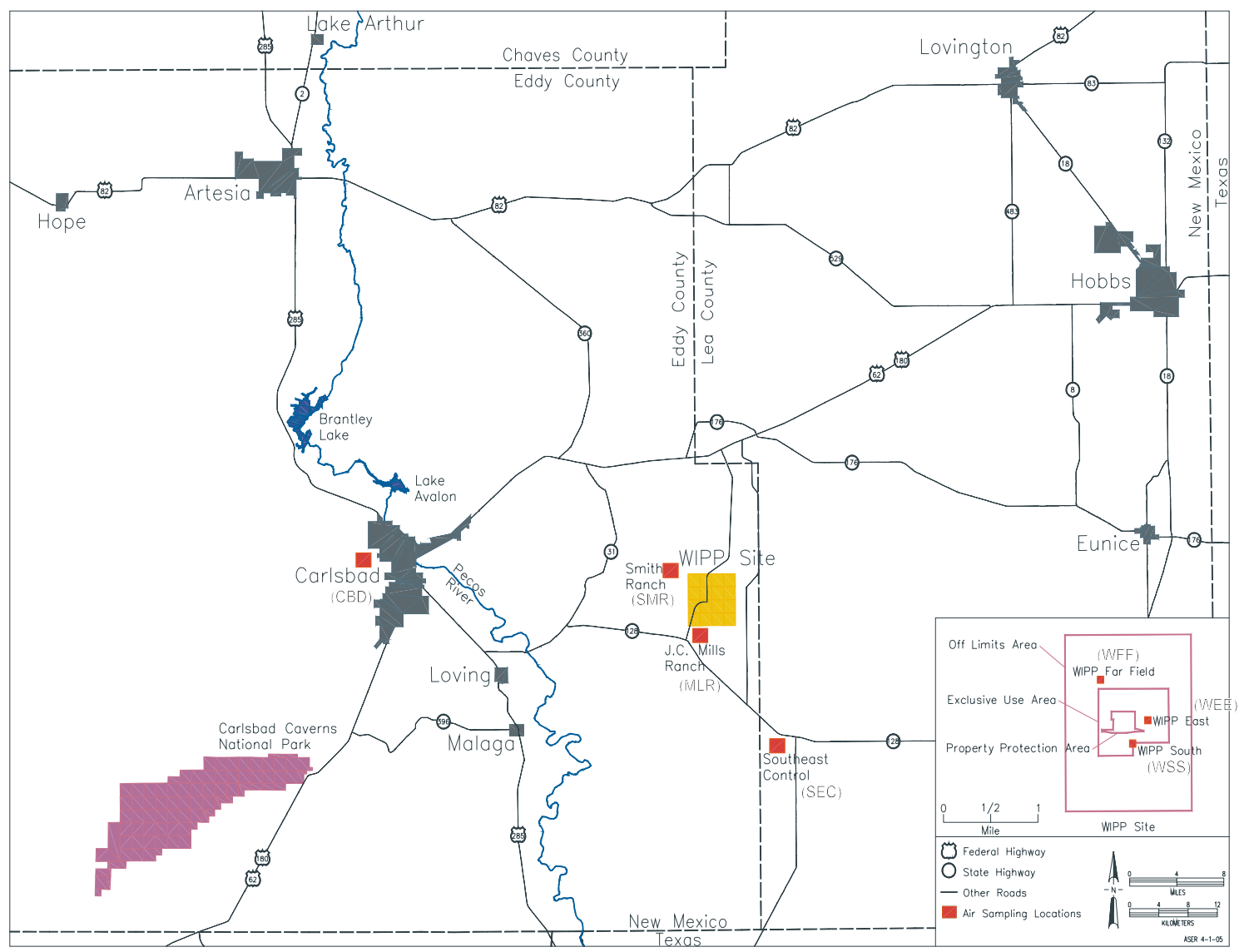

Figure 4.1 - Air Sampling Locations On and Near the WIPP Facility

\subsubsection{Sample Preparation}

Weekly air particulate samples are composited for each quarter. The composites are transferred into a Pyrex beaker, spiked with appropriate tracers $\left({ }^{243} \mathrm{Am}\right.$ and $\left.{ }^{242} \mathrm{Pu}\right)$, and heated in a Muffle furnace at $250^{\circ} \mathrm{C}\left(482^{\circ} \mathrm{F}\right)$ for two hours, followed by two hours at $375^{\circ} \mathrm{C}\left(707^{\circ} \mathrm{F}\right)$ and six hours at $525^{\circ} \mathrm{C}\left(977^{\circ} \mathrm{F}\right)$.

The ash is cooled, transferred quantitatively into a Teflon beaker by rinsing with concentrated nitric acid, and heated with concentrated hydrofluoric acid until completely dissolved. Hydrofluoric acid is removed by evaporating to dryness.

Approximately $25 \mathrm{~mL}(0.845 \mathrm{oz})$ of concentrated nitric acid and one gram $(0.0353 \mathrm{oz})$ of boric acid are added, heated, and finally evaporated to dryness. The residue is dissolved in $8 \mathrm{M}$ nitric acid for gamma spectrometry and determinations of ${ }^{90} \mathrm{Sr}$ and alpha-emitting radionuclides. 


\subsubsection{Determination of Individual Radionuclides}

Gamma-emitting radionuclides are measured in the air filters by gamma spectrometry. Strontium-90 and alpha-emitting radionuclides are determined by sequential separation and counting. Strontium-90 is counted with a gas proportional counter. Determination of actinides involved co-precipitation, ion exchange separation, and alpha spectrometry.

\subsubsection{Results and Discussion}

The minimum, maximum, and average concentrations for all sampling locations combined are reported in Table 4.2. Detailed data for each station are reported in Appendix G (Table G.1).

Natural uranium isotopes were not detected in the composite samples (Table G.1). Whenever the word "sample" is used in this section, it should be taken to mean "composite sample" and does not include blanks. Uranium-234, ${ }^{235} \mathrm{U}$, and ${ }^{238} \mathrm{U}$ were not detected at any of the sampling locations. None of these isotopes were detected so ANOVA comparisons between years and among locations were not performed.

Plutonium-238, ${ }^{239+240} \mathrm{Pu}$, and ${ }^{241} \mathrm{Am}$ were not detected in any low-volume air samples in 2006.

Concentrations of ${ }^{40} \mathrm{~K}$ (Table G.1) were detected in approximately 11 percent of the samples. Potassium-40 is ubiquitous in the earth's crust and thus would be expected to show up in environmental air samples. There was no significant difference in the concentrations of ${ }^{40} \mathrm{~K}$ detected among locations (ANOVA, $p=0.577$ ) or between 2005 and 2006 (ANOVA, $p=0.136$ ). The highest concentration of ${ }^{40} \mathrm{~K}$ detected $\left(2.81 \mathrm{E}-04 \mathrm{~Bq} / \mathrm{m}^{3}\right)$ fell within the baseline value (upper 99th percentile: $3.20 \mathrm{E}-04 \mathrm{~Bq} / \mathrm{m}^{3}$ ).

Cesium-137, ${ }^{90} \mathrm{Sr},{ }^{60} \mathrm{Co}$ and were not detected in any samples in 2006 . Since none of these isotopes were detected, ANOVA comparisons between years or among locations were not performed.

\begin{tabular}{|c|c|c|c|c|}
\hline Table 4.2 - & \multicolumn{4}{|c|}{$\begin{array}{l}\text { Minimum, Maximum, and Average Radionuclide Concentrations }\left(\mathrm{Bq} / \mathrm{m}^{3}\right) \text { in } \\
\text { Air Filter Composites from Stations Surrounding the WIPP Site. See } \\
\text { Appendix G for supporting data. }\end{array}$} \\
\hline Radionuclide & & {$[\mathrm{RN}]^{\mathrm{a}}$} & $2 \times$ TPU $^{b}$ & $\mathrm{MDC}^{\mathrm{C}}$ \\
\hline \multirow[t]{3}{*}{${ }^{241} \mathrm{Am}$} & Minimum $^{d}$ & $-1.84 \mathrm{E}-08$ & $5.71 \mathrm{E}-08$ & $6.20 \mathrm{E}-05$ \\
\hline & Maximum $^{d}$ & 8.14E-08 & 8.48E-08 & 1.98E-04 \\
\hline & Average $^{\mathrm{e}}$ & $1.94 \mathrm{E}-08$ & 5.16E-08 & 2.04E-04 \\
\hline \multirow[t]{3}{*}{${ }^{238} \mathrm{Pu}$} & Minimum & $-6.10 \mathrm{E}-08$ & $1.18 \mathrm{E}-07$ & 1.01E-05 \\
\hline & Maximum & 6.06E-08 & 8.87E-08 & 1.11E-04 \\
\hline & Average & 9.46E-09 & 6.07E-08 & $6.74 \mathrm{E}-05$ \\
\hline \multirow[t]{3}{*}{${ }^{239+240} \mathrm{Pu}$} & Minimum & $-3.03 E-08$ & 8.28E-08 & 1.09E-04 \\
\hline & Maximum & 1.13E-07 & 9.53E-08 & $1.24 \mathrm{E}-04$ \\
\hline & Average & 1.54E-08 & 4.84E-08 & 1.01E-04 \\
\hline
\end{tabular}




\begin{tabular}{|c|c|c|c|c|}
\hline \multirow{2}{*}{$\begin{array}{l}\text { Table } 4.2 \text { - } \\
\text { Radionuclide }\end{array}$} & \multicolumn{4}{|c|}{$\begin{array}{l}\text { Minimum, Maximum, and Average Radionuclide Concentrations }\left(\mathrm{Bq} / \mathrm{m}^{3}\right) \text { in } \\
\text { Air Filter Composites from Stations Surrounding the WIPP Site. See } \\
\text { Appendix G for supporting data. }\end{array}$} \\
\hline & & ${\text { [RN }]^{\mathrm{a}}}$ & $2 \times$ TPU $^{b}$ & MDC $^{c}$ \\
\hline \multirow[t]{3}{*}{${ }^{234} U$} & Minimum & $8.57 \mathrm{E}-07$ & $2.64 \mathrm{E}-07$ & $1.37 \mathrm{E}-03$ \\
\hline & Maximum & 3.37E-06 & 1.87E-06 & 1.37E-03 \\
\hline & Average & 1.98E-06 & 6.63E-07 & $1.28 \mathrm{E}-03$ \\
\hline \multirow{3}{*}{${ }^{235} U$} & Minimum & -8.27E-09 & 3.93E-08 & 1.24E-04 \\
\hline & Maximum & 5.05E-07 & 4.81E-07 & $1.24 \mathrm{E}-04$ \\
\hline & Average & 1.14E-07 & $1.14 \mathrm{E}-07$ & $1.50 \mathrm{E}-04$ \\
\hline \multirow[t]{3}{*}{${ }^{238} \mathrm{U}$} & Minimum & 7.86E-07 & 2.49E-07 & 6.93E-04 \\
\hline & Maximum & $2.95 \mathrm{E}-06$ & 4.76E-07 & 5.94E-04 \\
\hline & Average & 1.80E-06 & 6.08E-07 & $6.41 \mathrm{E}-04$ \\
\hline \multirow[t]{3}{*}{${ }^{40} \mathrm{~K}$} & Minimum & $-1.23 E-04$ & $1.40 \mathrm{E}-04$ & 2.67E-04 \\
\hline & Maximum & 1.47E-03 & 6.98E-04 & 8.19E-04 \\
\hline & Average & 4.03E-04 & 3.07E-04 & 3.93E-04 \\
\hline \multirow[t]{3}{*}{${ }^{60} \mathrm{Co}$} & Minimum & $-2.12 \mathrm{E}-05$ & 7.48E-05 & 8.05E-05 \\
\hline & Maximum & 4.38E-05 & 7.04E-05 & 7.96E-05 \\
\hline & Average & $1.00 \mathrm{E}-05$ & 3.56E-05 & 4.02E-05 \\
\hline \multirow[t]{3}{*}{${ }^{90} \mathrm{Sr}$} & Minimum & $-3.88 E-06$ & 6.74E-06 & $2.85 \mathrm{E}-03$ \\
\hline & Maximum & 5.55E-06 & 5.78E-06 & $2.57 \mathrm{E}-03$ \\
\hline & Average & 8.75E-07 & 5.35E-06 & 2.00E-03 \\
\hline \multirow{3}{*}{${ }^{137} \mathrm{Cs}$} & Minimum & $-8.75 E-05$ & 7.82E-05 & 8.12E-05 \\
\hline & Maximum & 2.68E-05 & 2.74E-05 & 3.42E-05 \\
\hline & Average & $-2.13 E-05$ & 3.31E-05 & $3.70 \mathrm{E}-05$ \\
\hline \multicolumn{5}{|c|}{$\begin{array}{l}\text { a Radionuclide concentration, values are for eight locations, four quarterly composites (Appendix G). } \\
\text { b Total propagated uncertainty } \\
\text { c Minimum detectable concentration } \\
\text { d Minimum and maximum reported for each radionuclide are based on [RN] while the associated } 2 \text { X TPU and MDC } \\
\text { values are inherited with the specific [RN]. } \\
\text { e Arithmetic average for concentration, } 2 \text { X TPU, and MDC. } \\
\text { * Gamma spectroscopy samples with confidence levels less than } 90 \text { percent - not considered "detects." }\end{array}$} \\
\hline
\end{tabular}

During 2006, duplicate samples were taken from four locations. There were no instances in which both the sample and its duplicate contained a detectable concentration of a radionuclide. Therefore, relative error ratios (RERs) were not calculated and are not shown for 2006 air filter composite samples.

\subsection{Groundwater}

\subsubsection{Sample Collection}

Groundwater samples were collected twice in 2006 from seven different wells around the WIPP site as shown in Figure 6.1. Six of these wells are completed in the Culebra Member of the Rustler Formation (wells WQSP-1 through WQSP-6) and the seventh (well WQSP-6A) is completed in the Dewey Lake Redbeds Formation. Approximately three bore volumes (approximately 3,800 liters [L] [1,004 gallons]) of water are pumped out of each well before collecting approximately $38 \mathrm{~L}$ ( 10 gallons) of water samples. The water samples are collected from depths ranging from 180-270 $\mathrm{m}(591-886 \mathrm{ft})$ from 
six wells (WQSP-1 to WQSP-6), and from a depth of $69 \mathrm{~m} \mathrm{(226} \mathrm{ft)} \mathrm{from} \mathrm{WQSP-6A.}$ Approximately $8 \mathrm{~L}$ (2 gallons) of water are sent to the laboratory for the determination of radionuclides of interest. The rest of the samples are used to analyze for nonradiological parameters or are put into storage. The radiological samples are acidified to $\mathrm{pH} \leq 2$ by titrating with concentrated nitric acid.

\subsubsection{Sample Preparation}

Groundwater sample containers are shaken to distribute suspended material evenly, and an aliquot is measured into a glass beaker. Tracers $\left({ }^{232} \mathrm{U},{ }^{243} \mathrm{Am}\right.$, and $\left.{ }^{242} \mathrm{Pu}\right)$ and carriers (strontium nitrate and barium nitrate) are added and the sample is then digested using concentrated nitric acid and hydrofluoric acid. The sample is then heated to dryness and wet ashed using concentrated nitric acid and hydrogen peroxide. Finally, the sample is heated to dryness again and the isotopic separation process is initiated.

\subsubsection{Determination of Individual Radionuclides}

The acidified water samples are used for the determination of the gamma-emitting radionuclides ${ }^{40} \mathrm{~K},{ }^{60} \mathrm{Co}$, and ${ }^{137} \mathrm{Cs}$, by gamma spectrometry. An aliquot of approximately $0.5 \mathrm{~L}(16.9 \mathrm{oz})$ is used for the determination of ${ }^{90} \mathrm{Sr}$ by gas proportional counter. Another aliquot is used for the sequential determinations of the uranium isotopes, the plutonium isotopes, and ${ }^{241} \mathrm{Am}$ by alpha spectrometry. Preparation of these samples for counting involves the co-precipitation of the actinides with an iron carrier, ion exchange chromatographic separation of individual radionuclides, and source preparation by micro-precipitation.

\subsubsection{Results and Discussion}

Isotopes of naturally occurring uranium were detected in every well in 2006 except for one sample taken at location WQSP-3 for ${ }^{235} U$ (Table 4.3). The concentrations of uranium isotopes were compared between 2005 and 2006 and also among sampling locations using ANOVA. Of the three uranium isotopes, significant variability was observed among sampling locations for ${ }^{238} U$ (ANOVA, ${ }^{234} U p=0.783,{ }^{235} U p=0.844$, $\left.{ }^{238} \mathrm{U} p=3.48 \mathrm{E}-05\right)$. There was no significant difference in the concentrations of uranium isotopes between 2005 and 2006 (ANOVA, ${ }^{234} U p=0.786,{ }^{235} U p=0.202,{ }^{238} U p=$ $0.790)$. Variability among sampling locations is expected since natural uranium in the earth's crust is distributed in a nonhomogenous fashion, and this variation is reflected in the amounts of uranium dissolved into groundwater.

Concentrations of uranium isotopes were also compared with baseline levels observed between 1985 and 1989 (baseline values: ${ }^{234} \mathrm{U}=1.30 \mathrm{E}+00 \mathrm{~Bq} / \mathrm{L},{ }^{235} \mathrm{U}=3.10 \mathrm{E}-02 \mathrm{~Bq} / \mathrm{L}$, $\left.{ }^{238} \mathrm{U}=3.20 \mathrm{E}-01 \mathrm{~Bq} / \mathrm{L}\right)$. Concentrations of ${ }^{234} \mathrm{U},{ }^{235} \mathrm{U},{ }^{238} \mathrm{U}$ were within the 99 percent confidence interval ranges of baseline levels (DOE/WIPP 92-037). Therefore, it is concluded that WIPP operation has not resulted in changes in the radiological background in the vicinity of the WIPP site. 


\section{Waste Isolation Pilot Plant Annual Site Environmental Report for 2006 DOE/WIPP-07-2225}

Plutonium-238, ${ }^{239+240} \mathrm{Pu}$, and ${ }^{241} \mathrm{Am}$ were also analyzed in these groundwater samples (Table 4.3). Plutonium-238, ${ }^{239+240} \mathrm{Pu}$, and ${ }^{241} \mathrm{Am}$ were not detected in any of the wells. None of these isotopes were detected, so ANOVA comparisons between years and among locations were not performed.

Cesium-137, ${ }^{90} \mathrm{Sr}$ and ${ }^{60} \mathrm{Co}$ were not detected in any of the samples. Since none of these isotopes were detected, there was insufficient data for ANOVA comparisons between years or among locations.

Potassium-40 was detected in all samples except for one sample taken from well WQSP-6 and both samples of WQSP-6A (Table 4.3). Potassium is ubiquitous throughout the earth's crust and therefore would be expected to show up in groundwater samples. The levels are higher than average in these sampling wells due to the extremely briny nature of the Culebra water and its proximity to the Salado formation, resulting in a high level of dissolved potassium salts. Even so, the concentrations of ${ }^{40} \mathrm{~K}$ observed during this reporting year fall within the 99 percent confidence interval range of the baseline concentrations (baseline concentration: $6.30 \mathrm{E}+01 \mathrm{~Bq} / \mathrm{L}$ ). There was a significant difference in ${ }^{40} \mathrm{~K}$ concentrations among sampling locations (ANOVA $p=5.75 E-07$ ), but not between 2005 and 2006 (ANOVA $p=0.814$ ). The difference in ${ }^{40} \mathrm{~K}$ concentrations is because this isotope is naturally occurring in the earth's crust and the concentration varies in different locations.

Table 4.3 - $\quad$ Radionuclide Concentrations (Bq/L) in Groundwater from Wells at the WIPP Site. See Chapter 6 for the sampling locations.

\begin{tabular}{|c|c|c|c|c|c|c|c|c|c|c|}
\hline \multirow[b]{2}{*}{ Location } & \multicolumn{10}{|l|}{ Sampling } \\
\hline & Round & {$[R N]^{a}$} & $2 \times$ TPU $^{\mathrm{b}}$ & $M^{\prime} C^{c}$ & {$[\mathrm{RN}]$} & $2 \times$ TPU & MDC & [RN] & $2 \times$ TPU & MDC \\
\hline & & & ${ }^{241} \mathrm{Am}$ & & & ${ }^{238} \mathrm{Pu}$ & & & ${ }^{239+240} \mathrm{Pu}$ & \\
\hline \multirow[t]{2}{*}{ WQSP-1 } & 22 & 1.59E-04 & 5.89E-04 & 6.38E-04 & -1.67E-04 & 3.27E-04 & 4.89E-04 & $-1.84 \mathrm{E}-04$ & 3.43E-04 & $5.01 \mathrm{E}-04$ \\
\hline & 23 & 2.82E-04 & 3.75E-04 & 4.57E-04 & 1.09E-04 & 4.02E-04 & 3.42E-04 & $-2.82 \mathrm{E}-05$ & 1.13E-04 & $4.28 \mathrm{E}-04$ \\
\hline \multirow[t]{2}{*}{ WQSP-2 } & 22 & $1.58 \mathrm{E}-04$ & 4.09E-04 & 4.55E-04 & -7.97E-06 & 3.17E-04 & 3.66E-04 & 5.61E-05 & 2.69E-04 & $3.41 \mathrm{E}-04$ \\
\hline & 23 & 7.26E-04 & 8.52E-04 & 6.31E-04 & $-3.85 E-06$ & 3.16E-04 & 3.56E-04 & $-2.73 E-05$ & 1.09E-04 & $3.68 \mathrm{E}-04$ \\
\hline \multirow[t]{2}{*}{ WQSP-3 } & 22 & 5.05E-04 & 7.16E-04 & 7.43E-04 & -1.03E-04 & $2.05 \mathrm{E}-04$ & 4.00E-04 & $-5.14 \mathrm{E}-05$ & 1.45E-04 & 3.75E-04 \\
\hline & 23 & 4.33E-04 & 7.70E-04 & 5.36E-04 & 4.44E-05 & 4.79E-04 & $5.89 \mathrm{E}-04$ & $1.01 \mathrm{E}-04$ & 4.35E-04 & $5.98 \mathrm{E}-04$ \\
\hline \multirow[t]{2}{*}{ WQSP-4 } & 22 & $1.22 \mathrm{E}-04$ & 9.34E-04 & 8.79E-04 & -9.31E-05 & $2.00 \mathrm{E}-04$ & 3.77E-04 & $-2.60 \mathrm{E}-05$ & 1.06E-04 & $3.65 \mathrm{E}-04$ \\
\hline & 23 & 4.64E-04 & $5.10 \mathrm{E}-04$ & $6.12 \mathrm{E}-04$ & -8.94E-05 & $2.00 \mathrm{E}-04$ & 4.40E-04 & $2.14 \mathrm{E}-04$ & 3.37E-04 & $3.78 \mathrm{E}-04$ \\
\hline \multirow[t]{2}{*}{ WQSP-5 } & 22 & 8.73E-04 & $1.11 \mathrm{E}-03$ & 8.50E-04 & $-3.59 \mathrm{E}-06$ & $2.95 \mathrm{E}-04$ & $3.60 \mathrm{E}-04$ & $-5.45 \mathrm{E}-05$ & $1.49 \mathrm{E}-04$ & 3.35E-04 \\
\hline & 23 & 6.87E-05 & 3.87E-04 & $6.58 \mathrm{E}-04$ & $1.04 \mathrm{E}-05$ & 4.12E-04 & 5.34E-04 & $3.44 \mathrm{E}-04$ & 5.72E-04 & $4.72 \mathrm{E}-04$ \\
\hline \multirow[t]{2}{*}{ WQSP-6 } & 22 & 5.78E-04 & 8.33E-04 & 8.38E-04 & $-3.51 \mathrm{E}-06$ & $2.89 \mathrm{E}-04$ & $3.54 \mathrm{E}-04$ & 1.67E-04 & $3.12 \mathrm{E}-04$ & $3.42 \mathrm{E}-04$ \\
\hline & 23 & 1.14E-05 & 4.51E-04 & 7.34E-04 & 2.26E-04 & 4.64E-04 & 4.42E-04 & $-1.00 \mathrm{E}-04$ & $2.21 \mathrm{E}-04$ & $3.80 \mathrm{E}-04$ \\
\hline \multirow[t]{3}{*}{ WQSP-6A } & 22 & $-4.80 \mathrm{E}-06$ & 3.63E-04 & $6.73 \mathrm{E}-04$ & $-4.12 \mathrm{E}-05$ & $1.28 \mathrm{E}-04$ & $3.54 \mathrm{E}-04$ & $-3.09 \mathrm{E}-05$ & 1.11E-04 & $3.41 \mathrm{E}-04$ \\
\hline & 23 & -9.86E-05 & $2.26 \mathrm{E}-04$ & $6.49 \mathrm{E}-04$ & -1.71E-04 & $2.55 \mathrm{E}-04$ & $3.42 \mathrm{E}-04$ & 3.41E-05 & 2.49E-04 & $3.42 \mathrm{E}-04$ \\
\hline & & & ${ }^{234} \mathrm{U}$ & & & ${ }^{235} \mathrm{U}$ & & & ${ }^{238} \mathrm{U}$ & \\
\hline \multirow[t]{2}{*}{ WQSP-1 } & 22 & $1.07 E+00$ & $4.28 \mathrm{E}-02$ & $1.32 \mathrm{E}-03$ & $1.44 \mathrm{E}-02$ & $2.64 \mathrm{E}-03$ & $5.01 \mathrm{E}-04$ & $1.88 \mathrm{E}-01$ & 1.07E-02 & $8.84 \mathrm{E}-04$ \\
\hline & 23 & $1.04 \mathrm{E}+00$ & 2.57E-01 & 1.89E-03 & 7.48E-03 & $3.09 \mathrm{E}-03$ & 7.11E-04 & $1.74 \mathrm{E}-01$ & 4.68E-02 & $1.12 \mathrm{E}-03$ \\
\hline \multirow[t]{2}{*}{ WQSP-2 } & 22 & $1.17 \mathrm{E}+00$ & 4.68E-02 & 1.16E-03 & 1.74E-02 & 3.04E-03 & $5.18 \mathrm{E}-04$ & $1.80 \mathrm{E}-01$ & 1.07E-02 & 8.08E-04 \\
\hline & 23 & $1.09 E+00$ & 3.71E-01 & 1.89E-03 & 1.34E-02 & $5.69 \mathrm{E}-03$ & 7.78E-04 & $1.75 \mathrm{E}-01$ & $6.03 E-02$ & 1.13E-03 \\
\hline \multirow[t]{2}{*}{ WQSP-3 } & 22 & 2.37E-01 & 1.25E-02 & 1.19E-03 & 3.56E-03 & 1.32E-03 & 4.73E-04 & 3.35E-02 & 3.77E-03 & 8.04E-04 \\
\hline & 23 & $2.82 \mathrm{E}-03$ & 1.49E-03 & 1.75E-03 & 1.70E-04 & $5.78 \mathrm{E}-04$ & 7.39E-04 & 1.37E-03 & 9.94E-04 & $1.04 \mathrm{E}-03$ \\
\hline \multirow[t]{2}{*}{ WQSP-4 } & 22 & 5.50E-01 & 2.53E-02 & 1.18E-03 & $9.10 \mathrm{E}-03$ & $2.26 \mathrm{E}-03$ & 4.98E-04 & 9.27E-02 & 7.23E-03 & 8.81E-04 \\
\hline & 23 & 5.26E-01 & 1.20E-01 & 1.66E-03 & 9.73E-03 & $3.24 \mathrm{E}-03$ & 5.32E-04 & 9.66E-02 & 2.28E-02 & $9.24 \mathrm{E}-04$ \\
\hline
\end{tabular}


Table 4.3 - $\quad$ Radionuclide Concentrations (Bq/L) in Groundwater from Wells at the WIPP Site. See Chapter 6 for the sampling locations.

\begin{tabular}{|c|c|c|c|c|c|c|c|c|c|c|}
\hline \multicolumn{3}{|c|}{ Sampling } & \multirow[b]{2}{*}{$2 \times$ TPU $^{\mathrm{b}}$} & \multirow[b]{2}{*}{$M^{\prime c}$} & \multirow[b]{2}{*}{ [RN] } & \multirow[b]{2}{*}{$2 \times$ TPU } & \multirow[b]{2}{*}{ MDC } & \multirow[b]{2}{*}{ [RN] } & \multirow[b]{2}{*}{$2 \times$ TPU } & \multirow[b]{2}{*}{ MDC } \\
\hline Location & Round & {$[R N]^{a}$} & & & & & & & & \\
\hline \multirow[t]{2}{*}{ WQSP-5 } & 22 & 6.00E-01 & $2.76 \mathrm{E}-02$ & $1.21 \mathrm{E}-03$ & $1.25 \mathrm{E}-02$ & $2.74 \mathrm{E}-03$ & $5.21 \mathrm{E}-04$ & 9.14E-02 & 7.35E-03 & $9.00 \mathrm{E}-04$ \\
\hline & 23 & 5.60E-01 & 2.49E-02 & 1.36E-03 & 8.54E-03 & $2.11 \mathrm{E}-03$ & 5.08E-04 & 8.12E-02 & $6.45 \mathrm{E}-03$ & 8.84E-04 \\
\hline \multirow[t]{2}{*}{ WQSP-6 } & 22 & 5.71E-01 & 2.53E-02 & $1.26 \mathrm{E}-03$ & $9.72 \mathrm{E}-03$ & $2.23 \mathrm{E}-03$ & 4.72E-04 & 7.38E-02 & $6.02 \mathrm{E}-03$ & 8.87E-04 \\
\hline & 23 & 4.43E-01 & $2.01 \mathrm{E}-02$ & 1.35E-03 & $6.96 \mathrm{E}-03$ & 1.89E-03 & 4.87E-04 & $5.65 E-02$ & $5.13 \mathrm{E}-03$ & 9.02E-04 \\
\hline \multirow[t]{3}{*}{ WQSP-6A } & 22 & $2.20 \mathrm{E}-01$ & 2.27E-02 & $2.06 \mathrm{E}-03$ & $9.81 \mathrm{E}-03$ & 4.42E-03 & 1.47E-03 & $1.35 \mathrm{E}-01$ & 1.65E-02 & 1.69E-03 \\
\hline & 23 & $2.21 \mathrm{E}-01$ & 1.25E-02 & 1.34E-03 & 8.07E-03 & 2.09E-03 & 5.03E-04 & 1.18E-01 & 8.22E-03 & 9.03E-04 \\
\hline & & & ${ }^{40} K$ & & & ${ }^{60} \mathrm{Co}$ & & & ${ }^{137} \mathrm{Cs}$ & \\
\hline \multirow[t]{2}{*}{ WQSP-1 } & 22 & $1.78 \mathrm{E}+01$ & $4.11 \mathrm{E}+00$ & $3.67 \mathrm{E}+00$ & 3.02E-01 & 3.87E-01 & $4.60 \mathrm{E}-01$ & 1.64E-01 & 3.06E-01 & $3.05 \mathrm{E}-01$ \\
\hline & 23 & $1.75 E+01$ & $4.06 \mathrm{E}+00$ & $4.05 E+00$ & $2.80 \mathrm{E}-01$ & 3.53E-01 & 4.29E-01 & $1.60 \mathrm{E}-01$ & $3.25 \mathrm{E}-01$ & 3.93E-01 \\
\hline \multirow[t]{2}{*}{ WQSP-2 } & 22 & $1.61 \mathrm{E}+01$ & $3.24 \mathrm{E}+00$ & $2.57 \mathrm{E}+00$ & $-1.25 \mathrm{E}-02$ & 3.14E-01 & 3.57E-01 & $-1.32 \mathrm{E}-02$ & 2.63E-01 & 3.08E-01 \\
\hline & 23 & $2.25 E+01$ & $5.78 \mathrm{E}+00$ & $7.15 E+00$ & *8.12E-01 & 6.09E-01 & 7.05E-01 & $-5.24 \mathrm{E}-01$ & $6.48 \mathrm{E}-01$ & 6.98E-01 \\
\hline \multirow[t]{2}{*}{ WQSP-3 } & 22 & $4.91 E+01$ & $7.44 \mathrm{E}+00$ & $3.17 \mathrm{E}+00$ & 7.49E-03 & 3.29E-01 & 3.76E-01 & 4.04E-02 & 2.52E-01 & 2.99E-01 \\
\hline & 23 & $5.90 \mathrm{E}+01$ & $9.56 \mathrm{E}+00$ & $7.14 \mathrm{E}+00$ & 3.77E-01 & $6.20 \mathrm{E}-01$ & 7.05E-01 & 2.83E-02 & $6.35 \mathrm{E}-01$ & 7.06E-01 \\
\hline \multirow[t]{2}{*}{ WQSP-4 } & 22 & $2.59 E+01$ & $4.91 \mathrm{E}+00$ & $4.20 \mathrm{E}+00$ & 3.76E-01 & $3.28 \mathrm{E}-01$ & 3.76E-01 & 8.72E-02 & $2.65 \mathrm{E}-01$ & 3.17E-01 \\
\hline & 23 & $2.57 E+01$ & $4.65 E+00$ & $3.58 \mathrm{E}+00$ & $-1.14 \mathrm{E}-01$ & $3.28 \mathrm{E}-01$ & 3.56E-01 & $-1.88 \mathrm{E}-01$ & 2.63E-01 & 2.86E-01 \\
\hline \multirow[t]{2}{*}{ WQSP-5 } & 22 & $1.01 \mathrm{E}+01$ & $3.18 \mathrm{E}+00$ & $4.04 \mathrm{E}+00$ & 2.25E-02 & 3.06E-01 & $3.52 \mathrm{E}-01$ & $-1.26 \mathrm{E}-01$ & 2.65E-01 & 2.98E-01 \\
\hline & 23 & $1.34 \mathrm{E}+01$ & $4.63 E+00$ & $6.38 \mathrm{E}+00$ & $1.20 \mathrm{E}-01$ & 5.17E-01 & 5.76E-01 & $-1.74 \mathrm{E}-01$ & 5.61E-01 & $6.18 \mathrm{E}-01$ \\
\hline \multirow[t]{2}{*}{ WQSP-6 } & 22 & $4.84 \mathrm{E}+00$ & $2.75 E+00$ & $4.10 \mathrm{E}+00$ & $2.55 \mathrm{E}-01$ & 3.11E-01 & 3.79E-01 & $-9.74 \mathrm{E}-02$ & 2.39E-01 & 2.71E-01 \\
\hline & 23 & 1.17E-01 & $5.27 \mathrm{E}+00$ & $6.18 \mathrm{E}+00$ & $-2.09 \mathrm{E}-01$ & 5.39E-01 & 5.75E-01 & $-8.22 \mathrm{E}-01$ & 5.99E-01 & $6.09 \mathrm{E}-01$ \\
\hline \multirow[t]{3}{*}{ WQSP-6A } & 22 & $1.92 E+00$ & $3.87 E+00$ & $4.49 \mathrm{E}+00$ & 3.44E-01 & 3.28E-01 & 4.12E-01 & 1.69E-01 & $2.60 \mathrm{E}-01$ & 3.20E-01 \\
\hline & 23 & $4.60 E+00$ & $5.10 \mathrm{E}+00$ & $5.82 \mathrm{E}+00$ & 5.41E-01 & 4.97E-01 & 5.73E-01 & $-2.66 \mathrm{E}-01$ & 5.52E-01 & 6.01E-01 \\
\hline & & & ${ }^{90} \mathrm{Sr}$ & & & & & & & \\
\hline \multirow[t]{2}{*}{ WQSP-1 } & 22 & $4.67 \mathrm{E}-03$ & 3.44E-02 & $3.95 \mathrm{E}-03$ & & & & & & \\
\hline & 23 & 2.19E-02 & 5.35E-02 & 5.79E-03 & & & & & & \\
\hline \multirow[t]{2}{*}{ WQSP-2 } & 22 & $-5.70 \mathrm{E}-02$ & 5.39E-02 & $5.48 \mathrm{E}-03$ & & & & & & \\
\hline & 23 & $5.66 \mathrm{E}-03$ & 2.27E-02 & 3.73E-03 & & & & & & \\
\hline \multirow[t]{2}{*}{ WQSP-3 } & 22 & 1.76E-02 & 3.77E-02 & $2.50 \mathrm{E}-03$ & & & & & & \\
\hline & 23 & $-1.01 \mathrm{E}-02$ & 4.06E-02 & 4.49E-03 & & & & & & \\
\hline \multirow[t]{2}{*}{ WQSP-4 } & 22 & $-8.22 \mathrm{E}-03$ & 2.48E-02 & $2.55 \mathrm{E}-03$ & & & & & & \\
\hline & 23 & $1.07 \mathrm{E}-02$ & 2.53E-02 & 3.88E-03 & & & & & & \\
\hline \multirow[t]{2}{*}{ WQSP-5 } & 22 & $-2.47 \mathrm{E}-02$ & 3.19E-02 & $2.90 \mathrm{E}-03$ & & & & & & \\
\hline & 23 & 6.99E-03 & 3.65E-02 & 4.13E-03 & & & & & & \\
\hline \multirow[t]{2}{*}{ WQSP-6 } & 22 & $2.70 \mathrm{E}-03$ & 3.53E-02 & 3.22E-03 & & & & & & \\
\hline & 23 & $-3.38 \mathrm{E}-03$ & 3.28E-02 & $3.50 \mathrm{E}-03$ & & & & & & \\
\hline WQSP-6A & 22 & $-1.26 \mathrm{E}-03$ & $2.66 \mathrm{E}-02$ & $2.20 \mathrm{E}-03$ & & & & & & \\
\hline & 23 & $-3.14 \mathrm{E}-03$ & $3.46 \mathrm{E}-02$ & 3.68E-03 & & & & & & \\
\hline
\end{tabular}

Duplicate samples for all radionuclides analyzed were collected from each of the wells as a check on the reproducibility of the sampling and measurement techniques employed. RERs for all duplicate pairs for which both the sample and the duplicate contained a detectable concentration of a radionuclide were calculated. These RERs are shown in Table 4.4 for Sampling Round 22 and in Table 4.5 for Sampling Round 23. Thirty-six of the RER values were less than one, indicating no difference between duplicate samples and good reproducibility. However, 12 of the duplicates from Round 22 and 23 had an RER greater than 1, indicating poor reproducibility. This is 
most likely due to inhomogeneities in the distributions of the radioisotope within the wells.

Table 4.4 - $\quad$ Results of Duplicate Groundwater Sample Analysis for Sampling Round 22. Units are Bq/L. See Chapter 6 for sampling locations.

\begin{tabular}{|c|c|c|c|c|c|c|c|c|}
\hline \multirow{2}{*}{ Location } & & \multicolumn{2}{|c|}{ Sample } & \multicolumn{4}{|c|}{ Duplicate } & \multirow[b]{2}{*}{ RER $^{\mathbf{d}}$} \\
\hline & & {$[R N]^{a}$} & $2 \times$ TPU $^{b}$ & $\mathrm{MDC}^{\mathrm{c}}$ & [RN] & $2 \times$ TPU & MDC & \\
\hline \multirow[t]{3}{*}{ WQSP-1 } & ${ }^{234} \mathrm{U}$ & $1.07 \mathrm{E}+00$ & 4.28E-02 & 1.32E-03 & $6.22 \mathrm{E}-01$ & 2.87E-02 & 1.40E-03 & 8.69 \\
\hline & ${ }^{235} \mathrm{U}$ & $1.44 \mathrm{E}-02$ & 2.64E-03 & 5.01E-04 & 1.13E-02 & 2.68E-03 & 6.06E-04 & 0.82 \\
\hline & ${ }^{238} \mathrm{U}$ & $1.88 \mathrm{E}-01$ & 1.07E-02 & 8.84E-04 & $1.04 \mathrm{E}-01$ & 8.13E-03 & $9.68 \mathrm{E}-04$ & 6.25 \\
\hline \multirow[t]{4}{*}{ WQSP-2 } & ${ }^{234} \mathrm{U}$ & $1.17 \mathrm{E}+00$ & 4.68E-02 & 1.16E-03 & 1.17E+00 & 4.84E-02 & $1.20 \mathrm{E}-03$ & 0.00 \\
\hline & ${ }^{235} \mathrm{U}$ & 1.74E-02 & 3.04E-03 & $5.18 \mathrm{E}-04$ & 2.08E-02 & 3.55E-03 & 5.67E-04 & 0.73 \\
\hline & ${ }^{238} \mathrm{U}$ & 1.80E-01 & 1.07E-02 & 8.08E-04 & 1.97E-01 & 1.19E-02 & 8.48E-04 & 1.06 \\
\hline & ${ }^{40} \mathrm{~K}$ & $1.61 \mathrm{E}+01$ & $3.24 \mathrm{E}+00$ & $2.57 E+00$ & $1.68 \mathrm{E}+01$ & $4.64 \mathrm{E}+00$ & $5.87 \mathrm{E}+00$ & 0.12 \\
\hline \multirow[t]{4}{*}{ WQSP-3 } & ${ }^{234} U$ & 2.37E-01 & 1.25E-02 & 1.19E-03 & 2.37E-01 & $1.27 \mathrm{E}-02$ & 1.19E-03 & 0.00 \\
\hline & ${ }^{235} \mathrm{U}$ & 3.56E-03 & 1.32E-03 & 4.73E-04 & 2.96E-03 & 1.20E-03 & 4.73E-04 & 0.34 \\
\hline & ${ }^{238} \mathrm{U}$ & 3.35E-02 & 3.77E-03 & 8.04E-04 & 3.29E-02 & 3.75E-03 & 8.04E-04 & 0.11 \\
\hline & ${ }^{40} \mathrm{~K}$ & $4.91 \mathrm{E}+01$ & $7.44 \mathrm{E}+00$ & $3.17 E+00$ & 4.77E+01 & $8.38 \mathrm{E}+00$ & $7.50 \mathrm{E}+00$ & 0.12 \\
\hline \multirow[t]{4}{*}{ WQSP-4 } & ${ }^{234} U$ & 5.50E-01 & $2.53 \mathrm{E}-02$ & $1.18 \mathrm{E}-03$ & $5.50 \mathrm{E}-01$ & $2.52 \mathrm{E}-02$ & 1.18E-03 & 0.00 \\
\hline & ${ }^{235} \mathrm{U}$ & 9.10E-03 & 2.26E-03 & 4.98E-04 & 1.07E-02 & 2.47E-03 & 5.00E-04 & 0.48 \\
\hline & ${ }^{238} \mathrm{U}$ & 9.27E-02 & 7.23E-03 & 8.81E-04 & 9.21E-02 & 7.20E-03 & 8.83E-04 & 0.06 \\
\hline & ${ }^{40} \mathrm{~K}$ & $2.59 \mathrm{E}+01$ & $4.91 \mathrm{E}+00$ & $4.20 \mathrm{E}+00$ & $2.62 \mathrm{E}+01$ & $5.65 \mathrm{E}+00$ & $6.17 \mathrm{E}+00$ & 0.04 \\
\hline \multirow[t]{4}{*}{ WQSP-5 } & ${ }^{234} \mathrm{U}$ & 6.00E-01 & 2.76E-02 & $1.21 \mathrm{E}-03$ & 5.57E-01 & 3.04E-02 & 1.40E-03 & 1.05 \\
\hline & ${ }^{235} \mathrm{U}$ & 1.25E-02 & 2.74E-03 & 5.21E-04 & 8.87E-03 & 2.89E-03 & 7.51E-04 & 0.91 \\
\hline & ${ }^{238} \mathrm{U}$ & $9.14 \mathrm{E}-02$ & 7.35E-03 & $9.00 \mathrm{E}-04$ & 8.31E-02 & 8.51E-03 & 1.09E-03 & 0.74 \\
\hline & ${ }^{40} \mathrm{~K}$ & $1.01 \mathrm{E}+01$ & $3.18 \mathrm{E}+00$ & $4.04 \mathrm{E}+00$ & $9.81 \mathrm{E}+00$ & $4.25 E+00$ & $6.18 \mathrm{E}+00$ & 0.05 \\
\hline \multirow[t]{3}{*}{ WQSP-6 } & ${ }^{234} \mathrm{U}$ & 5.71E-01 & 2.53E-02 & 1.26E-03 & 5.05E-01 & 2.41E-02 & 1.32E-03 & 1.89 \\
\hline & ${ }^{235} \mathrm{U}$ & $9.72 \mathrm{E}-03$ & $2.23 \mathrm{E}-03$ & 4.72E-04 & 7.51E-03 & $2.15 \mathrm{E}-03$ & $5.43 \mathrm{E}-04$ & 0.71 \\
\hline & ${ }^{238} \mathrm{U}$ & 7.38E-02 & $6.02 \mathrm{E}-03$ & 8.87E-04 & 6.98E-02 & 6.33E-03 & $9.45 \mathrm{E}-04$ & 0.46 \\
\hline \multirow[t]{3}{*}{ WQSP-6A } & ${ }^{234} U$ & 2.20E-01 & 2.27E-02 & 2.06E-03 & 2.23E-01 & $1.43 \mathrm{E}-02$ & $1.38 \mathrm{E}-03$ & 0.11 \\
\hline & ${ }^{235} \mathrm{U}$ & 9.81E-03 & 4.42E-03 & 1.47E-03 & 1.10E-02 & 2.88E-03 & $6.39 \mathrm{E}-04$ & 0.23 \\
\hline & ${ }^{238} \mathrm{U}$ & 1.35E-01 & 1.65E-02 & 1.69E-03 & 1.19E-01 & 9.53E-03 & $1.02 \mathrm{E}-03$ & 0.84 \\
\hline
\end{tabular}

${ }^{a}$ Radionuclide concentration

${ }^{\mathrm{b}}$ Total propagated uncertainty

${ }^{c}$ Minimum detectable concentration

${ }^{\mathrm{d}}$ Relative error ratio

Table 4.5 - Results of Duplicate Groundwater Sample Analysis for Sampling Round 23. Units are $\mathrm{Bq} / \mathrm{L}$. See Chapter 6 for sampling locations.

\begin{tabular}{|c|c|c|c|c|c|c|c|c|}
\hline \multicolumn{2}{|l|}{ Location } & \multicolumn{2}{|c|}{ Sample } & \multicolumn{4}{|c|}{ Duplicate } & \multirow[b]{2}{*}{ RER $^{\mathrm{d}}$} \\
\hline & & [RN] $^{\mathrm{a}}$ & $2 \times$ TPU $^{b}$ & MDC $^{\mathrm{C}}$ & {$[\mathrm{RN}]$} & $2 \times$ TPU & MDC & \\
\hline \multirow[t]{4}{*}{ WQSP-1 } & ${ }^{234} U$ & $1.04 \mathrm{E}+00$ & 2.57E-01 & 1.89E-03 & $9.45 E-01$ & $2.06 \mathrm{E}-01$ & 1.80E-03 & 0.29 \\
\hline & ${ }^{235} \mathrm{U}$ & 7.48E-03 & 3.09E-03 & 7.11E-04 & $9.16 \mathrm{E}-03$ & 3.07E-03 & 6.08E-04 & 0.39 \\
\hline & ${ }^{238} U$ & 1.74E-01 & 4.68E-02 & 1.12E-03 & $1.53 \mathrm{E}-01$ & 3.42E-02 & 1.03E-03 & 0.36 \\
\hline & ${ }^{40} \mathrm{~K}$ & $1.75 E+01$ & $4.06 E+00$ & $4.05 E+00$ & $1.50 E+01$ & $5.41 \mathrm{E}+00$ & $7.60 \mathrm{E}+00$ & 0.37 \\
\hline
\end{tabular}




\begin{tabular}{|c|c|c|c|c|c|c|c|c|}
\hline \multirow{3}{*}{ Location } & & \multirow{2}{*}{\multicolumn{2}{|c|}{ Sample }} & \multirow{2}{*}{\multicolumn{4}{|c|}{ Duplicate }} & \multirow[b]{3}{*}{$R_{R E R^{d}}$} \\
\hline & & & & & & & & \\
\hline & & [RN] $^{\mathrm{a}}$ & $2 \times$ TPU $^{b}$ & $\mathrm{MDC}^{\mathrm{C}}$ & [RN] & $2 \times$ TPU & MDC & \\
\hline \multirow[t]{4}{*}{ WQSP-2 } & ${ }^{234} U$ & $1.09 \mathrm{E}+00$ & $3.71 \mathrm{E}-01$ & $1.89 \mathrm{E}-03$ & $1.16 \mathrm{E}+00$ & $2.12 \mathrm{E}-01$ & $1.67 \mathrm{E}-03$ & 0.16 \\
\hline & ${ }^{235} U$ & 1.34E-02 & 5.69E-03 & 7.78E-04 & $1.74 \mathrm{E}-02$ & 4.31E-03 & $5.10 \mathrm{E}-04$ & 0.56 \\
\hline & ${ }^{238} \mathrm{U}$ & $1.75 \mathrm{E}-01$ & 6.03E-02 & 1.13E-03 & 1.83E-01 & $3.44 \mathrm{E}-02$ & 9.17E-04 & 0.12 \\
\hline & ${ }^{40} \mathrm{~K}$ & $2.25 \mathrm{E}+01$ & $5.78 \mathrm{E}+00$ & $7.15 \mathrm{E}+00$ & $1.41 \mathrm{E}+01$ & $3.52 E+00$ & $3.76 \mathrm{E}+00$ & 1.24 \\
\hline WQSP-3 & ${ }^{40} \mathrm{~K}$ & $5.90 \mathrm{E}+01$ & $9.56 \mathrm{E}+00$ & $7.14 \mathrm{E}+00$ & $4.70 \mathrm{E}+01$ & $7.49 E+00$ & $3.70 \mathrm{E}+00$ & 0.99 \\
\hline \multirow[t]{4}{*}{ WQSP-4 } & ${ }^{234} U$ & $5.26 \mathrm{E}-01$ & $1.20 \mathrm{E}-01$ & 1.66E-03 & 5.27E-01 & $2.27 \mathrm{E}-01$ & 1.97E-03 & 0.00 \\
\hline & ${ }^{235} \mathrm{U}$ & $9.73 \mathrm{E}-03$ & $3.24 \mathrm{E}-03$ & 5.32E-04 & 8.71E-03 & 4.91E-03 & 9.22E-04 & 0.17 \\
\hline & ${ }^{238} U$ & 9.66E-02 & $2.28 \mathrm{E}-02$ & 9.24E-04 & $9.12 \mathrm{E}-02$ & 4.01E-02 & $1.24 \mathrm{E}-03$ & 0.12 \\
\hline & ${ }^{40} \mathrm{~K}$ & $2.57 \mathrm{E}+01$ & $4.65 E+00$ & $3.58 E+00$ & $2.51 \mathrm{E}+01$ & $4.80 E+00$ & $3.64 \mathrm{E}+00$ & 0.09 \\
\hline \multirow[t]{4}{*}{ WQSP-5 } & ${ }^{234} \mathrm{U}$ & 5.60E-01 & $2.49 \mathrm{E}-02$ & 1.36E-03 & 4.90E-01 & 2.15E-02 & 1.34E-03 & 2.13 \\
\hline & ${ }^{235} \mathrm{U}$ & 8.54E-03 & 2.11E-03 & 5.08E-04 & $1.50 \mathrm{E}-02$ & $2.74 \mathrm{E}-03$ & 4.88E-04 & 1.87 \\
\hline & ${ }^{238} \mathrm{U}$ & $8.12 \mathrm{E}-02$ & $6.45 \mathrm{E}-03$ & 8.84E-04 & 7.13E-02 & 5.78E-03 & 8.68E-04 & 1.14 \\
\hline & ${ }^{40} \mathrm{~K}$ & $1.34 \mathrm{E}+01$ & $4.63 E+00$ & $6.38 E+00$ & $1.05 E+01$ & $4.74 \mathrm{E}+00$ & $6.97 E+00$ & 0.44 \\
\hline \multirow[t]{3}{*}{ WQSP-6 } & ${ }^{234} \mathrm{U}$ & 4.43E-01 & 2.01E-02 & 1.35E-03 & 5.51E-01 & $2.52 \mathrm{E}-02$ & 1.37E-03 & 3.35 \\
\hline & ${ }^{235} \mathrm{U}$ & 6.96E-03 & 1.89E-03 & 4.87E-04 & 7.00E-03 & 1.96E-03 & 5.16E-04 & 0.01 \\
\hline & ${ }^{238} \mathrm{U}$ & $5.65 \mathrm{E}-02$ & $5.13 \mathrm{E}-03$ & 9.02E-04 & 7.13E-02 & $6.14 \mathrm{E}-03$ & 9.26E-04 & 1.85 \\
\hline \multirow[t]{3}{*}{ WQSP-6A } & ${ }^{234} \mathrm{U}$ & $2.21 \mathrm{E}-01$ & $1.25 \mathrm{E}-02$ & 1.34E-03 & 2.44E-01 & 1.40E-02 & 1.38E-03 & 1.23 \\
\hline & ${ }^{235} \mathrm{U}$ & 8.07E-03 & 2.09E-03 & 5.03E-04 & $6.25 \mathrm{E}-03$ & $1.94 \mathrm{E}-03$ & 5.52E-04 & 0.64 \\
\hline & ${ }^{238} \mathrm{U}$ & 1.18E-01 & 8.22E-03 & 9.03E-04 & 1.27E-01 & 9.03E-03 & 9.42E-04 & 0.74 \\
\hline
\end{tabular}

\subsection{Surface Water}

\subsubsection{Sample Collection}

Surface water samples are collected from various locations around the WIPP site, as shown in Figure 4.2 (see Appendix $C$ for location codes). If a particular surface water collection location is dry, only the sediment is collected. Sediment results are described in Section 4.5.

Water from the sampling location is used to rinse 3.78-L (1-gallon) polyethylene containers at least three times. Approximately $3.78 \mathrm{~L}$ (1 gallon) of water is collected from each location. The samples are acidified immediately after collection with concentrated nitric acid to $\mathrm{pH} \leq 2$. Later, the samples are transferred to the WIPP Laboratories for analysis. Chain of custody is maintained throughout the process. 


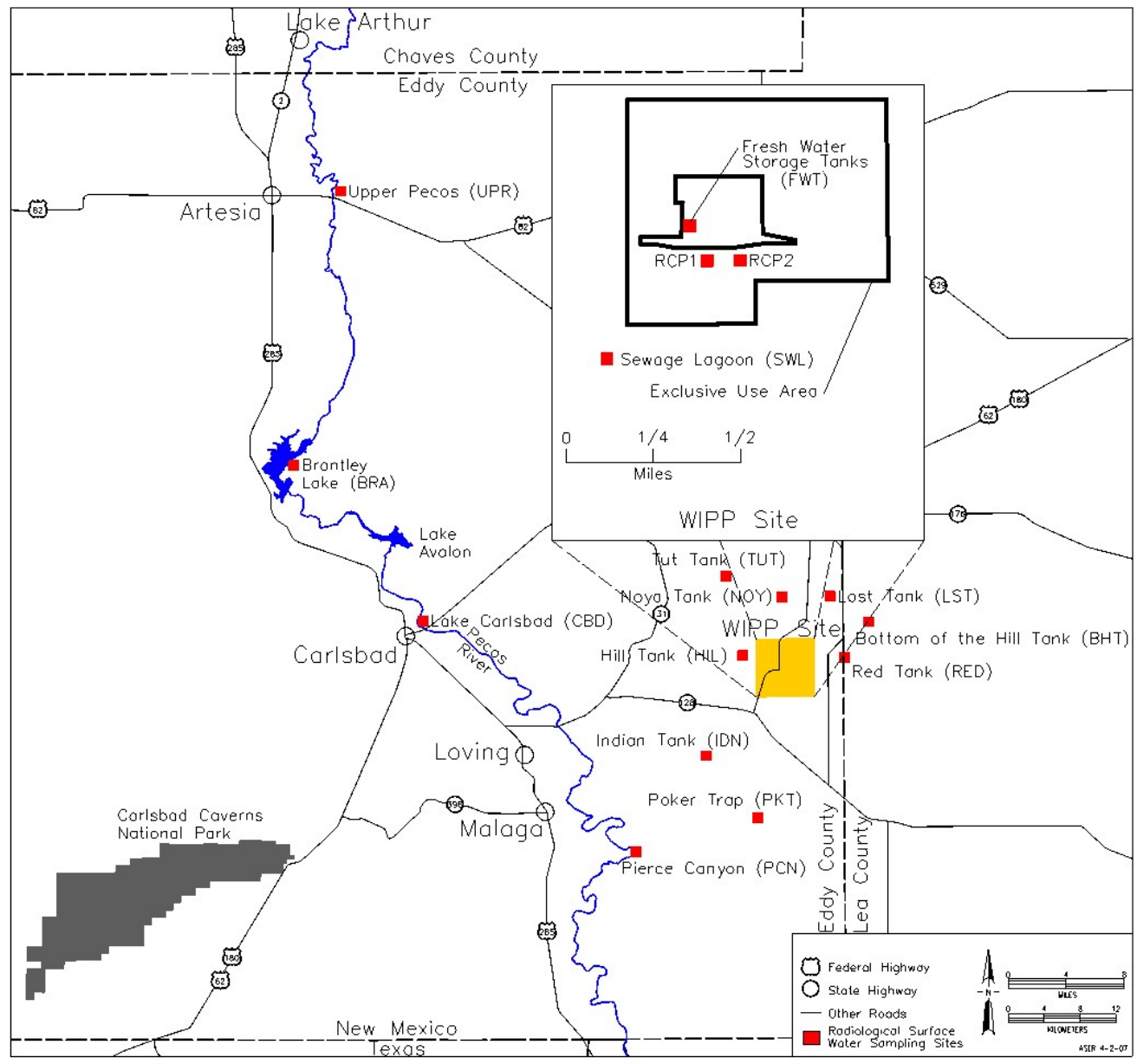

Figure 4.2 - Routine Surface Water Sampling Locations

\subsubsection{Sample Preparation}

Surface water sample containers are shaken to distribute suspended material evenly, and an aliquot is measured into a glass beaker. Tracers $\left({ }^{232} \mathrm{U},{ }^{243} \mathrm{Am}\right.$, and ${ }^{242} \mathrm{Pu}$ ) and carriers (strontium nitrate and barium nitrate) are added and the sample is then digested using concentrated nitric acid and hydrofluoric acid. The sample is then heated to dryness and wet ashed using concentrated nitric acid and hydrogen peroxide. Finally, the sample is heated to dryness again and the isotopic separation process is initiated.

\subsubsection{Determination of Individual Radionuclides}

Gamma-spectrometry is used for the determination of ${ }^{40} \mathrm{~K},{ }^{60} \mathrm{Co}$, and ${ }^{137} \mathrm{Cs}$. Strontium-90, a beta-emitting radionuclide, is determined by chemical separation and counting using a gas proportional counter. Uranium, plutonium, and americium are determined by alpha spectrometry. These alpha-emitting radionuclides are separated from the bulk of water samples by co-precipitation with an iron carrier. Ion-exchange chromatography is used for the separation of individual radionuclides. 


\subsubsection{Results and Discussion}

Uranium-234 was detected in fifteen of seventeen of samples, ${ }^{238} \mathrm{U}$ was detected in sixteen of seventeen samples, and ${ }^{235} U$ was detected in five of seventeen samples of surface water (Table 4.6). U-234 was not detected in COW or PKT and U-238 was not detected in COW (COW is a deionized water blank). The concentrations of uranium isotopes were compared between 2005 and 2006 and also among sampling locations using ANOVA for those sites sampled and detected in both years. Although significant variability was observed among sampling locations for two uranium isotopes (ANOVA, ${ }^{234} U p=8.44 \mathrm{E}-05,{ }^{235} \cup p=0.797$, and $\left.{ }^{238} \cup p=2.03 \mathrm{E}-05\right)$, there was no significant difference in the concentrations of uranium isotopes between 2005 and 2006 (ANOVA, ${ }^{234} U p=0.777,{ }^{235} U p=0.353$, and $\left.{ }^{238} U p=0.727\right)$. Variability among sampling locations is expected since natural uranium in the earth's crust varies widely and this variation is reflected in the amounts of uranium dissolved into surface water.

\begin{tabular}{|c|c|c|c|c|c|c|c|c|c|}
\hline \multirow[t]{2}{*}{ Location } & {$[\mathrm{RN}]^{\mathrm{a}}$} & $2 \times$ TPU $^{\mathrm{b}}$ & $\mathrm{MDC}^{\mathrm{C}}$ & [RN] & $2 \times$ TPU & MDC & [RN] & $2 \times$ TPU & MDC \\
\hline & \multicolumn{3}{|c|}{${ }^{234} U$} & \multicolumn{3}{|c|}{${ }^{235} \mathrm{U}$} & \multicolumn{3}{|c|}{${ }^{238} \mathrm{U}$} \\
\hline BRA & $8.34 \mathrm{E}-02$ & 1.92E-02 & $\overline{1.41 \mathrm{E}-03}$ & $2.47 \mathrm{E}-03$ & $1.31 \mathrm{E}-03$ & $5.23 \mathrm{E}-04$ & $4.60 \mathrm{E}-02$ & $1.10 \mathrm{E}-02$ & $9.04 \mathrm{E}-04$ \\
\hline $\mathrm{BHT}$ & $3.21 \mathrm{E}-03$ & $1.55 \mathrm{E}-03$ & 1.76E-03 & 3.37E-04 & 4.75E-04 & 5.81E-04 & 1.84E-03 & 1.11E-03 & $9.46 \mathrm{E}-04$ \\
\hline CBD & $1.23 \mathrm{E}-01$ & 3.04E-02 & 1.47E-03 & $3.54 \mathrm{E}-03$ & 1.77E-03 & $5.88 \mathrm{E}-04$ & $5.48 \mathrm{E}-02$ & $1.42 \mathrm{E}-02$ & $9.56 \mathrm{E}-04$ \\
\hline cow & 4.69E-04 & $5.21 \mathrm{E}-04$ & 1.73E-03 & $1.29 \mathrm{E}-04$ & 3.31E-04 & 5.45E-04 & $2.12 \mathrm{E}-04$ & 3.77E-04 & $9.09 \mathrm{E}-04$ \\
\hline FWT & $1.90 \mathrm{E}-02$ & 5.31E-03 & $1.75 \mathrm{E}-03$ & 4.35E-04 & $6.06 \mathrm{E}-04$ & $5.74 \mathrm{E}-04$ & $7.68 \mathrm{E}-03$ & $2.65 \mathrm{E}-03$ & $9.32 \mathrm{E}-04$ \\
\hline HIL & $1.28 \mathrm{E}-02$ & $6.16 \mathrm{E}-03$ & $1.72 \mathrm{E}-03$ & 8.34E-04 & 1.05E-03 & 9.04E-04 & $9.25 \mathrm{E}-03$ & 4.71E-03 & $1.21 \mathrm{E}-03$ \\
\hline HIL DUP & 1.70E-02 & $6.46 \mathrm{E}-03$ & 1.57E-03 & $8.49 \mathrm{E}-04$ & $9.18 \mathrm{E}-04$ & $7.20 \mathrm{E}-04$ & 1.04E-02 & 4.29E-03 & 1.06E-03 \\
\hline IDN & 2.98E-03 & 1.31E-03 & 1.69E-03 & 1.11E-04 & 3.01E-04 & 5.02E-04 & 1.40E-03 & 8.59E-04 & 8.74E-04 \\
\hline LST & 4.66E-03 & 1.72E-03 & 1.69E-03 & $-1.32 \mathrm{E}-04$ & 2.61E-04 & 5.75E-04 & $2.35 \mathrm{E}-03$ & 1.13E-03 & 8.76E-04 \\
\hline NOY & 1.04E-02 & 4.72E-03 & $1.62 \mathrm{E}-03$ & 6.30E-04 & 8.96E-04 & 7.75E-04 & 7.65E-03 & 3.69E-03 & 1.11E-03 \\
\hline PCN & 2.17E-01 & 6.51E-02 & 1.54E-03 & 8.89E-03 & $3.73 \mathrm{E}-03$ & $6.75 \mathrm{E}-04$ & 1.03E-01 & $3.15 \mathrm{E}-02$ & $1.03 \mathrm{E}-03$ \\
\hline PCN DUP & 2.08E-01 & 6.78E-02 & $1.58 \mathrm{E}-03$ & 4.96E-03 & 2.64E-03 & 7.24E-04 & $9.20 \mathrm{E}-02$ & 3.05E-02 & 1.07E-03 \\
\hline PKT & $1.24 \mathrm{E}-03$ & 8.80E-04 & $1.74 \mathrm{E}-03$ & $-2.78 \mathrm{E}-05$ & $1.31 \mathrm{E}-04$ & 5.61E-04 & $9.89 \mathrm{E}-04$ & 7.75E-04 & $9.22 \mathrm{E}-04$ \\
\hline RED & $1.49 \mathrm{E}-02$ & 4.15E-03 & 1.42E-03 & 2.89E-04 & 4.27E-04 & 5.30E-04 & $9.76 \mathrm{E}-03$ & 3.00E-03 & $9.09 \mathrm{E}-04$ \\
\hline SWL & 3.43E-03 & 1.37E-03 & 1.67E-03 & 9.44E-05 & 2.89E-04 & 4.77E-04 & 2.04E-03 & 1.02E-03 & 8.55E-04 \\
\hline TUT & 2.92E-03 & 1.34E-03 & 1.72E-03 & $1.50 \mathrm{E}-04$ & 2.96E-04 & 5.31E-04 & 2.30E-03 & 1.16E-03 & 8.98E-04 \\
\hline UPR & 4.55E-02 & 9.99E-03 & $1.68 \mathrm{E}-03$ & $1.05 \mathrm{E}-03$ & 7.55E-04 & 4.79E-04 & $2.45 \mathrm{E}-02$ & 5.80E-03 & 8.56E-04 \\
\hline
\end{tabular}

Concentrations of uranium isotopes were also compared with baseline levels observed between 1985 and 1989 (DOE/WIPP 92-037). The highest concentrations detected for ${ }^{234} U,{ }^{235} \mathrm{U}$, and ${ }^{238} \mathrm{U}$ were within the 99 percent confidence interval ranges of baseline levels (baseline levels: ${ }^{234} \mathrm{U}=3.30 \mathrm{E}-01 \mathrm{~Bq} / \mathrm{L},{ }^{235} \mathrm{U}=1.40 \mathrm{E}-02 \mathrm{~Bq} / \mathrm{L}$, and $\left.{ }^{238} \mathrm{U}=1.10 \mathrm{E}-01 \mathrm{~Bq} / \mathrm{L}\right)$.

These water samples were also analyzed for ${ }^{238} \mathrm{Pu},{ }^{239+240} \mathrm{Pu}$, and ${ }^{241} \mathrm{Am}$ (Table 4.7). None of these isotopes were detected so ANOVA comparisons between years and among locations were not performed. 
Table 4.7 - Americium and Plutonium Concentrations (Bq/L) in Surface Water Near the WIPP Site. See Appendix C for sampling location codes.

\begin{tabular}{|c|c|c|c|c|c|c|c|c|c|}
\hline Location & {$[\mathrm{RN}]^{\mathrm{a}}$} & $2 \times$ TPU $^{b}$ & $\mathrm{MDC}^{\mathrm{C}}$ & [RN] & $2 \times$ TPU & MDC & [RN] & $2 \times$ TPU & MDC \\
\hline & & ${ }^{241} \mathrm{Am}$ & & & ${ }^{238} \mathrm{Pu}$ & & & ${ }^{239+240} \mathrm{Pu}$ & \\
\hline BRA & $2.26 \mathrm{E}-04$ & 4.47E-04 & 4.45E-04 & $-9.48 \mathrm{E}-05$ & $3.42 \mathrm{E}-04$ & 3.87E-04 & $-9.11 \mathrm{E}-05$ & 1.89E-04 & 3.49E-04 \\
\hline BHT & $-2.98 \mathrm{E}-05$ & 3.63E-04 & 3.85E-04 & $-2.85 E-05$ & 3.48E-04 & 3.83E-04 & $-1.30 \mathrm{E}-04$ & 2.43E-04 & 3.95E-04 \\
\hline CBD & 3.27E-04 & $6.02 \mathrm{E}-04$ & $4.71 \mathrm{E}-04$ & $1.25 \mathrm{E}-04$ & 4.92E-04 & 4.19E-04 & $-6.63 \mathrm{E}-05$ & $1.70 \mathrm{E}-04$ & $3.81 \mathrm{E}-04$ \\
\hline Sow & 3.47E-04 & $5.15 \mathrm{E}-04$ & 3.67E-04 & $3.90 \mathrm{E}-04$ & $5.53 \mathrm{E}-04$ & 4.06E-04 & $-8.75 \mathrm{E}-05$ & 2.07E-04 & $4.18 \mathrm{E}-04$ \\
\hline WT & $-5.77 \mathrm{E}-05$ & 1.70E-04 & 4.02E-04 & $-9.83 E-05$ & 1.96E-04 & 3.38E-04 & 4.91E-05 & 2.45E-04 & $3.50 \mathrm{E}-04$ \\
\hline IL & 3.31E-04 & $1.08 \mathrm{E}-03$ & $9.16 \mathrm{E}-04$ & $-5.03 E-04$ & 1.07E-03 & 8.72E-04 & $-1.16 \mathrm{E}-04$ & 8.52E-04 & 8.32E-04 \\
\hline IL DUP & $-2.21 \mathrm{E}-05$ & 6.09E-04 & 6.30E-04 & 1.42E-03 & 1.52E-03 & $8.26 \mathrm{E}-04$ & 5.53E-04 & $1.02 \mathrm{E}-03$ & 7.87E-04 \\
\hline$D N$ & 1.33E-04 & 3.38E-04 & 3.33E-04 & 2.86E-05 & 3.08E-04 & 3.83E-04 & $-5.31 E-05$ & $1.55 \mathrm{E}-04$ & 3.95E-04 \\
\hline LST & 5.27E-05 & 3.73E-04 & $3.26 \mathrm{E}-04$ & $-1.57 E-04$ & 2.53E-04 & $3.49 \mathrm{E}-04$ & $-4.50 \mathrm{E}-05$ & 1.27E-04 & 3.60E-04 \\
\hline IOY & $-5.58 \mathrm{E}-05$ & $6.80 \mathrm{E}-04$ & 6.77E-04 & 8.68E-05 & 8.55E-04 & 7.32E-04 & $-2.13 E-04$ & 4.32E-04 & 6.94E-04 \\
\hline $\mathrm{CN}$ & 5.06E-04 & 9.23E-04 & 5.94E-04 & $-2.01 \mathrm{E}-04$ & 5.97E-04 & $5.75 \mathrm{E}-04$ & $-9.42 \mathrm{E}-05$ & 2.49E-04 & 5.37E-04 \\
\hline PCN DUP & $2.59 \mathrm{E}-04$ & $8.79 \mathrm{E}-04$ & 7.51E-04 & 4.77E-04 & 8.61E-04 & $5.58 \mathrm{E}-04$ & 9.63E-05 & 3.83E-04 & $5.20 \mathrm{E}-04$ \\
\hline KT & 9.09E-06 & 3.59E-04 & 4.07E-04 & $9.80 \mathrm{E}-05$ & 3.77E-04 & 3.58E-04 & 7.14E-05 & 3.91E-04 & 3.70E-04 \\
\hline ED & $-1.27 \mathrm{E}-04$ & 2.57E-04 & 4.18 & 2.57E-04 & 8.57E-04 & 4.54E-04 & 2.17E-05 & 3.34E-04 & 4.16E-04 \\
\hline SWL & 3.94E-06 & 3.19E-04 & 3.64E-04 & $-1.48 \mathrm{E}-04$ & $2.54 \mathrm{E}-04$ & 3.68E-04 & 5.46E-05 & 2.73E-04 & 3.80E-04 \\
\hline TUT & 8.17E-05 & 4.00E-04 & $3.55 \mathrm{E}-04$ & $-3.27 \mathrm{E}-05$ & 3.50E-04 & 3.83E-04 & 1.87E-04 & 3.60E-04 & 3.94E-04 \\
\hline UPR & 1.11E-04 & 4.23E-04 & $3.15 \mathrm{E}-04$ & 9.86E-05 & 4.87E-04 & $3.60 \mathrm{E}-04$ & $-4.54 \mathrm{E}-05$ & $1.38 \mathrm{E}-04$ & 3.72E-04 \\
\hline
\end{tabular}

Cesium-137, ${ }^{90} \mathrm{Sr},{ }^{60} \mathrm{Co}$ were not detected in any of the surface water samples (Table 4.8). Since these isotopes were not detected, ANOVA comparisons between years and among locations were not performed.

Potassium-40 was detected in 29 percent of the surface water samples (Table 4.8). Potassium is ubiquitous throughout the earth's crust, so it is expected to be found in some surface water samples due to leaching from sediments. Comparison of the maximum detected ${ }^{40} \mathrm{~K}(4.27 \mathrm{E}+01 \mathrm{~Bq} / \mathrm{L})$ with baseline data (baseline value:

7.60E+01 Bq/L) shows that it fell within the 99 percent confidence interval ranges of the baseline concentrations (DOE/WIPP 92-037). Since there were less detected concentrations in 2005 (only 20 percent was detected in 2005) than in 2006, there were insufficient data for ANOVA comparisons between years or among locations.

Table 4.8 - Selected Radionuclide Concentrations (Bq/L) in Surface Water Near the WIPP Site. See Appendix $C$ for sampling location codes.

\begin{tabular}{|c|c|c|c|c|c|c|}
\hline Location & {$[R N]^{a}$} & $2 \times$ TPU $^{b}$ & $\mathrm{MDC}^{\mathrm{C}}$ & [RN] & $2 \times$ TPU & MDC \\
\hline & \multicolumn{3}{|c|}{${ }^{137} \mathrm{Cs}$} & \multicolumn{3}{|c|}{${ }^{60} \mathrm{Co}$} \\
\hline BRA & $-4.85 E-01$ & $6.60 \mathrm{E}-01$ & $\overline{6.80 \mathrm{E}-01}$ & ${ }^{*} 8.28 \mathrm{E}-01$ & $5.98 \mathrm{E}-01$ & $\overline{6.98 E-01}$ \\
\hline BHT & -1.27E-01 & $6.28 \mathrm{E}-01$ & 6.73E-01 & ${ }^{*} 9.32 \mathrm{E}-01$ & 5.96E-01 & 6.97E-01 \\
\hline CBD & 1.97E-01 & 2.83E-01 & 3.49E-01 & 3.18E-01 & 3.36E-01 & 4.19E-01 \\
\hline cow & -1.92E-01 & 6.36E-01 & 6.79E-01 & $6.13 \mathrm{E}-01$ & 5.97E-01 & 6.91E-01 \\
\hline FWT & 1.70E-01 & 3.00E-01 & $3.65 \mathrm{E}-01$ & $-7.70 \mathrm{E}-02$ & 3.97E-01 & 4.30E-01 \\
\hline HIL & -1.39E-01 & 3.08E-01 & $3.25 \mathrm{E}-01$ & 1.07E-01 & 3.64E-01 & 4.18E-01 \\
\hline HIL DUP & $-5.10 \mathrm{E}-01$ & $6.79 \mathrm{E}-01$ & 7.00E-01 & *1.15E+00 & $5.98 \mathrm{E}-01$ & 7.06E-01 \\
\hline
\end{tabular}


Table 4.8 - Selected Radionuclide Concentrations (Bq/L) in Surface Water Near the WIPP Site. See Appendix $\mathrm{C}$ for sampling location codes.

\begin{tabular}{|c|c|c|c|c|c|c|}
\hline Location & {$[R N]^{a}$} & $2 \times$ TPU $^{b}$ & $M C^{c}$ & [RN] & $2 \times$ TPU & MDC \\
\hline IDN & $2.86 \mathrm{E}-01$ & $2.91 \mathrm{E}-01$ & $3.62 \mathrm{E}-01$ & 2.93E-01 & $3.70 \mathrm{E}-01$ & $4.48 \mathrm{E}-01$ \\
\hline LST & -5.76E-03 & 2.94E-01 & 3.27E-01 & $1.04 \mathrm{E}-01$ & 3.55E-01 & 4.09E-01 \\
\hline NOY & $-2.14 \mathrm{E}-01$ & 3.09E-01 & $3.40 \mathrm{E}-01$ & 2.19E-01 & 3.60E-01 & 4.27E-01 \\
\hline $\mathrm{PCN}$ & 3.54E-03 & 2.91E-01 & 3.25E-01 & $1.51 \mathrm{E}-01$ & $3.49 \mathrm{E}-01$ & 4.06E-01 \\
\hline PCN DUP & $-4.40 \mathrm{E}-01$ & 6.65E-01 & 6.38E-01 & *9.55E-01 & 6.18E-01 & 7.21E-01 \\
\hline PKT & 7.00E-02 & $2.96 \mathrm{E}-01$ & 3.34E-01 & 2.94E-01 & $3.42 \mathrm{E}-01$ & 4.16E-01 \\
\hline RED & -7.11E-02 & 2.95E-01 & $3.41 \mathrm{E}-01$ & 3.97E-01 & 3.52E-01 & 4.41E-01 \\
\hline SWL & $-9.48 \mathrm{E}-01$ & 6.16E-01 & 6.18E-01 & $-2.05 E-02$ & $5.46 \mathrm{E}-01$ & 6.00E-01 \\
\hline TUT & 7.50E-02 & 2.82E-01 & $3.20 \mathrm{E}-01$ & $-8.42 \mathrm{E}-02$ & 3.54E-01 & 3.81E-01 \\
\hline \multirow[t]{2}{*}{ UPR } & $-1.42 \mathrm{E}-01$ & 3.07E-01 & $3.46 \mathrm{E}-01$ & 2.94E-01 & $3.58 \mathrm{E}-01$ & 4.37E-01 \\
\hline & \multicolumn{3}{|c|}{${ }^{90} \mathrm{Sr}$} & \multicolumn{3}{|c|}{${ }^{40} \mathrm{~K}$} \\
\hline BRA & $2.02 \mathrm{E}-02$ & 3.33E-02 & $4.11 \mathrm{E}-03$ & $* 1.48 \mathrm{E}+01$ & $5.65 \mathrm{E}+00$ & $6.64 \mathrm{E}+00$ \\
\hline $\mathrm{BHT}$ & 6.73E-03 & 3.03E-02 & 3.83E-03 & $6.94 \mathrm{E}+00$ & $4.55 E+00$ & $7.02 \mathrm{E}+00$ \\
\hline CBD & $1.48 \mathrm{E}-02$ & $3.21 \mathrm{E}-02$ & 3.95E-03 & $-2.35 E+00$ & $3.98 \mathrm{E}+00$ & $3.95 E+00$ \\
\hline cow & 2.04E-02 & 3.47E-02 & 4.35E-03 & *1.10E+01 & $5.60 \mathrm{E}+00$ & $6.53 E+00$ \\
\hline FWT & 1.37E-02 & 3.18E-02 & $3.95 E-03$ & $2.83 \mathrm{E}+00$ & $1.46 \mathrm{E}+00$ & $1.92 \mathrm{E}+00$ \\
\hline HIL & $-3.65 E-03$ & 3.30E-02 & 4.19E-03 & $3.78 \mathrm{E}+00$ & $1.90 \mathrm{E}+00$ & $2.63 \mathrm{E}+00$ \\
\hline HIL DUP & 6.88E-03 & $3.40 \mathrm{E}-02$ & 4.18E-03 & 1.17E+01 & $4.88 \mathrm{E}+00$ & $7.05 E+00$ \\
\hline IDN & 2.86E-02 & 3.47E-02 & 4.27E-03 & $3.49 \mathrm{E}+00$ & $1.90 \mathrm{E}+00$ & $2.67 E+00$ \\
\hline LST & 8.96E-03 & 3.38E-02 & 4.31E-03 & $2.11 \mathrm{E}+00$ & $1.51 \mathrm{E}+00$ & $2.23 E+00$ \\
\hline NOY & $-2.78 \mathrm{E}-03$ & 3.45E-02 & 4.35E-03 & ${ }^{*} 6.31 \mathrm{E}+00$ & $3.59 \mathrm{E}+00$ & $4.65 E+00$ \\
\hline $\mathrm{PCN}$ & 4.34E-03 & 3.33E-02 & 4.17E-03 & ${ }^{*} 5.08 \mathrm{E}+00$ & $3.24 \mathrm{E}+00$ & $4.14 \mathrm{E}+00$ \\
\hline PCN DUP & 1.17E-02 & 3.35E-02 & 4.19E-03 & $6.07 E+00$ & $4.19 \mathrm{E}+00$ & $6.49 E+00$ \\
\hline PKT & $-1.18 \mathrm{E}-02$ & 3.59E-02 & 4.67E-03 & $3.43 E+00$ & $3.38 \mathrm{E}+00$ & $4.10 \mathrm{E}+00$ \\
\hline RED & 2.01E-03 & 3.27E-02 & 4.09E-03 & $2.57 E+00$ & $3.70 \mathrm{E}+00$ & $4.34 \mathrm{E}+00$ \\
\hline SWL & 2.62E-03 & 3.26E-02 & 4.16E-03 & $4.27 E+01$ & $7.53 \mathrm{E}+00$ & $6.61 \mathrm{E}+00$ \\
\hline TUT & $-4.73 E-03$ & 3.04E-02 & 3.87E-03 & $1.58 \mathrm{E}+00$ & $3.47 \mathrm{E}+00$ & $3.99 \mathrm{E}+00$ \\
\hline UPR & 9.24E-03 & 3.31E-02 & 4.18E-03 & $2.36 \mathrm{E}+00$ & $1.76 \mathrm{E}+00$ & $2.63 E+00$ \\
\hline
\end{tabular}

a Radionuclide concentration

${ }^{\mathrm{b}}$ Total propagated uncertainty

${ }^{\mathrm{C}}$ Minimum detectable concentration

* Gamma spectroscopy samples with confidence levels less than 90 percent - not considered "detects."

Duplicate samples were collected from two locations (HIL and PCN) to check the reproducibility of the sampling and measurement techniques. Radioisotope concentrations for samples and their duplicates passing the criteria for detection were compared by calculation of the associated RER values (Table 4.9). All RER values for $\mathrm{HIL}$ and PCN, with the exception of ${ }^{40} \mathrm{~K}$ at HIL, were less than 1.0 , indicating no difference between duplicate samples and confirming good reproducibility. The RER for ${ }^{40} \mathrm{~K}$ greater than one was most likely due to inhomogeneities in the distributions of the radioisotope within the sampling locations. 
Table 4.9 - Results of Duplicate Surface Water Sample Analysis. Results are Bq/L. See Appendix $C$ for sampling location codes.

\begin{tabular}{|c|c|c|c|c|c|c|c|c|}
\hline Location & & & Sample & & & Duplicate & & \\
\hline & & {$[\mathbf{R N}]^{\mathrm{a}}$} & $2 \times$ TPU $^{\mathrm{b}}$ & MDC $^{c}$ & RN & $2 \times$ TPU & MDC & RER $^{d}$ \\
\hline HIL & ${ }^{234} U$ & $1.28 \mathrm{E}-02$ & $6.16 \mathrm{E}-03$ & 1.72E-03 & 1.70E-02 & $6.46 \mathrm{E}-03$ & 1.57E-03 & 0.47 \\
\hline HIL & ${ }^{238} \mathrm{U}$ & $9.25 \mathrm{E}-03$ & 4.71E-03 & $1.21 \mathrm{E}-03$ & $1.04 \mathrm{E}-02$ & $4.29 \mathrm{E}-03$ & 1.06E-03 & 0.18 \\
\hline HIL & ${ }^{40} \mathrm{~K}$ & $3.78 \mathrm{E}+00$ & $1.90 \mathrm{E}+00$ & $2.63 E+00$ & 1.17E+01 & $4.88 \mathrm{E}+00$ & $7.05 E+00$ & 1.51 \\
\hline PCN & ${ }^{234} U$ & 2.17E-01 & $6.51 \mathrm{E}-02$ & $1.54 \mathrm{E}-03$ & $2.08 \mathrm{E}-01$ & $6.78 \mathrm{E}-02$ & $1.58 \mathrm{E}-03$ & 0.10 \\
\hline PCN & ${ }^{235} \mathrm{U}$ & 8.89E-03 & $3.73 E+03$ & $6.75 \mathrm{E}-04$ & 4.96E-03 & 2.64E-03 & 7.24E-04 & 0.86 \\
\hline $\mathrm{PCN}$ & ${ }^{238} \mathrm{U}$ & $1.03 \mathrm{E}-01$ & $3.15 \mathrm{E}-02$ & $1.03 \mathrm{E}-03$ & $9.20 \mathrm{E}-02$ & $3.05 \mathrm{E}-02$ & $1.07 \mathrm{E}-03$ & 0.25 \\
\hline
\end{tabular}

\subsection{Sediments}

\subsubsection{Sample Collection}

Sediment samples are collected from 12 locations around the WIPP site, mostly from the same water bodies from which the surface water samples are collected (Figure 4.3, see Appendix $C$ for location codes). The samples are collected in $1 \mathrm{~L}$ plastic containers from the top $15 \mathrm{~cm}$ (6 in.) of the sediments of the water bodies and transferred to the WIPP Laboratories for the determination of individual radionuclides.

\subsubsection{Sample Preparation}

Sediment samples are dried at $110^{\circ} \mathrm{C}\left(230^{\circ} \mathrm{F}\right)$ for several hours and homogenized by grinding to smaller particle sizes. A $2 \mathrm{~g}(0.08 \mathrm{oz})$ aliquot is dissolved by heating it with a mixture of nitric, hydrochloric, and hydrofluoric acids. The residue is heated with nitric and boric acids to remove hydrofluoric acid. Finally, the residue is dissolved in hydrochloric acid for the determination of individual radionuclides.

\subsubsection{Determination of Individual Radionuclides}

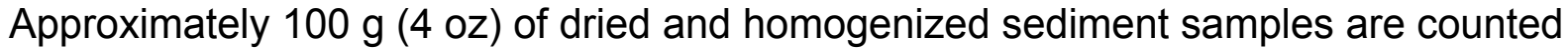
by gamma-spectrometry for the determinations of ${ }^{40} \mathrm{~K}$, ${ }^{60} \mathrm{Co}$, and ${ }^{137} \mathrm{Cs}$. Strontium-90 is determined from an aliquot of dissolved sediment samples by chemical separation and beta proportional counting. Uranium, plutonium, and americium are determined by alpha spectrometry after chemical separations, micro-precipitating, and filtering onto micro-filter papers. 


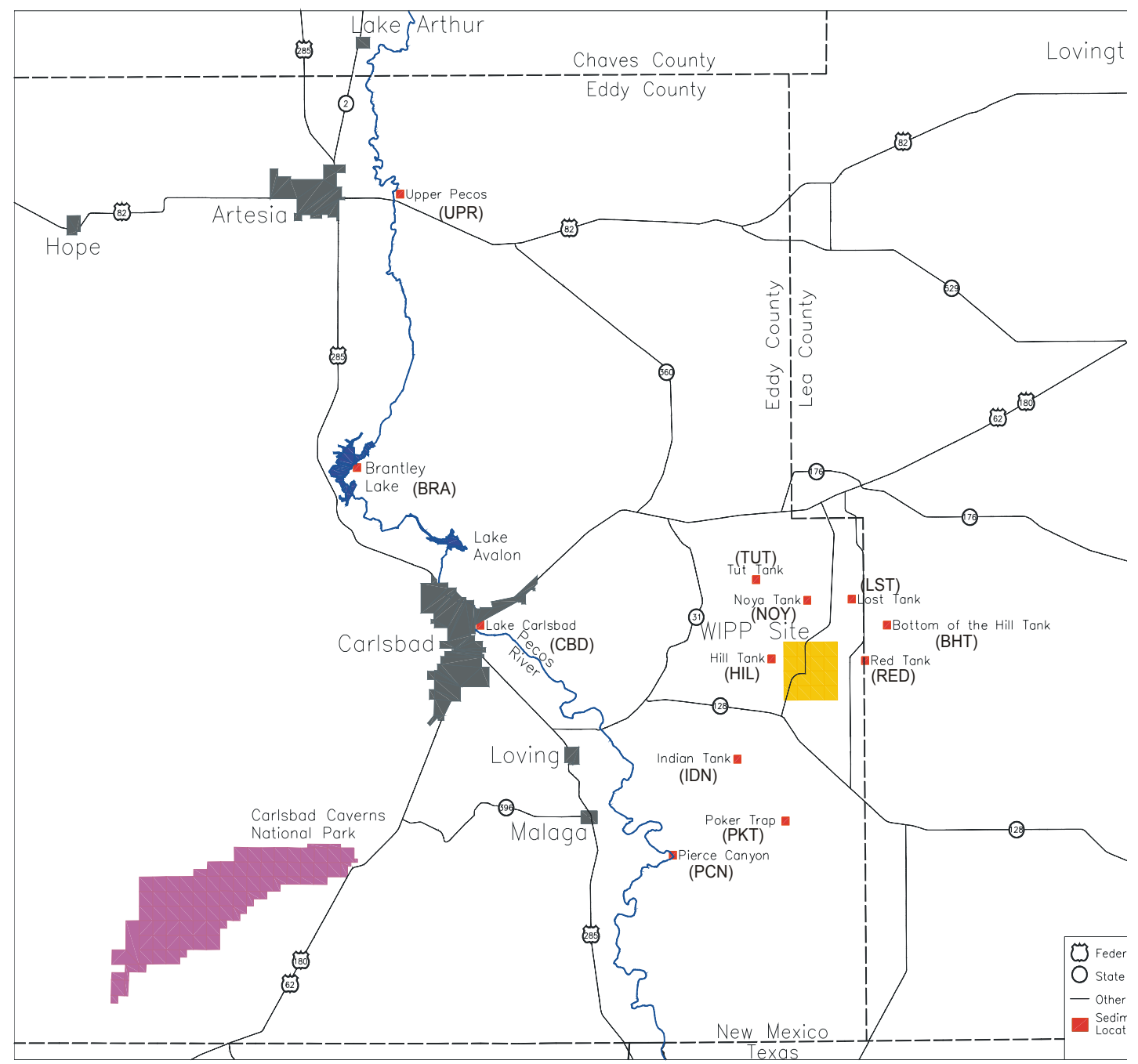

Figure 4.3 - Sediment Sampling Sites

\subsubsection{Results and Discussion}

Uranium-234, ${ }^{235} \mathrm{U}$, and ${ }^{238} \mathrm{U}$ were detected in every sediment sample (Table 4.10). There was some variation in uranium isotope concentration among sampling locations (ANOVA ${ }^{234} \cup p=0.049,{ }^{235} \cup p=0.456,{ }^{238} \cup p=0.137$ ). There was a significant difference between detected uranium isotope concentrations between 2005 and 2006 but only for ${ }^{235} \mathrm{U}$ (ANOVA ${ }^{234} \mathrm{U} p=0.574,{ }^{235} \mathrm{U} p=0.0103,{ }^{238} \mathrm{U} p=0.461$ ) with slightly lower concentrations in 2006 for ${ }^{235} \mathrm{U}$. Concentrations of all three uranium isotopes fell within the 99 percent confidence interval ranges of the baseline data $\left({ }^{234} \mathrm{U}: 1.10 \mathrm{E}-01 \mathrm{~Bq} / \mathrm{g} ;{ }^{235} \mathrm{U}: 3.20 \mathrm{E}-03 \mathrm{~Bq} / \mathrm{g} ;{ }^{238} \mathrm{U}: 5.00 \mathrm{E}-02 \mathrm{~Bq} / \mathrm{g}\right)$. 
Waste Isolation Pilot Plant Annual Site Environmental Report for 2006 DOE/WIPP-07-2225

\begin{tabular}{|c|c|c|c|c|c|c|c|c|c|}
\hline Location & {$[R N]^{a}$} & $\frac{T^{T P U^{b}}}{{ }^{234} \mathrm{U}}$ & MDC $^{c}$ & [RN] & TPU & MDC & [RN] & TPU & MDC \\
\hline BRA & $1.39 \mathrm{E}-02$ & $3.43 \mathrm{E}-03$ & $1.50 \mathrm{E}-03$ & $7.25 \mathrm{E}-04$ & $3.71 \mathrm{E}-04$ & $253 \mathrm{E}-04$ & $1.41 \mathrm{E}-02$ & $3.48 \mathrm{E}-03$ & 6.91E-04 \\
\hline $\mathrm{BHT}$ & 1.76E-02 & $3.54 \mathrm{E}-03$ & 1.48E-03 & 7.47E-04 & $3.39 \mathrm{E}-04$ & 2.37E-04 & $1.72 \mathrm{E}-02$ & $3.46 \mathrm{E}-03$ & $6.78 \mathrm{E}-04$ \\
\hline CBD & $2.22 \mathrm{E}-02$ & $5.37 \mathrm{E}-03$ & $1.50 \mathrm{E}-03$ & $9.42 \mathrm{E}-04$ & 4.42E-04 & $2.54 \mathrm{E}-04$ & 1.92E-02 & $4.68 \mathrm{E}-03$ & $6.91 \mathrm{E}-04$ \\
\hline HIL & 1.93E-02 & 5.03E-03 & 1.53E-03 & 1.16E-03 & $5.21 \mathrm{E}-04$ & $2.74 \mathrm{E}-04$ & 2.03E-02 & 5.27E-03 & 7.10E-04 \\
\hline HIL DUP & 2.03E-02 & 4.67E-03 & 1.52E-03 & 9.53E-04 & 4.27E-04 & 2.62E-04 & $2.05 \mathrm{E}-02$ & 4.72E-03 & 7.00E-04 \\
\hline IDN & $1.65 \mathrm{E}-02$ & $3.33 \mathrm{E}-03$ & $1.48 \mathrm{E}-03$ & 1.06E-03 & $4.05 \mathrm{E}-04$ & $2.31 \mathrm{E}-04$ & $1.66 \mathrm{E}-02$ & 3.33E-03 & $6.73 \mathrm{E}-04$ \\
\hline LST & 1.37E-02 & 3.04E-03 & 1.49E-03 & 6.32E-04 & 3.27E-04 & 2.46E-04 & $1.52 \mathrm{E}-02$ & 3.33E-03 & $6.85 \mathrm{E}-04$ \\
\hline NOY & 1.63E-02 & 4.13E-03 & 1.52E-03 & 7.36E-04 & 3.91E-04 & $2.70 \mathrm{E}-04$ & 1.64E-02 & 4.14E-03 & 7.07E-04 \\
\hline $\mathrm{PCN}$ & 1.46E-02 & 2.92E-03 & $1.50 \mathrm{E}-03$ & 4.82E-04 & $2.57 \mathrm{E}-04$ & 2.44E-04 & $1.08 \mathrm{E}-02$ & 2.21E-03 & 6.86E-04 \\
\hline PCN DUP & $2.16 \mathrm{E}-02$ & $4.78 \mathrm{E}-03$ & $1.51 \mathrm{E}-03$ & 1.03E-03 & $4.26 \mathrm{E}-04$ & $2.50 \mathrm{E}-04$ & $1.62 \mathrm{E}-02$ & $3.64 \mathrm{E}-03$ & $6.91 \mathrm{E}-04$ \\
\hline PKT & 1.84E-02 & 3.84E-03 & 1.51E-03 & 7.48E-04 & 3.39E-04 & 2.49E-04 & 1.87E-02 & 3.91E-03 & $6.90 \mathrm{E}-04$ \\
\hline RED & $1.23 \mathrm{E}-02$ & $2.70 \mathrm{E}-03$ & 1.51E-03 & 6.32E-04 & 3.11E-04 & 2.51E-04 & 1.09E-02 & 2.41E-03 & $6.92 \mathrm{E}-04$ \\
\hline TUT & 1.94E-02 & 4.01E-03 & 1.48E-03 & 1.07E-03 & $4.24 \mathrm{E}-04$ & 2.37E-04 & 2.09E-02 & 4.29E-03 & $6.78 \mathrm{E}-04$ \\
\hline UPR & 9.73E-03 & $2.58 \mathrm{E}-03$ & 1.49E-03 & 7.30E-04 & $3.80 \mathrm{E}-04$ & 2.51E-04 & $9.19 \mathrm{E}-03$ & $2.45 \mathrm{E}-03$ & 6.89E-04 \\
\hline
\end{tabular}

Sediment samples were analyzed for ${ }^{241} \mathrm{Am},{ }^{238} \mathrm{Pu}$, and ${ }^{239+240} \mathrm{Pu}$ (Table 4.11). Plutonium-238 was not detected in any samples. Americium-241 was detected in approximately 29 percent of the samples with the highest detected concentrations at location PKT (5.15E-04 Bq/g). Plutonium 239+240 was detected in approximately 36 percent of the samples with the highest detected concentration at location BHT $(5.26 \mathrm{E}-04 \mathrm{~Bq} / \mathrm{g})$. Comparison of detected value with baseline data for ${ }^{239+240} \mathrm{Pu}$ (baseline data: ${ }^{239+240} \mathrm{Pu}=1.90 \mathrm{E}-03 \mathrm{~Bq} / \mathrm{g}$ [no data available for ${ }^{241} \mathrm{Am}$ ]) shows that ${ }^{239+240} \mathrm{Pu}$ concentrations fell within the 99 percent confidence interval ranges of the baseline concentrations (DOE/WIPP 92-037). Since there were insufficient detections of ${ }^{241} \mathrm{Am}$ and ${ }^{239+240} \mathrm{Pu}$, ANOVA comparisons between years and among locations were not performed.

Table 4.11 -Americium and Plutonium Concentrations (Bq/g) in Sediment Near the WIPP Site. See Appendix $C$ for sampling location codes.

\begin{tabular}{|c|c|c|c|c|c|c|c|c|c|}
\hline Loca & $\mathrm{N}]^{\mathrm{a}}$ & TPU $^{b}$ & $D C^{c}$ & $\mathrm{RN}]$ & TPU & $D C$ & [RN] & TPU & MDC \\
\hline & & ${ }^{241} \mathrm{Am}$ & & & ${ }^{238} \mathrm{Pu}$ & & & ${ }^{240} \mathrm{Pu}$ & \\
\hline RA & 8. & 14E-04 & $.85 \mathrm{E}-04$ & 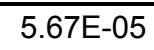 & $2.09 \mathrm{E}$ & $\overline{4}$ & $\overline{5}$ & $1.81 \mathrm{E}-04$ & ד \\
\hline -1T & 3.39E-04 & $3.09 \mathrm{E}$ & & 5.55 & 1.68E-04 & & $5.26 \mathrm{E}-04$ & $E-04$ & E-04 \\
\hline$B D$ & $1.28 \mathrm{E}$ & 1.43 & & 5.50 & 2.03 & & 1.44 & & \\
\hline L & 2.54 & 2.35 & & 1.5 & 6.96 & & 1.92 & & \\
\hline IL D & 8.84E-05 & 1.51 & 2.1 & $1.48 \mathrm{~b}$ & 8.37E-05 & 1.30E-04 & $8.84 \mathrm{E}-05$ & $=-04$ & $1.54 \mathrm{E}-04$ \\
\hline $\mathrm{N}$ & 4 & 2 & & 2.16 & 9.2 & -04 & $1.41 \mathrm{E}-04$ & $E-04$ & $E-04$ \\
\hline ST & 5 & 1.4 & & 3.0 & 1.0 & 04 & 3.04 & -04 & -04 \\
\hline OY & 1 & $1.5 \mathrm{~s}$ & & 2.2 & 5.1 & & 1.64 & -04 & -04 \\
\hline $\mathrm{CN}$ & 6.64E-05 & $1.25 \mathrm{E}-04$ & & 4.40 & 1.02E-04 & $1.24 \mathrm{E}-04$ & 2.03E-05 & 7.35E-05 & $1.49 \mathrm{E}-04$ \\
\hline $\mathrm{CN}$ & 9.99E-05 & 1.16E-04 & 2.00E-04 & $-1.35 E-05$ & 3.87E-05 & 1.15E-04 & 4.81E-06 & 7.65E-05 & 1.40E-04 \\
\hline KT & $5.15 \mathrm{E}-04$ & $2.70 \mathrm{E}-04$ & 2.11E-04 & 5.85E-05 & $1.02 \mathrm{E}-04$ & 1.30E-04 & 4.30E-04 & $2.48 \mathrm{E}-04$ & $1.55 \mathrm{E}-04$ \\
\hline
\end{tabular}


Table 4.11 -Americium and Plutonium Concentrations (Bq/g) in Sediment Near the WIPP Site. See Appendix $C$ for sampling location codes.

\begin{tabular}{|c|c|c|c|c|c|c|c|c|c|}
\hline Location & {$[\mathrm{RN}]^{\mathrm{a}}$} & TPU $^{b}$ & MDC $^{c}$ & [RN] & TPU & MDC & [RN] & TPU & MDC \\
\hline & & ${ }^{241} \mathrm{Am}$ & & & ${ }^{238} \mathrm{Pu}$ & & & ${ }^{239+240} \mathrm{Pu}$ & \\
\hline RED & 5.04E-05 & 1.03E-04 & $1.94 \mathrm{E}-04$ & $-7.70 \mathrm{E}-06$ & $2.92 \mathrm{E}-05$ & 1.15E-04 & $4.31 \mathrm{E}-05$ & 8.91E-05 & 1.40E-04 \\
\hline TUT & 1.47E-04 & 1.89E-04 & 2.43E-04 & 1.93E-05 & 1.47E-04 & 1.33E-04 & 1.93E-05 & 9.64E-05 & 1.70E-04 \\
\hline UPR & 7.45E-05 & 9.66E-05 & 1.73E-04 & $-5.51 E-05$ & $9.09 \mathrm{E}-05$ & 1.30E-04 & $9.65 \mathrm{E}-05$ & $1.43 \mathrm{E}-04$ & 1.67E-04 \\
\hline
\end{tabular}

Cesium-137 was detected in 71 percent of the sediment samples (Table 4.12). There was not a significant difference among either sampling locations (ANOVA, $p=0.149$ ), or between sampling years between 2005 and 2006 (ANOVA, $p=0.550$ ). In addition, all detected ${ }^{137} \mathrm{Cs}$ concentrations fell within the 99 percent confidence interval range of baseline concentrations $(3.50 \mathrm{E}-02 \mathrm{~Bq} / \mathrm{g})$. Although ${ }^{137} \mathrm{Cs}$ is a fission product, it is ubiquitous in soils because of global fallout from atmospheric nuclear weapons testing (Beck and Bennett, 2002; and UNSCEAR [United Nations Scientific Committee on the Effects of Atomic Radiation], 2000).

Strontium- 90 was not detected in any sediment samples. Cobalt-60 was not detected in any sediment samples except at location CBD. There were insufficient detections to permit analysis of variance among sampling locations or between years. Comparison of the detected concentration of ${ }^{60} \mathrm{Co}$ with baseline data (baseline data for ${ }^{60} \mathrm{Co}$ :

$5.90 \mathrm{E}-03 \mathrm{~Bq} / \mathrm{g}$ ) shows that it fell within the 99 percent confidence interval ranges of the baseline concentrations (DOE/WIPP 92-037).

Potassium-40 was detected in all sediment samples (Table 4.12). Although concentrations varied among sampling locations (ANOVA, $p=0.00596$ ), there was no statistically significant difference in concentrations between 2005 and 2006 (ANOVA, $p=0.0965$ ). All detected concentrations of ${ }^{40} \mathrm{~K}$ observed in these samples were within the 99 percent confidence interval range of baseline concentrations (baseline concentration: $1.20 \mathrm{E}+00 \mathrm{~Bq} / \mathrm{g}$ ). The difference in ${ }^{40} \mathrm{~K}$ concentrations is because this isotope is naturally occurring in the earth's crust and the concentration varies in different locations. Potassium is ubiquitous throughout the earth's crust and therefore would be expected to show up in sediment samples. 
Table 4.12 - Selected Radionuclide Concentrations (Bq/g) in Sediment Near the WIPP Site. See Appendix $\mathrm{C}$ for the sampling location codes.

\begin{tabular}{|c|c|c|c|c|c|c|}
\hline Location & {$[\mathrm{RN}]^{\mathrm{a}}$} & $2 \times$ TPU $^{b}$ & $M^{\prime} C^{c}$ & [RN] & $2 \times$ TPU & MDC \\
\hline & \multicolumn{3}{|c|}{${ }^{137} \mathrm{Cs}$} & \multicolumn{3}{|c|}{${ }^{60} \mathrm{Co}$} \\
\hline BRA & 3.39E-04 & $1.07 \mathrm{E}-04$ & $2.03 E-04$ & $4.83 \mathrm{E}-05$ & 3.57E-04 & $3.96 \mathrm{E}-04$ \\
\hline BHT & 1.22E-02 & 1.69E-03 & 7.16E-04 & 1.23E-03 & 1.14E-03 & 1.32E-03 \\
\hline CBD & 1.04E-03 & 2.06E-04 & 2.57E-04 & $5.25 \mathrm{E}-04$ & 3.88E-04 & 4.65E-04 \\
\hline HIL & 3.81E-03 & 7.52E-04 & 7.81E-04 & $-4.11 \mathrm{E}-05$ & 9.77E-04 & 1.06E-03 \\
\hline HIL DUP & 3.66E-03 & 8.06E-04 & 9.24E-04 & 8.09E-04 & 1.15E-03 & 1.31E-03 \\
\hline IDN & 4.46E-03 & $9.15 \mathrm{E}-04$ & 9.51E-04 & $6.53 \mathrm{E}-04$ & 1.32E-03 & $1.50 \mathrm{E}-03$ \\
\hline LST & 1.99E-03 & 4.17E-04 & 4.42E-04 & $-4.51 \mathrm{E}-04$ & $6.24 \mathrm{E}-04$ & 6.36E-04 \\
\hline NOY & 3.68E-04 & 3.04E-04 & 4.76E-04 & $2.76 \mathrm{E}-04$ & 7.95E-04 & 8.97E-04 \\
\hline PCN & 5.18E-05 & 3.92E-04 & 5.66E-04 & 2.36E-04 & 5.58E-04 & $6.35 \mathrm{E}-04$ \\
\hline PCN DUP & 1.15E-04 & 4.76E-04 & 5.62E-04 & 2.97E-04 & 6.14E-04 & 7.05E-04 \\
\hline PKT & 7.33E-03 & $1.02 \mathrm{E}-03$ & 4.93E-04 & 4.64E-06 & 7.84E-04 & 8.61E-04 \\
\hline RED & 8.10E-04 & 3.25E-04 & 4.54E-04 & 2.70E-04 & 7.94E-04 & 8.99E-04 \\
\hline TUT & 7.81E-04 & 2.62E-04 & 5.50E-04 & 1.69E-04 & 8.50E-04 & 9.41E-04 \\
\hline \multirow[t]{2}{*}{ UPR } & 1.62E-04 & $5.20 \mathrm{E}-04$ & $6.16 \mathrm{E}-04$ & 6.63E-04 & 6.86E-04 & 8.13E-04 \\
\hline & \multicolumn{3}{|c|}{${ }^{90} \mathrm{Sr}$} & \multicolumn{3}{|c|}{${ }^{40} \mathrm{~K}$} \\
\hline BRA & $-4.98 \mathrm{E}-03$ & $6.73 \mathrm{E}-03$ & $2.71 \mathrm{E}-03$ & $1.78 \mathrm{E}-01$ & $2.36 \mathrm{E}-02$ & $2.94 \mathrm{E}-03$ \\
\hline BHT & $-2.19 \mathrm{E}-03$ & 6.85E-03 & 2.71E-03 & 6.27E-01 & 1.10E-01 & 8.79E-03 \\
\hline CBD & -1.17E-03 & $6.88 \mathrm{E}-03$ & 2.70E-03 & 1.49E-01 & $2.01 \mathrm{E}-02$ & 3.79E-03 \\
\hline HIL & 1.58E-03 & 7.22E-03 & 2.62E-03 & 8.36E-01 & 1.14E-01 & 7.92E-03 \\
\hline HIL DUP & $-3.23 E-03$ & 7.23E-03 & 2.62E-03 & 8.88E-01 & 1.27E-01 & $9.79 \mathrm{E}-03$ \\
\hline IDN & $-2.50 \mathrm{E}-03$ & 6.87E-03 & 2.71E-03 & 6.83E-01 & 9.94E-02 & 1.32E-02 \\
\hline LST & $-2.65 \mathrm{E}-03$ & $6.89 \mathrm{E}-03$ & 2.71E-03 & $2.96 \mathrm{E}-01$ & 3.91E-02 & 5.27E-03 \\
\hline NOY & -1.29E-03 & 7.09E-03 & 2.61E-03 & 3.87E-01 & 5.64E-02 & $5.80 \mathrm{E}-03$ \\
\hline $\mathrm{PCN}$ & $-3.65 E-03$ & 6.85E-03 & 2.60E-03 & 1.87E-01 & 2.65E-02 & 5.10E-03 \\
\hline PCN DUP & 3.67E-03 & 7.23E-03 & 2.60E-03 & $1.86 \mathrm{E}-01$ & 2.79E-02 & 5.97E-03 \\
\hline PKT & $-9.59 \mathrm{E}-04$ & 7.02E-03 & 2.60E-03 & 5.54E-01 & 7.59E-02 & 6.60E-03 \\
\hline RED & $-5.26 \mathrm{E}-03$ & 7.05E-03 & 2.63E-03 & $3.26 \mathrm{E}-01$ & 4.79E-02 & $6.83 \mathrm{E}-03$ \\
\hline TUT & -3.78E-03 & $6.71 \mathrm{E}-03$ & 2.70E-03 & 6.92E-01 & $1.21 \mathrm{E}-01$ & $6.73 \mathrm{E}-03$ \\
\hline UPR & $-3.98 \mathrm{E}-04$ & $6.88 \mathrm{E}-03$ & 2.70E-03 & 2.39E-01 & 3.56E-02 & 7.14E-03 \\
\hline
\end{tabular}

${ }^{a}$ Radionuclide concentration

${ }^{b}$ Total propagated uncertainty

${ }^{\mathrm{c}}$ Minimum detectable

Duplicate analyses were performed for all the radionuclides in sediment samples from sampling locations HIL and PCN (Table 4.13). RERs were calculated for all isotopes for which the concentrations in both original and duplicate samples were detected. The RERs were less than one for all isotopes for location HIL, indicating acceptable reproducibility. The RER for location PCN for ${ }^{40} \mathrm{~K}$ was less than 1.0 , indicating acceptable reproducibility. However, all isotopes of uranium $\left({ }^{234} U,{ }^{235} U\right.$, and $\left.{ }^{238} U\right)$ at location PCN had an RER greater than one, indicating poor reproducibility. RERs greater than one were most likely due to inhomogeneities in the distributions of the radioisotope within the sampling locations. 
Table 4.13 - Results of Duplicate Sediment Sampling Analysis. Units are Bq/g. See Appendix $\mathrm{C}$ for sampling location codes.

\begin{tabular}{|c|c|c|c|c|c|c|c|c|}
\hline \multicolumn{2}{|c|}{ Location } & \multicolumn{3}{|c|}{ Sample } & \multicolumn{3}{|c|}{ Duplicate } & \multirow[b]{2}{*}{ RER $^{\mathrm{d}}$} \\
\hline & & {$[\mathrm{RN}]^{\mathrm{a}}$} & $2 \times$ TPU $^{b}$ & $\mathrm{MDC}^{\mathrm{C}}$ & [RN] & $2 \times$ TPU & MDC & \\
\hline \multirow[t]{5}{*}{ HIL } & ${ }^{234} U$ & 1.93E-02 & $5.03 E-03$ & $1.53 \mathrm{E}-03$ & $2.02 E-02$ & 4.67E-03 & $1.52 \mathrm{E}-03$ & 0.13 \\
\hline & ${ }^{235} \mathrm{U}$ & 1.16E-03 & 5.21E-04 & $2.74 \mathrm{E}-04$ & 9.53E-04 & 4.27E-04 & 2.62E-04 & 0.31 \\
\hline & ${ }^{238} \mathrm{U}$ & 2.03E-02 & 5.27E-03 & 7.10E-04 & $2.05 \mathrm{E}-02$ & 4.72E-03 & 7.00E-04 & 0.03 \\
\hline & ${ }^{40} \mathrm{~K}$ & 8.36E-01 & 1.14E-01 & 7.92E-03 & 8.88E-01 & 1.27E-01 & 9.79E-03 & 0.30 \\
\hline & ${ }^{137} \mathrm{Cs}$ & 3.81E-03 & 7.52E-04 & 7.81E-04 & 3.66E-03 & 8.06E-04 & 9.24E-04 & 0.14 \\
\hline \multirow[t]{4}{*}{$\mathrm{PCN}$} & ${ }^{234} \mathrm{U}$ & $1.46 \mathrm{E}-02$ & 2.93E-03 & 1.50E-03 & 2.16E-02 & 4.78E-03 & $1.51 \mathrm{E}-03$ & 1.25 \\
\hline & ${ }^{235} U$ & 4.82E-04 & 2.57E-04 & $2.44 \mathrm{E}-04$ & 1.03E-03 & 4.26E-04 & $2.50 \mathrm{E}-04$ & 1.10 \\
\hline & ${ }^{238} \mathrm{U}$ & 1.08E-02 & 2.21E-03 & 6.86E-04 & 1.62E-02 & $3.64 \mathrm{E}-03$ & 6.91E-04 & 1.27 \\
\hline & ${ }^{40} \mathrm{~K}$ & 1.87E-01 & 2.65E-02 & $5.10 \mathrm{E}-03$ & 1.86E-01 & 2.79E-02 & 5.97E-03 & 0.03 \\
\hline
\end{tabular}

\subsection{Soil Samples}

\subsubsection{Sample Collection}

Soil samples are collected from near the low-volume air samplers at six different locations around the WIPP site: MLR, SEC, SMR, WEE, WFF, and WSS (Figure 4.4). Samples are collected from each location in three incremental profiles: surface soil (0-2 cm [0-0.8 in.]), intermediate soil (2-5 cm [0.8-2 in.]), and deep soil (5-10 cm [2-4 in.]). Measurements of radionuclides in depth profiles provide information about their vertical movements in the soil systems. 


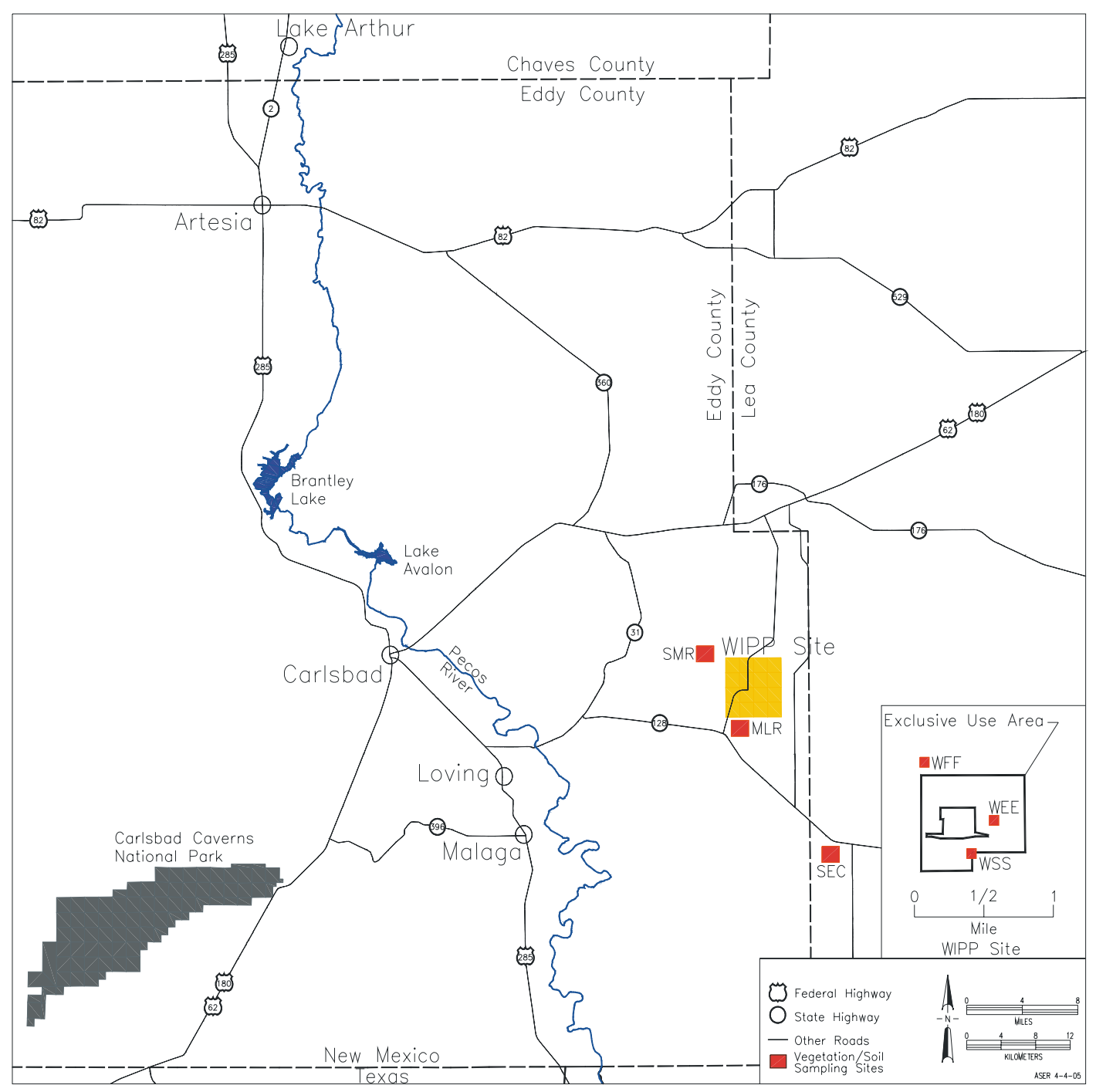

Figure 4.4 - Routine Soil and Vegetation Sampling Areas

\subsubsection{Sample Preparation}

Soil samples are dried at $110^{\circ} \mathrm{C}\left(230^{\circ} \mathrm{F}\right)$ for several hours and homogenized by grinding to small particle sizes. Two grams $(0.08 \mathrm{oz})$ of soil is dissolved by heating it with a mixture of nitric, hydrochloric, and hydrofluoric acids. Finally, the sample is heated with nitric and boric acids, and the residue is dissolved in hydrochloric acid for the determination of individual radionuclides.

\subsubsection{Determination of Individual Radionuclides}

Gamma-emitting radionuclides $\left({ }^{40} \mathrm{~K},{ }^{60} \mathrm{Co}\right.$, and $\left.{ }^{137} \mathrm{Cs}\right)$ are determined by counting an aliquot of well-homogenized ground soil samples by gamma spectrometry. Strontium-90 is analyzed from an aliquot of the sample solution by separating it from other stable and radioactive elements using radiochemical techniques and beta counting using a proportional counter. Another aliquot of the sample solution is used for 
the sequential determinations of the alpha-emitting radionuclides ${ }^{234} U,{ }^{235} \mathrm{U}$, and ${ }^{238} \mathrm{U}$; ${ }^{238} \mathrm{Pu}$ and ${ }^{239+240} \mathrm{Pu}$; and ${ }^{241} \mathrm{Am}$. These radionuclides are separated from the bulk of the inorganic materials present in the soil samples and from one another by radiochemical separations including co-precipitation and ion-exchange chromatography. Finally, the samples are micro-precipitated, filtered onto micro-filters, and counted on the alpha spectrometer.

\subsubsection{Results and Discussion}

Uranium-234, ${ }^{235} U$, and ${ }^{238} U$ were detected in every soil sample in 2006 with one exception for ${ }^{235} U$ where it was not detected in the WFF duplicate sample taken (Table 4.14). There was no variation in uranium isotope concentration among sampling locations (ANOVA, ${ }^{234} \mathrm{U} p=0.999 ;{ }^{235} \mathrm{U} p=0.961 ;{ }^{238} \mathrm{U} p=0.999$ ). There was a significant difference between all detected uranium isotope concentrations between 2005 and 2006 (ANOVA, ${ }^{234} \mathrm{U} p=2.84 \mathrm{E}-10 . ;{ }^{235} \mathrm{U} p=3.83 \mathrm{E}-06$; ${ }^{238} \mathrm{U} \mathrm{p}=3.46 \mathrm{E}-09$ ) with slightly lower concentrations in 2006 for all uranium isotopes.

All of the 2006 Uranium isotopes $\left({ }^{234} \mathrm{U}\right.$, highest concentration: $9.92 \mathrm{E}-03 \mathrm{~Bq} / \mathrm{g} ;{ }^{235} \mathrm{U}$, highest concentration: 7.03E-04 Bq/g; and ${ }^{238} \mathrm{U}$, highest concentration: $9.63 \mathrm{E}-03 \mathrm{~Bq} / \mathrm{g}$ ) fall within the 99 percent confidence interval range of baseline concentrations (2.20E-02 Bq/g, 1.70E-03 Bq/g, and 1.30E-02 Bq/g, respectively) (DOE/WIPP 92-037). These detected concentrations were similar to the range of natural concentrations of uranium found in soils throughout the world. The average concentration of ${ }^{238} \mathrm{U}$ in soil (upper crust) is 3.60E-02 Bq/g (NCRP [National Council for Radiation Protection and Measurements] Report No. 94, 1987a). The consistency of the measured uranium concentrations with natural uranium in soils throughout the world, the natural variability of uranium in soils, and the fact that none of the actinides, which would be expected to be released along with uranium, were detected in concentrations in excess of baseline quantities, suggests that these soil concentrations follow a pattern of natural variability consistent with the existence of natural uranium.

Table 4.14 - Uranium Concentrations (Bq/g) in Soil Near the WIPP Site. See Appendix C for sampling location codes.

\begin{tabular}{|c|c|c|c|c|c|c|c|c|c|c|}
\hline Location & $\begin{array}{l}\text { Depth } \\
\text { (cm) }\end{array}$ & $\mathrm{RN}]^{\mathrm{a}}$ & $2 \times T^{2} U^{b}$ & MDC $^{c}$ & [RN] & $2 \times$ TPU & MDC & [RN] & $2 \times$ TPU & MDC \\
\hline & & & ${ }^{234} \mathrm{U}$ & & & $235 \mathrm{U}$ & & & ${ }^{238} \mathrm{U}$ & \\
\hline MLR & $0-2$ & $9.14 \mathrm{E}-03$ & $1.08 \mathrm{E}-03$ & $9.22 \mathrm{E}-04$ & $5.43 E-04$ & $2.82 E-04$ & $2.23 E-04$ & $8.33 \mathrm{E}-03$ & $1.02 \mathrm{E}-03$ & $6.25 \mathrm{E}-04$ \\
\hline MLR & $2-5$ & $9.92 \mathrm{E}-03$ & 1.15E-03 & $9.25 \mathrm{E}-04$ & $6.81 \mathrm{E}-04$ & $3.20 \mathrm{E}-04$ & 2.27E-04 & $9.63 \mathrm{E}-03$ & 1.13E-03 & $6.28 \mathrm{E}-04$ \\
\hline MLR & $5-10$ & $9.21 \mathrm{E}-03$ & 1.07E-03 & $9.21 \mathrm{E}-04$ & 5.01E-04 & 2.68E-04 & 2.22E-04 & 1.03E-02 & $1.14 \mathrm{E}-03$ & $6.24 \mathrm{E}-04$ \\
\hline SEC & $0-2$ & 8.00E-03 & $9.27 \mathrm{E}-04$ & 8.86E-04 & $3.11 \mathrm{E}-04$ & 1.97E-04 & 2.09E-04 & 7.30E-03 & 8.82E-04 & 5.52E-04 \\
\hline SEC & $2-5$ & 7.85E-03 & 9.58E-04 & $9.17 \mathrm{E}-04$ & 4.01E-04 & 2.35E-04 & 2.16E-04 & 7.47E-03 & $9.30 \mathrm{E}-04$ & 5.57E-04 \\
\hline SEC & $5-10$ & 7.79E-03 & 9.83E-04 & $9.22 \mathrm{E}-04$ & $4.23 \mathrm{E}-04$ & 2.53E-04 & 2.23E-04 & $7.92 \mathrm{E}-03$ & 9.91E-04 & 5.63E-04 \\
\hline SMR & $0-2$ & $6.73 \mathrm{E}-03$ & 8.38E-04 & $9.10 \mathrm{E}-04$ & 4.92E-04 & 2.45E-04 & 2.08E-04 & $7.00 \mathrm{E}-03$ & 8.55E-04 & $6.12 \mathrm{E}-04$ \\
\hline SMR & $2-5$ & 8.73E-03 & 1.15E-03 & $9.40 \mathrm{E}-04$ & $3.84 \mathrm{E}-04$ & 2.69E-04 & $2.45 \mathrm{E}-04$ & 8.59E-03 & 1.14E-03 & $6.42 \mathrm{E}-04$ \\
\hline SMR & $5-10$ & 7.49E-03 & 1.03E-03 & $9.33 \mathrm{E}-04$ & 7.03E-04 & 3.39E-04 & 2.37E-04 & $7.52 \mathrm{E}-03$ & 1.03E-03 & 6.36E-04 \\
\hline WEE & $0-2$ & $6.29 \mathrm{E}-03$ & 8.58E-04 & $9.18 \mathrm{E}-04$ & 3.34E-04 & $2.20 \mathrm{E}-04$ & $2.18 \mathrm{E}-04$ & $6.54 \mathrm{E}-03$ & 8.72E-04 & $5.59 \mathrm{E}-04$ \\
\hline WEE & $2-5$ & 6.01E-03 & 7.88E-04 & $9.09 \mathrm{E}-04$ & 3.61E-04 & 2.11E-04 & 2.07E-04 & $6.30 \mathrm{E}-03$ & 8.08E-04 & $5.50 \mathrm{E}-04$ \\
\hline WEE & $5-10$ & $6.71 \mathrm{E}-03$ & 8.78E-04 & $9.16 \mathrm{E}-04$ & $3.00 \mathrm{E}-04$ & 2.02E-04 & 2.16E-04 & $7.20 \mathrm{E}-03$ & $9.10 \mathrm{E}-04$ & 5.57E-04 \\
\hline WFF & $0-2$ & $5.25 \mathrm{E}-03$ & 7.98E-04 & 8.97E-04 & $3.18 \mathrm{E}-04$ & $2.18 \mathrm{E}-04$ & 2.23E-04 & 4.85E-03 & 7.63E-04 & $5.62 \mathrm{E}-04$ \\
\hline WFF & $2-5$ & 4.74E-03 & 7.30E-04 & 8.91E-04 & $2.91 \mathrm{E}-04$ & 2.03E-04 & $2.15 \mathrm{E}-04$ & $5.26 \mathrm{E}-03$ & 7.66E-04 & 5.56E-04 \\
\hline
\end{tabular}


Table 4.14 - Uranium Concentrations (Bq/g) in Soil Near the WIPP Site. See Appendix C for sampling location codes.

\begin{tabular}{|c|c|c|c|c|c|c|c|c|c|c|}
\hline Location & $\begin{array}{c}\text { Depth } \\
\text { (cm) }\end{array}$ & {$[\mathbf{R N}]^{\mathrm{a}}$} & $2 \times T^{2} U^{b}$ & MDC $^{c}$ & [RN] & $2 \times$ TPU & MDC & [RN] & $2 \times$ TPU & MDC \\
\hline & & & ${ }^{234} \mathrm{U}$ & & & ${ }^{235} \mathrm{U}$ & & & ${ }^{238} \mathrm{U}$ & \\
\hline WFF & $5-10$ & 6.92E-03 & $9.79 \mathrm{E}-04$ & $9.07 \mathrm{E}-04$ & $2.40 \mathrm{E}-04$ & 2.01E-04 & $2.35 \mathrm{E}-04$ & 6.16E-03 & $9.18 \mathrm{E}-04$ & 5.73E-04 \\
\hline WSS & $0-2$ & 6.68E-03 & 8.47E-04 & $9.11 \mathrm{E}-04$ & $3.08 \mathrm{E}-04$ & $1.99 \mathrm{E}-04$ & 2.09E-04 & 7.27E-03 & 8.84E-04 & $6.14 \mathrm{E}-04$ \\
\hline WSS & $2-5$ & $6.70 \mathrm{E}-03$ & 8.66E-04 & $9.14 \mathrm{E}-04$ & $3.18 \mathrm{E}-04$ & 2.11E-04 & 2.14E-04 & 7.23E-03 & $9.02 \mathrm{E}-04$ & 6.17E-04 \\
\hline WSS & $5-10$ & $6.74 \mathrm{E}-03$ & 8.92E-04 & $9.18 \mathrm{E}-04$ & 4.40E-04 & 2.51E-04 & 2.18E-04 & 6.96E-03 & 9.03E-04 & $6.21 \mathrm{E}-04$ \\
\hline WFF DUP & $0-2$ & 5.37E-03 & 8.16E-04 & 8.99E-04 & 2.09E-04 & 1.86E-04 & $2.25 \mathrm{E}-04$ & $5.71 \mathrm{E}-03$ & 8.42E-04 & 5.65E-01 \\
\hline WFF DUP & $2-5$ & 4.93E-03 & 7.92E-04 & $9.01 \mathrm{E}-04$ & 2.61E-04 & 2.04E-04 & 2.28E-04 & $5.12 \mathrm{E}-03$ & 8.07E-04 & 5.67E-04 \\
\hline WFF DUP & $5-10$ & 6.79E-03 & 8.94E-04 & 8.93E-04 & $2.74 \mathrm{E}-04$ & 1.96E-04 & 2.18E-04 & $5.43 \mathrm{E}-03$ & 7.93E-04 & $5.59 \mathrm{E}-04$ \\
\hline
\end{tabular}

Plutonium-238, ${ }^{239+240} \mathrm{Pu}$, and ${ }^{241} \mathrm{Am}$ were also analyzed in these soil samples (Table 4.15). Plutonium-238 was detected in one of the duplicate samples at WFF. Plutonium-239+240 was detected in two samples (both at location SEC). Am-241 was detected in one sample (at location SEC). All detected concentrations of ${ }^{238} \mathrm{Pu}$, ${ }^{239+240} \mathrm{Pu}$, and ${ }^{241} \mathrm{Am}$ were extremely small and were relatively close to the respective MDCs. There were insufficient detections of ${ }^{238} \mathrm{Pu},{ }^{239+240} \mathrm{Pu}$, and ${ }^{241} \mathrm{Am}$ to permit analysis of variance among sampling locations or between years. However, the detected concentrations of all three actinides fell within the 99 percent confidence interval ranges of their respective baseline values (DOE/WIPP 92-037) (Baseline values: ${ }^{238} \mathrm{Pu}=2.40 \mathrm{E}-03 \mathrm{~Bq} / \mathrm{g},{ }^{239+240} \mathrm{Pu}=1.90 \mathrm{E}-03 \mathrm{~Bq} / \mathrm{g}$, and $\left.{ }^{241} \mathrm{Am}=8.00 \mathrm{E}-03 \mathrm{~Bq} / \mathrm{g}\right)$. Historically, soil samples collected in the same locations have shown positive results on numerous occasions (DOE/WIPP 03-2225). The Gnome Site lies approximately $9 \mathrm{~km}$ southwest of the WIPP boundary and was contaminated with actinides and fission products in 1961 when an underground detonation of a 3-kiloton ${ }^{239} \mathrm{Pu}$ device vented to the atmosphere.

Table 4.15 - Americium and Plutonium Concentrations (Bq/g) in Soil Near the WIPP Site. See Appendix $\mathbf{C}$ for the sampling location codes.

\begin{tabular}{|c|c|c|c|c|c|c|c|c|c|c|}
\hline Location & $\begin{array}{l}\text { Depth } \\
\text { (cm) }\end{array}$ & {$[\mathrm{RN}]^{\mathrm{a}}$} & $2 \times$ TPU $^{b}$ & MDC $^{c}$ & RN & $2 \times$ TPU & MDC & RN & $2 \times$ TPU & MDC \\
\hline & & & ${ }^{241} \mathrm{Am}$ & & & ${ }^{238} \mathrm{Pu}$ & & & ${ }^{239+240} \mathrm{Pu}$ & \\
\hline MLR & $0-2$ & 5.72E-05 & 1.87E-04 & $\overline{4.35 E-04}$ & 4.42E-05 & $1.43 E-04$ & $2.47 E-04$ & $6.86 \mathrm{E}-05$ & $2.14 \mathrm{E}-04$ & $2.10 \mathrm{E}-04$ \\
\hline MLR & $2-5$ & 9.35E-05 & 1.37E-04 & 3.69E-04 & $1.81 \mathrm{E}-04$ & 2.13E-04 & 1.95E-04 & 1.23E-05 & 1.15E-04 & $1.58 \mathrm{E}-04$ \\
\hline MLR & $5-10$ & 3.57E-05 & 1.32E-04 & 3.88E-04 & 4.54E-05 & $1.48 \mathrm{E}-04$ & 1.93E-04 & 2.73E-05 & $1.01 \mathrm{E}-04$ & $1.56 \mathrm{E}-04$ \\
\hline SEC & $0-2$ & $5.46 \mathrm{E}-04$ & 3.23E-04 & 3.37E-04 & 5.18E-05 & 1.08E-04 & $1.48 \mathrm{E}-04$ & 2.12E-04 & 1.53E-04 & 1.11E-04 \\
\hline SEC & $2-5$ & 2.09E-05 & $1.29 \mathrm{E}-04$ & 3.07E-04 & $1.04 \mathrm{E}-04$ & $1.51 \mathrm{E}-04$ & $1.56 \mathrm{E}-04$ & $1.51 \mathrm{E}-04$ & $1.55 \mathrm{E}-04$ & 1.18E-04 \\
\hline SEC & $5-10$ & 2.32E-04 & 2.18E-04 & 3.16E-04 & 6.49E-05 & 1.36E-04 & $1.53 \mathrm{E}-04$ & 1.82E-04 & $1.58 \mathrm{E}-04$ & 1.16E-04 \\
\hline SMR & $0-2$ & 4.87E-05 & $1.20 \mathrm{E}-04$ & 3.64E-04 & 8.23E-05 & 1.69E-04 & $1.90 \mathrm{E}-04$ & 1.67E-04 & $2.06 \mathrm{E}-04$ & 1.53E-04 \\
\hline SMR & $2-5$ & 8.71E-05 & 1.54E-04 & 3.76E-04 & 4.50E-05 & 1.17E-04 & $1.51 \mathrm{E}-04$ & 7.52E-05 & 1.02E-04 & 1.14E-04 \\
\hline SMR & $5-10$ & 2.70E-05 & 9.94E-05 & 3.63E-04 & $-1.25 \mathrm{E}-05$ & $9.16 \mathrm{E}-05$ & $1.56 \mathrm{E}-04$ & $7.25 \mathrm{E}-05$ & 1.12E-04 & 1.19E-04 \\
\hline WEE & $0-2$ & $-2.68 E-06$ & 1.07E-04 & 3.13E-04 & $1.88 \mathrm{E}-04$ & 2.00E-04 & $1.61 \mathrm{E}-04$ & 4.42E-05 & 1.02E-04 & $1.24 \mathrm{E}-04$ \\
\hline WEE & $2-5$ & 6.72E-05 & 1.35E-04 & 3.29E-04 & $-3.82 \mathrm{E}-05$ & $1.23 \mathrm{E}-04$ & $1.71 \mathrm{E}-04$ & 5.54E-05 & $1.09 \mathrm{E}-04$ & $1.34 \mathrm{E}-04$ \\
\hline WEE & $5-10$ & 8.45E-05 & 1.41E-04 & 3.11E-04 & 3.42E-06 & $1.28 \mathrm{E}-04$ & 1.64E-04 & 4.91E-05 & 1.03E-04 & 1.27E-04 \\
\hline WFF & $0-2$ & 1.11E-04 & 2.09E-04 & $3.45 \mathrm{E}-04$ & $-3.15 E-06$ & 1.16E-04 & $1.85 \mathrm{E}-04$ & 4.87E-05 & $1.34 \mathrm{E}-04$ & $1.48 \mathrm{E}-04$ \\
\hline WFF & $2-5$ & $6.70 \mathrm{E}-05$ & 1.71E-04 & 3.18E-04 & $1.33 \mathrm{E}-06$ & $1.08 \mathrm{E}-04$ & $1.81 \mathrm{E}-04$ & $1.03 E-04$ & $1.41 \mathrm{E}-04$ & $1.43 \mathrm{E}-04$ \\
\hline WFF & $5-10$ & 4.09E-06 & $1.54 \mathrm{E}-04$ & 3.30E-04 & $-1.50 \mathrm{E}-05$ & 1.11E-04 & 1.73E-04 & $2.38 \mathrm{E}-05$ & $8.25 \mathrm{E}-05$ & $1.35 \mathrm{E}-04$ \\
\hline WSS & $0-2$ & $2.48 \mathrm{E}-05$ & $1.30 \mathrm{E}-04$ & 3.83E-04 & $1.28 \mathrm{E}-06$ & 9.77E-05 & $1.71 \mathrm{E}-04$ & 4.95E-05 & 1.12E-04 & 1.33E-04 \\
\hline WSS & $2-5$ & -3.61E-05 & 6.81E-05 & 3.75E-04 & 3.69E-05 & $1.94 \mathrm{E}-04$ & $2.21 \mathrm{E}-04$ & 1.41E-04 & $1.96 \mathrm{E}-04$ & $1.84 \mathrm{E}-04$ \\
\hline
\end{tabular}


Table 4.15 - Americium and Plutonium Concentrations (Bq/g) in Soil Near the WIPP Site. See Appendix $\mathrm{C}$ for the sampling location codes.

\begin{tabular}{|c|c|c|c|c|c|c|c|c|c|c|}
\hline Location & $\begin{array}{l}\text { Depth } \\
\text { (cm) }\end{array}$ & {$[\mathrm{RN}]^{\mathrm{a}}$} & $2 \times$ TPU $^{b}$ & MDC $^{c}$ & RN & $2 \times$ TPU & MDC & RN & $2 \times$ TPU & MDC \\
\hline & & \multicolumn{3}{|c|}{${ }^{241} \mathrm{Am}$} & \multicolumn{3}{|c|}{${ }^{238} \mathrm{Pu}$} & \multicolumn{3}{|c|}{${ }^{239+240} \mathrm{Pu}$} \\
\hline WSS & $5-10$ & 9.67E-05 & $1.28 \mathrm{E}-04$ & 3.82E-04 & 7.24E-05 & $1.49 \mathrm{E}-04$ & $1.76 \mathrm{E}-04$ & 7.22E-06 & 9.91E-05 & 1.39E-04 \\
\hline WFF DUP & $0-2$ & 7.79E-06 & 1.44E-04 & $3.25 \mathrm{E}-04$ & 4.24E-05 & 1.33E-04 & 1.82E-04 & 1.09E-05 & $1.02 \mathrm{E}-04$ & $1.44 \mathrm{E}-04$ \\
\hline WFF DUP & $2-5$ & 2.52E-04 & 2.41E-04 & $3.22 \mathrm{E}-04$ & $-4.28 \mathrm{E}-05$ & 8.11E-05 & 1.83E-04 & 1.17E-04 & 1.76E-04 & $1.45 \mathrm{E}-04$ \\
\hline WFF DUP & $5-10$ & 2.38E-05 & 1.33E-04 & 3.23E-04 & 3.31E-04 & 2.13E-04 & $1.52 \mathrm{E}-04$ & 6.88E-05 & 1.06E-04 & 1.14E-04 \\
\hline
\end{tabular}

${ }^{a}$ Radionuclide concentration

${ }^{\mathrm{b}}$ Total propagated uncertainty

${ }^{\mathrm{c}}$ Minimum detectable concentration

Potassium-40 was detected in every sample (Table 4.16). This naturally occurring gamma-emitting radionuclide is ubiquitous in soils. There was no significant difference between concentrations of ${ }^{40} \mathrm{~K}$ among sampling locations (ANOVA, $p=0.768$ ), but there was a significant difference between 2005 and 2006 (ANOVA, $p=1.75 \mathrm{E}-07$ ). This corresponded to a decrease in ${ }^{40} \mathrm{~K}$ concentrations between sampling years 2005 and 2006. Potassium- 40 concentrations at all locations (highest concentration:

$2.79 \mathrm{E}-01 \mathrm{~Bq} / \mathrm{g}$ ) fall within the 99 percent confidence interval range of baseline levels (3.40E-01 Bq/g) (DOE/WIPP 92-037).

Cesium-137 was detected in all soil samples except one (at location WSS) (Table 4.16). There was no significant difference in the concentrations of ${ }^{137} \mathrm{Cs}$ detected among locations (ANOVA, $p=0.570$ ), but there was a statistically significant difference between 2005 and 2006 (ANOVA, $p=0.0022$ ) with slightly lower concentrations in 2006. All ${ }^{137} \mathrm{Cs}$ concentrations fell within the 99 percent confidence interval range of baseline values $(4.00 \mathrm{E}-02 \mathrm{~Bq} / \mathrm{g})$. Although ${ }^{137} \mathrm{Cs}$ is a fission product, it is ubiquitous in soils because of global fallout from atmospheric nuclear weapons testing (Beck and Bennett, 2002; and UNSCEAR, 2000).

Strontium-90 and ${ }^{60} \mathrm{Co}$ were not detected at any sampling locations (Table 4.16). Since there was insufficient data to permit analysis of variance among sampling locations or between years, ANOVA comparisons between years and among locations were not performed.

Table 4.16 - Selected Radionuclide Concentrations (Bq/g) in Soil Near the WIPP Site. See Appendix $\mathrm{C}$ for sampling location codes.

\begin{tabular}{|c|c|c|c|c|c|c|c|}
\hline Location & $\begin{array}{l}\text { Depth } \\
\text { (cm) }\end{array}$ & {$[R N]^{a}$} & $2 \times$ TPU $^{b}$ & MDC $^{c}$ & RN & $2 \times$ TPU & MDC \\
\hline & & \multicolumn{3}{|c|}{${ }^{137} \mathrm{Cs}$} & \multicolumn{3}{|c|}{${ }^{60} \mathrm{Co}$} \\
\hline MLR & $0-2$ & $1.15 \mathrm{E}-03$ & $2.22 \mathrm{E}-04$ & $2.37 \mathrm{E}-04$ & $-4.44 \mathrm{E}-05$ & $2.72 \mathrm{E}-04$ & $2.99 \mathrm{E}-04$ \\
\hline MLR & $2-5$ & 1.44E-03 & $2.11 \mathrm{E}-04$ & $1.73 \mathrm{E}-04$ & 1.60E-04 & 2.81E-04 & 3.16E-04 \\
\hline MLR & $5-10$ & $1.52 E-03$ & 2.74E-04 & 3.16E-04 & 3.88E-04 & 4.58E-04 & $5.40 \mathrm{E}-04$ \\
\hline SEC & $0-2$ & 2.73E-03 & 4.62E-04 & 3.61E-04 & 4.99E-06 & 4.58E-04 & 5.06E-04 \\
\hline SEC & $2-5$ & 3.33E-03 & 5.48E-04 & $3.91 \mathrm{E}-04$ & 3.10E-04 & 5.57E-04 & $6.45 \mathrm{E}-04$ \\
\hline SEC & $5-10$ & 4.39E-03 & 5.86E-04 & $2.35 \mathrm{E}-04$ & 2.79E-04 & 2.42E-04 & 2.80E-04 \\
\hline SMR & $0-2$ & 1.43E-03 & 5.34E-04 & 7.72E-04 & $-2.23 E-04$ & 4.48E-04 & 4.80E-04 \\
\hline SMR & $2-5$ & 1.44E-03 & 2.13E-04 & 1.73E-04 & $-2.92 \mathrm{E}-04$ & 2.96E-04 & 3.07E-04 \\
\hline
\end{tabular}


Table 4.16 - Selected Radionuclide Concentrations (Bq/g) in Soil Near the WIPP Site. See Appendix $\mathrm{C}$ for sampling location codes.

\begin{tabular}{|c|c|c|c|c|c|c|c|}
\hline Location & $\begin{array}{l}\text { Depth } \\
\text { (cm) }\end{array}$ & {$[R N]^{a}$} & $2 \times$ TPU $^{\mathrm{b}}$ & MDC $^{c}$ & RN & $2 \times$ TPU & MDC \\
\hline SMR & $5-10$ & $1.44 \mathrm{E}-03$ & 2.36E-04 & 1.96E-04 & $-4.21 \mathrm{E}-05$ & 2.67E-04 & $2.95 E-04$ \\
\hline WEE & $0-2$ & 5.05E-04 & 1.84E-04 & 2.50E-04 & $-4.66 \mathrm{E}-05$ & 3.89E-04 & 4.35E-04 \\
\hline WEE & $2-5$ & 1.02E-03 & $1.60 \mathrm{E}-04$ & 1.63E-04 & *2.79E-04 & 2.42E-04 & 2.77E-04 \\
\hline WEE & $5-10$ & 1.18E-03 & $2.12 \mathrm{E}-04$ & 2.06E-04 & 9.16E-05 & 2.60E-04 & 2.93E-04 \\
\hline WFF & $0-2$ & 8.34E-04 & 2.74E-04 & 3.57E-04 & 1.69E-04 & 5.74E-04 & $6.53 \mathrm{E}-04$ \\
\hline WFF & $2-5$ & 5.84E-04 & $2.18 \mathrm{E}-04$ & 2.93E-04 & $1.45 \mathrm{E}-04$ & 5.48E-04 & $6.22 \mathrm{E}-04$ \\
\hline WFF & $5-10$ & 7.50E-04 & $1.61 \mathrm{E}-04$ & $1.84 \mathrm{E}-04$ & 8.90E-05 & 2.23E-04 & $2.55 \mathrm{E}-04$ \\
\hline WSS & $0-2$ & 8.24E-04 & $2.75 \mathrm{E}-04$ & 3.74E-04 & 1.34E-04 & 4.17E-04 & 4.82E-04 \\
\hline WSS & $2-5$ & 5.30E-04 & 1.08E-04 & 1.63E-04 & 9.28E-05 & 1.66E-04 & 2.87E-04 \\
\hline WSS & $5-10$ & 1.93E-04 & 2.15E-04 & $3.44 \mathrm{E}-04$ & $-1.86 \mathrm{E}-04$ & 4.37E-04 & 4.71E-04 \\
\hline WFF DUP & $0-2$ & $9.09 \mathrm{E}-04$ & $2.65 \mathrm{E}-04$ & 3.35E-04 & 9.79E-05 & 4.26E-04 & 4.79E-04 \\
\hline WFF DUP & $2-5$ & 8.78E-04 & 3.00E-04 & 4.10E-04 & $-2.16 \mathrm{E}-04$ & 4.59E-04 & 4.81E-04 \\
\hline WFF DUP & $5-10$ & 1.16E-04 & 2.96E-04 & $3.41 \mathrm{E}-04$ & 2.08E-04 & 5.53E-04 & 6.33E-04 \\
\hline
\end{tabular}

\begin{tabular}{|c|c|c|c|c|c|c|c|}
\hline \multirow[b]{2}{*}{ MLR } & \multirow[b]{2}{*}{$0-2$} & \multicolumn{2}{|c|}{${ }^{90} \mathrm{Sr}$} & 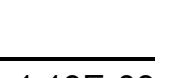 & \multicolumn{2}{|c|}{${ }^{40} \mathrm{~K}$} & \multirow[b]{2}{*}{$3.26 \mathrm{E}-03$} \\
\hline & & $-8.63 \mathrm{E}-03$ & 1.49E-02 & $\overline{1.19 E-03}$ & $2.40 \mathrm{E}-01$ & 3.08E-02 & \\
\hline MLR & $2-5$ & $-6.03 E-04$ & 7.36E-03 & 9.81E-04 & 2.69E-01 & $3.44 \mathrm{E}-02$ & 3.26E-03 \\
\hline MLR & $5-10$ & -5.29E-03 & 6.98E-03 & 9.48E-04 & 2.79E-01 & 3.69E-02 & 4.29E-03 \\
\hline SEC & $0-2$ & 1.29E-03 & 8.43E-03 & 1.49E-03 & $1.28 \mathrm{E}-01$ & 2.29E-02 & 4.01E-03 \\
\hline SEC & $2-5$ & 3.98E-03 & 9.88E-03 & 1.69E-03 & $1.51 \mathrm{E}-01$ & 2.29E-02 & $6.48 \mathrm{E}-03$ \\
\hline SEC & $5-10$ & $-1.46 \mathrm{E}-03$ & 9.31E-03 & 1.64E-03 & 1.43E-01 & 2.13E-02 & $2.84 \mathrm{E}-03$ \\
\hline SMR & $0-2$ & $-4.46 \mathrm{E}-03$ & $6.20 \mathrm{E}-03$ & 8.61E-04 & 1.93E-01 & 2.58E-02 & 3.86E-03 \\
\hline SMR & $2-5$ & $-4.29 E-03$ & $6.42 \mathrm{E}-03$ & 8.82E-04 & 2.00E-01 & 2.57E-02 & 3.37E-03 \\
\hline SMR & $5-10$ & 8.64E-04 & $6.60 \mathrm{E}-03$ & 8.83E-04 & $1.90 \mathrm{E}-01$ & 2.44E-02 & 3.30E-03 \\
\hline WEE & $0-2$ & $-5.33 E-03$ & 9.54E-03 & 1.70E-03 & 1.36E-01 & 1.85E-02 & 3.03E-03 \\
\hline WEE & $2-5$ & $-5.14 \mathrm{E}-03$ & 1.00E-02 & 1.73E-03 & 1.54E-01 & 1.98E-02 & 3.08E-03 \\
\hline WEE & $5-10$ & -7.07E-03 & 1.40E-02 & 2.17E-03 & $1.82 \mathrm{E}-01$ & 2.34E-02 & $3.18 \mathrm{E}-03$ \\
\hline WFF & $0-2$ & 2.20E-03 & 7.60E-03 & 1.39E-03 & 1.66E-01 & $2.50 \mathrm{E}-02$ & 6.31E-03 \\
\hline WFF & $2-5$ & 8.66E-04 & 7.57E-03 & $1.40 \mathrm{E}-03$ & 1.69E-01 & 2.52E-02 & $5.61 \mathrm{E}-03$ \\
\hline WFF & $5-10$ & 9.14E-04 & 7.12E-03 & 1.34E-03 & 1.45E-01 & 2.15E-02 & $2.55 \mathrm{E}-03$ \\
\hline WSS & $0-2$ & $-2.06 \mathrm{E}-03$ & 6.62E-03 & 8.99E-04 & 1.87E-01 & 2.51E-02 & $3.82 \mathrm{E}-03$ \\
\hline WSS & $2-5$ & 2.65E-04 & 6.77E-03 & 8.95E-04 & 1.84E-01 & 2.37E-02 & $3.09 \mathrm{E}-03$ \\
\hline WSS & $5-10$ & 3.06E-04 & $6.44 \mathrm{E}-03$ & 8.64E-04 & 2.00E-01 & 2.67E-02 & 3.38E-03 \\
\hline WFF DUP & $0-2$ & 4.75E-04 & $6.75 \mathrm{E}-03$ & 1.29E-03 & 1.38E-01 & 2.47E-02 & 3.96E-03 \\
\hline WFF DUP & $2-5$ & 1.63E-03 & 6.91E-03 & 1.31E-03 & $6.50 \mathrm{E}-02$ & 1.21E-02 & 3.38E-03 \\
\hline WFF DUP & $5-10$ & $3.46 \mathrm{E}-03$ & 7.39E-03 & 1.35E-03 & 1.57E-01 & $2.38 \mathrm{E}-02$ & $6.40 \mathrm{E}-03$ \\
\hline
\end{tabular}

Soil samples collected from one location (WFF) were divided into two parts and analyzed separately (Table 4.17). RERs were calculated for those duplicate pairs for which each sample and duplicate were detected. Approximately 86 percent of the RER 
values were less than one, indicating no difference between duplicate samples and good reproducibility. RERs greater than one were most likely due to inhomogeneities in the distributions of the radioisotope within the sampling locations.

Table 4.17 -Results of Duplicate Soil Sampling Analysis in Soil Near the WIPP Site. Units are $\mathrm{Bq} / \mathrm{g}$. See Appendix $\mathrm{C}$ for sampling locations.

\begin{tabular}{|c|c|c|c|c|c|c|c|c|c|}
\hline Location & $\begin{array}{l}\text { Depth } \\
\text { (cm) }\end{array}$ & & & Sample & & & Duplicate & & \\
\hline & & & [RN] $^{\mathrm{a}}$ & $2 \times$ TPU $^{b}$ & MDC $^{c}$ & RN & $2 \times$ TPU & MDC & $\mathbf{R E R}^{\mathrm{d}}$ \\
\hline WFF & $0-2$ & ${ }^{234} U$ & $5.25 \mathrm{E}-03$ & 7.98E-04 & 8.97E-04 & 5.37E-03 & 8.16E-04 & 8.99E-04 & 0.11 \\
\hline WFF & $2-5$ & & 4.74E-03 & 7.30E-04 & 8.91E-04 & 4.93E-03 & 7.92E-04 & 9.01E-04 & 0.18 \\
\hline WFF & $5-10$ & & 6.92E-03 & 9.79E-04 & 9.07E-04 & 6.79E-03 & 8.94E-04 & 8.93E-04 & 0.10 \\
\hline WFF & $2-5$ & ${ }^{235} U$ & 2.91E-04 & 2.03E-04 & 2.15E-04 & 2.61E-04 & 2.04E-04 & 2.28E-04 & 0.10 \\
\hline WFF & $5-10$ & & $2.40 \mathrm{E}-04$ & 2.01E-04 & 2.35E-04 & 2.74E-04 & 1.96E-04 & 2.18E-04 & 0.12 \\
\hline WFF & $0-2$ & ${ }^{238} U$ & 4.85E-03 & 7.63E-04 & $5.62 \mathrm{E}-04$ & 5.71E-03 & 8.42E-04 & 5.65E-04 & 0.76 \\
\hline WFF & $2-5$ & & $5.26 \mathrm{E}-03$ & 7.66E-04 & 5.56E-04 & $5.12 \mathrm{E}-03$ & 8.07E-04 & 5.67E-04 & 0.13 \\
\hline WFF & $5-10$ & & 6.16E-03 & $9.18 \mathrm{E}-04$ & 5.73E-04 & 5.43E-03 & 7.93E-04 & 5.59E-04 & 0.60 \\
\hline WFF & $0-2$ & ${ }^{40} \mathrm{~K}$ & 1.66E-01 & 2.50E-02 & 6.31E-03 & 1.38E-01 & 2.47E-02 & 3.96E-03 & 0.80 \\
\hline WFF & $2-5$ & & 1.69E-01 & 2.52E-02 & 5.61E-03 & $6.50 \mathrm{E}-02$ & 1.21E-02 & 3.38E-03 & 3.72 \\
\hline WFF & $5-10$ & & $1.45 \mathrm{E}-01$ & $2.15 \mathrm{E}-02$ & $2.55 \mathrm{E}-03$ & 1.57E-01 & 2.38E-02 & 6.40E-03 & 0.37 \\
\hline WFF & $0-2$ & ${ }^{137} \mathrm{Cs}$ & 8.34E-04 & 2.74E-04 & 3.57E-04 & 9.09E-04 & 2.65E-04 & 3.35E-04 & 0.20 \\
\hline WFF & $2-5$ & & 5.84E-04 & $2.18 \mathrm{E}-04$ & 2.93E-04 & 8.78E-04 & 3.00E-04 & 4.10E-04 & 0.79 \\
\hline WFF & $5-10$ & & 7.50E-04 & 1.61E-04 & $1.84 \mathrm{E}-04$ & 1.16E-03 & 2.96E-04 & $3.41 \mathrm{E}-04$ & 1.22 \\
\hline
\end{tabular}

\subsection{Biota}

\subsubsection{Sample Collection}

Rangeland vegetation samples are collected from the same six locations from which the soil samples are collected (Figure 4.4). Also collected are fauna samples when available. All biota samples are analyzed for concentrations of the radionuclides of interest.

\subsubsection{Sample Preparation}

\section{$\underline{\text { Vegetation }}$}

The vegetation samples are chopped into 2.5-5-cm (1-2-in.) pieces, mixed together well, and air dried at room temperature. Weighed aliquots are taken from the bulk of the chopped vegetation samples from each location. The aliquots are transferred into separate containers and dried at $100^{\circ} \mathrm{C}\left(212^{\circ} \mathrm{F}\right)$. Gamma spectrometric determinations of ${ }^{40} \mathrm{~K},{ }^{60} \mathrm{Co}$, and ${ }^{137} \mathrm{Cs}$ are performed directly from these aliquots. The samples are then dry-ashed, followed by wet-ashing and dissolution in $8 \mathrm{M}$ nitric acid. Aliquots from the dissolved samples are taken for the determinations of ${ }^{90} \mathrm{Sr},{ }^{234} \mathrm{U},{ }^{235} \mathrm{U},{ }^{238} \mathrm{U},{ }^{238} \mathrm{Pu}$, ${ }^{239+240} \mathrm{Pu}$, and ${ }^{241} \mathrm{Am}$. 


\section{$\underline{\text { Animals }}$}

The samples of tissue are placed in a digestion beaker, concentrated nitric acid is added to cover the sample and the sample is heated until nearly dry. The sample is then wet-ashed using nitric acid and hydrogen peroxide until the residue is light colored. The residue is dissolved in nitric acid and transferred to a Teflon beaker. Concentrated hydrofluoric acid is added and the sample is heated to dryness. Concentrated nitric acid and boric acid are added and the sample is heated again to dryness. The sample is then dissolved in nitric acid and transferred back into its original glass beaker. It is then heated in a Muffle furnace at $350-375^{\circ} \mathrm{C}\left(652-707^{\circ} \mathrm{F}\right)$ for $8-12$ hours. If gamma analysis is required, $0.5 \mathrm{M}$ nitric acid is added to the sample to $500 \mathrm{~mL}(16.9 \mathrm{oz})$, and it is heated to dryness after counting is completed. The sample then undergoes another wet ashing and made ready for the isotopic separation process.

\subsubsection{Results and Discussion}

\section{$\underline{\text { Vegetation }}$}

Uranium-238 was detected in one of six vegetation samples. Neither ${ }^{234} U$ nor ${ }^{235} \mathrm{U}$ were detected in any of the samples (Table 4.18). Since ${ }^{234} U$ and ${ }^{235} U$ were not detected and ${ }^{238} \mathrm{U}$ was only detected in one sample, there was insufficient data for ANOVA comparisons. In addition, comparison of the detected uranium concentration $\left({ }^{238} \mathrm{U}=1.15 \mathrm{E}-03 \mathrm{~Bq} / \mathrm{g}\right)$ with the baseline value $\left({ }^{238} \mathrm{U}=6.90 \mathrm{E}-04 \mathrm{~Bq} / \mathrm{g}\right)$ suggests higher concentrations of this isotope in 2006 than during the years in which the baseline data were collected (1985-1989, DOE/WIPP 92-037). The word "suggest" must be used, as the small sample sizes analyzed in the baseline study did not permit the fitting of probability distributions to the baseline results. This resulted in comparisons of 2006 data having to be made to the mean of a few baseline samples as opposed to the upper $99^{\text {th }}$ percentile as was done for other environmental media. This was true for all radioisotopes in vegetation samples.

Americium-241, ${ }^{238} \mathrm{Pu}$, and ${ }^{239+240} \mathrm{Pu}$ were not detected in any of the vegetation samples (Table 4.18); therefore, a statistical comparison between locations or years was not prepared.

Potassium-40 was detected in every vegetation sample (Table 4.18). The detected concentrations of ${ }^{40} \mathrm{~K}$ in vegetation was significantly different among locations (ANOVA, $p=0.0165$ ), but there was no statistical difference between 2005 and 2006 (ANOVA, $p=0.944)$. In addition, ${ }^{40} \mathrm{~K}$ concentrations fell within the range of baseline levels $\left({ }^{40} \mathrm{~K}=3.20 \mathrm{E}+00 \mathrm{~Bq} / \mathrm{g}\right)$. The difference in ${ }^{40} \mathrm{~K}$ concentrations is because this isotope is naturally occurring in the earth's crust and the concentration varies in different locations for vegetation.

Cesium-137, ${ }^{60} \mathrm{Co}$, and ${ }^{90} \mathrm{Sr}$ were not detected in any vegetation samples (Table 4.19). 
Waste Isolation Pilot Plant Annual Site Environmental Report for 2006 DOE/WIPP-07-2225

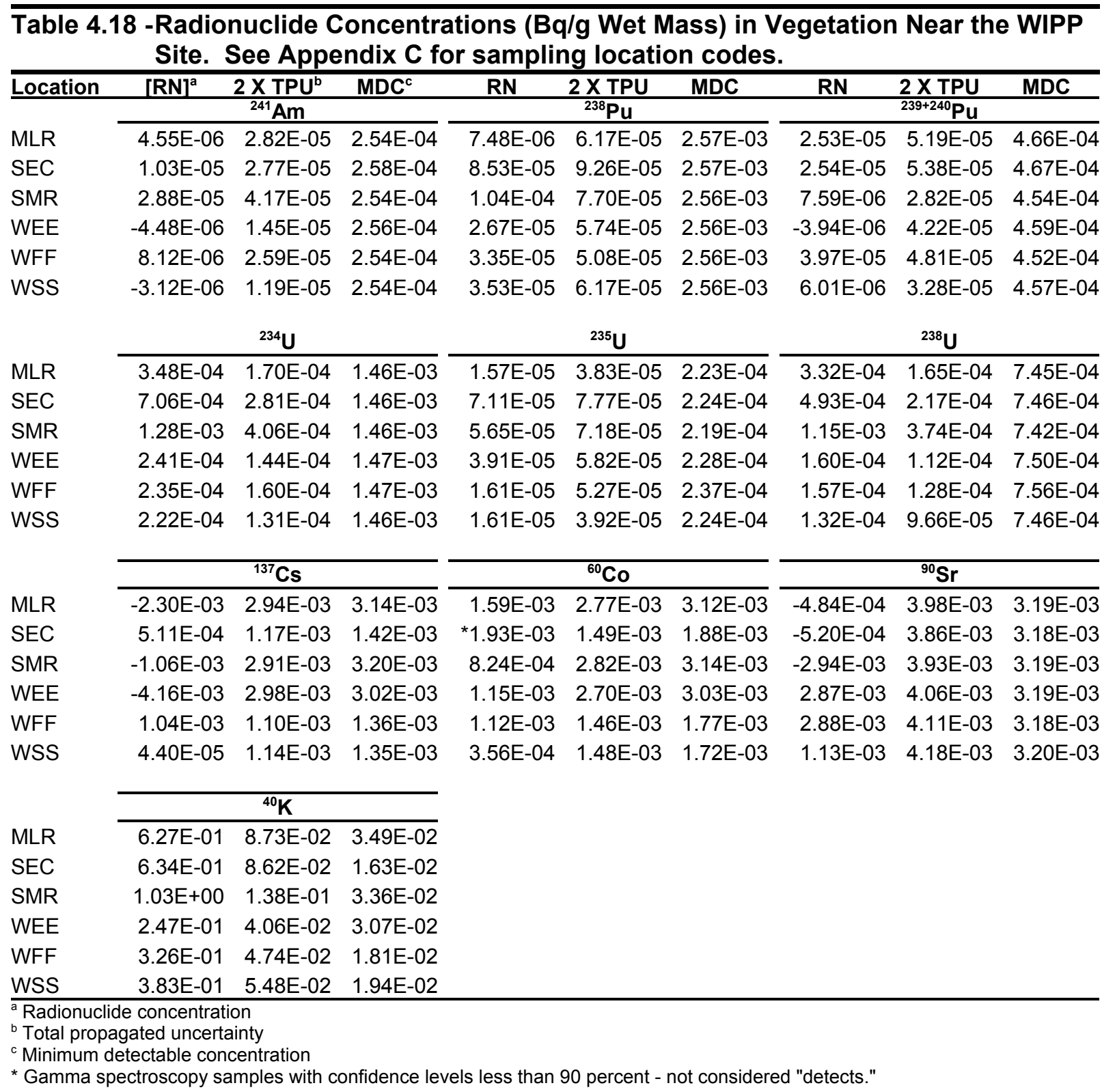

A duplicate analysis of the vegetation sample from sampling location MLR was performed for all the radionuclides of interest. RERs were calculated for those duplicate pairs for which each sample and duplicate were detected (Table 4.19). The reported duplicate had an RER greater than 1, indicating poor reproducibility. This is most likely due to inhomogeneities in the distributions of the radioisotope in the location. 
Table 4.19 - Results of Duplicate Vegetation Sample Analysis. Units are Bq/g. See Appendix $\mathrm{C}$ for sampling location codes.

\begin{tabular}{|c|c|c|c|c|c|c|}
\hline Location & & Sample & & Duplicate & & \\
\hline MLR & $\begin{array}{l}\text { [RN] }]^{\mathrm{a}} \\
6.27 \mathrm{E}-01\end{array}$ & $\begin{array}{cc}\mathbf{2} \mathbf{X ~ T P U}^{\mathbf{b}} & \text { MDC }^{\mathbf{c}} \\
8.73 \mathrm{E}-02 & 3.49 \mathrm{E}-02\end{array}$ & $\begin{array}{l}{[\mathrm{RN}]} \\
5.04 \mathrm{E}-01\end{array}$ & $\begin{array}{l}2 \times \text { TPU } \\
6.97 \mathrm{E}-02\end{array}$ & $\begin{array}{l}\text { MDC } \\
1.66 \mathrm{E}-02\end{array}$ & $\begin{array}{r}\text { RER }^{\mathbf{d}} \\
1.1\end{array}$ \\
\hline
\end{tabular}

${ }^{a}$ Radionuclide concentration

b Total propagated uncertainty

${ }^{c}$ Minimum detectable concentration

${ }^{\mathrm{d}}$ Relative error ratio

\section{$\underline{\text { Animals }}$}

Potassium-40 was detected in the deer, quail, rabbit and fish samples (Table 4.20). The remaining isotopes of interest were not detected in the animal samples. Although there were too few samples to allow statistical comparison between years, detected radionuclide concentrations in all samples fell within the range of concentrations for the same animals determined during baseline data analyses (DOE/WIPP 92-037). These results can be used only as a gross indication of uptakes, as the sample sizes are too small to provide a thorough analysis; however, the data do not suggest any contribution to animal uptake of the radionuclides of interest due to WIPP facility operations. Due to the limited sample sizes of only one sample per animal type, duplicate analyses were not performed.

\section{Table 4.20 - Radionuclide Concentrations (Bq/g Wet Mass) in Deer, Quail, Rabbit, and} Fish Near the WIPP Site. See Appendix C for sampling location codes.

\begin{tabular}{|c|c|c|c|c|c|c|c|c|c|}
\hline & {$[\mathrm{RN}]^{\mathrm{a}}$} & $2 \times$ TPU $^{\mathrm{b}}$ & $\mathrm{MDC}^{\mathrm{C}}$ & [RN] & $2 \times$ TPU & MDC & [RN] & $2 \times$ TPU & MDC \\
\hline & \multicolumn{3}{|c|}{${ }^{241} \mathrm{Am}$} & \multicolumn{3}{|c|}{${ }^{238} \mathrm{Pu}$} & \multicolumn{3}{|c|}{${ }^{239+240} \mathrm{Pu}$} \\
\hline Deer (SOO) & $1.47 \mathrm{E}-06$ & $2.15 \mathrm{E}-06$ & $2.24 \mathrm{E}-04$ & $4.52 \mathrm{E}-08$ & $1.18 \mathrm{E}-06$ & $6.31 \mathrm{E}-05$ & $-1.05 \mathrm{E}-07$ & $4.21 \mathrm{E}-07$ & 3.83E-05 \\
\hline Quail (WFF) & 2.87E-06 & 3.41E-06 & $2.25 \mathrm{E}-04$ & $1.06 \mathrm{E}-07$ & $9.85 E-07$ & $6.29 \mathrm{E}-05$ & 3.70E-06 & $2.41 \mathrm{E}-06$ & 3.82E-05 \\
\hline Rabbit (SOO) & 1.33E-06 & $1.43 \mathrm{E}-06$ & 2.73E-04 & 2.81E-07 & $1.23 \mathrm{E}-06$ & 6.26E-05 & $-1.16 \mathrm{E}-07$ & 3.54E-07 & $6.26 \mathrm{E}-05$ \\
\hline \multirow[t]{2}{*}{ Fish (PCN) } & $-8.66 \mathrm{E}-08$ & 3.39E-07 & 1.49E-04 & 3.93E-07 & $1.68 \mathrm{E}-06$ & $6.38 \mathrm{E}-05$ & $-2.67 \mathrm{E}-07$ & 8.49E-07 & 8.85E-05 \\
\hline & \multicolumn{3}{|c|}{${ }^{234} \mathrm{U}$} & \multicolumn{3}{|c|}{${ }^{235} \mathrm{U}$} & \multicolumn{3}{|c|}{${ }^{238} \mathrm{U}$} \\
\hline Deer (SOO) & $7.10 \mathrm{E}-06$ & $4.32 \mathrm{E}-06$ & $8.06 \mathrm{E}-04$ & $4.22 \mathrm{E}-07$ & $1.80 \mathrm{E}-06$ & $1.38 \mathrm{E}-04$ & $6.47 \mathrm{E}-06$ & $4.12 \mathrm{E}-06$ & $5.21 \mathrm{E}-04$ \\
\hline Quail (WFF) & $1.84 \mathrm{E}-04$ & $1.71 \mathrm{E}-05$ & 8.05E-04 & 9.87E-06 & $4.08 \mathrm{E}-06$ & 1.37E-04 & $1.82 \mathrm{E}-04$ & 1.70E-05 & $5.21 \mathrm{E}-04$ \\
\hline Rabbit (SOO) & 4.26E-05 & 7.93E-06 & 1.03E-03 & 2.94E-07 & $1.02 \mathrm{E}-06$ & $1.50 \mathrm{E}-04$ & 3.56E-05 & 7.21E-06 & $5.95 \mathrm{E}-04$ \\
\hline \multirow[t]{2}{*}{ Fish (PCN) } & 2.38E-04 & 5.53E-05 & 1.41E-03 & 8.08E-06 & 3.70E-06 & $1.62 \mathrm{E}-04$ & $1.06 \mathrm{E}-04$ & 2.57E-05 & $6.19 \mathrm{E}-04$ \\
\hline & \multicolumn{3}{|c|}{${ }^{137} \mathrm{Cs}$} & \multicolumn{3}{|c|}{${ }^{60} \mathrm{Co}$} & \multicolumn{3}{|c|}{${ }^{90} \mathrm{Sr}$} \\
\hline Deer (SOO) & $2.10 \mathrm{E}-04$ & $8.36 \mathrm{E}-04$ & $9.43 \mathrm{E}-04$ & $-4.85 \mathrm{E}-05$ & 8.09E-04 & $9.02 \mathrm{E}-04$ & $-1.69 \mathrm{E}-05$ & $6.60 \mathrm{E}-05$ & $6.23 \mathrm{E}-04$ \\
\hline Quail (WFF) & 2.03E-04 & 3.36E-04 & 4.08E-04 & 2.45E-04 & 4.39E-04 & $5.22 \mathrm{E}-04$ & $-3.99 \mathrm{E}-05$ & $6.41 \mathrm{E}-05$ & $6.23 \mathrm{E}-04$ \\
\hline Rabbit (SOO) & $-4.40 \mathrm{E}-04$ & 7.38E-04 & 7.97E-04 & 4.66E-04 & $6.82 \mathrm{E}-04$ & 7.73E-04 & 9.03E-04 & $1.99 \mathrm{E}-04$ & $2.78 \mathrm{E}-03$ \\
\hline \multirow[t]{2}{*}{ Fish (PCN) } & $-6.52 \mathrm{E}-05$ & $1.80 \mathrm{E}-04$ & $2.05 \mathrm{E}-04$ & $-4.02 E-05$ & $2.62 \mathrm{E}-04$ & $2.94 \mathrm{E}-04$ & 3.06E-05 & 1.06E-04 & $2.62 \mathrm{E}-03$ \\
\hline & \multicolumn{3}{|c|}{${ }^{40} \mathrm{~K}$} & & & & & & \\
\hline Deer (SOO) & $1.19 \mathrm{E}-01$ & $1.75 \mathrm{E}-02$ & $9.47 \mathrm{E}-03$ & & & & & & \\
\hline Quail (WFF) & $9.66 \mathrm{E}-02$ & 1.39E-02 & 4.42E-03 & & & & & & \\
\hline Rabbit (SOO) & $9.35 \mathrm{E}-02$ & $1.41 \mathrm{E}-02$ & 8.55E-03 & & & & & & \\
\hline Fish (PCN) & 8.76E-02 & $1.20 \mathrm{E}-02$ & $2.58 \mathrm{E}-03$ & & & & & & \\
\hline
\end{tabular}




\subsection{Potential Dose from WIPP Operations}

\subsubsection{Dose Limits}

Compliance with the regulatory standards is determined by comparing annual radiation doses to the regulatory limits. The regulatory limits can be found in 40 CFR Part 191, Subpart A. The referenced standard specifies that the combined annual dose equivalent to any member of the public in the general environment resulting from discharges of radioactive material and direct radiation from such management and storage shall not exceed $25 \mathrm{mrem}$ to the whole body and $75 \mathrm{mrem}$ to any critical organ. In addition, in a 1995 MOU between the EPA and the DOE, the DOE agreed that WIPP would comply with NESHAP. The NESHAP standard states that the emissions of radionuclides to the ambient air from DOE facilities shall not exceed those amounts that would cause any member of the public to receive in any year an EDE of 10 mrem per year. The EDE is the weighted sum of the doses to the individual organs of the body. The dose to each organ is weighted according to the risk that dose represents. These organ doses are then added together, and that total is the EDE. In this manner, the risk from different sources of radiation can be controlled by a single standard.

Compliance with the above regulatory requirements is determined by monitoring, extracting and calculating the EDE. Calculating the EDE to members of the public requires the use of CAP88-PC or other EPA approved computer models and procedures. The WIPP Effluent Monitoring Program generally uses CAP88-PC. CAP88-PC is a set of computer programs, datasets and associated utility programs for estimating dose and risk from radionuclide air emissions. CAP88-PC uses a Gaussian Plume dispersion model, which predicts air concentrations, deposition rates, concentrations in food, and intake rates for people. CAP88-PC estimates dose and risk to individuals and populations from multiple pathways. Dose and risk is calculated for ingestion, inhalation, ground level air immersion, and ground surface irradiation exposure pathways.

The Safe Drinking Water Act (40 CFR §141.66, "Maximum Contaminant Levels for Radionuclides") states that average annual concentrations for beta- and gamma-emitting human-made radionuclides in drinking water shall not result in an annual dose equivalent greater than 0.04 millisieverts ( $\mathrm{mSv})(4 \mathrm{mrem})$. It is important to note that all of these dose equivalent limits are set for radionuclides released to the environment from DOE operations. They do not include, but are limits in addition to, doses from natural background radiation or from medicinal procedures.

\subsubsection{Background Radiation}

There are several sources of natural radiation: cosmic and cosmogenic radiation (from outer space and the earth's atmosphere), terrestrial radiation (from the earth's crust), and internal radiation (naturally occurring radiation in our bodies, such as ${ }^{40} \mathrm{~K}$ ). The most common sources of terrestrial radiation are uranium, thorium, and their decay products. Potassium-40 is another source of terrestrial radiation. While not a major radiation source, ${ }^{40} \mathrm{~K}$ in the southeastern New Mexico environment may be due to the 
deposition of tailings from local potash mining. Radon gas, a decay product of uranium, is a widely known naturally occurring terrestrial radionuclide. In addition to natural radioactivity, small amounts of radioactivity from aboveground nuclear weapons tests that occurred from 1945 through 1980 and the 1986 Chernobyl nuclear accident are also present in the environment. Together, these sources of radiation are called "background" radiation.

Naturally occurring radiation in our environment can deliver both internal and external doses. Internal dose is received as a result of the intake of radionuclides. The routes of intake of radionuclides for members of the public are ingestion and inhalation. Ingestion includes eating and drinking food or drink containing radionuclides. Inhalation includes the intake of radionuclides through breathing radioactive particulates such as the decay products of radon. External dose can occur from submersion in contaminated air or deposition of contaminants on surfaces. The average annual dose received by a member of the public from naturally occurring radionuclides is approximately $3 \mathrm{mSv}$ (300 mrem) (Table 4.21).

\section{Table 4.21 - Annual Estimated Average Radiation Dose Received by a Member of the Population of the United States from Naturally Occurring Radiation Sources} (adapted from NCRP, 1987a)

\begin{tabular}{lcc}
\hline \multicolumn{1}{c}{ Source } & \multicolumn{2}{c}{ Average Annual EDE } \\
& $(\mathbf{m S v})$ & (mrem) \\
\hline Inhaled (Radon and Decay Products) & 2 & 200 \\
Internal Radionuclides & 0.39 & 39 \\
Terrestrial Radiation & 0.28 & 28 \\
Cosmic Radiation & 0.27 & 27 \\
Cosmogenic Radioactivity & 0.01 & 1 \\
Rounded Total from Natural Sources & 3 & 300 \\
\hline
\end{tabular}

\subsubsection{Dose from Air Emissions}

The 40 CFR Part 191, Subpart A, standard limits radiation doses to members of the public in the general environment. The DOE has identified air emissions as the major pathway of concern for the WIPP facility.

Compliance with Subpart A (40 CFR §191.03[b]) and the NESHAP standard (40 CFR §61.92) is determined by comparing annual radiation doses to the maximally exposed individual (MEI) to the regulatory standards. As recommended by the EPA, the DOE uses computer modeling to calculate radiation doses for compliance with the Subpart A and NESHAP standards. Compliance procedures for DOE facilities (40 CFR §61.93[a]) require the use of CAP88-PC or AIRDOS-PC computer models, or an equivalent, to calculate dose to members of the public. Source term input for CAP88-PC was determined by radiochemical analyses of filter air samples taken from Stations $\mathrm{A}, \mathrm{B}$, and C. Air filter samples were analyzed for ${ }^{241} \mathrm{Am},{ }^{239+240} \mathrm{Pu},{ }^{238} \mathrm{Pu}$, and ${ }^{90} \mathrm{Sr}$ because these radionuclides constitute over 98 percent of the dose potential from 
$\mathrm{CH}$ waste. Measured activity values greater than the 2 sigma TPU and MDC values were used as a part of the source terms for the air emission pathway. For measured results less than the 2 sigma TPU and MDC values, either the 2 sigma TPU or MDC values, whichever were greater, were used as part of the source term (see Table 4.1). CAP88-PC dose calculations are based on the assumption that exposed persons remain at home during the entire year and all vegetables, milk, and meat consumed are home produced. Thus, this dose calculation is a maximum potential dose which encompasses dose from inhalation, submersion, deposition, and ingestion of radionuclides emitted via the air pathway from the WIPP facility.

\subsubsection{Total Potential Dose from WIPP Operations}

The radiation dose equivalent received by members of the public as a result of the management and storage of TRU radioactive wastes at any disposal facility operated by the DOE is regulated under 40 CFR Part 191, Subpart A. Specific standards state that the combined annual dose equivalent to any member of the public in the general environment resulting from the discharges of radioactive material and direct radiation from management and storage shall not exceed $0.25 \mathrm{mSv}(25 \mathrm{mrem})$ to the whole body and $0.75 \mathrm{mSv}$ (75 mrem) to any other critical organ. Section 4.8.4.3 discusses the potential dose equivalent received from radionuclides released to the air from WIPP. The following sections discuss the potential dose equivalent through other pathways and the total potential dose equivalent a member of the public may have received from the WIPP facility during 2006.

\subsubsection{Potential Dose from Water Ingestion Pathway}

The potential dose to individuals from the ingestion of WIPP facility-related radionuclides transported in water is determined to be near zero for several reasons. Drinking water for communities near the WIPP facility comes from groundwater sources that are not expected to be affected by WIPP facility contaminants based on current radionuclide transport scenarios summarized in DOE/WIPP 95-2065. The only credible pathway for contaminants from the WIPP facility to accessible groundwater is through the Culebra Member of the Rustler Formation as stated in DOE/CAO 96-2184, Title 40 CFR Part 191 Compliance Certification Application for the Waste Isolation Pilot Plant. Water from the Culebra is naturally not potable due to high levels of total dissolved solids (TDS). Water from the Dewey Lake Redbeds Formation is suitable for livestock consumption having TDS values below 10,000 milligrams per liter (mg/L). Groundwater and surface water samples collected around the WIPP facility during 2006 did not contain radionuclide concentrations discernable from those in samples collected prior to WIPP receiving waste.

\subsubsection{Potential Dose from Wild Game Ingestion}

Game animals sampled during 2006 were mule deer, rabbit, fish, and quail. The only radionuclides detected were not different from baseline levels measured prior to commencement of waste shipments to the WIPP facility. Therefore, no dose from 
WIPP facility-related radionuclides could have been received by any individual from this pathway during 2006.

\subsubsection{Total Potential Dose from All Pathways}

The only credible pathway from the WIPP facility to humans is through air emissions and, therefore, this is the only pathway for which a dose is calculated. The total radiological dose and atmospheric release at WIPP in 2006 is summarized in Table 4.22 for the regulations in both 40 CFR $\$ 61.92$ and 40 CFR $§ 191.03(b)$.

In compliance with 40 CFR Part 191, Subpart A, the receptor selected is assumed to reside year-round at the fence line in the northwest sector. For 2006, the dose to this receptor was estimated to be less than $8.16 \mathrm{E}-07 \mathrm{mSv}(8.16 \mathrm{E}-05 \mathrm{mrem})$ per year for the whole body and less than 1.30E-05 mSv (1.30E-03 mrem) per year to the critical organ. These values are in compliance with the requirements specified in 40 CFR §191.03(b).

For the NESHAP standard (40 CFR §61.92), the EDE potentially received by the MEI in 2006 assumed to be residing $7.5 \mathrm{~km}$ (4.66 miles) west-northwest of WIPP is calculated to be less than 3.93E-08 mSv (3.93E-06 mrem) per year for the whole body. This value is in compliance with 40 CFR $\$ 61.92$ requirements.

As required by DOE Order 5400.5, Chapter II, Section 6.b, the collective dose to the public within $80 \mathrm{~km}$ (50 miles) of the WIPP facility has been evaluated. The collective dose to the public is a factor considered in developing the field program for the ALARA process as required by DOE Order 5400.5, Chapter II, Section 2.a(2).

\section{Table 4.22 - WIPP Radiological Dose and Release Summary}

\begin{tabular}{|c|c|c|c|c|c|c|c|}
\hline \multicolumn{8}{|c|}{ WIPP Radiological Atmospheric Releases ${ }^{\text {a }}$ During 2006} \\
\hline \multicolumn{2}{|c|}{${ }^{238} \mathrm{Pu}$} & \multicolumn{2}{|c|}{${ }^{239+240} \mathrm{Pu}$} & \multicolumn{2}{|c|}{${ }^{241} \mathrm{Am}$} & \multicolumn{2}{|r|}{${ }^{90} \mathrm{Sr}$} \\
\hline \multirow{2}{*}{\multicolumn{2}{|c|}{$\begin{array}{l}\text { 4.03E-08 } \mathrm{Ci}^{\mathrm{b}} \\
1.49 \mathrm{E}-03 \mathrm{~Bq}^{\mathrm{c}}\end{array}$}} & \multirow{2}{*}{\multicolumn{2}{|c|}{$\begin{array}{l}4.05 \mathrm{E}-08 \mathrm{Ci} \\
1.50 \mathrm{E}-03 \mathrm{~Bq}\end{array}$}} & \multirow{2}{*}{\multicolumn{2}{|c|}{$\begin{array}{l}5.70 \mathrm{E}-08 \mathrm{Ci} \\
2.11 \mathrm{E}-03 \mathrm{~Bq}\end{array}$}} & \multirow{2}{*}{\multicolumn{2}{|c|}{$\begin{array}{l}2.74 \mathrm{E}-06 \mathrm{Ci} \\
1.01 \mathrm{E}-05 \mathrm{~Bq}\end{array}$}} \\
\hline & & & & & & & \\
\hline \multicolumn{8}{|c|}{ WIPP Radiological Dose Reporting Table in 2006} \\
\hline \multirow{2}{*}{ Pathway } & \multicolumn{2}{|c|}{$\begin{array}{l}\text { EDE to the Maximally } \\
\text { Exposed Individual } \\
\text { at } 7,500 \text { Meters WNW }\end{array}$} & \multirow{2}{*}{$\begin{array}{l}\text { Percent of } \\
\text { EPA } \\
\text { 10-mrem/ } \\
\text { Year Limit to } \\
\text { Member of } \\
\text { the Public }\end{array}$} & \multicolumn{2}{|c|}{$\begin{array}{l}\text { Estimated Population Dose } \\
\text { Within } 50 \text { miles }\end{array}$} & \multirow{2}{*}{$\begin{array}{c}\text { Estimated } \\
\text { Population } \\
\text { Within } \\
50 \text { Miles }^{d}\end{array}$} & $\begin{array}{l}\text { Estimated } \\
\text { Natural } \\
\text { Radiation } \\
\text { Population }\end{array}$ \\
\hline & (mrem/year) & (mSv/year) & & $\begin{array}{l}\text { (person- } \\
\text { rem/year) }\end{array}$ & $\begin{array}{c}\text { (person-Sv/ } \\
\text { year) }\end{array}$ & & (person-rem) \\
\hline Air & 3.93E-06 & 3.93E-08 & 3.93E-05 & 1.19E-05 & 1.19E-07 & 100,944 & 30,288 \\
\hline Water & $N / A^{f}$ & $\mathrm{~N} / \mathrm{A}$ & $\mathrm{N} / \mathrm{A}$ & $\mathrm{N} / \mathrm{A}$ & $\mathrm{N} / \mathrm{A}$ & $\mathrm{N} / \mathrm{A}$ & $\mathrm{N} / \mathrm{A}$ \\
\hline $\begin{array}{c}\text { Other } \\
\text { Pathways }\end{array}$ & N/A & $\mathrm{N} / \mathrm{A}$ & N/A & $\mathrm{N} / \mathrm{A}$ & $\mathrm{N} / \mathrm{A}$ & $\mathrm{N} / \mathrm{A}$ & $\mathrm{N} / \mathrm{A}$ \\
\hline
\end{tabular}


Waste Isolation Pilot Plant Annual Site Environmental Report for 2006 DOE/WIPP-07-2225

\begin{tabular}{|c|c|c|c|c|c|c|}
\hline \multicolumn{7}{|c|}{ WIPP Radiological Dose Reporting Table in 2006} \\
\hline \multirow[t]{2}{*}{ Pathway } & \multicolumn{2}{|c|}{$\begin{array}{l}\text { Dose equivalent to the whole } \\
\text { body of the receptor who } \\
\text { resides year-round at WIPP } \\
\text { fence line } 350 \text { meters NW }\end{array}$} & \multirow{2}{*}{$\begin{array}{l}\text { Percent of } \\
\text { EPA } \\
\text { 25-mrem/year } \\
\text { Whole Body } \\
\text { Limit }\end{array}$} & \multicolumn{2}{|c|}{$\begin{array}{l}\text { Dose equivalent to the critical } \\
\text { organ of the receptor who } \\
\text { resides year-round at WIPP } \\
\text { fence line } 350 \text { meters NW }\end{array}$} & \multirow[t]{2}{*}{$\begin{array}{l}\text { Percent of EPA } \\
\text { 75-mrem/year } \\
\text { Critical Organ } \\
\text { Limit }\end{array}$} \\
\hline & (mrem/year) & (mSv/year) & & (mrem/year) & (mSv/year) & \\
\hline Air & 8.16E-05 & 8.16E-07 & $3.26 \mathrm{E}-04$ & $1.30 \mathrm{E}-03$ & $1.30 \mathrm{E}-05$ & 1.73E-03 \\
\hline Water & $N / A^{f}$ & $\mathrm{~N} / \mathrm{A}$ & $\mathrm{N} / \mathrm{A}$ & $\mathrm{N} / \mathrm{A}$ & $\mathrm{N} / \mathrm{A}$ & $\mathrm{N} / \mathrm{A}$ \\
\hline $\begin{array}{c}\text { Other } \\
\text { Pathways }\end{array}$ & N/A & $\mathrm{N} / \mathrm{A}$ & N/A & N/A & N/A & $\mathrm{N} / \mathrm{A}$ \\
\hline \multicolumn{7}{|c|}{$\begin{array}{l}\text { Total releases from the combination of Stations A, B, and C. Values are calculated from detected activities or either the } \\
\text { 2-Sigma TPU or MDC values, whichever are greater (where activities were less than the 2-Sigma TPU and MDC values) and } \\
\text { multiplied by the ratio of flow to stack flow volumes. }\end{array}$} \\
\hline \multicolumn{7}{|c|}{ Curies } \\
\hline \multicolumn{7}{|c|}{ Becquerels } \\
\hline \multicolumn{7}{|c|}{ Source: 2000 Census Data } \\
\hline \multirow{2}{*}{\multicolumn{7}{|c|}{ Estimated natural radiation populations dose $=($ Estimated population within 50 miles $) \times(300 \mathrm{mrem} / \mathrm{year})$}} \\
\hline Not appli & & & & & & \\
\hline
\end{tabular}

\subsubsection{Dose to Nonhuman Biota}

Dose limits for populations of aquatic and terrestrial organisms are discussed in NCRP Report No. 109, Effects of Ionizing Radiation on Aquatic Organisms (NCRP, 1991), and the International Atomic Energy Agency (Technical Report Series No. 332), Effects of Ionizing Radiation on Plants and Animals at Levels Implied by Current Radiation Protection Standards. Those dose limits are:

- $\quad$ Aquatic animals $-10 \mathrm{mGy} / \mathrm{d}(1 \mathrm{rad} / \mathrm{d})$

- $\quad$ Terrestrial plants $-10 \mathrm{mGy} / \mathrm{d}(1 \mathrm{rad} / \mathrm{d})$

- Terrestrial animals $-1 \mathrm{mGy} / \mathrm{d}(0.1 \mathrm{rad} / \mathrm{d})$

The DOE has considered establishing these dose standards for aquatic and terrestrial biota in proposed rule 10 CFR Part 834, "Radiation Protection of the Public and the Environment," but has delayed finalizing this rule until guidance for demonstrating compliance was developed. A Graded Approach for Evaluating Radiation Doses to Aquatic and Terrestrial Biota (DOE-STD-1153-2002) was developed to meet this need. The DOE requires reporting of radiation doses to nonhuman biota in the ASER using DOE-STD-1153-2002.

DOE-STD-1153-2002 requires an initial general screening using conservative assumptions. In the initial screen, biota concentration guides (BCGs) are derived using conservative assumptions for a variety of generic organisms. The maximum concentration detected (MCD) of radionuclides in soil, sediment, and water during environmental monitoring are divided by the BCGs and the results are summed for each organism. If the sum of these fractions is less than 1 , the site is deemed to have passed the screen and no further action is required. This screening evaluation is 
intended to provide a very conservative evaluation of whether the site is in compliance with the recommended limits.

This guidance was used to screen radionuclide concentrations observed around WIPP during 2006 using the maximum radionuclide concentrations listed in Table 4.23, and the sum of fractions was less than one for all media.

\section{Table 4.23 - General Screening Results for Potential Radiation Dose to Nonhuman Biota from Radionuclide Concentrations in Surface Water (Bq/L), Sediment (Bq/g), and Soil $(\mathrm{Bq} / \mathrm{g})$ Near the WIPP Site in 2006}

\begin{tabular}{|c|c|c|c|c|}
\hline Medium & Radionuclide & MCD & $\mathrm{BCG}^{\mathrm{a}}$ & Concentration/BCG \\
\hline \multicolumn{5}{|c|}{ Aquatic System Evaluation } \\
\hline \multirow[t]{9}{*}{ Sediment(Bq/g) } & ${ }^{60} \mathrm{Co}$ & $5.25 \mathrm{E}-04$ & $5.00 E+01$ & $1.05 \mathrm{E}-05$ \\
\hline & ${ }^{90} \mathrm{Sr}$ & $\mathrm{ND}^{\mathrm{c}}$ & $2.00 E+01$ & $N A^{d}$ \\
\hline & ${ }^{137} \mathrm{Cs}$ & $1.22 \mathrm{E}-02$ & $1.00 E+02$ & $1.22 \mathrm{E}-04$ \\
\hline & ${ }^{234} U$ & 2.22E-02 & $2.00 E+02$ & 1.11E-04 \\
\hline & ${ }^{235} \mathrm{U}$ & 1.16E-03 & $1.00 \mathrm{E}+02$ & 1.16E-05 \\
\hline & ${ }^{238} \mathrm{U}$ & 2.09E-02 & $9.00 \mathrm{E}+01$ & 2.32E-04 \\
\hline & ${ }^{238} \mathrm{Pu}$ & ND & $2.00 E+02$ & NA \\
\hline & ${ }^{239} \mathrm{Pu}$ & $5.26 \mathrm{E}-04$ & $2.00 E+02$ & 2.63E-06 \\
\hline & ${ }^{241} \mathrm{Am}$ & $5.15 E-4$ & $2.00 E+02$ & 2.58E-06 \\
\hline \multirow[t]{10}{*}{ Water $^{b}(\mathrm{~Bq} / \mathrm{L})$} & ${ }^{60} \mathrm{Co}$ & ND & $1.00 \mathrm{E}+02$ & 6.13E-03 \\
\hline & ${ }^{90} \mathrm{Sr}$ & ND & $1.00 E+01$ & NA \\
\hline & ${ }^{137} \mathrm{Cs}$ & ND & $2.00 \mathrm{E}+00$ & NA \\
\hline & ${ }^{234} U$ & 2.17E-01 & $7.00 E+00$ & 3.10E-02 \\
\hline & ${ }^{235} \mathrm{U}$ & 8.89E-03 & $8.00 E+00$ & $1.11 \mathrm{E}-03$ \\
\hline & ${ }^{238} \mathrm{U}$ & 1.03E-01 & $8.00 E+00$ & 1.29E-02 \\
\hline & ${ }^{238} \mathrm{Pu}$ & ND & $7.00 \mathrm{E}+00$ & NA \\
\hline & ${ }^{239} \mathrm{Pu}$ & ND & $7.00 \mathrm{E}+00$ & NA \\
\hline & ${ }^{241} \mathrm{Am}$ & ND & $2.00 \mathrm{E}+01$ & NA \\
\hline & & & SUM OF FRACTIONS & 4.55E-02 \\
\hline \multicolumn{5}{|c|}{ Terrestrial System Evaluation } \\
\hline \multirow[t]{9}{*}{ Soil $(\mathrm{Bq} / \mathrm{g})$} & ${ }^{60} \mathrm{Co}$ & ND & $3.00 E+01$ & NA \\
\hline & ${ }^{90} \mathrm{Sr}$ & ND & 8.00E-01 & NA \\
\hline & ${ }^{137} \mathrm{Cs}$ & 4.39E-03 & 8.00E-01 & 5.49E-03 \\
\hline & ${ }^{234} U$ & $9.92 \mathrm{E}-03$ & $2.00 E+02$ & 4.96E-05 \\
\hline & ${ }^{235} \mathrm{U}$ & 7.03E-04 & $1.00 E+02$ & 7.03E-06 \\
\hline & ${ }^{238} \mathrm{U}$ & 1.03E-02 & $6.00 \mathrm{E}+01$ & $1.72 \mathrm{E}-04$ \\
\hline & ${ }^{238} \mathrm{Pu}$ & $3.31 \mathrm{E}-04$ & $2.00 E+02$ & 1.66E-06 \\
\hline & ${ }^{239} \mathrm{Pu}$ & $2.12 \mathrm{E}-04$ & $2.00 E+02$ & 1.06E-06 \\
\hline & ${ }^{241} \mathrm{Am}$ & 5.46E-04 & $1.00 \mathrm{E}+02$ & $5.46 \mathrm{E}-06$ \\
\hline \multirow[t]{5}{*}{ Water $(\mathrm{Bq} / \mathrm{L})$} & ${ }^{60} \mathrm{Co}$ & ND & $4.00 E+04$ & NA \\
\hline & ${ }^{90} \mathrm{Sr}$ & ND & $2.00 E+04$ & NA \\
\hline & ${ }^{137} \mathrm{Cs}$ & ND & $2.00 E+04$ & NA \\
\hline & ${ }^{234} U$ & 2.17E-01 & $1.00 E+04$ & 2.17E-05 \\
\hline & ${ }^{235} U$ & 8.89E-03 & $2.00 E+04$ & 4.45E-07 \\
\hline
\end{tabular}




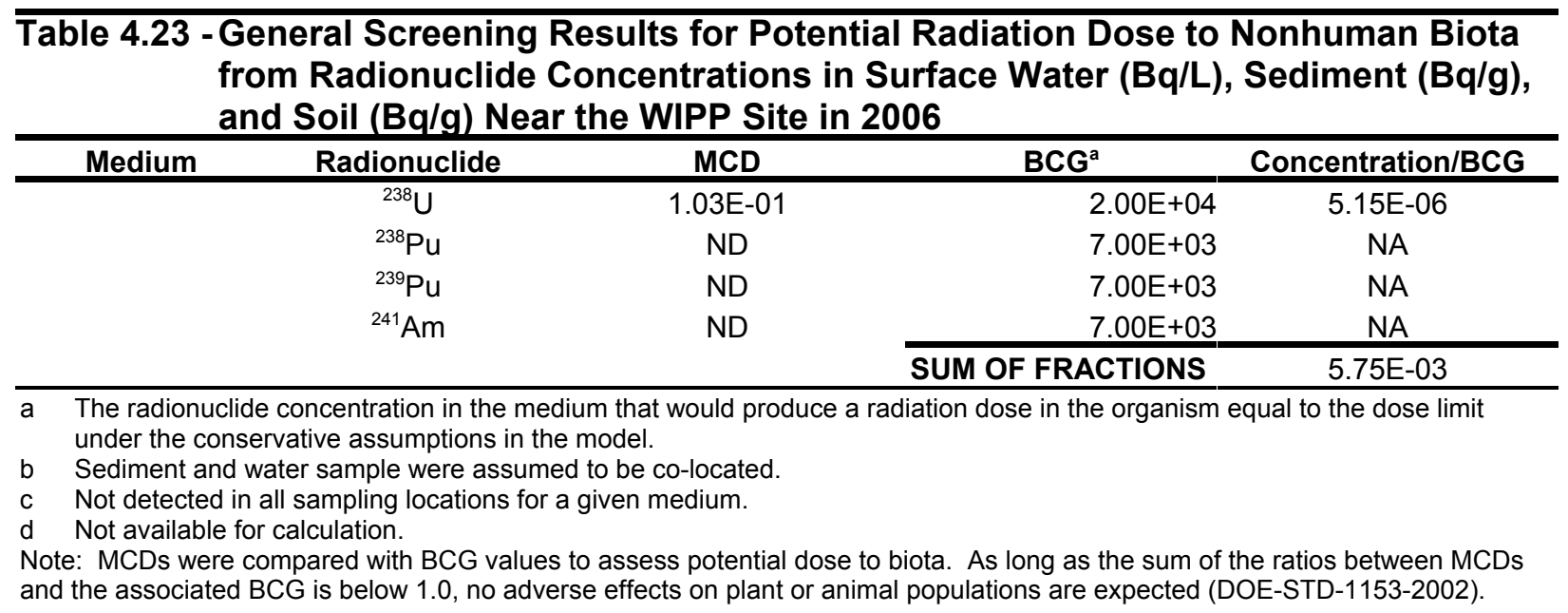

\subsubsection{Release of Property Containing Residual Radioactive Material}

There was no release of radiologically contaminated materials or property from the WIPP facility in 2006.

\subsection{Radiological Program Conclusions}

\section{Effluent Monitoring}

For 2006, the EDE to the receptor (hypothetical MEI) who resides year-round at the fence line is less than $8.16 \mathrm{E}-07 \mathrm{mSv}(8.16 \mathrm{E}-05 \mathrm{mrem})$ per year for the whole body, and is less than $1.30 \mathrm{E}-05 \mathrm{mSv}(1.30 \mathrm{E}-03 \mathrm{mrem})$ per year for the critical organ. For the WIPP Effluent Monitoring Program, Figure 4.5 and Table 4.24 show the dose to the whole body for the hypothetical MEI for CY 1999 to CY 2006. In addition, Figure 4.6 and Table 4.26 show the dose to the critical organ for the hypothetical MEI for CY 1999 to CY 2006. These dose equivalent values are below the $25 \mathrm{mrem}$ to the whole body and 75 mrem to any critical organ in accordance with the provisions of 40 CFR §191.03(b). 


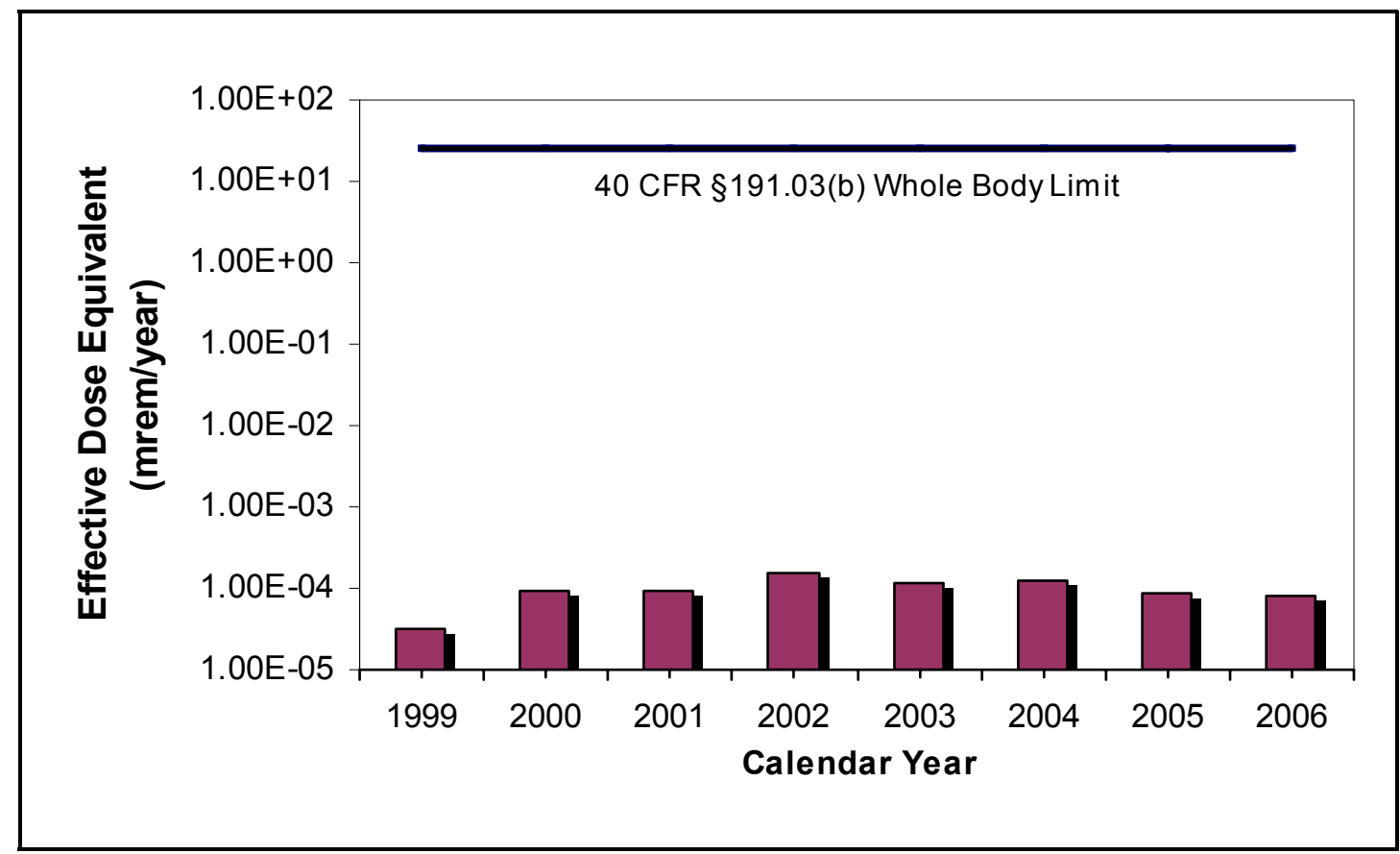

Figure 4.5 - Dose to the Whole Body for the Hypothetical Maximally Exposed Individual at the WIPP Fence Line

Table 4.24 - Comparison of Dose to the Whole Body to EPA Limit of $25 \mathrm{mrem} /$ year per 40 CFR \$191.03(b)

\begin{tabular}{|c|c|c|}
\hline Year & Annual Dose (mrem/yr) & Percent of EPA Limit \\
\hline 1999 & $3.10 \mathrm{E}-05$ & 124 millionth \\
\hline 2000 & $9.35 \mathrm{E}-05$ & 374 millionth \\
\hline 2001 & $8.99 \mathrm{E}-05$ & 360 millionth \\
\hline 2002 & $1.51 \mathrm{E}-04$ & 604 millionth \\
\hline 2003 & $1.15 \mathrm{E}-04$ & 460 millionth \\
\hline 2004 & $1.27 \mathrm{E}-04$ & 508 millionth \\
\hline 2005 & $8.86 \mathrm{E}-05$ & 354 millionth \\
\hline 2006 & $8.16 \mathrm{E}-05$ & 326 millionth \\
\hline $\begin{array}{c}\text { 40 CFR §191.03(b) } \\
\text { Whole Body Limit }\end{array}$ & 25 & \\
\hline
\end{tabular}




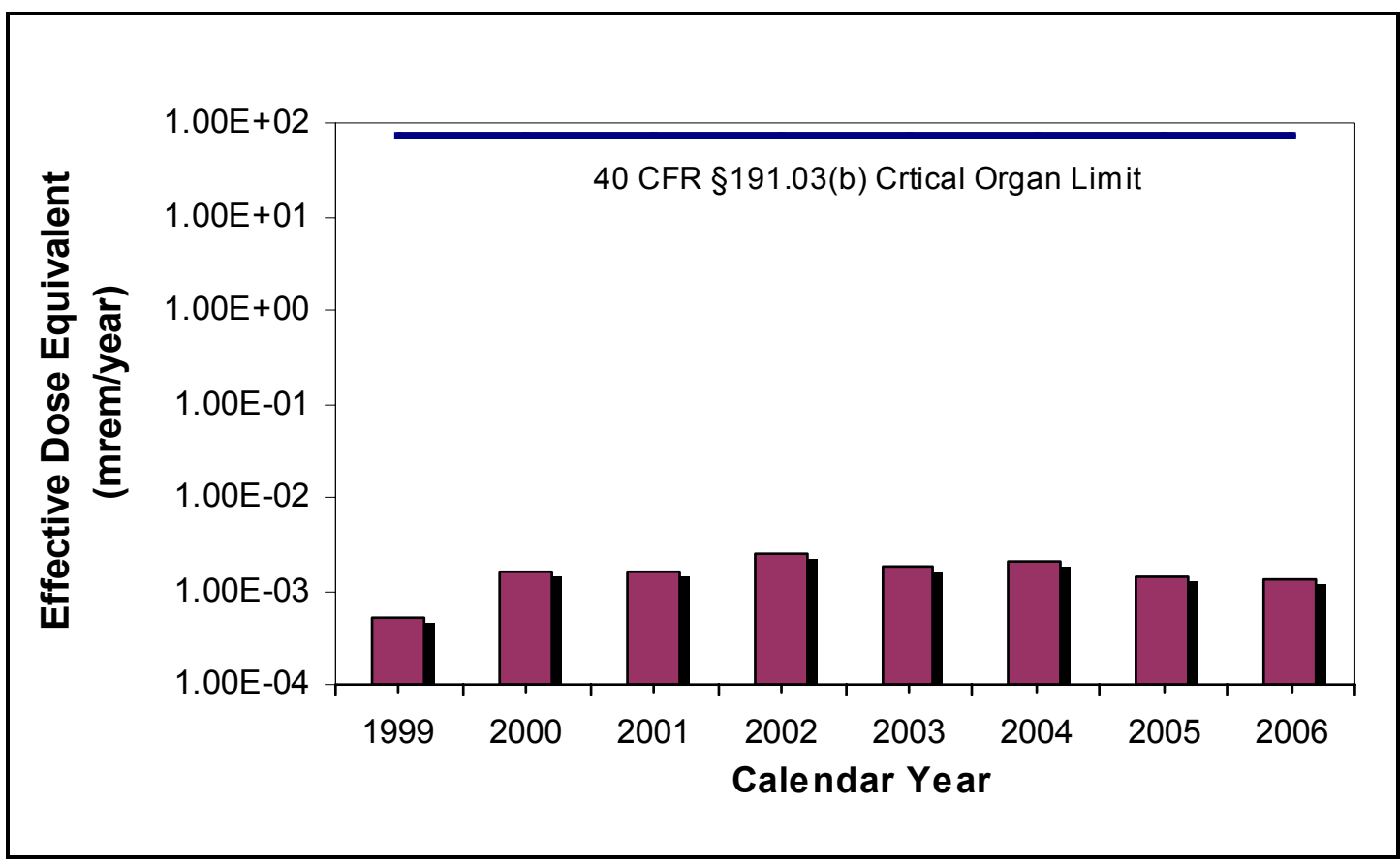

Figure 4.6 - Dose to the Critical Organ for Hypothetical Maximally Exposed Individual at the WIPP Fence Line

Table 4.25 - Comparison of Dose to the Critical Organ to EPA Limit of 75 mrem/year per 40 CFR §191.03(b)

\begin{tabular}{|c|c|c|}
\hline Year & Annual Dose (mrem/yr) & Percent of EPA Limit \\
\hline 1999 & $5.30 \mathrm{E}-04$ & 707 millionth \\
\hline 2000 & $1.63 \mathrm{E}-03$ & 2170 millionth \\
\hline 2001 & $1.56 \mathrm{E}-03$ & 2080 millionth \\
\hline 2002 & $2.46 \mathrm{E}-03$ & 3280 millionth \\
\hline 2003 & $1.85 \mathrm{E}-03$ & 2470 millionth \\
\hline 2004 & $2.11 \mathrm{E}-03$ & 2810 millionth \\
\hline 2005 & $1.41 \mathrm{E}-03$ & 1880 millionth \\
\hline 2006 & $1.30 \mathrm{E}-03$ & 1730 millionth \\
\hline $\begin{array}{l}\text { 40 CFR §191.03(b) } \\
\text { Critical Organ Limit }\end{array}$ & 75 & \\
\hline
\end{tabular}

In addition, for 2006, the EDE to the MEI individual from normal operations conducted at the WIPP facility is less than 3.93E-08 mSv (3.93E-06 mrem) per year. For the WIPP Effluent Monitoring Program, Figure 4.7 and Table 4.26 show the EDE to the MEI for CY 1999 to CY 2006. Note that these EDE values are more than six orders of magnitude below the EPA NESHAP standard of 10 mrem per year as specified in 40 CFR $\S 61.92$. 


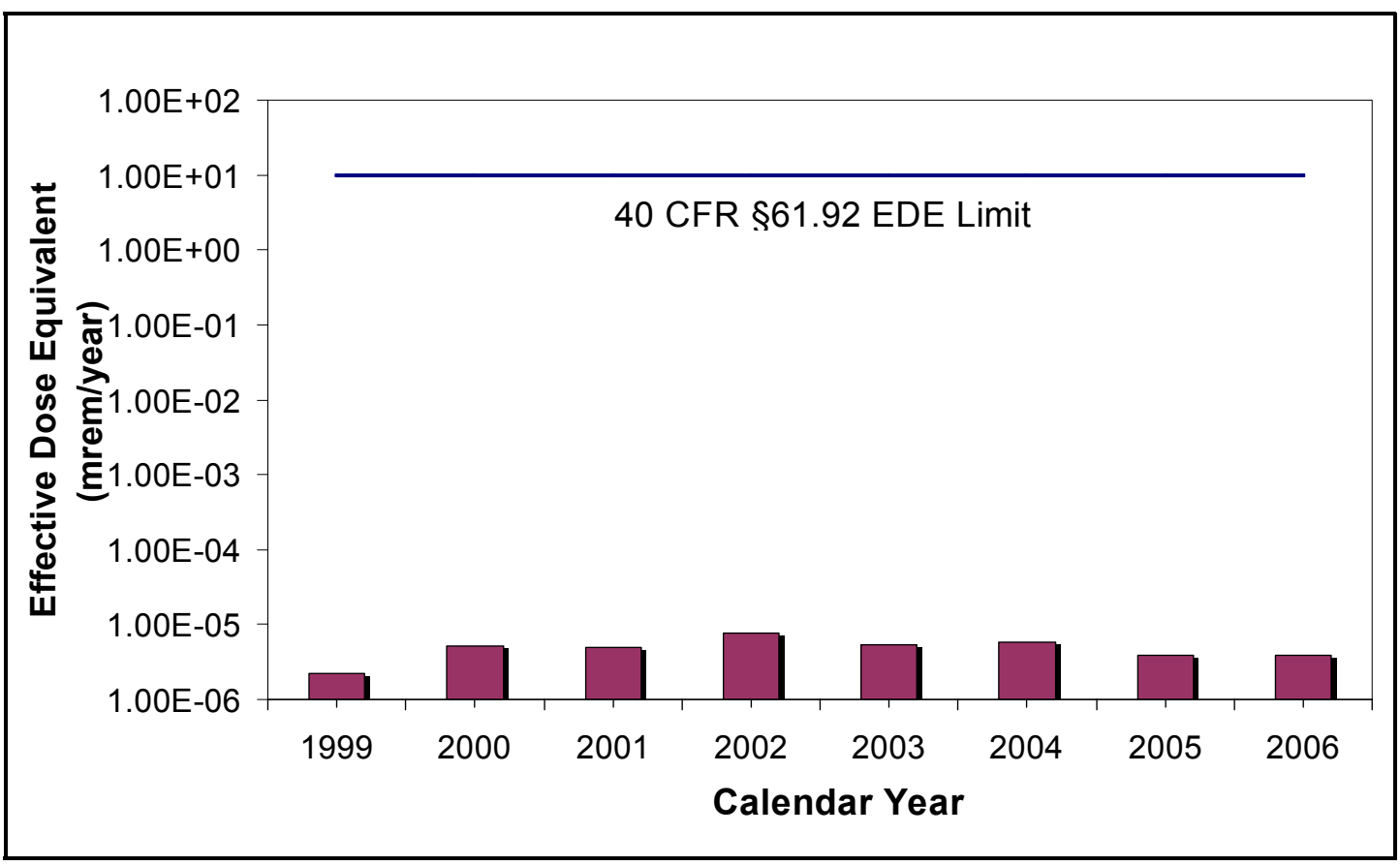

Figure 4.7 - WIPP EDE to the Off-Site MEI

Table 4.26 - Comparison of EDEs to EPA Limit of $10 \mathrm{mrem} /$ year per 40 CFR $\S 61.92$

\begin{tabular}{|c|c|c|}
\hline Year & Annual Dose (mrem/yr) & Percent of EPA Limit \\
\hline 1999 & $2.23 \mathrm{E}-06$ & 22.3 millionth \\
\hline 2000 & $5.18 \mathrm{E}-06$ & 51.8 millionth \\
\hline 2001 & $4.96 \mathrm{E}-06$ & 49.6 millionth \\
\hline 2002 & $7.61 \mathrm{E}-06$ & 76.1 millionth \\
\hline 2003 & $5.43 \mathrm{E}-06$ & 54.3 millionth \\
\hline 2004 & $5.69 \mathrm{E}-06$ & 56.9 millionth \\
\hline 2005 & $3.85 \mathrm{E}-06$ & 38.5 millionth \\
\hline 2006 & $3.93 \mathrm{E}-06$ & 39.3 millionth \\
\hline
\end{tabular}

\section{Environmental Monitoring}

Radionuclide concentrations observed in environmental monitoring were extremely small and comparable to radiological baseline levels. Appendix $\mathrm{H}$ contains graphs comparing detected concentrations of radionuclides to their respective baseline values. In cases where the radionuclide concentrations slightly exceeded baseline levels (uranium isotopes and ${ }^{40} \mathrm{~K}$ in some samples), these differences are most likely due to natural spatial variability and they are so far below the regulatory limit that they are nonimpactive. 


\section{CHAPTER 5 - ENVIRONMENTAL NONRADIOLOGICAL PROGRAM INFORMATION}

Nonradiological programs at WIPP include land management, meteorological monitoring, VOC monitoring, seismic monitoring, certain aspects of liquid effluent, and groundwater monitoring. VOC monitoring is performed to comply with the provisions of the WIPP HWFP. Surface water monitoring is performed in accordance with DP-831. Radiological and nonradiological groundwater monitoring is discussed in Chapters 4 and 6 , respectively.

\subsection{Principal Functions of Nonradiological Sampling}

The principal functions of the nonradiological environmental surveillance program are to:

- $\quad$ Assess the impacts of WIPP operations on the surrounding ecosystem;

- Monitor ecological conditions in the Los Medaños region;

- $\quad$ Provide environmental data which are important to the mission of the WIPP project, but which have not or will not be acquired by other programs; and

- $\quad$ Comply with applicable commitments identified with existing agreements (e.g., BLM/DOE Memorandum of Understanding and Interagency Agreements).

\subsection{Land Management Programs}

On October 30, 1992, the WIPP LWA was approved by Congress. This act transferred the responsibility for the management of the WIPP Land Withdrawal Area from the Secretary of the Interior to the Secretary of Energy. In accordance with Sections 3(a)(1) and (3) of the act, these lands:

... are withdrawn from all forms of entry, appropriation, and disposal under the public land laws ... are reserved for the use of the Secretary ... for the construction, experimentation, operation, repair and maintenance, disposal, shutdown, monitoring, decommissioning, and other authorized activities associated with the purposes of WIPP as set forth in Section 213 of the Department of Energy National Security and Military Application of the Nuclear Energy Authorization Act of 1980 (Pub. L. 96-164; 93 Stat. 1259, 1265), and this Act.

The DOE developed the LMP as required by Section 4 of the WIPP LWA. The LMP identifies resource values, promotes multiple-use management, and identifies long-term goals for the management of WIPP lands until the culmination of the decommissioning phase. The LMP was developed in consultation and cooperation with the BLM and the state of New Mexico.

The LMP sets forth cooperative arrangements and protocols for addressing WIPP-related land management actions. Commitments contained in current permits, agreements, or concurrent Memoranda of Understanding with other agencies will be 
respected when addressing and evaluating land use management activities and future amendments that affect the management of WIPP lands.

\subsubsection{Land Use Requests}

Parties who wish to conduct activities that may impact lands under the jurisdiction of WIPP, but outside the Property Protection Area, are required by the LMP to prepare a land use request. A land use request consists of a narrative description of the project, a completed environmental review, and a map depicting the location of the proposed activity. This documentation is used to determine if applicable regulatory requirements have been met prior to the approval of a proposed project. A land use request may be submitted to the Land Use Coordinator by any WIPP organization or outside entity wishing to complete any construction, right-of-way, pipeline easement, or similar action within the WIPP Land Withdrawal Area or on lands used in the operation of the WIPP facility, under the jurisdiction of the DOE. During 2006, nine requests were submitted for review and approval; all met applicable criteria and were approved.

\subsubsection{Wildlife Population Monitoring}

In 1995, the USFWS provided an updated list of threatened and endangered species for Eddy and Lea Counties, New Mexico. Included were 18 species that may be present on WIPP lands. A comprehensive evaluation in support of the SEIS-II (Waste Isolation Pilot Plant Disposal Phase Final Supplemental Environmental Impact Statement, DOE/EIS-0026-S-2) was conducted in 1996 to determine the presence or absence of threatened or endangered species in the vicinity of the WIPP site and WIPP's effect on these species. Results indicated that activities associated with the operation of WIPP had no impact on any threatened or endangered species.

WIPP employees continue to consider resident species when planning activities that may impact their habitat in accordance with the DOE/BLM Memorandum of Understanding, the Joint Powers Agreement with the state of New Mexico, and 50 CFR Part 17, "Endangered and Threatened Plants and Wildlife." One example of considering resident species has included protecting the Lesser Prairie Chicken (a candidate for listing under the Endangered Species Act) and its habitat in accordance with BLM guidance. Favorable habitat for the Lesser Prairie Chicken has been observed within the WIPP Land Withdrawal Area and areas affected by WIPP operational activities.

\subsubsection{Reclamation of Disturbed Lands}

Reclamation serves to mitigate the effects of WIPP-related activities on affected plant and animal communities. The objective of the reclamation program is to reclaim lands used in the operation of WIPP that are no longer needed for WIPP operations. Reclamation activities are intended to reduce soil erosion, increase the rate of plant colonization and succession, and provide habitat for wildlife in disturbed areas. 
The WIPP facility follows a reclamation program and a long-range reclamation plan in accordance with the LMP and specified permit conditions. As locations are identified for reclamation, WIPP personnel reclaim these areas by using the best acceptable reclamation practices. Seed mixes used reflect those species indigenous to the area with priority given to those plant species which are conducive to soil stabilization, wildlife, and livestock needs. Additionally, special seed mixes identified by the BLM are used where necessary to preserve the habitat of the Lesser Prairie Chicken.

\subsubsection{Oil and Gas Surveillance}

Oil and gas activities within $1.6 \mathrm{~km}(1 \mathrm{mi})$ of the WIPP boundary are routinely monitored in accordance with the LMP to identify new activities associated with oil and gas exploration and production, including:

- $\quad$ Survey staking

- Geophysical exploration

- $\quad$ Drilling

- $\quad$ Pipeline construction

- Work-overs

- $\quad$ Changes in well status

- $\quad$ Anomalous occurrences (e.g., leaks, spills, accidents, etc.)

During 2006, WIPP surveillance teams conducted 49 scheduled surveillances and approximately 240 field inspections. Field personnel drove onto 49 well locations to inspect for conditions that may compromise WIPP properties. Inspections were conducted as needed. During 2006, no major leaks or occurrences were observed.

Proposed new well locations, staked within one mile of the WIPP site, are field verified. This ensures that the proposed location is of sufficient distance from the WIPP boundary to protect the WIPP site from potential trespass. If a well is within $330 \mathrm{ft}$ of the WIPP Land Withdrawal Area, the driller is required to submit daily deviation surveys to the WIPP Land Use Coordinator to assess the horizontal drift of the well bore during drilling. During 2006, daily logs were transmitted to WIPP for six new wells. Deviation calculations showed that there were no trespass conditions.

\subsection{Meteorological Monitoring}

The WIPP meteorological station is located $600 \mathrm{~m}(1,970 \mathrm{ft})$ northeast of the Waste Handling Building. The main function of the station is to provide data for atmospheric dispersion modeling. The station measures and records wind speed, wind direction,

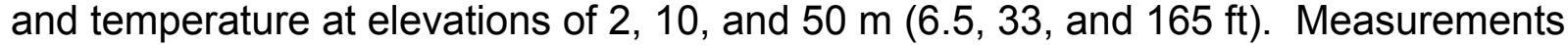

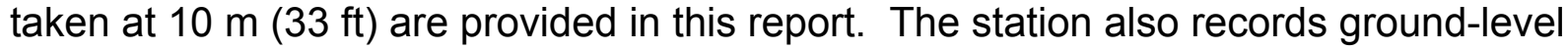
measurements of barometric pressure, relative humidity, precipitation, and solar radiation. 


\subsubsection{Climatic Data}

The precipitation at the WIPP site for 2006 was $476 \mathrm{~mm}$ (18.74 in.). Figure 5.1 displays the monthly precipitation at WIPP.

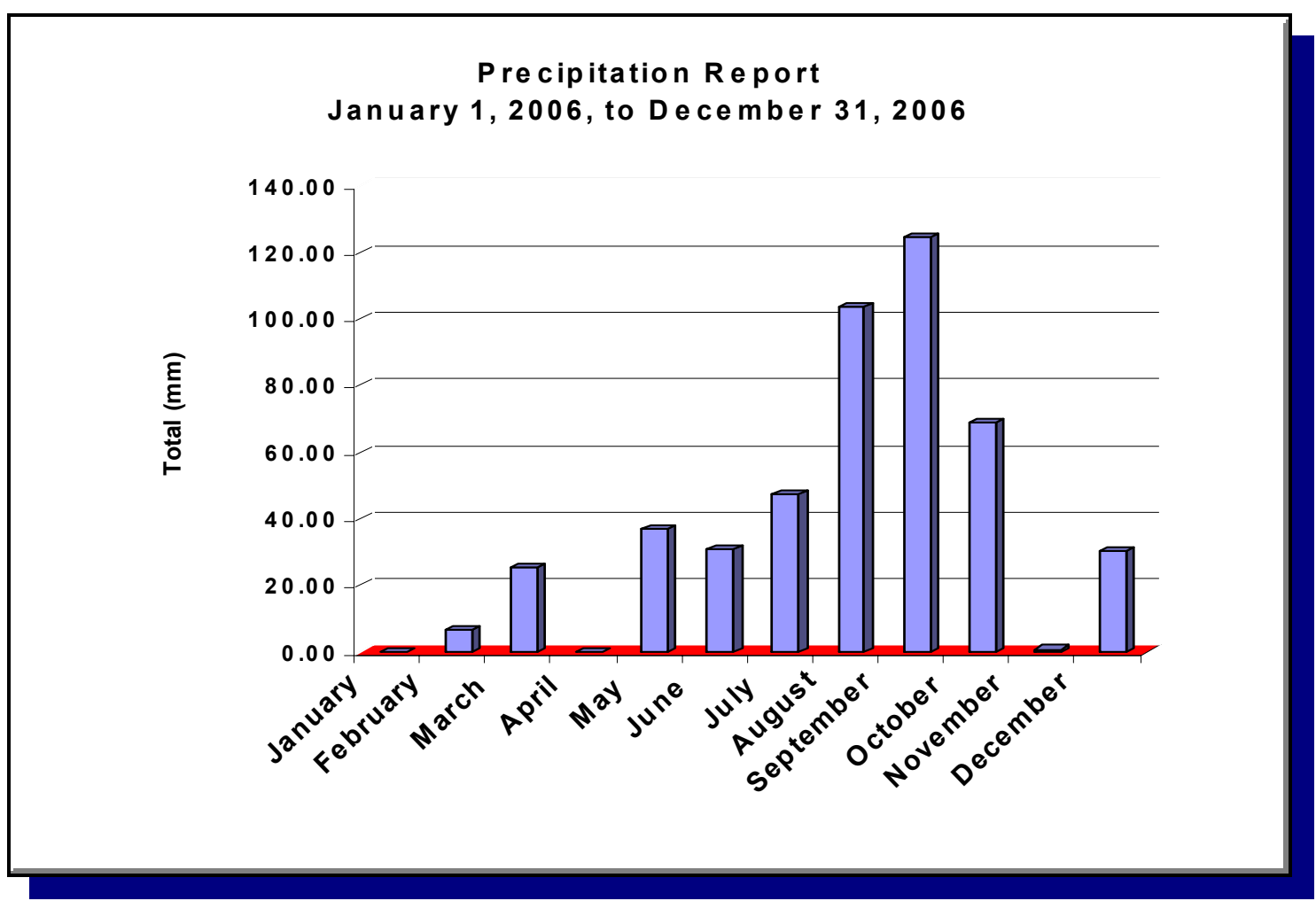

Figure 5.1 - 2006 Precipitation at WIPP

January 1, 2006, to December 31, 2006

$\begin{array}{cc}\text { Month } & \begin{array}{c}\text { Total } \\ (\mathbf{m m})\end{array} \\ \text { Jan } & 0.00 \\ \text { Feb } & 6.35 \\ \text { Mar } & 25.4 \\ \text { Apr } & 0.00 \\ \text { May } & 37.09 \\ \text { Jun } & 30.99 \\ \text { Jul } & 47.49 \\ \text { Aug } & 103.63 \\ \text { Sep } & 124.71 \\ \text { Oct } & 69.09 \\ \text { Nov } & 0.76 \\ \text { Dec } & 30.48\end{array}$


The mean temperature at the WIPP site in 2006 was $18.3^{\circ} \mathrm{C}\left(65^{\circ} \mathrm{F}\right)$. The mean monthly temperatures for the WIPP area ranged from $28.0^{\circ} \mathrm{C}\left(82.4^{\circ} \mathrm{F}\right)$ during July to $7.0^{\circ} \mathrm{C}$ $\left(44.6^{\circ} \mathrm{F}\right)$ in December. The lowest recorded temperature was $-6.0^{\circ} \mathrm{C}\left(21.1^{\circ} \mathrm{F}\right)$ in November. The maximum recorded temperature was $39.6^{\circ} \mathrm{C}\left(103.3^{\circ} \mathrm{F}\right)$ in June. Monthly temperatures are illustrated in Figures 5.2, 5.3, and 5.4.

Temperature Report - Highs

January 1, 2006, to December 31, 2006, Elevation 10.0 Meters

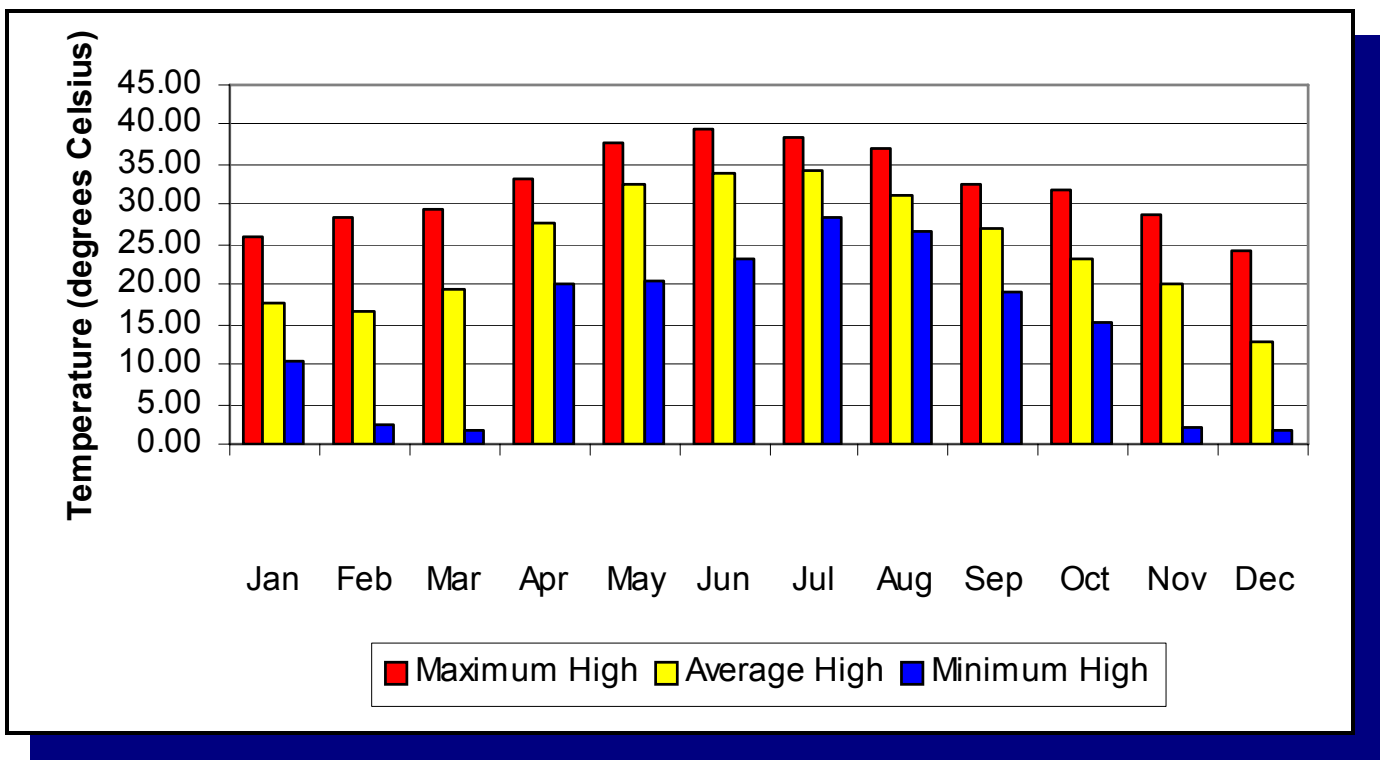

Figure 5.2 - WIPP High Temperatures for 2006

$\begin{array}{lccc}\text { Month } & \text { Maximum High } & \begin{array}{c}\text { Average High } \\ 17.52^{\circ} \mathrm{C}\end{array} & \begin{array}{c}\text { Minimum High } \\ \text { Jan }\end{array} \\ \text { Feb } & 25.80^{\circ} \mathrm{C} & 10.36^{\circ} \mathrm{C} \\ \text { Mar } & 28.39^{\circ} \mathrm{C} & 16.65^{\circ} \mathrm{C} & 2.44^{\circ} \mathrm{C} \\ \text { Apr } & 29.50^{\circ} \mathrm{C} & 19.41^{\circ} \mathrm{C} & 1.75^{\circ} \mathrm{C} \\ \text { May } & 33.33^{\circ} \mathrm{C} & 27.53^{\circ} \mathrm{C} & 19.97^{\circ} \mathrm{C} \\ \text { Jun } & 37.81^{\circ} \mathrm{C} & 32.41^{\circ} \mathrm{C} & 20.29^{\circ} \mathrm{C} \\ \text { Jul } & 39.55^{\circ} \mathrm{C} & 33.82^{\circ} \mathrm{C} & 23.33^{\circ} \mathrm{C} \\ \text { Aug } & 38.44^{\circ} \mathrm{C} & 34.18^{\circ} \mathrm{C} & 28.51^{\circ} \mathrm{C} \\ \text { Sep } & 36.96^{\circ} \mathrm{C} & 31.17^{\circ} \mathrm{C} & 26.60^{\circ} \mathrm{C} \\ \text { Oct } & 32.51^{\circ} \mathrm{C} & 27.10^{\circ} \mathrm{C} & 19.04^{\circ} \mathrm{C} \\ \text { Nov } & 31.86^{\circ} \mathrm{C} & 23.25^{\circ} \mathrm{C} & 15.07^{\circ} \mathrm{C} \\ \text { Dec } & 28.58^{\circ} \mathrm{C} & 20.18^{\circ} \mathrm{C} & 1.96^{\circ} \mathrm{C} \\ & 24.29^{\circ} \mathrm{C} & 12.93^{\circ} \mathrm{C} & 1.65^{\circ} \mathrm{C}\end{array}$


Temperature Report - Averages

January 1, 2006, to December 31, 2006, Elevation 10.0 Meters

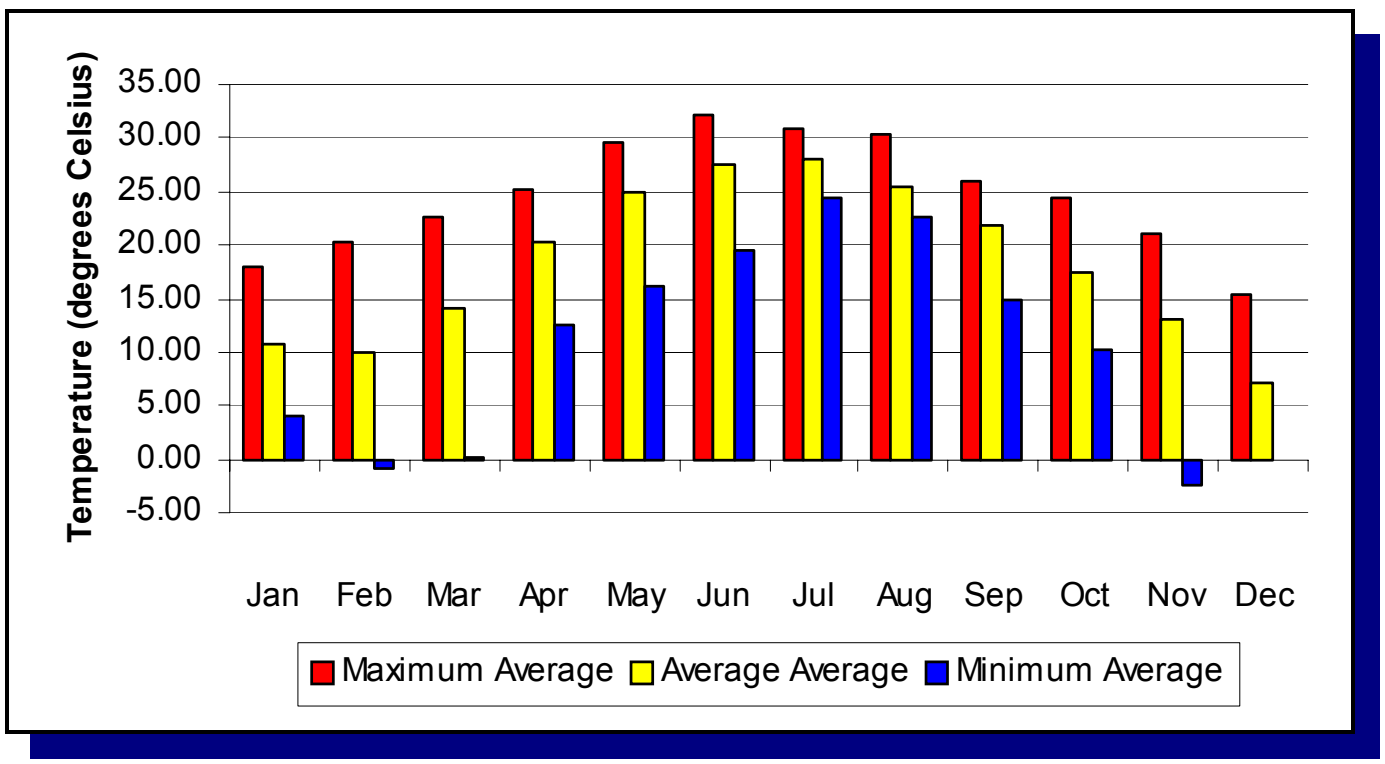

Figure 5.3 - 2006 Average Temperatures at WIPP

$\begin{array}{lccc}\text { Month } & \text { Maximum Average } & \begin{array}{c}\text { Average Average } \\ \text { Jan }\end{array} & \begin{array}{c}\text { Minimum Average } \\ 17.90^{\circ} \mathrm{C}\end{array} \\ \text { Feb } & 20.41^{\circ} \mathrm{C} & 10.63^{\circ} \mathrm{C} & 3.97^{\circ} \mathrm{C} \\ \text { Mar } & 22.52^{\circ} \mathrm{C} & 13.97^{\circ} \mathrm{C} & -0.78^{\circ} \mathrm{C} \\ \text { Apr } & 25.22^{\circ} \mathrm{C} & 20.35^{\circ} \mathrm{C} & 0.24^{\circ} \mathrm{C} \\ \text { May } & 29.51^{\circ} \mathrm{C} & 24.86^{\circ} \mathrm{C} & 12.66^{\circ} \mathrm{C} \\ \text { Jun } & 32.16^{\circ} \mathrm{C} & 27.54^{\circ} \mathrm{C} & 16.06^{\circ} \mathrm{C} \\ \text { Jul } & 30.91^{\circ} \mathrm{C} & 27.94^{\circ} \mathrm{C} & 19.50^{\circ} \mathrm{C} \\ \text { Aug } & 30.34^{\circ} \mathrm{C} & 25.45^{\circ} \mathrm{C} & 24.35^{\circ} \mathrm{C} \\ \text { Sep } & 26.01^{\circ} \mathrm{C} & 21.75^{\circ} \mathrm{C} & 22.60^{\circ} \mathrm{C} \\ \text { Oct } & 24.30^{\circ} \mathrm{C} & 17.43^{\circ} \mathrm{C} & 14.84^{\circ} \mathrm{C} \\ \text { Nov } & 20.97^{\circ} \mathrm{C} & 13.12^{\circ} \mathrm{C} & 10.15^{\circ} \mathrm{C} \\ \text { Dec } & 15.48^{\circ} \mathrm{C} & 7.05^{\circ} \mathrm{C} & -2.46^{\circ} \mathrm{C} \\ & & & -0.04^{\circ} \mathrm{C}\end{array}$




\section{Temperature Report - Lows \\ January 1, 2006, to December 31, 2006, Elevation 10.0 meters}

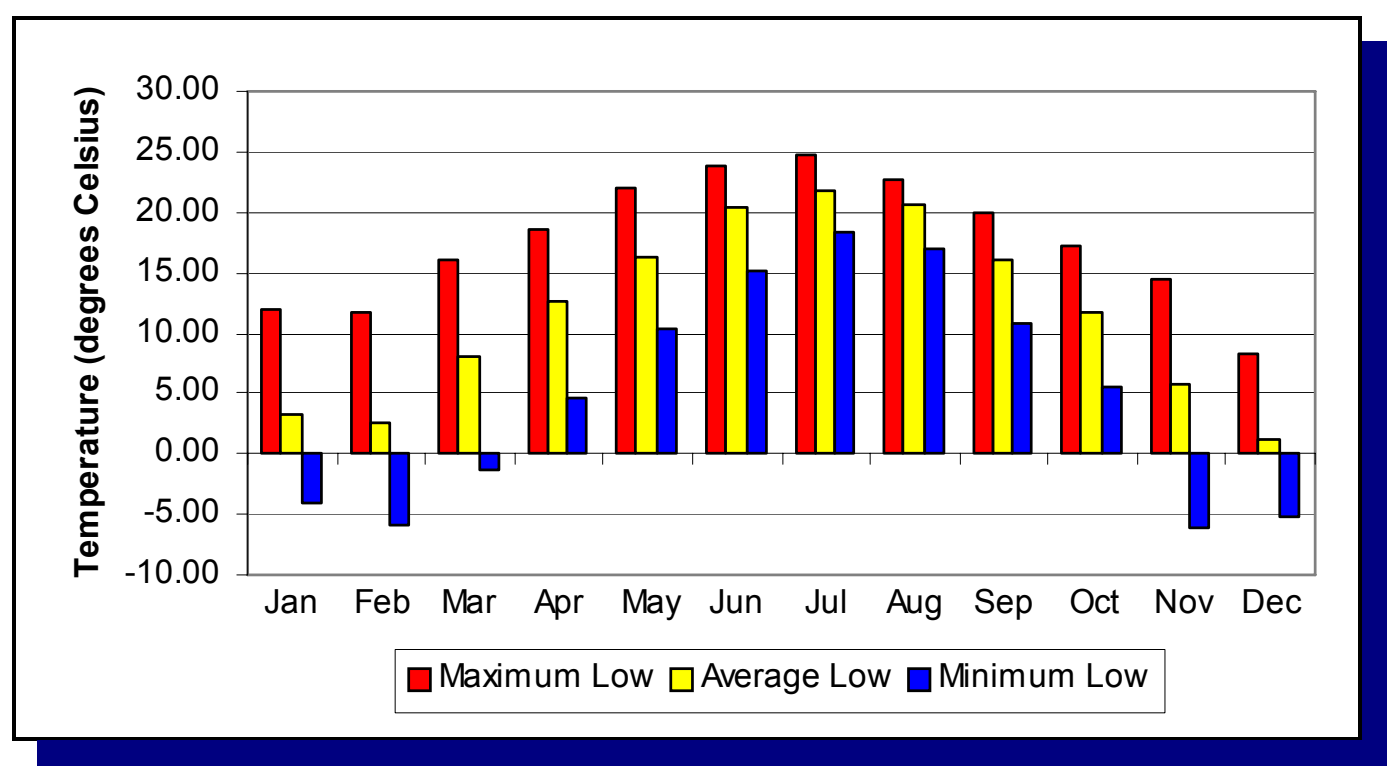

Figure 5.4 - 2006 Low Temperatures at WIPP

$\begin{array}{lccc}\text { Month } & \text { Maximum Low } & \text { Average Low } & \text { Minimum Low } \\ \text { Jan } & 11.85^{\circ} \mathrm{C} & 3.31^{\circ} \mathrm{C} & -3.99^{\circ} \mathrm{C} \\ \text { Feb } & 11.69^{\circ} \mathrm{C} & 2.62^{\circ} \mathrm{C} & -5.97^{\circ} \mathrm{C} \\ \text { Mar } & 15.99^{\circ} \mathrm{C} & 8.11^{\circ} \mathrm{C} & -1.38^{\circ} \mathrm{C} \\ \text { Apr } & 18.57^{\circ} \mathrm{C} & 12.73^{\circ} \mathrm{C} & 4.57^{\circ} \mathrm{C} \\ \text { May } & 21.98^{\circ} \mathrm{C} & 16.20^{\circ} \mathrm{C} & 10.45^{\circ} \mathrm{C} \\ \text { Jun } & 23.72^{\circ} \mathrm{C} & 20.47^{\circ} \mathrm{C} & 15.25^{\circ} \mathrm{C} \\ \text { Jul } & 24.66^{\circ} \mathrm{C} & 21.73^{\circ} \mathrm{C} & 18.41^{\circ} \mathrm{C} \\ \text { Aug } & 22.78^{\circ} \mathrm{C} & 20.52^{\circ} \mathrm{C} & 16.98^{\circ} \mathrm{C} \\ \text { Sep } & 20.02^{\circ} \mathrm{C} & 16.09^{\circ} \mathrm{C} & 10.79^{\circ} \mathrm{C} \\ \text { Oct } & 17.29^{\circ} \mathrm{C} & 11.72^{\circ} \mathrm{C} & 5.50^{\circ} \mathrm{C} \\ \text { Nov } & 14.40^{\circ} \mathrm{C} & 5.79^{\circ} \mathrm{C} & -6.04^{\circ} \mathrm{C} \\ \text { Dec } & 8.26^{\circ} \mathrm{C} & 1.11^{\circ} \mathrm{C} & -5.14^{\circ} \mathrm{C}\end{array}$

\subsubsection{Wind Direction and Wind Speed}

Winds in the WIPP area are predominantly from the southeast. In 2006, wind speed measured at the $10-\mathrm{m}$ (33-ft) level was calm (less than 0.5 meters per second $[\mathrm{m} / \mathrm{s}]$ ) (1.1 miles per hour [mph]) approximately 0.5 percent of the time. Winds of 3.71 to $6.30 \mathrm{~m} / \mathrm{s}$ (8.30 to $14.09 \mathrm{mph}$ ) were the most prevalent over 2006, occurring 36.2 percent of the time. Figure 5.5 displays the annual wind data at WIPP for 2006. 


\section{Wind Speed Report (Meters/Second) \\ January 1, 2006 to December 31, 2006, Elevation 10.0 Meters}

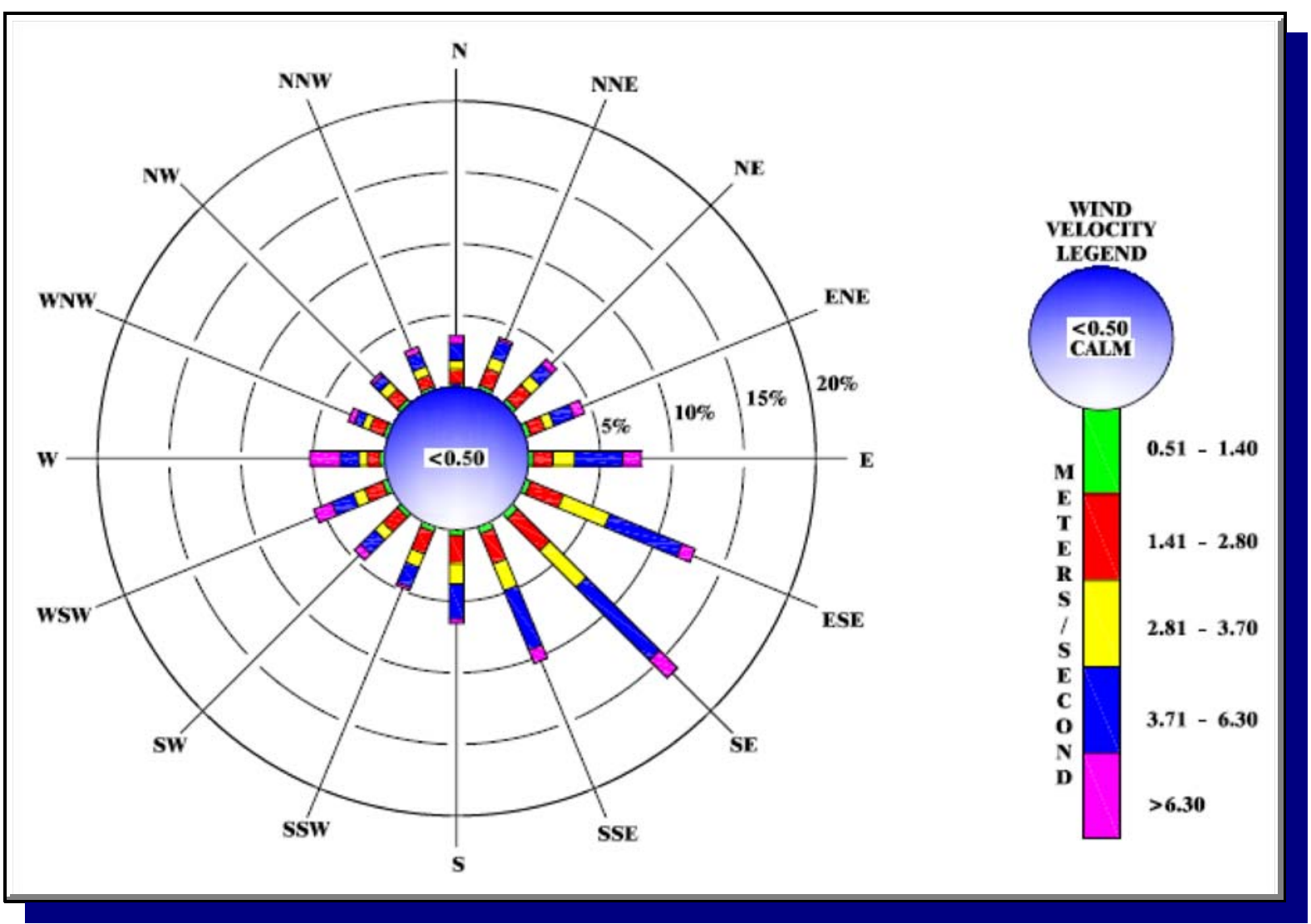

Figure 5.5 - Wind Speed Report

Wind Direction

E

ENE

NE

NNE

$\mathrm{N}$

NNW

NW

WNW

W

WSW

SW

SSW

$S$

SSE

SE

ESE

\section{0-.50 m/s}

$$
0.05
$$

0.05

0.05

0.02

0.02

0.03

0.04

0.04

0.03

0.03

0.02

0.03

0.03

0.03

0.03

0.05

$0.53 \%$

$$
\begin{gathered}
0.36 \\
0.41 \\
0.38 \\
0.36 \\
0.28 \\
0.28 \\
0.34 \\
0.32 \\
0.36 \\
0.40 \\
0.35 \\
0.39 \\
0.39 \\
0.52 \\
0.51 \\
0.40 \\
6.03 \%
\end{gathered}
$$

\section{gure 5.5-Wind Speed Report}

Total Percent Occurrence by Direction

$$
7.91
$$

4.49

4.38

$0.88 \quad 1.15$

$0.85 \quad 1.27$

$0.62 \quad 1.18$

$0.66 \quad 1.06$

$0.72 \quad 0.68$

$0.54 \quad 0.60$

$0.59 \quad 1.30$

$0.87 \quad 1.61$

$0.78 \quad 1.40$

$1.02 \quad 1.51$

$1.43 \quad 2.44$

$2.01 \quad 4.49$

$3.58 \quad 7.22$

$3.50 \quad 5.45$

$20.25 \%$

$36.19 \%$

1.29

0.78
0.48

0.21

0.54

0.43

0.24

0.44

2.11

1.34

0.61

0.22

0.30

1.01

1.76

0.97

$12.73 \%$ 


\subsection{Volatile Organic Compound Monitoring}

VOC monitoring was implemented on April 21, 1997, in accordance with WP 12-VC.01, Confirmatory Volatile Organic Compound Monitoring Program. This program is a requirement of the HWFP. VOC monitoring is performed to verify that VOCs emitted by the waste are within the concentration limits specified by the HWFP.

Nine target compounds, which contribute approximately 99 percent of the calculated human health risks from RCRA constituents, were chosen for monitoring. These target compounds are shown in Table 5.1 .

On November 16, 2006, new HWFP conditions were implemented requiring the addition of disposal room VOC monitoring to the program. This new requirement included the addition of sampling locations within active hazardous waste facility units. Within each active unit, two sampling locations are required for each closed room, one at the exhaust side of the room and one at the inlet side of the room. In addition, each room actively receiving waste is required to be sampled at the exhaust side of the room. The sampling frequency for disposal room sampling is biweekly. Disposal room sampling terminates in each unit upon initiation of panel closure activities. Typical disposal room VOC sampling locations are shown in Figure 5.6.

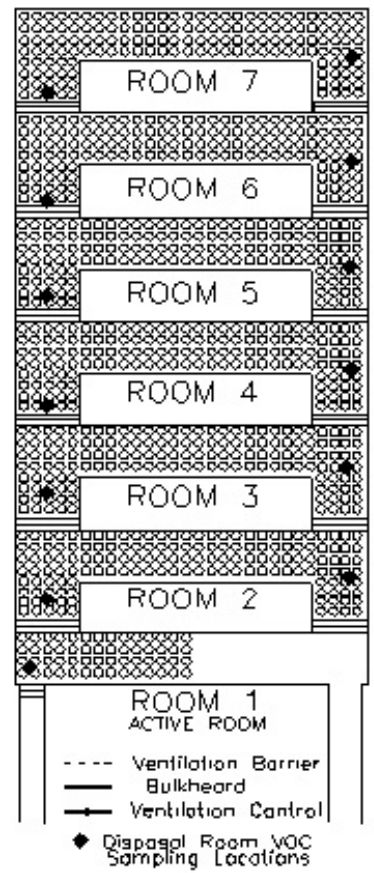

Figure 5.6 - Typical Disposal Room VOC Sampling Locations 
Disposal room VOC monitoring included sampling in Panel 3 when the permit condition became effective. Active sampling locations were two locations in each closed room (rooms Seven through Two) and one location at the exhaust side of Room One.

Repository VOC sampling for target compounds is performed semiweekly at two ambient air monitoring stations. The stations are identified as VOC-A, located downstream from hazardous waste disposal unit Panel 1 in Drift E300, and VOC-B, located upstream from the active panel. In April of 2005, Panel 3 became the active panel and remained so throughout 2006. VOC-B was moved to Drift S3080, upstream from Panel 3. As waste is placed in new panels, VOC-B will be relocated to ensure that it samples underground air before it passes the waste panels. The location of VOC-A is not anticipated to change.

Target compounds found in VOC-B represent background concentrations found in the underground. The VOC concentrations measured at this location are VOCs entering the mine through the air intake shaft and VOCs contributed by facility operations upstream of the waste panels. Differences measured between the two stations represent any VOC contributions from the waste panels. Any positive concentration differences in the annual averages between the two stations must be less than the concentrations of concern listed in the HWFP (Table 5.1).

Table 5.1 - Concentrations of Concern for Volatile Organic Compounds, from Attachment N of the HWFP (No. NM4890139088-TSDF)

\begin{tabular}{|c|c|c|}
\hline Compound & $\begin{array}{l}\text { Concentration of } \\
\text { Concern ppbv }^{\mathrm{a}}\end{array}$ & $\begin{array}{c}\text { Room Based Limits } \\
\text { ppmv }^{\mathrm{b}}\end{array}$ \\
\hline 1,1,1-Trichloroethane & 590 & 33700 \\
\hline 1,1,2,2-Tetrachloroethane & 50 & 2960 \\
\hline 1,1-Dichloroethylene & 100 & 5490 \\
\hline 1,2-Dichloroethane & 45 & 2400 \\
\hline Carbon tetrachloride & 165 & 9625 \\
\hline Chlorobenzene & 220 & 13000 \\
\hline Chloroform & 180 & 9930 \\
\hline Methylene chloride & 1930 & 100000 \\
\hline Toluene & 190 & 11000 \\
\hline
\end{tabular}

${ }^{a}$ Parts per billion by volume

${ }^{\mathrm{b}}$ Parts per million by volume

VOC sampling reported in this section was performed using guidance included in Compendium Method TO-15, Determination of Volatile Organic Compounds (VOCs) in Air Collected in Specially-Prepared Canisters and Analysis By Gas Chromatography/ Mass Spectrometry (GC/MS) (EPA, 1999) as a basis. The samples were analyzed using gas chromatography/mass spectrometry under an established QA/QC program. Laboratory analytical procedures were developed based on the concepts contained in both TO-15 and the draft EPA Contract Laboratory Program Volatile Organics Analysis of Ambient Air in Canisters (EPA, 1994). 
For repository VOC sampling, the routine method reporting limits (MRLs) and MCDs are shown in Table 5.2. For dilution factors greater than one, the $5.0 \mathrm{ppbv}$ and $2.0 \mathrm{ppbv}$ values are multiplied by the dilution factor to calculate the MRLs for the diluted sample. It should be noted that the MRLs are between 20 times and 386 times lower than the respective concentrations of concern for the nine target compounds.

The results of 2006 repository VOC monitoring, compared to 2005, indicated a decrease in the maximum and average concentration of carbon tetrachloride, toluene, and 1,1,1-trichloroethane in air downstream of Panel 1. Although the sample results for 2006 showed an increase in carbon tetrachloride and 1,1,1-trichloroethane detections, repository VOC sample results were well below the concentrations of concern listed in Table 5.1.

\begin{tabular}{lcc}
\hline \multicolumn{3}{c}{ Table 5.2 - Repository Air VOC MRLs and MCDs } \\
\hline \multicolumn{1}{c}{ Compound } & $\begin{array}{c}\text { MRL } \\
(\text { ppbv) }\end{array}$ & $\begin{array}{c}\text { MCD } \\
\text { (ppbv) }\end{array}$ \\
\hline 1,1,1-Trichloroethane & 5 & 16.01 \\
1,1,2,2-Tetrachloroethane & 2 & $<\mathrm{MRL}$ \\
1,1-Dichloroethylene & 5 & $<\mathrm{MRL}$ \\
1,2-Dichloroethane & 2 & $<\mathrm{MRL}$ \\
Carbon Tetrachloride & 2 & 14.52 \\
Chlorobenzene & 2 & $<\mathrm{MRL}$ \\
Chloroform & 2 & $<\mathrm{MRL}$ \\
Methylene chloride & 5 & $<\mathrm{MRL}$ \\
Toluene & 5 & $<\mathrm{MRL}$ \\
\hline${ }^{a}$ Parts per billion by volume & \multicolumn{3}{c}{}
\end{tabular}

For disposal room VOC monitoring, 39 samples were collected during 2006. The routine MRLs and MCDs are shown in Table 5.3. Three of the nine target compounds were detected above the MRL. The most substantial results were at least three orders of magnitude below the lower action level as described by the HWFP. 


\begin{tabular}{lcc}
\hline \multicolumn{3}{c}{ Table 5.3 - Disposal Room VOC MRLs and MCDs } \\
\hline \multicolumn{1}{c}{ Compound } & $\begin{array}{c}\text { MRL } \\
\text { (ppmv) }^{\text {b }}\end{array}$ & $\begin{array}{c}\text { MCD } \\
\text { (ppmv) }\end{array}$ \\
\hline 1,1,1-Trichloroethane & .5 & 9.9 \\
1,1,2,2-Tetrachloroethane & .5 & $<\mathrm{MRL}$ \\
1,1-Dichloroethylene & .5 & $<\mathrm{MRL}$ \\
1,2-Dichloroethane & .5 & $<\mathrm{MRL}$ \\
Carbon Tetrachloride & .5 & 4.2 \\
Chlorobenzene & .5 & $<\mathrm{MRL}$ \\
Chloroform & .5 & $<\mathrm{MRL}$ \\
Methylene chloride & .5 & 3.78 \\
Toluene & .5 & $<\mathrm{MRL}$ \\
\hline
\end{tabular}

${ }^{\mathrm{b}}$ Parts per million by volume

\subsection{Seismic Activity}

Currently, seismicity within $300 \mathrm{~km}$ (186 mi) of the WIPP site is being monitored by the New Mexico Institute of Mining and Technology (NMIMT) using data from a nine-station network approximately centered on the site (Figure 5.7). Station signals are transmitted to the NMIMT Seismological Observatory in Socorro. When appropriate, readings from the WIPP network stations are combined with readings from an additional NMIMT network in the central Rio Grande Rift. Occasionally, data are also exchanged with the University of Texas at El Paso and Texas Tech University in Lubbock, both of which operate stations in West Texas.

The mean operational efficiency of the WIPP seismic monitoring stations during 2006 was approximately 93.7 percent. From January 1 through December 31, 2006, locations for 49 seismic events were recorded within $300 \mathrm{~km}$ (186 mi) of WIPP. These data included origin times, epicenter coordinates, and magnitudes. The strongest recorded event (magnitude 2.4) occurred on January 27, 2006, and was located approximately $78 \mathrm{~km}(48 \mathrm{mi})$ northwest of the site. The closest event to the site was located approximately $68 \mathrm{~km}(42 \mathrm{mi})$ northwest and had a magnitude of 1.0 . These events had no effect on WIPP structures. 


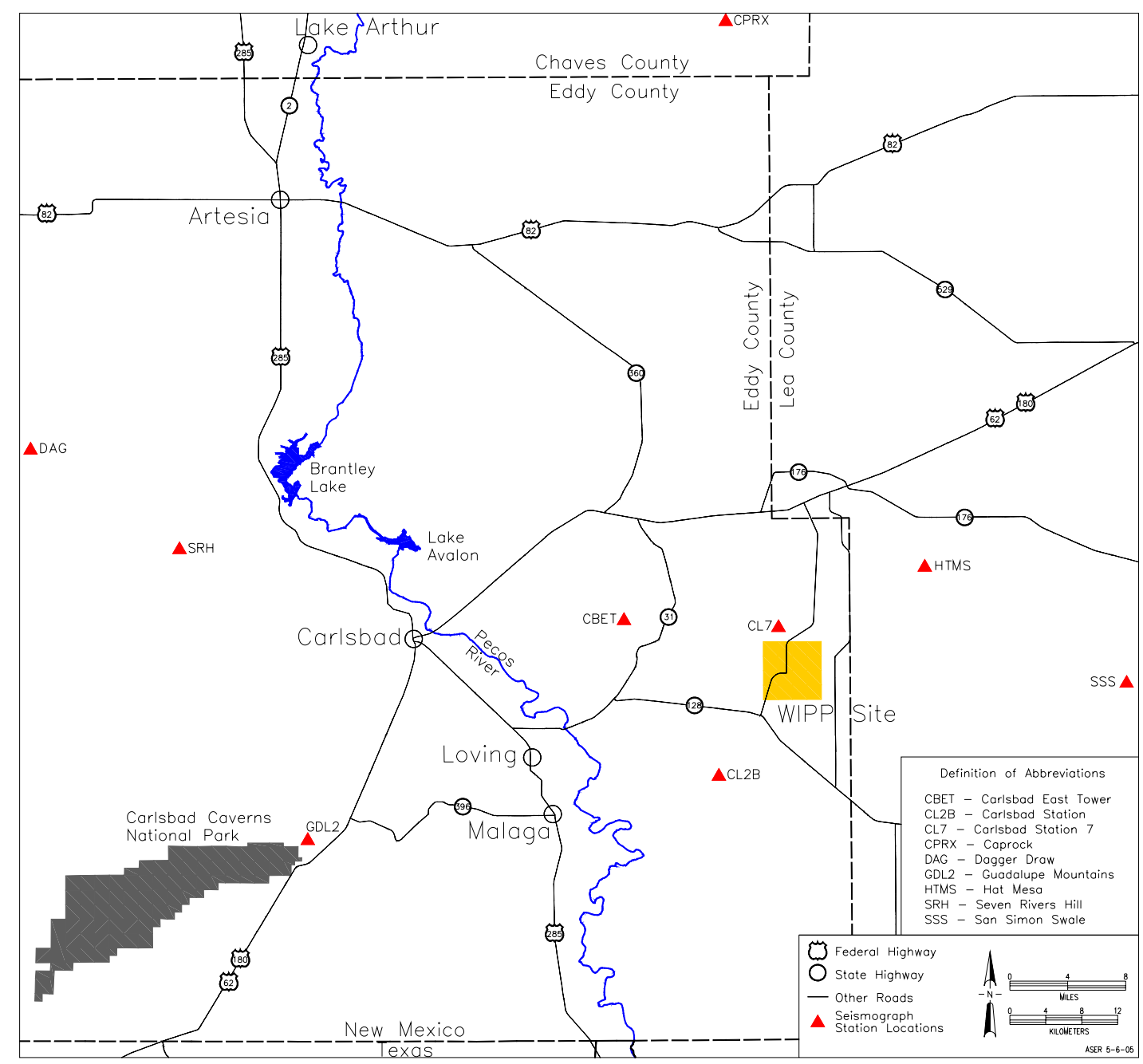

Figure 5.7 - WIPP Seismograph Station Locations

\subsection{Liquid Effluent Monitoring}

The NMED Ground and Surface Water Protection regulations set forth in 20.6.2 NMAC regulate discharges that could impact surface water or groundwater. WIPP compliance with the Ground and Surface Water Protection Regulations is discussed in Chapter 2, Section 2.2.6. The WIPP site has no discharges that could impact surface water. The WIPP facility does have DP-831 for discharges to the sewage lagoons and the $\mathrm{H}-19$ Evaporation Pond, and for the control of subsurface infiltration from active and inactive salt piles.

The WIPP sewage system consists of lined ponds that allow for the evaporation of liquids. The sewage treatment facility is permitted for the disposal of up to $87,064 \mathrm{~L}$ (23,000 gallons) per day of sewage effluent and up to $7,570 \mathrm{~L}$ (2,000 gallons) of nonhazardous brine water to the north evaporation pond. 
The H-19 Evaporation Pond is permitted for the treatment of up to $30,283 \mathrm{~L}$ $(8,000$ gallons $)$ per day of nonhazardous brine waters from groundwater monitoring and observation wells, mine dewatering and condensate collected from the mine ventilation system. The permit also authorizes the discharge of up to $378 \mathrm{~L}$ (100 gallons) of neutralized acid waste; however, neutralized acid waste is no longer generated at the WIPP facility.

A DP-831 modification approved on December 22, 2003, addressed infiltration of storm water containing high total dissolved solids to the subsurface from a 16-acre salt pile accumulated from mining. In accordance with the DP-831 modification, a new salt storage area with a 60-mil synthetic liner and an associated double-lined evaporation pond with leak detection was constructed to contain and evaporate salt contact storm water runoff. Additionally, the salt pile evaporation pond and three storm water evaporation ponds were lined with 60-mil high-density polyethylene liners to collect storm water runoff for evaporation and minimize the infiltration of storm water. Another discharge permit modification was approved on December 29, 2006, which incorporated the site preliminary design and validation material pile into the discharge permit. The modification required the installation of three groundwater monitoring wells around the pile. Additionally, the permit modification incorporated a more detailed closure plan into the permit.

Discharge monitoring reports are submitted semiannually to the NMED to demonstrate compliance with the inspection, monitoring, and reporting requirements identified in DP-831. The permit requires semiannual sampling of the sewage lagoons and the $\mathrm{H}-19$ Evaporation Pond and annual sampling of the storm water infiltration control ponds. There are no regulatory limits associated with the analytes. Detection limits vary with each analytical event based on the required sample dilutions. Analytical data from the discharge monitoring reports are summarized in Tables 5.4 through 5.6. Subsurface shallow water monitoring results are outlined in Chapter 6. 


\section{Waste Isolation Pilot Plant Annual Site Environmental Report for 2006 DOE/WIPP-07-2225}

Table 5.4 - Sewage Lagoon and H-19 Semiannual Analytical Results for January 1 through June 30, 2006

\begin{tabular}{|c|c|c|c|c|c|c|c|c|}
\hline \multirow{2}{*}{\begin{tabular}{|c|} 
Analyte \\
Nitrate $(\mathrm{mg} / \mathrm{L})$ \\
\end{tabular}} & \multicolumn{2}{|c|}{$\begin{array}{c}\text { Influent to Facultative } \\
\text { Lagoon System }\end{array}$} & \multicolumn{2}{|c|}{ Evaporation Pond B } & \multicolumn{2}{|c|}{ Evaporation Pond C } & \multicolumn{2}{|c|}{$\begin{array}{c}\text { H-19 Evaporation } \\
\text { Pond }\end{array}$} \\
\hline & $<1.00$ & & $<0.10$ & & $N / A^{a}$ & & $\mathrm{~N} / \mathrm{A}$ & \\
\hline $\mathrm{TKN}^{\mathrm{b}}(\mathrm{mg} / \mathrm{L})$ & 119 & & 19 & & $\mathrm{~N} / \mathrm{A}$ & & $\mathrm{N} / \mathrm{A}$ & \\
\hline $\operatorname{TDS}^{\mathrm{c}}(\mathrm{mg} / \mathrm{L})$ & 716.0 & & 19,700 & & 4,700 & & $\mathrm{NS}^{f}$ & \\
\hline & Activity & TPU $2 \sigma^{d}$ & Activity & TPU $2 \sigma$ & Activity & TPU $2 \sigma$ & Activity & TPU $2 \sigma$ \\
\hline $\mathrm{U}^{233 / 234}(\mathrm{~Bq} / \mathrm{L})^{\mathrm{e}}$ & 6.44E-02 & 7.07E-03 & $1.74 \mathrm{E}-02$ & $3.11 \mathrm{E}-03$ & 1.39E-02 & $2.53 E-03$ & NS & NS \\
\hline $\mathrm{U}^{235}(\mathrm{~Bq} / \mathrm{L})$ & $1.44 \mathrm{E}-03$ & 1.14E-03 & $4.38 \mathrm{E}-04$ & $6.02 \mathrm{E}-04$ & $-2.92 \mathrm{E}-05$ & $1.26 \mathrm{E}-04$ & NS & $\overline{N S}$ \\
\hline $\mathrm{U}^{238}(\mathrm{~Bq} / \mathrm{L})$ & $2.92 \mathrm{E}-02$ & $4.58 \mathrm{E}-03$ & $7.29 \mathrm{E}-03$ & 1.99E-03 & $5.29 \mathrm{E}-03$ & $1.55 \mathrm{E}-03$ & NS & $\overline{N S}$ \\
\hline $\mathrm{Pu}^{238}(\mathrm{~Bq} / \mathrm{L})$ & $-1.52 \mathrm{E}-04$ & $7.08 \mathrm{E}-04$ & 1.73E-04 & $7.06 \mathrm{E}-04$ & $3.15 \mathrm{E}-04$ & $6.87 \mathrm{E}-04$ & NS & $\mathrm{NS}$ \\
\hline $\mathrm{Pu}^{239+240}(\mathrm{~Bq} / \mathrm{L})$ & $-1.75 \mathrm{E}-04$ & 3.84E-04 & $8.38 \mathrm{E}-05$ & $3.87 \mathrm{E}-04$ & $-8.50 \mathrm{E}-05$ & $2.18 \mathrm{E}-04$ & NS & $\overline{N S}$ \\
\hline $\mathrm{Am}^{241}(\mathrm{~Bq} / \mathrm{L})$ & $-7.91 \mathrm{E}-05$ & $2.45 \mathrm{E}-04$ & $6.57 \mathrm{E}-05$ & $3.42 \mathrm{E}-04$ & $-4.75 \mathrm{E}-05$ & $1.47 \mathrm{E}-04$ & NS & $\overline{N S}$ \\
\hline $\mathrm{Sr}^{90}(\mathrm{~Bq} / \mathrm{L})$ & $-1.53 \mathrm{E}-03$ & $2.20 \mathrm{E}-02$ & $2.89 \mathrm{E}-03$ & $2.55 \mathrm{E}-02$ & $-9.52 \mathrm{E}-03$ & $2.51 \mathrm{E}-02$ & NS & $\mathrm{NS}$ \\
\hline
\end{tabular}

a $\mathrm{N} / \mathrm{A}$ : The analytical parameter is not required.

b Total Kjeldahl Nitrogen (as N)

c Total dissolved solids

d TPU 2 o = total propagated uncertainty at 2-sigma (95\% confidence interval)

e Becquerel per lite.

f Not sampled, insufficient water

\section{Table 5.5 - Sewage Lagoon and H-19 Semiannual Analytical Results for July 1 through} December 31, 2006

\begin{tabular}{|l|c|c|c|c|c|c|c|c|}
\hline \multicolumn{1}{|c|}{ Analyte } & \multicolumn{2}{|c|}{$\begin{array}{c}\text { Influent to Facultative } \\
\text { Lagoon System }\end{array}$} & Evaporation Pond B & Evaporation Pond C & \multicolumn{2}{c|}{ H-19 Evaporation } \\
Pond
\end{tabular}

${ }^{a} \mathrm{~N} / \mathrm{A}:$ The analytical parameter is not required.

b Total Kjeldahl Nitrogen (as N).

c Total dissolved solids.

d TPU $2 \sigma=$ total propagated uncertainty at 2-sigma (95\% confidence interval).

e Becquerel per liter. 
Waste Isolation Pilot Plant Annual Site Environmental Report for 2006 DOE/WIPP-07-2225

Table 5.6 - Infiltration Control Evaporation Ponds Annual Analytical Results for January 1 through December 31, 2006

\begin{tabular}{|l|c|c|c|c|c|c|}
\hline \multicolumn{1}{|c|}{ Evaporation Pond } & $\begin{array}{c}\text { Chloride } \\
\mathbf{m g} / \mathbf{L}\end{array}$ & $\begin{array}{c}\text { Nitrate-N } \\
\mathbf{m g} / \mathbf{L}\end{array}$ & $\begin{array}{c}\text { Sulfate } \\
\mathbf{m g} / \mathbf{L}\end{array}$ & $\begin{array}{c}\text { TDS } \\
\mathbf{m g} / \mathbf{L}\end{array}$ & $\begin{array}{c}\text { Selenium } \\
\mathbf{m g} / \mathbf{L}\end{array}$ & $\begin{array}{c}\text { Chromium } \\
\mathbf{m g} / \mathbf{L}\end{array}$ \\
\hline Salt Pile Evaporation Pond & 5,830 & $<2.00$ & 71.7 & 8,470 & $<0.010$ & $<0.010$ \\
\hline $\begin{array}{l}\text { Salt Storage Extension } \\
\text { Evaporation Basin }\end{array}$ & 204,000 & 1.87 & 11,000 & 249,000 & $<0.0100$ & $<0.010$ \\
\hline Pond 1 & 70.2 & $<1.00$ & 10.0 & 208.0 & $<0.010$ & $<0.010$ \\
\hline Pond 2 & 156 & $<1.00$ & 10.6 & 334.0 & $<0.010$ & $<0.010$ \\
\hline Pond A & 129 & $<1.00$ & 12.8 & 299.0 & $<0.010$ & $<0.010$ \\
\hline
\end{tabular}




\section{CHAPTER 6 - SITE HYDROLOGY, GROUNDWATER MONITORING, AND PUBLIC DRINKING WATER PROTECTION}

Current groundwater monitoring activities for the WIPP facility are outlined in the WIPP Groundwater Monitoring Program Plan (WP 02-1). In addition, the WIPP facility has detailed procedures for performing specific activities, such as pumping system installations, field parameter analyses and documentation, and QA records management. Groundwater monitoring activities are also included in the Environmental Monitoring Plan.

\subsection{Site Hydrology}

The hydrology at and surrounding the WIPP site has been studied extensively over the last 30 years. A summary of the hydrology in this area is contained in the following sections. Figure 6.1 presents the WIPP stratigraphy.

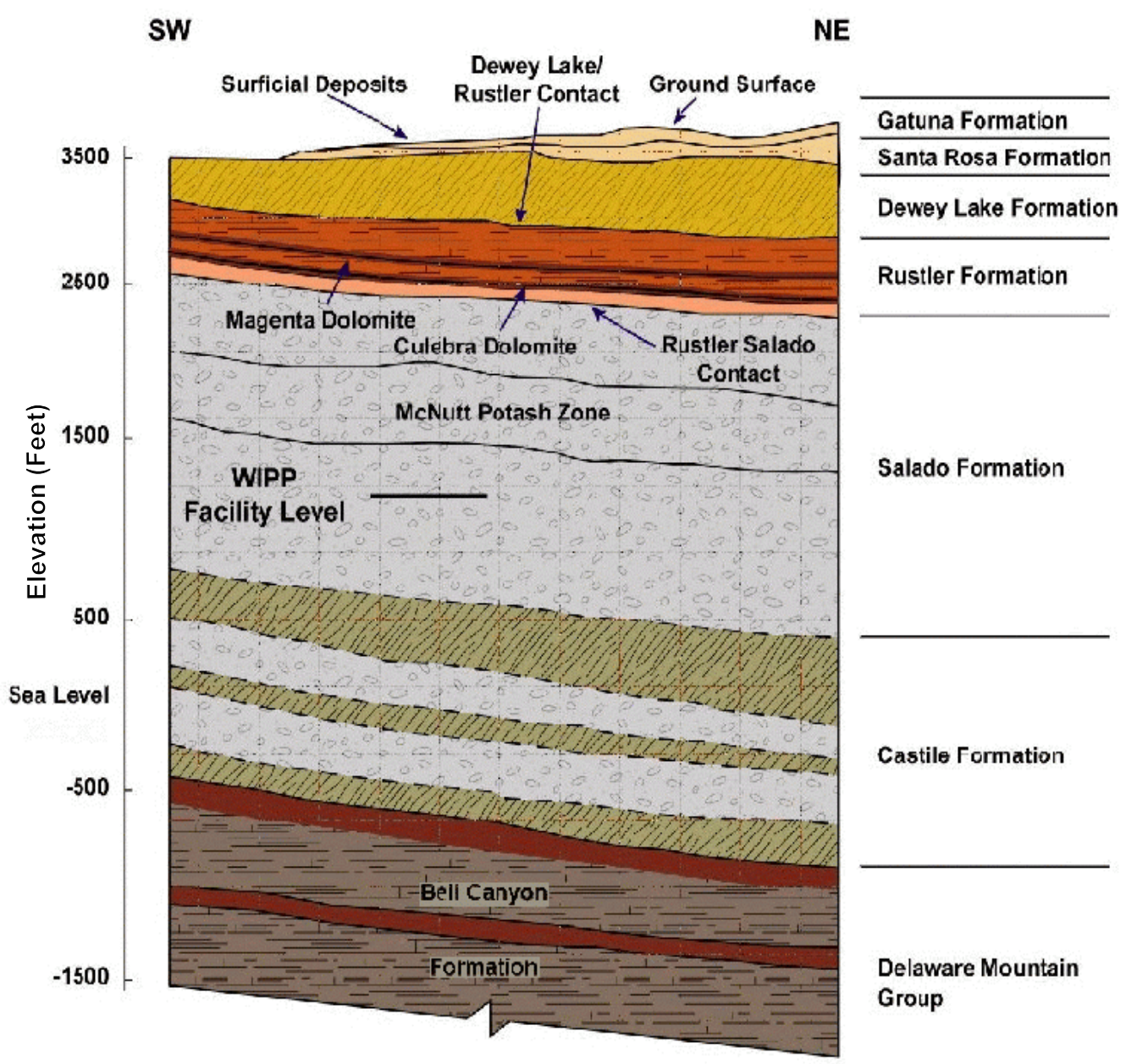

Figure 6.1 - WIPP Stratigraphy 


\subsubsection{Surface Hydrology}

Surface water is absent at the WIPP site. The nearest significant surface water body, Laguna Grande de la Sal, is $13 \mathrm{~km}(8 \mathrm{mi})$ west-southwest of the center of the WIPP site in Nash Draw where shallow brine ponds occur. Small, manmade livestock watering holes ("tanks") occur several kilometers from the WIPP site, but are not hydrologically connected to the formations overlying the WIPP repository.

\subsubsection{Subsurface Hydrology}

Several water-bearing zones have been identified and extensively studied at and near the WIPP site. Limited amounts of potable water are found in the middle Dewey Lake Formation and the overlying Triassic Dockum group in the southern part of the WIPP Land Withdrawal Area. Two water-bearing units, the Culebra and Magenta dolomites, occur in the Rustler Formation and produce brackish to saline water at and in the vicinity of the site. Another very low transmissivity, saline water-bearing zone is the Rustler-Salado contact.

\subsubsection{Hydrology of the Castile Formation}

The Castile Formation is composed of a sequence of three thick anhydrite beds separated by two thick halite beds. This formation acts as an aquitard, separating the Salado Formation from the underlying water-bearing sandstones of the Bell Canyon Formation. In the halite zones, the occurrence of circulating groundwater is restricted because halite at these depths does not readily maintain secondary porosity, open fractures, or solution channels.

No regional groundwater flow system appears to be present in the Castile Formation in the vicinity of WIPP. The only significant water present in the formation occurs in isolated brine reservoirs in fractured anhydrite. Wells have encountered pressurized brine reservoirs in the upper anhydrite unit of the Castile Formation in the vicinity of the WIPP site. Two such encounters have been made by the following boreholes. Borehole ERDA-6, located northeast of the current WIPP site encountered a pressurized brine reservoir in 1975. Borehole WIPP-12 encountered another brine reservoir one mile north of the center of the WIPP site in 1981. Both encounters were hydrologically and chemically tested in 1981 and were found to be not connected with each other.

\subsubsection{Hydrology of the Salado Formation}

The massive halite beds within the Salado Formation host the WIPP facility horizon. The Salado Formation represents a regional aquiclude due to the hydraulic properties of the bedded halite that forms most of the formation. In the halites, the presence of circulating groundwater is restricted because halites do not readily maintain primary porosity, solution channels, or open fractures. 
The results of permeability testing, both within the facility and from the surface, are generally consistent with a hydraulic conductivity of the undisturbed salt mass of less than $6.5 \mathrm{E}-09 \mathrm{~m}$ per day $(\mathrm{m} / \mathrm{d})(2.1 \mathrm{E}-08 \mathrm{ft} / \mathrm{d})$, with the more pure (less argillaceous) halites having even lower permeability. Anhydrite interbeds typically have hydraulic conductivities ranging from $6.5 \mathrm{E}-09 \mathrm{~m} / \mathrm{d}$ to $6.5 \mathrm{E}-07 \mathrm{~m} / \mathrm{d}(2.1 \mathrm{E}-08$ to $2.1 \mathrm{E}-06 \mathrm{ft} / \mathrm{d})$ (Beauheim and Roberts, 2002). The only significant variation to these extremely low permeabilities occurs in the immediate vicinity of the underground workings (Stormont et al., 1991). This increase is believed to be a result of near-field fracturing due to the excavation.

Small quantities of brine have been observed to collect in boreholes drilled into Marker Bed 139 a few feet below the floor of the WIPP rooms and have also been observed to seep out of the excavated walls. The long-term performance assessment for the WIPP site assumes that small quantities of brine will be present in the WIPP repository.

\subsubsection{Hydrology of the Rustler-Salado Contact}

In Nash Draw and areas immediately west of the site, the Rustler-Salado contact exists as a dissolution residue capable of transmitting water. Eastward from Nash Draw toward the WIPP site, the amount of dissolution decreases and the transmissivity of this interval decreases (Mercer, 1983). Small quantities of brine were found in this zone at the WIPP site in the WIPP test holes (Mercer and Orr, 1977).

\subsubsection{Hydrology of the Culebra Member}

The Culebra Member of the Rustler Formation is the most transmissive hydrologic unit in the WIPP site area and is considered the most significant potential hydrologic pathway for a radiologic release to the accessible environment.

Tests show that the Culebra is a fractured, heterogeneous system with varying local anisotropic characteristics (Mercer and Orr, 1977; Mercer, 1983; Beauheim, 1986, 1987; Beauheim and Ruskauff, 1998). Calculated transmissivities for the Culebra within the WIPP site boundary have a wide range with values between $8.4 \mathrm{E}-03$ to approximately $6.4 \mathrm{~m}^{2} / \mathrm{d}\left(9.0 \mathrm{E}-02\right.$ to approximately $\left.69 \mathrm{ft}^{2} / \mathrm{d}\right)$; the majority of the values are less than $9.3 \mathrm{E}-02 \mathrm{~m}^{2} / \mathrm{d}\left(1 \mathrm{ft}^{2} / \mathrm{d}\right.$ ) (Beauheim, 1987). Transmissivities generally decrease from west to east across the site area. The regional flow direction of groundwater in the Culebra Dolomite is generally south.

\subsubsection{Hydrology of the Magenta Member}

The Magenta Dolomite is situated above the Culebra and, though not the water-bearing zone of interest for monitoring of a facility release, is of interest in understanding waterlevel changes that occur in the Culebra. The Magenta has been tested in 18 cased and open holes at and around the WIPP site. Transmissivities within the WIPP site range from 2.0E-04 to $3.5 \mathrm{E}-02 \mathrm{~m}^{2} / \mathrm{d}\left(2.1 \mathrm{E}-03\right.$ to $3.8 \mathrm{E}-01 \mathrm{ft}^{2} / \mathrm{d}$ ) (Beauheim et al., 1991; Beauheim and Ruskauff, 1998). 


\subsubsection{Hydrology of the Dewey Lake Formation}

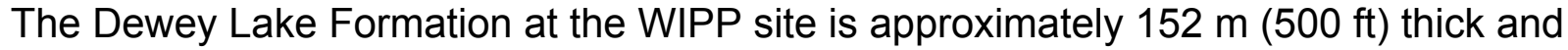
consists of alternating thin beds of siltstone and fine-grained sandstone. The upper Dewey Lake consists of a thick, generally unsaturated section. The middle Dewey Lake is the interval immediately above a cementation change, from carbonate (above) to sulfate (below), where saturated conditions and a natural water table have been

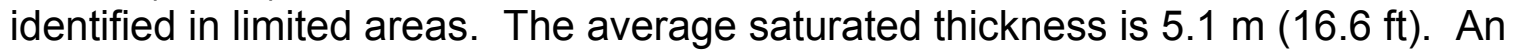
anthropogenic saturated zone has been observed in the overlying Santa Rosa Formation and in the upper part of the Dewey Lake since 1995. This is described in Section 6.6. The lower Dewey Lake is below the sulfate cementation change, with much lower permeabilities.

WIPP monitoring well WQSP-6A intersects natural water in the Dewey Lake. At this location, the saturated horizon is within the middle portion of the formation. The saturated zone at well WQSP-6A is both vertically and laterally distinct from the water at $\mathrm{C}-2811$, which is located about one mile to the northeast. The Dewey Lake generally does not yield a water supply to wells; however, about one mile south of the WIPP site, domestic and stock supply wells produce water from the middle Dewey Lake (Cooper and Glanzman, 1971).

\subsubsection{Hydrology of the Santa Rosa and Gatuña Formations}

Within the WIPP site boundary, the Santa Rosa is relatively thin to absent. At the air

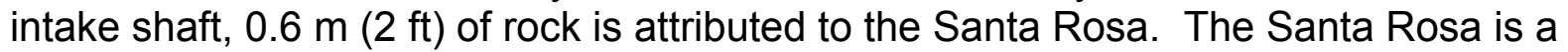
maximum of $78 \mathrm{~m}(255 \mathrm{ft}$ ) thick in exploratory potash holes drilled for WIPP, east of the site boundary. The Santa Rosa is thicker to the east. The geologic data from design studies have been incorporated with data from drilling to investigate shallow subsurface water in the Santa Rosa to provide structure and thickness maps of the Santa Rosa in the vicinity of the WIPP surface structures area. These results are consistent with the broader regional distribution of the Santa Rosa (DOE/WIPP 04-3231).

Water in the Santa Rosa has been found in the center part of the WIPP site and since no water was found in this zone during the mapping of the shafts in 1980s, this water is deemed to be anthropogenic (Daniel B. Stephens \& Associates, Inc., 2003). To assess the quantity and quality of this water, piezometers PZ-1 to PZ-12 were installed in the area between the WIPP shafts. Also, three wells, C-2505, C-2506 and C-2507 were drilled and tested in 1996 and 1997 (Exhaust Shaft Hydraulic Assessment Data Report, DOE/WIPP 97-2219).

The Gatuña Formation unconformably overlies the Santa Rosa Formation at the WIPP site. This formation ranges in thickness from approximately 6 to $9 \mathrm{~m} \mathrm{(19} \mathrm{to} 31 \mathrm{ft})$ at the WIPP site and consists of silt, sand, and clay, with deposits formed in localized depressions.

The Gatuña is water-bearing in some areas, with saturation occurring in discontinuous perched zones. However, because of its erratic distribution, the Gatuña has no known 
continuous saturation zone. Drilling at the WIPP site, including 30 exploration borings drilled between 1978 and 1979, did not identify any saturated zones in the Gatuña (Daniel B. Stephens \& Associates, Inc., 2003).

\subsection{Groundwater Monitoring}

\subsubsection{Program Objectives}

The objectives of the groundwater monitoring program are to:

- Determine the physical and chemical characteristics of groundwater;

- Maintain surveillance of groundwater levels and water chemistry surrounding the WIPP facility throughout the operational lifetime of the facility; and

- Document and identify effects, if any, of WIPP operations on groundwater parameters.

Data obtained by the WIPP groundwater monitoring program support two major programs at WIPP: (1) the RCRA detection monitoring program supporting the HWFP in compliance with 20.4.1.500 NMAC, and (2) performance assessment supporting the Compliance Certification Application (DOE/CAO 96-2184) and five-year recertification applications.

Baseline water chemistry data were collected from 1995 through 1997 and reported in the Waste Isolation Pilot Plant RCRA Background Groundwater Quality Baseline Report (DOE/WIPP 98-2285). The baseline data were expanded in 2000 to include ten rounds of sampling instead of five. The data were published in Addendum 1, Waste Isolation Pilot Plant RCRA Background Groundwater Quality Baseline Update Report (IT Corporation, 2000). These baseline data are compared to water quality data collected semiannually at DMP wells.

\subsubsection{Summary of 2006 Activities}

Routine groundwater monitoring activities include groundwater quality sampling, groundwater level monitoring, and the pressure density survey, as described in this section. These annual programs are required by the HWFP. Supporting activities during 2006 included drilling of five new wells (Section 6.3), hydraulic testing and non-HWFP groundwater quality sampling (Section 6.4), and well maintenance (Section 6.5). Table 6.1 categorizes WIPP groundwater monitoring activities at the end of 2006. Wells are classified by purpose (i.e., remediation, waste management, and environmental surveillance). All of the WIPP groundwater monitoring wells are used for environmental surveillance. Appendix F, Table F.9, lists all active wells at WIPP at the end of 2006, after all new well drilling and plugging and abandonment described in subsequent sections had taken place. 
Radiological data from 2006 from the groundwater monitoring program are summarized in Chapter 4. The remainder of the results from the groundwater monitoring program are contained in this chapter.

Table 6.1 - Summary of 2006 DOE WIPP Region Groundwater Monitoring Program

\begin{tabular}{|l|c|c|c|c|}
\hline \multirow{2}{*}{} & \multicolumn{3}{|c}{ Purposes for Which Monitoring Was Performed } \\
\cline { 2 - 5 } & Remediation & $\begin{array}{c}\text { Waste } \\
\text { Management }\end{array}$ & $\begin{array}{c}\text { Environmental } \\
\text { Surveillance }\end{array}$ & Other Drivers \\
\hline Number of Active Wells Monitored & N/A & N/A & 79 & N/A \\
\hline Number of Samples Taken & N/A & N/A & $28^{*}$ & N/A \\
\hline Number of Water Level Measurements & N/A & N/A & 739 & N/A \\
\hline Number of Analyses Performed & N/A & N/A & 1708 & $7 \%^{* *}$ \\
\hline$\%$ of Analyses that are Non-Detects & N/A & N/A & N/A \\
\hline
\end{tabular}

* Primary and duplicate samples taken from seven wells, twice per year. Sixty-one constituents analyzed per sample.

** All VOCs, SVOCs, and the majority of trace metals were nondetect. Most detections are the routine major water chemistry parameters.

Regular monthly groundwater level data were gathered from 79 wells across the WIPP region (Figure 6.2), five of which were equipped with production-injection-packers (PIPs) to allow groundwater level surveillance of more than one zone through the same well. Table F.8 shows the water level data. Water levels were not taken where access was poor (WIPP-27), or in certain wells whenever testing equipment was present. 


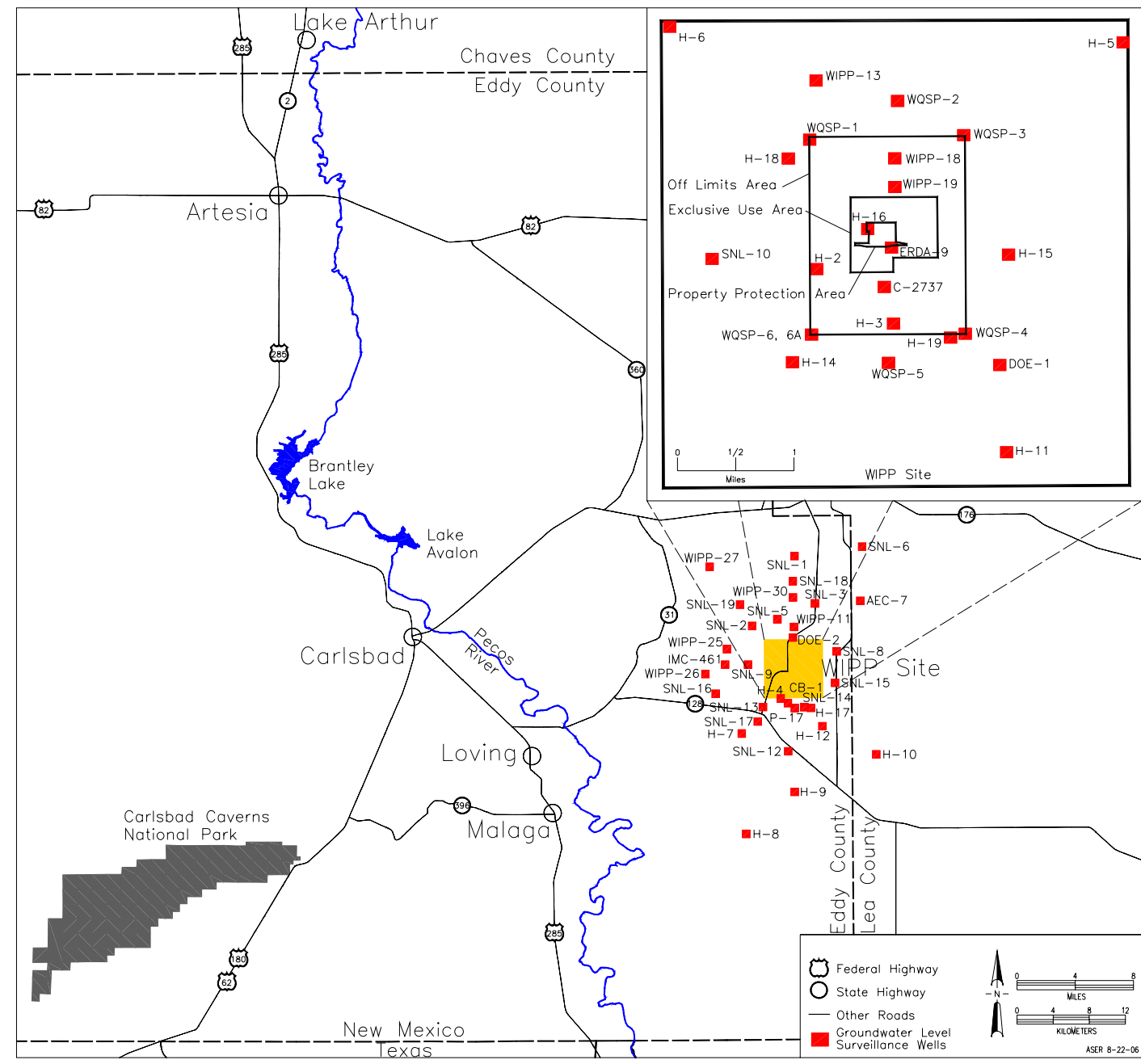

Figure 6.2 - Groundwater Level Surveillance Wells (insert represents the groundwater surveillance wells in WIPP Land Withdrawal Area)

\subsubsection{Groundwater Quality Sampling}

The HWFP Module $V$ requires groundwater quality sampling twice a year, from March through May (Round 22 for 2006) and, again, from September through November (Round 23 for 2006). Sampling for groundwater quality was performed at seven DMP well sites during 2006 (Figure 6.3). Field analyses for oxygen-reduction potential, specific gravity, specific conductance, acidity or alkalinity, chloride, divalent cations, and total iron were performed periodically during the sampling. 


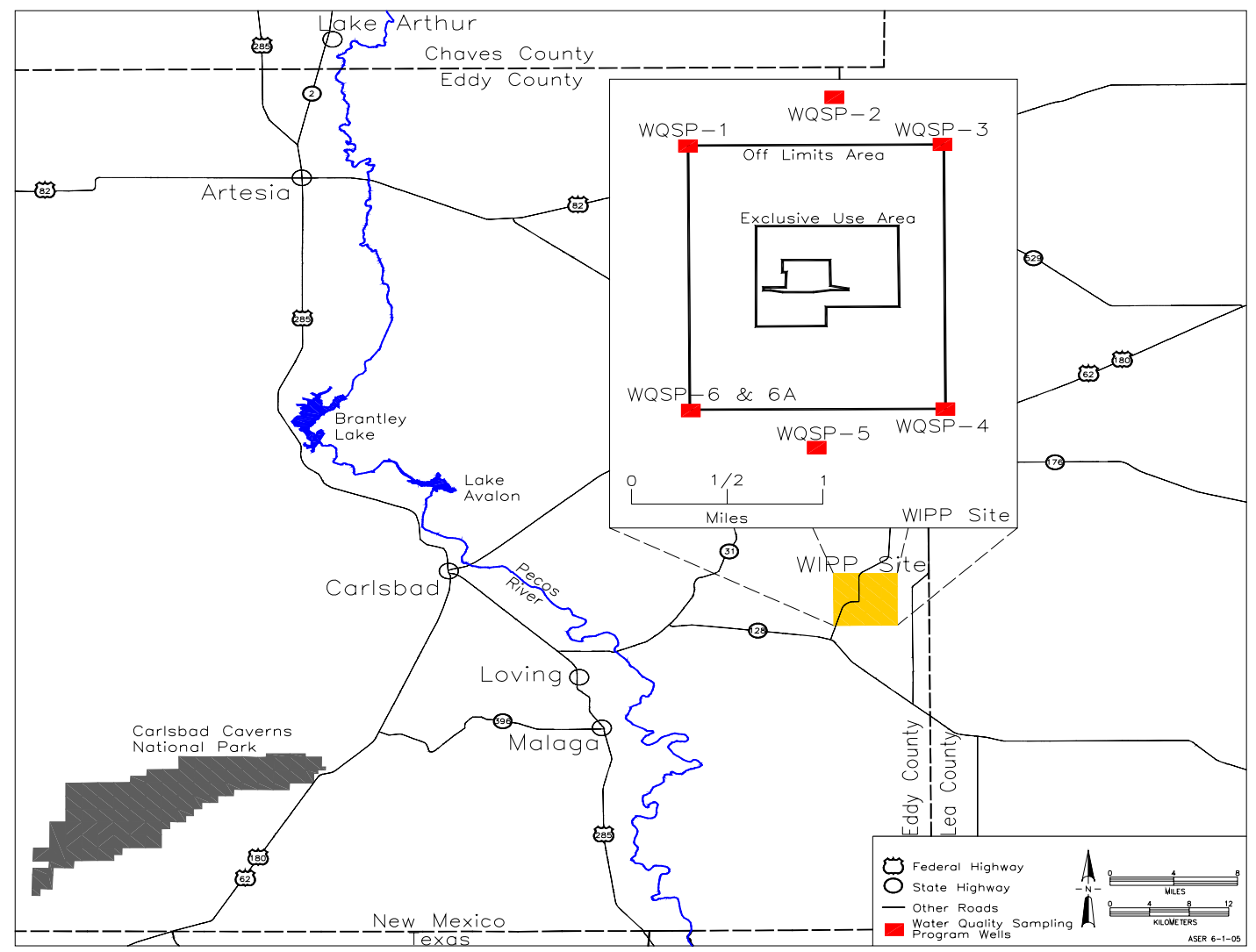

Figure 6.3 - Water Quality Sampling Program Wells

Primary and duplicate samples for groundwater quality were taken in each of the seven DMP wells: six wells completed in the Culebra (WQSP-1 through WQSP-6) and one well completed in the Dewey Lake (WQSP-6A), for a total of fourteen samples analyzed per sampling round.

The HWFP specifies the point of compliance as "the vertical surface located at the hydraulically down gradient limit of the underground hazardous waste facility units that extends to the Culebra Member of the Rustler Formation." The HWFP groundwater monitoring network was not installed immediately down gradient of this plane.

Monitoring at the sited locations will allow for detection of releases before contaminants could be released beyond the WIPP Land Withdrawal Area boundary.

Wells WQSP-1, WQSP-2, and WQSP-3 are located up-gradient of the WIPP shaft area. The locations of the three up-gradient wells were selected to be representative of the groundwater moving down-gradient onto the WIPP site. WQSP-4, WQSP-5, and WQSP-6 were located down-gradient of the WIPP shaft area. WQSP-4 was also specifically located to monitor a zone of higher transmissivity around wells DOE-1 (now plugged and abandoned) and H-11. WQSP-6a was installed in the Dewey Lake at the WQSP-6 well pad to assess shallower groundwater conditions at this location. 
The difference between the depth of the WIPP repository and the depth of the DMP

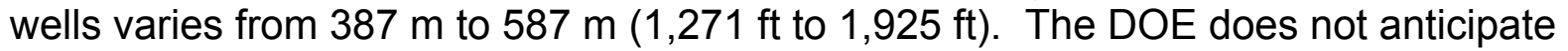
finding WIPP-related contamination in groundwater because no pathways for migration of hazardous constituents to the Culebra exist. In order for contaminated liquid to move from the repository into the Culebra, two conditions must be met. First, sufficient water has to accumulate in the waste disposal areas to leach contaminants from the disposed waste. Second, sufficient pressure would have to build up in the disposal region to overcome the hydrostatic head between the repository and the Culebra, assuming that any pathway exists after the shafts and boreholes are sealed. The first condition is unlikely due to the low moisture content of the Salado and the waste, and the second condition is not expected to occur for hundreds of years after repository closure.

Table 6.2 lists the analytical parameters included in the 2006 groundwater-sampling program.

\begin{tabular}{|c|c|c|c|c|c|}
\hline \multicolumn{6}{|c|}{ Table 6.2 - Analytical Parameters for Which Groundwater Was Analyzed } \\
\hline CAS No. ${ }^{a}$ & Parameter & $\begin{array}{c}\text { EPA } \\
\text { Method } \\
\text { Number }\end{array}$ & CAS No. & Parameter & $\begin{array}{c}\text { EPA } \\
\text { Method } \\
\text { Number }\end{array}$ \\
\hline $71-55-6$ & 1,1,1-Trichloroethane & $8260 \mathrm{~B}$ & $7782-50-5$ & Chloride & 300 \\
\hline $79-34-5$ & 1,1,2,2-Tetrachloroethane & $8260 \mathrm{~B}$ & & Density ${ }^{b}$ & \\
\hline $79-00-5$ & 1,1,2-Trichloroethane & $8260 \mathrm{~B}$ & $7727-37-9$ & Nitrate (as N) & 300 \\
\hline $75-34-3$ & 1,1-Dichloroethane & $8260 \mathrm{~B}$ & & $\mathrm{pH}$ & 150.1 \\
\hline $75-35-4$ & 1,1-Dichloroethylene & $8260 B$ & & Specific conductance & 120.1 \\
\hline $107-06-2$ & 1,2-Dichloroethane & $8260 B$ & & Sulfate & 300 \\
\hline $56-23-5$ & Carbon tetrachloride & $8260 \mathrm{~B}$ & & Total dissolved solids & 160.1 \\
\hline $108-90-7$ & Chlorobenzene & $8260 \mathrm{~B}$ & & Total organic carbon & 415.1 \\
\hline $67-66-3$ & Chloroform & $8260 \mathrm{~B}$ & & Total organic halogen & $9020 \mathrm{~B}$ \\
\hline $540-59-0$ & cis-1,2-Dichloroethylene & $8260 B$ & & Total suspended solids & 160.2 \\
\hline $540-59-0$ & trans-1, 2-Dichloroethylene & $8260 B$ & & & \\
\hline $78-93-3$ & Methyl ethyl ketone & $8260 B$ & & & \\
\hline $75-09-2$ & Methylene chloride & $8260 B$ & & & \\
\hline $127-18-4$ & Tetrachloroethylene & $8260 \mathrm{~B}$ & $7440-36-0$ & Alkalinity & 310.1 \\
\hline $108-88-3$ & Toluene & $8260 B$ & $7440-38-2$ & Antimony & $6010 \mathrm{~B}$ \\
\hline $79-01-6$ & Trichloroethylene & $8260 B$ & $7440-39-3$ & Arsenic & $6010 \mathrm{~B}$ \\
\hline $75-69-4$ & Trichlorofluoromethane & $8260 B$ & $7440-41-7$ & Barium & $6010 \mathrm{~B}$ \\
\hline $75-01-4$ & Vinyl chloride & $8260 B$ & $7440-43-9$ & Beryllium & $6010 \mathrm{~B}$ \\
\hline $1330-20-7$ & Xylene & $8260 B$ & $7440-70-2$ & Cadmium & $6010 \mathrm{~B}$ \\
\hline $95-50-1$ & 1,2-Dichlorobenzene & $8270 \mathrm{C}$ & $7440-47-3$ & Calcium & $6010 \mathrm{~B}$ \\
\hline $106-46-7$ & 1,4-Dichlorobenzene & $8270 \mathrm{C}$ & $7439-89-6$ & Chromium & $6010 \mathrm{~B}$ \\
\hline $51-28-5$ & 2,4-Dinitrophenol & $8270 \mathrm{C}$ & $7439-92-1$ & Iron & $6010 \mathrm{~B}$ \\
\hline $121-14-2$ & 2,4-Dinitrotoluene & $8270 \mathrm{C}$ & $7439-95-4$ & Lead & $6010 \mathrm{~B}$ \\
\hline $95-48-7$ & 2-Methylphenol & $8270 \mathrm{C}$ & $7439-97-6$ & Magnesium & $6010 \mathrm{~B}$ \\
\hline $108-39-4 /$ & 3-Methylphenol/ & $8270 \mathrm{C}$ & 2023473 & Mercury & $7470 A$ \\
\hline $106-44-5$ & 4-Methylphe & & 2023692 & Nickel & $6010 \mathrm{~B}$ \\
\hline $118-74-1$ & Hexachlorobenzene & $8270 \mathrm{C}$ & $7782-49-2$ & Potassium & $6010 \mathrm{~B}$ \\
\hline
\end{tabular}


Waste Isolation Pilot Plant Annual Site Environmental Report for 2006 DOE/WIPP-07-2225

\begin{tabular}{|c|c|c|c|c|c|}
\hline CAS No. ${ }^{a}$ & Parameter & $\begin{array}{c}\text { EPA } \\
\text { Method } \\
\text { Number }\end{array}$ & CAS No. & Parameter & $\begin{array}{c}\text { EPA } \\
\text { Method } \\
\text { Number }\end{array}$ \\
\hline $67-72-1$ & Hexachloroethane & $8270 \mathrm{C}$ & $7440-22-4$ & Selenium & 6010B \\
\hline $98-95-3$ & Nitrobenzene & $8270 \mathrm{C}$ & $7440-23-5$ & Silver & $6010 \mathrm{~B}$ \\
\hline $87-86-5$ & Pentachlorophenol & $8270 \mathrm{C}$ & $7440-28-0$ & Sodium & $6010 \mathrm{~B}$ \\
\hline $110-86-1$ & Pyridine & $8270 \mathrm{C}$ & $7440-62-2$ & Thallium & $6010 \mathrm{~B}$ \\
\hline $78-83-1$ & Isobutanol & 8015B & $7440-66-6$ & Vanadium & $6010 \mathrm{~B}$ \\
\hline
\end{tabular}

\subsubsection{Evaluation of Groundwater Quality}

The quality of the Culebra water sampled at the WIPP site is naturally poor and not suitable for human consumption or for agricultural purposes, because the TDS concentrations are generally above $10,000 \mathrm{mg} / \mathrm{L}$. In 2006, TDS concentrations in the Culebra (as measured in WQSP wells) varied from a low of $30,000 \mathrm{mg} / \mathrm{L}$ (WQSP-5) to a high of $225,000 \mathrm{mg} / \mathrm{L}$ (WQSP-3). The groundwater of the Culebra is considered to be Class III water by EPA guidelines.

Water quality measurements performed in the Dewey Lake indicate that the water is considerably better quality than that from the Culebra. In 2006, the TDS values in water from the well WQSP-6A, obtained from the Dewey Lake, averaged 3,340 mg/L. This water is suitable for livestock consumption, and is classified as Class II water by EPA guidelines. Saturation of the Dewey Lake in the area of WIPP is discontinuous. In addition to this naturally occurring groundwater, anthropogenic shallow subsurface water has been encountered in the upper Dewey Lake at the Santa Rosa contact (see Section 6.6).

Because of the highly variable TDS values within the Culebra, baseline groundwater quality was defined for each individual well. The analytical results for detectable constituents are plotted as Time Trend Plots compared to the baseline established prior to 2000 (Appendix E, Figures E.1 through E.98). The results of analyses for each parameter or constituent for the two sampling sessions in 2006 (Rounds 22 and 23) are summarized in Appendix F, Tables F.1 through F.7.

In these tables, either the $95^{\text {th }}$ upper tolerance limit value (UTLV) or the $95^{\text {th }}$ percentile value (as calculated for the background sampling rounds) is presented for each parameter depending on the type of distribution exhibited by the parameter or constituent. Both values represent the value beneath which 95 percent of the values in a population are expected to occur. The UTLVs were calculated for data that exhibited a normal or a lognormal distribution. The $95^{\text {th }}$ percentile was determined for data that were considered nonparametric; having neither a normal nor a lognormal distribution. Due to the large number of nondetectable concentrations of organic compounds, the limits for organic compounds were considered nonparametric and based on the contract 
required reporting limit for the contract laboratory. These values have been recomputed after baseline sampling was completed in 2000, and were used for sampling Rounds 22 and 23 to evaluate potential contamination of the local groundwater.

In a few isolated cases during 2006, reported concentrations of some parameters, such as potassium, calcium, magnesium, sulfate, chloride, and TDS slightly exceeded the calculated $95^{\text {th }}$ percentile or the $95^{\text {th }}$ UTLV. Such exceedences do not indicate the presence of contamination. The $95^{\text {th }}$ UTLV or percentile is a value representing where 5 percent of the concentration in the population will be greater than the UTLV or percentile. WIPP groundwater in the Culebra has very high concentrations of dissolved solids and major cations and anions. The laboratory reported concentrations for parameters such as sulfate and chloride are variable between rounds.

\subsubsection{Groundwater Level Surveillance}

Groundwater surface elevations in the vicinity of WIPP have been and may still be affected by localized disturbances, such as pumping tests for site characterization dating to the 1980s, water quality sampling, or well development. Other causes of groundwater surface elevation changes may be natural groundwater level fluctuations and industrial water use for agriculture, mining, and resource exploration.

Well bores were used to perform surveillance of five water-bearing zones in the WIPP area:

- $\quad$ Shallow Subsurface water (Santa Rosa/Dewey Lake Interface)

- $\quad$ Dewey Lake

- Magenta

- Culebra

- Bell Canyon

The two zones of interest are the Culebra and Magenta (see Figure 6.1). Throughout 2006, and until such time as wells were plugged or new wells brought into the network, water levels in up to 53 Culebra wells were measured (includes the Culebra zone of dual completion wells) and 15 wells in the Magenta (includes the Magenta zone of dual completion wells). One Dewey Lake well and two Bell Canyon wells were monitored. Sixteen wells in the shallow zone of the Santa Rosa/Dewey Lake interface were monitored. Groundwater level measurements were taken monthly in at least one accessible well bore at each well site for each available formation (Figure 6.2). Redundant well bores (well bores located on well pads with multiple wells completed in the same formation) at each well site were measured on a quarterly basis (Appendix $F$, Table F.8).

A breakout of groundwater zone(s) intercepted by each well measured at least once in 2006 is given in Appendix F, Table F.9. Note that five existing wells (WIPP-30, Culebra/Magenta; C-2737, Culebra/Magenta; WIPP-25, Culebra/Magenta; H-9c, Culebra/Magenta; and H-15, Culebra/Magenta) are completed at multiple depths. By using packers, these wells monitor more than one formation. 
Water elevation trend analysis was performed for 39 of 53 wells completed or isolated to the Culebra. The subset of wells analyzed were those which had a sufficient period of record to analyze through CY 2006, did not display anomalous levels, and were representative of more than one well at a given well pad (Appendix F, Table F.9). Excluded from trend analysis were AEC-7 (water level rising through the bottom seal and not representative of Culebra water) and SNL-15 (water level up over 40 feet and therefore not in equilibrium).

The dominant trend through 2006 was a spatially uniform, rising freshwater equivalent level in the Culebra, with a slight plateau in the last three months of the year. By "dominant," it is meant that (a) water levels rose in 32 of 39 wells from January through December (or shorter periods in wells that still had a discernable trend), (b) the average water level rise was 2.1 feet, and (c) the general water level rise is best indicated by nearly half of measured water level rising in the 2.5-to-3.0-foot range.

Water levels in the Culebra Dolomite Member of the Rustler Formation, and to a lesser extent in the Magenta Member, have generally been rising throughout the history of WIPP. The rise was not recognized until recently because of well drilling and testing, shaft sinking, and other activities that disturbed water levels. Since the major activities associated with WIPP site characterization are completed, and other groundwater disturbing activities are minimal, the rise in water levels has become evident.

The water-level rise is not monotonic, but shows variations related to factors both known and hypothesized. Water levels in the Culebra in Nash Draw, west of the WIPP site, respond to major rainfall events within a few days (Hillesheim et al., 2006). It is hypothesized that the change in head in Nash Draw then propagates under Livingston Ridge to the WIPP site in the succeeding weeks or months. It is also hypothesized that the Culebra may be receiving leakage through poorly plugged and abandoned drillholes, or through fractures in Nash Draw, from higher hydrologic units and/or potash tailings piles north of the WIPP site. For example, the observed long-term rise in water levels might be caused by the leakage into the Culebra of approximately 74 acre-ft/yr of the approximately 2,200 acre-ft/yr of brine discharged onto the Intrepid East tailings pile north of the WIPP site, and/or by the leakage of a similar volume through 26 potash exploration holes north, west, and south of the WIPP site that may not have been properly plugged through the Culebra (Lowry and Beauheim, 2004; 2005). Likewise, a number of plugged and abandoned oil or gas wells have been identified, mostly to the east and south of the WIPP site, that may not be plugged through the Culebra with cement and could, hypothetically, be sources of leakage that affects the head in the Culebra (Powers, 2004).

If the rise in water levels is due to any of these causes, it is expected to continue for the foreseeable future. Because of the wide areal distribution of the rise, it is not resulting in significant changes in the hydraulic gradient in the Culebra, which is what controls the rate and direction of groundwater flow. The DOE uses updated heads in calculating potential radionuclide releases through the Culebra in the performance assessments that are part of each Compliance Recertification Application. 
Figures 6.4 through 6.10 provide hydrographs of the DMP wells for CY 2006. The six Culebra wells (Figures 6.4 through 6.9; WQSP-6A is Dewey Lake) are typical of the hydrographs of the 53 wells analyzed for Culebra water level trends, though for this particular subset, none were in decline. The HWFP requires that the NMED be notified if a cumulative groundwater surface elevation change of more than two feet is observed in any DMP well which is not attributable to site tests or natural stabilization of the site hydrologic system. All of the DMP wells trended in line with the overall hydrologic system. The water level rise in the WQSP wells is part of a regional trend. There is no anomalous rise in the DMP wells outside this regional trend.

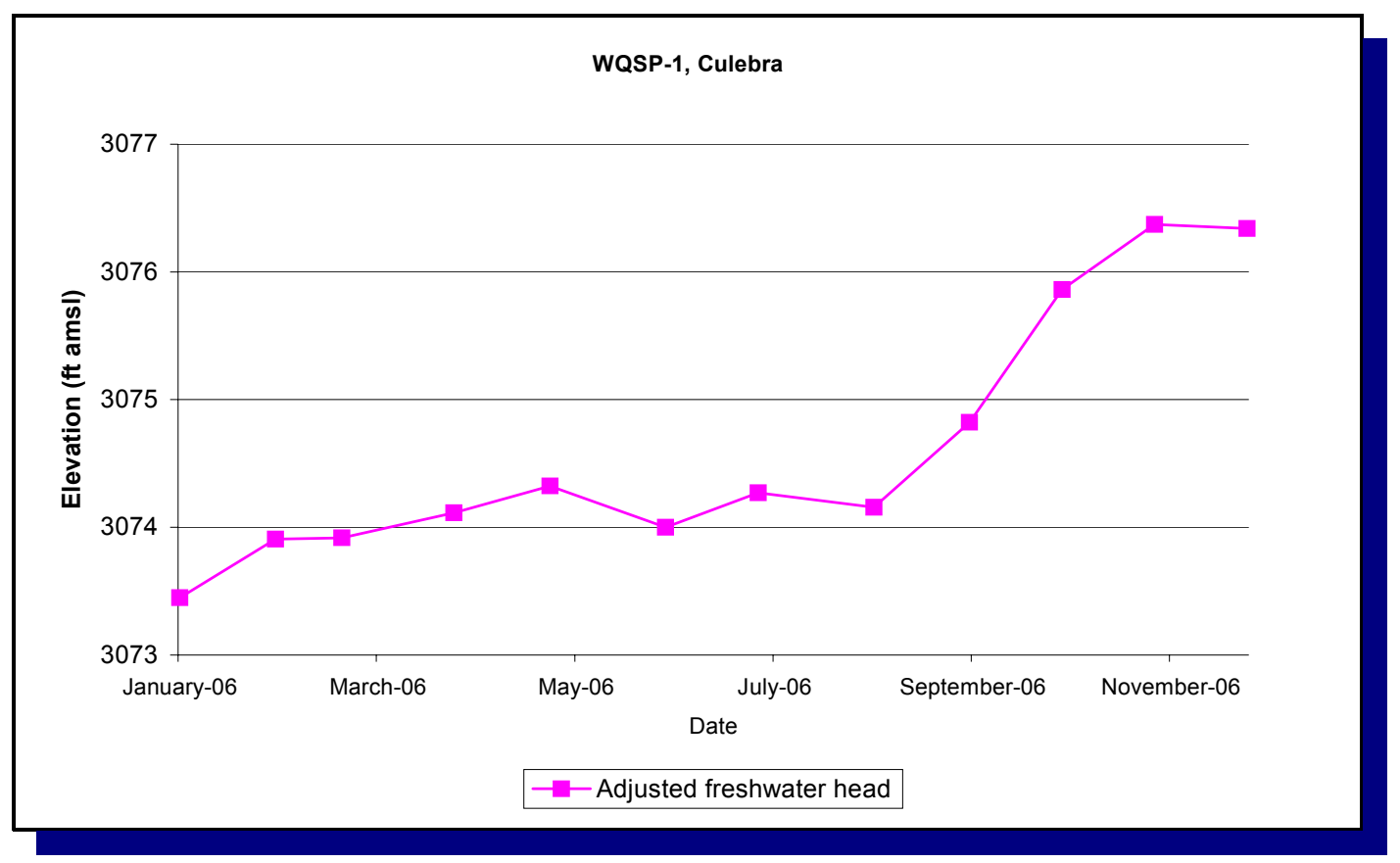

Figure 6.4 - Hydrograph of WQSP-1 
Waste Isolation Pilot Plant Annual Site Environmental Report for 2006 DOE/WIPP-07-2225

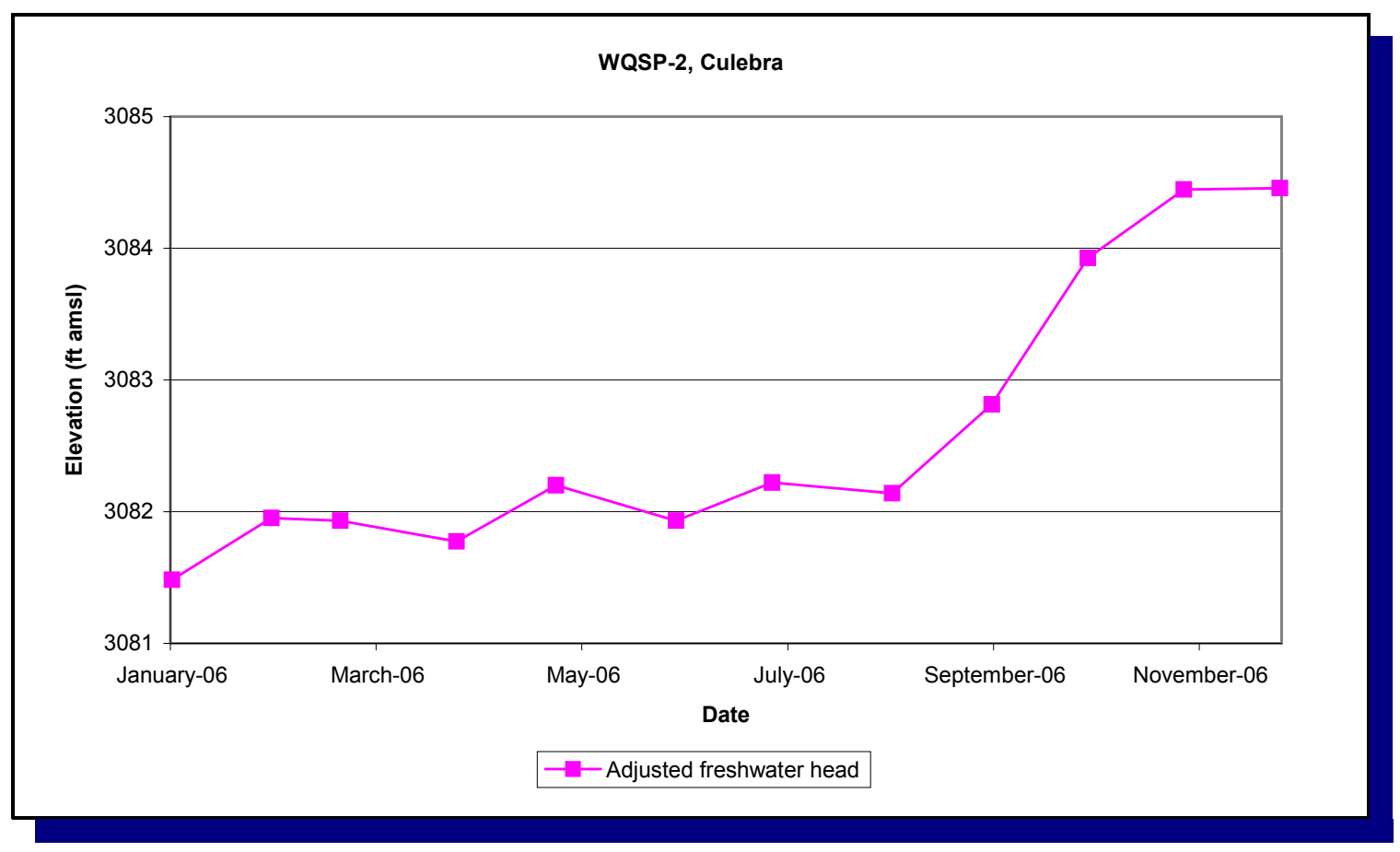

Figure 6.5 - Hydrograph of WQSP-2

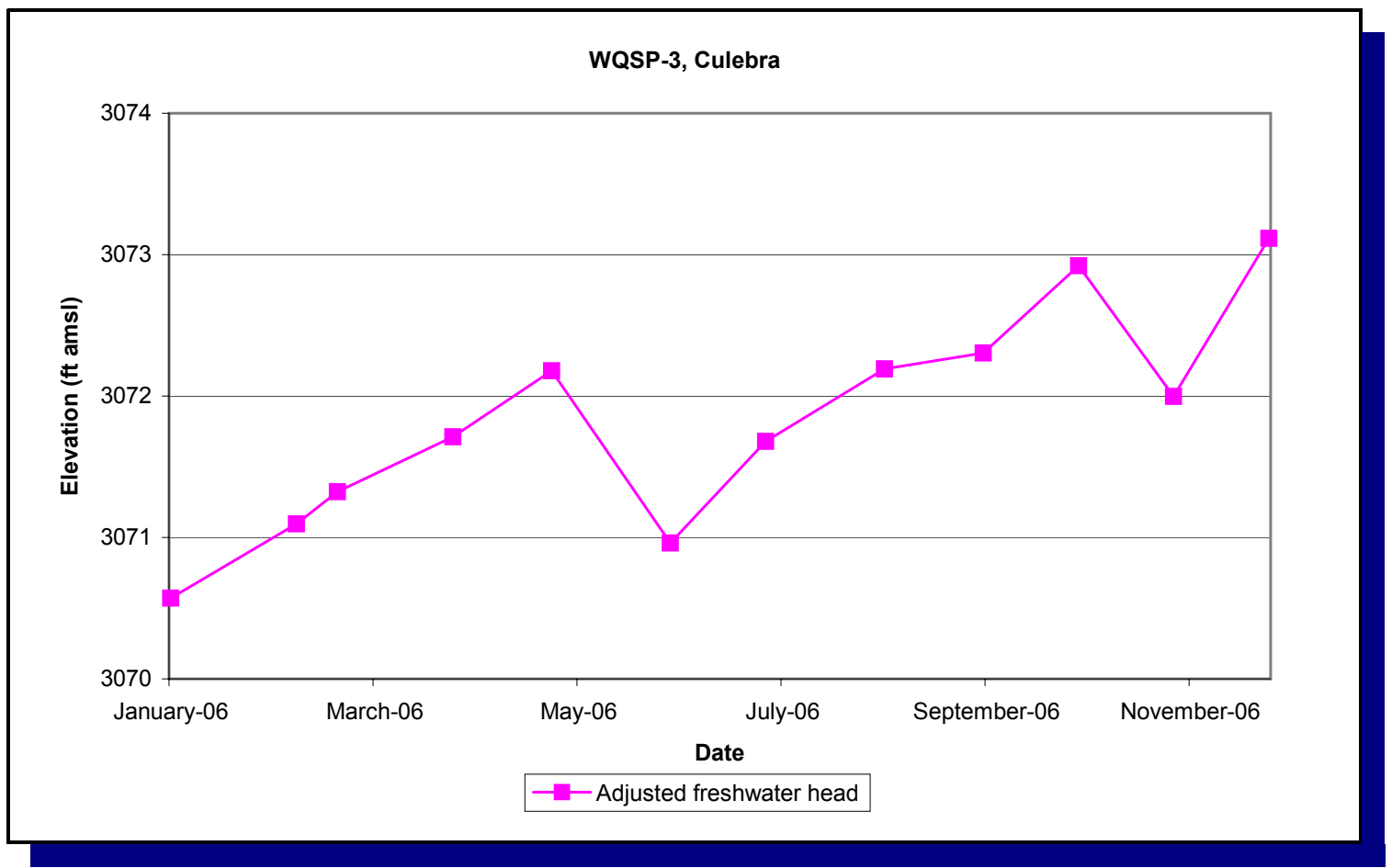

Figure 6.6 - Hydrograph of WQSP-3 
Waste Isolation Pilot Plant Annual Site Environmental Report for 2006 DOE/WIPP-07-2225

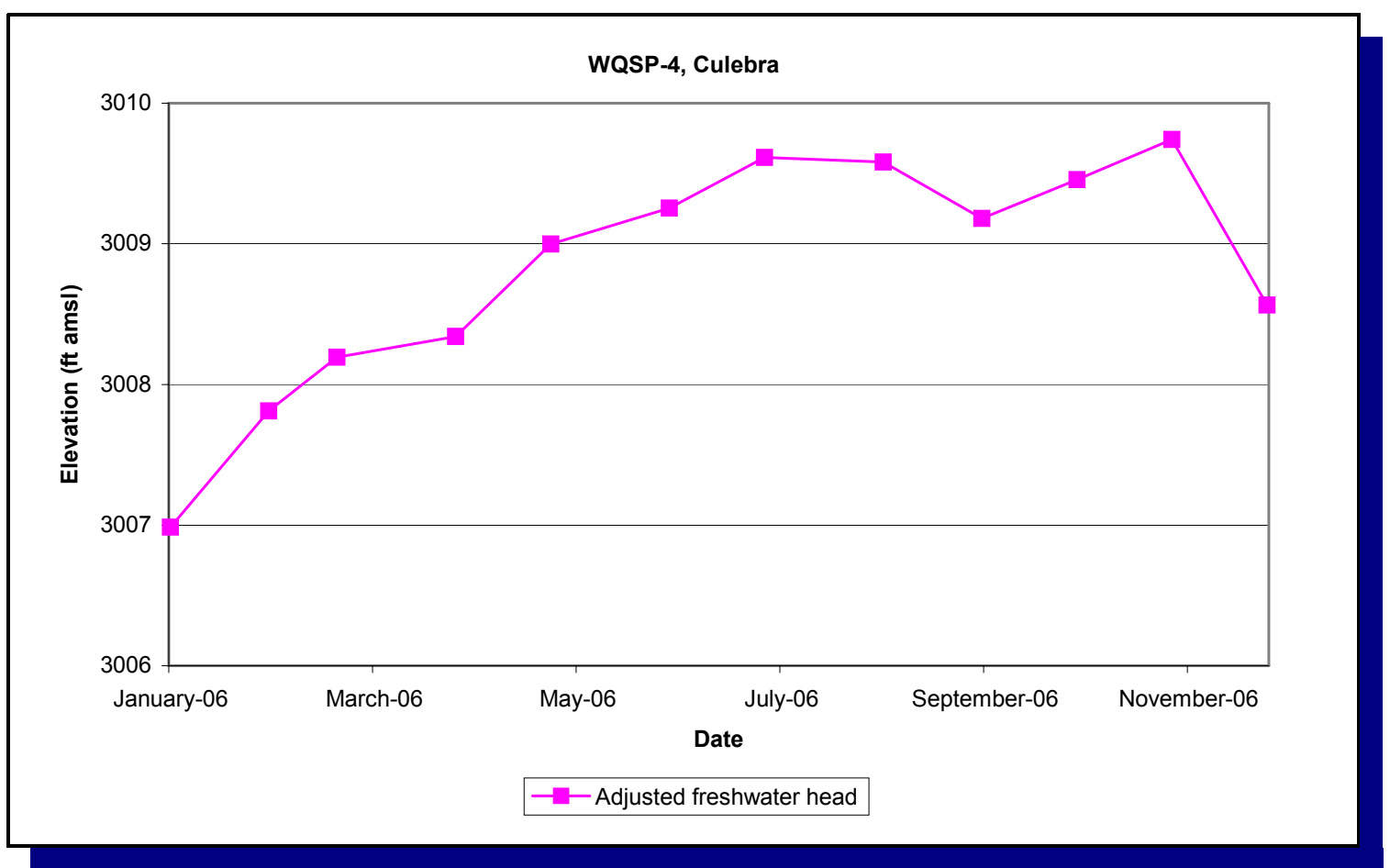

Figure 6.7 - Hydrograph of WQSP-4

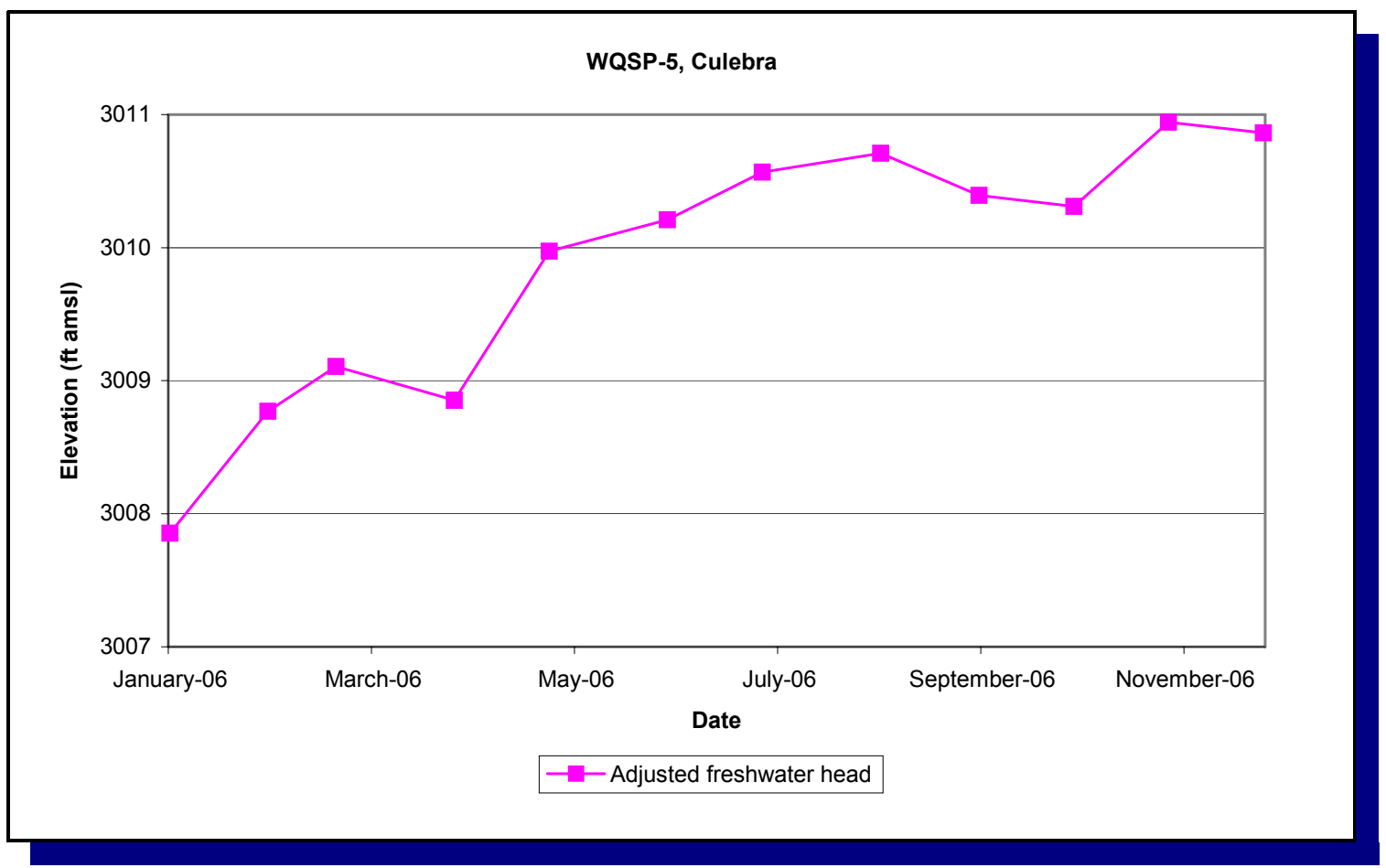

Figure 6.8 - Hydrograph of WQSP-5 


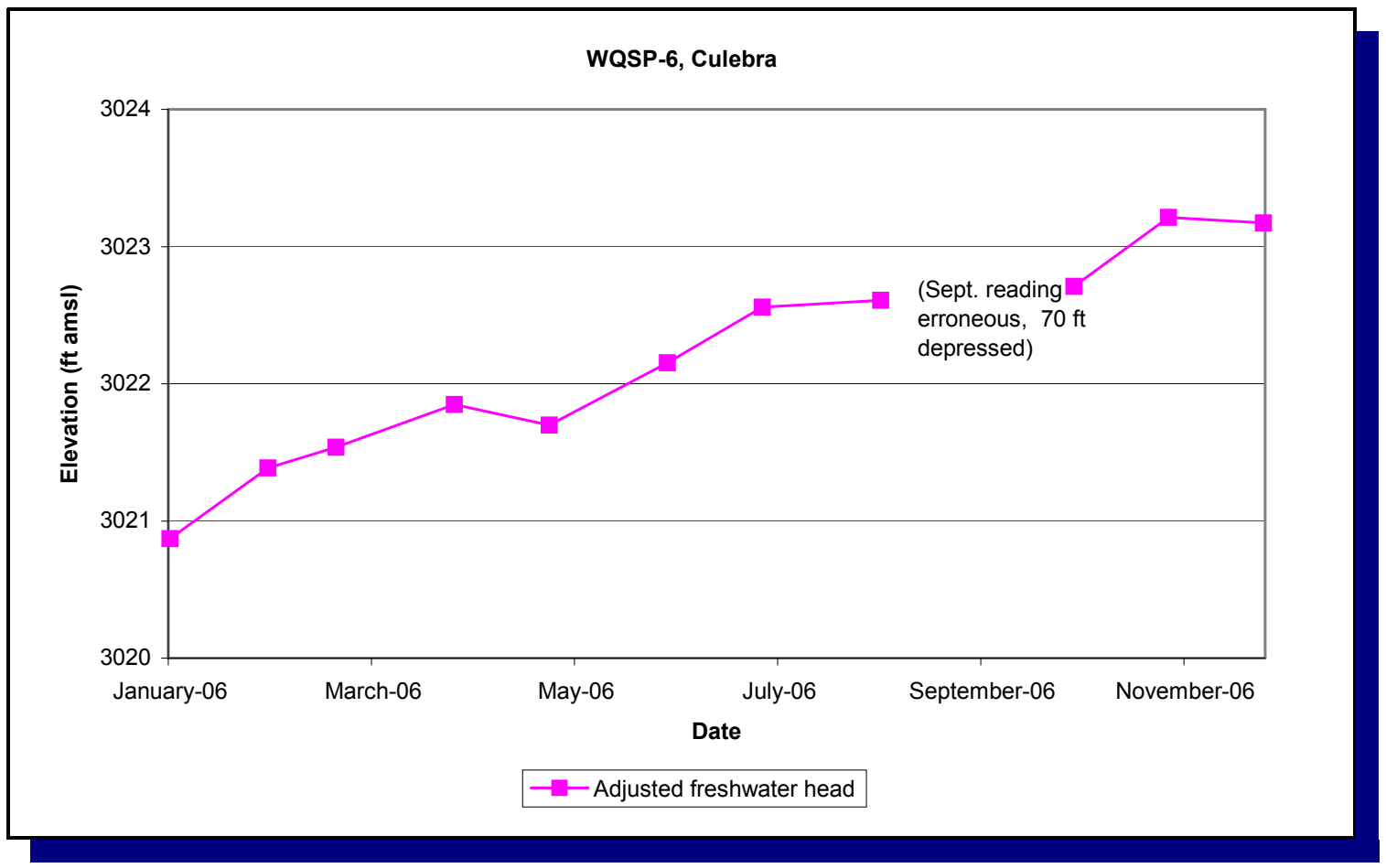

Figure 6.9 - Hydrograph of WQSP-6

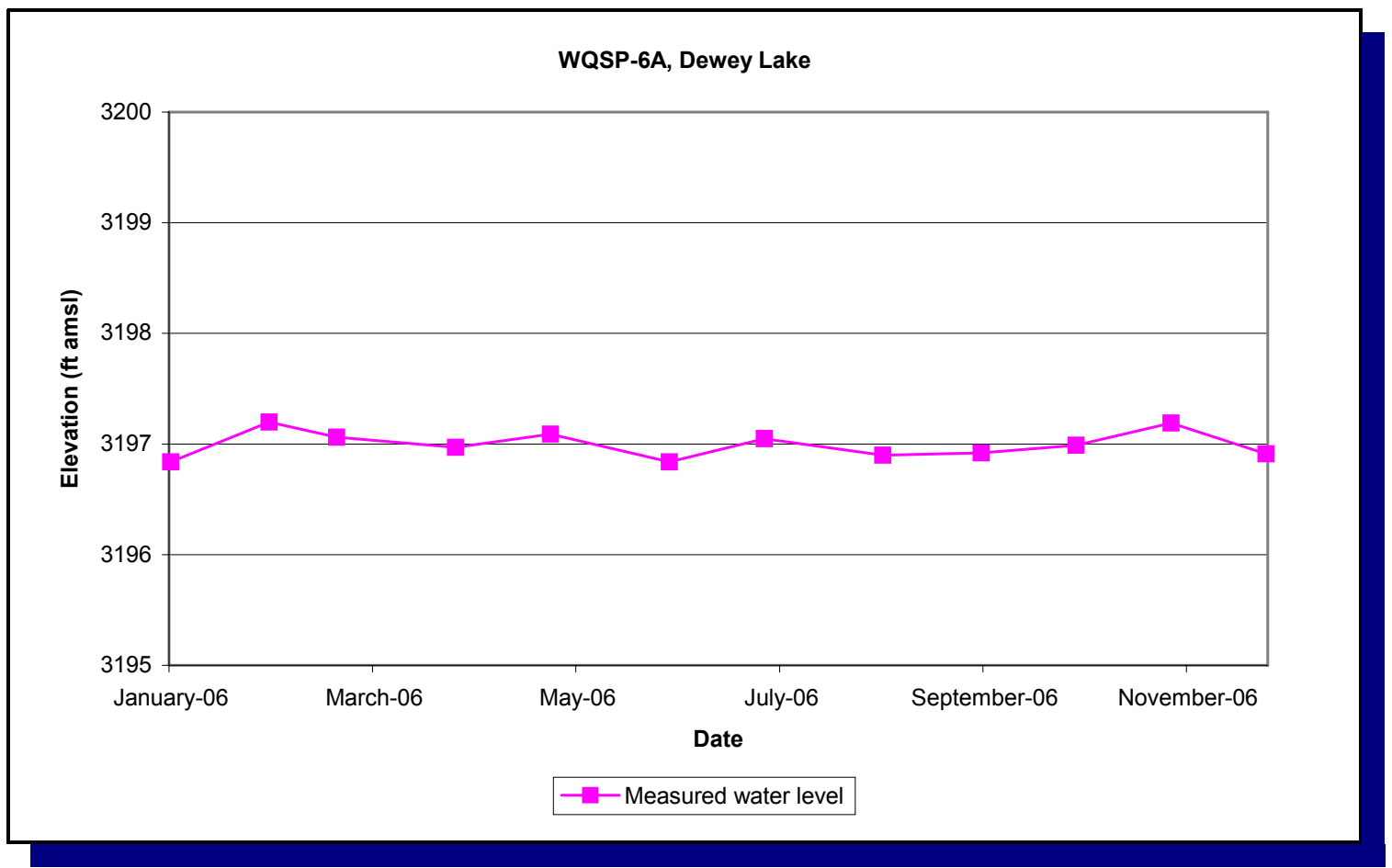

Figure 6.10 - Hydrograph of WQSP-6A 
Groundwater level data were transmitted on a monthly basis to the NMED, Sandia National Laboratories (SNL), and the CBFO Technical Assistance Contractor. A copy of the data was placed in the operating record for inspection by authorized agencies.

Regional Culebra flow is well-documented in the WIPP body of literature to be generally south. For the WIPP site, equivalent freshwater heads for November 2006 were used to contour the potentiometric surface map. Qualitatively, this month was judged to have a large number of Culebra water levels available, few wells affected by pumping events, and all wells in quasi-steady state with few individual wells contrary to the general water level trend. Table 6.3 shows the water level data set. Wells AEC-7 and SNL-15 were excluded from the data set for reasons stated earlier. Surrogate water levels were used as close to the November period to fill spatial reference points needed for contouring. The density data set used since June 2005, and through present, to adjust measured water levels to the adjusted freshwater head is shown and referenced. These densities were selected in consultation with the Scientific Advisor (SNL) as most representative for each well, based on a comprehensive review of historical measurements. The Scientific Advisor may adjust the density data set for groundwater modeling for the next Compliance Recertification Application, as new data are obtained. Different pressure density surveys may provide slightly different densities simply because of measurement error. Density is considered an innate property of the groundwater, susceptible to change only when stresses are induced such as well development, extended pumping, or water injection for slug tests. Hence, new density values are used only after such stresses have been induced in a well.

Table 6.3 - Water Level Elevations for the November 2006 Potentiometric Surface, Culebra Hydraulic Unit

\begin{tabular}{|c|c|c|c|c|c|}
\hline Well I.D. & $\begin{array}{c}\text { Date of } \\
\text { Measurement }\end{array}$ & $\begin{array}{c}\text { Adjusted } \\
\text { Freshwater } \\
\text { Head } \\
\text { (feet, msl) } \\
\end{array}$ & $\begin{array}{l}\text { Density Used } \\
\text { (grams/cc) }\end{array}$ & Source & Notes \\
\hline AEC-7 & See comment & 3062.00 & 1.089 & $\begin{array}{l}2000 \text { Pressure } \\
\text { Density survey }\end{array}$ & $\begin{array}{l}\text { Freshwater head of } 3,270.27 \\
\text { for November } 2006 \text { not } \\
\text { representative of Culebra } \\
\text { water. Heads rising since } \\
\text { September } 2004 \text { due to } \\
\text { leakage from Salado. } \\
\text { Surrogate value of } 3062 \text { used, } \\
\text { September } 2003 \text { through } \\
\text { March } 2004 \text { (typical). } \\
\text { Contours inferred in NE } \\
\text { quadrant. }\end{array}$ \\
\hline C-2737 (PIP) & $11 / 9 / 06$ & 3015.72 & 1.010 & $\begin{array}{l}2003 \text { water quality } \\
\text { test, average of } 17 \\
\text { specific gravity } \\
\text { readings, August - } \\
\text { September }\end{array}$ & \\
\hline DOE-1 & $\begin{array}{l}\text { See comment } \\
\text { in Notes. }\end{array}$ & 3031.85 & 1.099 & $\begin{array}{l}2004 \text { Pressure } \\
\text { Density survey }\end{array}$ & $\begin{array}{l}\text { Plugged and abandoned } \\
\text { September } 30,2006 \text {; water } \\
\text { levels were unreliable after } \\
\text { late } 2003 \text { due to leaking } \\
\text { packer. }\end{array}$ \\
\hline
\end{tabular}




\section{Waste Isolation Pilot Plant Annual Site Environmental Report for 2006 DOE/WIPP-07-2225}

\section{Table 6.3 - Water Level Elevations for the November 2006 Potentiometric Surface, Culebra Hydraulic Unit}

\begin{tabular}{|c|c|c|c|c|c|}
\hline Well I.D. & $\begin{array}{c}\text { Date of } \\
\text { Measurement }\end{array}$ & $\begin{array}{c}\text { Adjusted } \\
\text { Freshwater } \\
\text { Head } \\
\text { (feet, msl) }\end{array}$ & $\begin{array}{c}\text { Density Used } \\
\text { (grams/cc) }\end{array}$ & Source & Notes \\
\hline ERDA-9 & $11 / 9 / 2006$ & 3033.95 & 1.067 & $\begin{array}{l}\text { Average density } \\
\text { from SNL Troll } \\
\text { data, 05/26, 06/30, } \\
\text { 08/03, and } \\
\text { 09/30/04 }\end{array}$ & \\
\hline $\mathrm{H}-02 \mathrm{~B} 2$ & $11 / 9 / 2006$ & 3049.25 & 1.013 & $\begin{array}{l}2004 \text { Pressure } \\
\text { Density survey }\end{array}$ & \\
\hline $\mathrm{H}-03 \mathrm{~B} 2$ & $11 / 9 / 2006$ & 3011.22 & 1.036 & $\begin{array}{l}2003 \text { Pressure } \\
\text { Density survey }\end{array}$ & \\
\hline $\mathrm{H}-04 \mathrm{~B}$ & $11 / 8 / 2006$ & 3005.68 & 1.011 & $\begin{array}{l}2004 \text { Pressure } \\
\text { Density survey }\end{array}$ & \\
\hline $\mathrm{H}-05 \mathrm{~B}$ & $11 / 6 / 2006$ & 3081.50 & 1.099 & $\begin{array}{l}2004 \text { Pressure } \\
\text { Density survey }\end{array}$ & \\
\hline $\mathrm{H}-06 \mathrm{~B}$ & $11 / 6 / 2006$ & 3074.21 & 1.041 & $\begin{array}{l}2004 \text { Pressure } \\
\text { Density survey }\end{array}$ & \\
\hline H-07B1 & $11 / 8 / 2006$ & 3001.08 & 1.002 & DOE/WIPP 88-030 & \\
\hline $\mathrm{H}-09 \mathrm{C}(\mathrm{PIP})$ & $11 / 8 / 2006$ & 2995.27 & 1.005 & $\begin{array}{l}2002 \text { SNL } \\
\text { Measurement }\end{array}$ & \\
\hline $\mathrm{H}-10 \mathrm{C}$ & $11 / 9 / 2006$ & 3032.36 & 1.009 & $\begin{array}{l}2004 \text { Pressure } \\
\text { Density survey }\end{array}$ & \\
\hline $\mathrm{H}-11 \mathrm{~B} 4$ & $11 / 9 / 2006$ & 3006.96 & 1.064 & $\begin{array}{l}2003 \text { Pressure } \\
\text { Density survey }\end{array}$ & \\
\hline $\mathrm{H}-12$ & $11 / 9 / 2006$ & 3001.75 & 1.083 & $\begin{array}{l}2000 \text { Pressure } \\
\text { Density survey }\end{array}$ & \\
\hline $\mathrm{H}-15$ & $10 / 26 / 2006$ & 3024.28 & 1.097 & $\begin{array}{l}2004 \text { Troll data, } \\
\text { Jan - Feb average }\end{array}$ & $\begin{array}{l}\text { Testing in progress; SNL Troll } \\
\text { data used to estimate the } \\
\text { water level. }\end{array}$ \\
\hline $\mathrm{H}-17$ & $11 / 9 / 2006$ & 3007.07 & 1.136 & $\begin{array}{l}2004 \text { Pressure } \\
\text { Density survey }\end{array}$ & \\
\hline $\mathrm{H}-19 \mathrm{~B} 0$ & $11 / 8 / 2006$ & 3014.14 & 1.067 & $\begin{array}{l}2004 \text { Pressure } \\
\text { Density survey for } \\
\text { H-19B2 }\end{array}$ & $\begin{array}{l}\mathrm{H}-19 B 2, \mathrm{H}-19 \mathrm{~B} 3, \mathrm{H}-19 \mathrm{~B} 4 \\
\mathrm{H}-19 \mathrm{~B} 5, \mathrm{H}-19 \mathrm{~B} 6, \mathrm{H}-19 \mathrm{~B} 7\end{array}$ \\
\hline I-461 & $11 / 6 / 2006$ & 3054.74 & 1.004 & $\begin{array}{l}2004 \text { average } \\
\text { density from six } \\
\text { Troll } \\
\text { measurements, } \\
\text { August - } \\
\text { September }\end{array}$ & \\
\hline P-17 & $7 / 10 / 2006$ & 3006.22 & 1.069 & $\begin{array}{l}2004 \text { Pressure } \\
\text { Density survey }\end{array}$ & $\begin{array}{l}\text { Plugged and abandoned, } \\
\text { August } 18 \text { 2006; last } \\
\text { measured July 10, } 2006\end{array}$ \\
\hline SNL-01 & $11 / 6 / 2006$ & 3087.90 & 1.028 & $\begin{array}{l}\text { Specific gravity } \\
\text { meter reading, } \\
03 / 10 / 05\end{array}$ & \\
\hline SNL-02 & $11 / 6 / 2006$ & 3078.08 & 1.010 & $\begin{array}{l}\text { Specific gravity } \\
\text { meter reading, } \\
01 / 24 / 05\end{array}$ & \\
\hline
\end{tabular}


Waste Isolation Pilot Plant Annual Site Environmental Report for 2006 DOE/WIPP-07-2225

Table 6.3 - Water Level Elevations for the November 2006 Potentiometric Surface, Culebra Hydraulic Unit

\begin{tabular}{|c|c|c|c|c|c|}
\hline Well I.D. & $\begin{array}{c}\text { Date of } \\
\text { Measurement }\end{array}$ & $\begin{array}{c}\text { Adjusted } \\
\text { Freshwater } \\
\text { Head } \\
\text { (feet, msl) }\end{array}$ & $\begin{array}{c}\text { Density Used } \\
\text { (grams/cc) }\end{array}$ & Source & Notes \\
\hline SNL-03 & $11 / 6 / 2006$ & 3086.46 & 1.035 & $\begin{array}{l}\text { Specific gravity } \\
\text { meter reading, } \\
04 / 16 / 04\end{array}$ & \\
\hline SNL-05 & $11 / 6 / 2006$ & 3081.71 & 1.011 & $\begin{array}{l}\text { Specific gravity } \\
\text { meter reading, } \\
07 / 24 / 04\end{array}$ & \\
\hline SNL-06 & & No meas. & & & $\begin{array}{l}\text { Water level too deep for } \\
\text { probe; }>1,000 \mathrm{ft} \text {. }\end{array}$ \\
\hline SNL-08 & $11 / 6 / 2006$ & 3054.71 & 1.056 & $\begin{array}{l}2005 \text { Pressure } \\
\text { Density survey }\end{array}$ & \\
\hline SNL-09 & $11 / 6 / 2006$ & 3058.80 & 1.022 & $\begin{array}{l}\text { Specific gravity } \\
\text { meter reading, } \\
12 / 6 / 03\end{array}$ & \\
\hline SNL-10 & $11 / 30 / 2006$ & 3053.77 & 1.001 & $\begin{array}{l}\text { Density meter, well } \\
\text { development, } \\
\text { 06/22/06 }\end{array}$ & $\begin{array}{l}\text { Last monthly water level } \\
3,054.64 \text { measured in } \\
\text { September } 2006 \text { before } \\
\text { testing; SNL Troll data used to } \\
\text { estimate the water level; } \\
\text { pumped between } 10 / 30 / 06 \\
\text { and } 11 / 03 / 06 \text { and appears } \\
\text { recovered. }\end{array}$ \\
\hline SNL-12 & $11 / 6 / 2006$ & 3002.41 & 1.004 & $\begin{array}{l}\text { Specific gravity } \\
\text { meter reading, } \\
08 / 14 / 04\end{array}$ & \\
\hline SNL-13 & $11 / 6 / 2006$ & 3015.03 & 1.054 & $\begin{array}{l}\text { Density meter, well } \\
\text { development, } \\
\text { 05/30/05 }\end{array}$ & \\
\hline SNL-14 & $11 / 1 / 2006$ & 3010.97 & 1.062 & $\begin{array}{l}\text { Specific gravity } \\
\text { meter reading, } \\
08 / 14 / 05\end{array}$ & $\begin{array}{l}\text { Last monthly water level } \\
\text { measured in September } 2006 \\
\text { before testing; SNL Troll data } \\
\text { used to estimate the water } \\
\text { level. }\end{array}$ \\
\hline SNL-15 & See comment & $\begin{array}{l}\text { Do not use } \\
\text { meas. }\end{array}$ & 1.230 & $\begin{array}{l}2005 \text { Pressure } \\
\text { Density survey }\end{array}$ & $\begin{array}{l}\text { Water level up about } 42 \text { feet } \\
\text { since April } 2006, \text { still rising } \\
\text { several feet per month. } \\
\text { Abnormally depressed from } \\
\text { projected steady Culebra } \\
\text { head at this location, no good } \\
\text { for potentiometric surface, do } \\
\text { not use November value of } \\
2,881.05 \text {. Well still recovering } \\
\text { from development. }\end{array}$ \\
\hline SNL-16 & $11 / 8 / 2006$ & 3013.61 & 1.014 & $\begin{array}{l}2006 \text { Specific } \\
\text { gravity meter } \\
\text { reading, SNL } \\
\text { testing }\end{array}$ & \\
\hline SNL-17 & $11 / 6 / 2006$ & 3007.10 & 1.001 & $\begin{array}{l}\text { Density meter, well } \\
\text { development, } \\
\text { 07/20/06 }\end{array}$ & \\
\hline
\end{tabular}


Waste Isolation Pilot Plant Annual Site Environmental Report for 2006 DOE/WIPP-07-2225

Table 6.3 - Water Level Elevations for the November 2006 Potentiometric Surface, Culebra Hydraulic Unit

\begin{tabular}{|c|c|c|c|c|c|}
\hline Well I.D. & $\begin{array}{c}\text { Date of } \\
\text { Measurement }\end{array}$ & $\begin{array}{c}\text { Adjusted } \\
\text { Freshwater } \\
\text { Head } \\
\text { (feet, msl) }\end{array}$ & $\begin{array}{c}\text { Density Used } \\
\text { (grams/cc) }\end{array}$ & Source & Notes \\
\hline SNL-18 & $11 / 6 / 2006$ & 3078.97 & 1.015 & $\begin{array}{l}2006 \text { Specific } \\
\text { gravity meter } \\
\text { reading, SNL } \\
\text { testing }\end{array}$ & \\
\hline SNL-19 & $11 / 6 / 2006$ & 3078.00 & 1.007 & $\begin{array}{l}2006 \text { Specific } \\
\text { gravity meter } \\
\text { reading, SNL } \\
\text { testing }\end{array}$ & \\
\hline WIPP-11 & $11 / 9 / 2006$ & 3088.85 & 1.038 & $\begin{array}{l}2005 \text { pumping test } \\
\text { water sample, } \\
02 / 20 / 05\end{array}$ & \\
\hline WIPP-13 & $11 / 8 / 2006$ & 3082.34 & 1.050 & $\begin{array}{l}2004 \text { Pressure } \\
\text { Density survey }\end{array}$ & \\
\hline WIPP-19 & $11 / 8 / 2006$ & 3068.78 & 1.060 & $\begin{array}{l}2004 \text { Pressure } \\
\text { Density survey }\end{array}$ & \\
\hline WIPP-25 (PIP) & $11 / 9 / 2006$ & 3078.72 & 1.022 & $\begin{array}{l}2004 \text { pumping test } \\
\text { water sample, } \\
\text { 09/22/04 }\end{array}$ & $\begin{array}{l}\text { Last monthly water level } \\
\text { measured January 2006; SNL } \\
\text { Troll data used to estimate the } \\
\text { water level. }\end{array}$ \\
\hline WIPP-26 & $8 / 15 / 2006$ & 3025.47 & 1.019 & $\begin{array}{l}2003 \text { Pressure } \\
\text { Density survey }\end{array}$ & $\begin{array}{l}\text { Plugged and abandoned, } \\
\text { October } 12,2006 \text {; last } \\
\text { monthly water level measured } \\
08 / 15 / 06\end{array}$ \\
\hline WIPP-27 (PIP) & & No meas. & 1.040 & $\begin{array}{l}\text { Specific gravity } \\
\text { meter reading, } \\
02 / 23 / 05\end{array}$ & $\begin{array}{l}\text { Plugged and abandoned, } \\
\text { August 9, 2006; last } \\
\text { measured 11/08/05. Access } \\
\text { road washed out all of } \\
\text { CY } 2006\end{array}$ \\
\hline WIPP-30 (PIP) & $11 / 6 / 2006$ & 3087.84 & 1.025 & $\begin{array}{l}\text { SAND 89-7068, } \\
\text { Volume } 2\end{array}$ & \\
\hline WQSP-1 & $11 / 8 / 2006$ & 3076.37 & 1.040 & $\begin{array}{l}2004 \text { Round } 18 \\
\text { sampling, March } \\
\text { through May }\end{array}$ & \\
\hline WQSP-2 & $11 / 8 / 2006$ & 3084.45 & 1.040 & $\begin{array}{l}2004 \text { Round } 18 \\
\text { sampling, March } \\
\text { through May }\end{array}$ & \\
\hline WQSP-3 & $11 / 8 / 2006$ & 3072.00 & 1.140 & $\begin{array}{l}2004 \text { Round } 18 \\
\text { sampling, March } \\
\text { through May }\end{array}$ & \\
\hline WQSP-4 & $11 / 8 / 2006$ & 3009.74 & 1.060 & $\begin{array}{l}2004 \text { Round } 18 \\
\text { sampling, March } \\
\text { through May }\end{array}$ & \\
\hline WQSP-5 & $11 / 8 / 2006$ & 3010.94 & 1.020 & $\begin{array}{l}2004 \text { Round } 18 \\
\text { sampling, March } \\
\text { through May }\end{array}$ & \\
\hline WQSP-6 & $11 / 8 / 2006$ & 3023.21 & 1.010 & $\begin{array}{l}2004 \text { Round } 18 \\
\text { sampling, March } \\
\text { through May }\end{array}$ & \\
\hline
\end{tabular}


Water level contours of the Culebra for November 2006 are shown on Figure 6.11. These were created using SURFER version 8.06 .39 surface mapping software by Golden Software. The well coordinates $(X, Y)$ are based on a comprehensive resurvey of the well network (see Section 6.5). Forty-four water level elevation data points (Z) from Table 6.3 were used. The method used to generate the data grid was kriging with 100 rows and 73 columns (7,300 nodes). After kriging and contouring the entire spectrum of wells in the database (44 used), the contour map was excised to that seen in Figure 6.11. Although this figure is visually scaled down to focus on the site, the contours represent the entire network of data points used in the kriging and contouring process. The shaping of the contours at the LWA boundary thus represents far-range control afforded by wells not seen on the figure. 


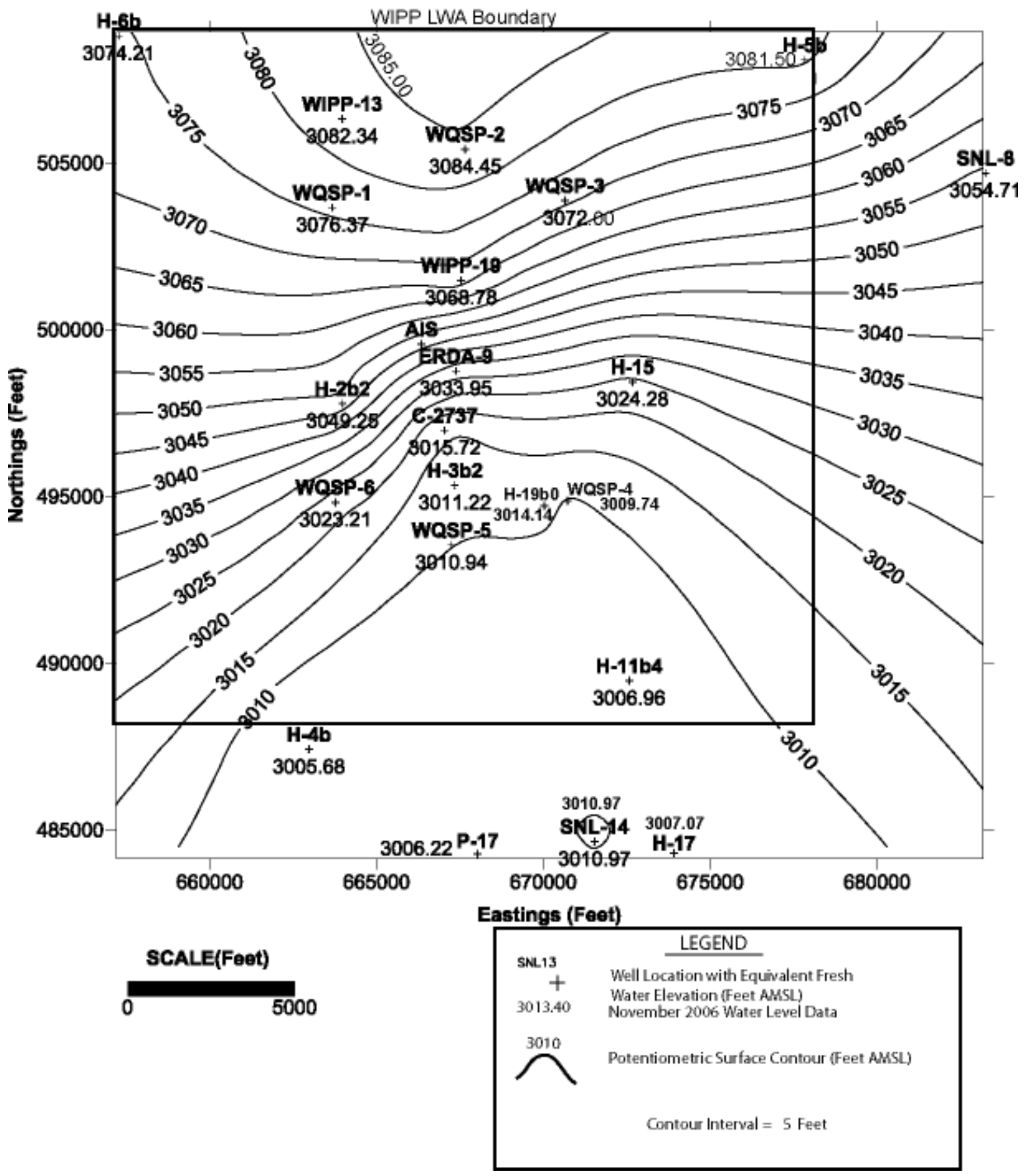

Figure 6.11 - Culebra Potentionmetric Surface Map 
Culebra flow rates across the WIPP Land Withdrawal Area were determined for three flow paths across the site, and calculating the discharge velocity for these flow paths was calculated using the following equation.

$q=K i$

Where:

$\mathrm{K}=$ geometric mean of hydraulic conductivity values for the flow domain $\mathrm{i}=$ hydraulic gradient across the flow segment (i.e., incremental gradient $=$ perpendicular distance between contour for each segment)

The discharge velocity across the WIPP Land Withdrawal Area ranged from a high of $1.30 \mathrm{E}-04 \mathrm{~m} / \mathrm{d}(4.27 \mathrm{E}-04 \mathrm{ft} / \mathrm{d})$ to a low of $4.34 \mathrm{E}-05 \mathrm{~m} / \mathrm{d}(1.42 \mathrm{E}-04 \mathrm{ft} / \mathrm{d})$. The average discharge velocity across the WIPP Land Withdrawal Area was calculated to be 1.06E-04 m/d (3.48E-04 ft/d). Typical segment gradients ranged from 0.002 to 0.006 ; hydraulic conductivity was set to $0.022 \mathrm{~m} / \mathrm{d}(0.071 \mathrm{ft} / \mathrm{d})$.

\subsubsection{Pressure Density Surveys}

At the WIPP site, variable TDS concentrations result in variability in groundwater density. WIPP measures the density of well-bore fluids in water level monitoring wells to adjust water levels to their equivalent fresh-water head values. This allows more accurate determination of relative heads between wells.

In 2006, density measurements were taken in 47 wells, as shown in Table 6.4. Most were from pressure density surveys, whereas for the WQSP wells, field hydrometer tests were used.

\begin{tabular}{lrccc}
\hline \multicolumn{4}{c}{ Table 6.4 - Pressure Density Survey for 2006 } \\
\hline Well I.D. & \multicolumn{1}{c}{$\begin{array}{c}\text { Date } \\
\text { Measured }\end{array}$} & $\begin{array}{c}\text { Hydraulic } \\
\text { Unit }\end{array}$ & $\begin{array}{c}\text { Density } \\
\text { (grams/cc) }\end{array}$ & Notes/Associated Wells on Pad \\
\hline AEC-7 & $11 / 29 / 2006$ & Culebra & 1.211 & Not representative of Culebra water \\
C-2737 & $8 / 8 / 2006$ & Culebra & 1.027 & \\
H-02B2 & $8 / 8 / 2006$ & Culebra & 1.000 & \\
H-03B2 & $8 / 14 / 2006$ & Culebra & 1.009 & \\
H-04B & $8 / 16 / 2006$ & Culebra & 1.021 & \\
H-05B & $8 / 17 / 2006$ & Culebra & 1.099 & \\
H-06B & $8 / 3 / 2006$ & Culebra & 1.043 & \\
H-07B1 & $8 / 16 / 2006$ & Culebra & 1.006 & \\
H-09C & $8 / 29 / 2006$ & Culebra & 1.007 & \\
H-10C & $8 / 21 / 2006$ & Culebra & 1.005 & \\
H-11B4 & $8 / 14 / 2006$ & Culebra & 1.071 & \\
H-12 & $8 / 21 / 2006$ & Culebra & 1.108 & \\
H-17 & $8 / 16 / 2006$ & Culebra & 1.134
\end{tabular}


Waste Isolation Pilot Plant Annual Site Environmental Report for 2006 DOE/WIPP-07-2225

\begin{tabular}{|c|c|c|c|c|}
\hline \multicolumn{5}{|c|}{ Table 6.4 - Pressure Density Survey for 2006} \\
\hline Well I.D. & $\begin{array}{c}\text { Date } \\
\text { Measured }\end{array}$ & $\begin{array}{l}\text { Hydraulic } \\
\text { Unit }\end{array}$ & $\begin{array}{c}\text { Density } \\
\text { (grams/cc) }\end{array}$ & Notes/Associated Wells on Pad \\
\hline $\mathrm{H}-19 \mathrm{~B} 0$ & $8 / 14 / 2006$ & Culebra & 1.071 & $\begin{array}{l}\mathrm{H}-19 \mathrm{~B} 2, \mathrm{H}-19 \mathrm{~B} 3, \mathrm{H}-19 \mathrm{~B} 4, \mathrm{H}-19 \mathrm{~B} 5, \mathrm{H}-19 \mathrm{~B} 6, \\
\mathrm{H}-19 \mathrm{~B} 7\end{array}$ \\
\hline $\mathrm{I}-461$ & $8 / 29 / 2006$ & Culebra & 1.017 & \\
\hline SNL-01 & $8 / 1 / 2006$ & Culebra & 1.027 & \\
\hline SNL-02 & $8 / 28 / 2006$ & Culebra & 1.017 & \\
\hline SNL-03 & $8 / 1 / 2006$ & Culebra & 1.028 & \\
\hline SNL-05 & $7 / 26 / 2006$ & Culebra & 1.010 & \\
\hline SNL-08 & $8 / 22 / 2006$ & Culebra & 1.051 & \\
\hline SNL-09 & $8 / 3 / 2006$ & Culebra & 1.024 & \\
\hline SNL-10 & $8 / 28 / 2006$ & Culebra & 1.004 & \\
\hline SNL-12 & $8 / 22 / 2006$ & Culebra & 1.006 & \\
\hline SNL-13 & $7 / 26 / 2006$ & Culebra & 1.008 & \\
\hline SNL-14 & $7 / 25 / 2006$ & Culebra & 1.038 & \\
\hline SNL-15 & $8 / 22 / 2006$ & Culebra & 1.221 & \\
\hline SNL-16 & $7 / 26 / 2006$ & Culebra & 1.00 & \\
\hline WIPP-11 & $8 / 1 / 2006$ & Culebra & 1.039 & \\
\hline WIPP-13 & $8 / 17 / 2006$ & Culebra & 1.041 & \\
\hline WIPP-19 & $8 / 17 / 2006$ & Culebra & 1.055 & \\
\hline WIPP-30 & $8 / 29 / 2006$ & Culebra & 1.007 & \\
\hline WQSP-1 & $11 / 15 / 2006$ & Culebra & 1.048 & Round 23 , field hydrometer \\
\hline WQSP-2 & $11 / 1 / 2006$ & Culebra & 1.047 & Round 23 , field hydrometer \\
\hline WQSP-3 & $10 / 25 / 2006$ & Culebra & 1.145 & Round 23 , field hydrometer \\
\hline WQSP-4 & $10 / 18 / 2006$ & Culebra & 1.074 & Round 23 , field hydrometer \\
\hline WQSP-5 & $10 / 4 / 2006$ & Culebra & 1.025 & Round 23 , field hydrometer \\
\hline WQSP-6 & $9 / 13 / 2006$ & Culebra & 1.014 & Round 23 , field hydrometer \\
\hline $\mathrm{H}-02 \mathrm{~B} 1$ & 8/8/2006 & Magenta & 1.009 & \\
\hline $\mathrm{H}-03 \mathrm{~B} 1$ & 8/8/2006 & Magenta & 1.007 & \\
\hline $\mathrm{H}-04 \mathrm{C}$ & $8 / 16 / 2006$ & Magenta & 1.009 & \\
\hline $\mathrm{H}-06 \mathrm{C}$ & $8 / 3 / 2006$ & Magenta & 1.007 & \\
\hline $\mathrm{H}-08 \mathrm{~A}$ & $8 / 22 / 2006$ & Magenta & 1.032 & \\
\hline $\mathrm{H}-10 \mathrm{~A}$ & $8 / 21 / 2006$ & Magenta & 1.004 & \\
\hline $\mathrm{H}-11 \mathrm{~B} 2$ & $8 / 14 / 2006$ & Magenta & 1.040 & \\
\hline $\mathrm{H}-14$ & $8 / 16 / 2006$ & Magenta & 1.006 & \\
\hline $\mathrm{H}-18$ & 8/3/2006 & Magenta & 1.006 & \\
\hline WIPP-18 & $8 / 17 / 2006$ & Magenta & 1.004 & \\
\hline Notes: & $\begin{array}{l}\text { SNL-6, water } \\
\text { ERDA-9, tub } \\
\text { H-15, SNL-1 } \\
\text { WIPP-27 (PI }\end{array}$ & $\begin{array}{l}\text { level too de } \\
\text { ing obstructe } \\
\text { 7, SNL-18, } \\
\text { P), inaccess }\end{array}$ & $\begin{array}{l}\text { p for probe } \\
\text { above ideal } \\
\text { NL-19, WIPP. } \\
\text { le due to bac }\end{array}$ & $\begin{array}{l}\text { sampling interval } \\
-25, \text { testing in progress } \\
\text { d road }\end{array}$ \\
\hline
\end{tabular}




\subsection{Drilling Activities}

Five wells were drilled and completed in the Culebra during 2006: SNL-16, SNL-17, SNL-19, SNL-10, and SNL-18, in that order. These wells were drilled to provide new monitoring and testing locations to support continued area-wide modeling of groundwater flow in the Culebra. The new hydrologic testing and modeling is intended to address the issue of region-wide rises in Culebra water levels observed over the past several years. The wells were drilled to the south, west, and north of the WIPP site to provide additional geologic and hydrologic information such as degree of dissolution in the upper Salado, fracturing and transmissivity of the Culebra along the upper Salado dissolution margin, and hydrologic information from areas of Nash Draw along potential discharge and recharge paths.

SNL-16 (permitted by the New Mexico State Engineer as C-3220) was drilled during April 2006 to provide geological data and hydrological testing of the Culebra southwest of WIPP within the southeastern arm of Nash Draw and south of WIPP-26. Specific details of drilling, geophysical logging, and well completion will be presented in the Basic Data Report for Drillhole SNL-16 (C-3220), when published.

SNL-17 (permitted by the New Mexico State Engineer as C-3222) was drilled and completed in late April to early May 2006 to provide geological data and hydrological testing of the Culebra in an area south of the WIPP site and adjacent to an escarpment considered to mark the boundary of upper Salado dissolution. SNL-17 will serve as a general replacement for $\mathrm{H}-7$ when it is plugged and abandoned. The original well was replaced in July 2006 with a well drilled on the same pad, following discovery of failure of the bottom plug in the original well. Specific details of drilling, geophysical logging, and well completion will be presented in the Basic Data Report for Drillhole SNL-17 (C-3222) and SNL-17A, when published.

SNL-19 (permitted by the New Mexico State Engineer as C-3234) was drilled and completed in May 2006 to provide geological data and hydrological testing of the Culebra in an area west of the WIPP site and within Nash Draw to determine if recharge is occurring to the north and west of this location. Specific details of drilling, geophysical logging, and well completion will be presented in the Basic Data Report for Drillhole SNL-19 (C-3234), when published.

SNL-10 (permitted by the New Mexico State Engineer as C-3221) was drilled and completed from late May to mid-June 2006 to provide geological data and hydrological testing of the Culebra along the western side of the WIPP site. Specific details of drilling, geophysical logging, and well completion will be presented in the Basic Data Report for Drillhole SNL-10 (C-3221), when published.

SNL-18 (permitted by the New Mexico State Engineer as C-3233) was drilled and completed in late June 2006 to provide geological data and hydrological testing of the Culebra along Livingston Ridge north of the WIPP site and generally between WIPP-30 and SNL-1. Specific details of drilling, geophysical logging, and well completion will be presented in the Basic Data Report for Drillhole SNL-18 (C-3233), when published. 
All wells were developed to produce non-turbid water, free of sediment. Development methods included bailing, jetting, and pumping.

\subsection{Hydraulic Testing and Other Water Quality Sampling}

Hydrologic testing was performed throughout CY 2006. Tests were performed on three wells that had been drilled and completed in 2005. In February, pneumatic slug tests were conducted at SNL-13. In late February, a slug test was performed on SNL-15, and in December, a slug test was performed on SNL-8.

Pumping tests were performed in 2006 on newly drilled wells as they were completed. SNL-16 was pump tested between June 5 and 9 . SNL-19 was pump tested between July 24 and 28, SNL-18 was tested between August 14 and 18, SNL-17 between September 11 and 15, and SNL-10 between October 30 and November 3. These tests will support the next WIPP Compliance Recertification Application due in November 2009.

In March, existing well $\mathrm{H}-15$ (a dual completion well) was configured for continuous monitoring of both the Culebra and Magenta using transducers and a packer system. This monitoring continued through December 2006.

In addition to pumping tests primarily for hydraulic characterization, SNL performed sampling to obtain basic water chemistry data and age-dating at selected wells. Among these were IMC-461, H-19b0, and SNL-13.

\subsection{Well Maintenance}

Well maintenance activities for 2006 consisted of resetting a packer in one well, plugging and abandonment of four monitoring wells and a comprehensive resurvey of the well network.

In April, leakage of the packer separating the Magenta and Culebra of WIPP-30 was suspected due to water level behavior in the Magenta. This well's packer was pulled and reset in April, with each zone's water levels restored to normal behavior.

WIPP plugged and abandoned four wells in 2006: WIPP-27 (August 9), P-17 (August 18), DOE-1 (September 30), and WIPP-26 (October 12). All were in stages of casing failure due to the corrosive groundwater. The plugging and abandonment program continues to address the most deteriorated wells on a priority basis, and replacement when these wells are in critical area for water level determination.

A comprehensive resurvey of the WIPP well network was conducted by a private survey company, Pyeatt's Surveying of Carlsbad, New Mexico, in September through November 2006. This survey was commissioned to validate surveys taken over the years by different companies at different times. Top of casing elevations for this survey supersede those reported in all other surveys, and will be used in WIPP monthly water level reports beginning in January 2007. 
The survey of the groundwater-monitoring wells used global positioning system (GPS)/real-time kinetic methods. Two GPS units were used to establish the New Mexico East State Plane Coordinates North American Datum (NAD) 83 location and elevation coordinates of each well. The accuracy of the GPS traverse closed at 1 in 100,000. Field data was collected in NAD83 and North American Vertical Datum (NAVD) 88 formats. The data were then processed to produce the NAD27 and NGVD29 coordinates.

Survey results are shown in Table 6.5. It should be noted that the top of tubing elevation is only a floating reference for those wells which have packers set to isolate the Culebra. The first time the tubing and packer assembly is reset, the reference elevation will change.

\begin{tabular}{|c|c|c|c|c|c|c|}
\hline \multicolumn{7}{|c|}{ Table 6.5 - Monitoring Well Elevations } \\
\hline Well (1) & $\begin{array}{l}\text { Hydraulic } \\
\text { Unit }\end{array}$ & $\begin{array}{l}\text { Northings } \\
\text { NAD27 } \\
\text { (feet) }\end{array}$ & $\begin{array}{l}\text { Eastings } \\
\text { NAD27 } \\
\text { (feet) }\end{array}$ & $\begin{array}{c}\text { Reference } \\
\text { Point } \\
\text { Elevation } \\
\text { NAVD29 } \\
\text { (feet) }\end{array}$ & Reference Point & $\begin{array}{c}\text { Ground } \\
\text { Surface } \\
\text { Elevation }\end{array}$ \\
\hline AEC-7 & Culebra & $523,115.0$ & $691,844.2$ & $3,656.99$ & Well (Inner) casing & $3,656.1$ \\
\hline C-2737 (PIP) & Culebra & $497,103.6$ & $666,961.5$ & $3,400.56$ & Inner tubing elevation & $3,396.2$ \\
\hline C-2737 & Magenta & & & $3,400.76$ & Surface (Outer) Casing & \\
\hline C-2811 & Santa Rosa & $497,093.3$ & $666,855.2$ & $3,399.10$ & $\begin{array}{l}\text { Protective casing } \\
\text { measuring point }\end{array}$ & $3,396.1$ \\
\hline CB-1 & Bell Canyon & $486,061.8$ & $665,522.0$ & $3,328.80$ & Well (Inner) casing & $3,326.1$ \\
\hline DOE-2 & Bell Canyon & $509,872.1$ & $667,287.5$ & $3,419.64$ & Well (Inner) casing & $3,417.4$ \\
\hline ERDA-9 & Culebra & $498,884.6$ & $667,294.4$ & $3,409.92$ & Well (Inner) casing & $3,408.9$ \\
\hline $\mathrm{H}-02 \mathrm{~B} 1$ & Magenta & $497,908.3$ & $663,866.8$ & $3,378.49$ & $\begin{array}{l}\text { Protective casing } \\
\text { measuring point }\end{array}$ & $3,376.8$ \\
\hline $\mathrm{H}-02 \mathrm{~B} 2$ & Culebra & $497,906.1$ & $663,896.7$ & $3,378.36$ & Well (Inner) casing & $3,376.8$ \\
\hline $\mathrm{H}-03 \mathrm{~B} 1$ & Magenta & $495,419.8$ & $667,357.6$ & $3,390.71$ & Well (Inner) casing & $3,388.7$ \\
\hline $\mathrm{H}-03 \mathrm{~B} 2$ & Culebra & $495,456.7$ & $667,264.8$ & $3,389.91$ & Well (Inner) casing & $3,388.7$ \\
\hline $\mathrm{H}-03 \mathrm{D}$ & Dewey Lake & $495,402.4$ & $667,332.2$ & $3,390.44$ & Well (Inner) casing & $3,388.2$ \\
\hline $\mathrm{H}-04 \mathrm{~B}$ & Culebra & $487,538.8$ & $662,891.8$ & $3,333.58$ & $\begin{array}{l}\text { Protective casing } \\
\text { measuring point }\end{array}$ & $3,332.5$ \\
\hline $\mathrm{H}-04 \mathrm{C}$ & Magenta & $487,591.9$ & $662,976.5$ & $3,334.28$ & $\begin{array}{l}\text { Protective casing } \\
\text { measuring point }\end{array}$ & $3,333.3$ \\
\hline $\mathrm{H}-05 \mathrm{~B}$ & Culebra & $508,213.3$ & $677,754.4$ & $3,506.77$ & $\begin{array}{l}\text { Protective casing } \\
\text { measuring point }\end{array}$ & $3,505.0$ \\
\hline $\mathrm{H}-06 \mathrm{~B}$ & Culebra & $508,931.8$ & $657,192.7$ & $3,347.69$ & $\begin{array}{l}\text { Protective casing } \\
\text { measuring point }\end{array}$ & $3,346.9$ \\
\hline $\mathrm{H}-06 \mathrm{C}$ & Magenta & $508,846.4$ & $657,244.5$ & $3,348.69$ & $\begin{array}{l}\text { Protective casing } \\
\text { measuring point }\end{array}$ & $3,347.3$ \\
\hline H-07B1 & Culebra & $475,051.3$ & $648,857.3$ & $3,163.72$ & $\begin{array}{l}\text { Protective casing } \\
\text { measuring point }\end{array}$ & $3,162.3$ \\
\hline $\mathrm{H}-07 \mathrm{C}(2)$ & Culebra & $475,024.8$ & $648,761.1$ & $3,163.56$ & $\begin{array}{l}\text { Protective casing } \\
\text { measuring point }\end{array}$ & $3,161.7$ \\
\hline $\mathrm{H}-08 \mathrm{~A}$ & Magenta & $438,680.4$ & $650,330.4$ & $3,433.28$ & $\begin{array}{l}\text { Protective casing } \\
\text { measuring point }\end{array}$ & $3,433.2$ \\
\hline
\end{tabular}


Waste Isolation Pilot Plant Annual Site Environmental Report for 2006 DOE/WIPP-07-2225

\begin{tabular}{|c|c|c|c|c|c|c|}
\hline \multicolumn{7}{|c|}{ Table 6.5 - Monitoring Well Elevations } \\
\hline Well (1) & $\begin{array}{l}\text { Hydraulic } \\
\text { Unit }\end{array}$ & $\begin{array}{c}\text { Northings } \\
\text { NAD27 } \\
\text { (feet) }\end{array}$ & $\begin{array}{c}\text { Eastings } \\
\text { NAD27 } \\
\text { (feet) }\end{array}$ & $\begin{array}{c}\text { Reference } \\
\text { Point } \\
\text { Elevation } \\
\text { NAVD29 } \\
\text { (feet) }\end{array}$ & Reference Point & $\begin{array}{l}\text { Ground } \\
\text { Surface } \\
\text { Elevation }\end{array}$ \\
\hline $\mathrm{H}-08 \mathrm{C}(3)$ & $\begin{array}{l}\text { Rustler/ } \\
\text { Salado }\end{array}$ & $438,585.2$ & $650,346.3$ & & Location survey only & $3,433.3$ \\
\hline H-09C (PIP) & Culebra & $453,900.8$ & $667,917.1$ & $3,407.12$ & Inner tubing elevation & $3,405.5$ \\
\hline $\mathrm{H}-09 \mathrm{C}$ & Magenta & & & $3,407.05$ & Surface (Outer) Casing & \\
\hline $\mathrm{H}-10 \mathrm{~A}$ & Magenta & $467,570.8$ & $697,465.4$ & $3,688.45$ & $\begin{array}{l}\text { Protective casing } \\
\text { measuring point }\end{array}$ & $3,687.7$ \\
\hline $\mathrm{H}-10 \mathrm{C}$ & Culebra & $467,522.2$ & $697,551.9$ & $3,688.40$ & $\begin{array}{l}\text { Protective casing } \\
\text { measuring point }\end{array}$ & $3,687.5$ \\
\hline $\mathrm{H}-11 \mathrm{~B} 2$ & Magenta & $489,520.4$ & $672,642.0$ & $3,411.86$ & Well (Inner) casing & $3,410.4$ \\
\hline $\mathrm{H}-11 \mathrm{~B} 4$ & Culebra & $489,595.7$ & $672,490.7$ & $3,410.79$ & Well (Inner) casing & $3,409.2$ \\
\hline $\mathrm{H}-12$ & Culebra & $477,540.9$ & $678,075.4$ & $3,427.33$ & Well (Inner) casing & $3,425.2$ \\
\hline $\mathrm{H}-14$ & Magenta & $493,690.2$ & $662,789.2$ & $3,347.08$ & Well (Inner) casing & $3,345.6$ \\
\hline $\mathrm{H}-15$ (PIP) & Culebra & $498,559.2$ & $672,588.4$ & $3,482.19$ & Inner tubing elevation & $3,479.8$ \\
\hline $\mathrm{H}-15$ & Magenta & & & $3,480.89$ & Surface (Outer) Casing & \\
\hline $\mathrm{H}-17$ & Culebra & $484,285.4$ & $673,835.0$ & $3,385.24$ & Well (Inner) casing & $3,383.4$ \\
\hline $\mathrm{H}-18$ & Magenta & $502,909.7$ & $662,626.8$ & $3,414.21$ & Well (Inner) casing & $3,413.1$ \\
\hline $\mathrm{H}-19 \mathrm{~B} 0$ & Culebra & $494,836.7$ & $669,956.3$ & $3,418.33$ & Well (Inner) casing & $3,416.6$ \\
\hline H-19B2 & Culebra & $494,786.0$ & $669,955.6$ & $3,418.93$ & Well (Inner) casing & $3,416.7$ \\
\hline $\mathrm{H}-19 \mathrm{~B} 3$ & Culebra & $494,861.4$ & $669,999.3$ & $3,419.02$ & Well (Inner) casing & $3,416.7$ \\
\hline H-19B4 & Culebra & $494,861.8$ & $669,912.5$ & $3,418.98$ & Well (Inner) casing & $3,416.3$ \\
\hline $\mathrm{H}-19 \mathrm{~B} 5$ & Culebra & $494,817.6$ & $669,916.2$ & $3,418.58$ & Well (Inner) casing & $3,416.3$ \\
\hline H-19B6 & Culebra & $494,906.2$ & $669,967.9$ & $3,419.02$ & Well (Inner) casing & $3,416.7$ \\
\hline $\mathrm{H}-19 \mathrm{~B} 7$ & Culebra & $494,807.3$ & $669,959.8$ & $3,418.94$ & Well (Inner) casing & $3,416.5$ \\
\hline IMC-461 & Culebra & $500,029.3$ & $642,645.9$ & $3,283.61$ & Well (Inner) casing & $3,281.1$ \\
\hline SNL-01 & Culebra & $539,423.3$ & $667,827.4$ & $3,512.84$ & Well (Inner) casing & $3,510.0$ \\
\hline SNL-02 & Culebra & $514,022.6$ & $652,349.6$ & $3,323.06$ & Well (Inner) casing & $3,320.8$ \\
\hline SNL-03 & Culebra & $522,141.5$ & $675,337.6$ & $3,488.95$ & Well (Inner) casing & $3,487.9$ \\
\hline SNL-05 & Culebra & $516,443.8$ & $661,740.4$ & $3,379.98$ & Well (Inner) casing & $3,377.4$ \\
\hline SNL-06 & Culebra & $542,849.9$ & $692,338.9$ & $3,646.11$ & Well (Inner) casing & $3,643.1$ \\
\hline SNL-08 & Culebra & $504,820.4$ & $683,170.2$ & $3,555.73$ & Well (Inner) casing & $3,552.0$ \\
\hline SNL-09 & Culebra & $499,949.4$ & $650,921.9$ & $3,360.96$ & Well (Inner) casing & $3,358.2$ \\
\hline SNL-10 & Culebra & $498,346.1$ & $659,196.1$ & $3,377.59$ & Well (Inner) casing & $3,374.1$ \\
\hline SNL-12 & Culebra & $468,650.1$ & $665,555.1$ & $3,339.45$ & Well (Inner) casing & $3,337.1$ \\
\hline SNL-13 & Culebra & $484,696.0$ & $656,371.1$ & $3,294.22$ & Well (Inner) casing & $3,291.1$ \\
\hline SNL-14 & Culebra & $484,773.4$ & $671,451.4$ & $3,368.40$ & Well (Inner) casing & $3,365.0$ \\
\hline SNL-15 & Culebra & $493,513.2$ & $682,543.1$ & $3,479.93$ & Well (Inner) casing & $3,477.3$ \\
\hline SNL-16 & Culebra & $489,396.0$ & $639,328.3$ & $3,133.00$ & Well (Inner) casing & $3,130.1$ \\
\hline SNL-17 & Culebra & $479,510.1$ & $654,596.0$ & $3,238.06$ & Well (Inner) casing & $3,235.5$ \\
\hline SNL-18 & Culebra & $530,337.5$ & $667,193.0$ & $3,375.44$ & Well (Inner) casing & $3,371.7$ \\
\hline SNL-19 & Culebra & $521,984.6$ & $648,134.5$ & $3,222.65$ & Well (Inner) casing & $3,219.1$ \\
\hline WIPP-11 & Culebra & $513,746.3$ & $667,689.1$ & $3,427.78$ & $\begin{array}{l}\text { Protective casing } \\
\text { measuring point }\end{array}$ & $3,425.5$ \\
\hline WIPP-13 & Culebra & $506,444.7$ & $663,892.3$ & $3,405.67$ & $\begin{array}{l}\text { Protective casing } \\
\text { measuring point }\end{array}$ & $3,404.8$ \\
\hline
\end{tabular}


Waste Isolation Pilot Plant Annual Site Environmental Report for 2006 DOE/WIPP-07-2225

\begin{tabular}{|c|c|c|c|c|c|c|}
\hline Well (1) & $\begin{array}{c}\text { Hydraulic } \\
\text { Unit }\end{array}$ & $\begin{array}{l}\text { Northings } \\
\text { NAD27 } \\
\text { (feet) }\end{array}$ & $\begin{array}{l}\text { Eastings } \\
\text { NAD27 } \\
\text { (feet) }\end{array}$ & $\begin{array}{c}\text { Reference } \\
\text { Point } \\
\text { Elevation } \\
\text { NAVD29 } \\
\text { (feet) }\end{array}$ & Reference Point & $\begin{array}{l}\text { Ground } \\
\text { Surface } \\
\text { Elevation }\end{array}$ \\
\hline WIPP-18 & Magenta & $502,910.7$ & $667,445.0$ & $3,457.57$ & $\begin{array}{l}\text { Protective casing } \\
\text { measuring point }\end{array}$ & $3,455.9$ \\
\hline WIPP-19 & Culebra & $501,604.6$ & $667,451.4$ & $3,435.11$ & Well (Inner) casing & $3,432.4$ \\
\hline WIPP-25 (PIP) & Culebra & $505,854.4$ & $643,348.7$ & $3,214.50$ & Inner tubing elevation & $3,211.8$ \\
\hline WIPP-25 & Magenta & & & $3,214.24$ & Surface (Outer) Casing & \\
\hline WIPP-30 (PIP) & Culebra & $524,351.3$ & $667,520.1$ & $3,429.23$ & Inner tubing elevation & $3,426.7$ \\
\hline WIPP-30 & Magenta & & & $3,430.22$ & Surface (Outer) Casing & \\
\hline WQSP-1 & Culebra & $503,783.8$ & $663,595.0$ & $3,419.43$ & Well (Inner) casing & $3,416.1$ \\
\hline WQSP-2 & Culebra & $505,537.3$ & $667,579.6$ & $3,464.06$ & Well (Inner) casing & $3,460.8$ \\
\hline WQSP-3 & Culebra & $503,991.5$ & $670,572.8$ & $3,480.33$ & Well (Inner) casing & $3,477.5$ \\
\hline WQSP-4 & Culebra & $494,986.5$ & $670,644.7$ & $3,433.27$ & Well (Inner) casing & $3,430.4$ \\
\hline WQSP-5 & Culebra & $493,665.4$ & $667,164.8$ & $3,384.58$ & Well (Inner) casing & $3,381.7$ \\
\hline WQSP-6 & Culebra & $494,948.3$ & $663,680.6$ & $3,364.91$ & Well (Inner) casing & $3,361.6$ \\
\hline WQSP-6A & Dewey Lake & $494,974.4$ & $663,615.0$ & $3,364.06$ & Well (Inner) casing & $3,361.6$ \\
\hline Notes & \multicolumn{6}{|c|}{$\begin{array}{l}\text { 1. PIP refers to production/injection packer, suspended on inner tubing } \\
\text { 2. Transferred to Bureau of Land Management, September } 2005 \\
\text { 3. Transferred to Bureau of Land Management, September } 2005\end{array}$} \\
\hline
\end{tabular}

\subsection{Shallow Subsurface Water Monitoring Program}

Shallow subsurface water occurs beneath the WIPP site at a depth of less than $100 \mathrm{ft}$ below ground level at the contact between the Santa Rosa and the Dewey Lake (Figure 6.1). The formations containing shallow water, specifically at the site, yield generally less than one gallon per minute in monitoring wells and piezometers and the water contains high concentrations of TDS and chloride; to the south, yields are greater. The origin of this water is believed to be primarily from anthropogenic sources, with some contribution from natural sources. The shallow subsurface water occurs not only under the WIPP site surface facilities but also to the south as indicated by shallow water in drill hole C-2811, about one half mile south of the waste handling shaft (Figure 6.12). Natural shallow groundwater occurs in the middle part of the Dewey Lake at the southern portion of the WIPP site and to the south of the WIPP site. To date, there is no indication that the shallow subsurface water has affected the naturally occurring groundwater in the Dewey Lake.

Since discovery of the shallow subsurface water in 1995, 12 piezometers and four wells (C-2505, C-2506, C-2507, and C-2811) have been part of a monitoring program to measure spatial and temporal changes in shallow subsurface water levels and water quality. Shallow subsurface water monitoring activities during 2006 included shallow subsurface water level surveillance at these 16 locations (Figure 6.12). 
An application was submitted to the NMED Ground Water Quality Bureau to modify the existing permit, DP-831, to address discharges associated with salt storage operations. In this application it was proposed to build a new salt storage area and a new salt storage evaporation basin, and to reshape the existing salt pile and close it by installing a geotextile/synthetic liner cover. Additionally, the application proposed installing synthetic liners in all existing evaporation ponds at the facility. The liners are designed to limit infiltration of surface water to the shallow subsurface. The DP-831 permit modification application also proposed a monitoring and sampling plan for the shallow subsurface water well/piezometer network.

The application was approved by the NMED Ground Water Quality Bureau and a Discharge Permit Modification for DP-831 was issued on December 22, 2003. Another modification to this permit was issued on December 29, 2006, that incorporated all requirements of the 2003 permit. These permit requirements are modifications to the salt storage and evaporation pond operations described above; quarterly monitoring of water levels, and semiannual sampling from twelve wells/piezometers. Required parameters for laboratory analysis are nitrate, sulfate, chloride, TDS, selenium, and chromium. Field parameters ( $\mathrm{pH}$, conductivity, and temperature) are also to be measured during serial sampling. Additional information regarding the status of this permit is found in Section 2.2.6. 
Waste Isolation Pilot Plant Annual Site Environmental Report for 2006 DOE/WIPP-07-2225

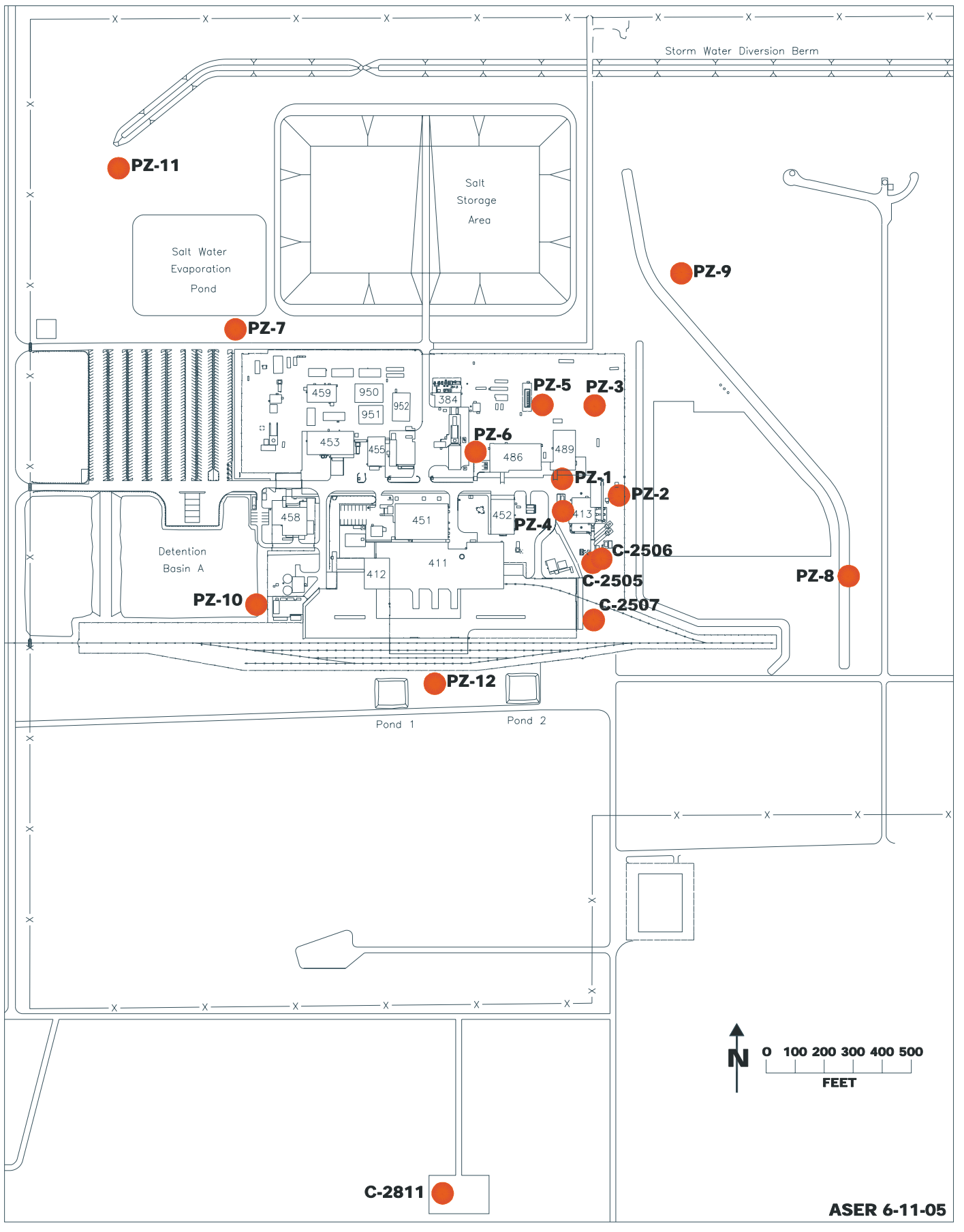

Figure 6.12 - Locations of SSW Wells (Piezometers PZ-1 through 12;

Wells C-2811, C-2505, C-2506, and C-2507 


\subsubsection{Shallow Subsurface Water Quality Sampling}

DP-831, as modified, requires ten shallow subsurface water (SSW) wells to be sampled on a semiannual basis. Wells PZ-1, PZ-5, PZ-6, PZ-7, PZ-9, PZ-10, PZ-11, PZ-12, C-2811, and C-2507 are sampled for this program. These wells were sampled in May and October 2006 and laboratory analyzed for the parameters presented in the previous section. Results are indicated in Table 6.6.

\begin{tabular}{|c|c|c|c|c|c|c|c|}
\hline \multirow[b]{2}{*}{$\begin{array}{c}\text { Monitoring } \\
\text { Site }\end{array}$} & \multicolumn{5}{|c|}{ General Chemistry Parameters } & \multicolumn{2}{|c|}{ Trace Metals } \\
\hline & $\begin{array}{c}\text { Sample } \\
\text { Date }\end{array}$ & $\begin{array}{l}\text { Nitrate } \\
(\mathrm{mg} / \mathrm{L})\end{array}$ & $\begin{array}{l}\text { Sulfate } \\
(\mathrm{mg} / \mathrm{L})\end{array}$ & $\begin{array}{c}\text { Chloride } \\
\text { (mg/L) }\end{array}$ & $\begin{array}{c}\text { TDS } \\
(\mathrm{mg} / \mathrm{L})\end{array}$ & $\begin{array}{c}\text { Selenium } \\
\text { (mg/L) }\end{array}$ & $\begin{array}{c}\text { Chromium } \\
\text { (mg/L) }\end{array}$ \\
\hline PZ-1 & $5 / 16 / 06$ & $<2.5$ & 2490 & 62400 & 113000 & 0.0510 & $<0.0100$ \\
\hline PZ-1 & $10 / 10 / 06$ & $<1.00$ & 1390 & 55300 & 70200 & $<0.0500$ & $<0.0250$ \\
\hline PZ-5 & $5 / 16 / 06$ & 2.56 & 1520 & 18300 & 32600 & 0.0710 & $<0.0100$ \\
\hline PZ-5 & $10 / 10 / 06$ & 5.04 & 1330 & 28800 & 47400 & $<0.0500$ & $<0.0250$ \\
\hline PZ-6 & $5 / 16 / 06$ & 7.69 & 3050 & 68800 & 115000 & $<0.0100$ & $<0.0100$ \\
\hline PZ-6 & $10 / 10 / 06$ & 252 & 2790 & 79800 & 134000 & $<0.0500$ & $<0.0250$ \\
\hline PZ-7 & $5 / 15 / 06$ & $<5.3$ & 3190 & 54100 & 139000 & 0.0680 & $<0.0100$ \\
\hline PZ-7 & $10 / 9 / 06$ & $<1.00$ & 2890 & 66800 & 81500 & $<0.00100$ & $<0.0500$ \\
\hline PZ-9 & $5 / 16 / 06$ & 3.01 & 4350 & 84700 & 153000 & 0.0230 & $<0.0100$ \\
\hline PZ-9 & $10 / 10 / 06$ & $<20.0$ & 3370 & 102000 & 135000 & $<0.0500$ & $<0.0250$ \\
\hline PZ-10 & $5 / 15 / 06$ & 3.42 & 539 & 460 & 1830 & 0.0140 & $<0.0100$ \\
\hline PZ-10 & $10 / 9 / 06$ & 5.5 & 549 & 350 & 1600 & $<0.00100$ & $<0.0500$ \\
\hline PZ-11 & $5 / 15 / 06$ & $<5.3$ & 3090 & 71000 & 133000 & $<0.0100$ & $<0.0100$ \\
\hline PZ-11 & 10/9/06 & $<1.00$ & 2550 & 85800 & 123000 & $<0.00100$ & $<0.0500$ \\
\hline PZ-12 & $5 / 15 / 06$ & 20.6 & 866 & 4510 & 8790 & 0.0190 & $<0.0100$ \\
\hline PZ-12 & $10 / 9 / 06$ & 13.2 & 795 & 5340 & 9150 & $<0.00100$ & $<0.0500$ \\
\hline C-2811 & $5 / 15 / 06$ & 6.94 & 511 & 1760 & 3740 & 0.0310 & $<0.0100$ \\
\hline C-2811 & $10 / 9 / 06$ & 6.05 & 402 & 1310 & 2100 & $<0.00100$ & $<0.0500$ \\
\hline C-2507 & $5 / 16 / 06$ & 7.37 & 1040 & 1930 & 5300 & 0.0510 & $<0.0100$ \\
\hline C-2507 & $10 / 10 / 06$ & 5.04 & 1330 & 28800 & 47400 & $<0.0500$ & $<0.0250$ \\
\hline
\end{tabular}

\subsubsection{Shallow Subsurface Water Level Surveillance}

Sixteen wells were used to perform surveillance of the shallow subsurface waterbearing horizon in the Santa Rosa Formation and the upper portion of the Dewey Lake Redbeds Formation. Water levels were collected quarterly for all locations presented in Figure 6.12 (Appendix F, Table F.8). Well PZ-8 was dry during 2006.

Groundwater elevation measurements in the shallow subsurface water indicate that flow moves east and south away from a potentiometric high located near PZ-7 adjacent to 
the Salt Pile Evaporation Pond (Figure 6.13). A potentiometric low is located near both PZ-12 and PZ-8.

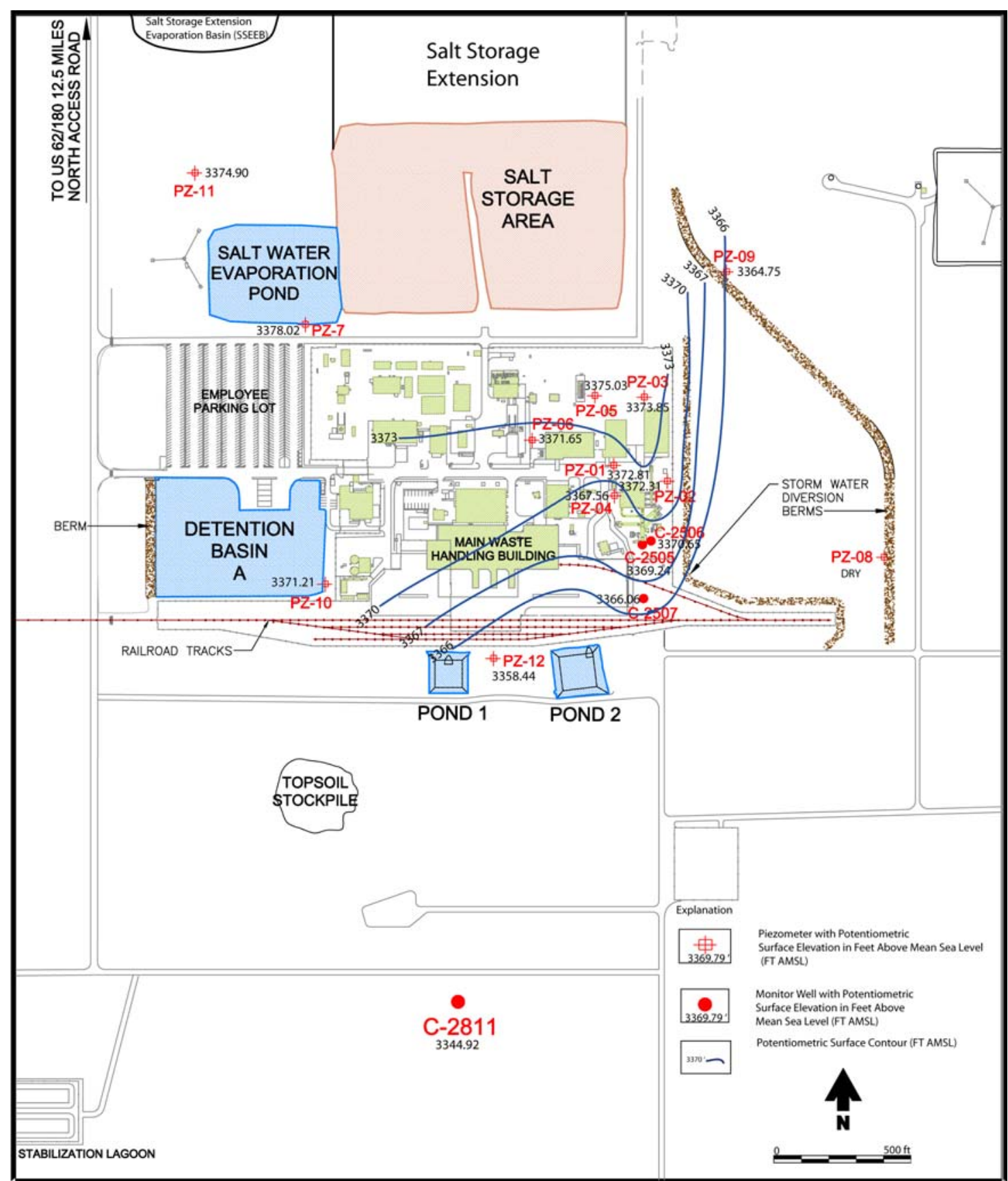

Figure 6.13 - Contour Plot of SSW Potentiometric Surface in the Santa Rosa Formation 


\subsection{Public Drinking Water Protection}

The water wells nearest the WIPP site that are using the natural shallow groundwater for domestic use are the Barn Well and Ranch Well located on the J. C. Mills Ranch. These wells are located approximately three miles south-southwest of the WIPP surface facilities, and about 1.75 miles south of WQSP-6A (see Figure 6.3 for location of WQSP-6A). TDS concentrations in the Barn Well have ranged from 630 to $720 \mathrm{mg} / \mathrm{L}$, and TDS concentrations in the Ranch Well have ranged from 2,800 to 3,300 mg/L (DOE, 1996).

Because of the nearest potable water supply at the Mills Ranch and the discovery of shallow subsurface water at the site, a water budget analysis of the shallow subsurface water was performed by Daniel B. Stephens \& Associates. The analysis was performed to evaluate important hydrologic processes controlling the shallow subsurface water and provide:

- An estimate of the volume of water contained within the perched zone

- Quantification of seepage inputs to the SSW from past and current practices

- A model of SSW accumulation, flow conditions, and potential long-term migration

- Determination of the effects of engineered seepage reduction measures that could be implemented at existing seepage sources

The water budget analysis included compilation of recorded discharges, site drainage summary, surface infiltration modeling, saturated flow modeling, and long-term migration modeling. Water budget results indicated that seepage from five primary sources (salt pile and four surface water detention basins) provided sufficient recharge to account for the observed shallow subsurface water saturated lens and that the lens is expected to spread.

The potential extent for long-term shallow subsurface water migration was examined by expanding the saturated flow model domain to include the 16-square-mile WIPP land withdrawal area. The long-term migration model simulations indicated that the engineered seepage controls would substantially reduce the extent of migration (Daniel B. Stephens \& Associates, Inc., 2003). 


\section{CHAPTER 7 - QUALITY ASSURANCE}

The fundamental objective of a QA program, as applied to environmental work, is to ensure that high-quality measurements are produced and reported from the analyses of samples collected using proven methods and practices. The defensibility of data generated by laboratories must be based on sound scientific principles, method evaluations, and data verification and validation.

In 2006, WIPP Laboratories performed the radiological analyses of WIPP environmental samples, while contract laboratories, Air Toxics, in Folsom, California; CEMRC (Carlsbad Environmental Monitoring and Research Center), in Carlsbad, New Mexico; and TraceAnalysis, Inc., in Lubbock, Texas, performed the nonradiological analyses. These laboratories were required contractually to have documented QA programs, including standard procedures to perform the work. The WIPP Laboratories and TraceAnalysis, Inc., were required to participate in intercomparison programs with such entities as the National Institute of Standards and Technology Radiochemistry Intercomparison Program (NRIP), the Mixed Analyte Performance Evaluation Program (MAPEP), the Environmental Resource Associates ${ }^{\circledR}$ interlaboratory assessment, and/or other reputable intercomparison programs. Laboratories used by the WIPP program are required to meet the applicable requirements of the CBFO Quality Assurance Program Document (DOE/CBFO-94-1012), as flowed down through the Washington TRU Solutions LLC Quality Assurance Program Description (WP 13-1).

The laboratories also used one or more of these accepted protocols in their QA program:

- $\quad$ American Society of Mechanical Engineers [ASME] NQA [Nuclear Quality Assurance] -1-1989; ASME NQA-2a-1990 Addenda, Part 2.7, to ASME NQA-2-1989 edition; and ASME NQA-3-1989 edition (excluding Section 2.1[b] and [c], and Section 17.1)

- $\quad$ Title 10 CFR Part 50, Appendix B, "Quality Assurance Criteria for Nuclear Power Plants and Fuel Reprocessing Plants"

- $\quad$ EPA/600 4-83-004, Interim Guidelines and Specification for Preparing Quality Assurance Project Plans

- U.S. Nuclear Regulatory Commission Regulatory Guide 4.15, Rev. 1, Quality Assurance for Radiological Monitoring Program-Effluent Streams and the Environment 
- ISO/IEC DIS 17025, General Requirements for the Competence of Testing and Calibration Laboratories, International Organization for Standardization

- National Environmental Laboratory Accreditation Program (NELAP)

The WIPP sampling program and its analytical laboratories operate in accordance with Quality Assurance Plans and Quality Assurance Project Plans that incorporate QA requirements for sampling in the WTS Quality Assurance Program Description. These plans contain such elements as:

- Management and Organization

- Quality System and Description

- $\quad$ Personnel Qualification and Training

- $\quad$ Procurement of Products and Services

- Documents and Records

- $\quad$ Computer hardware and Software

- $\quad$ Planning

- Management of Work Process (Standard Operating Procedures)

- $\quad$ Assessment and Response

- $\quad$ Quality Improvement

To ensure that the quality of the systems, processes, and deliverables are maintained or improved, three layers of assessments and audits are performed:

- $\quad$ DOE/CBFO performs assessments and audits of the WTS QA program.

- WTS performs internal assessments and audits of their own QA program.

- WTS performs assessments and audits of subcontractor QA programs as applied to WTS contract work.

Along with protocols listed above, WIPP personnel must also implement DOE Order $414.1 \mathrm{C}$. The data quality objectives for the sampling program are completeness, precision, accuracy, comparability, and representativeness.

Representativeness is the extent to which measurements actually represent the true environmental condition or population at the time a sample was collected. The primary objective of environmental monitoring is to protect the health and safety of the 
population surrounding the WIPP facility. Samples of ambient air, surface water, sediment, soil, groundwater, and biota were collected from areas representative of potential pathways for intake.

The samples were collected using generally accepted methodologies for environmental sampling and approved procedures, ensuring that the samples are representative of the media sampled. These samples were analyzed for natural radioactivity, fallout radioactivity from nuclear weapons tests, and other anthropogenic radionuclides. The reported concentrations at various locations are representative of the baseline information for radionuclides of interest at the WIPP facility.

Sections $7.1,7.2$, and 7.3 discuss the quality control results for the WIPP Laboratories, CEMRC and Air Toxics, and TraceAnalysis, Inc., respectively, in terms of how they met the performance evaluation parameters.

\subsection{WIPP Laboratories}

\subsubsection{Completeness}

The statement of work for analyses performed by WIPP Laboratories states that "analytical completeness, as measured by the amount of valid data collected versus the amount of data expected or needed, shall be greater than 90 percent for WTS sampling programs." For radiological sampling and analysis programs, this contract requirement translates into the following quantitative definition.

Completeness is expressed as the number of samples analyzed with valid results as a percent of the total number of samples submitted for analysis, or

$$
\% C=\frac{V}{n} \times 100
$$

Where:

$\% \mathrm{C}=$ Percent Completeness

$V=$ Number of Samples with Valid Results

$\mathrm{n}=$ Number of Samples Submitted for Analysis

Samples and measurements for all environmental media (air particulate composites, groundwater, surface water, soil, sediment, and animal and plant tissues) were 100 percent complete for 2006. 


\subsubsection{Precision}

The statement of work states that analytical precision (as evaluated through replicate measurements) will meet or surpass control criteria or guidelines established in the industry-standard methods used for sample analysis. To ensure overall quality of analysis of environmental samples, precision was evaluated for both sample collection and sample analysis. Precision or reproducibility in sample collection was evaluated through comparison of analytical results for duplicate collected samples. A portable low-volume air sampler was rotated in each quarter from location to location, and was operated along with routine stationary air particulate samplers. There were no results of these duplicate comparisons shown for 2006 as there were no instances in which both the sample and the duplicate met the detection criteria. The duplicate samples for other environmental media were collected at the same time, same place, and under similar conditions as routine samples. Tables 4.4 and 4.5, 4.9, 4.13, 4.17, and 4.19 show duplicate results for groundwater, surface water, sediment, soil, and vegetation samples, respectively.

The measure of precision used is the RER. The RER is expressed as follows:

$$
R E R=\frac{\mid(\text { MeanActivity })_{\text {ori }}-(\text { MeanActivity })_{\text {dup }} \mid}{\sqrt{(2 \times S D)^{2} \text { ori }+(2 \times S D)^{2} \text { dup }}}
$$

Where:

$(\text { Mean Activity })_{\text {ori }} \quad=\quad$ Mean Activity of Original Sample

$(\text { Mean Activity })_{\text {dup }} \quad=\quad$ Mean Activity of Duplicate Sample

SD $\quad=\quad$ Standard Deviation of Original and Duplicate Samples

RER results equal to or less than one are acceptable and considered to demonstrate reproducibility. RERs for some collection duplicates were less than one for multiple constituents, indicating good reproducibility of sampling techniques and methods. One or more duplicate pairs for groundwater, sediments, soil, and vegetation showed RERs greater than one, indicating poor reproducibility (Tables 4.4 and 4.5, 4.9, 4.13, 4.17, and 4.19). The cause is unclear but may be due to inhomogeneities in the sampled media.

Laboratory precision was verified through analysis by the laboratory of replicate samples. Replicate analyses are performed on 10 percent of samples when sample volume allows. A second aliquot is taken of the chosen sample and prepared and analyzed with the associated batch. If the sample replicates do not meet the RER acceptance criterion, the entire batch is re-aliquoted and analyzed again. If the RER acceptance criterion is not met the second time, it indicates that the original sample is inhomogeneous. All laboratory replicates passed the RER acceptance criterion, indicating acceptable laboratory precision. 


\subsubsection{Accuracy}

The SOW requires accuracy (as evaluated through analytical spikes) to meet or surpass control criteria or guidelines established in the industry-standard methods used for sample analysis. Instrument accuracy was assured/controlled by using National Institute of Standards and Technology (NIST) traceability for instrument calibration. Overall analytical accuracy is maintained through the use of NIST-traceable, spiked, laboratory control samples (LCSs). Analysis of LCSs containing the isotopes of interest is performed on a 10 percent basis (one per every ten samples or part thereof). Results must be within plus or minus 20 percent of the known values. If this criterion is not met, the entire batch of samples is reanalyzed. LCS results for each isotope are tracked on a running basis on control charts. All LCS results fell within the acceptable ranges, indicating good accuracy.

Accuracy is also ensured through participation by the laboratory in the DOE MAPEP and NRIP interlaboratory comparison programs, as discussed in more detail in Section 7.1.4 below. Under these programs, the WIPP Laboratories analytical results of furnished samples are compared with the results obtained by the MAPEP and NRIP. Performance is established by percent bias, calculated as shown below.

$$
\% \text { Bias }=\frac{\left(A_{m}-A_{k}\right)}{A_{k}} \times 100
$$

Where:

$\begin{array}{lll}\% \text { Bias } & = & \text { Percent Bias } \\ A_{m} & = & \text { Measured Sample Activity } \\ A_{k} & = & \text { Known Sample Activity }\end{array}$

\subsubsection{Comparability}

The statement of work requires analytical comparability to be assured through the consistent use of standard sampling and analytical methods, and analytical methods that are equivalent in method performance criteria and reporting units for specific lists of target parameters. Sampling comparability is maintained through the use of standardized sample collection methods and procedures that govern the disposition of the samples and their transfer to the laboratory. The WIPP Laboratories ensure consistency through the use of standard analytical methods coupled with specific procedures that govern the handling of samples and the reporting of analysis results.

Comparability is reinforced through participation by the WIPP Laboratories in interlaboratory comparison programs. In 2006, the WIPP Laboratories participated in the DOE MAPEP and the NRIP programs. The MAPEP and NRIP prepared QC samples containing various alpha-, beta-, and gamma-emitting nuclides in synthetic urine, synthetic feces, air filter, water, soil, and vegetation media and distribute them to participating laboratories. The programs are interlaboratory comparisons in that results from the participants are compared with the experimentally determined results of 
MAPEP and NRIP. Also, the administering programs assess the results as acceptable or not, based on the accuracy of the analyses.

Tables 7.1 and 7.2 contain the NRIP comparisons for synthetic urine and soil, and MAPEP results for air filter, water, soil, and vegetation, respectively for 2006 . NRIP results were rated as "P" (for pass) for all applicable radionuclides in synthetic urine. The criterion for NRIP acceptance is -25 percent/50 percent. The soil samples were "emergency preparedness" samples and are not rated with a pass/fail system. The rationale for NRIP not assigning these results in terms of a pass/fail criterion is as follows. An emergency preparedness sample is evaluated in terms of how many nuclides and estimate activity levels can be identified within eight hours, as if it were an actual emergency. These estimated values are not expected to compare to normal analysis results, which may take several days to produce.

All MAPEP bias results were acceptable (-25 percent/+50 percent) for all radionuclides and media of interest at the WIPP site with the exception of plutonium in air filter and water and ${ }^{90} \mathrm{Sr}$ in soil. In the first case, the issue was not reporting a value that was not above the minimum detected activity (a MAPEP requirement). In the second case it was determined that there was a large amount of calcium in the soil which interfered with the detection of strontium. In both cases, corrective actions were taken to prevent reoccurrence of the problems.

\subsubsection{Representativeness}

According to the statement of work, analytical representativeness is assured through the application of technically sound and accepted approaches for environmental investigations, industry-standard procedures for sample collection, and monitoring for potential sample cross-contamination through the analysis of field-generated and laboratory blank samples. These conditions were satisfied through the sample collection and analysis practices of the WIPP environmental monitoring program. The environmental media samples (air, groundwater, surface water, soil, sediment, and biota) were collected from areas representative of potential pathways for intake. The samples were collected using generally accepted methodologies for environmental sampling and approved procedures, ensuring that they would be representative of the media sampled. Both sample collection blanks and analytical method blanks were used to check for cross-contamination and ensure sample purity.

\section{Table 7.1 - NRIP for WIPP Laboratories, 2006}

\begin{tabular}{|c|c|c|c|c|c|c|c|c|c|c|c|c|}
\hline \multirow[b]{3}{*}[RN]{$^{b}$} & \multicolumn{6}{|c|}{$\begin{array}{c}\text { Synthetic Urine (Bq/sample) } \\
\text { NRIP06-SU }\end{array}$} & \multicolumn{4}{|c|}{$\begin{array}{c}\text { Soil }(\mathrm{Bq} / \mathrm{kg}) \\
\text { Emergency Preparedness } \\
\text { NRIP06-SS }\end{array}$} & \multirow[b]{3}{*}{$\mathbf{E}$} & \multirow[b]{3}{*}{$\begin{array}{c}\% \\
\text { Bias } \\
\end{array}$} \\
\hline & \multicolumn{2}{|c|}{ Reported } & \multicolumn{2}{|c|}{$\mathrm{NIST}^{\mathrm{a}}$} & \multirow[b]{2}{*}{$E^{c}$} & \multirow[b]{2}{*}{$\begin{array}{c}\% \\
\text { Bias }\end{array}$} & \multicolumn{2}{|c|}{ Reported } & \multicolumn{2}{|c|}{ NIST } & & \\
\hline & Value & $\begin{array}{l}\% 2 \sigma \\
\text { Error }\end{array}$ & Value & $\begin{array}{l}\% 2 \sigma \\
\text { Error }\end{array}$ & & & Value & $\begin{array}{l}\% 2 \sigma \\
\text { Error }\end{array}$ & Value & $\begin{array}{l}\% 2 \sigma \\
\text { Error }\end{array}$ & & \\
\hline${ }^{241} \mathrm{Am}$ & 1.38 & 7.89 & 1.610 & 0.95 & $\mathrm{P}$ & -14.3 & 5.51 & 17.6 & 7.58 & 0.95 & $\mathrm{~N} / \mathrm{A}$ & -27.3 \\
\hline${ }^{238} \mathrm{Pu}$ & 1.62 & 6.85 & 1.767 & 0.68 & $\mathrm{P}$ & -8.3 & 5.25 & 13.37 & 8.14 & 0.68 & $N / A$ & -35.5 \\
\hline${ }^{239+240} \mathrm{Pu}$ & 1.61 & 6.86 & 1.685 & 0.68 & $\mathrm{P}$ & -4.4 & 6.02 & 12.53 & 8.45 & 0.76 & $N / A$ & -28.8 \\
\hline
\end{tabular}


Waste Isolation Pilot Plant Annual Site Environmental Report for 2006 DOE/WIPP-07-2225

\section{Table 7.1 - NRIP for WIPP Laboratories, 2006}

Synthetic Urine (Bq/sample) NRIP06-SU

\begin{tabular}{|c|c|c|c|c|c|c|c|c|c|c|c|c|}
\hline \multirow[b]{3}{*}[RN]{$^{b}$} & \multicolumn{6}{|c|}{ Nir $00-50$} & & \multirow[b]{3}{*}{$\mathbf{E}$} & \multirow[b]{3}{*}{$\begin{array}{c}\% \\
\text { Bias }\end{array}$} \\
\hline & \multicolumn{2}{|c|}{ Reported } & \multicolumn{2}{|c|}{ NIST $^{a}$} & \multirow[b]{2}{*}{$E^{c}$} & \multirow[b]{2}{*}{$\begin{array}{c}\% \\
\text { Bias }\end{array}$} & \multicolumn{2}{|c|}{ Reported } & \multicolumn{2}{|c|}{ NIST } & & \\
\hline & Value & $\begin{array}{l}\% 2 \sigma \\
\text { Error }\end{array}$ & Value & $\begin{array}{l}\% 2 \sigma \\
\text { Error }\end{array}$ & & & Value & $\begin{array}{l}\% 2 \sigma \\
\text { Error }\end{array}$ & Value & $\begin{array}{l}\% 2 \sigma \\
\text { Error }\end{array}$ & & \\
\hline${ }^{137} \mathrm{Cs}$ & 1040 & 18.2 & 1022.0 & 0.68 & $P$ & 1.8 & 1680 & 13.1 & 1915 & 0.68 & $\mathrm{~N} / \mathrm{A}$ & -12.3 \\
\hline${ }^{234} U$ & 4.00 & 4.93 & 4.003 & 0.98 & $P$ & -0.1 & 9.87 & 13.5 & 10.26 & 0.98 & $N / A$ & -3.8 \\
\hline${ }^{238} \mathrm{U}$ & 4.10 & 4.90 & 4.156 & 0.60 & $P$ & -1.3 & 9.35 & 13.38 & 10.65 & 0.60 & $N / A$ & -12.2 \\
\hline${ }^{60} \mathrm{Co}$ & 725 & 18.2 & 692.7 & 0.54 & $\mathrm{P}$ & 4.7 & $\mathrm{NR}^{\mathrm{d}}$ & NR & NR & NR & $N / A$ & $N / A$ \\
\hline
\end{tabular}

${ }^{a}$ National Institute of Standards and Technology

${ }^{\mathrm{b}}$ Radionuclide

${ }^{\mathrm{c}}$ Evaluation Rating $(\mathrm{P}=$ pass, $\mathrm{F}=$ fail)

${ }^{\mathrm{d}}$ Not reported

${ }^{\text {e }}$ Not applicable

Note: Emergency preparedness samples were not given a pass/fail rating.

Emergency Preparedness NRIP06-SS

\section{Soil $(B q / k g)$}

Table 7.2 - Mixed Analyte Performance Evaluation Review for WIPP Laboratories, 2006 MATRIX: Air Filter (Bq/Filter) MAPEP-06RdF15

MATRIX: Water Standard (Bq/L) MAPEP-06 MaW15

\begin{tabular}{|c|c|c|c|c|c|c|c|c|}
\hline \multirow[b]{2}{*}[RN]{$^{a}$} & & & & & & & & \\
\hline & $\begin{array}{l}\text { Reported } \\
\text { Value }\end{array}$ & $\begin{array}{l}\text { MAPEP }^{b} \\
\text { Value }\end{array}$ & $E^{c}$ & $\%$ Bias & $\begin{array}{l}\text { Reported } \\
\text { Value }\end{array}$ & $\begin{array}{l}\text { MAPEP } \\
\text { Value }\end{array}$ & E & $\%$ Bias \\
\hline${ }^{241} \mathrm{Am}$ & 0.0889 & 0.093 & $A$ & -4.4 & 1.24 & 1.3 & $A$ & -4.6 \\
\hline${ }^{60} \mathrm{Co}$ & 2.20 & 2.186 & A & 0.6 & 160 & 153.5 & A & 4.2 \\
\hline${ }^{134} \mathrm{Cs}$ & 2.89 & 2.934 & $A$ & -1.5 & 94.1 & 95.1 & $A$ & -1.0 \\
\hline${ }^{137} \mathrm{Cs}$ & 2.50 & 2.531 & A & -1.2 & 0.0658 & 0.0 & A & $N / A^{e}$ \\
\hline${ }^{238} \mathrm{Pu}$ & 0.0616 & 0.067 & A & -8.1 & 0.870 & 0.91 & A & -4.4 \\
\hline${ }^{239+240} \mathrm{Pu}$ & 0.000606 & 0.00041 & A & 47.8 & 0.0 & 0.0 & $A$ & $\mathrm{~N} / \mathrm{A}$ \\
\hline${ }^{90} \mathrm{Sr}$ & 0.738 & 0.792 & A & -6.8 & 12.3 & 13.16 & A & -6.5 \\
\hline${ }^{234 / 233} U$ & 0.0206 & 0.02 & $A$ & 3.0 & 2.18 & 2.09 & A & 4.3 \\
\hline${ }^{238} \mathrm{U}$ & 0.0200 & 0.021 & A & -4.8 & 2.19 & 2.17 & A & 0.9 \\
\hline \multicolumn{5}{|c|}{$\begin{array}{l}\text { MATRIX: Soil Standard (Bq/kg) } \\
\text { MAPEP-06-MaS15 }\end{array}$} & \multicolumn{4}{|c|}{$\begin{array}{l}\text { MATRIX: Vegetation (Bq/sample) } \\
\text { MAPEP-06-RdV15 }\end{array}$} \\
\hline [RN] & $\begin{array}{l}\text { Reported } \\
\text { Value }\end{array}$ & $\begin{array}{l}\text { MAPEP } \\
\text { Value }\end{array}$ & $\mathbf{E}$ & $\%$ Bias & $\begin{array}{l}\text { Reported } \\
\text { Value }\end{array}$ & $\begin{array}{l}\text { MAPEP } \\
\text { Value }\end{array}$ & E & $\%$ Bias \\
\hline${ }^{241} \mathrm{Am}$ & 56.5 & 57.08 & $A$ & -1.0 & 0.158 & 0.156 & $\bar{A}$ & 1.3 \\
\hline${ }^{60} \mathrm{Co}$ & 445 & 447.1 & $A$ & -0.5 & 4.38 & 4.52 & $A$ & -3.1 \\
\hline${ }^{134} \mathrm{Cs}$ & $N R^{d}$ & NR & $N / A$ & $\mathrm{~N} / \mathrm{A}$ & NR & NR & $\mathrm{N} / \mathrm{A}$ & $\mathrm{N} / \mathrm{A}$ \\
\hline${ }^{137} \mathrm{Cs}$ & 326 & 339.69 & $A$ & -4.0 & 2.83 & 3.074 & $A$ & -7.9 \\
\hline${ }^{238} \mathrm{Pu}$ & 58.7 & 61.15 & $A$ & -4.0 & 0.145 & 0.137 & $A$ & 5.8 \\
\hline${ }^{239+240} \mathrm{Pu}$ & 42.8 & 45.85 & $A$ & -6.6 & 0.174 & 0.164 & $A$ & 6.1 \\
\hline${ }^{90} \mathrm{Sr}$ & -1.57 & 314.35 & $\mathrm{~N}$ & -100.5 & 1.62 & 1.561 & $A$ & 3.8 \\
\hline${ }^{234 / 233} U$ & 34.1 & 37 & A & -7.8 & 0.221 & 0.208 & $A$ & 1.3 \\
\hline${ }^{238} \mathrm{U}$ & 35.2 & 38.85 & $A$ & -9.4 & 0.223 & 0.216 & $A$ & 3.2 \\
\hline
\end{tabular}

${ }^{a}$ Mixed Analyte Performance Evaluation Program

${ }^{\mathrm{b}}$ Radionuclide

${ }^{\mathrm{c}}$ Evaluation Rating $(\mathrm{A}=$ acceptable, $\mathrm{W}=$ Acceptable with warning, $\mathrm{N}=$ Not acceptable)

${ }^{\mathrm{d}}$ Not reported

${ }^{\text {e }}$ Not applicable 


\subsection{CEMRC and Air Toxics}

CEMRC performed the majority of the analyses of VOC samples collected in the WIPP underground during 2006. Air Toxics analyzed samples 1898-1913. The analyses that Air Toxics provided did not include all required QA criteria. Three separate but consecutive analyses were performed by Air Toxics during the reporting period. Analytical Batch 0602523 containing samples 1898-1905 was analyzed outside of the 24-day hold time and did not contain a laboratory control sample duplicate (LCSD). Analytical Batch 0602596 containing samples 1906-1909 did not contain a LCSD. Analytical Batch 0603103 containing samples 1910-1913 did not contain a LCSD or a laboratory duplicate.

For all analytical batches, the data received from Air Toxics was determined to be usable due to the number of satisfactory QA parameters that were completed meeting the criteria for each of those analyses. These data were qualified with a "Q" defining results as useable but lacking complete QA results.

\subsubsection{Completeness}

Completeness is defined in WP 12-VC.01 as being "the percentage of the ratio of the number of valid sample results received versus the total number of samples collected." The VOC monitoring program must maintain a completeness of 90 percent. For 2006, 251 samples (including field duplicates) were collected, of which 251 produced valid data. This results in a program completion percentage of 100 percent.

\subsubsection{Precision}

Precision is evaluated by two means in the VOC monitoring program. These are by comparing laboratory duplicate samples and also field duplicate samples. The laboratory duplicate samples consist of an LCS and LCSD. The field duplicate is a duplicate sample that is collected parallel with the original sample. Both of these duplicate samples are evaluated using the relative percent difference (RPD), as defined in WP 12-VC.01. The RPD is calculated using the following equation.

$$
R P D=\frac{(A-B)}{(|A+B|) / 2} \times 100
$$

Where: $A=$ Original Sample Result

B = Duplicate Sample Result

During 2006, a LCS and LCSD were generated and evaluated for all but the three data packages discussed in section 7.2 above. The result from the evaluation of the comparison resulted in 100 percent of the data within the acceptable range. 
Field duplicate samples are also collected and compared for precision. The acceptable range for the concentrations resulting from analysis is \pm 35 percent. For 2006 , each field duplicate met the acceptance criteria.

\subsubsection{Accuracy}

The VOC monitoring program evaluates both quantitative and qualitative accuracy. The quantitative evaluation includes performance verification for instrument calibrations, LCS recoveries, and sample internal standard areas. Qualitative evaluation consists of the evaluation of standard ion abundance for the instrument tune; that is, a mass calibration check performed prior to analyses of calibration curves and samples.

\subsubsection{Quantitative Accuracy}

$\underline{\text { Instrument Calibrations }}$

Instrument calibrations are required to have a Relative Standard Deviation percentage of less than 30 percent for each analyte of the calibration. This is calculated by first calculating the Relative Response Factor as indicated below:

Relative Response Factor $=\quad \underline{\text { (Analyte Response)(Internal Standard Concentration })}$ (Internal Standard Response)(Analyte Concentration)

Relative Standard Deviation $=\quad$ Standard Deviation of Relative Response Factor Average Relative Response Factor of Analyte $\times 100$

During 2006, 100 percent of instrument calibrations met the $\pm<30$ percent criteria.

\section{$\underline{\text { LCS recoveries }}$}

LCS recoveries are required to have a percent recovery of $\pm<25$ percent. LCS recoveries are calculated as follows:

Percent Recovery $=$ Concentration Result Introduced Concentration $\times 100$

During 2006, 100 percent of the LCS recoveries met the $\pm<25$ percent criterion.

\section{Internal Standard Area}

Internal standard areas are compared to a calibrated standard to evaluate accuracy. The acceptance criteria is \pm 40 percent.

During 2006, 100 percent of all standards met this criterion. 


\section{Sensitivity}

The method detection limit for each of the nine target compounds must be evaluated before sampling begins to meet sensitivity requirements. The initial and annual method detection limit evaluation is performed in accordance with 40 CFR Part 136, "Guidelines Establishing Test Procedures for the Analysis of Pollutants," and with EPA/530-SW-90-021, as revised and retitled, "Quality Assurance and Quality Control" (Chapter 1 of SW-846) (1996). For 2006, CEMRC completed method detection limit studies in March and July.

\subsubsection{Qualitative Accuracy}

The standard ion abundance criteria for bromofluorobenzene is used to evaluate the accuracy of the analytical system in the identification of target analytes as well as unknown contaminants (qualitative accuracy). This ensures that the instrumentation is correctly identifying individual compounds during the analysis of air samples.

During 2006, all ion abundance criteria were within tolerance.

\subsubsection{Comparability}

There is no HWFP requirement for comparability in the VOC monitoring program. However, CEMRC and Air Toxics use NIST traceable standards for each set of analyses. This practice is driven by Method TO-15 (EPA, 1999) and the contract statements of work.

\subsubsection{Representativeness}

There is no HWFP requirement for representativeness in the VOC monitoring program.

\subsection{TraceAnalysis, Inc.}

TraceAnalysis, Inc., of Lubbock, Texas, was subcontracted for 2006 to perform the analyses of groundwater samples collected at the WIPP site.

\subsubsection{Completeness}

The WIPP groundwater detection monitoring program samples seven monitoring wells twice each year. For 2006, all seven wells were sampled for all required parameters on schedule. TraceAnalysis, Inc., completed all required analyses without losing sample or data integrity and provided all analytical results, as prescribed by the HWFP. For 2006, 14 sets of water samples were collected which produced complete and valid data. LCSs and LCSDs were used to demonstrate that extractions were performed properly. For 2006, the completeness percentage was 100 percent. 


\subsubsection{Precision}

Precision for water quality analyses was based on the RPD between reported concentrations for the original sample analyses and the duplicate analyses as well as the results for LCSs and LCSDs. For 2006, precision was acceptable for both sampling Rounds 22 and 23 . The precision for the general chemistry analyses averaged 3.17 percent RPD for Round 22, and 3.36 percent RPD for Round 23. Precision for metals averaged 1.44 percent RPD for Round 22, and 2.91 percent RPD for Round 23. Precision for VOCs averaged 0.28 percent RPD for Round 22, and 0.46 percent RPD for Round 23. Precision for SVOCs averaged 2.12 percent RPD for Round 22, and 3.40 percent RPD for Round 23.

\subsubsection{Accuracy}

Accuracy of the groundwater-sample analyses was based on the percentage of recovery of individual chemical parameters from the LCSs and LCSDs. The recoveries from the LCSs and LCSDs were evaluated to determine if they exceeded the \pm 25 percent criterion for the general chemistry parameters, metals, and VOCs. SVOC recoveries were evaluated based on the individual prescribed recovery ranges specific to each chemical compound. For 2006, all recoveries from LCSs and LCSDs were within the acceptable range for general chemistry, metals and VOCs. The majority of SVOC recovery results were also within the acceptable range. Four SVOC LCS and LCSD results were recovered above the prescribed recovery percentage range during Round 22 analyses, and no SVOC results were recovered above the percentage range during Round 23 analyses.

\subsubsection{Comparability}

The HWFP requires that groundwater analytical results be comparable by reporting data in consistent units and collecting and analyzing samples using consistent methodology. These comparability requirements are met through the use of consistent, approved standard operating procedures for sample collection and analyses. In addition, TraceAnalysis, Inc., participated in an Absolute Grade PT Program interlaboratory assessment running from October to November 2006 and 92 percent of the parameters analyzed were acceptable. The program assesses comparability with other laboratories around the country.

\subsubsection{Representativeness}

The groundwater detection monitoring program is designed to collect representative groundwater samples from specific monitoring well locations. During the sampling process, serial samples are collected to help determine when final samples should be collected. Field water quality analyses are conducted to determine that the water being pumped from the monitoring wells is stable and representative of the natural groundwater at each well. A final sample is collected only when it is determined from serial sampling that the produced water is representative of natural groundwater at each location. 
Waste Isolation Pilot Plant Annual Site Environmental Report for 2006

DOE/WIPP-07-2225

This page intentionally left blank 


\section{Appendix A}

References

10 CFR Part 50, Appendix B. "Quality Assurance Criteria for Nuclear Power Plants and Fuel Reprocessing Plants." Code of Federal Regulations. Office of the Federal Register, National Archives and Records Administration, Washington, D.C.

10 CFR Part 834. "Radiation Protection of the Public and the Environment"; Proposed Rule. Code of Federal Regulations. Office of the Federal Register, National Archives and Records Administration, Washington, D.C.

10 CFR Part 1021. "National Environmental Policy Act Implementing Procedures." Code of Federal Regulations. Office of the Federal Register, National Archives and Records Administration, Washington, D.C.

40 CFR Part 61. "National Emission Standards for Hazardous Air Pollutants." Code of Federal Regulations. Office of the Federal Register, National Archives and Records Administration, Washington, D.C.

40 CFR Part 136, "Guidelines Establishing Test Procedures for the Analysis of Pollutants." Code of Federal Regulations. Office of the Federal Register, National Archives and Records Administration, Washington, D.C.

40 CFR Part 141. "National Primary Drinking Water Regulations." Code of Federal Regulations. Office of the Federal Register, National Archives and Records Administration, Washington, D.C.

40 CFR Part 143. "National Secondary Drinking Water Regulations." Code of Federal Regulations. Office of the Federal Register, National Archives and Records Administration, Washington, D.C.

40 CFR Parts 150-189. Federal Insecticide, Fungicide, and Rodenticide Act (FIFRA) Regulations. Code of Federal Regulations. Office of the Federal Register, National Archives and Records Administration, Washington, D.C.

40 CFR Part 191. "Environmental Radiation Protection Standards for Management and Disposal of Spent Nuclear Fuel, High-Level and Transuranic Radioactive Wastes." Code of Federal Regulations. Office of the Federal Register, National Archives and Records Administration, Washington, D.C.

40 CFR Part 191, Subpart A, "Environmental Standards for Management and Storage." Code of Federal Regulations. Office of the Federal Register, National Archives and Records Administration, Washington, D.C.

40 CFR Part 191, Subpart B, "Environmental Standards for Disposal." Code of Federal Regulations. Office of the Federal Register, National Archives and Records Administration, Washington, D.C. 
40 CFR Part 191, Subpart C, "Environmental Standards for Ground-Water Protection." Code of Federal Regulations. Office of the Federal Register, National Archives and Records Administration, Washington, D.C.

40 CFR Part 194. "Criteria for the Certification and Re-Certification of the Waste Isolation Pilot Plant's Compliance With the 40 CFR Part 191 Disposal Regulations." Code of Federal Regulations. Office of the Federal Register, National Archives and Records Administration, Washington, D.C.

40 CFR §194.4, "Conditions of Compliance Certification." Code of Federal Regulations. Office of the Federal Register, National Archives and Records Administration, Washington, D.C.

40 CFR §194.21, "Inspections." Code of Federal Regulations. Office of the Federal Register, National Archives and Records Administration, Washington, D.C.

40 CFR Part 262. "Standards Applicable to Generators of Hazardous Waste." Code of Federal Regulations. Office of the Federal Register, National Archives and Records Administration, Washington, D.C.

40 CFR Part 264. "Standards for Owners and Operators of Hazardous Waste Treatment, Storage, and Disposal Facilities." Code of Federal Regulations. Office of the Federal Register, National Archives and Records Administration, Washington, D.C.

40 CFR Part 270, "EPA Administered Permit Programs: the Hazardous Waste Permit Program." Code of Federal Regulations. Office of the Federal Register, National Archives and Records Administration, Washington, D.C.

40 CFR Part 280, "Technical Standards and Corrective Action Requirements for Owners and Operators of Underground Storage Tanks (UST)." Code of Federal Regulations. Office of the Federal Register, National Archives and Records Administration, Washington, D.C.

40 CFR Part 300, "National Oil and Hazardous Substances Pollution Contingency Plan." Code of Federal Regulations. Office of the Federal Register, National Archives and Records Administration, Washington, D.C.

40 CFR Part 302. "Designation, Reportable Quantities, and Notification." Code of Federal Regulations. Office of the Federal Register, National Archives and Records Administration, Washington, D.C.

40 CFR Part 761. "Polychlorinated Biphenyls (PCBs) Manufacturing, Processing, Distribution in Commerce, and Use Prohibitions." Code of Federal Regulations. Office of the Federal Register, National Archives and Records Administration, Washington, D.C. 
40 CFR Parts 1500-1508. "Council on Environmental Quality." Code of Federal Regulations. Office of the Federal Register, National Archives and Records Administration, Washington, D.C.

50 CFR Part 17, "Endangered and Threatened Plants and Wildlife." Code of Federal Regulations. Office of the Federal Register, National Archives and Records Administration, Washington, D.C.

20.2.72 NMAC. "Construction Permits." Title 20, New Mexico Administrative Code. (Air Quality Control Regulation 702). Santa Fe, NM.

20.4.1 NMAC. "Hazardous Waste Management." Title 20, New Mexico Administrative Code. Santa Fe, NM.

20.5 NMAC. "Petroleum Storage Tanks." Title 20, New Mexico Administrative Code. Sante Fe, NM.

20.6.2 NMAC. "Ground and Surface Water Protection." Title 20, New Mexico Administrative Code. Santa Fe, NM.

20.7.10 NMAC. "Drinking Water." Title 20 New Mexico Administrative Code. Santa Fe, NM.

7 U.S.C. $\S \S 136$, et seq. Federal Insecticide, Fungicide, and Rodenticide Act (FIFRA). U.S. Government Printing Office, Washington, D.C.

15 U.S.C. $\S \S 2601$, et seq. Toxic Substances Control Act. U.S. Government Printing Office, Washington, D.C.

16 U.S.C. $\S \S 470$, et seq. National Historic Preservation Act. United States Code. U.S. Government Printing Office, Washington, D.C.

16 U.S.C. §§1531, et seq. Endangered Species Act of 1973. United States Code. U.S. Government Printing Office, Washington, D.C.

16 U.S.C. $\S \S 703$, et seq. Migratory Bird Treaty Act. United States Code. U.S. Government Printing Office, Washington, D.C.

33 U.S.C. $\S \S 1251$, et seq. Federal Water Pollution Control Act of 1948 (Clean Water Act), Section 402. United States Code. U.S. Government Printing Office, Washington, D.C.

42 U.S.C. §§300f, et seq. Safe Drinking Water Act. United States Code. U.S. Government Printing Office, Washington, D.C.

42 U.S.C. §2011, et seq. Atomic Energy Act of 1954, as amended. United States Code. U.S. Government Printing Office, Washington, D.C. 
42 U.S.C. §§4321, et seq. National Environmental Policy Act. United States Code. U.S. Government Printing Office, Washington, D.C.

42 U.S.C. $\S \S 6901$, et seq. Resource Conservation and Recovery Act. United States Code. U.S. Government Printing Office, Washington, D.C.

42 U.S.C. $\S \S 6912,6939 c$, and 6961. Federal Facilities Compliance Act of 1992. United States Code. U.S. Government Printing Office, Washington, D.C.

42 U.S.C. $\S \S 7401$, et seq. Clean Air Act. United States Code. U.S. Government Printing Office, Washington, D.C.

42 U.S.C. $§ \S 9601$, et seq. Comprehensive Environmental Response, Compensation, and Liability Act (including the Superfund Amendments and Reauthorization Act of 1986). United States Code. U.S. Government Printing Office, Washington, D.C.

42 U.S.C. §10101, et seq. Nuclear Waste Policy Act of 1982. United States Code. U.S. Government Printing Office, Washington, D.C.

42 U.S.C. $\S 11101$. Superfund Amendments and Reauthorization Act of 1986 (SARA) Title III. United States Code. U.S. Government Printing Office, Washington, D.C.

43 U.S.C. $\S \S 1701$, et seq. Federal Land Policy and Management Act. United States Code. U.S. Government Printing Office, Washington, D.C.

49 U.S.C. $\S \S 5101$, et seq.; 49 CFR Parts 105-179. Hazardous Materials Transportation Act. United States Code. U.S. Government Printing Office, Washington, D.C.

ANSI N13.30. 1996. Performance Criteria for Radiobioassay. Health Physics Society, Washington, D.C.

ASME NQA-1-1989 and Supplementary Requirements, Quality Assurance Program Requirements for Nuclear Facilities

ASME NQA-2a-1990 addenda, Part 2.7, Quality Assurance Requirements of Computer Software for Nuclear Facility Applications

ASME NQA-3-1989 (excluding Section 2.1(b) and (c), and Section 17.1), Quality Assurance Program Requirements for the Collection of Scientific and Technical Information for Site Characterization of High-Level Nuclear Waste

Beauheim, R. L. 1986. Analysis of Pumping Tests of the Culebra Dolomite Conducted at the H-3 Hydropad at the Waste Isolation Pilot Plant (WIPP) Site, SAND86-2311, Sandia National Laboratories, Albuquerque, NM. 
Beauheim, R. L. 1987. Interpretations of Single-Well Hydraulic Tests Conducted at and Near the Waste Isolation Pilot Plant (WIPP) Site, 1983-1987, SAND 87-0039, Sandia National Laboratories, Albuquerque, NM.

Beauheim, R. L., T. F. Dale, and J. F. Pickens. 1991. Interpretations of Single-Well Hydraulic Tests of the Rustler Formation Conducted in the Vicinity of the Waste Isolation Pilot Plant Site, 1988-1989. SAND-890869, Sandia National Laboratories, Albuquerque, NM.

Beauheim, R. L., and G. J. Ruskauff. 1998. Analysis of Hydraulic Tests of the Culebra and Magenta Dolomites and Dewey Lake Redbeds Conducted at the Waste Isolation Pilot Plant Site, SAND 98-0049, Sandia National Laboratories, Albuquerque, NM.

Beauheim, R. L., and R. M. Roberts. 2002. "Hydrology and Hydraulic Properties of a Bedded Evaporite Formation." Journal of Hydrology, v. 259, pp. 66-88

Beck, Harold L. and Burton G. Bennet. 2002. Historical Overview of Atmospheric Nuclear Weapon Testing and Estimates of Fallout in the Continental United States. Health Phys 82:591-608.

Cooper, J. B., and V. M. Glanzman. 1971. "Geohydrology of Project Gnome Site, Eddy County, New Mexico." Professional Paper 712-A, U.S. Geological Survey, Washington, DC.

Daniel B. Stephens \& Associates, Inc. 2003. Water Budget Analysis of the Shallow Subsurface Water at the Waste Isolation Pilot Plant, Carlsbad, NM.

DOE/CAO 96-2184. 1996. Title 40 CFR Part 191 Compliance Certification Application for the Waste Isolation Pilot Plant. U.S. Department of Energy, Carlsbad Field Office. Carlsbad, NM.

DOE/EH-0173T. 1991. Environmental Regulatory Guide for Radiological Effluent Monitoring and Environmental Surveillance, Department of Environment, Safety, and Health, U.S. Department of Energy, Washington, D.C.

DOE. 2006a. Letter to Ms. Elizabeth A. Cotsworth (EPA) from David C. Moody (CBFO), dated April 10, 2006.

DOE. 2006b. Letter to Ms. Bonnie C. Gitlin (EPA) from David C. Moody (CBFO), dated February 27, 2006.

DOE. 2006c. CBFO Annual Review of the WIPP Integrated Safety Management System of September 2006. Waste Isolation Pilot Plant, Carlsbad, NM.

DOE Order 231.1A. 2003. Environment, Safety, and Health Reporting. U.S. Department of Energy, Washington, D.C. 
DOE Order 414.1C. 2005. Quality Assurance. U.S. Department of Energy, Washington, D.C.

DOE Order 430.2A. 2002. Departmental Energy and Utilities Management. U.S. Department of Energy, Washington, D.C.

DOE Order 435.1. 1999. Radioactive Waste Management. U.S. Department of Energy, Washington, D.C.

DOE Order 450.1. 2003. Environmental Protection Program. U.S. Department of Energy, Washington D.C.

DOE Order 451.1B. 2001. National Environmental Compliance Policy Act Compliance Program. U.S. Department of Energy, Washington, D.C.

DOE Order 5400.5. 1993. Radiation Protection of the Public and the Environment. U.S. Department of Energy, Washington, D.C.

DOE/EIS-0026-S-2. 1997. Waste Isolation Pilot Plant Disposal Phase Final Supplemental Environmental Impact Statement (SEIS-II). Volumes 1 through 3. U.S. Department of Energy, Washington, D.C.

DOE-STD-1153-2002. 2003. A Graded Approach for Evaluating Radiation Doses to Aquatic and Terrestrial Biota. National Technical Information Service, Washington, D.C.

DOE/CBFO-94-1012. 1994. Quality Assurance Program Document. Waste Isolation Pilot Plant, Carlsbad, NM.

DOE/WIPP 92-037. 1992. Statistical Summary of the Radiological Baseline for the Waste Isolation Pilot Plant. Waste Isolation Pilot Plant, Carlsbad, NM.

DOE/WIPP 93-004. 2002. Waste Isolation Pilot Plant Land Management Plan. Waste Isolation Pilot Plant, Carlsbad, NM.

DOE/WIPP 95-2065. 2004. Waste Isolated Pilot Plant Contact Handled (CH) Documented Safety Analysis. Waste Isolation Pilot Plant, Carlsbad, NM.

DOE/WIPP 97-2219. 1997. Exhaust Shaft Hydraulic Assessment Data Report. Waste Isolation Pilot Plant. Carlsbad, NM.

DOE/WIPP 98-2285. 1998. Waste Isolation Pilot Plant RCRA Background Groundwater Quality Baseline Report. Waste Isolation Pilot Plant, Carlsbad, NM.

DOE/WIPP 99-2194. 2004. Waste Isolation Pilot Plant Environmental Monitoring Plan. Waste Isolation Pilot Plant, Carlsbad, NM. 
DOE/WIPP-02-3122. 2006. Transuranic Waste Acceptance Criteria for the Waste Isolation Pilot Plant. Waste Isolation Pilot Plant, Carlsbad, NM.

DOE/WIPP-02-3286. 2006. Waste Isolation Pilot Plant Contact-Handled Waste Handling Emergency Planning Hazards Assessment. Waste Isolation Pilot Plant, Carlsbad, NM.

DOE/WIPP 03-2225. 2003. Waste Isolation Pilot Plant 2002 Site Environmental Report. Waste Isolation Pilot Plant, Carlsbad, NM.

DOE/WIPP 04-3231. 2004. Title 40 CFR Part 191 Subparts B and C Compliance Recertification Application 2004. Waste Isolation Pilot Plant, Carlsbad, NM.

DOE/WIPP 04-3310. 2004. CBFO/WTS Environmental Policy Statement. Waste Isolation Pilot Plant, Carlsbad, NM.

DOE/WIPP 05-3318. 2005. Waste Isolation Pilot Plant Environmental Management System Description. Waste Isolation Pilot Plant, Carlsbad, NM.

DOE/WIPP-05-3331. 2005. Waste Isolation Pilot Plant Remote-Handled Waste Handling Emergency Planning Hazards Assessment. Waste Isolation Pilot Plant, Carlsbad, NM.

DOE/WIPP-06-2171. 2006. Waste Isolation Pilot Plant Biennial Environmental Compliance Report. Waste Isolation Pilot Plant, Carlsbad, NM.

DOE/WIPP 06-3317. 2006. The Annual Change Report - 2005-2006. Waste Isolation Pilot Plant, Carlsbad, NM.

DOE/WIPP-07-2293. 2007. WIPP Subsidence Monument Leveling Survey 2005. Waste Isolation Pilot Plant, Carlsbad, NM.

DOE/WIPP-07-3333. 2007. WIPP Environmental Management System Annual Report for Fiscal Year 2006. Waste Isolation Pilot Plant, Carlsbad, NM.

DP-831. 2003. WIPP Discharge Permit. New Mexico Environment Department, Santa Fe, NM.

EPA. 2006a. Letter to Dr. Lloyd Piper (CBFO) from Bonnie Gitlin (EPA), dated June 30, 2006.

EPA. 2006b. Letter to Dr. Dave Moody (CBFO) from Bonnie Gitlin (EPA), dated July 12, 2006.

EPA. 2006c. Letter to Dr. David Moody (CBFO) from Juan Reyes (EPA), dated September 19, 2006. 
EPA. 2006d. Letter to David C. Moody (CBFO) from Bonnie Gitlin (EPA), dated June 9, 2006.

EPA. 2006e. Letter to David C. Moody (CBFO) from Bonnie Gitlin (EPA), dated June 1, 2006.

EPA Compendium Method TO-15. 1999. Determination of Volatile Organic Compounds (VOCs) in Air Collected in Specially-Prepared Canisters and Analysis By Gas Chromatography/Mass Spectrometry (GC/MS) U.S. Environmental Protection Agency, Washington, D.C.

EPA/530-SW-90-021. 1996. Quality Assurance and Quality Control. U.S. Environmental Protection Agency, Washington, D.C.

EPA/600 4-83-004. 1983. Interim Guidelines and Specification for Preparing Quality Assurance Project Plans. U.S. Environmental Protection Agency, Washington, D.C.

Executive Order 13101. 1998. Greening the Government Through Waste Prevention, Recycling, and Federal Acquisition. Office of the President, Washington, D.C.

Executive Order 13148. 1998. Greening the Government Through Leadership in Environmental Management. Office of the President, Washington, D.C.

Executive Order 13423. 2007. Strengthening Federal Environmental, Energy, and Transportation Management. Office of the President, Washington, D.C.

Fernald. 1994. Waste Acceptance Criteria for Off-Site Generators. Fernald Environmental Management Project. U.S. Department of Energy, Cincinnati, Ohio.

Hillesheim, M. B., R.L. Beauheim, and R. G. Richardson. 2006. "Overview of the WIPP Groundwater Monitoring Programs with Inferences about Karst in the WIPP Vicinity," in L. Land, V. W. Lueth, W. Raatz, P. Boston, and D. L. Love, eds., Caves and Karst of Southeastern New Mexico. New Mexico Geological Society, 57th Annual Fall Field Conference Guidebook. 277-286.

International Atomic Energy Agency. 1992. Technical Report Series No. 332, Effects of Ionizing Radiation on Plants and Animals at Levels Implied by Current Radiation Protection Standards. Vienna, Australia.

ISO 14001. Environmental Management Systems - Specification with Guidance for Use. 2004. International Organizations for Standardization, Geneva, Switzerland. 
ISO/IEC 17025. 2006. General Requirements for the Competence of Testing and Calibration Laboratories, International Organization for Standardization, Geneva, Switzerland.

IT Corporation. 2000. Waste Isolation Pilot Plant RCRA Background Groundwater Quality Baseline Update Report. Albuquerque, NM.

Lowry, T. S., and R. L. Beauheim. 2004. Analysis Report, Task 2 of AP-110, Evaluation of Water-Level Rise in the Culebra Due to Recharge from Refining Process Water Discharged onto Potash Tailings Piles. ERMS\# 536239. Carlsbad, NM: Sandia WIPP Records Center.

Lowry, T. S., and R. L. Beauheim. 2005. Analysis Report, Task 3 of AP-110, Evaluation of Water-Level Rise in the Culebra Due to Leakage Through Poorly Plugged and Abandoned Potash Boreholes. ERMS\# 540187. Carlsbad, NM: Sandia WIPP Records Center.

Mercer, J. W. 1983. Geohydrology of the Proposed Waste Isolation Pilot Plant Site, Los Medaños Area, Southeastern New Mexico, Water Resources investigations, Report 83-4016, U.S. Geological Survey.

Mercer, J. W. and B. R. Orr. 1977. Review and Analysis of Geologic Conditions Near the Site of a Potential Nuclear Waste Repository Eddy and Lea Counties, New Mexico, U.S. Geological Survey Open-File Rept., 77-123.

Minnema, D. M. and L. W. Brewer. 1983. Background Radiation Measurements at Waste Isolation Pilot Plant Site, Carlsbad, New Mexico. SAND83-1296.

MP 1.28, Integrated Safety Management. Washington TRU Solutions LLC, Waste Isolation Pilot Plant, Carlsbad, NM.

NCRP. 1987a. Report No. 94, Exposure of the Population in the United States and Canada from Natural Background Radiation. National Council on Radiation Protection and Measurements. Bethesda, MD.

NCRP. 1987b. Report No. 087, Use of Bioassay Procedures for Assessment of Internal Radionuclide Deposition. National Council on Radiation Protection and Measurements. Bethesda, MD.

NCRP. 1991. Report No. 109, Effects of Ionizing Radiation on Aquatic Organisms. National Council on Radiation Protection and Measurements. Bethesda, MD.

NM4890139088-TSDF. 1999. Waste Isolation Pilot Plant Hazardous Waste Facility Permit. New Mexico Environment Department, Santa Fe, NM.

NMSA 1978. §74-2. New Mexico Air Quality Control Act. New Mexico Statutes Annotated 1978. State of New Mexico, Santa Fe, NM. 
NMSA 1978. §74-4-1. New Mexico Hazardous Waste Act. New Mexico Statutes Annotated 1978. State of New Mexico, Santa Fe, NM.

NMSA 1978. §74-6-1. New Mexico Water Quality Act. New Mexico Statutes Annotated. State of New Mexico, Santa Fe, NM.

Pacific Northwest National Laboratory. 1999. Hanford Decision Level for Alpha Spectrometry Bioassay Analyses Based on the Sample Specific Total Propagated Uncertainty (99352). J. A. MacLellan, Radiation and Health Technology. Richland, WA.

Powers, D. W. 2004. Analysis Report, Task 1B of AP-110, Identify Plugged and Abandoned Oil or Gas Wells Not Sealed Through the Culebra with Cement, and Units to Which the Culebra Might Be Connected. ERMS\# 538279. Carlsbad, NM: Sandia WIPP Records Center.

Public Law 96-164. National Security and Military Applications of Nuclear Energy Authorization Act of 1980.

Public Law 102-579. Waste Isolation Pilot Plant Land Withdrawal Act. October 1992, as amended October 1996 by Public Law 104-201.

Stormont, J. C., C. L. Howard, and J. J. K. Daemen. 1991. Changes in Rock Salt Permeability Due to Nearby Excavation. In: Roegiers, J. C. (Ed.), Rock Mechanics as a Multidisciplinary Science. Proceedings of the $32^{\text {nd }}$ U.S. Symposium, the University of Oklahoma, Norman, Oklahoma, July 10-12, 1991. A. A. Balkema, Brookfield, VT, pp. 899-907.

U.S. Nuclear Regulatory Commission Docket-71-9218. TRUPACT-II Safety Analysis Report for Packaging. Nuclear Regulator Commission, Washington, D.C.

UNSCEAR. 2000. Sources and Effects of lonizing Radiation. 2000 Report, Vol. 1. United Nations Scientific Committee on the Effects of Atomic Radiation.

WP 02-1, WIPP Groundwater Monitoring Program Plan. Washington TRU Solutions LLC. Waste Isolation Pilot Plant, Carlsbad, NM.

WP 02-EC.07, Waste Isolation Pilot Plant Affirmative Procurement Plan. Washington TRU Solutions LLC. Waste Isolation Pilot Plant, Carlsbad, NM.

WP 02-EC.11, Waste Isolation Pilot Plant Pollution Prevention Program Plan. Washington TRU Solutions LLC. Waste Isolation Pilot Plant, Carlsbad, NM.

WP 02-EC.13, Environmental Assessment Plan. Washington TRU Solutions LLC. Waste Isolation Pilot Plant, Carlsbad, NM. 
Waste Isolation Pilot Plant Annual Site Environmental Report for 2006 DOE/WIPP-07-2225

WP 02-EM3004, Radiological Data Verification and Validation. Washington TRU Solutions LLC. Waste Isolation Pilot Plant, Carlsbad, NM.

WP 12-VC.01, Confirmatory Volatile Organic Compound Monitoring Program. Washington TRU Solutions LLC. Waste Isolation Pilot Plant, Carlsbad, NM.

WP 13-1, Washington TRU Solutions LLC Quality Assurance Program Description. Washington TRU Solutions LLC. Waste Isolation Pilot Plant, Carlsbad, NM. 
Waste Isolation Pilot Plant Annual Site Environmental Report for 2006

DOE/WIPP-07-2225

This page intentionally left blank 


\section{Waste Isolation Pilot Plant Annual Site Environmental Report for 2006 DOE/WIPP-07-2225}

\section{Appendix B \\ Active Environmental Permits}

\begin{tabular}{|c|c|c|c|c|c|}
\hline & Granting Agency & Type of Permit & $\begin{array}{c}\text { Permit } \\
\text { Number }\end{array}$ & Granted & Expiration \\
\hline 1 & $\begin{array}{l}\text { Department of the Interior, } \\
\text { Bureau of Land Management }\end{array}$ & Right-of-Way for Water Pipeline & NM53809 & $8 / 17 / 83$ & None \\
\hline 2 & $\begin{array}{l}\text { Department of the Interior, } \\
\text { Bureau of Land Management }\end{array}$ & Right-of-Way for the North Access Road & NM55676 & $8 / 24 / 83$ & None \\
\hline 3 & $\begin{array}{l}\text { Department of the Interior, } \\
\text { Bureau of Land Management }\end{array}$ & Right-of-Way for Railroad & NM55699 & $9 / 27 / 83$ & None \\
\hline 4 & $\begin{array}{l}\text { Department of the Interior, } \\
\text { Bureau of Land Management }\end{array}$ & $\begin{array}{l}\text { Right-of-Way for Dosimetry and Aerosol } \\
\text { Sampling Sites }\end{array}$ & NM63136 & $7 / 31 / 86$ & $7 / 31 / 11$ \\
\hline 5 & $\begin{array}{l}\text { Department of the Interior, } \\
\text { Bureau of Land Management }\end{array}$ & $\begin{array}{l}\text { Right-of-Way for Seven Subsidence } \\
\text { Monuments }\end{array}$ & NM65801 & $11 / 7 / 86$ & None \\
\hline 6 & $\begin{array}{l}\text { Department of the Interior, } \\
\text { Bureau of Land Management }\end{array}$ & Right-of-Way for Aerosol Sampling Site & NM77921 & $8 / 18 / 89$ & $8 / 18 / 19$ \\
\hline 7 & $\begin{array}{l}\text { Department of the Interior, } \\
\text { Bureau of Land Management }\end{array}$ & Right-of-Way for 2 Survey Monuments & NM82245 & $12 / 13 / 89$ & $12 / 13 / 19$ \\
\hline 8 & $\begin{array}{l}\text { Department of the Interior, } \\
\text { Bureau of Land Management }\end{array}$ & Right-of-Way for telephone cable & NM46029 & $7 / 3 / 90$ & $9 / 4 / 11$ \\
\hline 9 & $\begin{array}{l}\text { Department of the Interior, } \\
\text { Bureau of Land Management }\end{array}$ & Right-of-Way for SPS Powerline & NM43203 & $2 / 20 / 96$ & $10 / 19 / 11$ \\
\hline 10 & $\begin{array}{l}\text { Department of the Interior, } \\
\text { Bureau of Land Management }\end{array}$ & Right-of-Way for South Access Road & NM46130 & $8 / 17 / 81$ & $8 / 17 / 31$ \\
\hline 11 & $\begin{array}{l}\text { Department of the Interior, } \\
\text { Bureau of Land Management }\end{array}$ & Right-of-Way for South Access Road Fence & NM94304 & $3 / 15 / 95$ & none \\
\hline 12 & $\begin{array}{l}\text { Department of the Interior, } \\
\text { Bureau of Land Management }\end{array}$ & Right-of-Way for Duval telephone line & NM60174 & $11 / 6 / 96$ & $3 / 8 / 15$ \\
\hline 13 & $\begin{array}{l}\text { Department of the Interior, } \\
\text { Bureau of Land Management }\end{array}$ & Right-of-Way for Wells AEC-7 \& AEC-8 & NM108365 & $8 / 30 / 02$ & $8 / 30 / 32$ \\
\hline 14 & $\begin{array}{l}\text { Department of the Interior, } \\
\text { Bureau of Land Management }\end{array}$ & Right-of-Way for ERDA-6 & NM108365 & $8 / 30 / 02$ & $8 / 30 / 32$ \\
\hline 15 & $\begin{array}{l}\text { Department of the Interior, } \\
\text { Bureau of Land Management }\end{array}$ & $\begin{array}{l}\text { Right-of-Way for Monitoring Well C-2756 } \\
\text { (P-18) }\end{array}$ & NM108365 & $8 / 30 / 02$ & $8 / 30 / 32$ \\
\hline 16 & $\begin{array}{l}\text { Department of the Interior, } \\
\text { Bureau of Land Management }\end{array}$ & $\begin{array}{l}\text { Right-of-way for Monitoring Well C-2664 } \\
\text { (Cabin Baby) }\end{array}$ & NM107944 & $4 / 23 / 02$ & $4 / 23 / 32$ \\
\hline 17 & $\begin{array}{l}\text { Department of the Interior, } \\
\text { Bureau of Land Management }\end{array}$ & Right-of-Way for Seismic Monitoring Station & NM85426 & $9 / 23 / 91$ & None \\
\hline 18 & $\begin{array}{l}\text { Department of the Interior, } \\
\text { Bureau of Land Management }\end{array}$ & $\begin{array}{l}\text { Right-of-Way for Wells C-2725 (H-4A), } \\
\text { C-2775 (H-4B), \& C-2776 (H-4C) }\end{array}$ & NM108365 & $8 / 30 / 02$ & $8 / 30 / 32$ \\
\hline 19 & $\begin{array}{l}\text { Department of the Interior, } \\
\text { Bureau of Land Management }\end{array}$ & $\begin{array}{l}\text { Right-of-Way for Monitoring Wells C-2723 } \\
\text { (WIPP-25), C-2724 (WIPP-26), C-2722 } \\
\text { (WIPP-27), C-2636 (WIPP-28), C-2743 } \\
\text { (WIPP-29), \& C-2727 (WIPP-30) }\end{array}$ & NM108365 & $8 / 30 / 02$ & $8 / 30 / 32$ \\
\hline 20 & $\begin{array}{l}\text { Department of the Interior, } \\
\text { Bureau of Land Management }\end{array}$ & Right-of-Way for Monitoring Well WIPP-11 & NM108365 & $9 / 15 / 04$ & $9 / 20 / 34$ \\
\hline 21 & $\begin{array}{l}\text { Department of the Interior, } \\
\text { Bureau of Land Management }\end{array}$ & $\begin{array}{l}\text { Right-of-Way easement for WIPP well bore } \\
\text { SNL-2 }\end{array}$ & 109174 & $4 / 15 / 03$ & $4 / 15 / 33$ \\
\hline 22 & $\begin{array}{l}\text { Department of the Interior, } \\
\text { Bureau of Land Management }\end{array}$ & $\begin{array}{l}\text { Right-of-Way easement for WIPP well bore } \\
\text { SNL-9 }\end{array}$ & 109175 & $4 / 15 / 03$ & $4 / 15 / 33$ \\
\hline 23 & $\begin{array}{l}\text { Department of the Interior, } \\
\text { Bureau of Land Management }\end{array}$ & $\begin{array}{l}\text { Right-of-Way easement for WIPP well bore } \\
\text { SNL-12 }\end{array}$ & 109176 & $4 / 15 / 03$ & $4 / 15 / 33$ \\
\hline
\end{tabular}




\section{Waste Isolation Pilot Plant Annual Site Environmental Report for 2006 DOE/WIPP-07-2225}

\begin{tabular}{|c|c|c|c|c|c|}
\hline & Granting Agency & Type of Permit & $\begin{array}{l}\text { Permit } \\
\text { Number }\end{array}$ & Granted & Expiration \\
\hline 24 & $\begin{array}{l}\text { Department of the Interior, } \\
\text { Bureau of Land Management }\end{array}$ & $\begin{array}{l}\text { Right-of-Way easement for WIPP well bore } \\
\text { SNL-1 (access road) }\end{array}$ & 109177 & $6 / 17 / 03$ & $6 / 17 / 33$ \\
\hline 25 & $\begin{array}{l}\text { Department of the Interior, } \\
\text { Bureau of Land Management }\end{array}$ & $\begin{array}{l}\text { Right-of-Way easement for WIPP well bore } \\
\text { SNL-11 }\end{array}$ & 110735 & $10 / 17 / 03$ & $10 / 17 / 33$ \\
\hline 26 & $\begin{array}{l}\text { Department of the Interior, } \\
\text { Bureau of Land Management }\end{array}$ & $\begin{array}{l}\text { Right-of-Way easement for WIPP well bore } \\
\text { SNL-5 }\end{array}$ & 110735 & $10 / 17 / 03$ & $10 / 17 / 33$ \\
\hline 27 & $\begin{array}{l}\text { Department of the Interior, } \\
\text { Bureau of Land Management }\end{array}$ & Right-of-Way grant for SNL-16 and 17 & NM108365 & $12 / 21 / 05$ & $8 / 30 / 32$ \\
\hline 28 & $\begin{array}{l}\text { U.S. Department of the Interior, } \\
\text { Fish and Wildlife Service }\end{array}$ & $\begin{array}{l}\text { Concurrence that WIPP construction } \\
\text { activities will have no significant impact on } \\
\text { federally-listed threatened or endangered } \\
\text { species }\end{array}$ & None & $5 / 29 / 80$ & None \\
\hline 29 & $\begin{array}{l}\text { New Mexico Commissioner of } \\
\text { Public Lands }\end{array}$ & Right-of-Way for High Volume Air Sampler & RW-22789 & $10 / 3 / 85$ & $10 / 3 / 20$ \\
\hline 30 & $\begin{array}{l}\text { New Mexico Commissioner of } \\
\text { Public Lands }\end{array}$ & Monitoring Well SNL-3 & RW-28537 & $7 / 31 / 03$ & $7 / 31 / 38$ \\
\hline 31 & $\begin{array}{l}\text { New Mexico Commissioner of } \\
\text { Public Lands }\end{array}$ & Monitoring Well SNL-1 & RW-28535 & $8 / 27 / 03$ & $8 / 27 / 38$ \\
\hline 32 & $\begin{array}{l}\text { New Mexico Commissioner of } \\
\text { Public Lands }\end{array}$ & $\begin{array}{l}\text { Right-of-Way Easement for Accessing State } \\
\text { Trust Lands in Eddy \& Lea Counties }\end{array}$ & RW-25430 & $9 / 28 / 04$ & $9 / 28 / 14$ \\
\hline 33 & $\begin{array}{l}\text { New Mexico Environment } \\
\text { Department Air Quality Bureau }\end{array}$ & $\begin{array}{l}\text { Operating Permit for two backup diesel } \\
\text { generators }\end{array}$ & $310-\mathrm{M}-2$ & $12 / 7 / 93$ & None \\
\hline 34 & $\begin{array}{l}\text { New Mexico Department of Game } \\
\text { and Fish }\end{array}$ & $\begin{array}{l}\text { Concurrence that WIPP construction } \\
\text { activities will have no significant impact on } \\
\text { state-listed threatened or endangered } \\
\text { species }\end{array}$ & None & $5 / 26 / 89$ & None \\
\hline 35 & \begin{tabular}{|l} 
New Mexico Environment \\
Department-UST Bureau
\end{tabular} & Underground Storage Tanks & \begin{tabular}{|c|} 
Facility No. \\
31539 \\
\end{tabular} & $7 / 1 / 06$ & $6 / 30 / 07$ \\
\hline 36 & New Mexico State Engineer Office & $\begin{array}{l}\text { Monitoring Well Exhaust Shaft Exploratory } \\
\text { Borehole }\end{array}$ & C-2801 & $2 / 23 / 01$ & None \\
\hline 37 & New Mexico State Engineer Office & Monitoring Well & $\mathrm{C}-2811$ & $3 / 2 / 02$ & None \\
\hline 38 & New Mexico State Engineer Office & $\begin{array}{l}\text { Monitoring Well Exhaust Shaft Exploratory } \\
\text { Borehole }\end{array}$ & C-2802 & $2 / 23 / 01$ & None \\
\hline 39 & New Mexico State Engineer Office & $\begin{array}{l}\text { Monitoring Well Exhaust Shaft Exploratory } \\
\text { Borehole }\end{array}$ & C-2803 & $2 / 23 / 01$ & None \\
\hline 40 & New Mexico State Engineer Office & Appropriation: WQSP-1 Well & C-2413 & $10 / 21 / 96$ & None \\
\hline 41 & New Mexico State Engineer Office & Appropriation: WQSP-2 Well & C-2414 & $10 / 21 / 96$ & None \\
\hline 42 & New Mexico State Engineer Office & Appropriation: WQSP-3 Well & C-2415 & $10 / 21 / 96$ & None \\
\hline 43 & New Mexico State Engineer Office & Appropriation: WQSP-4 Well & C-2416 & $10 / 21 / 96$ & None \\
\hline 44 & New Mexico State Engineer Office & Appropriation: WQSP-5 Well & C-2417 & $10 / 21 / 96$ & None \\
\hline 45 & New Mexico State Engineer Office & Appropriation: WQSP-6 Well & C-2418 & $10 / 21 / 96$ & None \\
\hline 46 & New Mexico State Engineer Office & Appropriation: WQSP-6a Well & C-2419 & $10 / 21 / 96$ & None \\
\hline 47 & New Mexico State Engineer Office & Monitoring Well AEC-7 & C-2742 & $11 / 6 / 00$ & None \\
\hline 48 & New Mexico State Engineer Office & Monitoring Well AEC-8 & C-2744 & $11 / 6 / 00$ & None \\
\hline 49 & New Mexico State Engineer Office & Monitoring Well Cabin Baby & C-2664 & $7 / 30 / 99$ & None \\
\hline 50 & New Mexico State Engineer Office & Monitoring Well DOE-1 & C-2757 & $11 / 6 / 00$ & None \\
\hline 51 & New Mexico State Engineer Office & Monitoring Well DOE-2 & C-2682 & $4 / 17 / 00$ & None \\
\hline 52 & New Mexico State Engineer Office & Monitoring Well ERDA-9 & C-2752 & $11 / 6 / 00$ & None \\
\hline 53 & New Mexico State Engineer Office & Monitoring Well $\mathrm{H}-1$ & C-2765 & $11 / 6 / 00$ & None \\
\hline 54 & New Mexico State Engineer Office & Monitoring Well H-2A & C-2762 & $11 / 6 / 00$ & None \\
\hline
\end{tabular}




\section{Waste Isolation Pilot Plant Annual Site Environmental Report for 2006 DOE/WIPP-07-2225}

\section{Table B.1 - Active Environmental Permits for the Waste Isolation Pilot Plant - Calendar Year 2006 (Does Not Include Hazardous Waste Facility Permit or DP-831)}

\begin{tabular}{|c|c|c|c|c|c|}
\hline & Granting Agency & Type of Permit & $\begin{array}{c}\text { Permit } \\
\text { Number }\end{array}$ & Granted & Expiration \\
\hline 55 & New Mexico State Engineer Office & Monitoring Well H-2B1 & C-2758 & $11 / 6 / 00$ & None \\
\hline 56 & New Mexico State Engineer Office & Monitoring Well H-2B2 & C-2763 & $11 / 6 / 00$ & None \\
\hline 57 & New Mexico State Engineer Office & Monitoring Well $\mathrm{H}-2 \mathrm{C}$ & C-2759 & $11 / 6 / 00$ & None \\
\hline 58 & New Mexico State Engineer Office & Monitoring Well H-3B1 & C-2764 & $11 / 6 / 00$ & None \\
\hline 59 & New Mexico State Engineer Office & Monitoring Well H-3B2 & C-2760 & $11 / 6 / 00$ & None \\
\hline 60 & New Mexico State Engineer Office & Monitoring Well H-3B3 & C-2761 & $11 / 6 / 00$ & None \\
\hline 61 & New Mexico State Engineer Office & Monitoring Well H-3D & C-3207 & $11 / 6 / 00$ & None \\
\hline 62 & New Mexico State Engineer Office & Monitoring Well $\mathrm{H}-4 \mathrm{~A}$ & C-2725 & $11 / 6 / 00$ & None \\
\hline 63 & New Mexico State Engineer Office & Monitoring Well H-4B & C-2775 & $11 / 6 / 00$ & None \\
\hline 64 & New Mexico State Engineer Office & Monitoring Well $\mathrm{H}-4 \mathrm{C}$ & C-2776 & $11 / 6 / 00$ & None \\
\hline 65 & New Mexico State Engineer Office & Monitoring Well H-5A & C-2746 & $11 / 6 / 00$ & None \\
\hline 66 & New Mexico State Engineer Office & Monitoring Well H-5B & C-2745 & $11 / 6 / 00$ & None \\
\hline 67 & New Mexico State Engineer Office & Monitoring Well $\mathrm{H}-5 \mathrm{C}$ & C-2747 & $11 / 6 / 00$ & None \\
\hline 68 & New Mexico State Engineer Office & Monitoring Well H-6A & C-2751 & $11 / 6 / 00$ & None \\
\hline 69 & New Mexico State Engineer Office & Monitoring Well H-6B & C-2749 & $11 / 6 / 00$ & None \\
\hline 70 & New Mexico State Engineer Office & Monitoring Well H-6C & C-2750 & $11 / 6 / 00$ & None \\
\hline 71 & New Mexico State Engineer Office & Monitoring Well $\mathrm{H}-7 \mathrm{~A}$ & C-2694 & $4 / 17 / 00$ & None \\
\hline 72 & New Mexico State Engineer Office & Monitoring Well H-7B1 & C-2770 & $11 / 6 / 00$ & None \\
\hline 73 & New Mexico State Engineer Office & Monitoring Well H-7B2 & C-2771 & $11 / 6 / 00$ & None \\
\hline 74 & New Mexico State Engineer Office & Monitoring Well $\mathrm{H}-7 \mathrm{C}$ & C-2772 & $11 / 6 / 00$ & None \\
\hline 75 & New Mexico State Engineer Office & Monitoring Well $\mathrm{H}-8 \mathrm{~A}$ & C-2780 & $11 / 6 / 00$ & None \\
\hline 76 & New Mexico State Engineer Office & Monitoring Well H-8B & C-2781 & $11 / 6 / 00$ & None \\
\hline 77 & New Mexico State Engineer Office & Monitoring Well $\mathrm{H}-8 \mathrm{C}$ & C-2782 & $11 / 6 / 00$ & None \\
\hline 78 & New Mexico State Engineer Office & Monitoring Well $\mathrm{H}-9 \mathrm{~A}$ & C-2785 & $11 / 6 / 00$ & None \\
\hline 79 & New Mexico State Engineer Office & Monitoring Well H-9B & C-2783 & $11 / 6 / 00$ & None \\
\hline 80 & New Mexico State Engineer Office & Monitoring Well H-9C & C-2784 & $11 / 6 / 00$ & None \\
\hline 81 & New Mexico State Engineer Office & Monitoring Well $\mathrm{H}-10 \mathrm{~A}$ & C-2779 & $11 / 6 / 00$ & None \\
\hline 82 & New Mexico State Engineer Office & Monitoring Well $\mathrm{H}-10 \mathrm{~B}$ & C-2778 & $11 / 6 / 00$ & None \\
\hline 83 & New Mexico State Engineer Office & Monitoring Well $\mathrm{H}-10 \mathrm{C}$ & C-2695 & $4 / 17 / 00$ & None \\
\hline 84 & New Mexico State Engineer Office & Monitoring Well H-11B1 & C-2767 & $11 / 6 / 00$ & None \\
\hline 85 & New Mexico State Engineer Office & Monitoring Well H-11B2 & C-2687 & $4 / 17 / 00$ & None \\
\hline 86 & New Mexico State Engineer Office & Monitoring Well H-11B3 & C-2768 & $11 / 6 / 00$ & None \\
\hline 87 & New Mexico State Engineer Office & Monitoring Well H-11B4 & C-2769 & $11 / 6 / 00$ & None \\
\hline 88 & New Mexico State Engineer Office & Monitoring Well H-12 & C-2777 & $11 / 6 / 00$ & None \\
\hline 89 & New Mexico State Engineer Office & Monitoring Well H-14 & C-2766 & $11 / 6 / 00$ & None \\
\hline 90 & New Mexico State Engineer Office & Monitoring Well $\mathrm{H}-15$ & C-2685 & $4 / 17 / 00$ & None \\
\hline 91 & New Mexico State Engineer Office & Monitoring Well $\mathrm{H}-16$ & C-2753 & $11 / 6 / 00$ & None \\
\hline 92 & New Mexico State Engineer Office & Monitoring Well H-17 & C-2773 & $11 / 6 / 00$ & None \\
\hline 93 & New Mexico State Engineer Office & Monitoring Well H-18 & C-2683 & $4 / 17 / 00$ & None \\
\hline 94 & New Mexico State Engineer Office & Monitoring Well P-17 & C-2774 & $11 / 6 / 00$ & None \\
\hline 95 & New Mexico State Engineer Office & Monitoring Well WIPP-12 & C-2639 & $1 / 12 / 99$ & None \\
\hline 96 & New Mexico State Engineer Office & Monitoring Well WIPP-13 & C-2748 & $11 / 6 / 00$ & None \\
\hline 97 & New Mexico State Engineer Office & Monitoring Well WIPP-18 & C-2684 & $4 / 17 / 00$ & None \\
\hline 98 & New Mexico State Engineer Office & Monitoring Well WIPP-19 & C-2755 & $11 / 6 / 00$ & None \\
\hline
\end{tabular}


Waste Isolation Pilot Plant Annual Site Environmental Report for 2006 DOE/WIPP-07-2225

\begin{tabular}{|c|c|c|c|c|c|}
\hline & Granting Agency & Type of Permit & $\begin{array}{c}\text { Permit } \\
\text { Number }\end{array}$ & Granted & Expiration \\
\hline 99 & New Mexico State Engineer Office & Monitoring Well WIPP-21 & C-2754 & $11 / 6 / 00$ & None \\
\hline 100 & New Mexico State Engineer Office & Monitoring Well WIPP-25 & C-2723 & $7 / 26 / 00$ & None \\
\hline 101 & New Mexico State Engineer Office & Monitoring Well WIPP-26 & C-2724 & $11 / 6 / 00$ & None \\
\hline 102 & New Mexico State Engineer Office & Monitoring Well WIPP-27 & C-2722 & $11 / 6 / 00$ & None \\
\hline 103 & New Mexico State Engineer Office & Monitoring Well WIPP-28 & C-2636 & $1 / 12 / 99$ & None \\
\hline 104 & New Mexico State Engineer Office & Monitoring Well WIPP-29 & C-2743 & $11 / 6 / 00$ & None \\
\hline 105 & New Mexico State Engineer Office & Monitoring Well WIPP-30 & C-2727 & $8 / 4 / 00$ & None \\
\hline 106 & New Mexico State Engineer Office & Monitoring Well SNL-2 & C-2948 & $2 / 14 / 03$ & None \\
\hline 107 & New Mexico State Engineer Office & Monitoring Well SNL-9 & C-2950 & $2 / 14 / 03$ & None \\
\hline 108 & New Mexico State Engineer Office & Monitoring Well SNL-12 & C-2954 & $2 / 25 / 03$ & None \\
\hline 109 & New Mexico State Engineer Office & Monitoring Well SNL-1 & C-2953 & $2 / 25 / 03$ & None \\
\hline 110 & New Mexico State Engineer Office & Monitoring Well SNL-3 & C-2949 & $2 / 14 / 03$ & None \\
\hline 111 & New Mexico State Engineer Office & Monitoring Well WTS-4 & C-2960 & $3 / 18 / 03$ & None \\
\hline 112 & New Mexico State Engineer Office & Monitoring Well SNL-5 & C-3002 & $10 / 1 / 03$ & None \\
\hline 113 & New Mexico State Engineer Office & Monitoring Well IMC-461 & C-3015 & $11 / 25 / 03$ & None \\
\hline 114 & New Mexico State Engineer Office & Monitoring Well SNL-11 & C-3003 & $10 / 1 / 03$ & None \\
\hline 115 & New Mexico State Engineer Office & Monitoring Well SNL10 & C03221 & $7 / 26 / 05$ & $7 / 31 / 07$ \\
\hline 116 & New Mexico State Engineer Office & Monitoring Well SNL16 & $\mathrm{C} 03220$ & $7 / 26 / 05$ & $7 / 31 / 07$ \\
\hline 117 & New Mexico State Engineer Office & Monitoring Well SNL17 & C03222 & $7 / 26 / 05$ & $7 / 31 / 07$ \\
\hline 118 & New Mexico State Engineer Office & Monitoring Well SNL18 & $\mathrm{C} 03233$ & $10 / 6 / 05$ & $10 / 31 / 06$ \\
\hline 119 & New Mexico State Engineer Office & Monitoring Well SNL19 & $\mathrm{C} 03234$ & $10 / 6 / 05$ & $10 / 31 / 06$ \\
\hline
\end{tabular}




\section{Appendix C \\ Location Codes}

Table C.1 - Codes Used to Identify the Sites from Which Samples Were Collected

\begin{tabular}{llll}
\hline Code & \multicolumn{1}{c}{ Location } & \multicolumn{1}{c}{ Code } & \multicolumn{1}{c}{ Location } \\
\hline BHT & Bottom of the Hill Tank & RCP1 & Rainwater Catchment Pond (1) \\
BRA & Brantley Lake & RCP2 & Rainwater Catchment Pond (2) \\
CBD & Carlsbad & RED & Red Tank \\
COW & Coyote Well (deionized water blank) & SEC & South East Control \\
FWT & Fresh Water Tank & SMR & Smith Ranch \\
HIL & Hill Tank & SOO & Sample of Opportunity* \\
IDN & Indian Tank & SWL & Sewage Lagoons \\
LST & Lost Tank & TUT & Tut Tank \\
MLR & Mills Ranch & UPR & Upper Pecos River \\
NOY & Noya Tank & WAB & WIPP Air Blank \\
PCN & Pierce Canyon & WEE & WIPP East \\
PEC & Pecos River & WFF & WIPP Far Field \\
PKT & Poker Trap & WQSP & Water Quality Sample Program \\
& & WSS & WIPP South \\
\hline
\end{tabular}

* Sample taken where found 
Waste Isolation Pilot Plant Annual Site Environmental Report for 2006

DOE/WIPP-07-2225

This page intentionally left blank 


\section{Appendix D Equations}

\section{Detection}

All radionuclides with the exception of ${ }^{137} \mathrm{Cs},{ }^{60} \mathrm{Co}$, and ${ }^{40} \mathrm{~K}$ are considered "detected" if the radionuclide concentration is greater than the minimum detectable concentration and the total propagated uncertainty at the two sigma level. For the exceptions noted, these radionuclides are considered detected if they meet the criteria listed above and the confidence level from which the peak or peaks associated with them can be identified by the gamma spectroscopy software at a confidence level of 90 percent or greater.

\section{Minimum Detectable Concentration (MDC)}

The MDC is the smallest amount (activity or mass) of a radionuclide in a sample that will be detected with a 5 percent probability of nondetection while accepting a 5 percent probability of erroneously deciding that a positive quantity of a radionuclide is present in an appropriate blank sample. This method assures that any claimed MDC has at least a 95 percent chance of being detected. It is possible to achieve a very low level of detection by analyzing a large sample size and counting for a very long time.

The WIPP Laboratories used the following equation for calculating the MDCs for each radionuclide in various sample matrices:

$$
M D C=\frac{4.66 \sqrt{S}}{K T}+\frac{3.00}{K T}
$$

Where:

$$
\begin{aligned}
& S=\quad \begin{array}{l}
\text { Net method blank counts; when method blank counts }=0 \text {, average } \\
\text { of the last } 30 \text { blanks analyzed are substituted }
\end{array} \\
& K=\quad \begin{array}{l}
\text { A correction factor that includes items such as unit conversions, } \\
\text { sample volume/weight, decay correction, detector efficiency, } \\
\text { chemical recovery and abundance correction, etc. }
\end{array} \\
& T=\begin{array}{l}
\text { Counting time where the background and sample counting time are } \\
\text { identical }
\end{array}
\end{aligned}
$$

For further evaluation of the MDC, refer to ANSI N13.30, Performance Criteria for Radiobioassay.

\section{Total Propagated Uncertainty (TPU)}

The TPU is an estimate of the uncertainty in the measurement due to all sources, including counting error, measurement error, chemical recovery error, detector efficiency, randomness of radioactive decay, and any other sources of uncertainty. 
The TPU for each data point must be reported at $2 \sigma$ level. $\operatorname{TPU}_{2 \sigma}$ is found by multiplying $\mathrm{TPU}_{1 \sigma}$ by 1.96 after using the following equation:

$$
T P U_{1 \sigma}=\frac{\sqrt{\sigma_{N C R}^{2}+(N C R)^{2} *\left(R E_{E F F}^{2}+R E_{A L I}^{2}+R E_{R}^{2}+\Sigma R E_{C F}^{2}\right)}}{2.22 * E F F * A L I * R * A B N_{S} * e^{-\lambda \Delta t} * C F}
$$

Where:

$$
\begin{aligned}
\mathrm{EFF}= & \text { Detector Efficiency } \\
\mathrm{ALI}= & \text { Sample Aliquot Volume or Mass } \\
\mathrm{R} & =\text { Sample Tracer/Carrier Recovery } \\
\mathrm{ABN} & =\text { Abundance Fraction of the Emissions Used for } \\
& \text { Identification/Quantification } \\
\sigma^{2}{ }_{\mathrm{NCR}}= & \text { Variance of the Net Sample Count Rate } \\
\mathrm{NCR}= & \text { Net Sample Count Rate } \\
\mathrm{RE}^{2} & =\text { Square of the Relative Error of the Efficiency Term } \\
\mathrm{RE}^{2}{ }_{\mathrm{EFF}}= & \text { Square of the Relative Error of the Aliquot } \\
\mathrm{RE}^{2}{ }_{\mathrm{ALI}}= & \text { Square of the Relative Error of the Sample Recovery } \\
\mathrm{RE}^{2}{ }_{\mathrm{CF}}= & \text { Square of the Relative Error of Other Correction Factors } \\
\lambda & =\text { Radionuclide Decay Constant = In 2/(half-life) [Same units as the } \\
& \text { half-life used to compute } \lambda \text { ] } \\
\Delta \mathrm{A}= & \text { Time from Sample Collection to Radionuclide Separation or } \\
& \text { Mid-Point of Count Time (Same units as half-life) } \\
\mathrm{CF}= & \text { Other Correction Factors as Appropriate (i.e., ingrowth factor, } \\
& \text { self-absorption factor, etc.). }
\end{aligned}
$$

For further discussion of TPU, refer to ANSI N13.30 and/or Waste Acceptance Criteria for Off-Site Generators, Fernald Environmental Management Project (DOE, 1994).

\section{Relative Error Ratio (RER)}

The Relative Error Ratio is a method, similar to a t-test, with which to compare duplicate results (see Chapters 4 and 8; WP 02-EM3004, Radiological Data Verification and Validation).

$$
R E R=\frac{\left|x_{A}-x_{B}\right|}{\sqrt{\left(2 \sigma_{A}\right)^{2}+\left(2 \sigma_{R}\right)^{2}}}
$$

Where:

$$
\begin{array}{ll}
\overline{X_{A}} & =\text { Mean Activity of Population A } \\
\overline{X_{B}} & =\text { Mean Activity of Population B } \\
\sigma_{A} & =\text { Standard Deviation of Population A } \\
\sigma_{B} & =\text { Standard Deviation of Population B }
\end{array}
$$




\section{Percent Bias (\% Bias)}

The percent bias is a measure of the accuracy of radiochemical separation methods and counting instruments; that is, a measure of how reliable the results of analyses are when compared to the actual values.

$$
\% B I A S=\left[\frac{A_{m}-A_{k}}{A_{k}}\right] * 100 \%
$$

Where:

$\begin{array}{lll}\% \text { BIAS } & = & \text { Percent Bias } \\ A_{m} & = & \text { Measured Sample Activity } \\ A_{k} & = & \text { Known Sample Activity }\end{array}$


Waste Isolation Pilot Plant Annual Site Environmental Report for 2006

DOE/WIPP-07-2225

This page intentionally left blank 


\section{Appendix E \\ Time Trend Plots for Detectable Constituents in Groundwater}

The figures in this appendix show the concentrations of various groundwater constituents relative to the "baseline period" concentrations. Baseline concentrations were measured from 1995 through 2000 . These plots indicate the sample and duplicate concentration values with respect to sample round, and the baseline period is represented by plotted data for Rounds 1 through 10. Sampling Round 22 occurred March through May 2006 and sampling Round 23 occurred September through November 2006. See Appendix F for specific concentration information on the WQSP groundwater wells.

An example of a time trend analysis is a comparison between the baseline period concentrations and the data collected during subsequent sampling rounds. One illustration is in total suspended solids (TSS) concentrations which, as shown in the time trend graphs in this appendix, exhibit a change from the early sampling rounds to latter rounds in all WQSP wells. Early round analyses were performed by different subcontract laboratories than those since Round 7. In many cases, the laboratories that performed TSS analyses prior to Round 7 had higher minimum detection levels than the current laboratory. Those higher detection levels appear as higher concentrations for TSS during early sampling rounds. Also, some of the higher reported concentrations for early sampling rounds were the result of the wells being newly drilled and the formation and gravel pack having some fine-grained material that was eventually removed by pumping and sampling.

Other notable trends and observations include:

Magnesium ion concentrations reported for wells WQSP-1, 2, 3, 4, 5, and 6 showed an overall increase during Rounds 9 to 21 . Well WQSP-1 exceeded the $95^{\text {th }}$ UTLV during Rounds 21 and 23. Well WQSP-3 exceeded the $95^{\text {th }}$ UTLV during Round 20, and well WQSP-5 exceeded the $95^{\text {th }}$ UTLV during Round 10. However, wells WQSP-2, 3, 4, 5, 6, and 6A showed a decrease in magnesium ion concentrations during Rounds 22 and 23.

- $\quad$ Potassium ion concentrations reported for wells WQSP-1 and 2 showed an overall increase during Rounds 7 to 22, and well WQSP-6 showed an overall increase in potassium ion concentration during Rounds 8 to 22 . The potassium ion concentrations reported for wells WQSP-3, 4, 5, and 6A during Rounds 7 to 22 appear to be on a slightly increasing trend. Although the current contract laboratory has reported unusually high potassium ion concentrations during the rounds identified above, the potassium ion concentrations reported during Round 23 for wells WQSP-1, 2, 3, 4, 5, and 6 appear to be similar to the concentrations reported during Rounds 1 to 6 . The potassium ion concentration during Round 23 for well WQSP-6A was the lowest thus far. The charge balance for Round 23 was also improved. 
Sodium ion concentrations reported for wells WQSP-1, 2, 3, 4, and 5 showed an overall increase during Rounds 17 to 23 . Wells WQSP-1, 2, 4, and 5 had the highest sodium ion concentration thus far during Round 23. The highest sodium ion concentrations recorded thus far in wells WQSP-6 and 6A occurred during Round 1, with an overall decreasing trend during Rounds 1 to 23. Well WQSP-6 had one of the lowest recorded sodium ion concentrations during Round 22, and well WQSP-6A had the lowest recorded sodium ion concentration during Round 23.

•

Total organic halogens (TOX) had been reported at relatively high and highly variable concentrations during rounds prior to Round 19 in wells WQSP-1, 3, $4,5,6$, and $6 \mathrm{~A}$. A new contract laboratory began performing TOX analyses with Round 19. The previous laboratory reported having great difficulty with TOX analyses for WIPP brines due to the great concentrations of inorganic halogens interfering with the analysis. The new laboratory has reported lower and consistent concentrations for TOX since Round 19 and through Round 23.

- Well WQSP-6A has shown a clear trend of decreasing ion concentrations for calcium, magnesium and chloride (in addition to sodium, as identified above) corresponding with decreasing values for TDS and specific conductance since the early sampling rounds.

- $\quad$ Chloride ion concentrations reported for wells WQSP-2, 3, 4, and 5 showed an overall increase during Rounds 19 to 23 . Wells WQSP-1 and 6 showed a slight increase in chloride ion concentrations during Rounds 19 to 23.

- $\quad$ Sulfate ion concentrations reported for all WQSP wells showed an overall increase during Rounds 19 to 23 . Wells WQSP-3, 4 , and 5 showed the largest increases in sulfate ion concentrations during Rounds 19 to 23.

Total suspended solids were unusually high in WQSP-6 in Round 22. The cause is unknown.

The apparent fluctuations of reported chloride, magnesium, potassium, sodium and sulfate ion concentrations observed in all of the WQSP wells during Rounds 7 to 23 may be indicative of the problems with very high to extremely high dissolved solids concentrations, and sources of analytical error thus introduced by sample dilution, as well as matrix interference. 


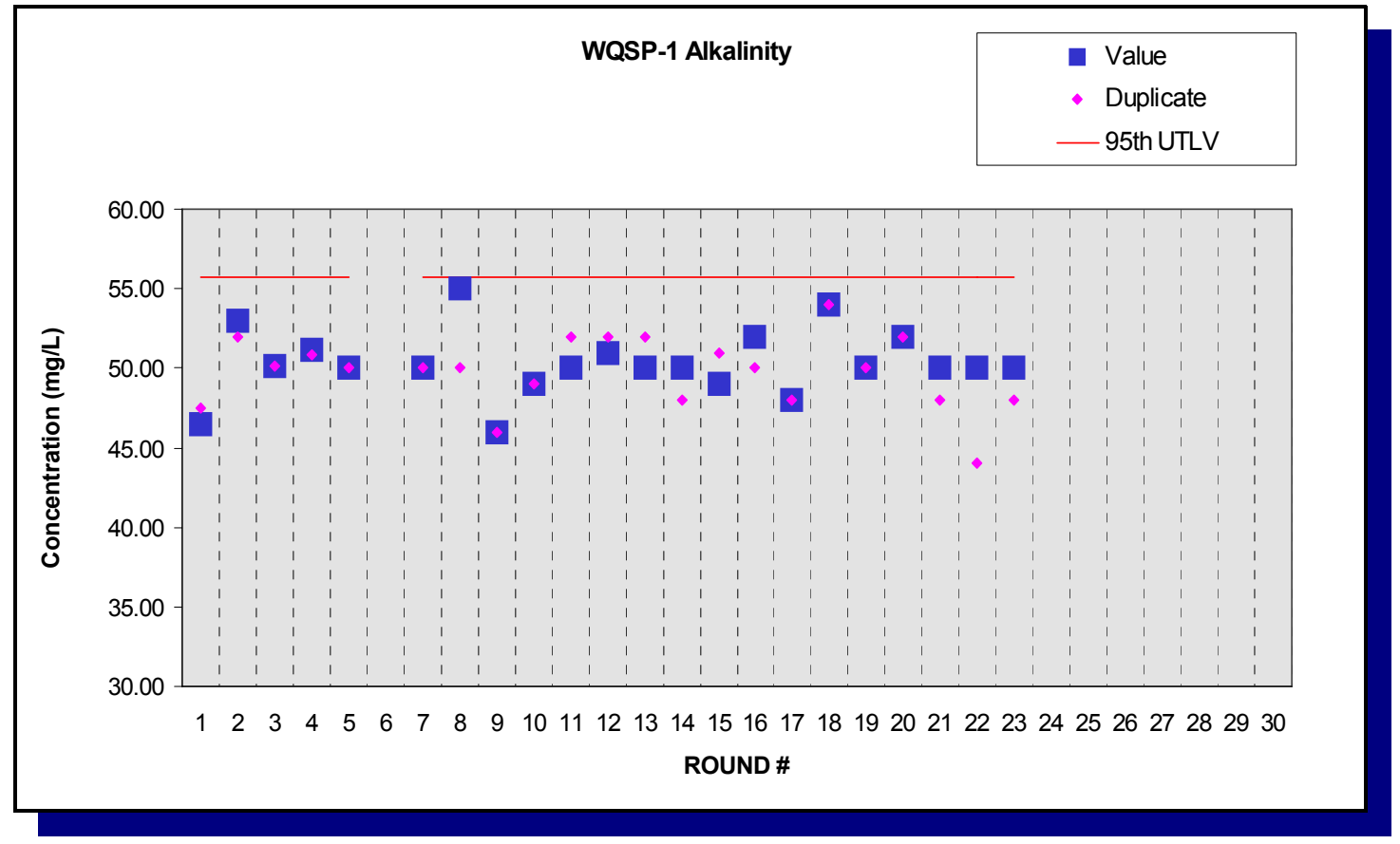

Figure E.1 - Time Trend Plot for Alkalinity at WQSP-1

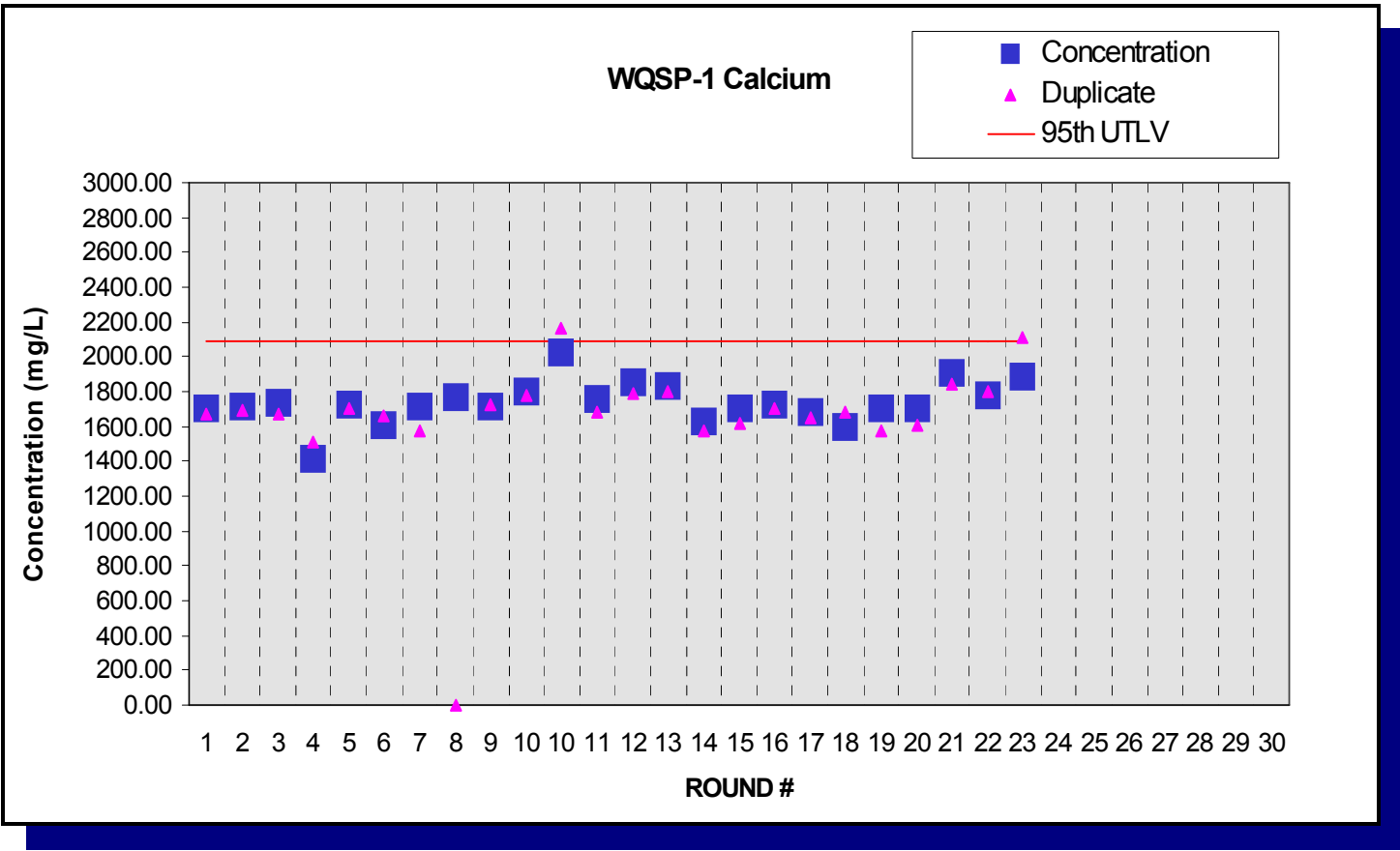

Figure E.2 - Time Trend Plot for Calcium at WQSP-1 


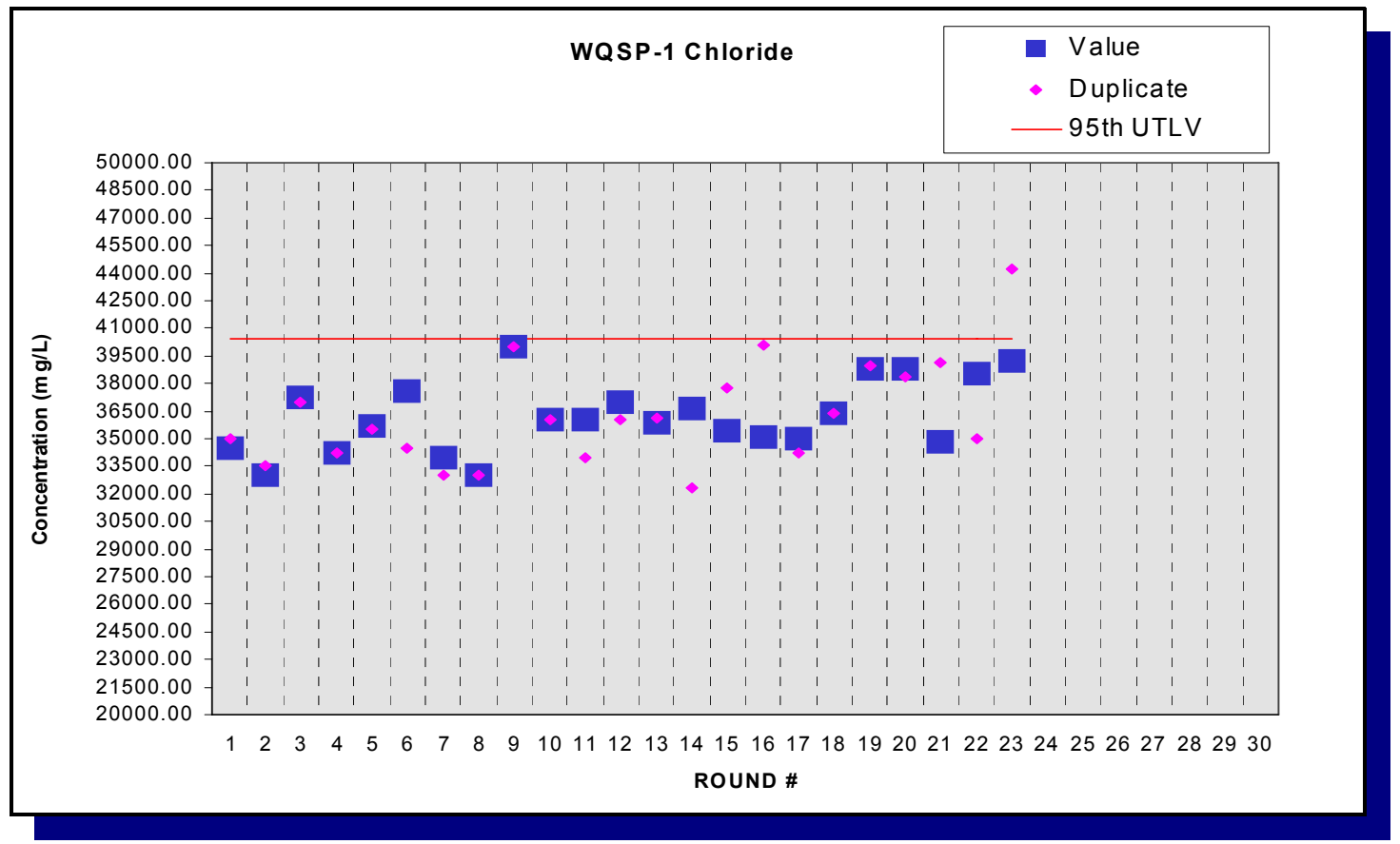

Figure E.3 - Time Trend Plot for Chloride at WQSP-1

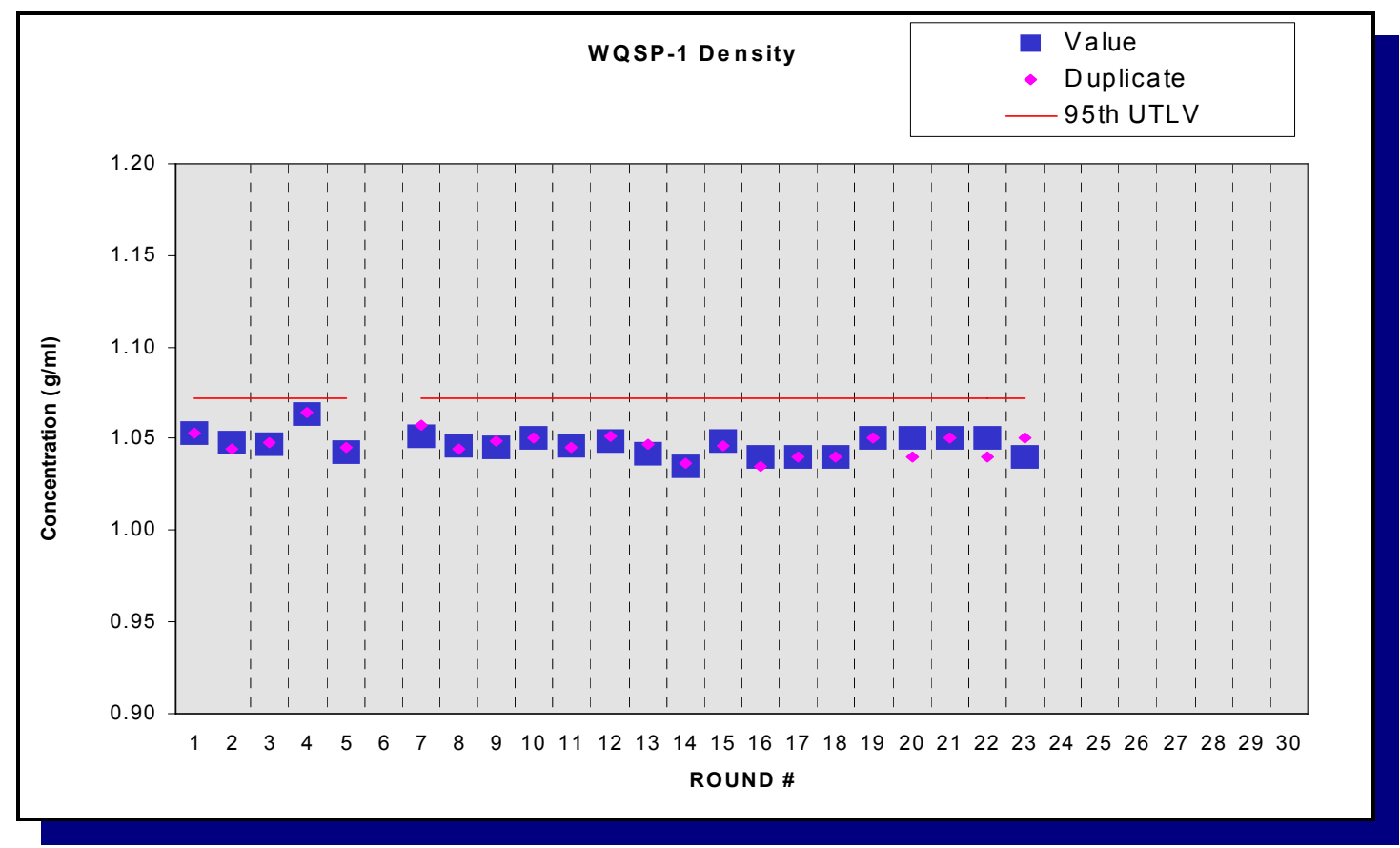

Figure E.4 - Time Trend Plot for Density at WQSP-1 


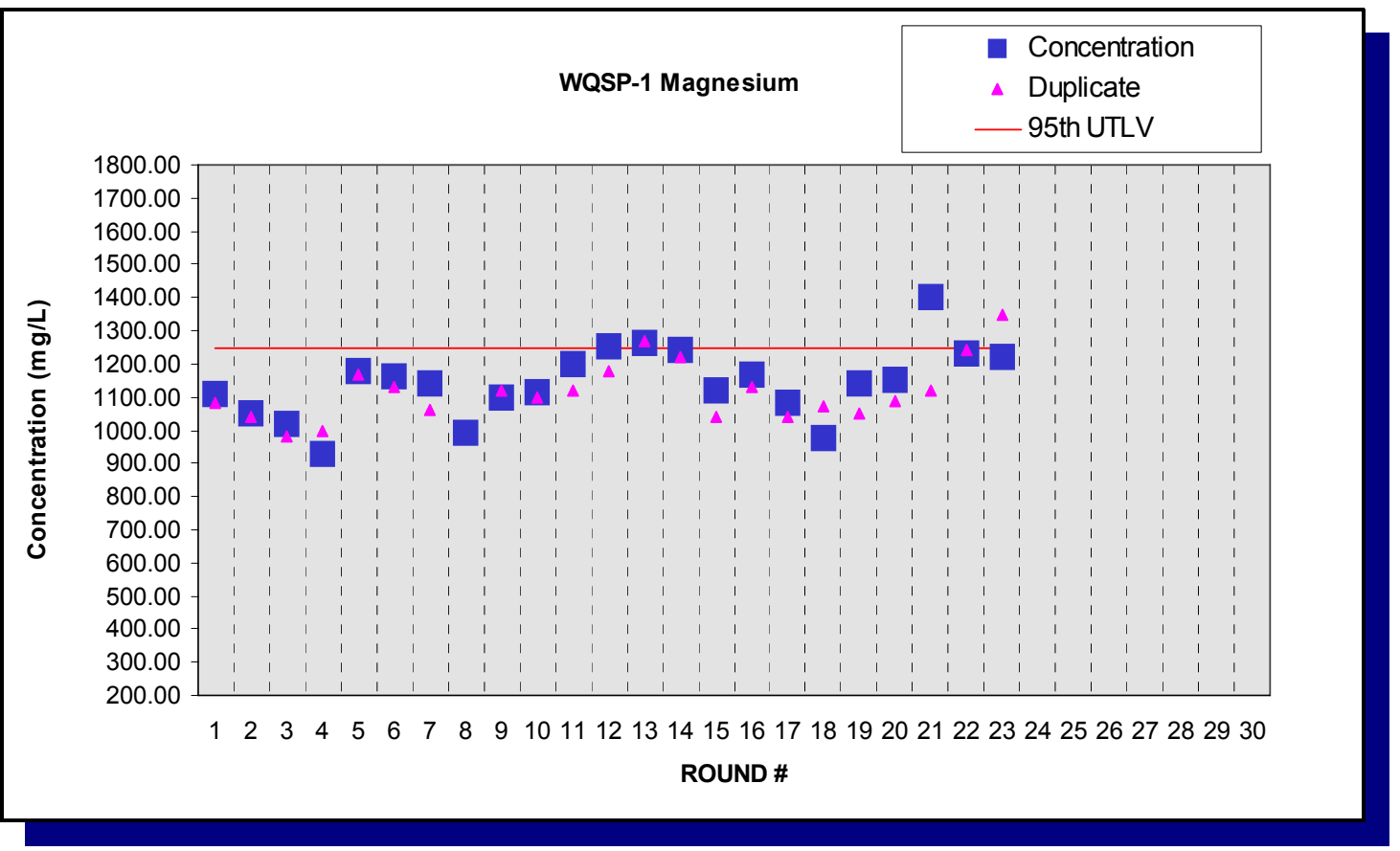

Figure E.5 - Time Trend Plot for Magnesium at WQSP-1

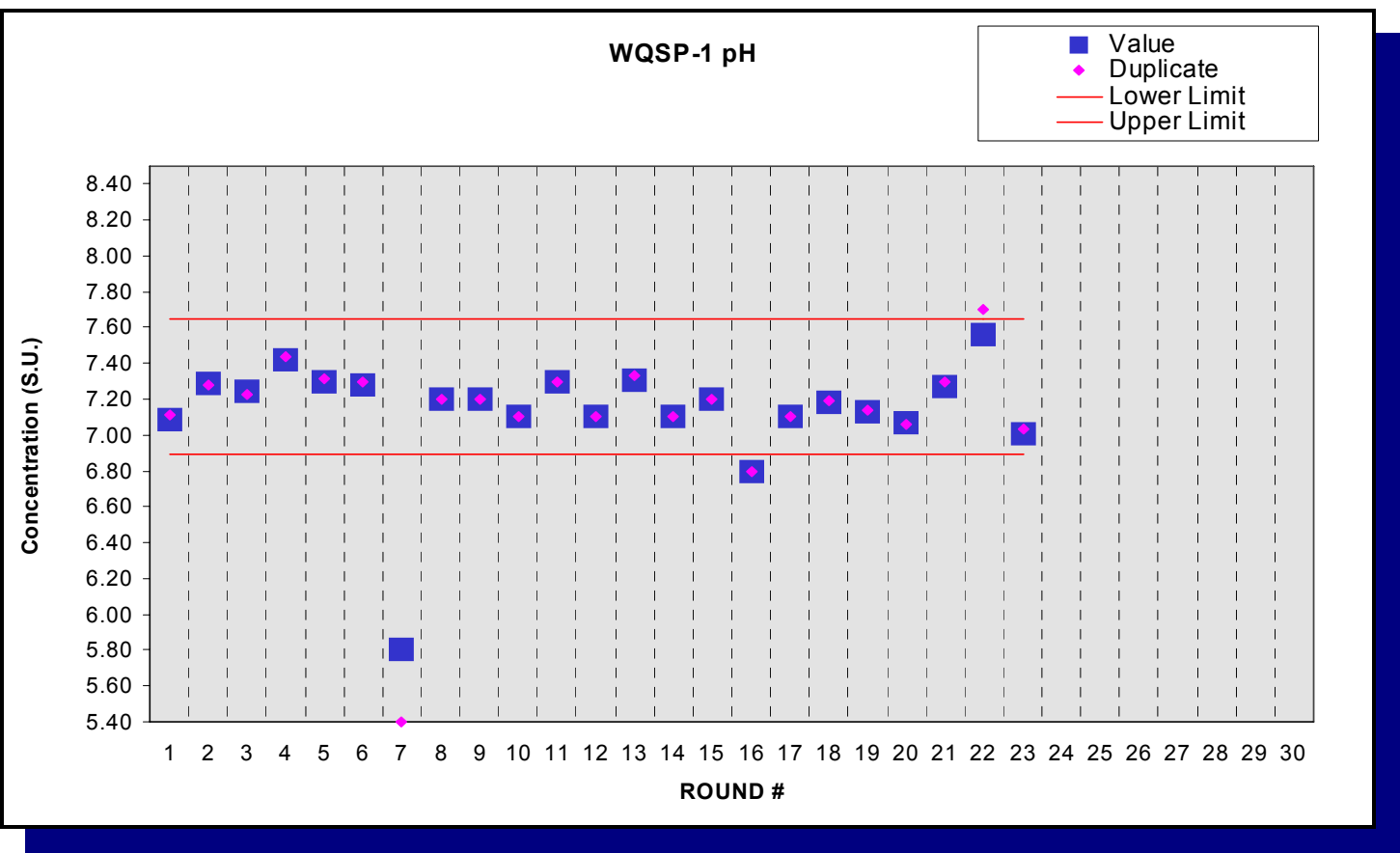

Figure E.6 - Time Trend Plot for pH at WQSP-1 


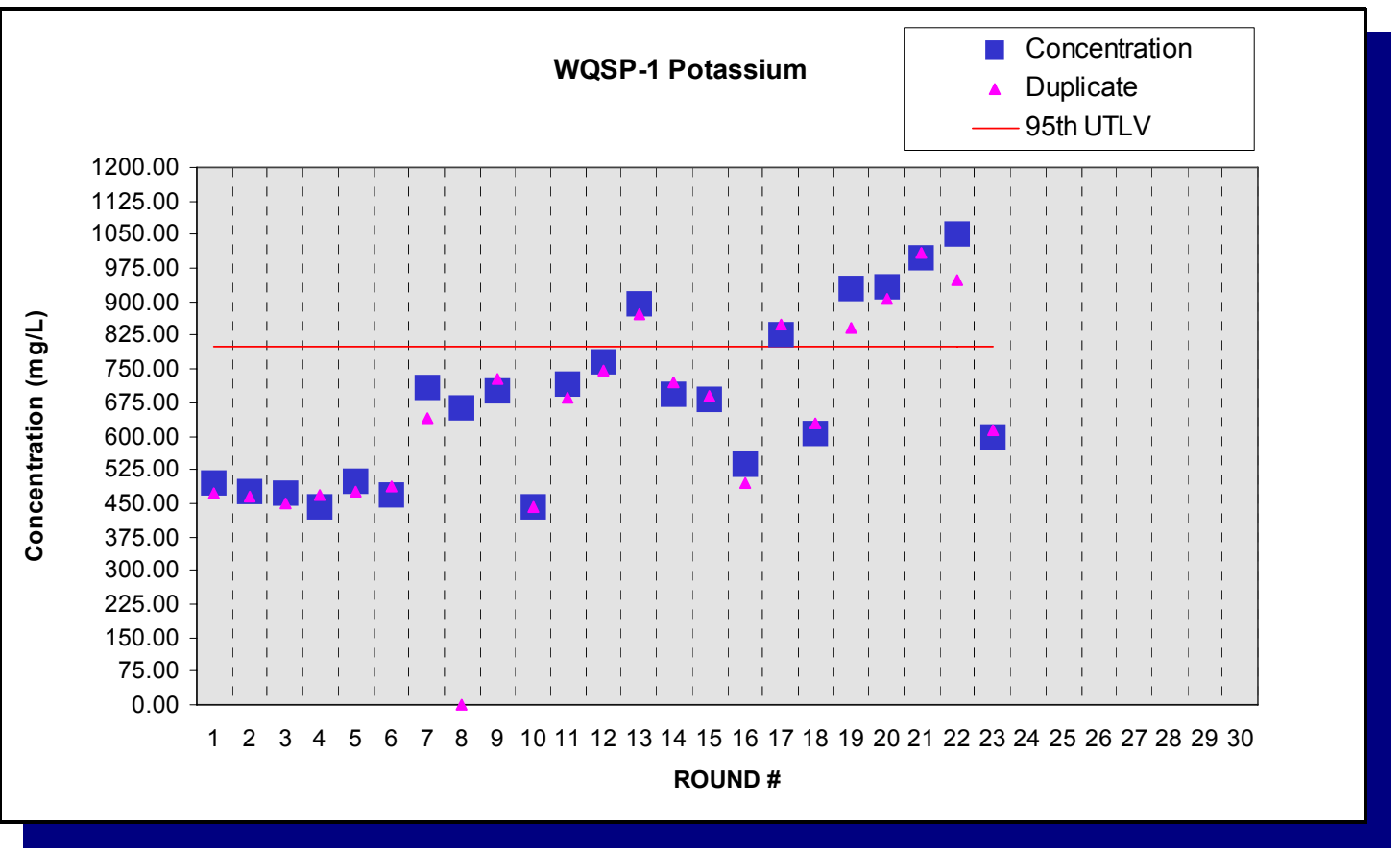

Figure E.7 - Time Trend Plot for Potassium at WQSP-1

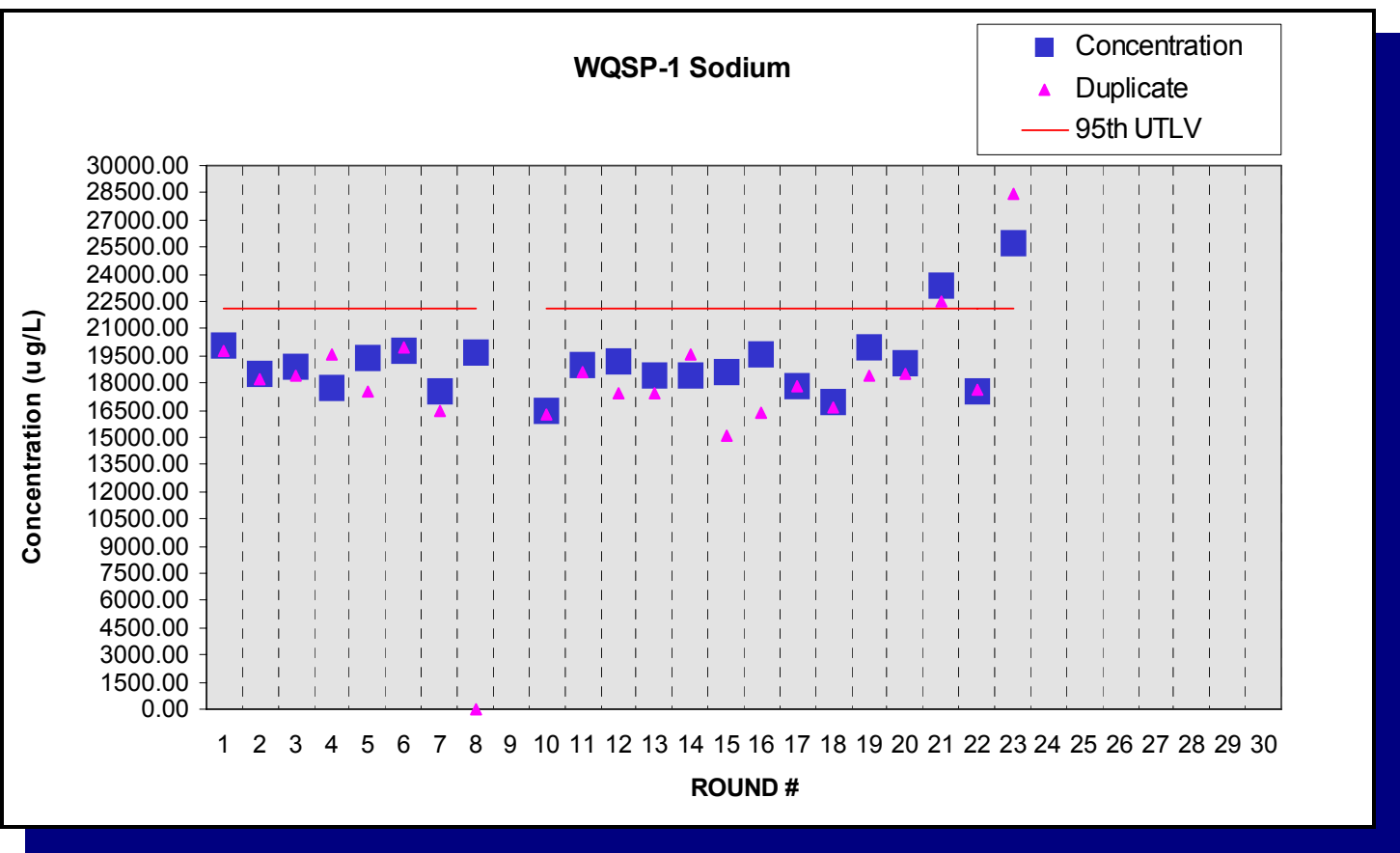

Figure E.8 - Time Trend Plot for Sodium at WQSP-1 


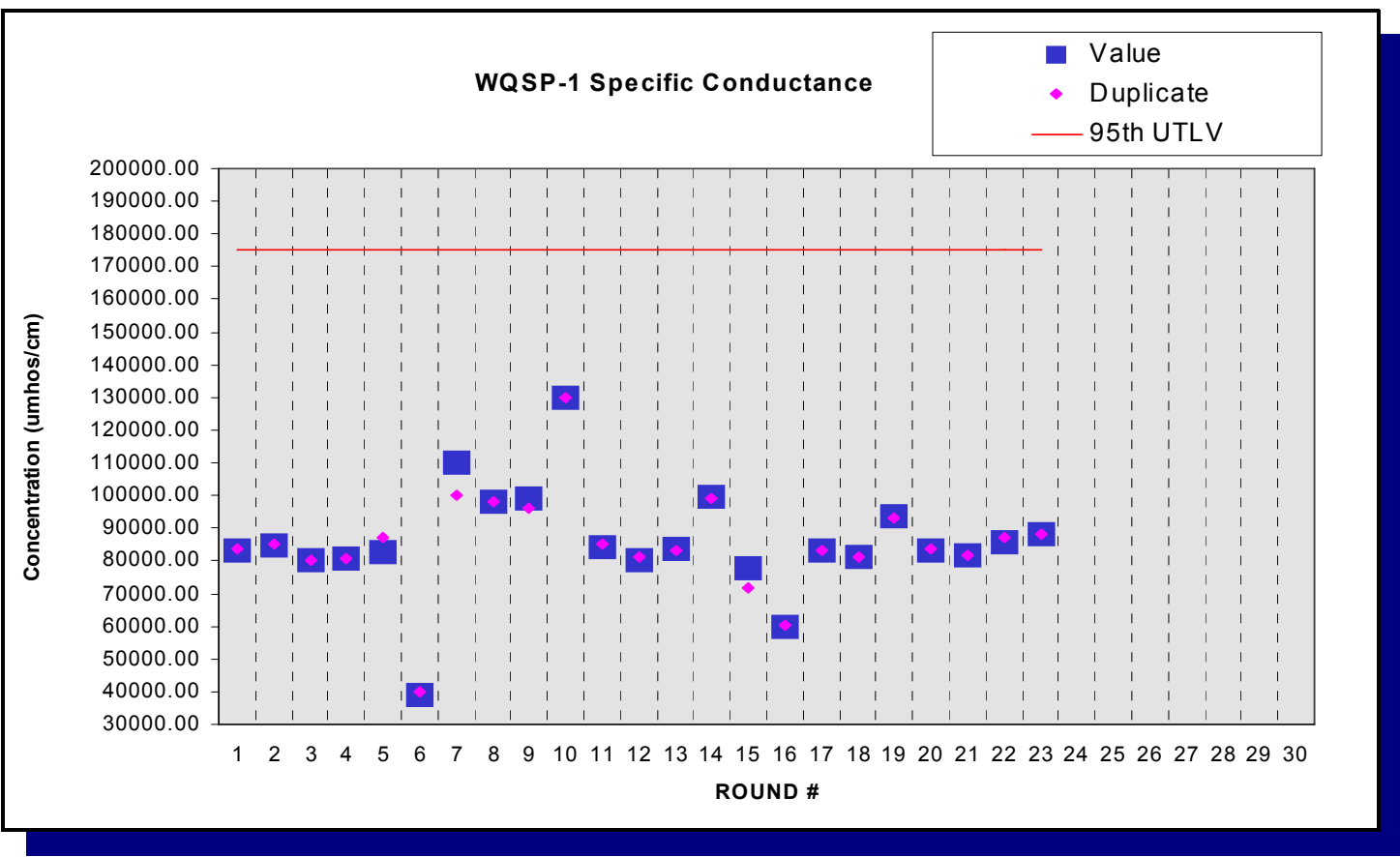

Figure E.9 - Time Trend Plot for Specific Conductance at WQSP-1

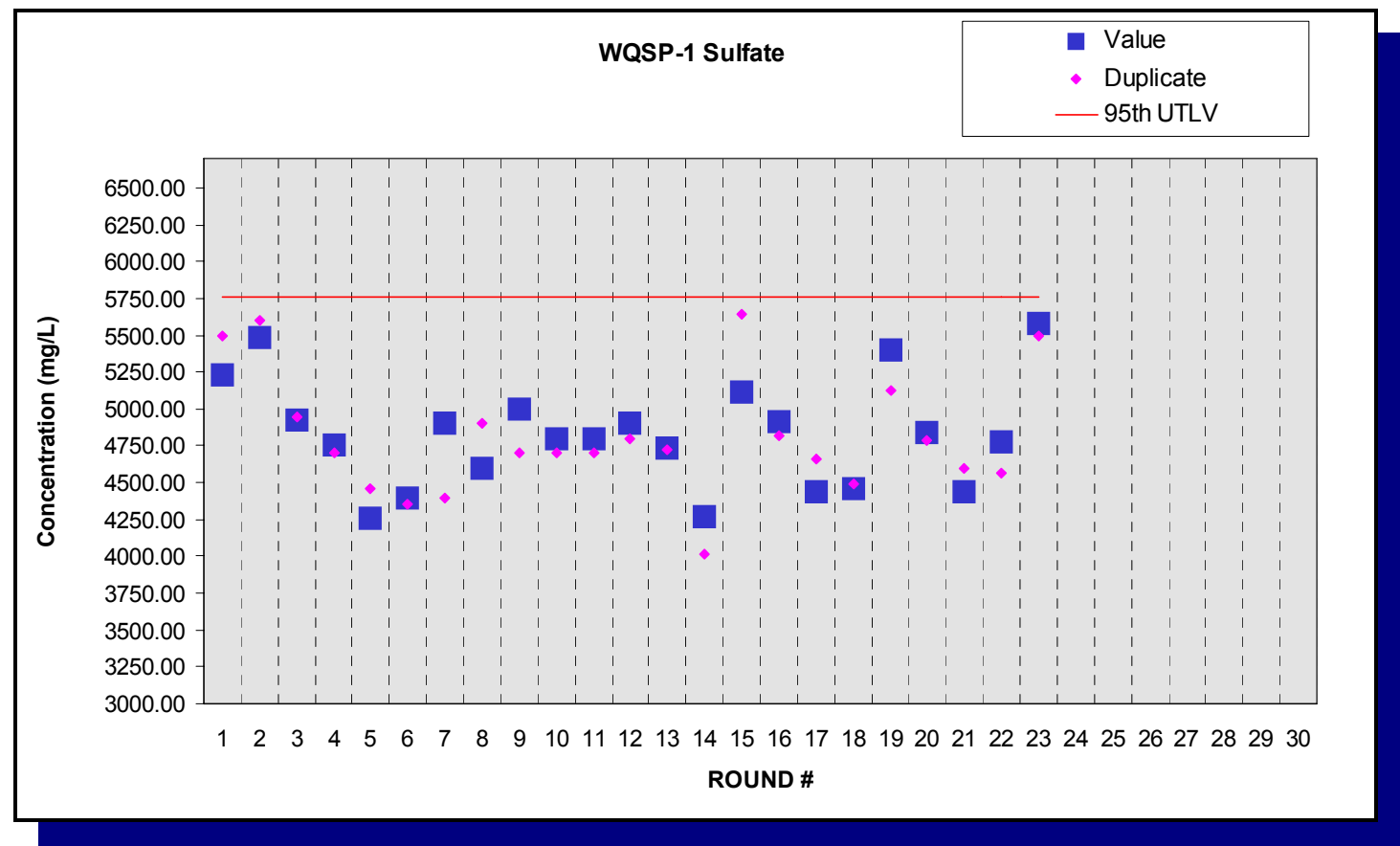

Figure E.10 - Time Trend Plot for Sulfate at WQSP-1 


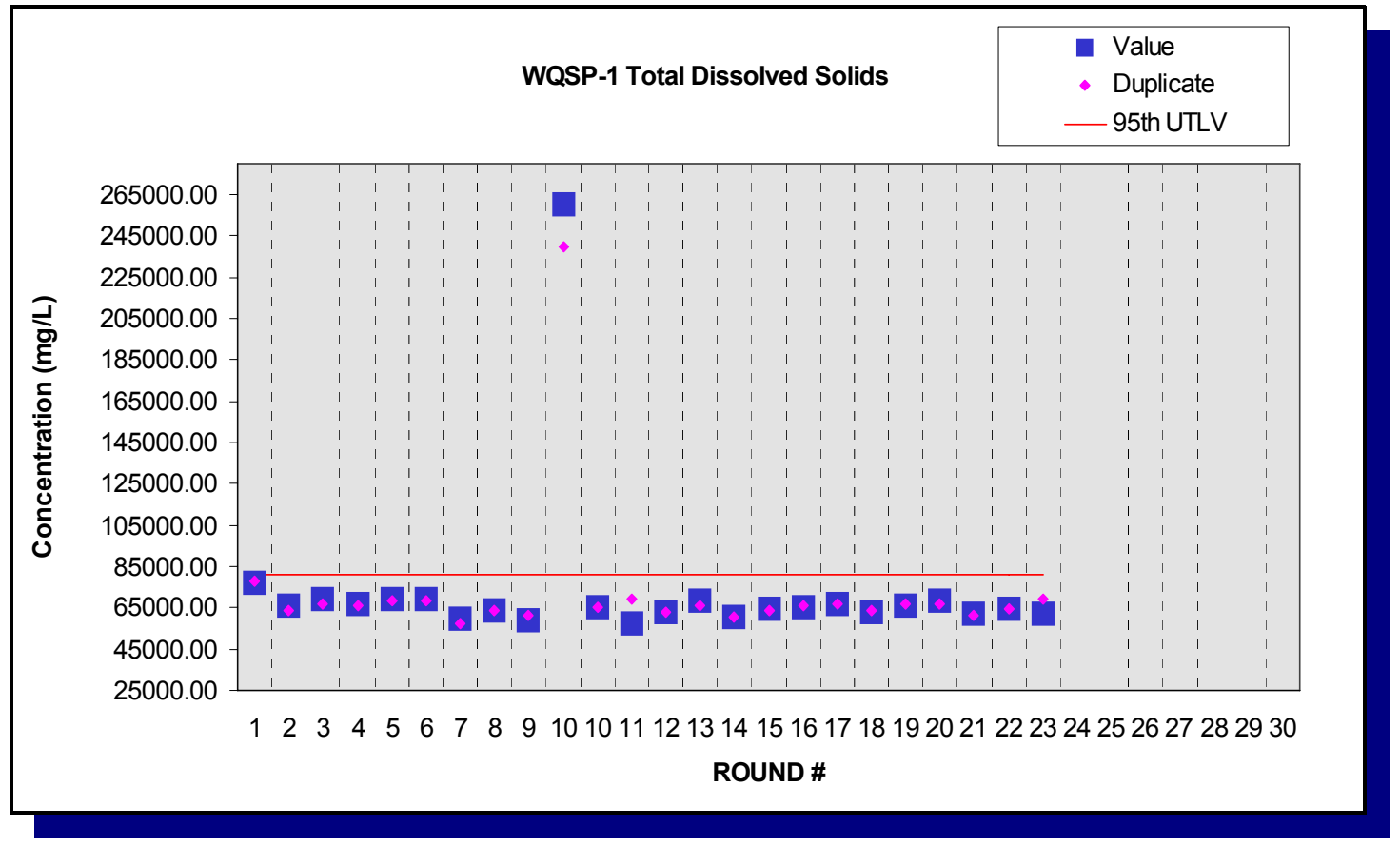

Figure E.11 - Time Trend Plot for Total Dissolved Solids at WQSP-1

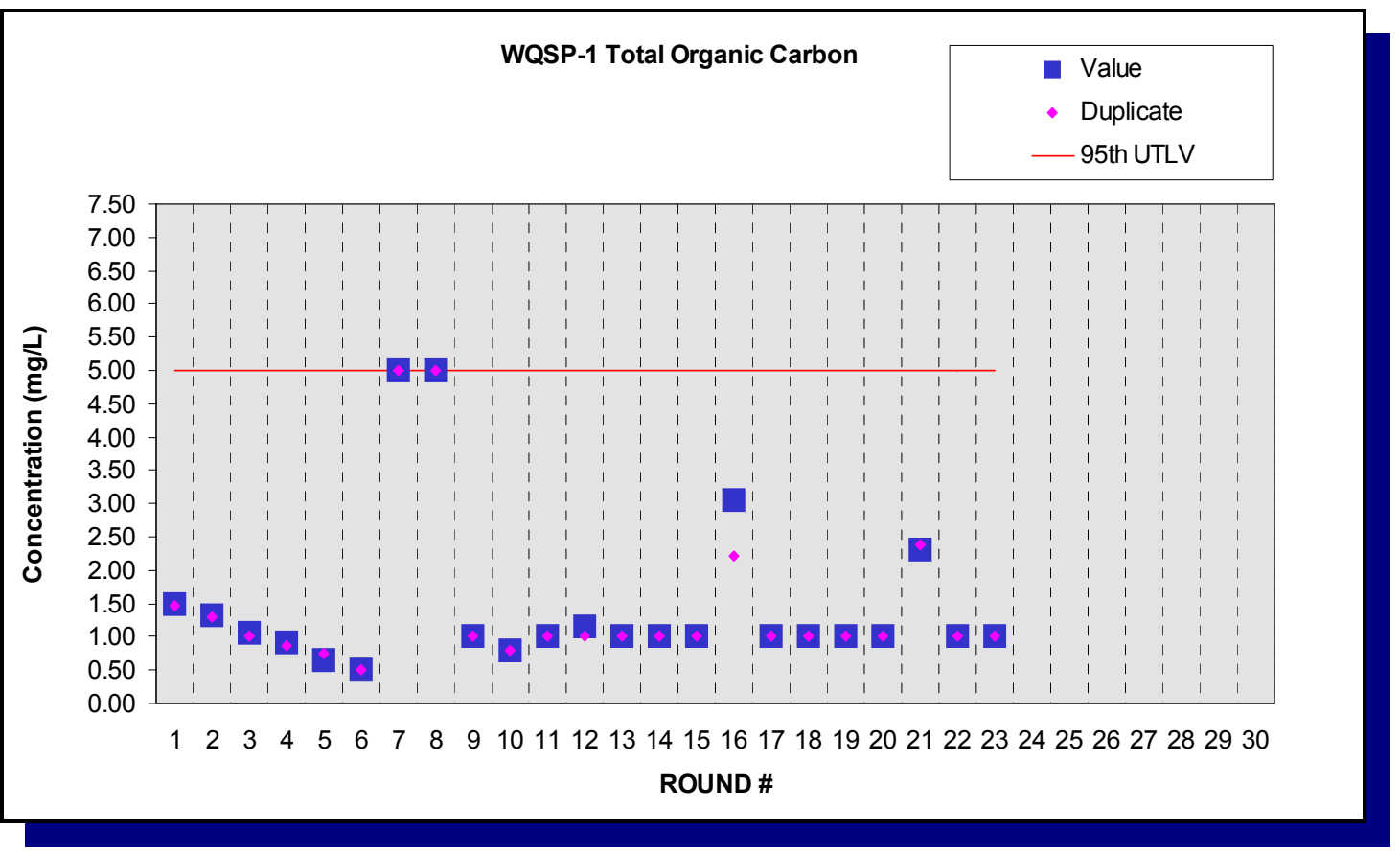

Figure E.12 - Time Trend Plot for Total Organic Carbon at WQSP-1 


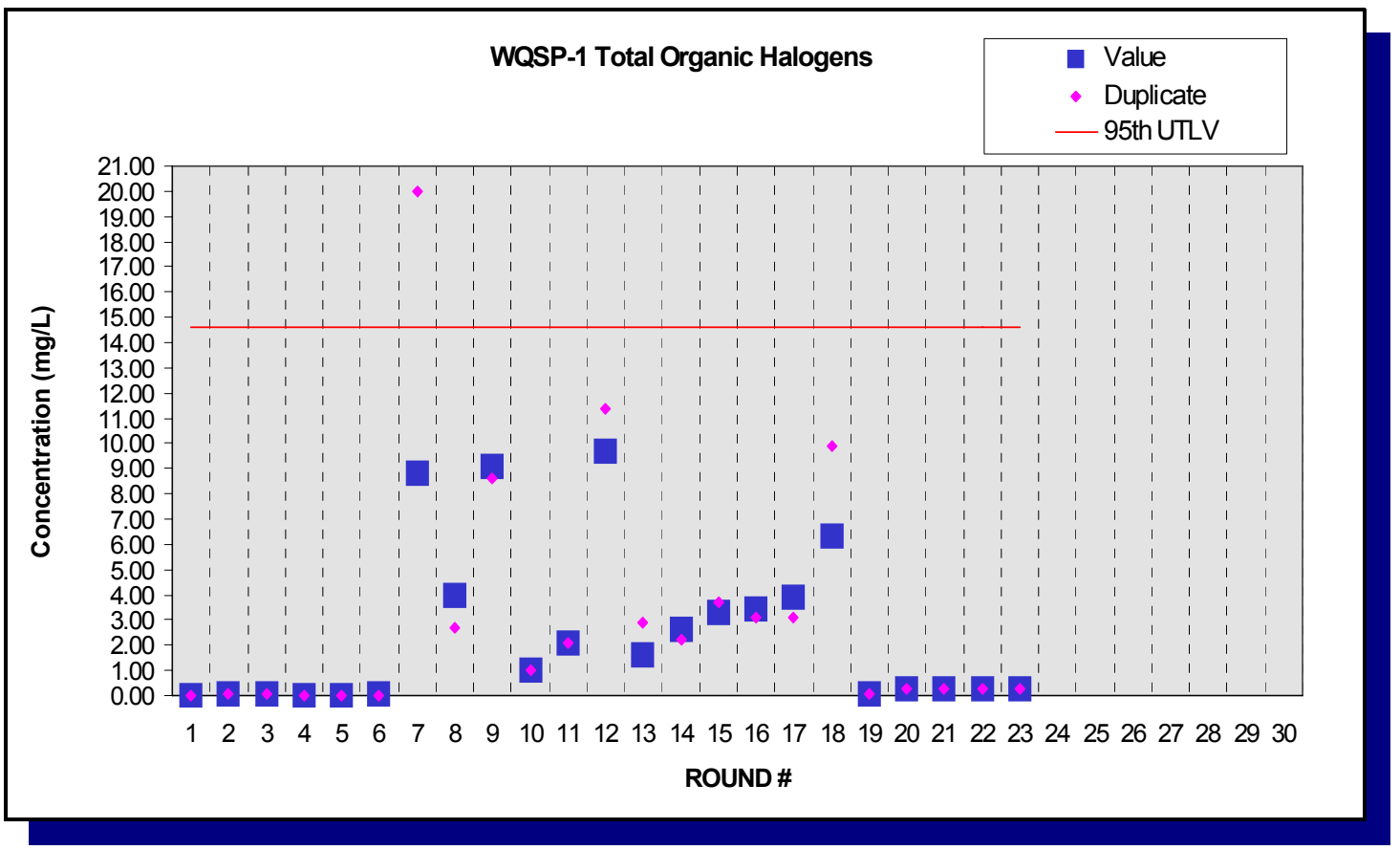

Figure E.13 - Time Trend Plot for Total Organic Halogens at WQSP-1

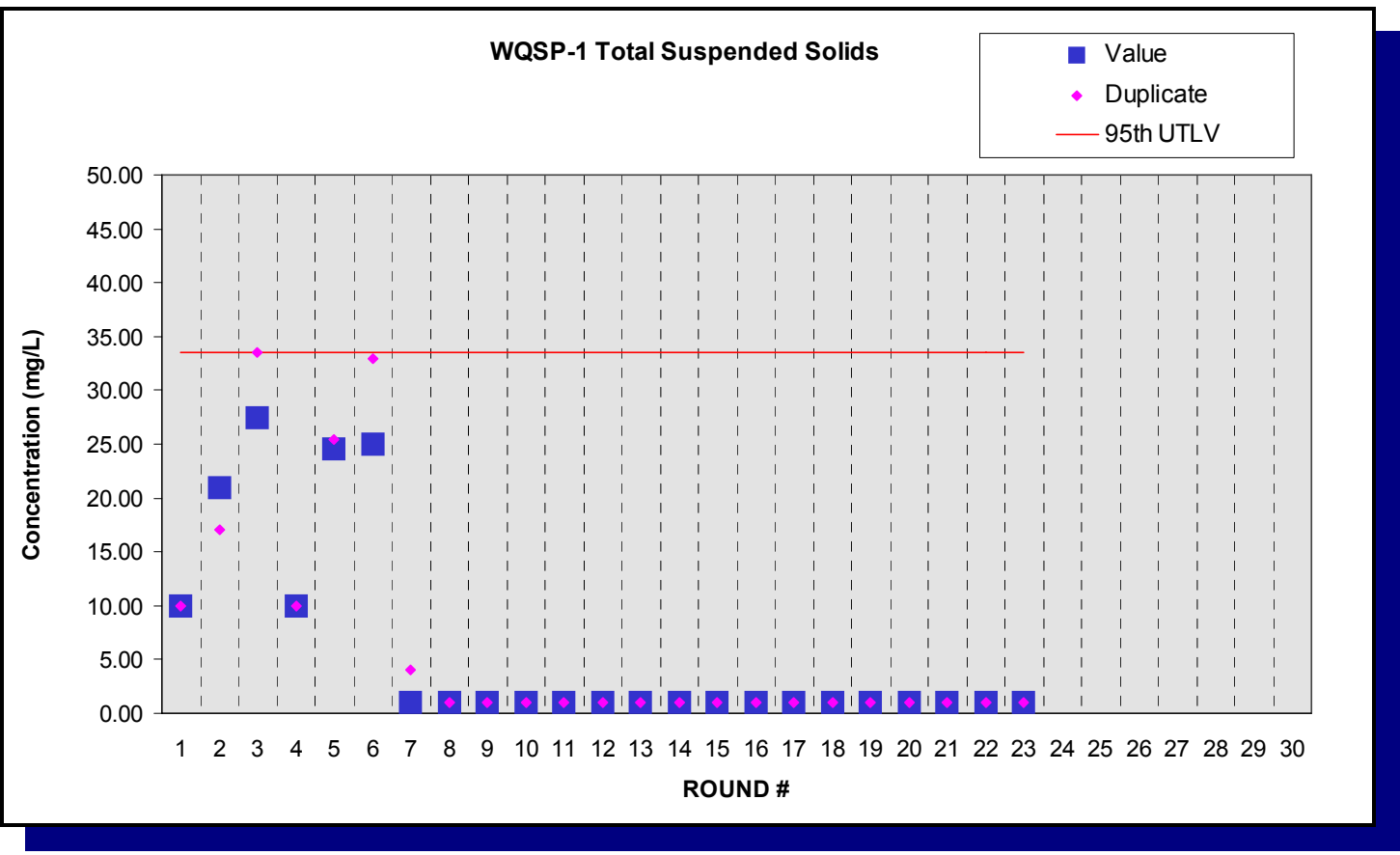

Figure E.14 - Time Trend Plot for Total Suspended Solids at WQSP-1 


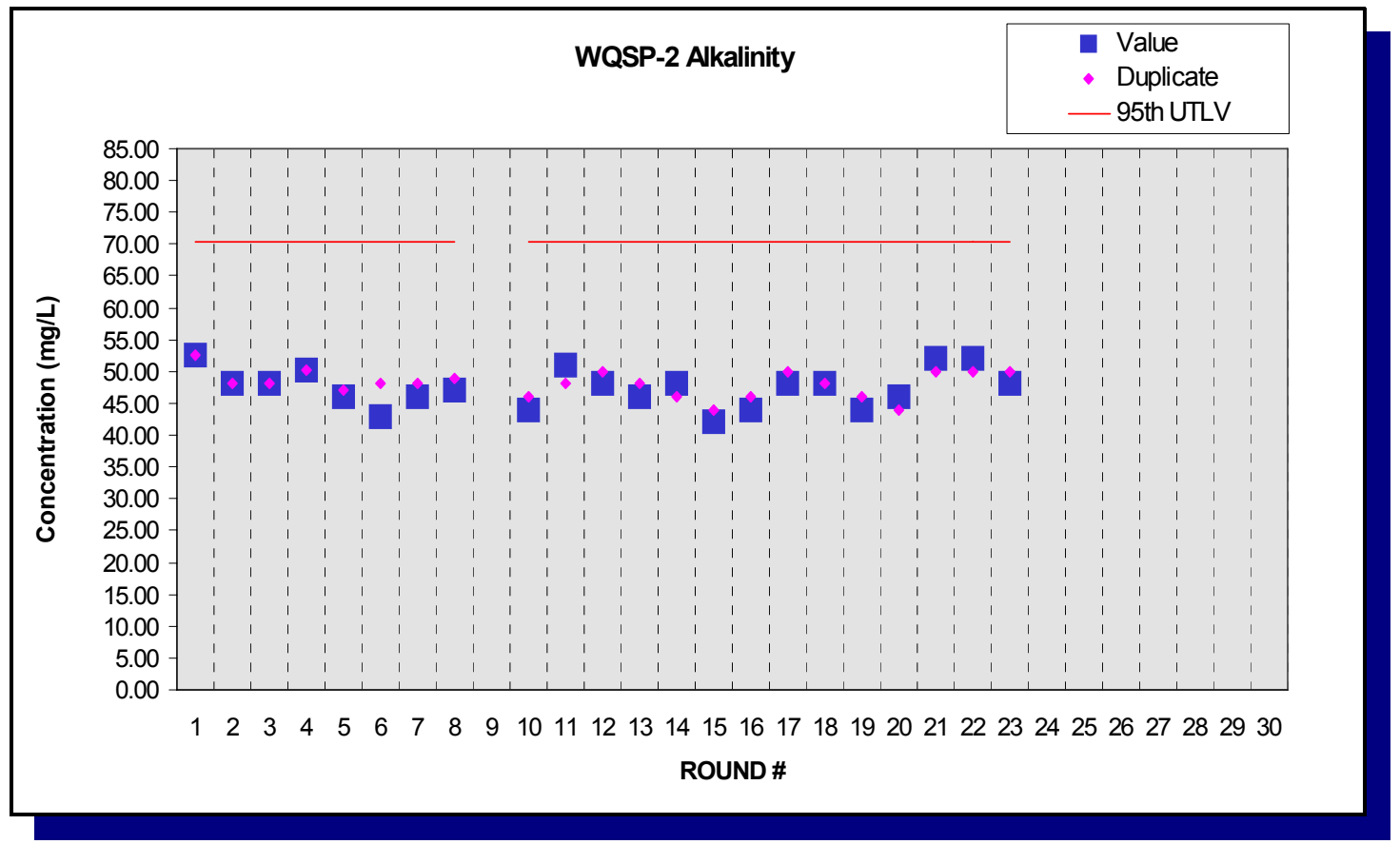

Figure E.15 - Time Trend Plot for Alkalinity at WQSP-2

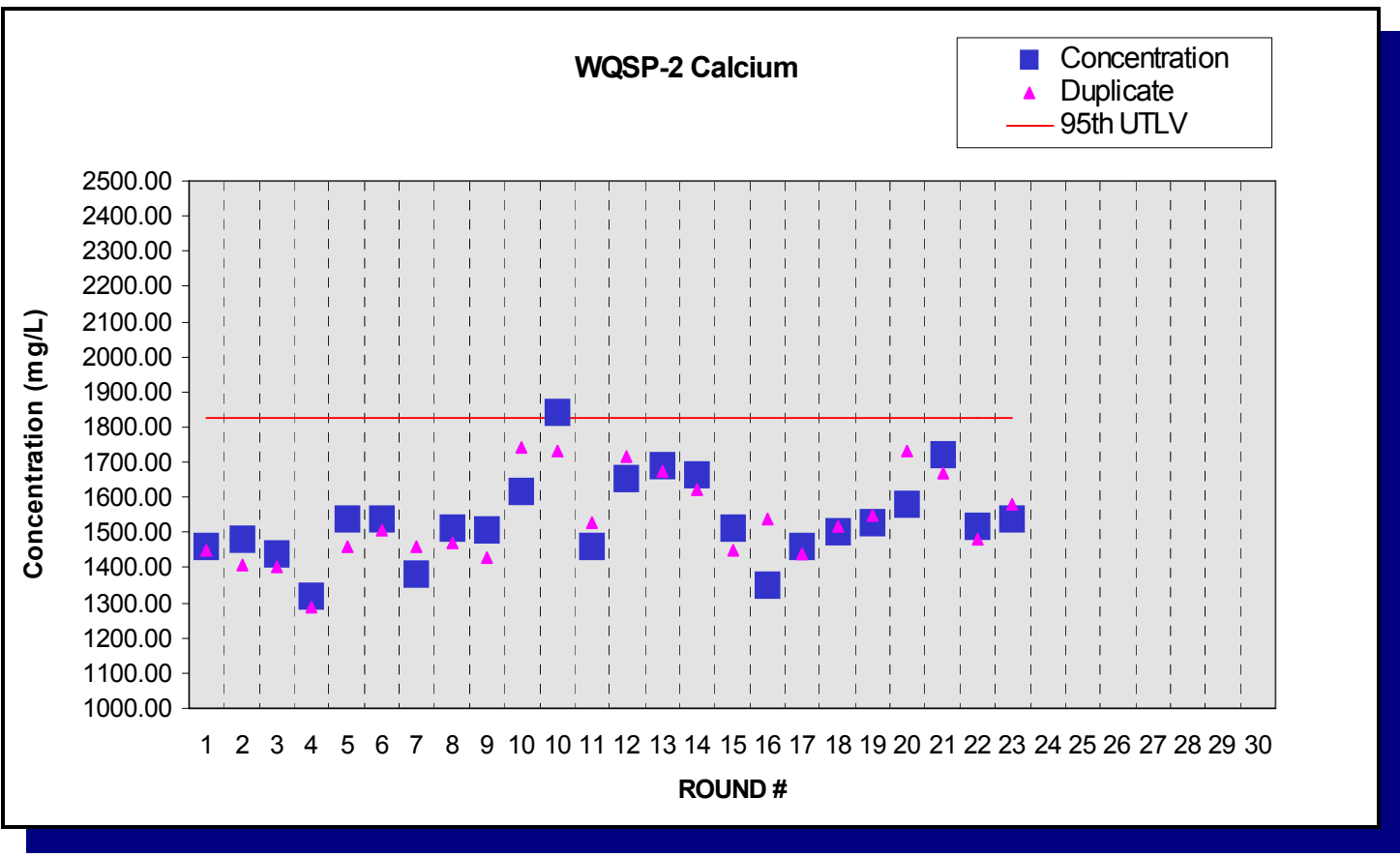

Figure E.16 - Time Trend Plot for Calcium at WQSP-2 


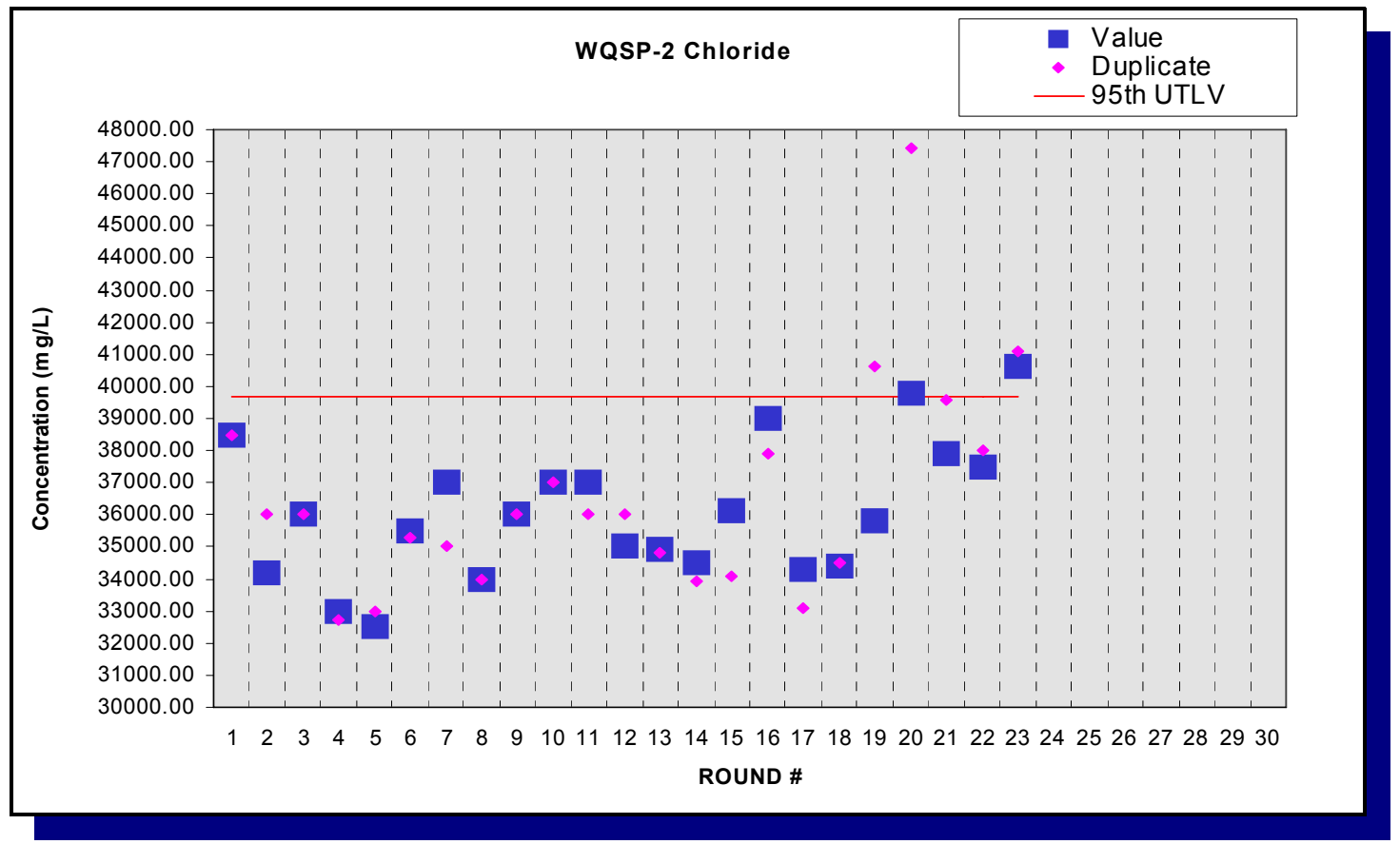

Figure E.17 - Time Trend Plot for Chloride at WQSP-2

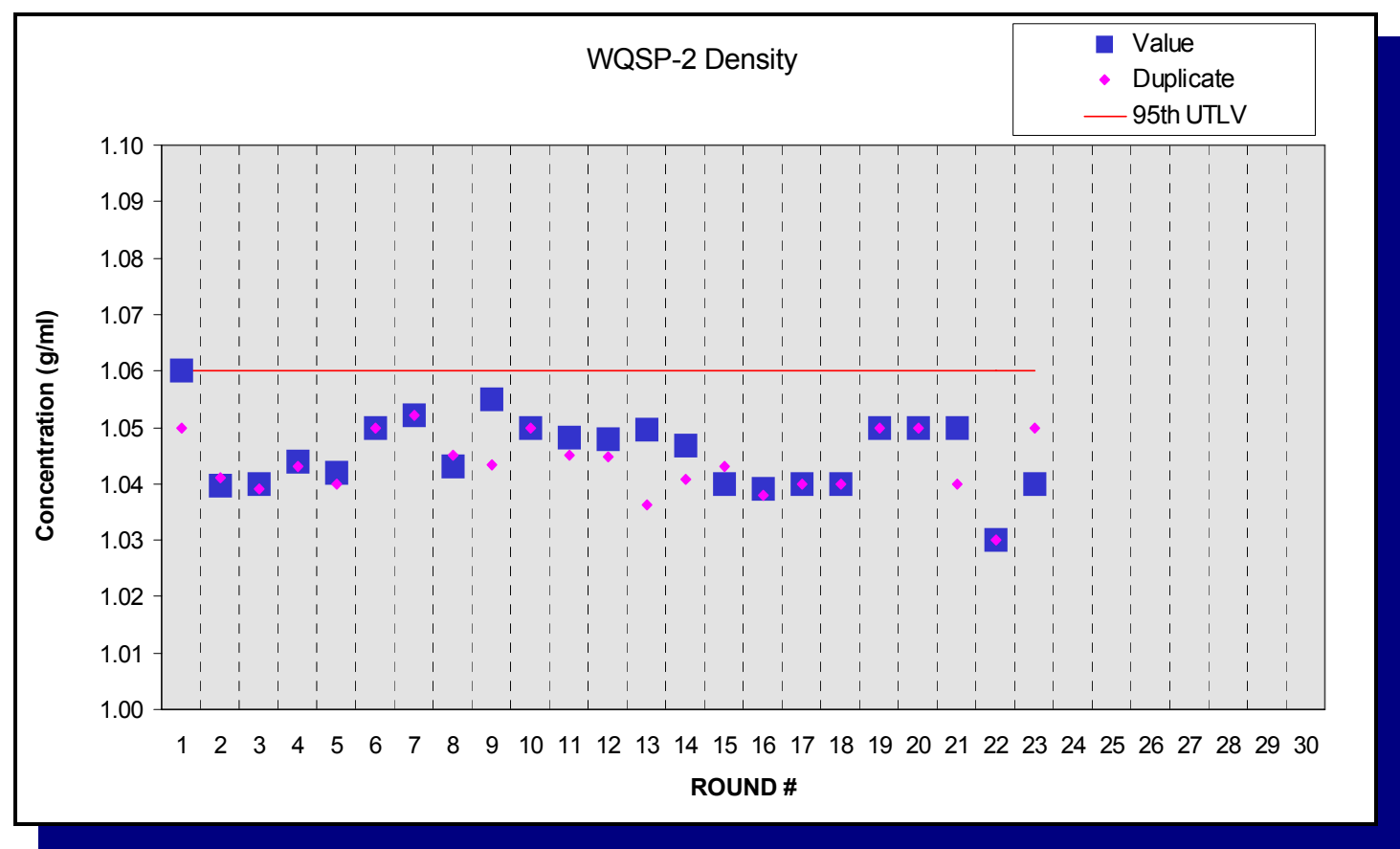

Figure E.18 - Time Trend Plot for Density at WQSP-2 


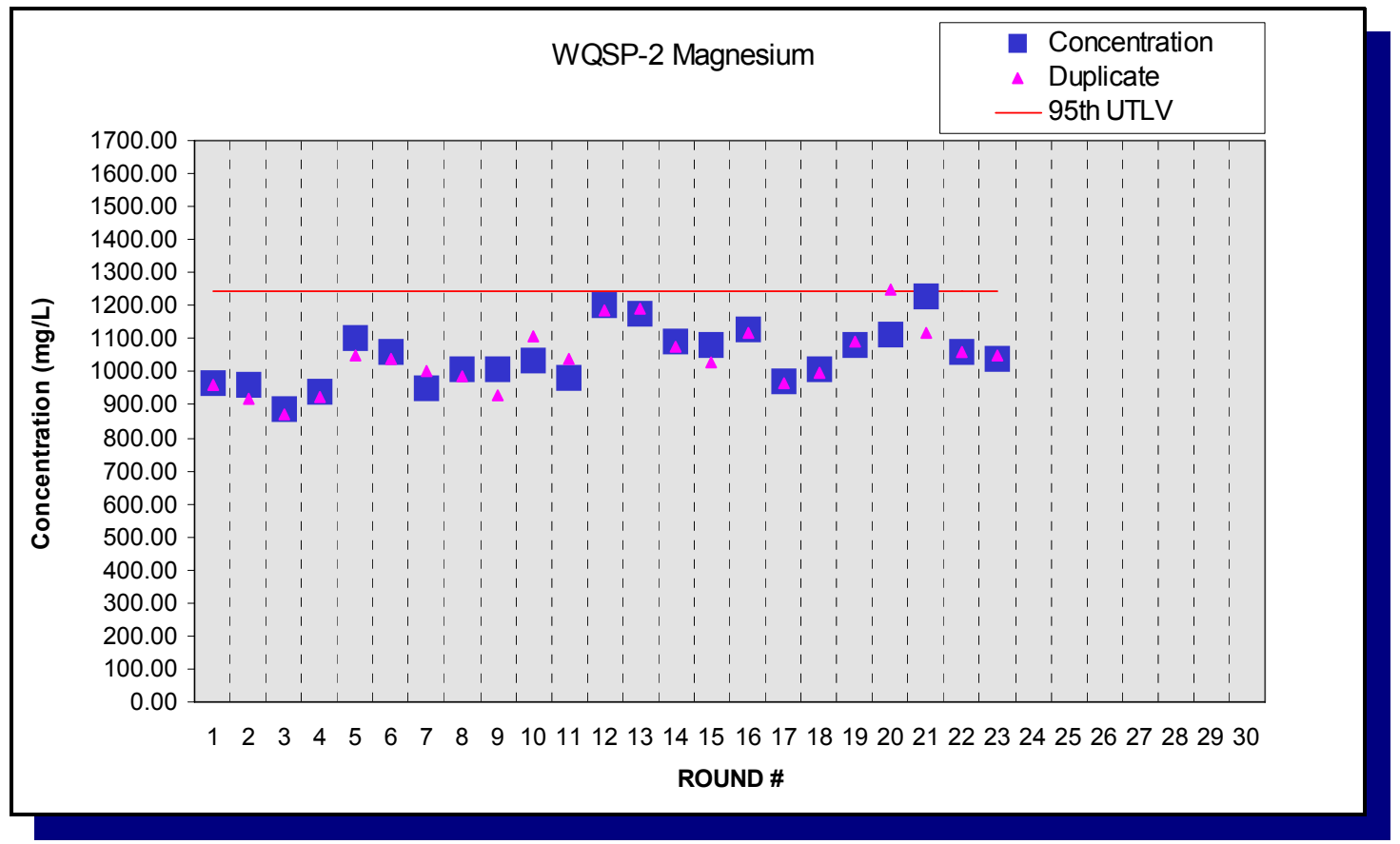

Figure E.19 - Time Trend Plot for Magnesium at WQSP-2

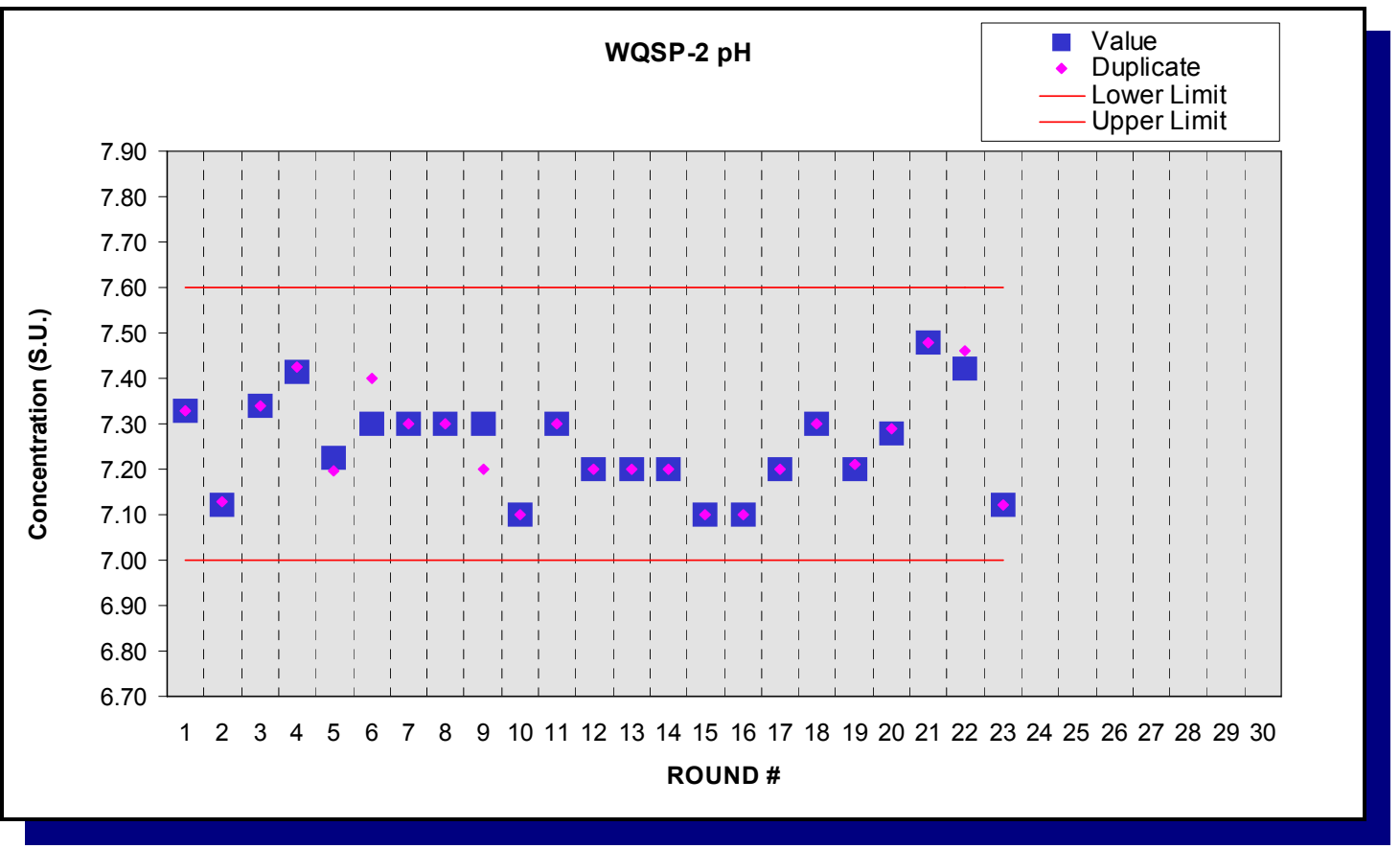

Figure E.20 - Time Trend Plot for pH at WQSP-2 


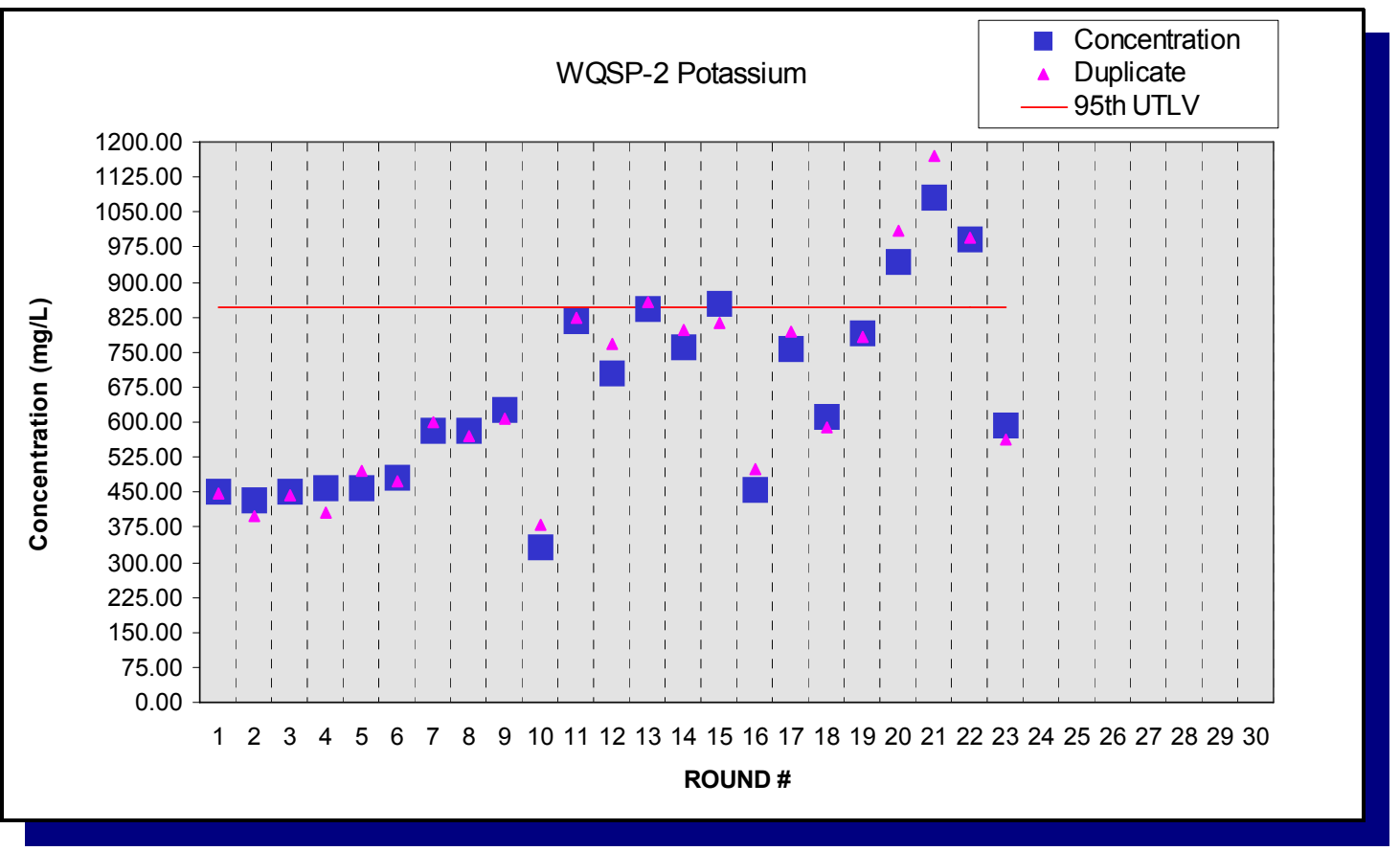

Figure E.21 - Time Trend Plot for Potassium at WQSP-2

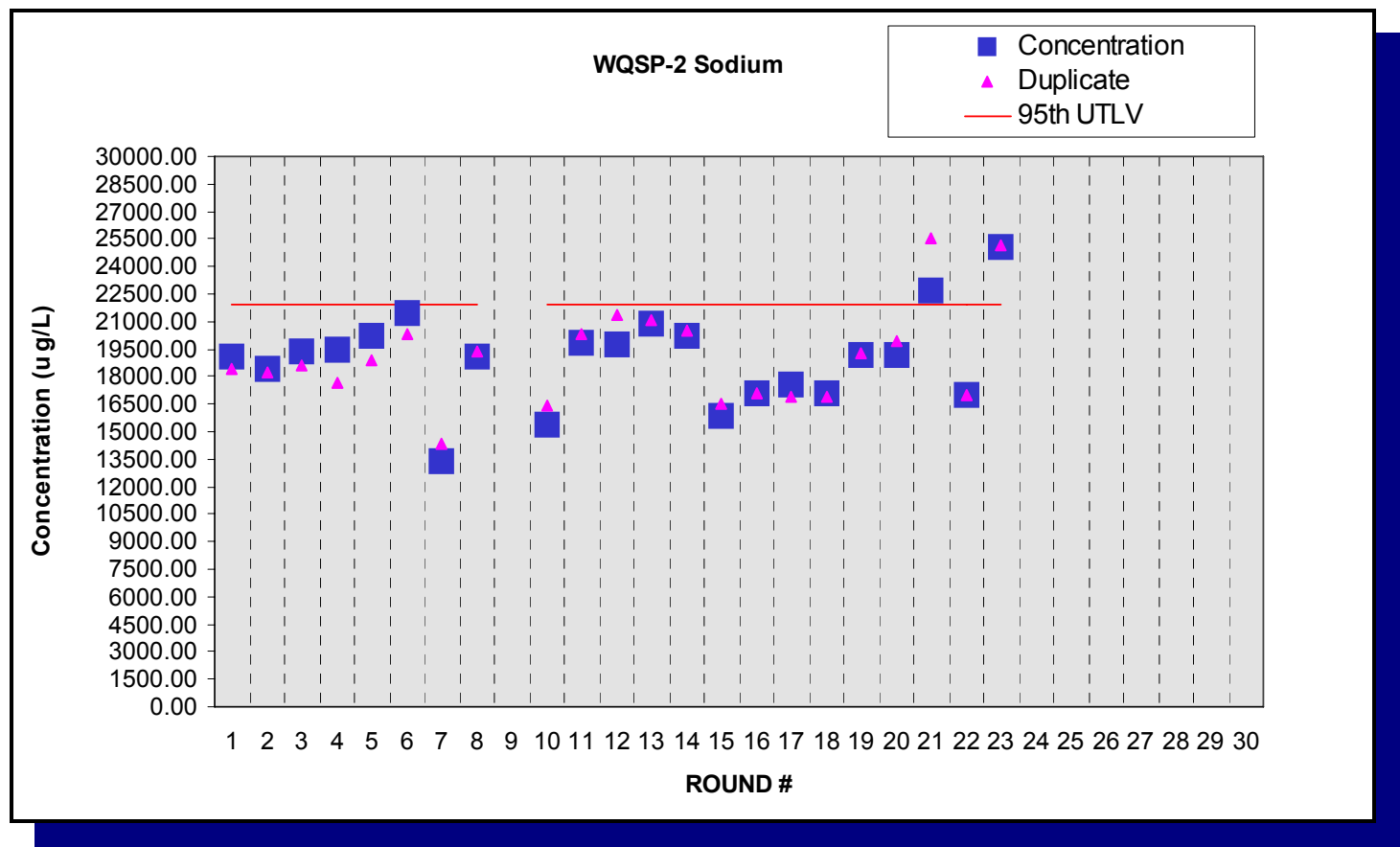

Figure E.22 - Time Trend Plot for Sodium at WQSP-2 


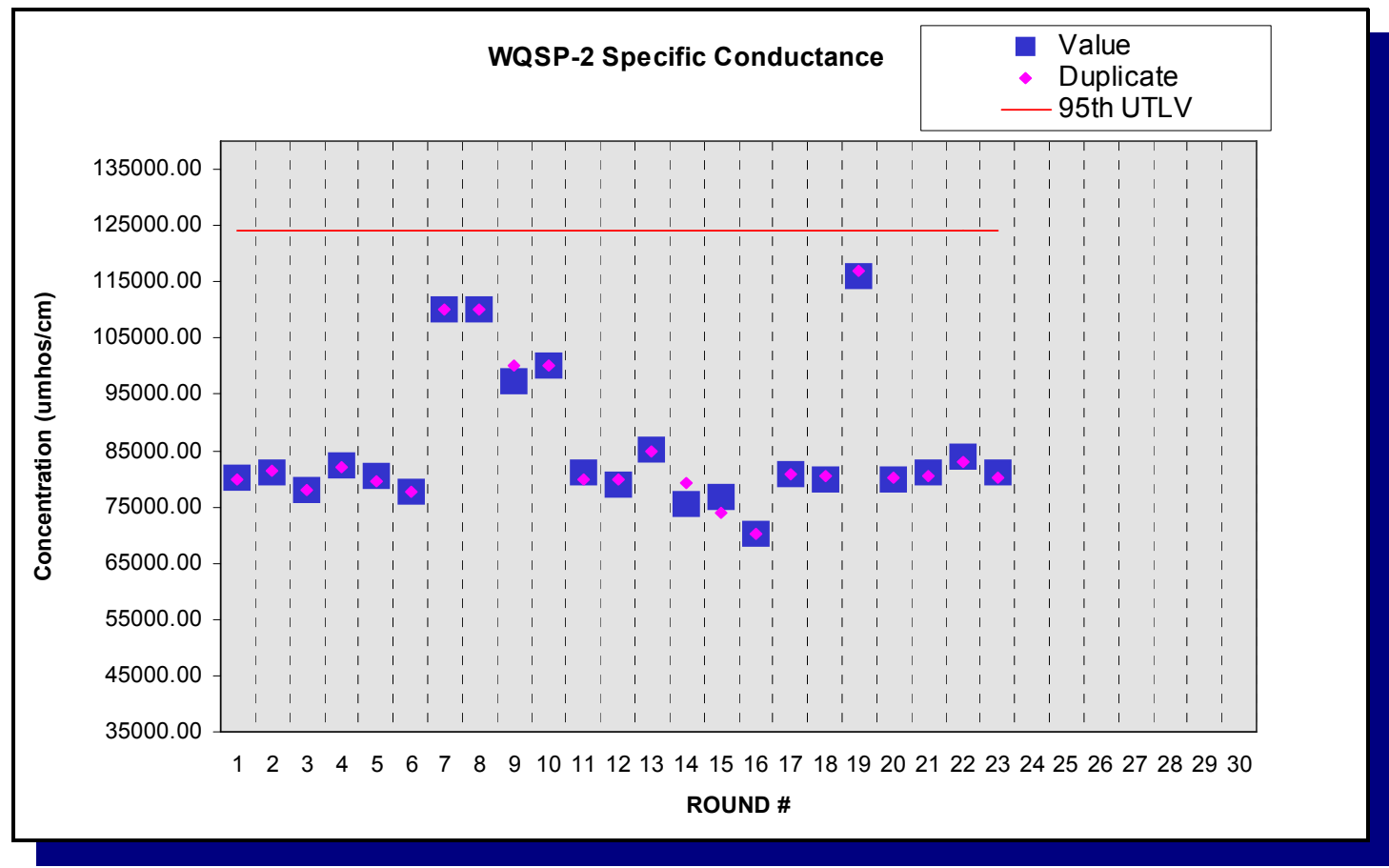

Figure E.23 - Time Trend Plot for Specific Conductance at WQSP-2

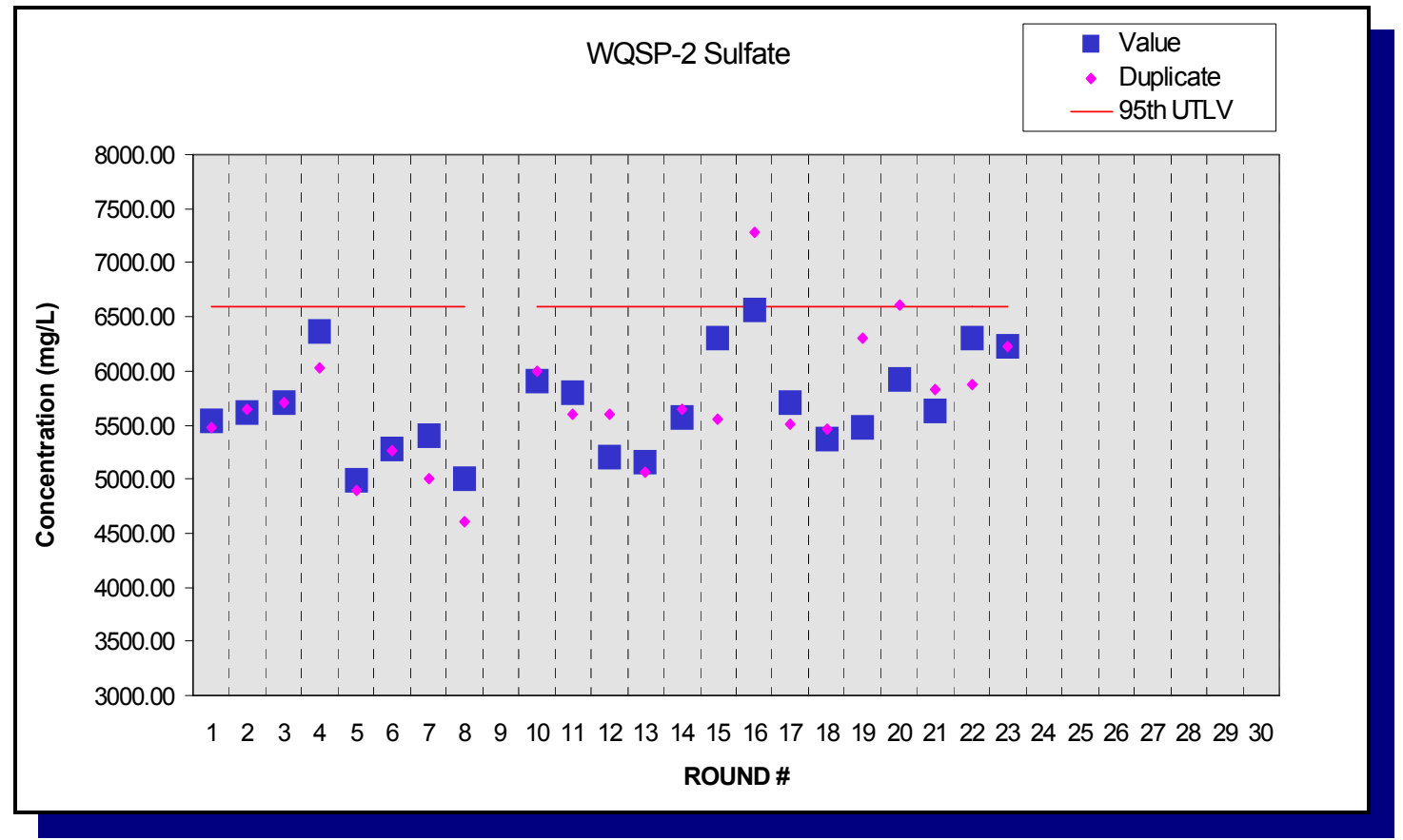

Figure E.24 - Time Trend Plot for Sulfate at WQSP-2 


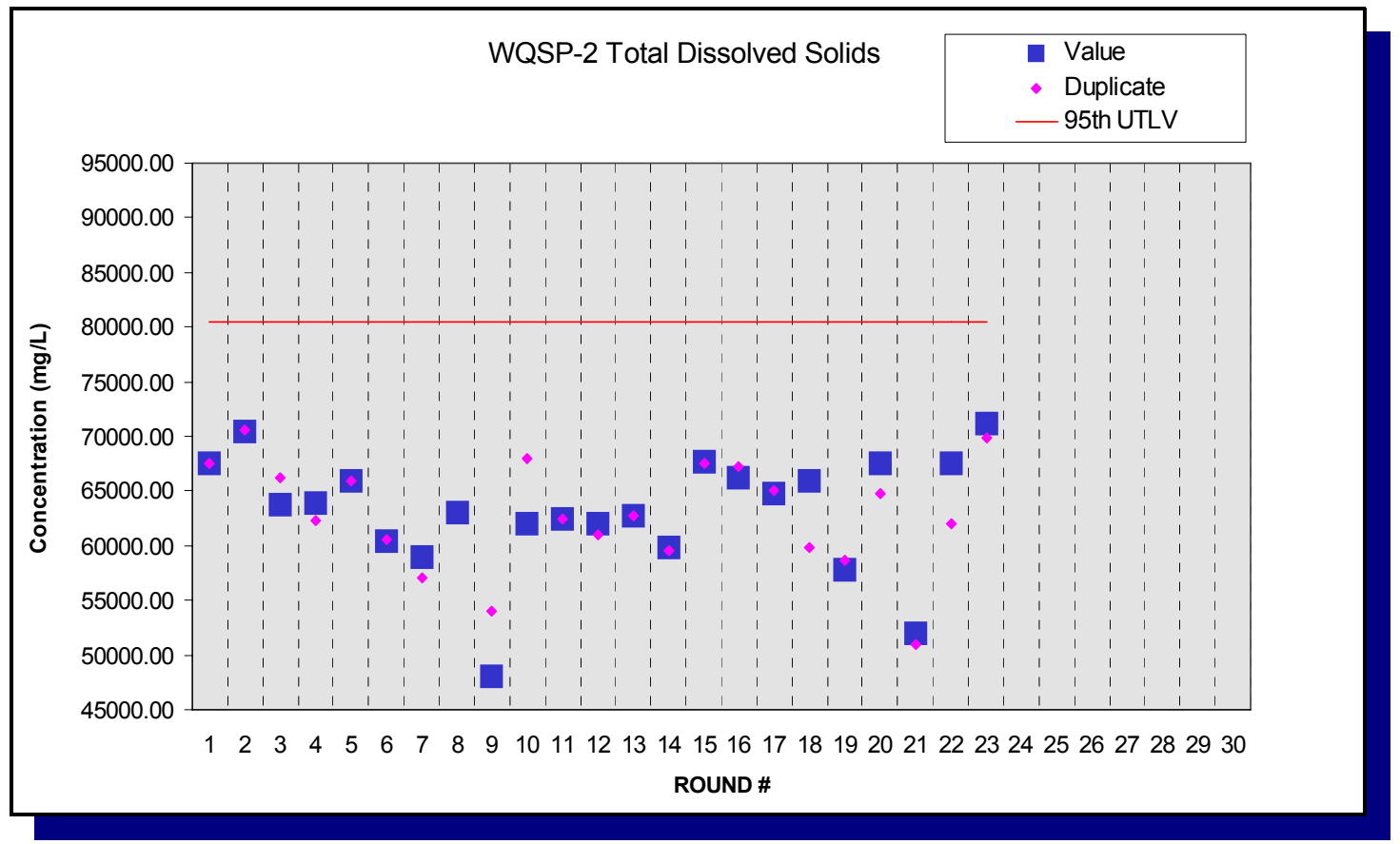

Figure E.25 - Time Trend Plot for Total Dissolved Solids at WQSP-2

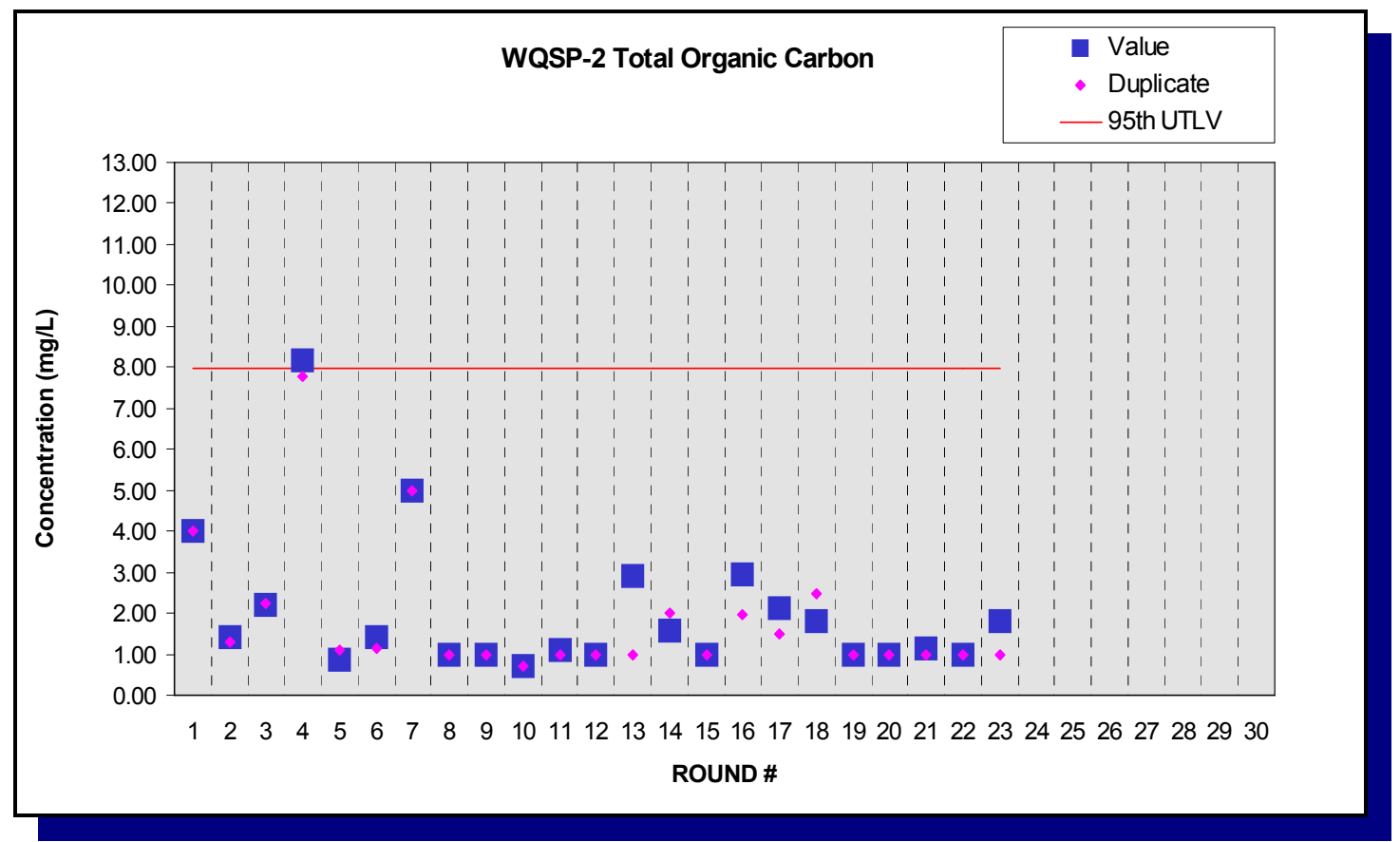

Figure E.26 - Time Trend Plot for Total Organic Carbon at WQSP-2 


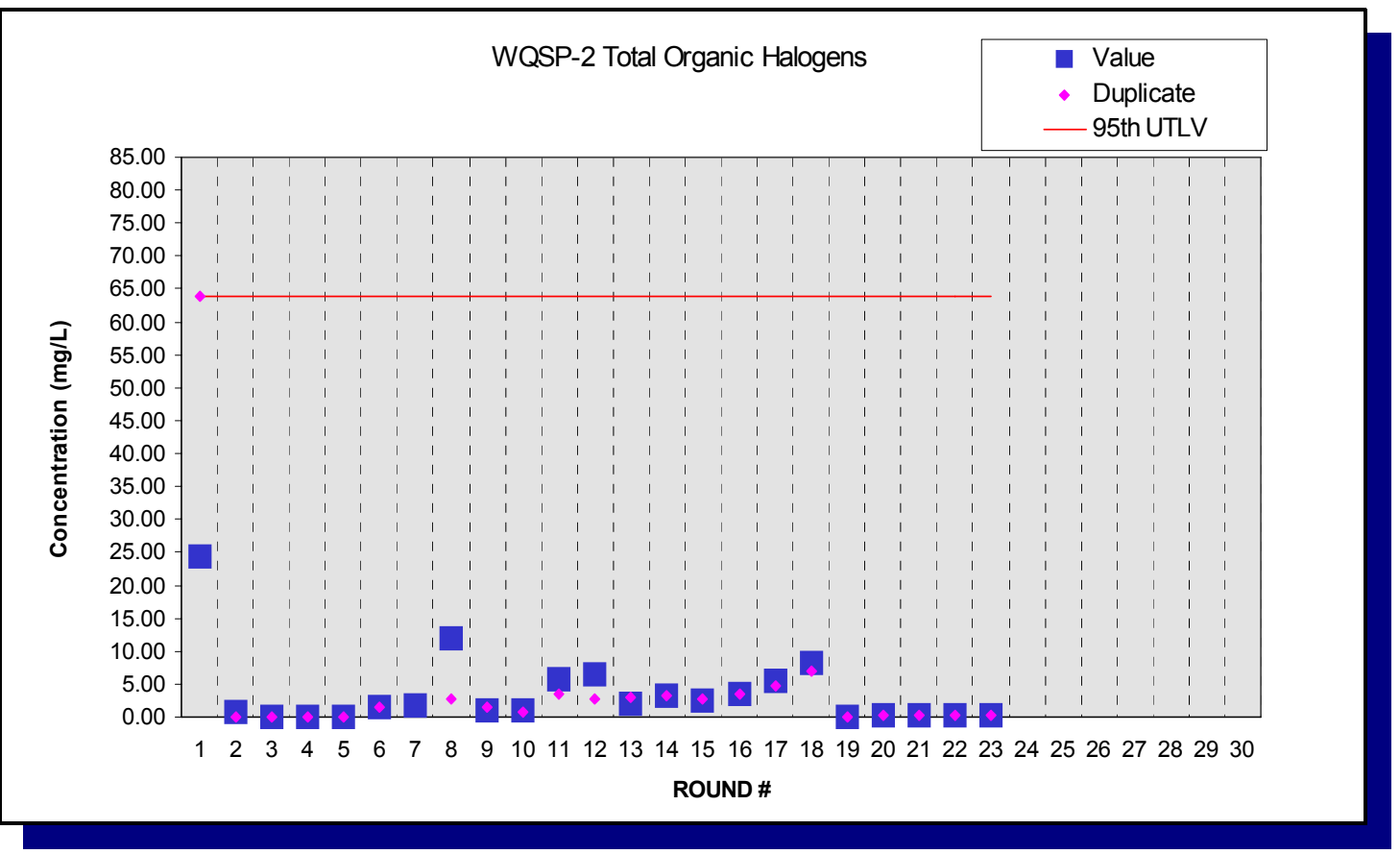

Figure E.27 - Time Trend Plot for Total Organic Halogens at WQSP-2

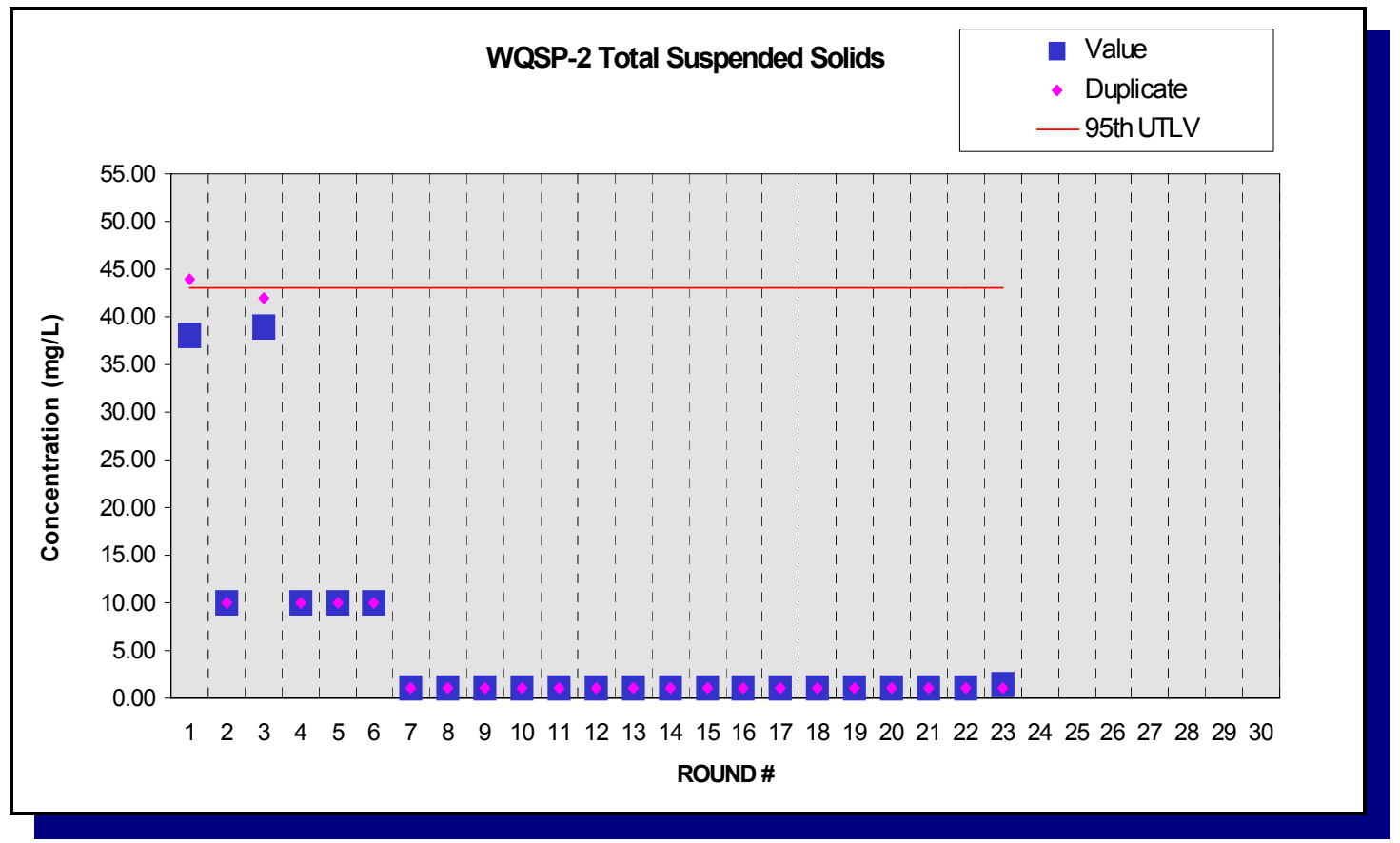

Figure E.28 - Time Trend Plot for Total Suspended Solids at WQSP-2 


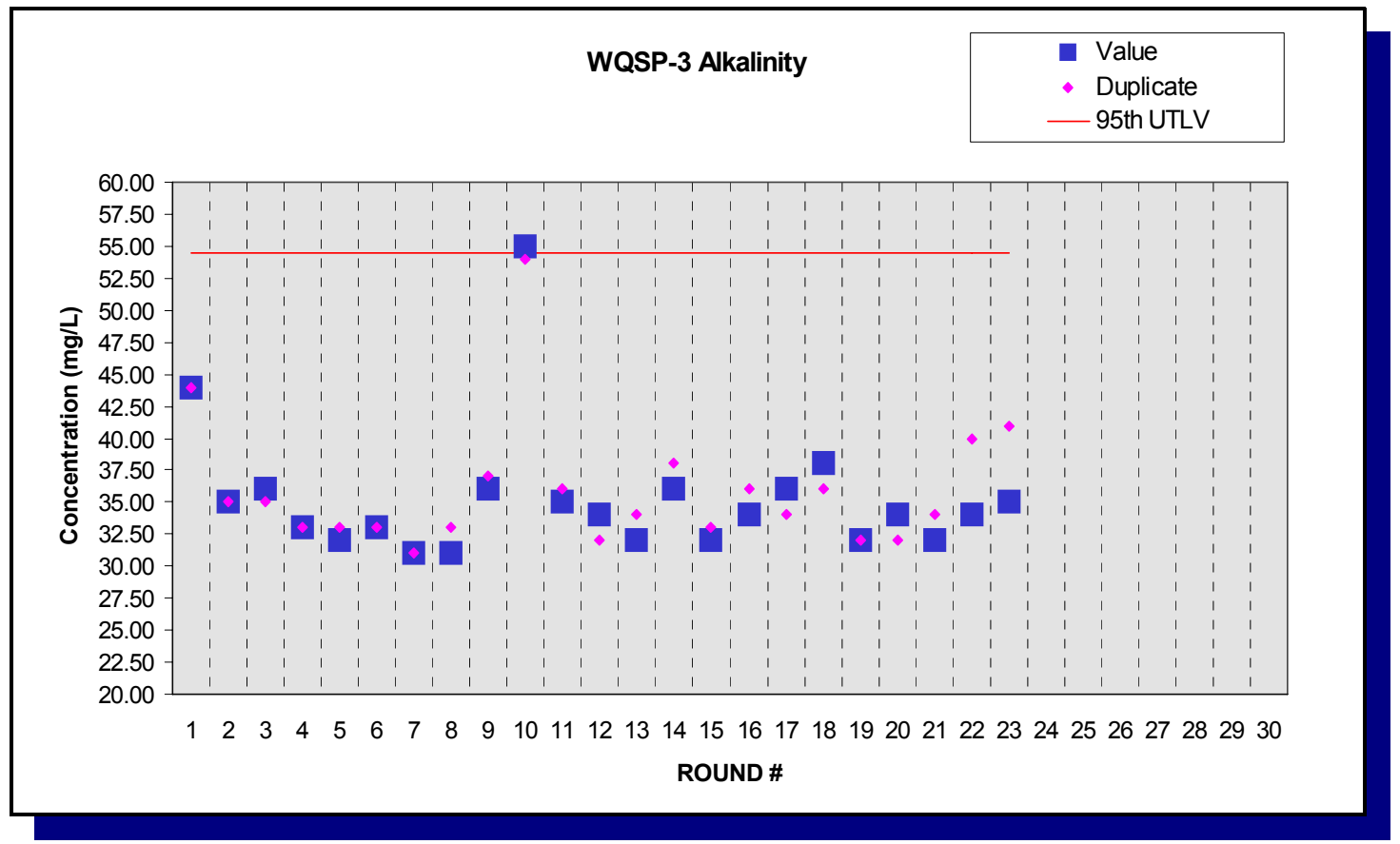

Figure E.29 - Time Trend Plot for Alkalinity at WQSP-3

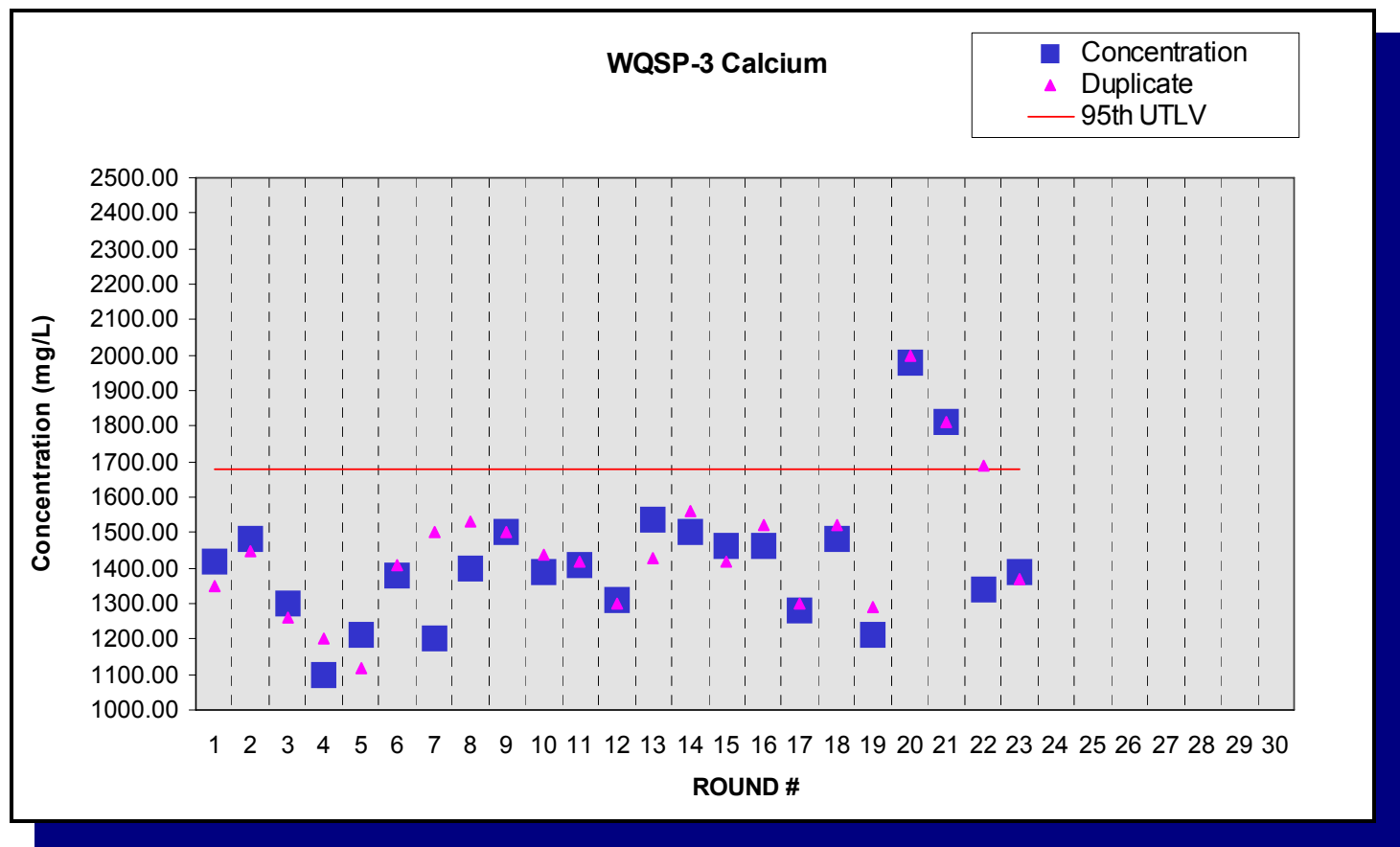

Figure E.30 - Time Trend Plot for Calcium at WQSP-3 


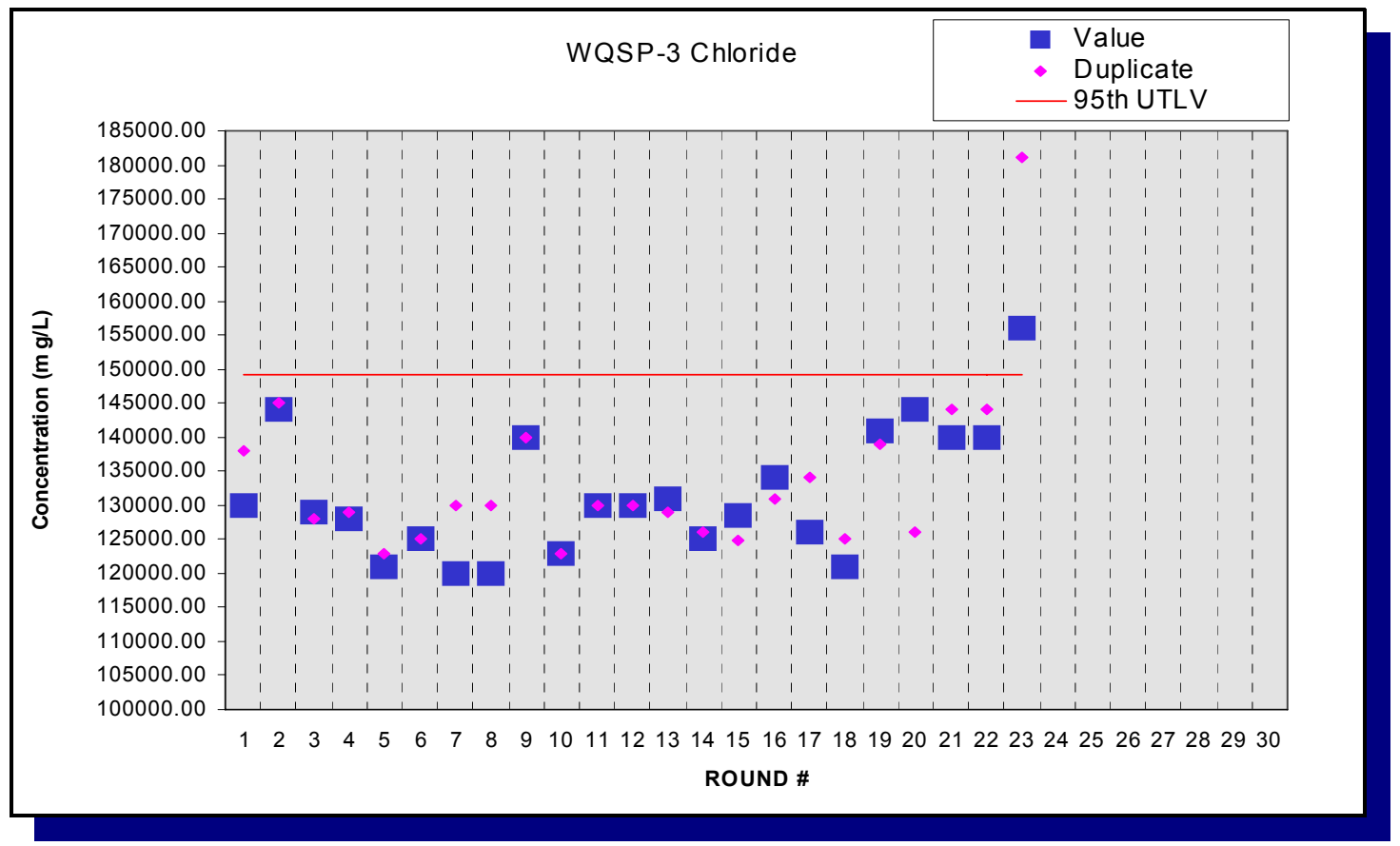

Figure E.31 - Time Trend Plot for Chloride at WQSP-3

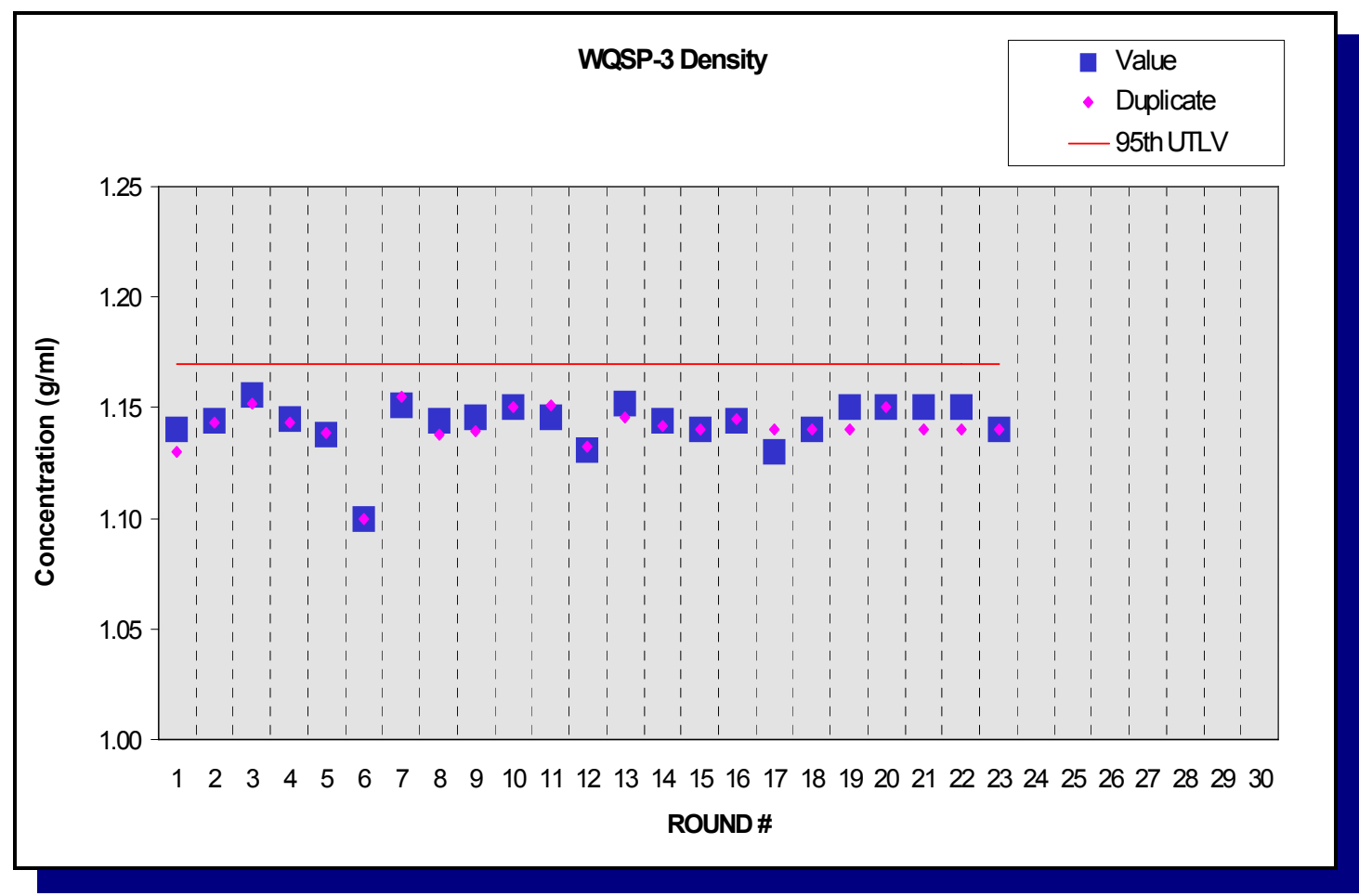

Figure E.32 - Time Trend Plot for Density at WQSP-3 


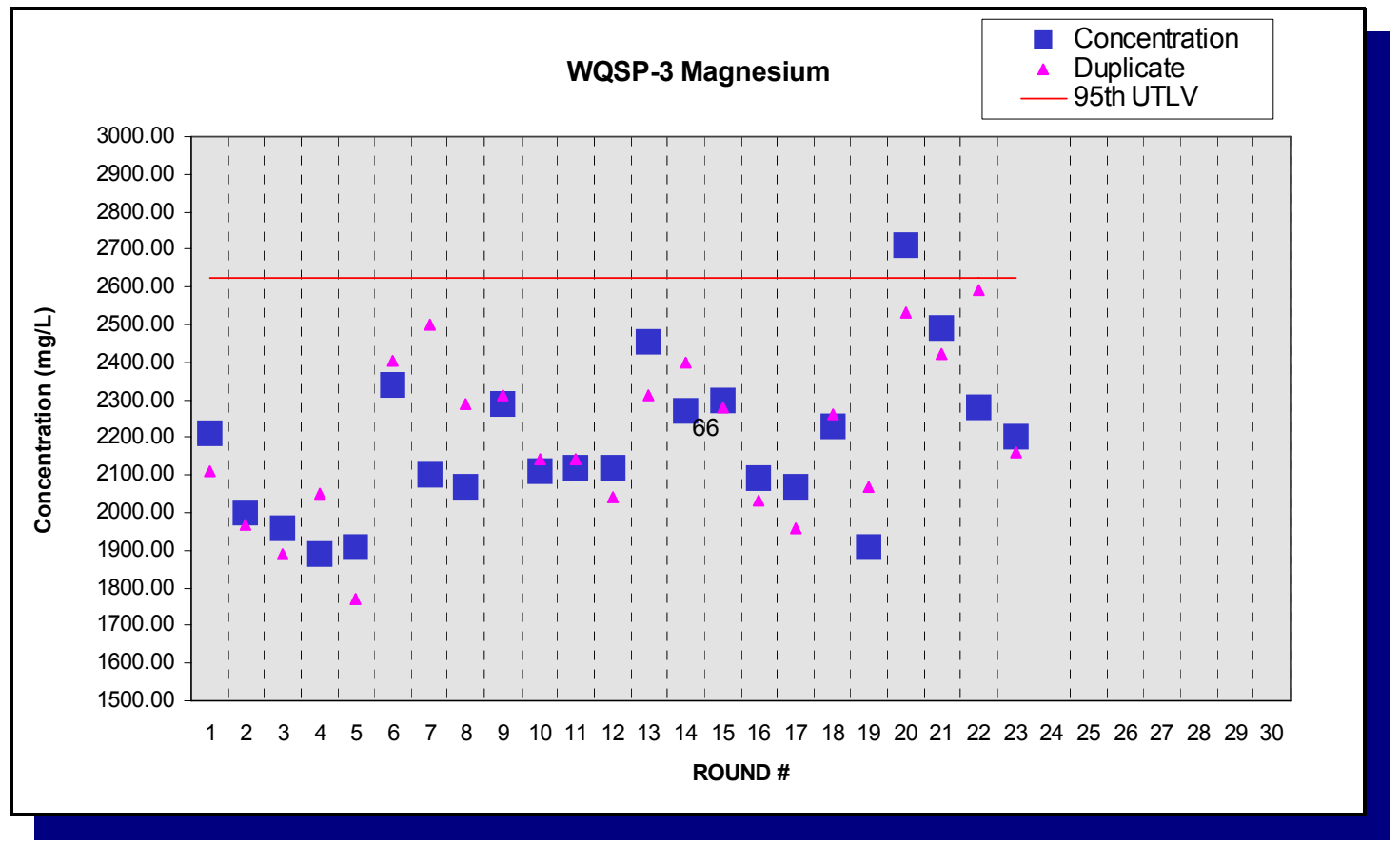

Figure E.33 - Time Trend Plot for Magnesium at WQSP-3

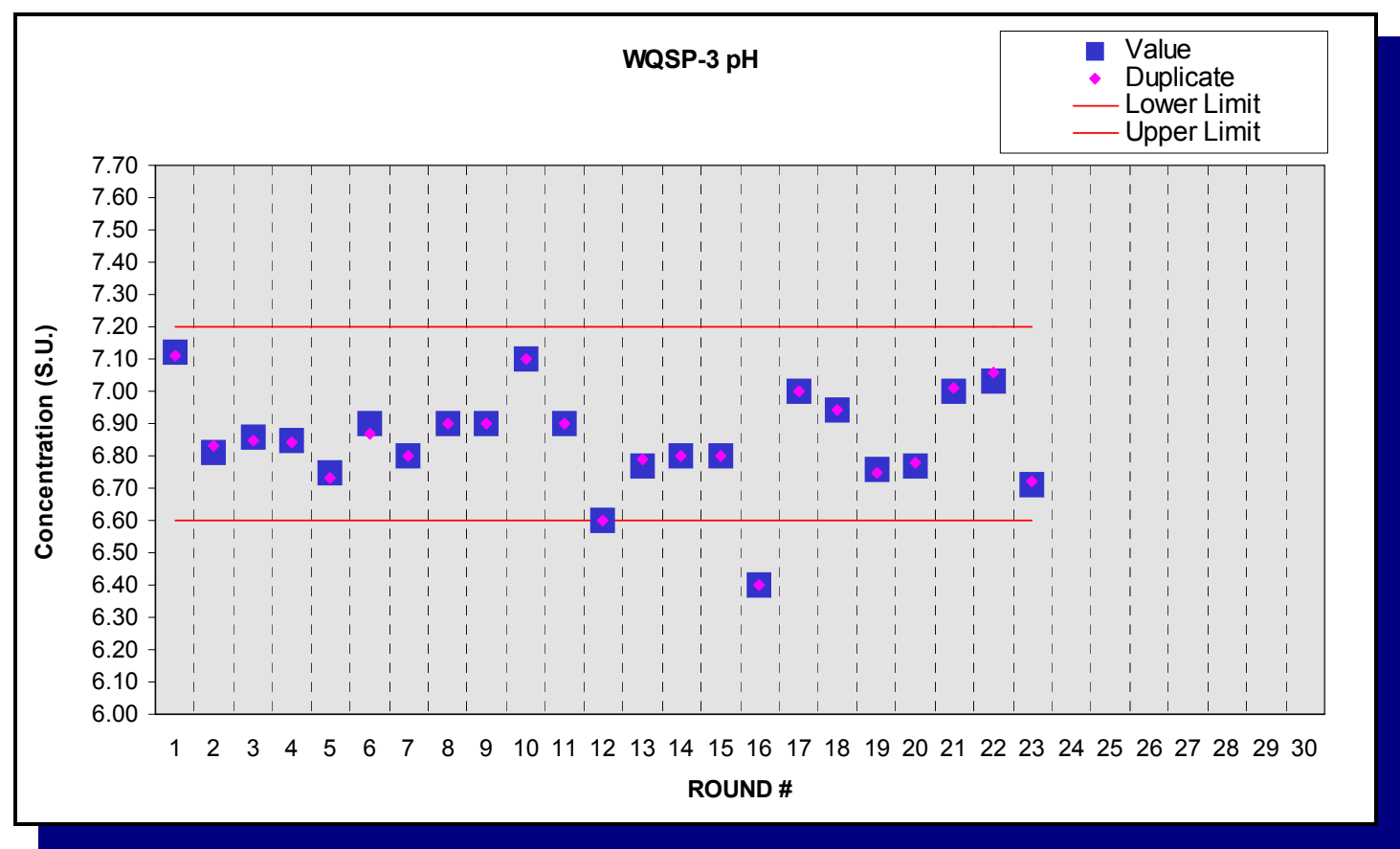

Figure E.34 - Time Trend Plot for pH at WQSP-3 


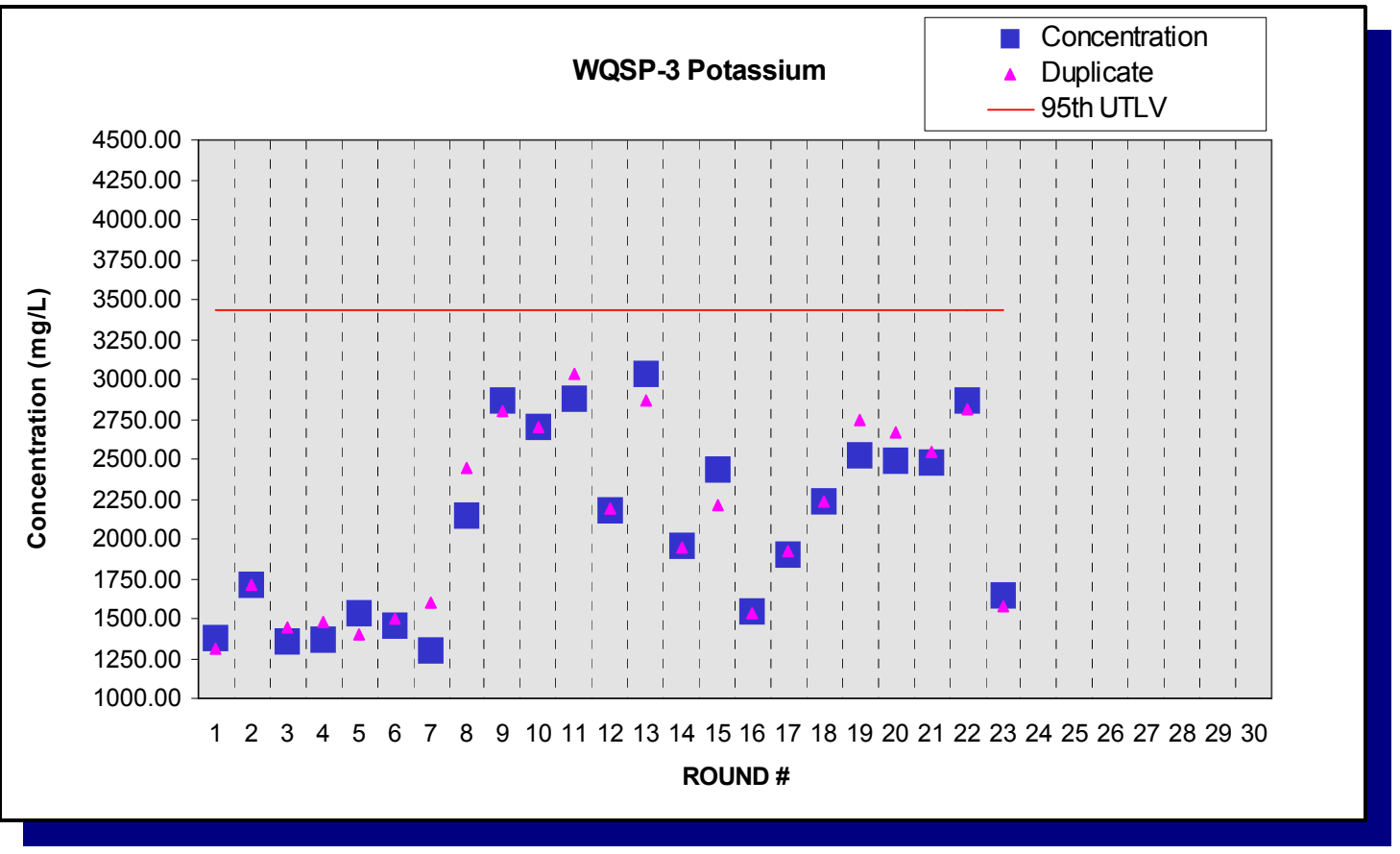

Figure E.35 - Time Trend Plot for Potassium at WQSP-3

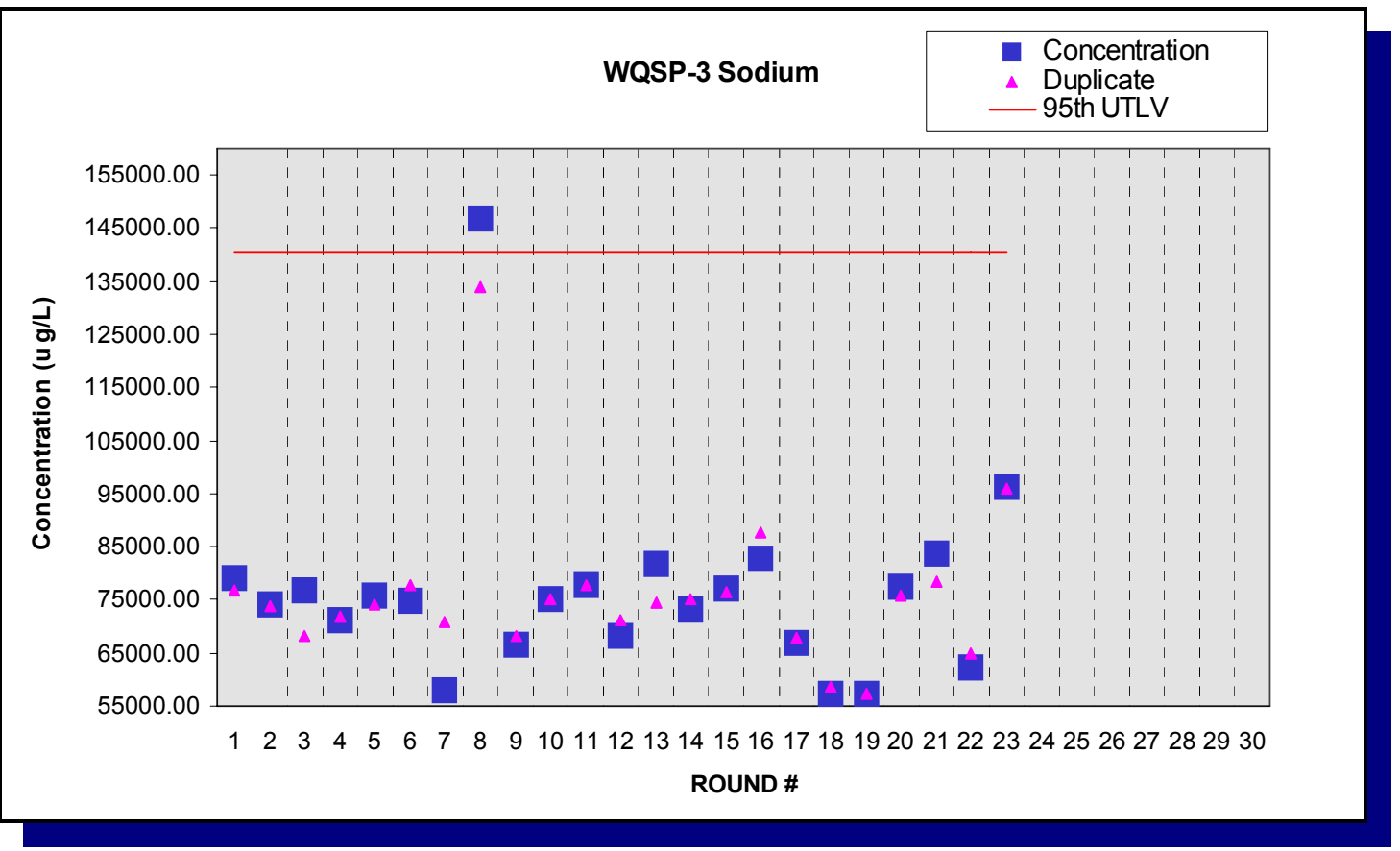

Figure E.36 - Time Trend Plot for Sodium at WQSP-3 


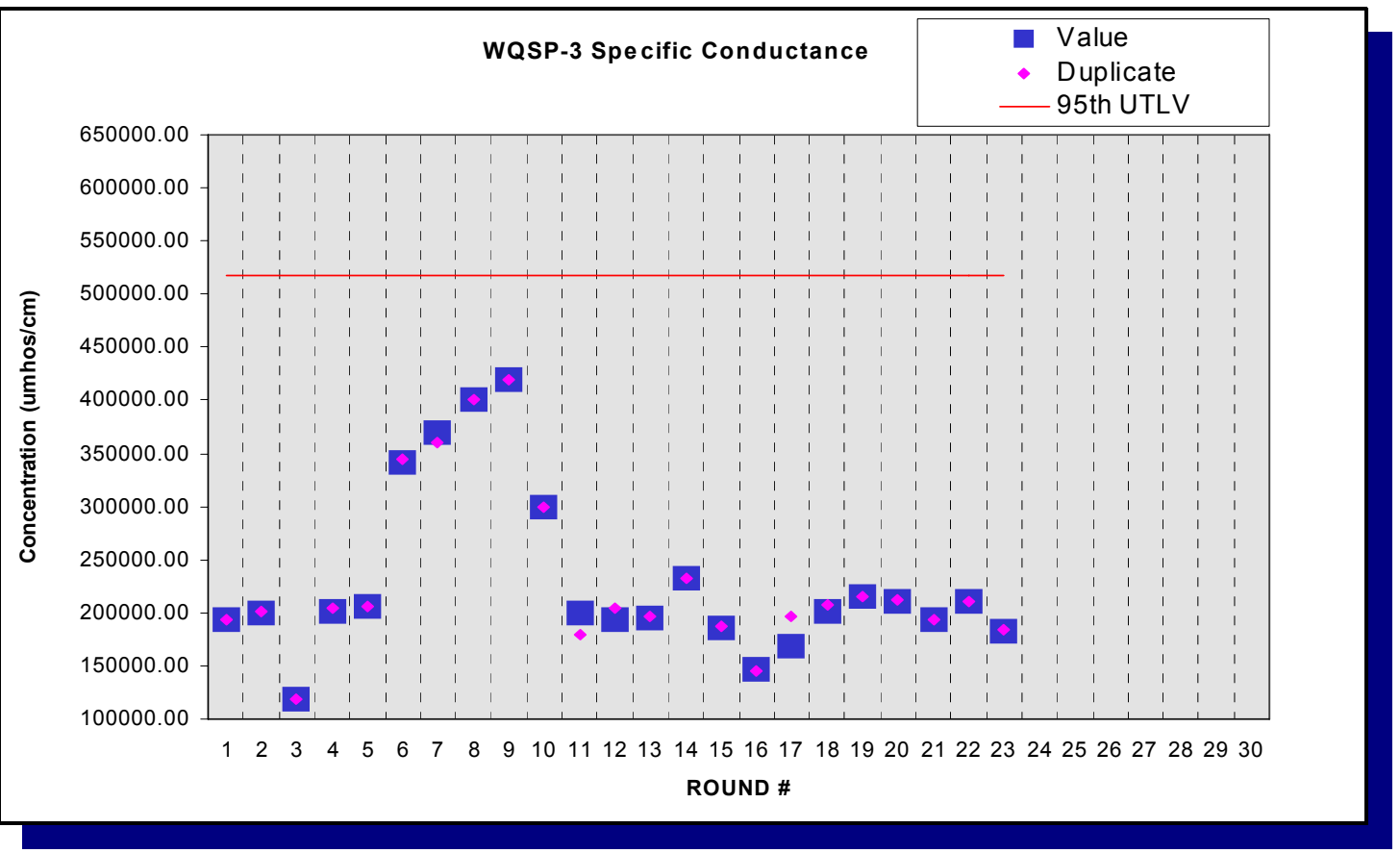

Figure E.37 - Time Trend Plot for Specific Conductance at WQSP-3

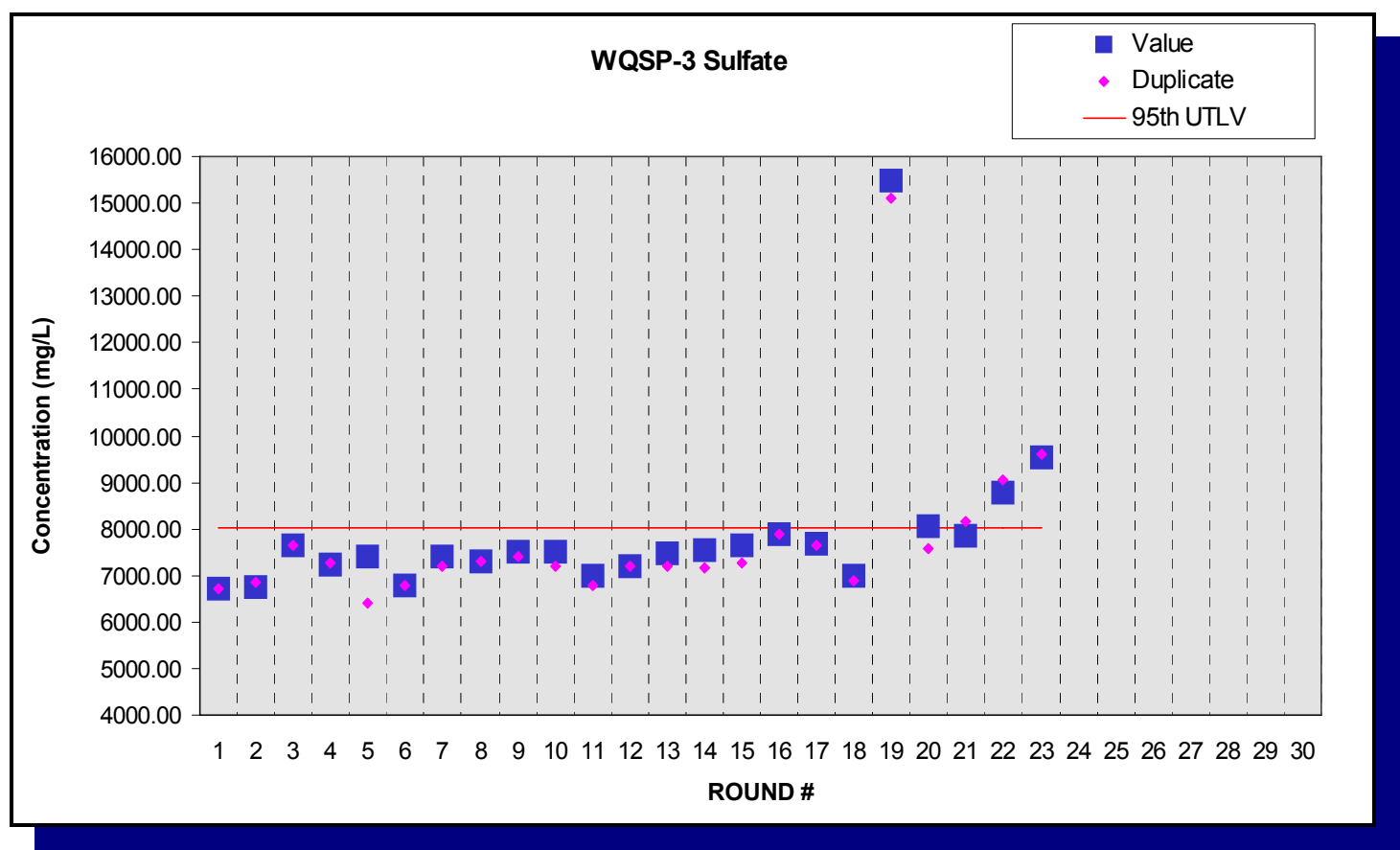

Figure E.38 - Time Trend Plot for Sulfate at WQSP-3 


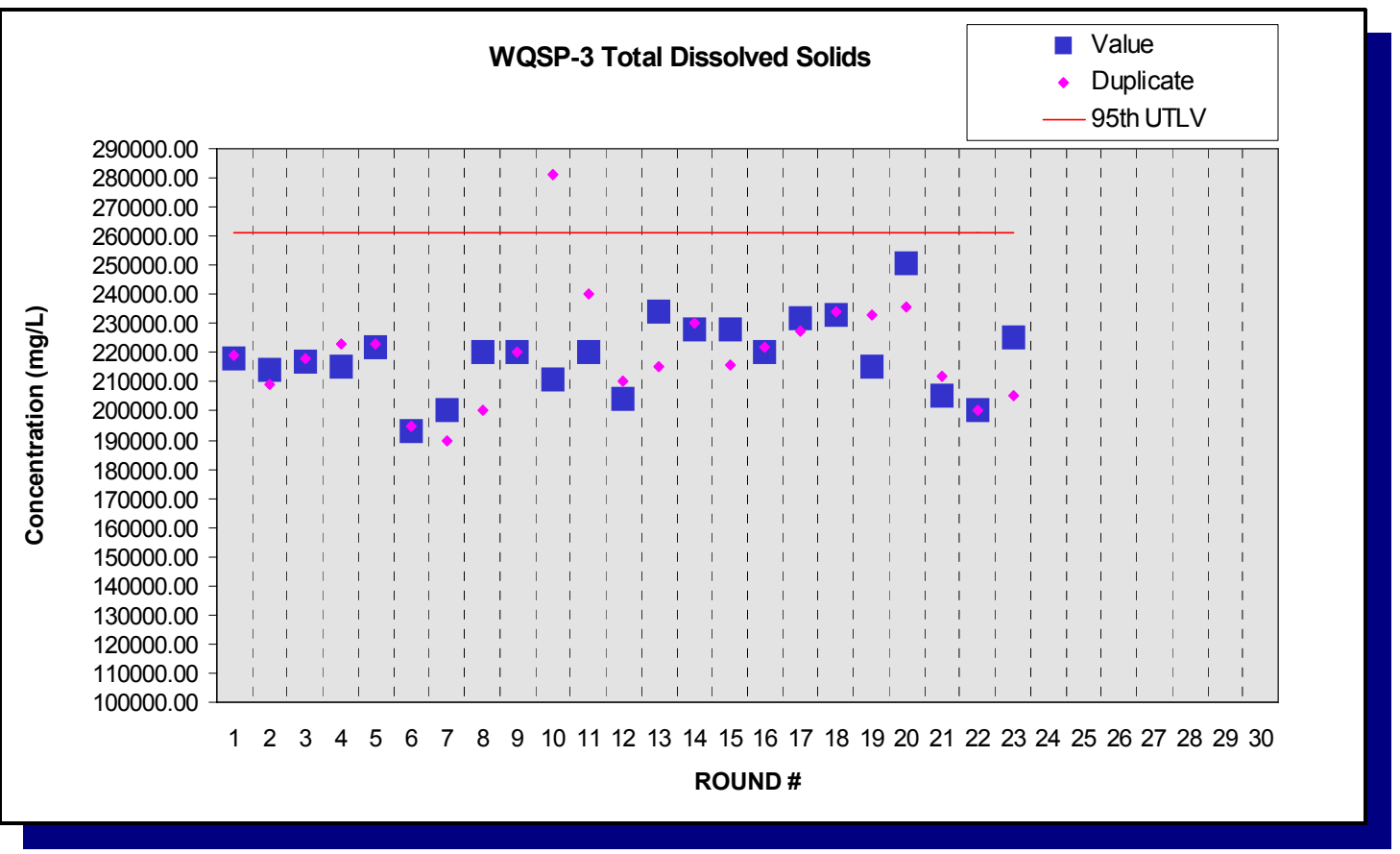

Figure E.39 - Time Trend Plot for Total Dissolved Solids at WQSP-3

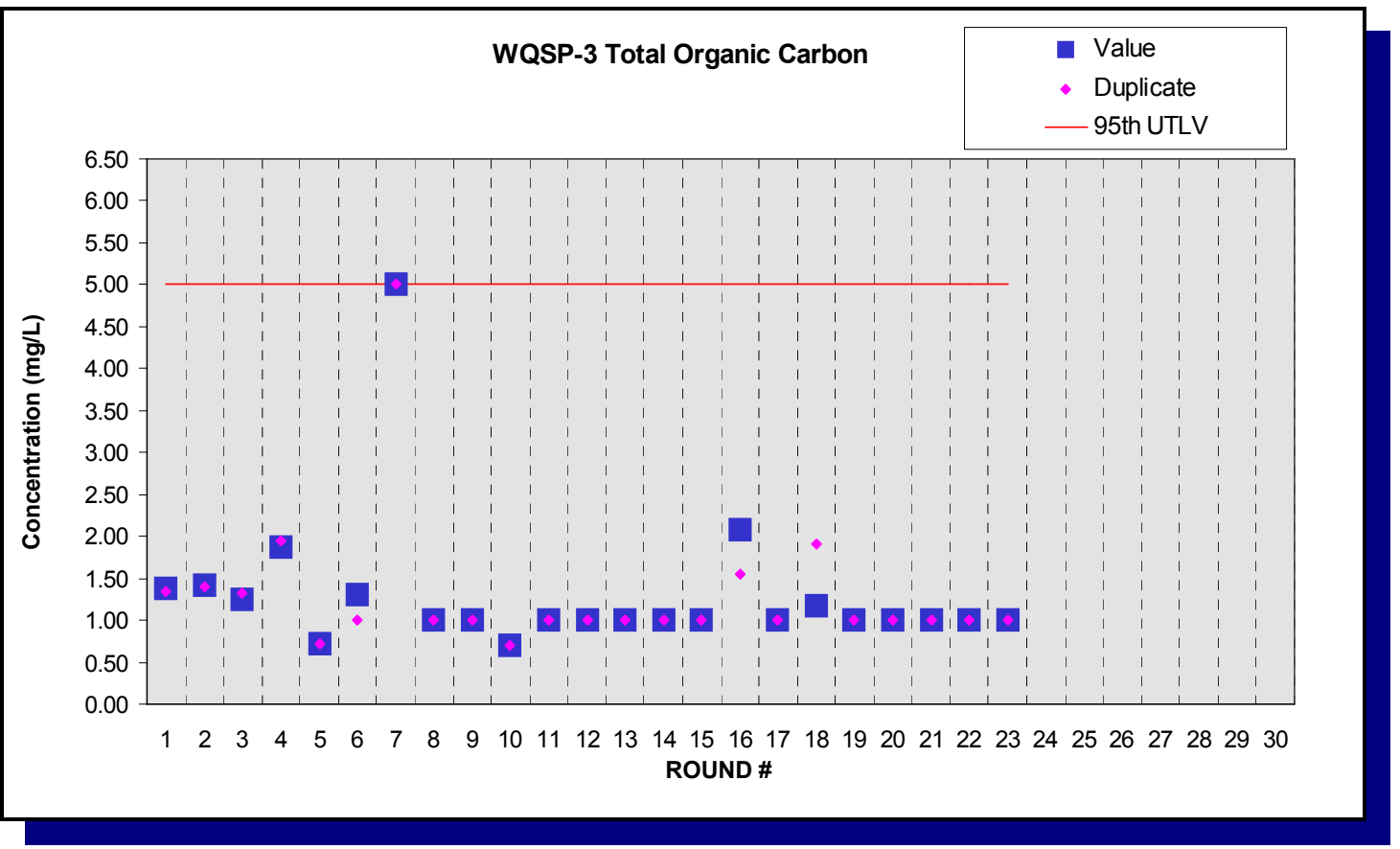

Figure E.40 - Time Trend Plot for Total Organic Carbon at WQSP-3 


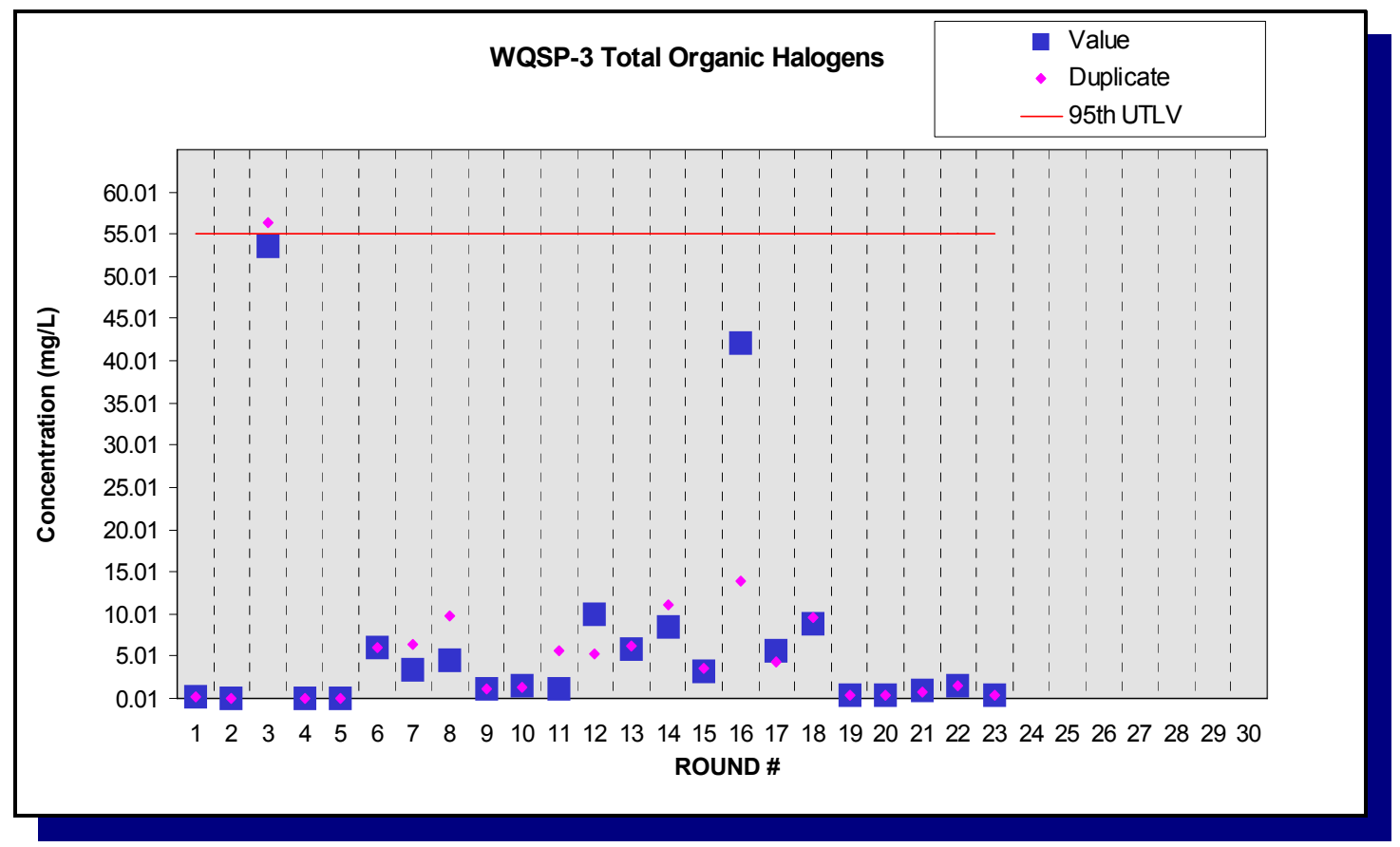

Figure E.41 - Time Trend Plot for Total Organic Halogens at WQSP-3

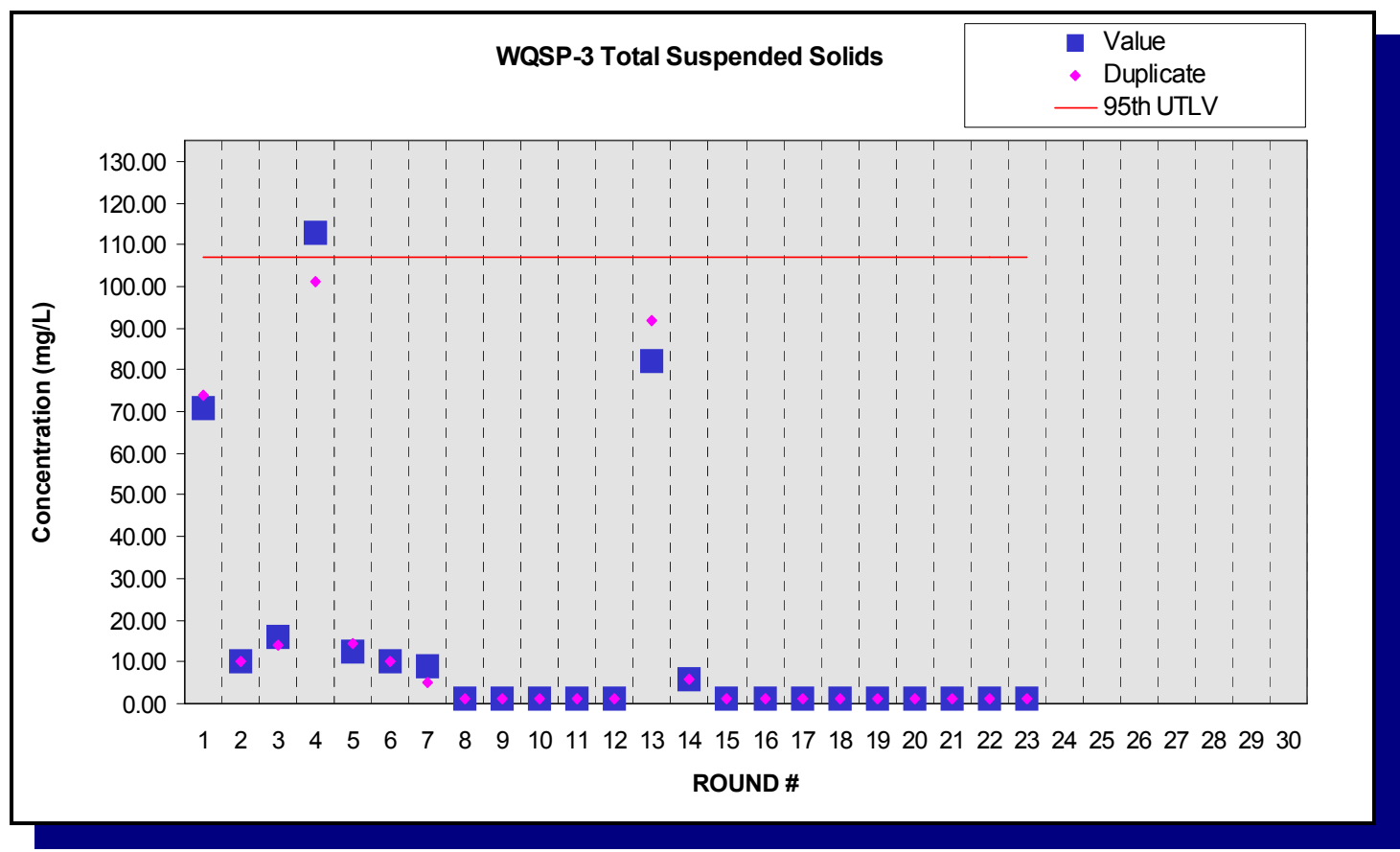

Figure E.42 - Time Trend Plot for Total Suspended Solids at WQSP-3 


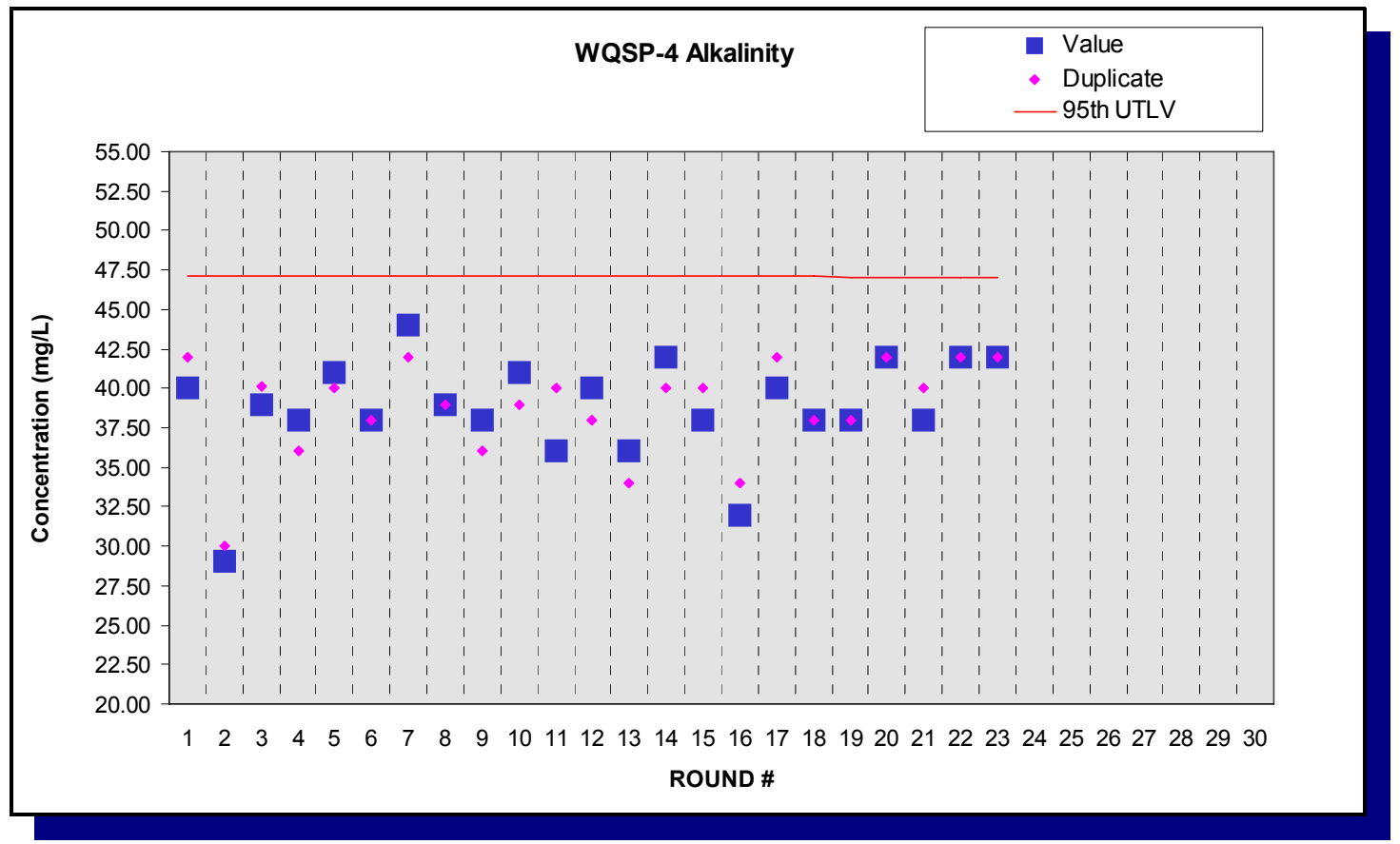

Figure E.43 - Time Trend Plot for Alkalinity at WQSP-4

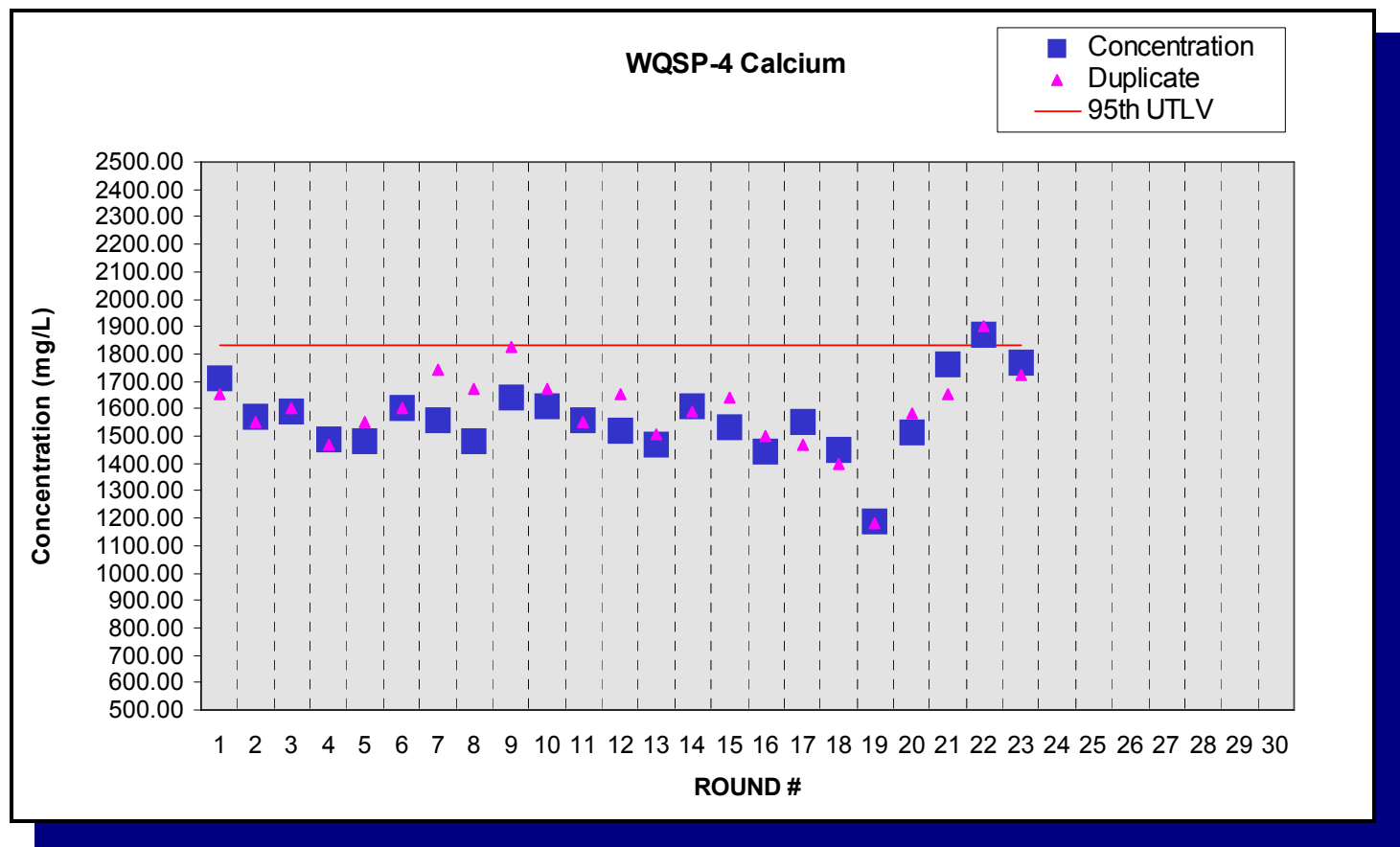

Figure E.44 - Time Trend Plot for Calcium at WQSP-4 


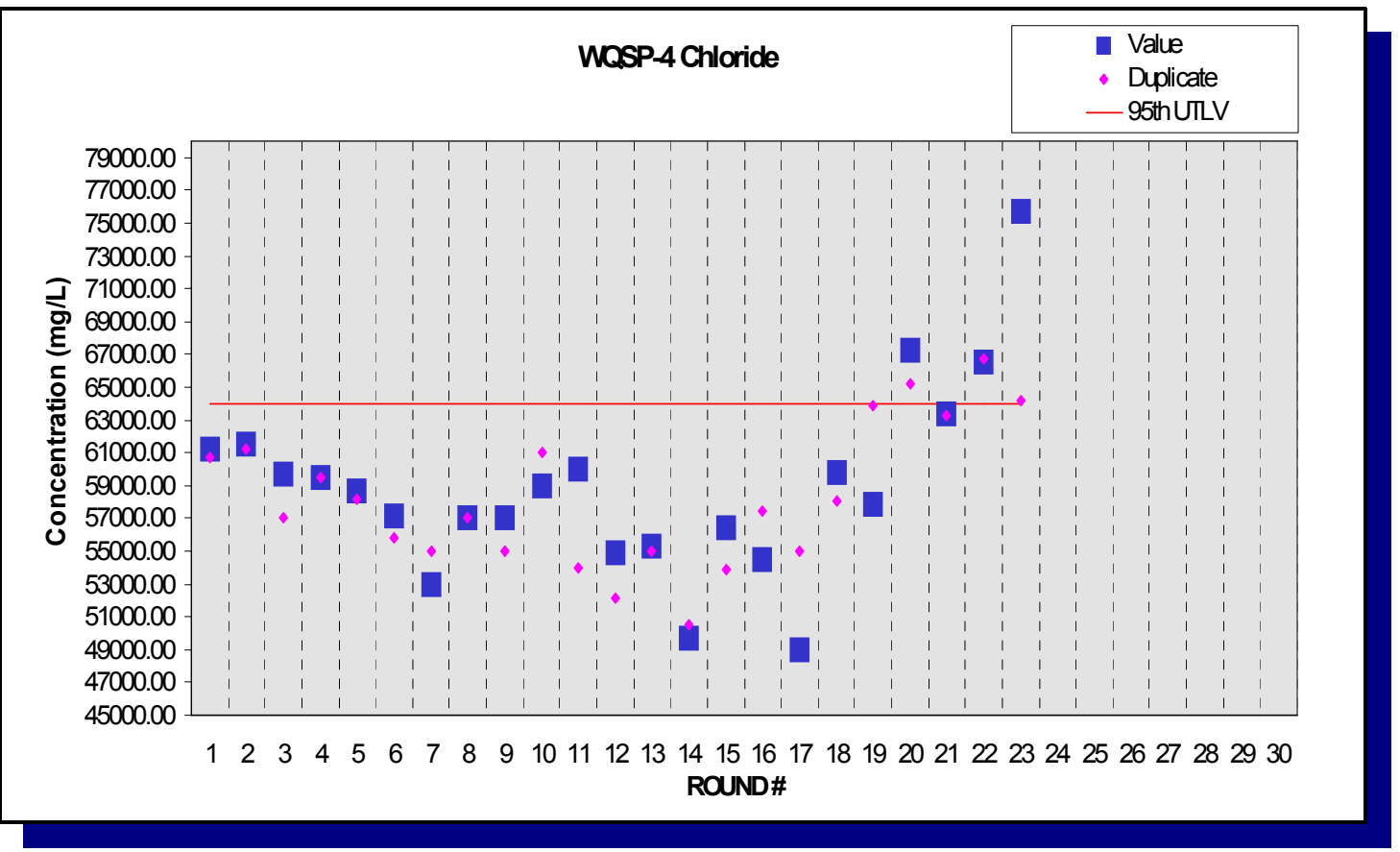

Figure E.45 - Time Trend Plot for Chloride at WQSP-4

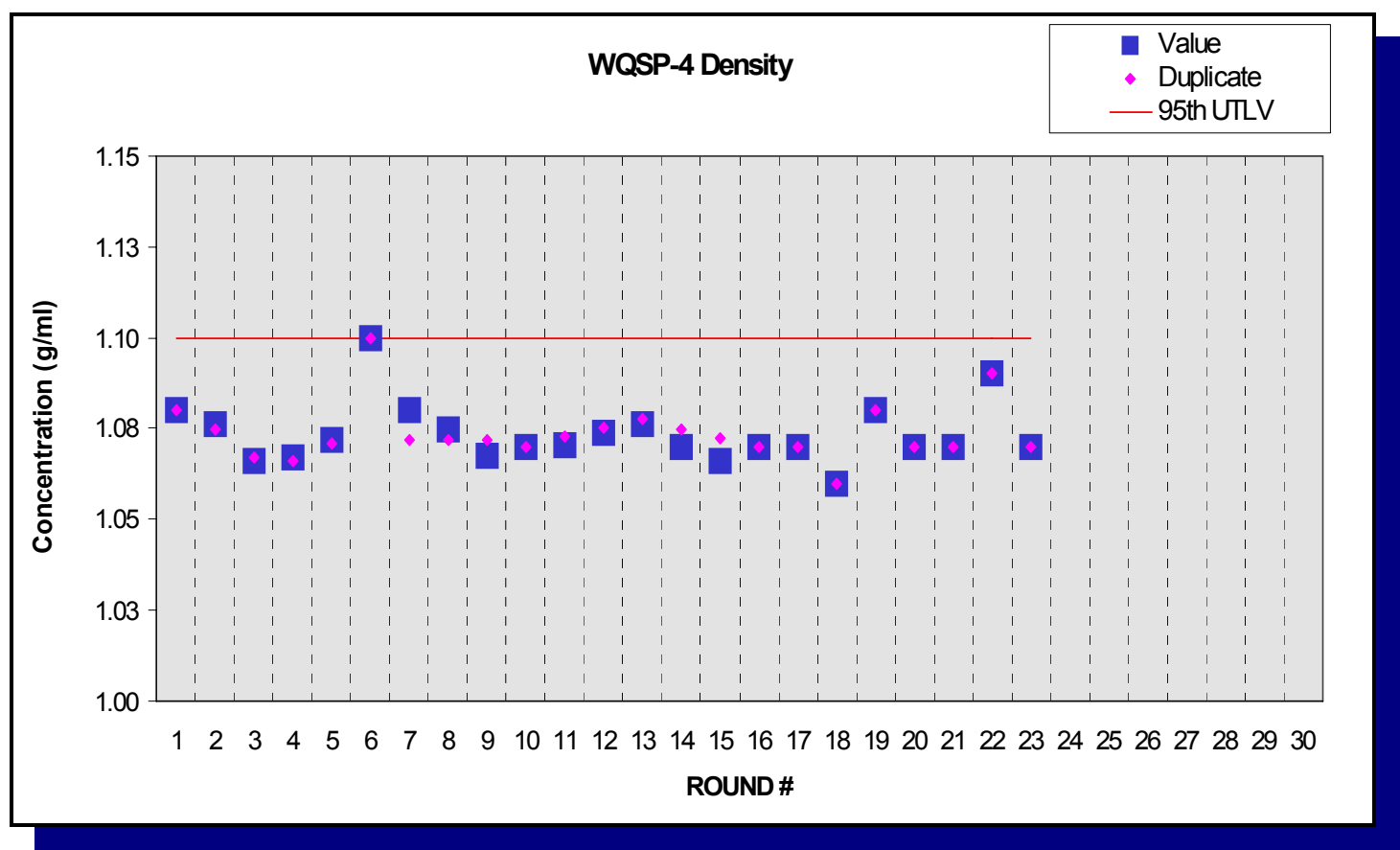

Figure E.46 - Time Trend Plot for Density at WQSP-4 


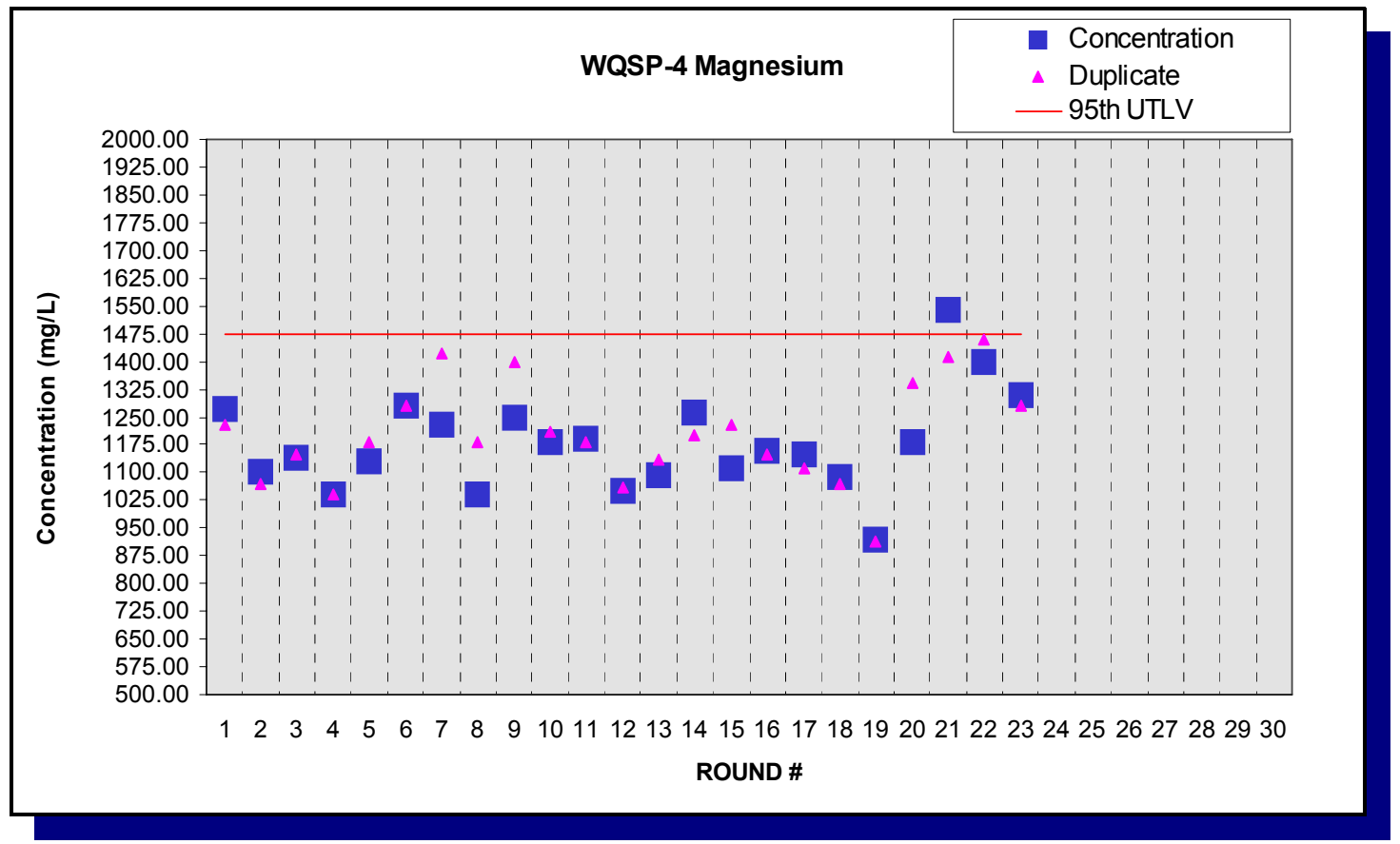

Figure E.47 - Time Trend Plot for Magnesium at WQSP-4

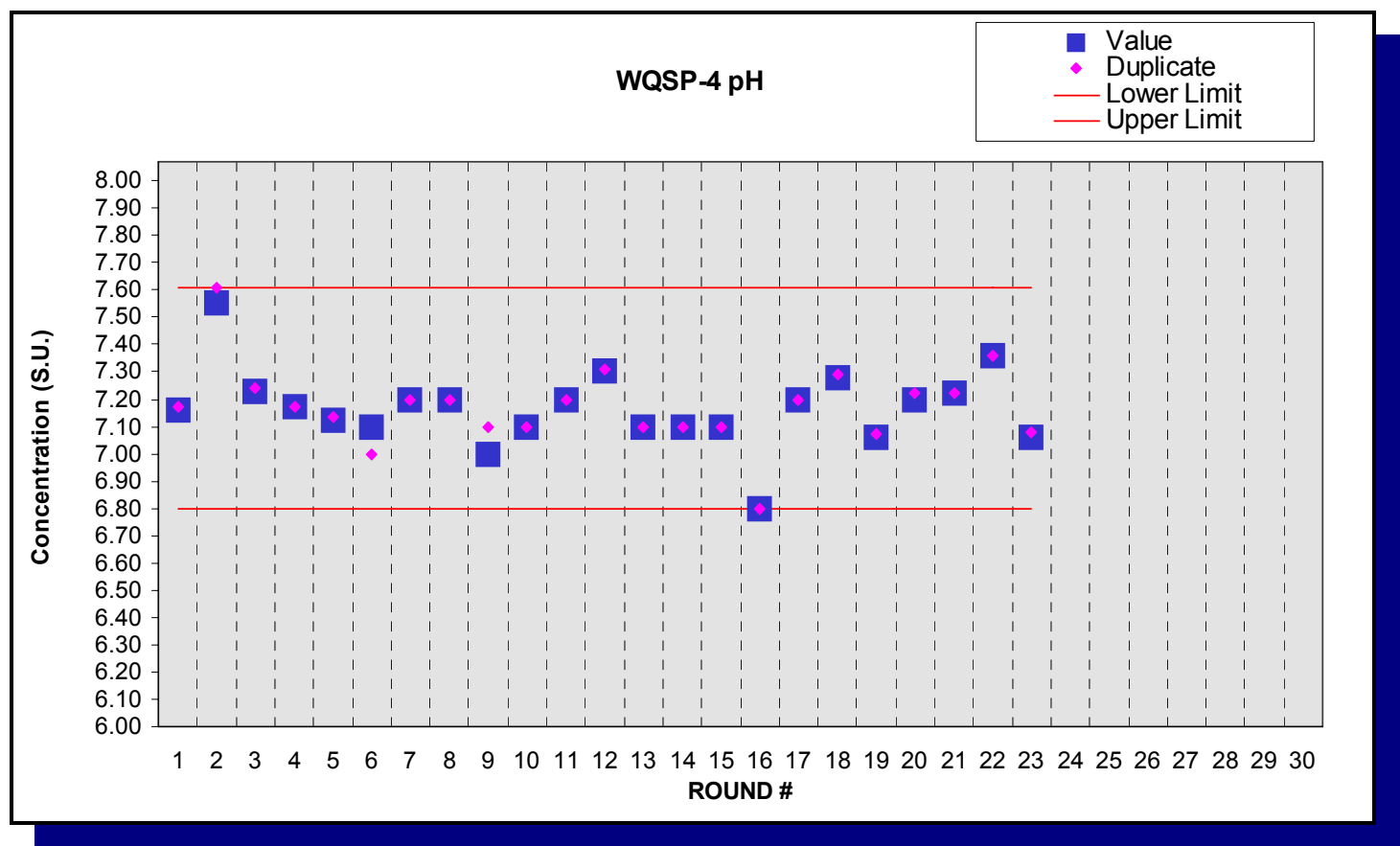

Figure E.48 - Time Trend Plot for pH at WQSP-4 


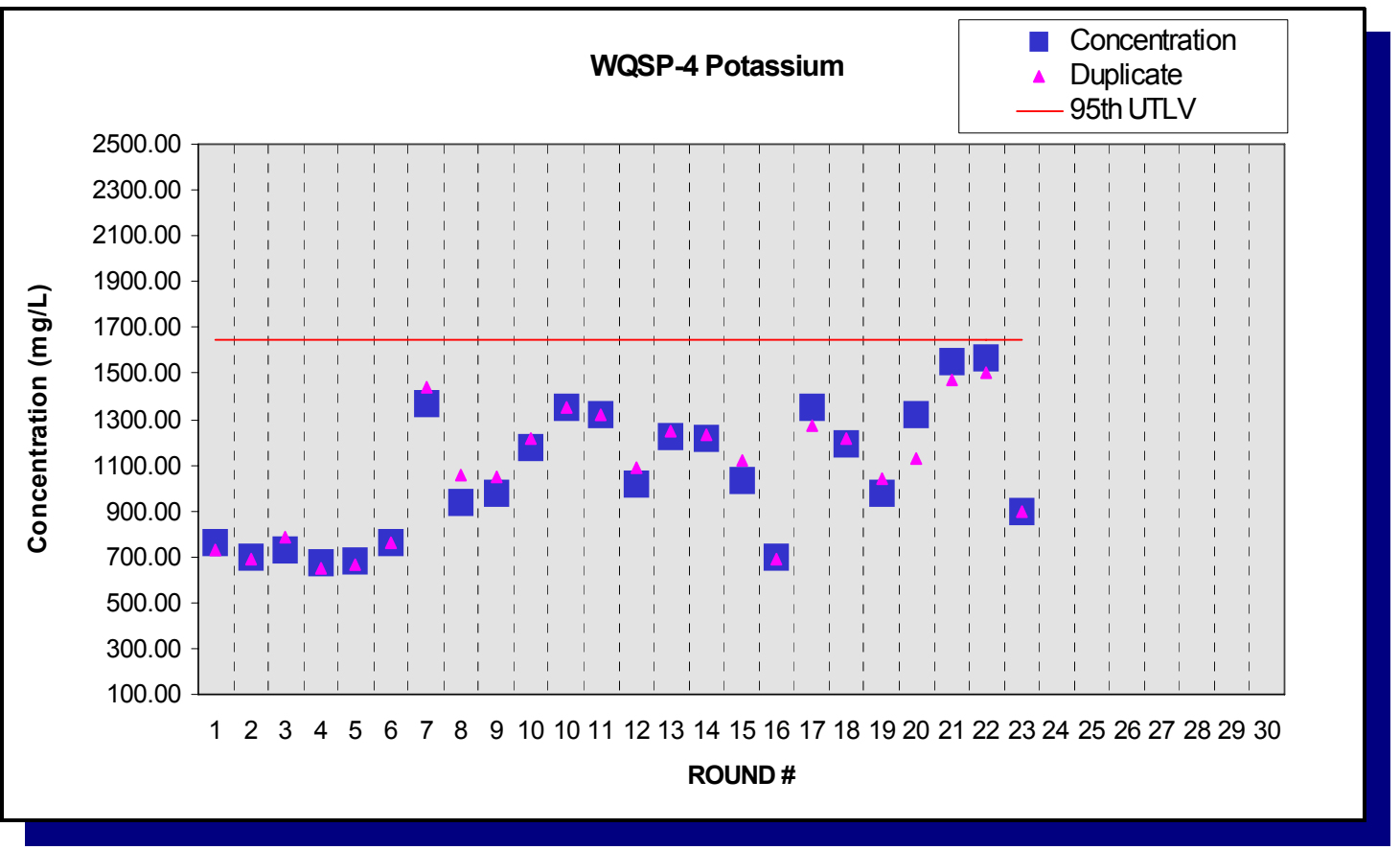

Figure E.49 - Time Trend Plot for Potassium at WQSP-4

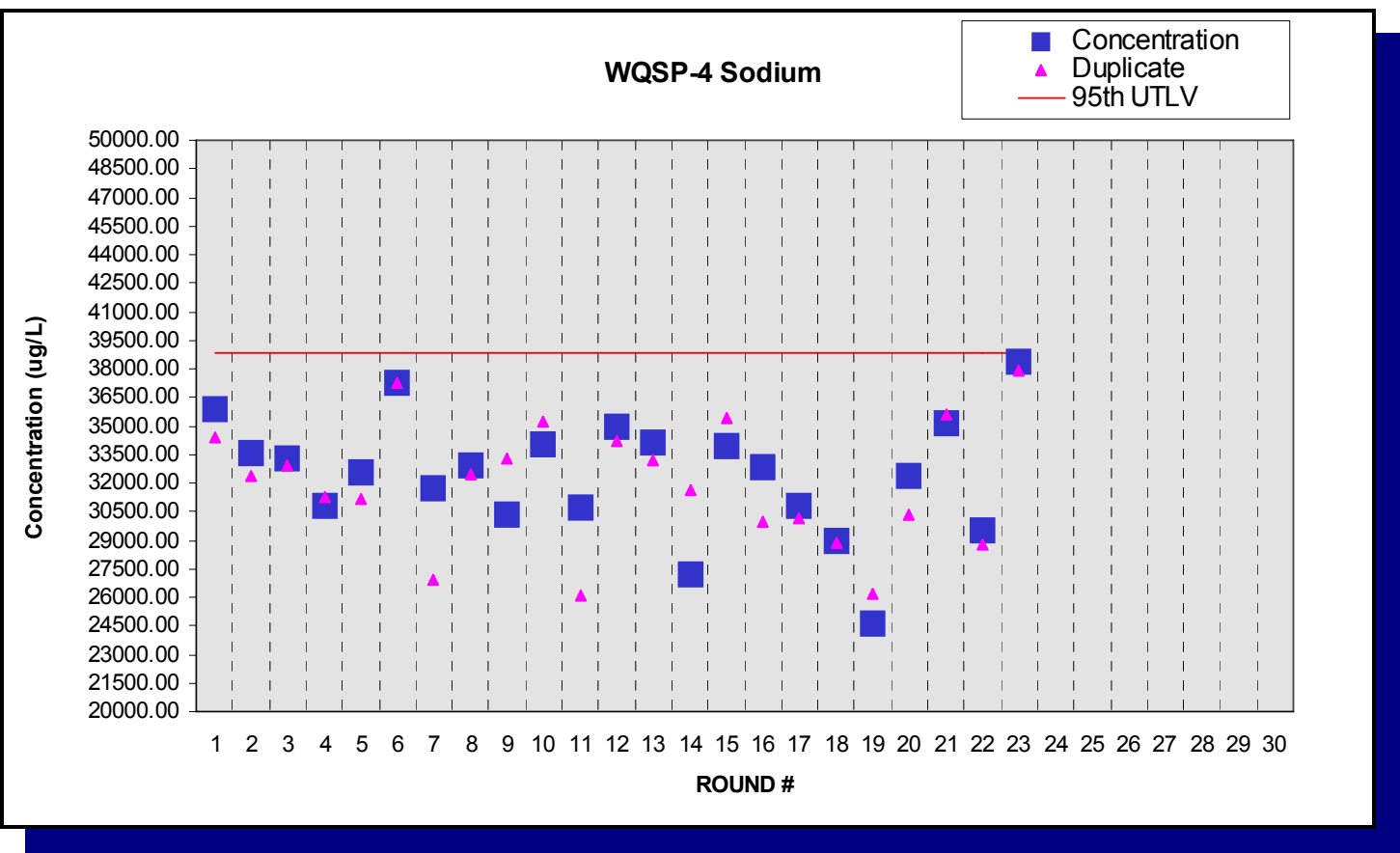

Figure E.50 - Time Trend Plot for Sodium at WQSP-4 


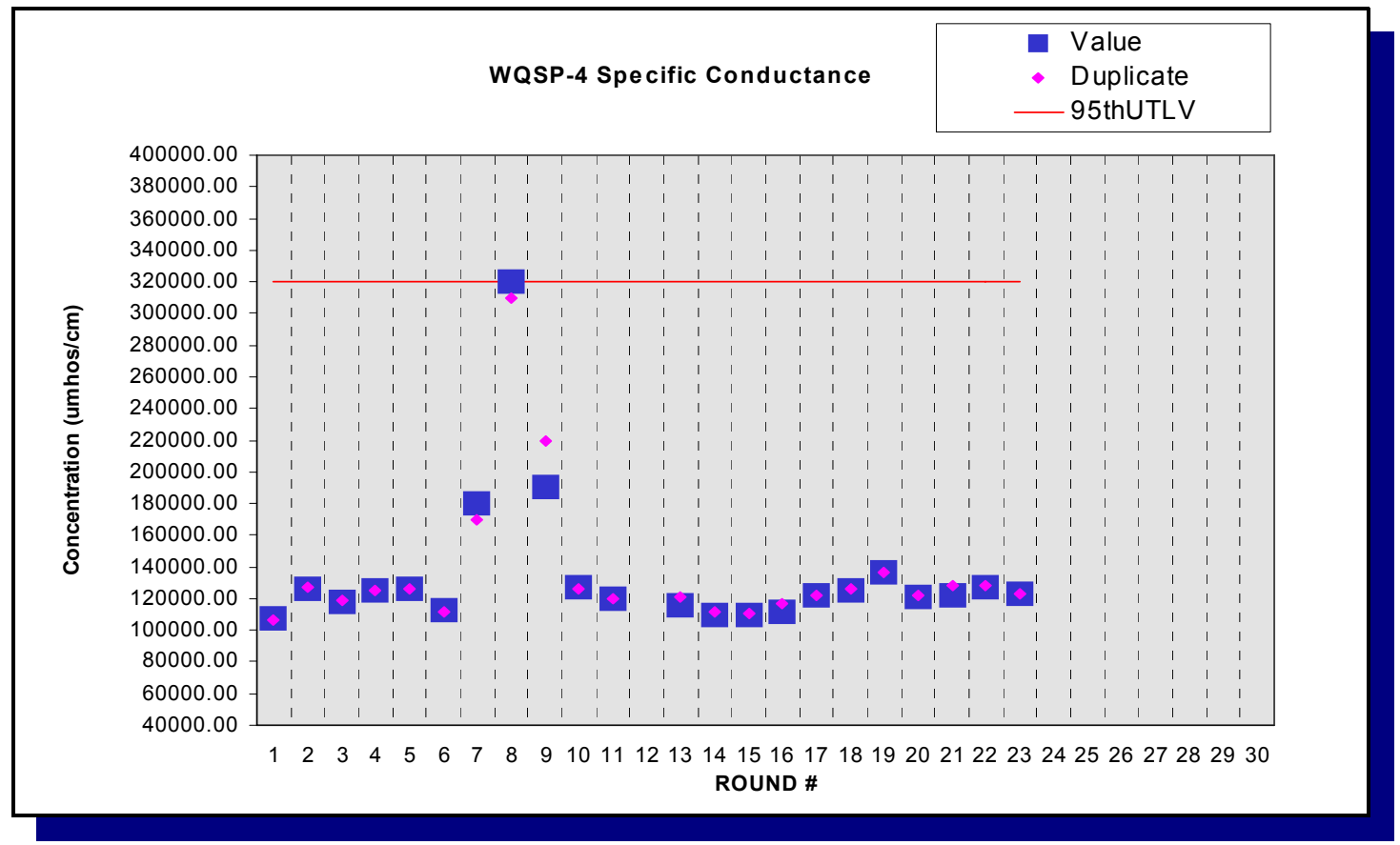

Figure E.51 - Time Trend Plot for Specific Conductance at WQSP-4

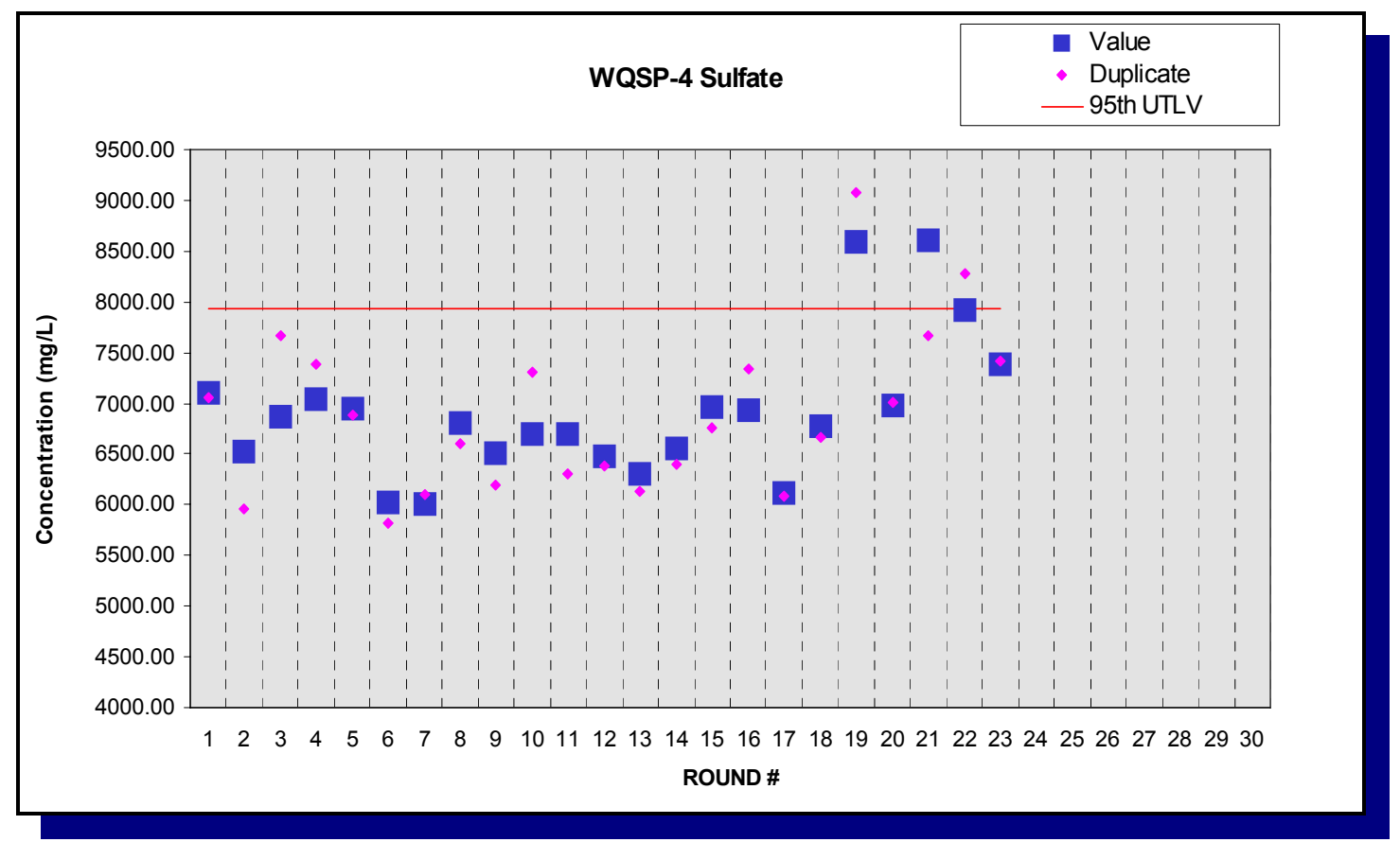

Figure E.52 - Time Trend Plot for Sulfate at WQSP-4 


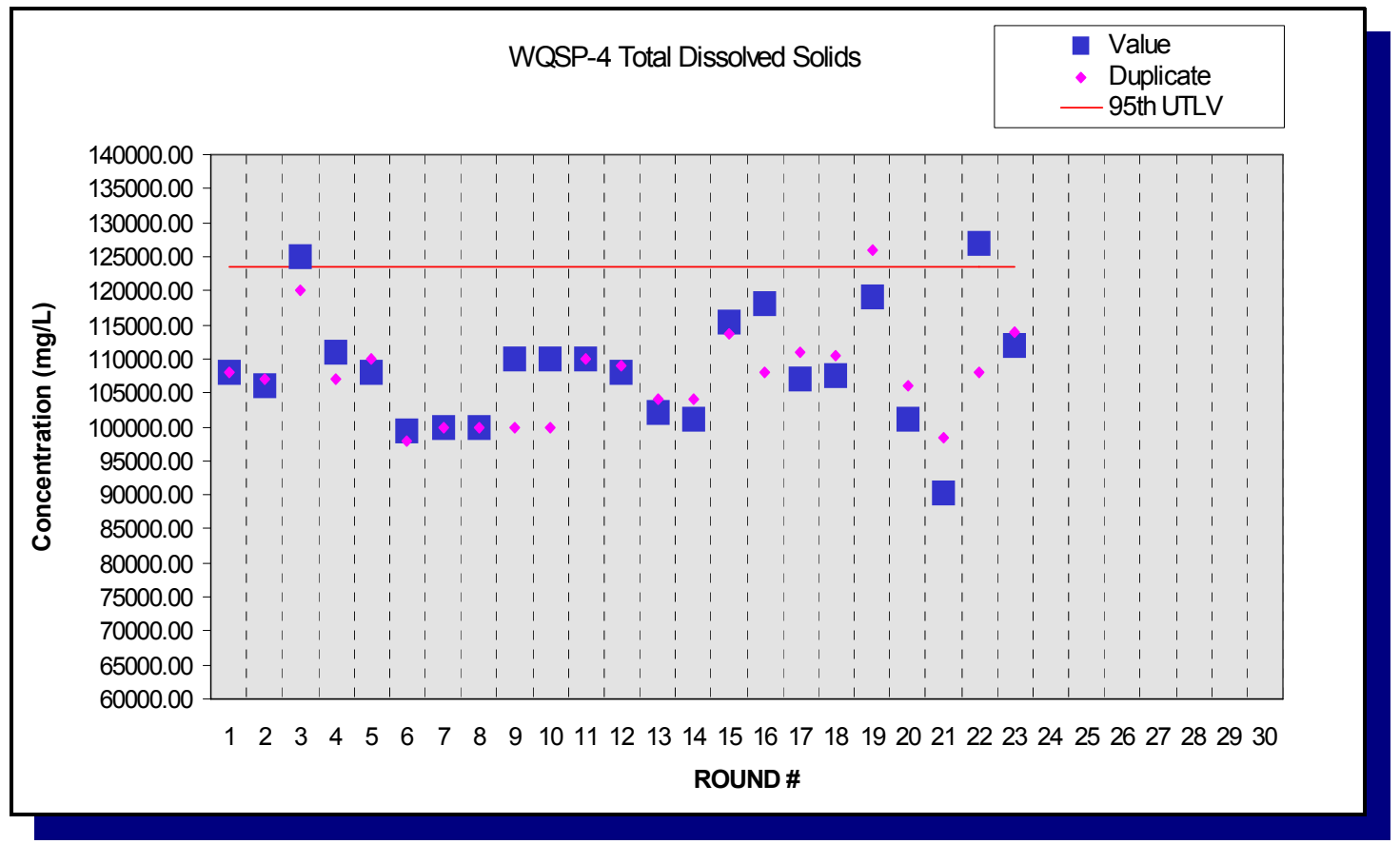

Figure E.53 - Time Trend Plot for Total Dissolved Solids at WQSP-4

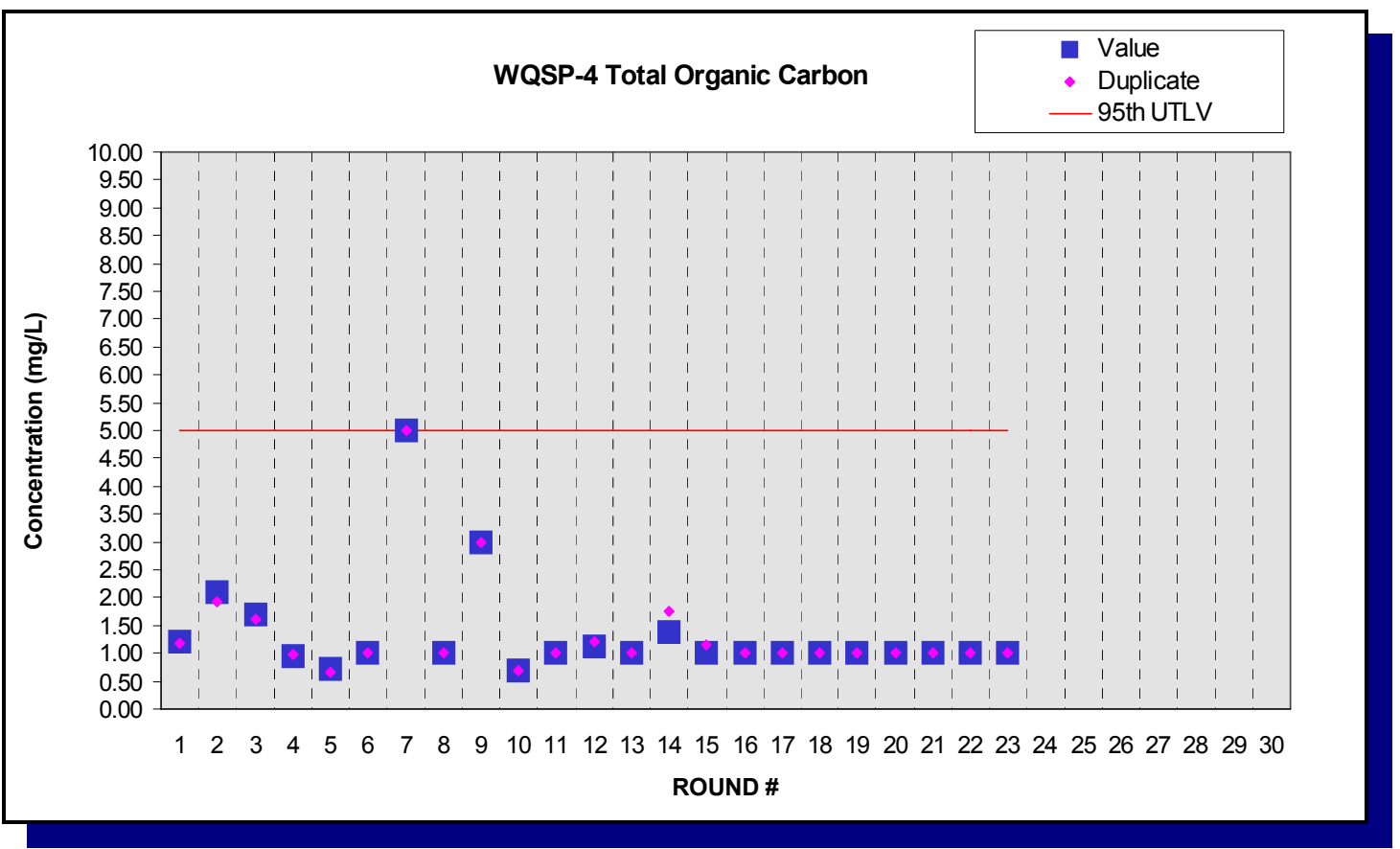

Figure E.54 - Time Trend Plot for Total Organic Carbon at WQSP-4 


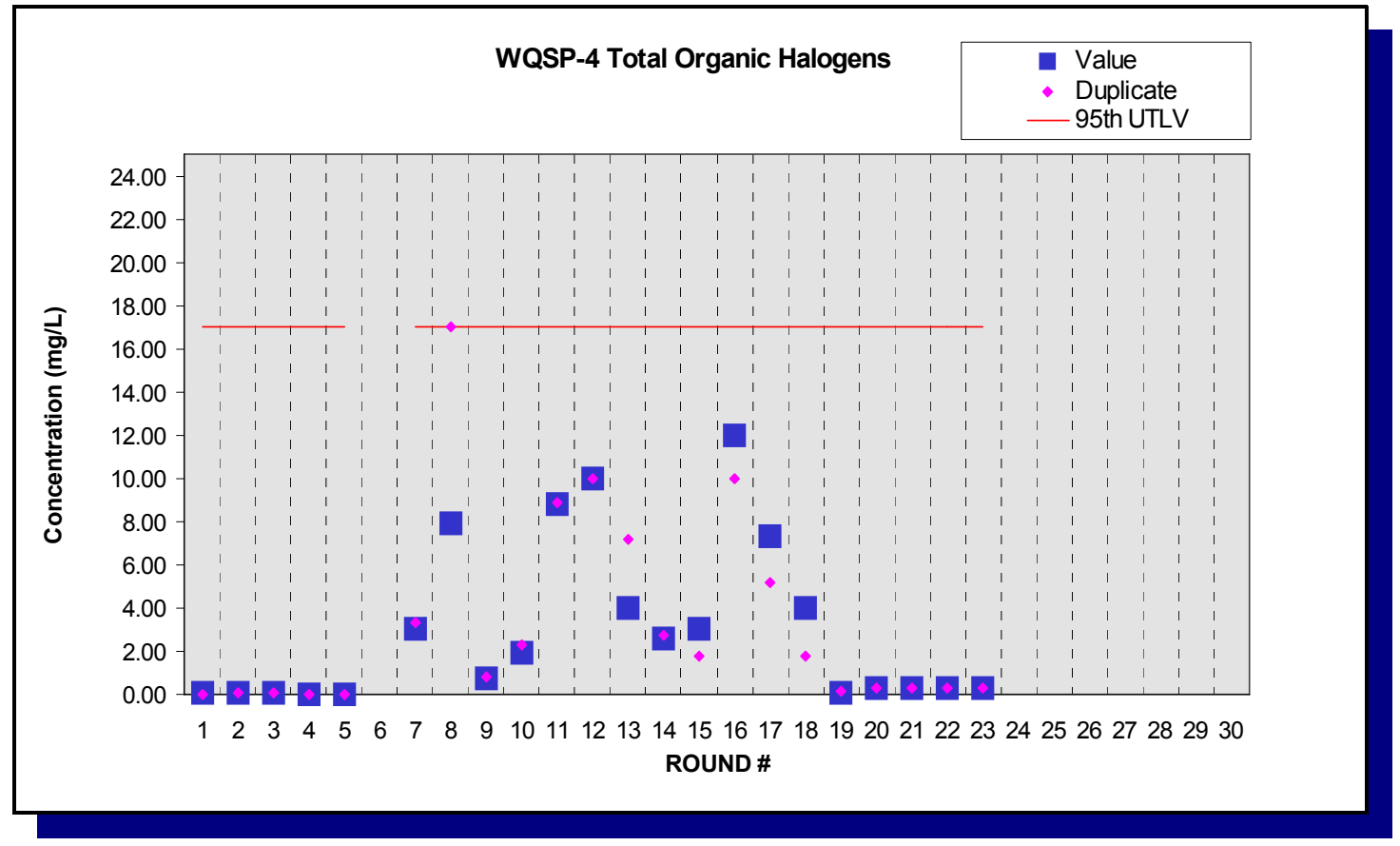

Figure E.55 - Time Trend Plot for Total Organic Halogens at WQSP-4

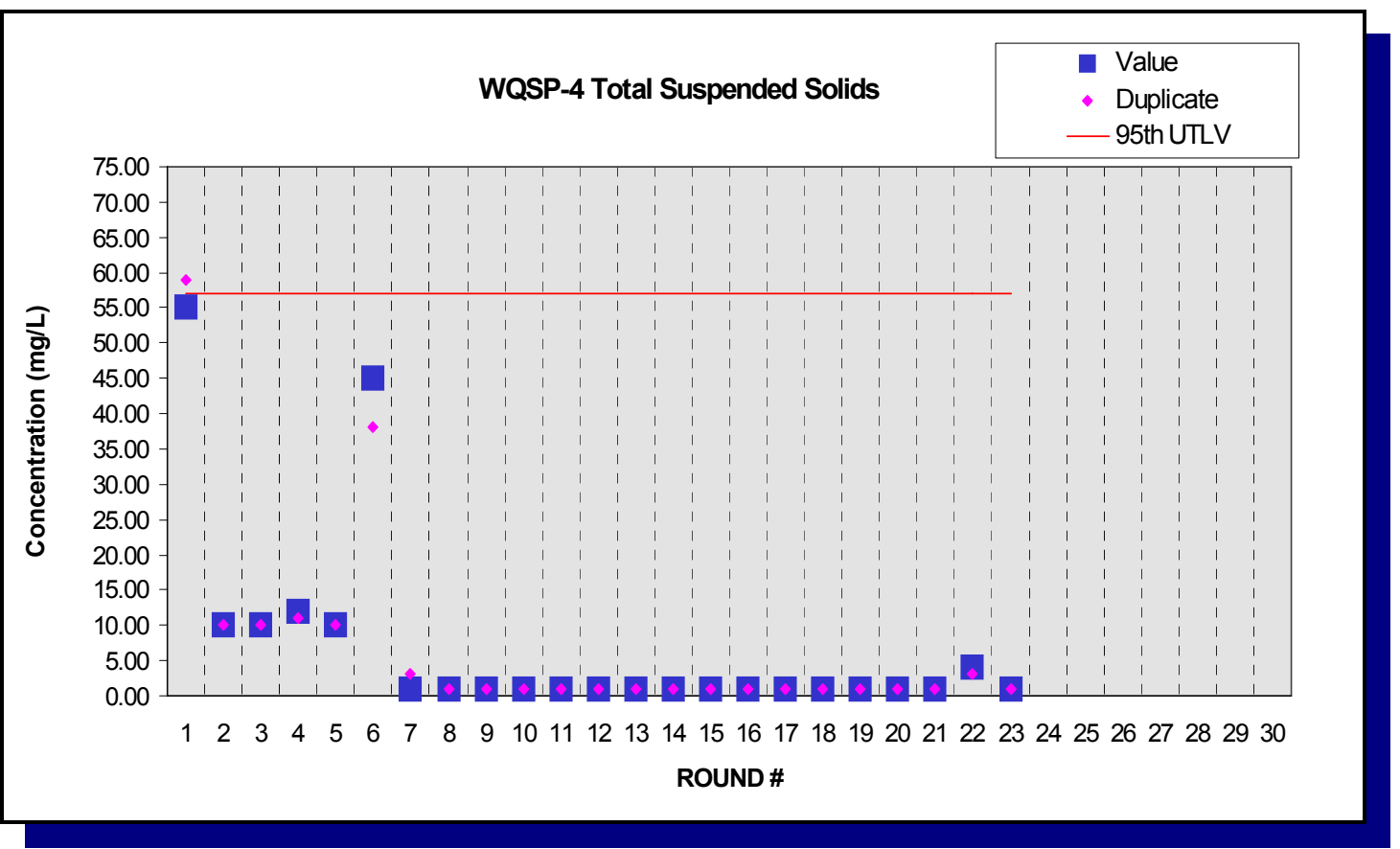

Figure E.56 - Time Trend Plot for Total Suspended Solids at WQSP-4 


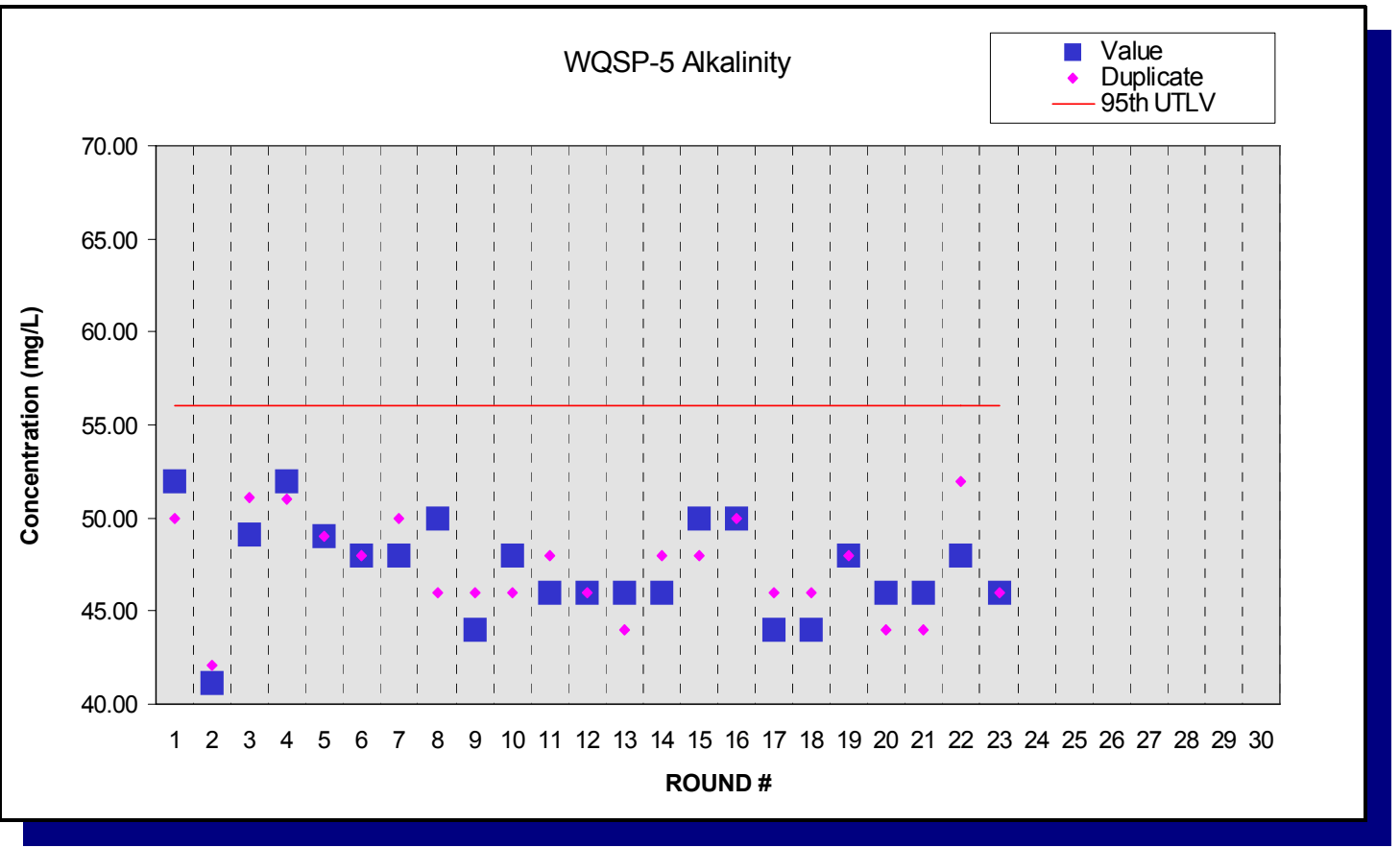

Figure E.57 - Time Trend Plot for Alkalinity at WQSP-5

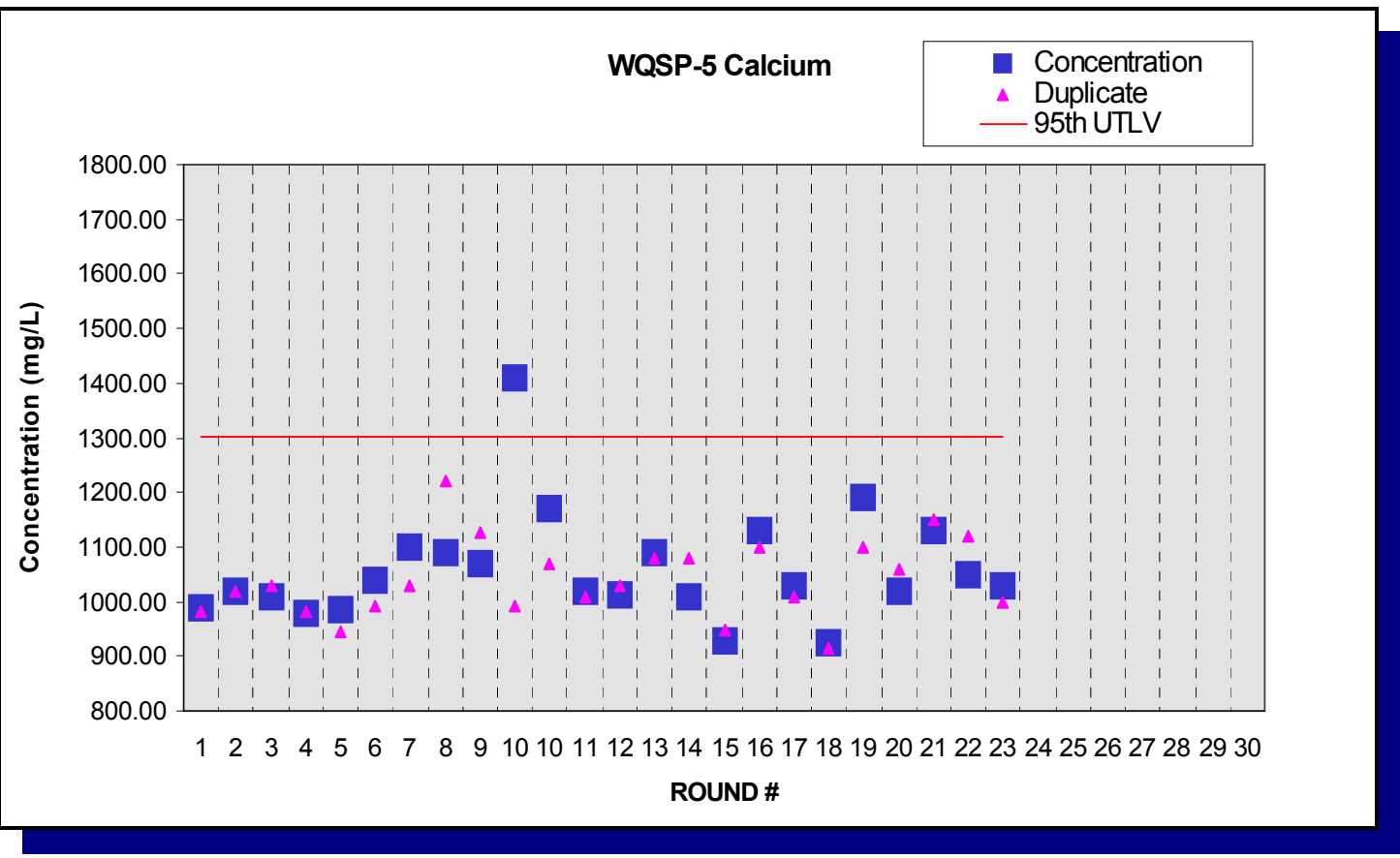

Figure E.58 - Time Trend Plot for Calcium at WQSP-5 


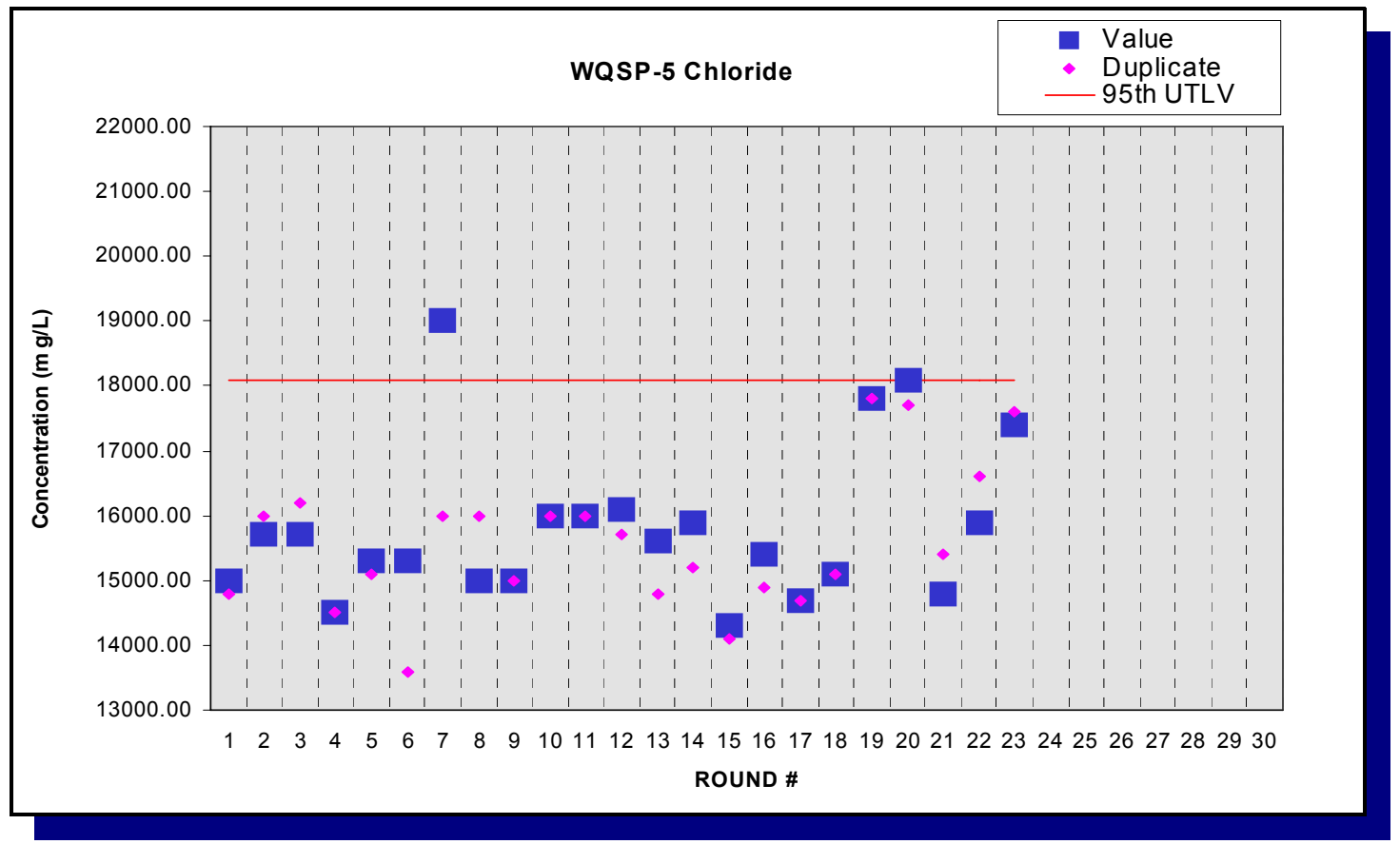

Figure E.59 - Time Trend Plot for Chloride at WQSP-5

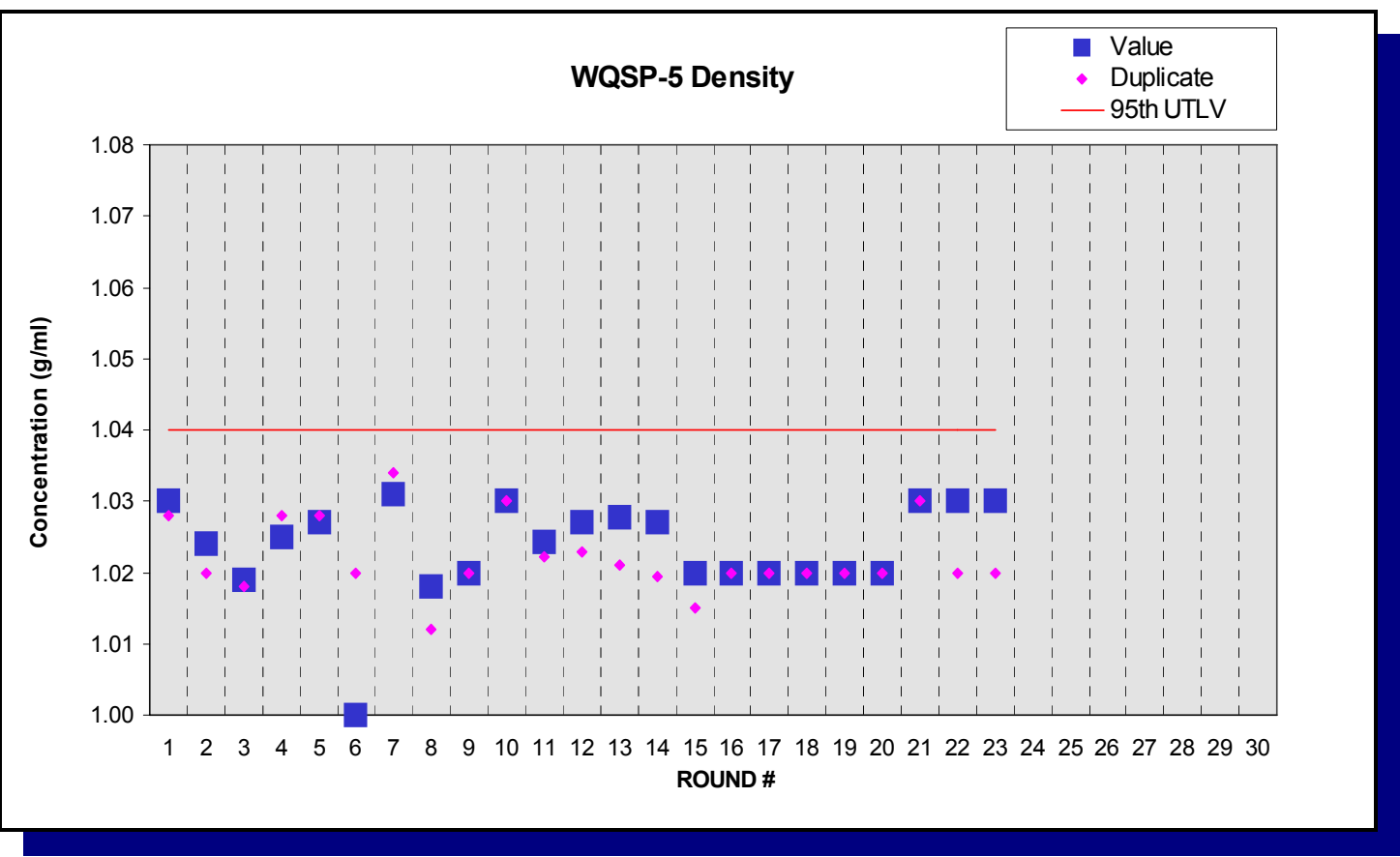

Figure E.60 - Time Trend Plot for Density at WQSP-5 


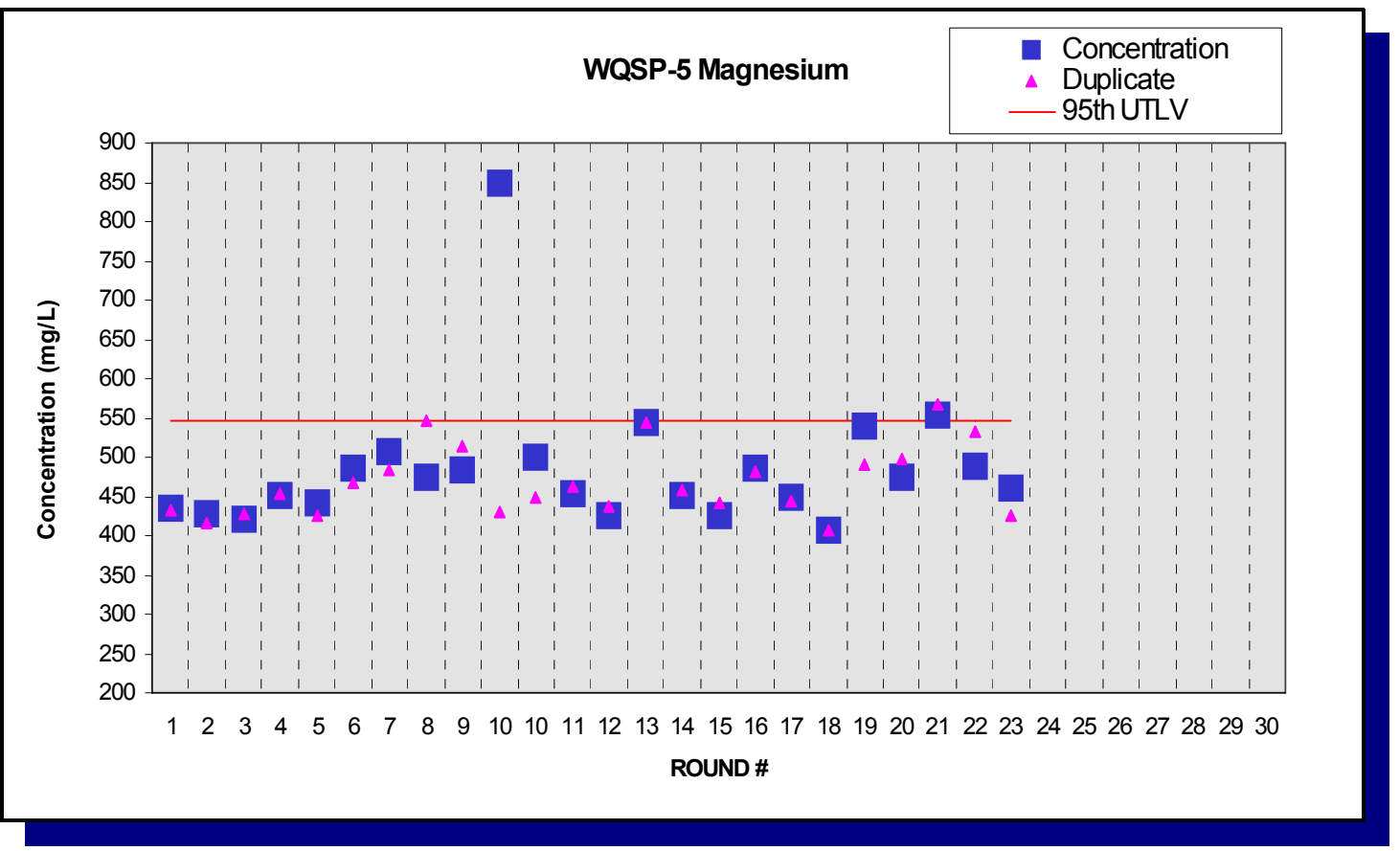

Figure E.61 - Time Trend Plot for Magnesium at WQSP-5

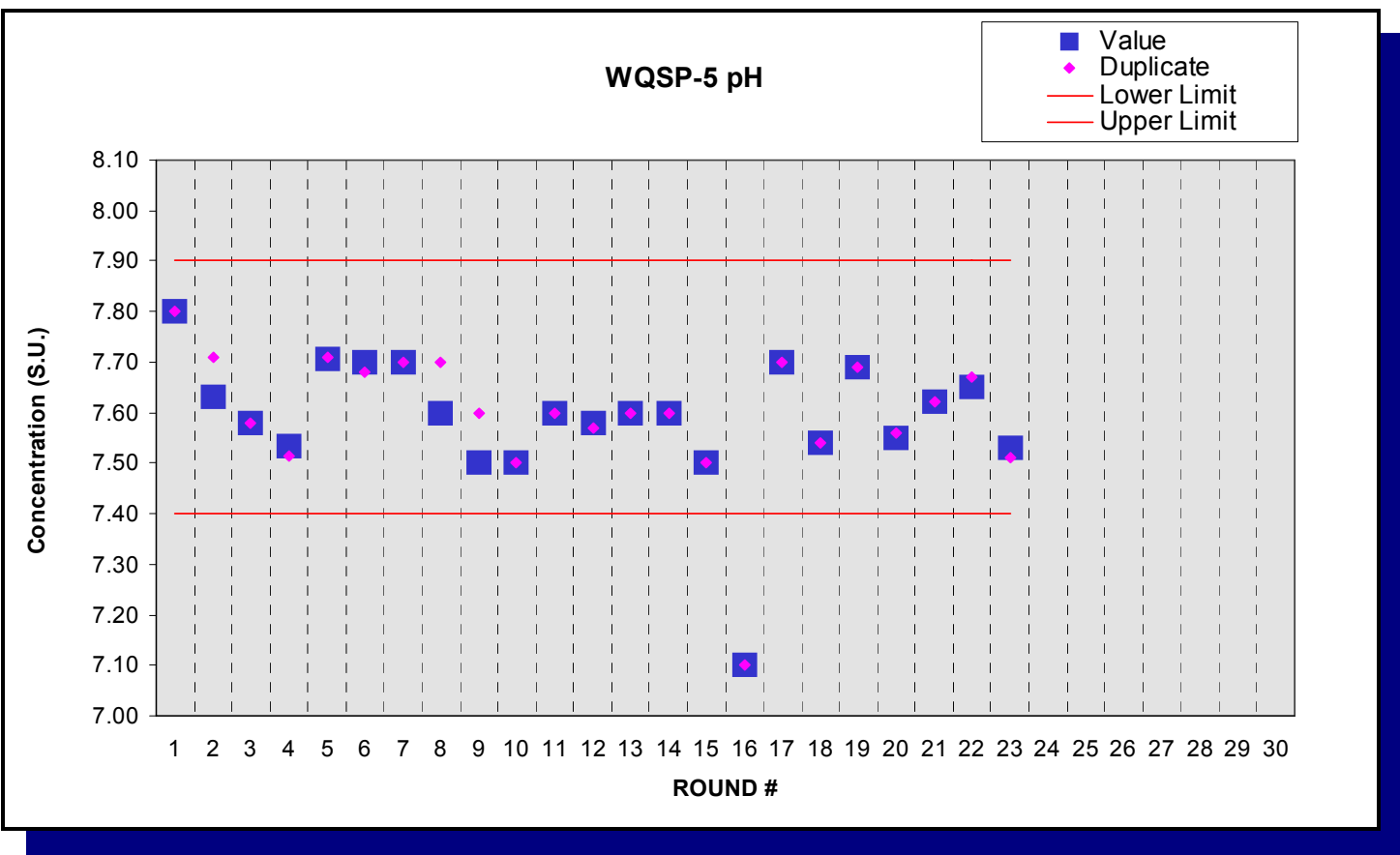

Figure E.62 - Time Trend Plot for pH at WQSP-5 


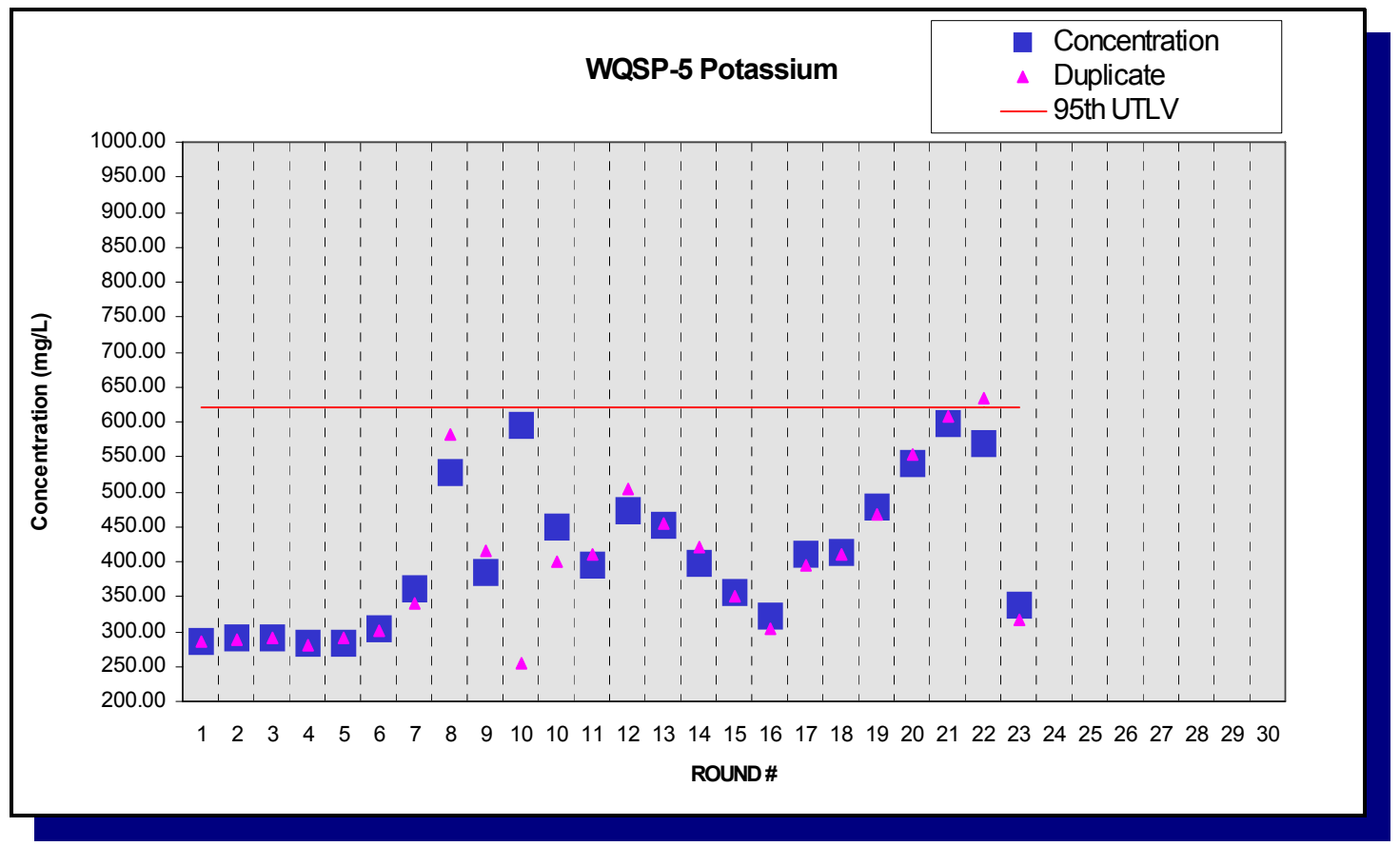

Figure E.63 - Time Trend Plots for Potassium at WQSP-5

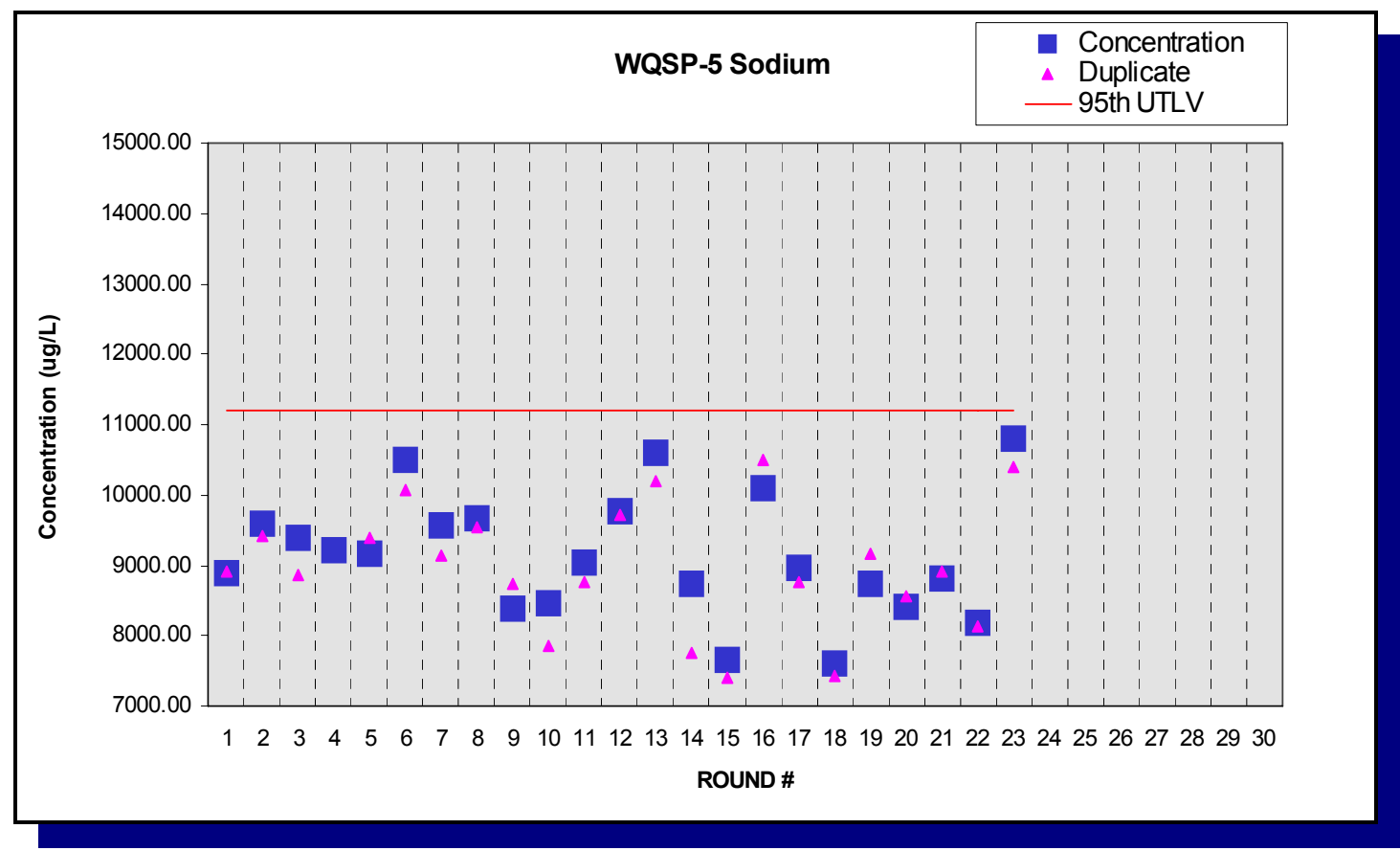

Figure E.64 - Time Trend Plots for Sodium at WQSP-5 


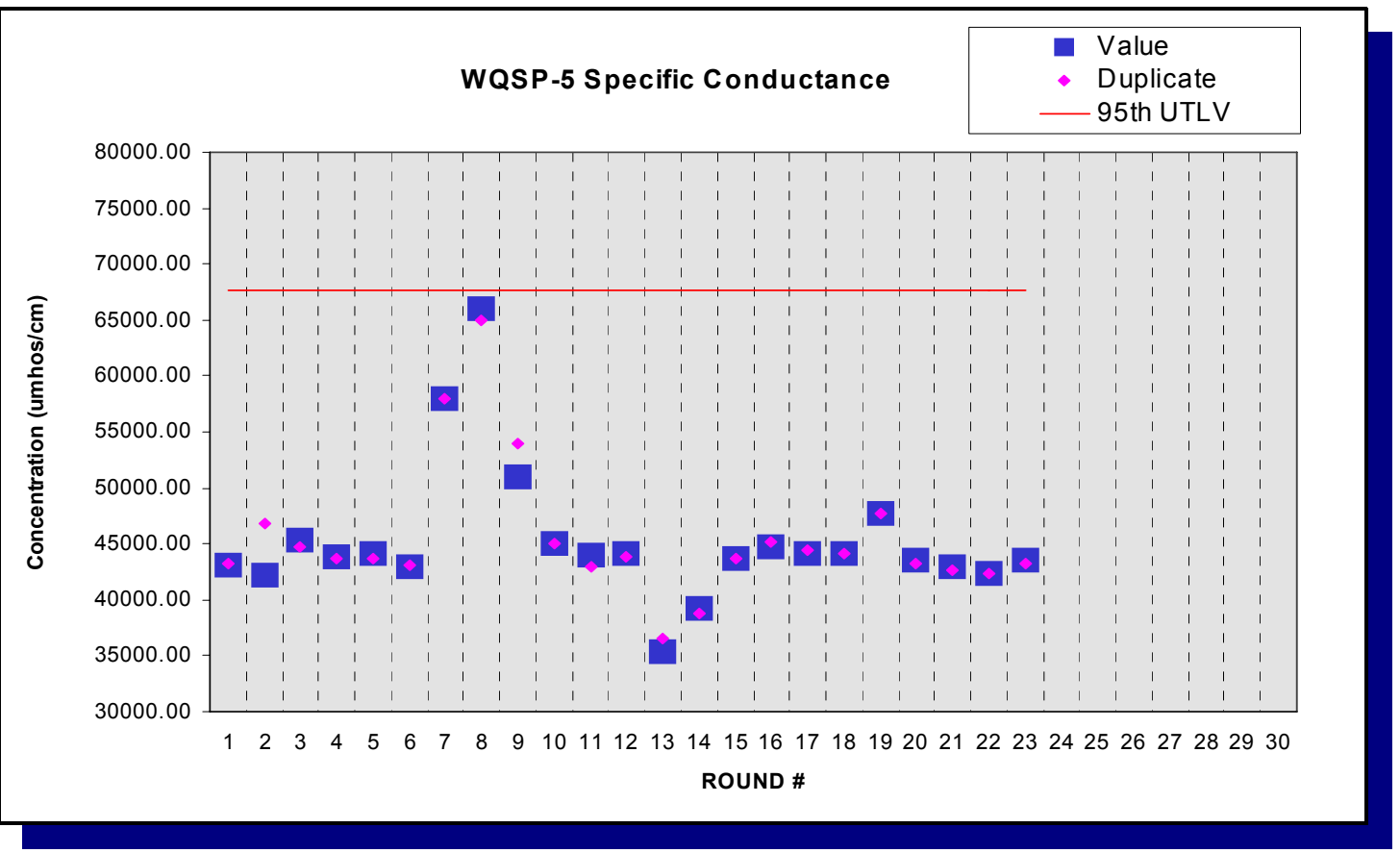

Figure E.65 - Time Trend Plot for Specific Conductance at WQSP-5

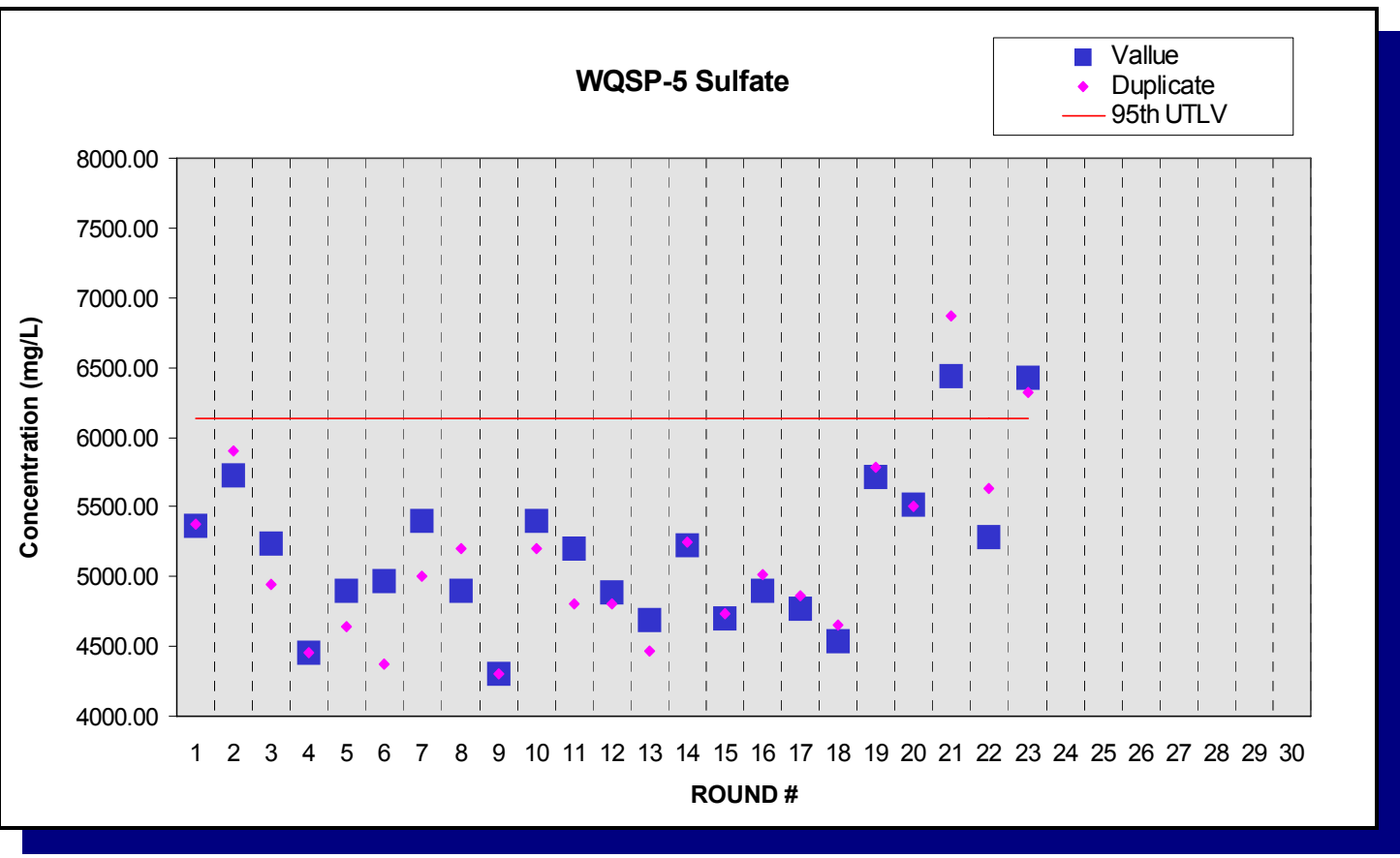

Figure E.66 - Time Trend Plot for Sulfate at WQSP-5 


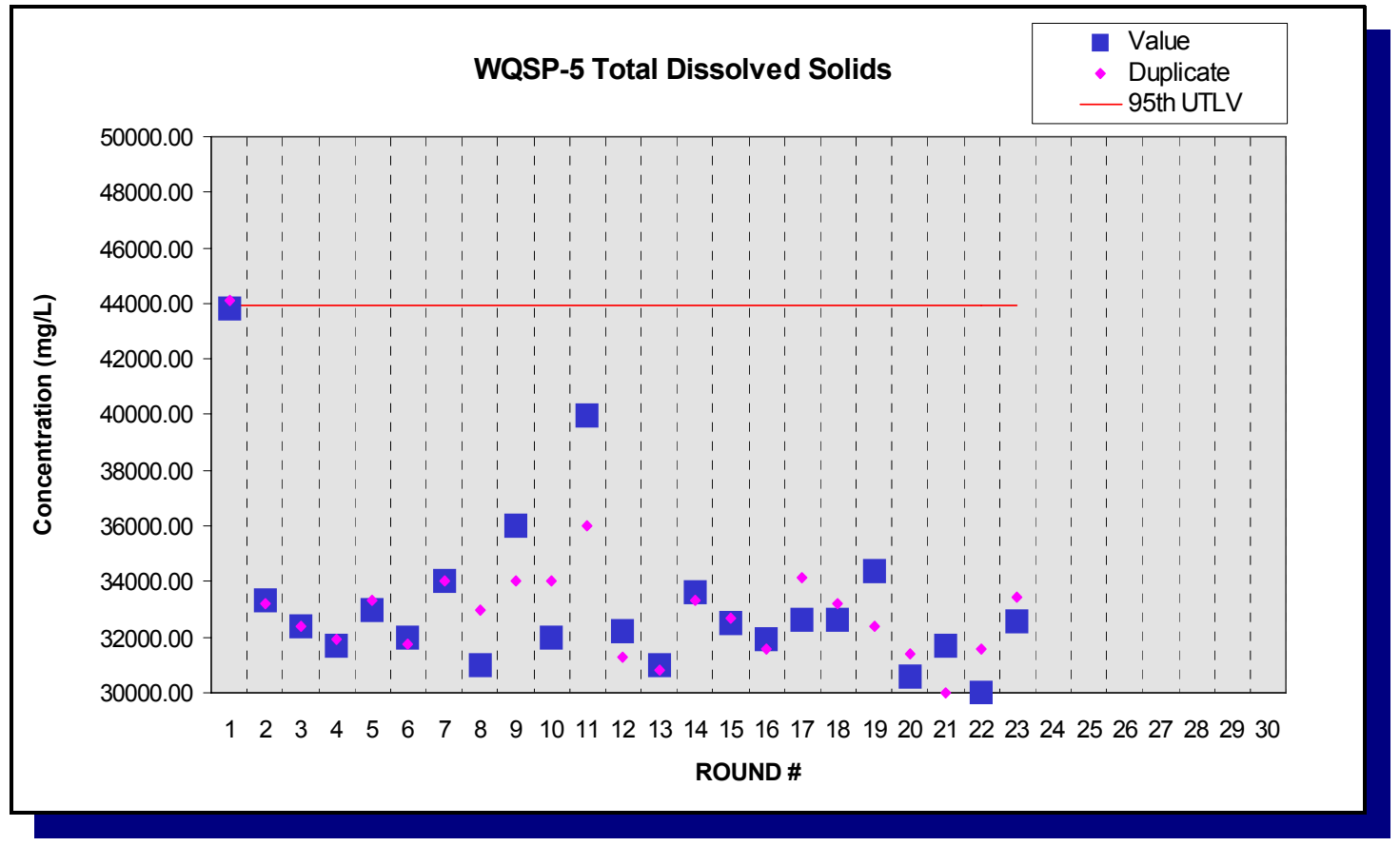

Figure E.67 - Time Trend Plot for Total Dissolved Solids at WQSP-5

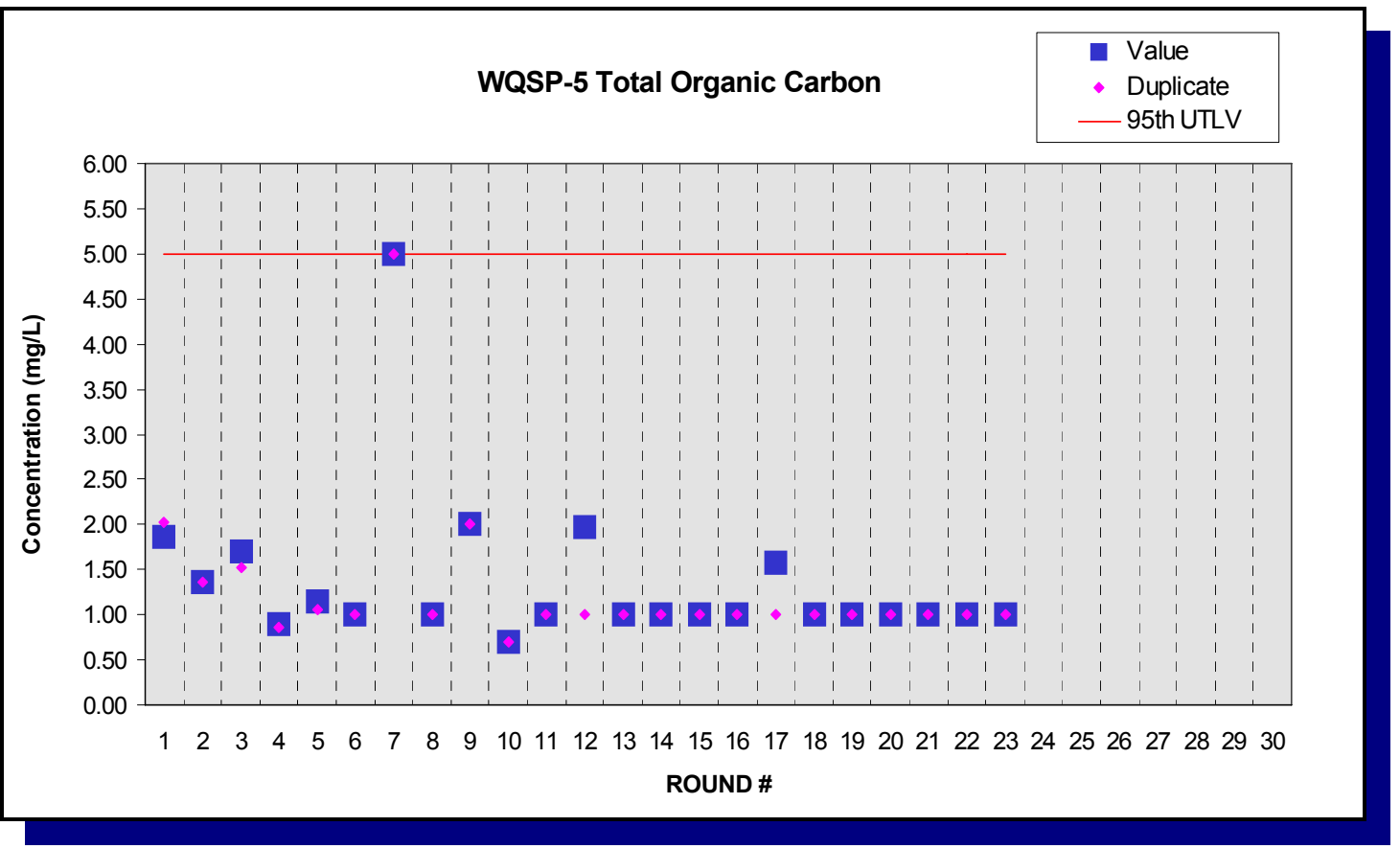

Figure E.68 - Time Trend Plot for Total Organic Carbon at WQSP-5 


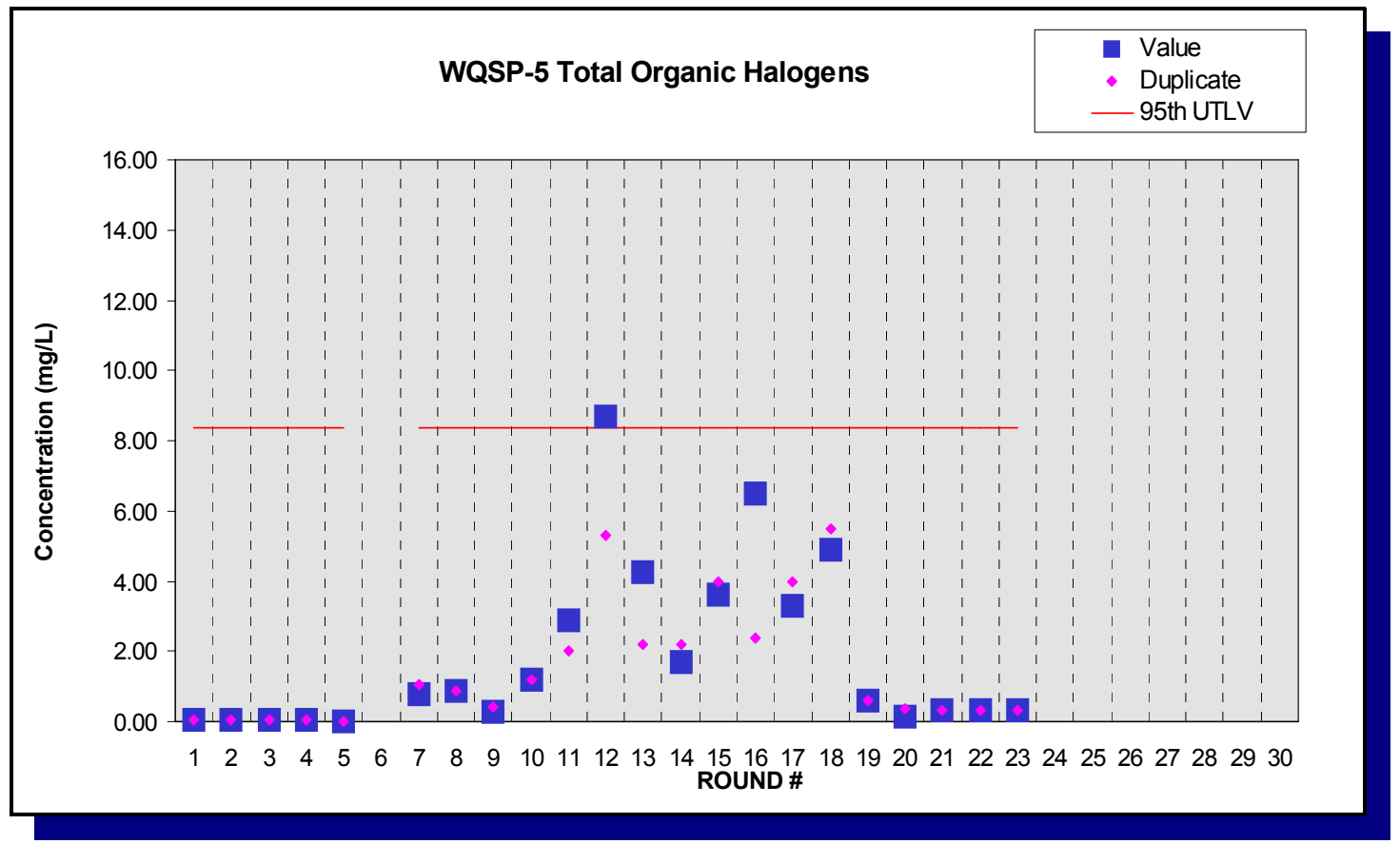

Figure E.69 - Time Trend Plot for Total Organic Halogens at WQSP-5

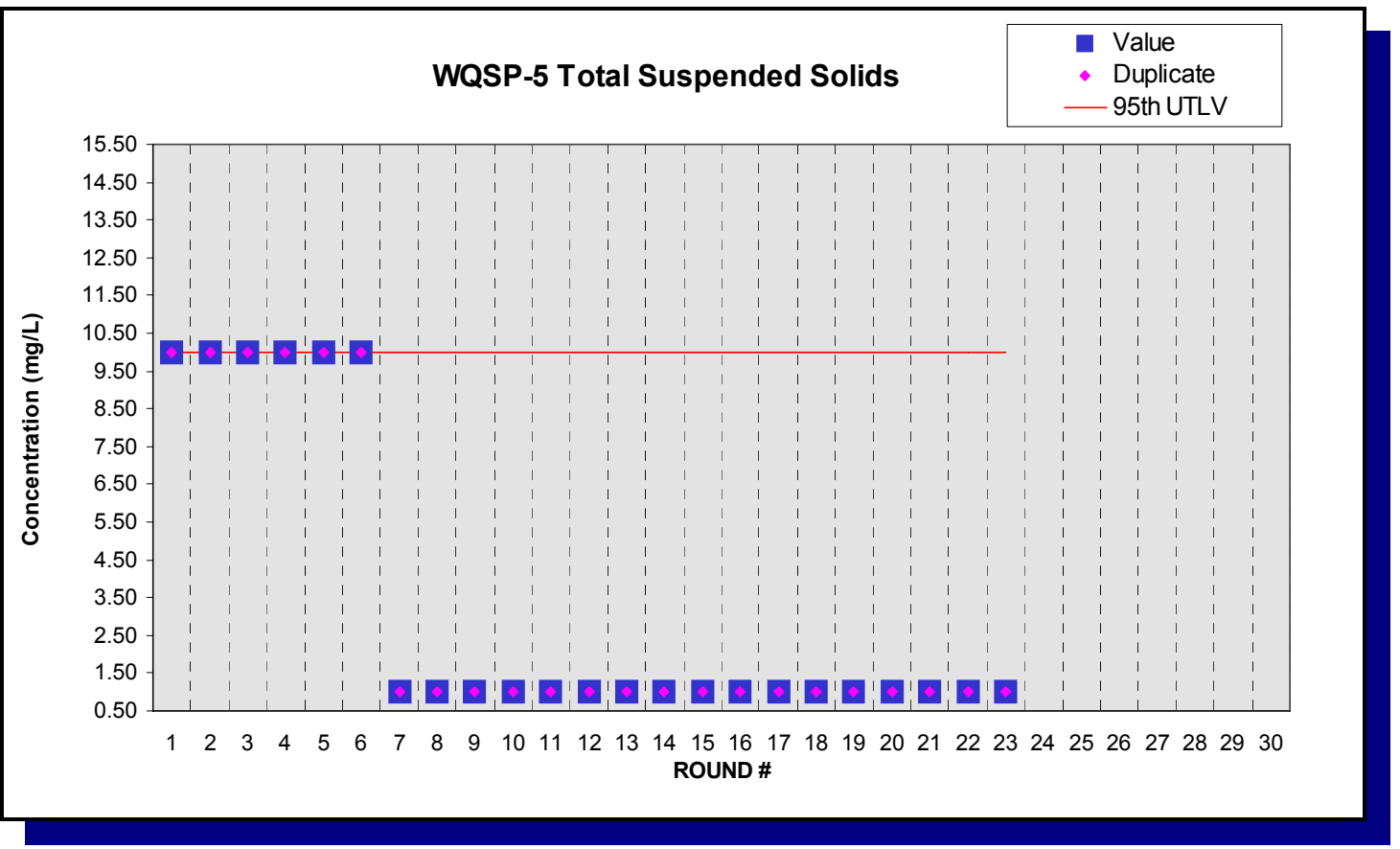

Figure E.70 - Time Trend Plot for Total Suspended Solids at WQSP-5 


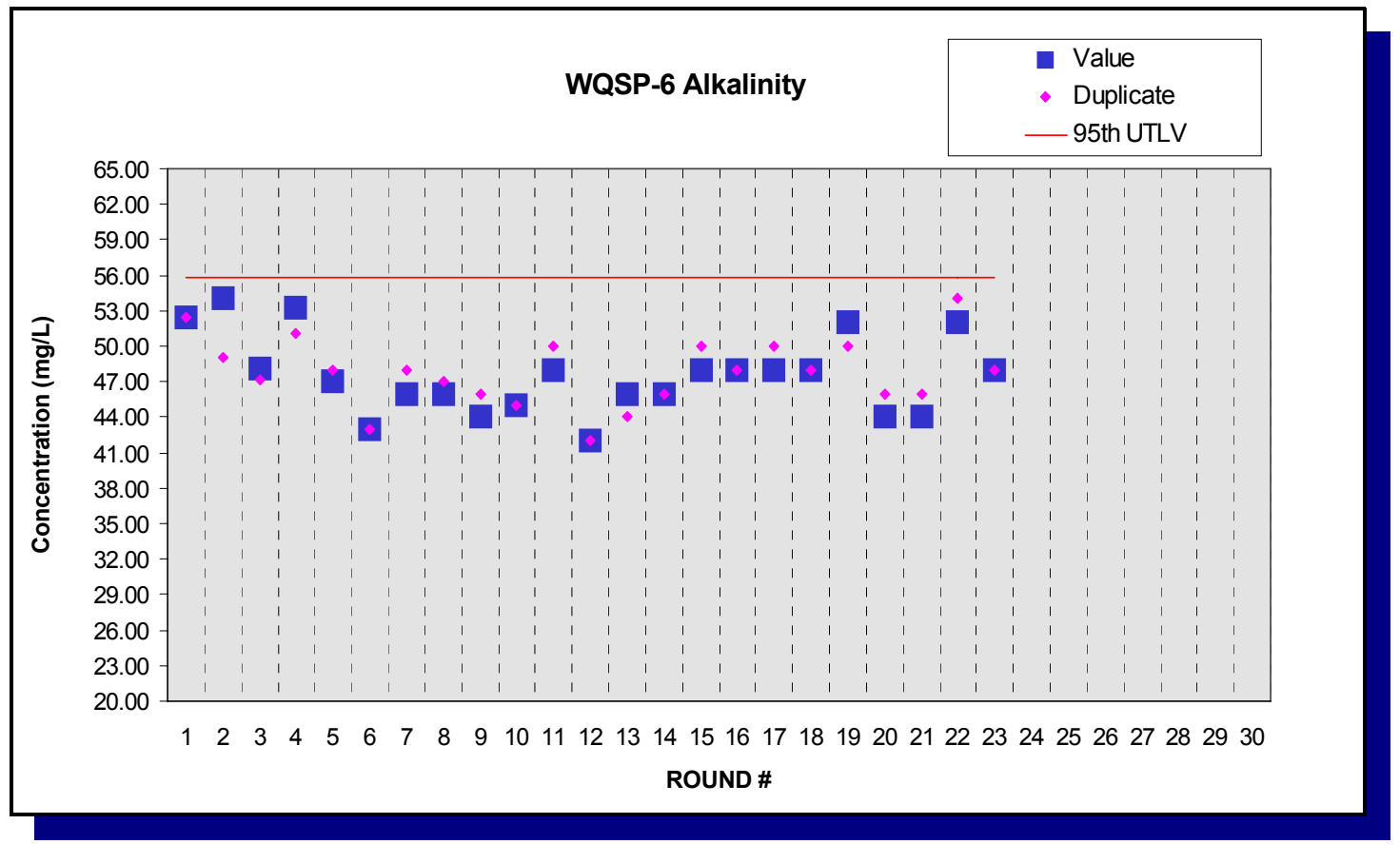

Figure E.71 - Time Trend Plot for Alkalinity at WQSP-6

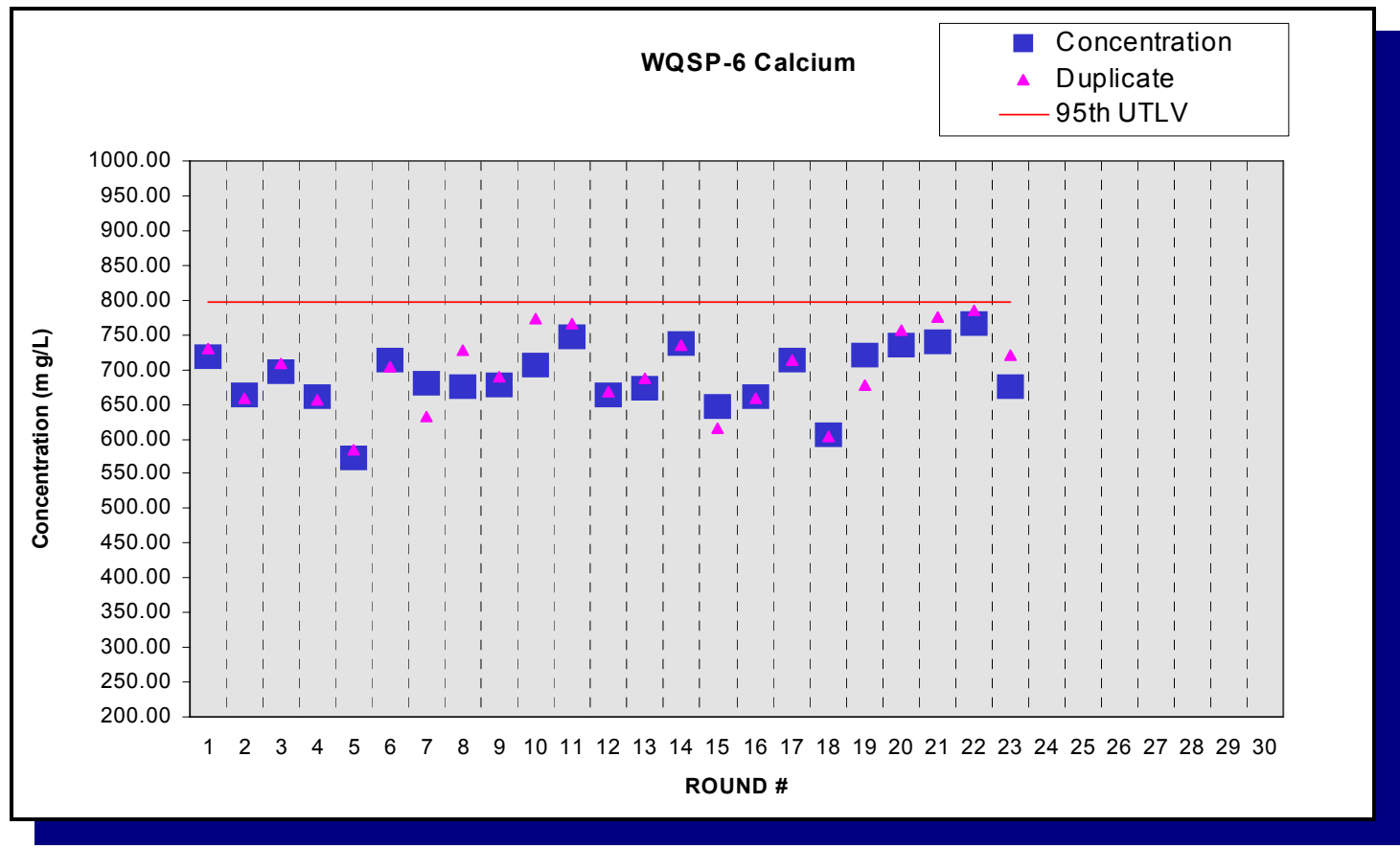

Figure E.72 - Time Trend Plot for Calcium at WQSP-6 


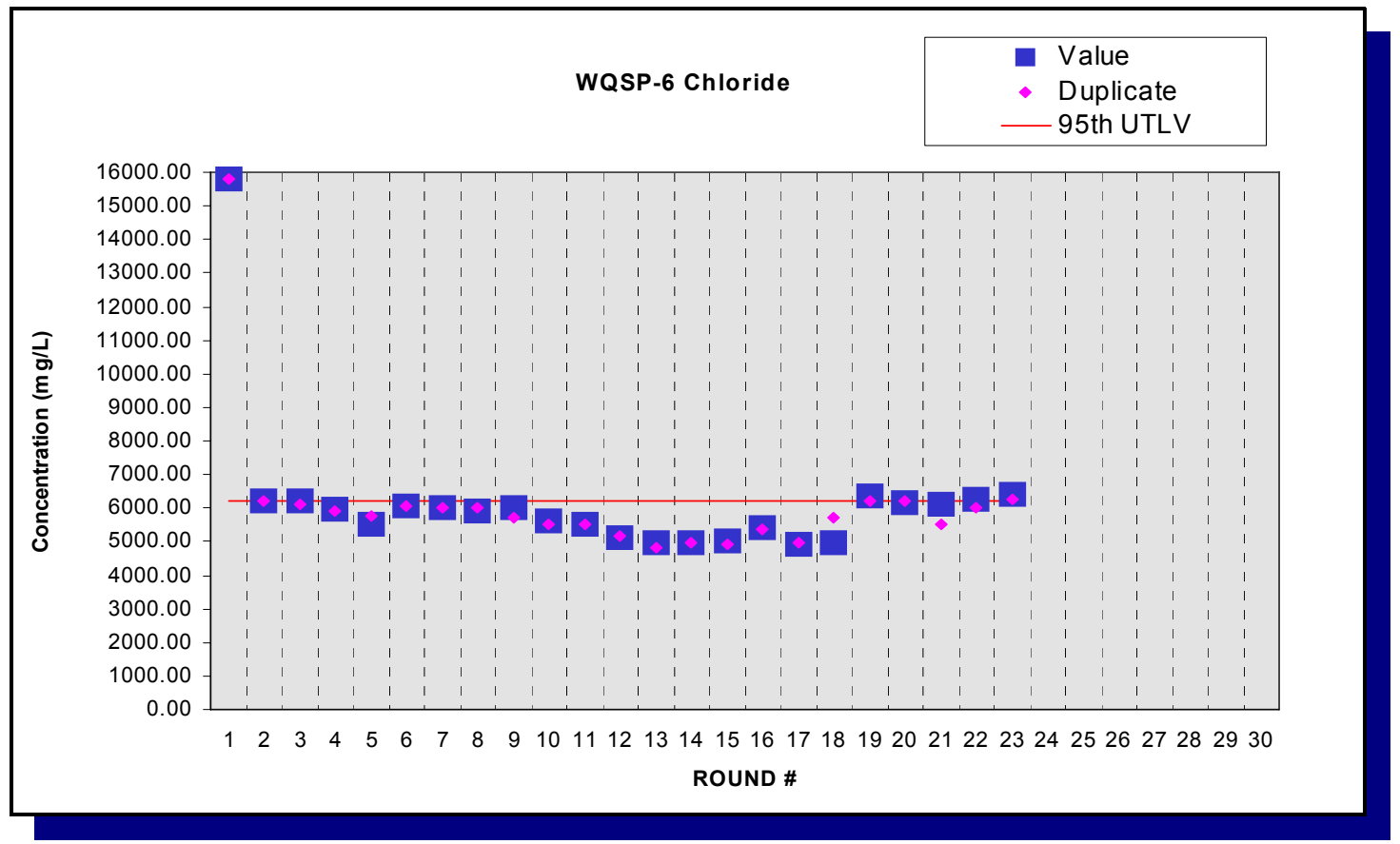

Figure E.73 - Time Trend Plot for Chloride at WQSP-6

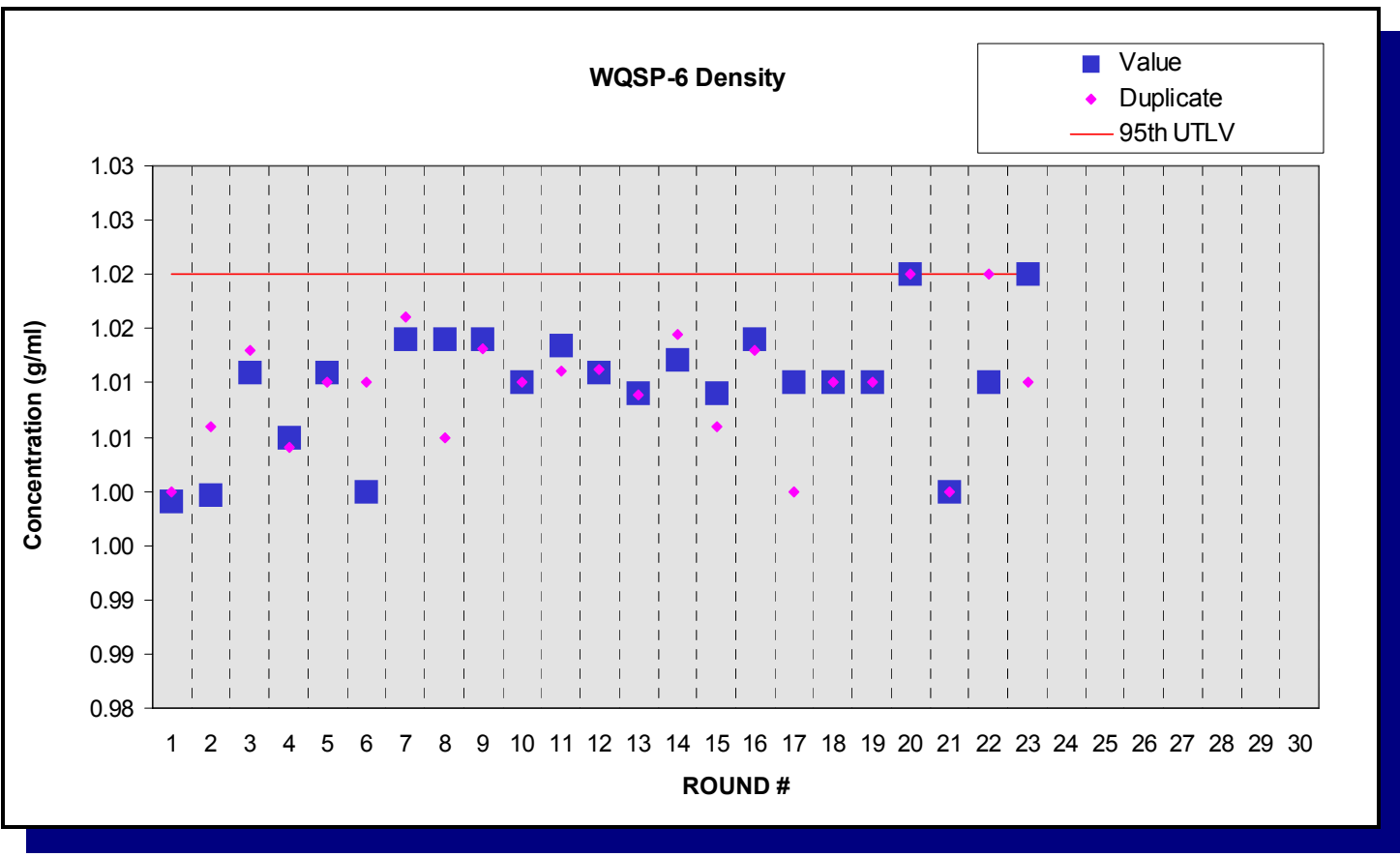

Figure E.74 - Time Trend Plot for Density at WQSP-6 


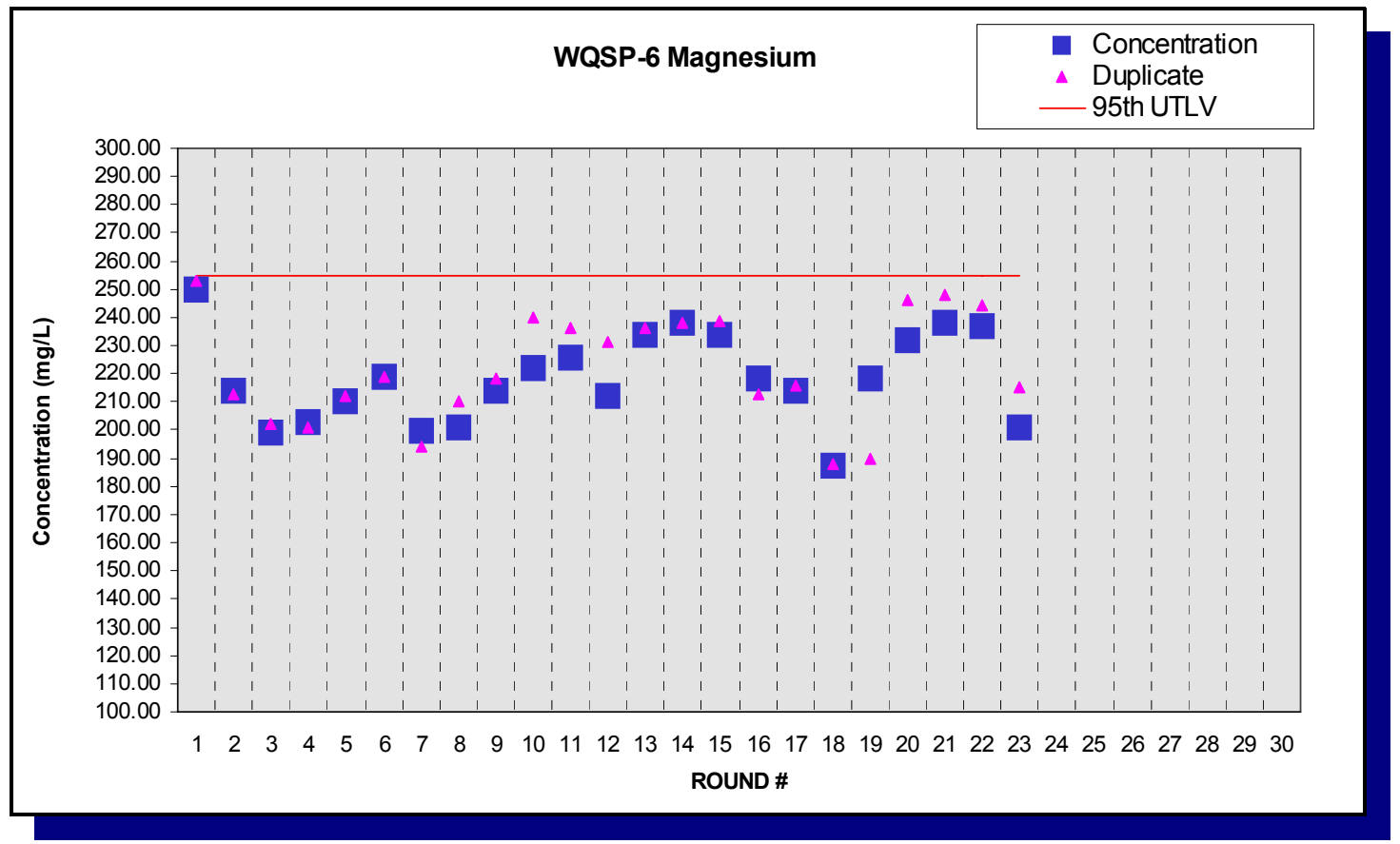

Figure E.75 - Time Trend Plot for Magnesium at WQSP-6

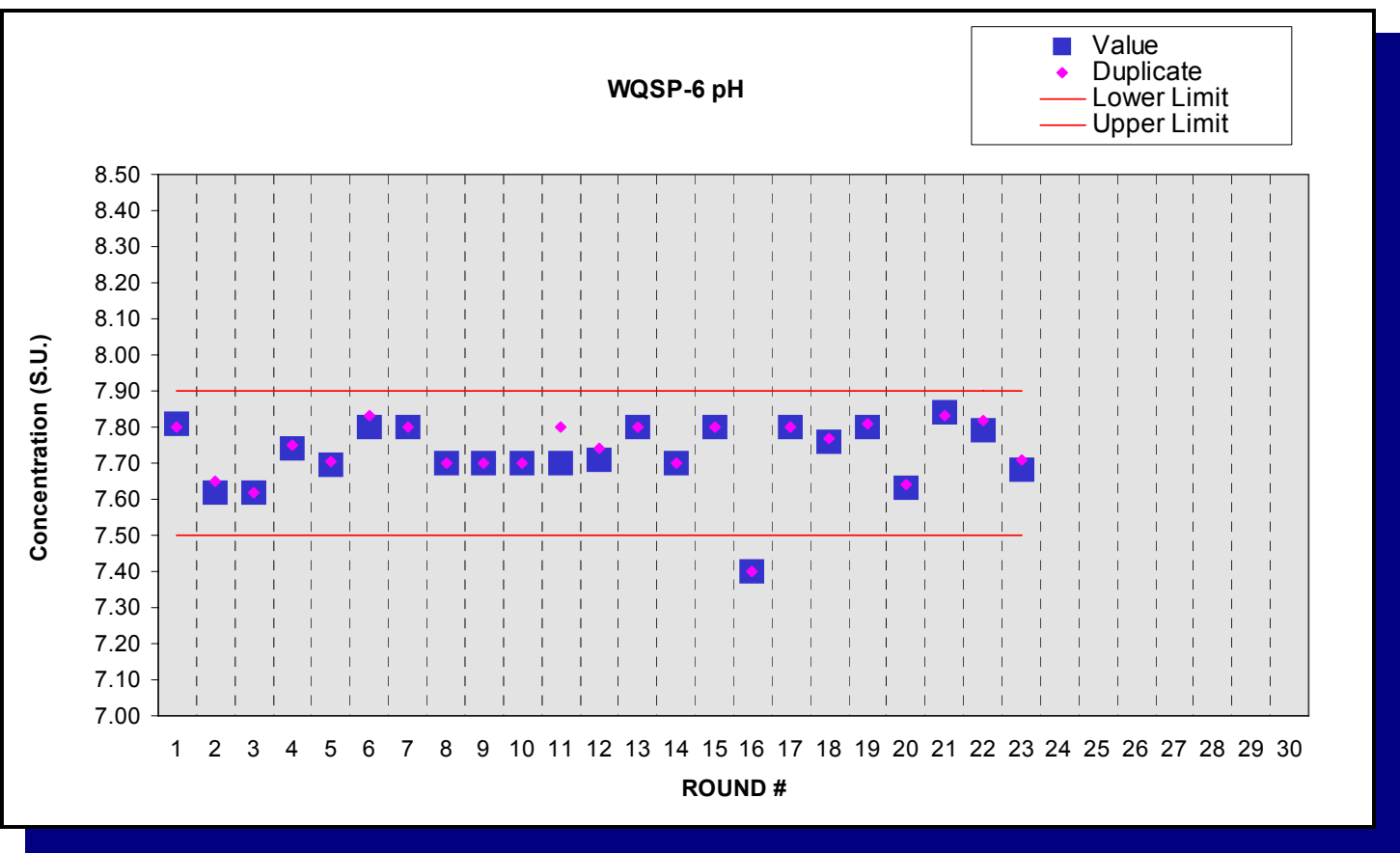

Figure E.76 - Time Trend Plot for pH at WQSP-6 


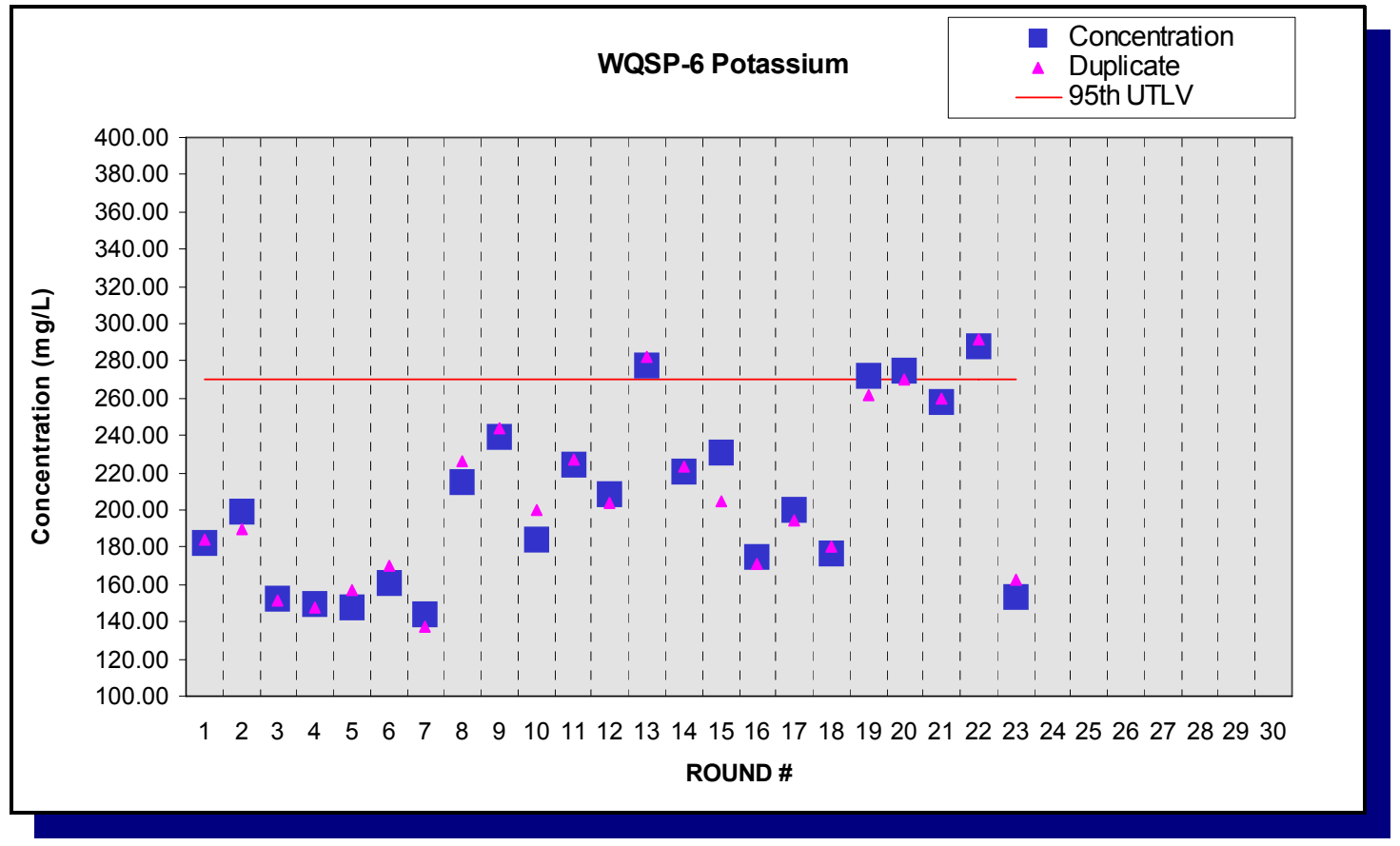

Figure E.77 - Time Trend Plot for Potassium at WQSP-6

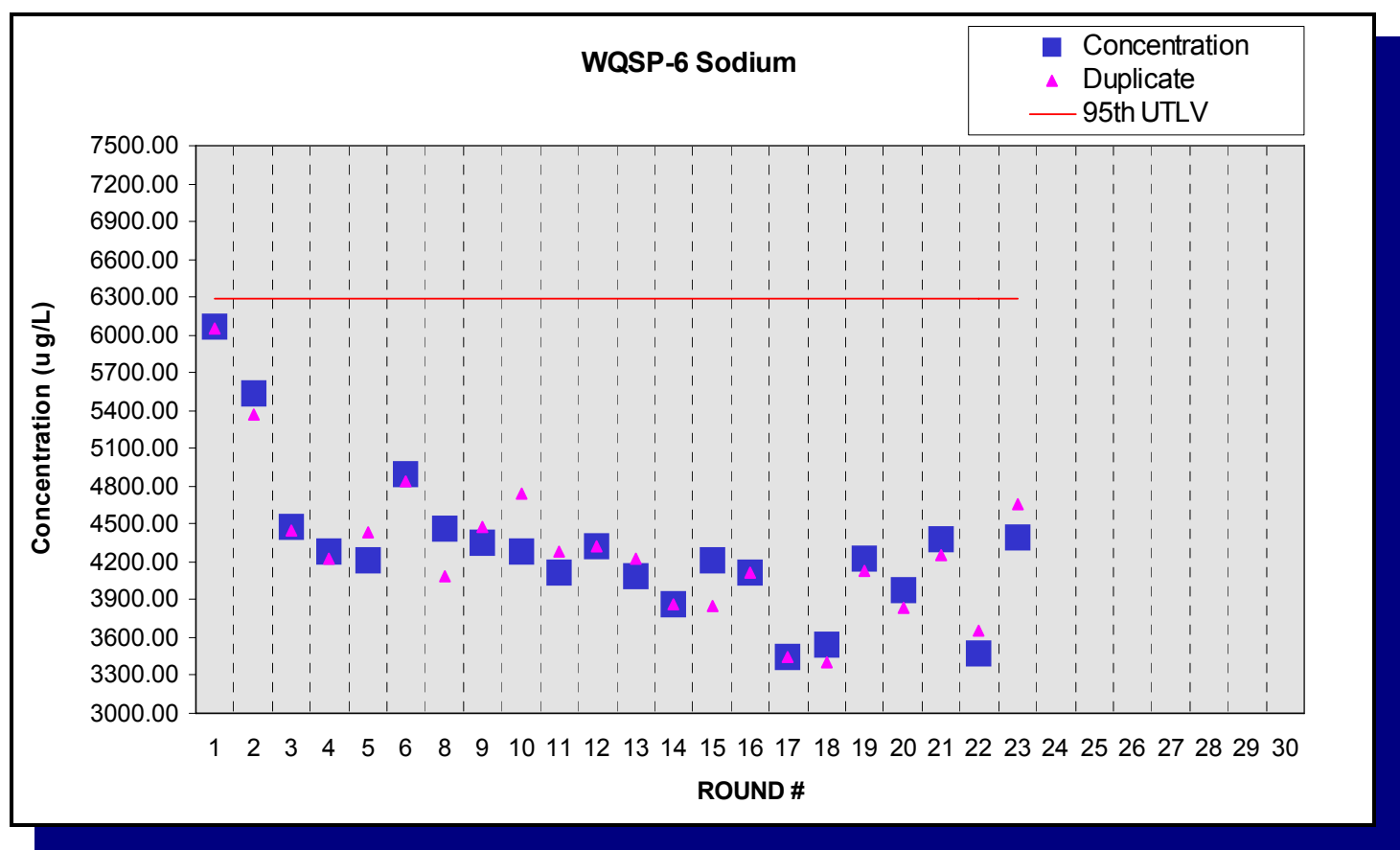

Figure E.78 - Time Trend Plot for Sodium at WQSP-6 


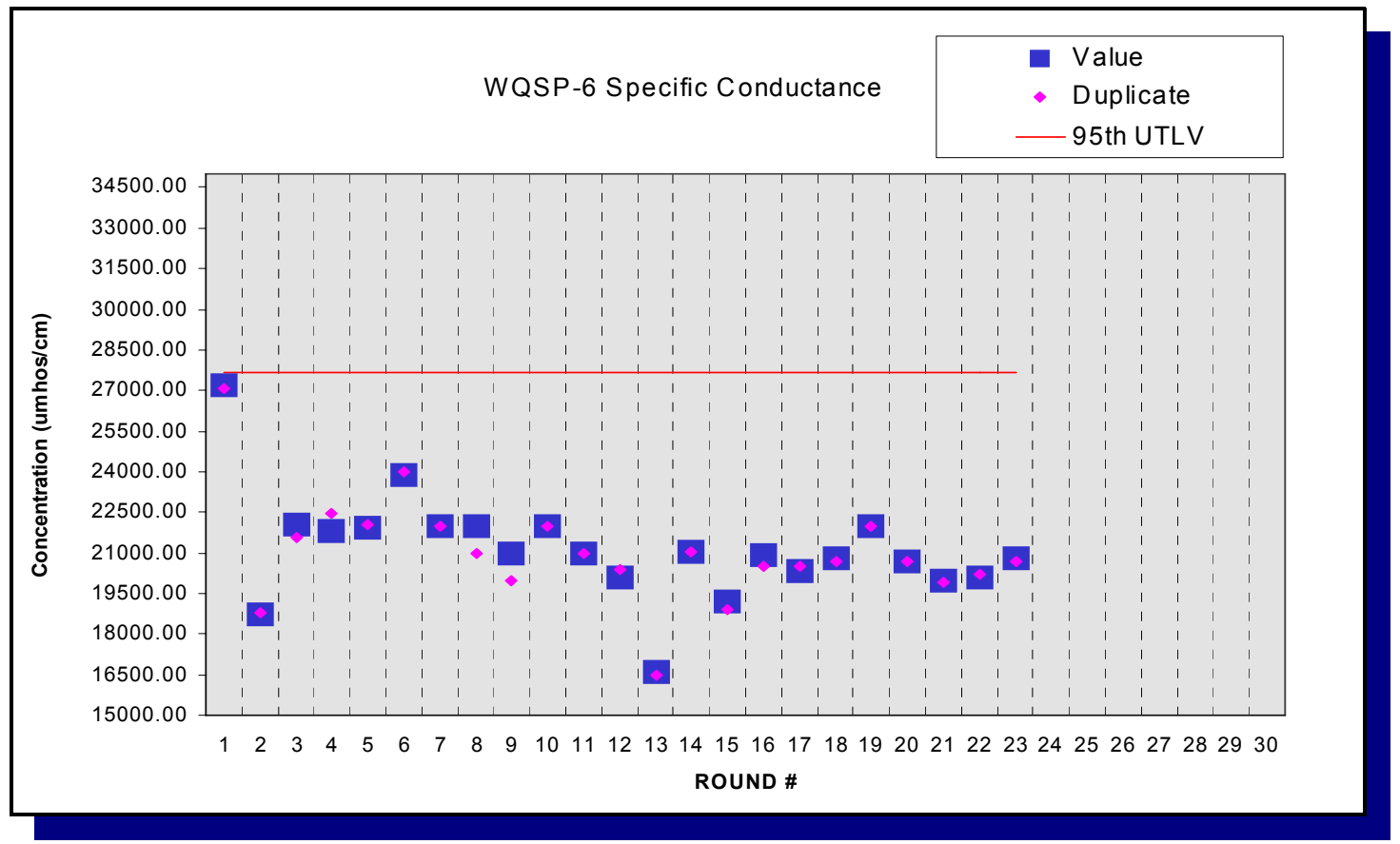

Figure E.79 - Time Trend Plot for Specific Conductance at WQSP-6

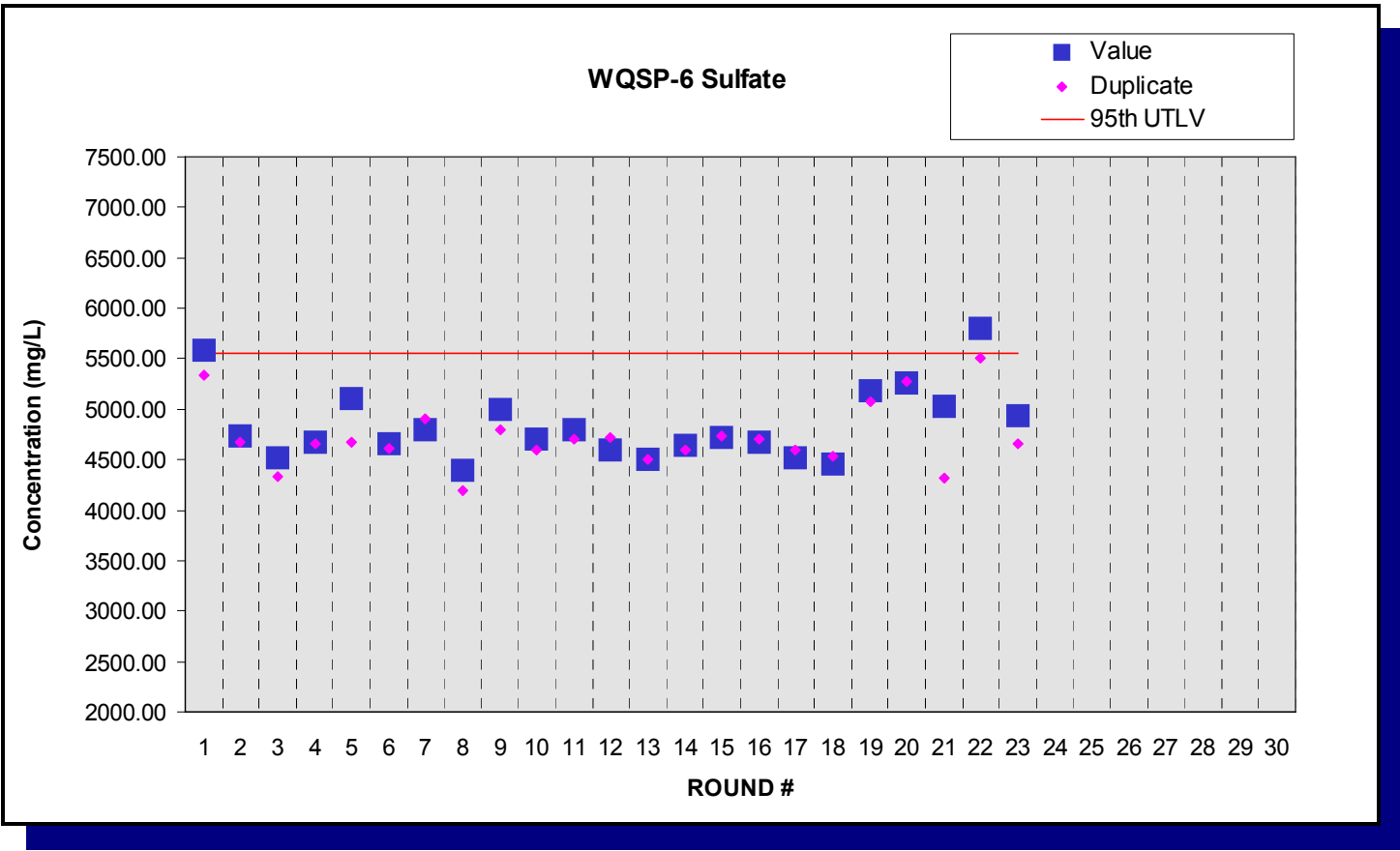

Figure E.80 - Time Trend Plot for Sulfate in WQSP-6 


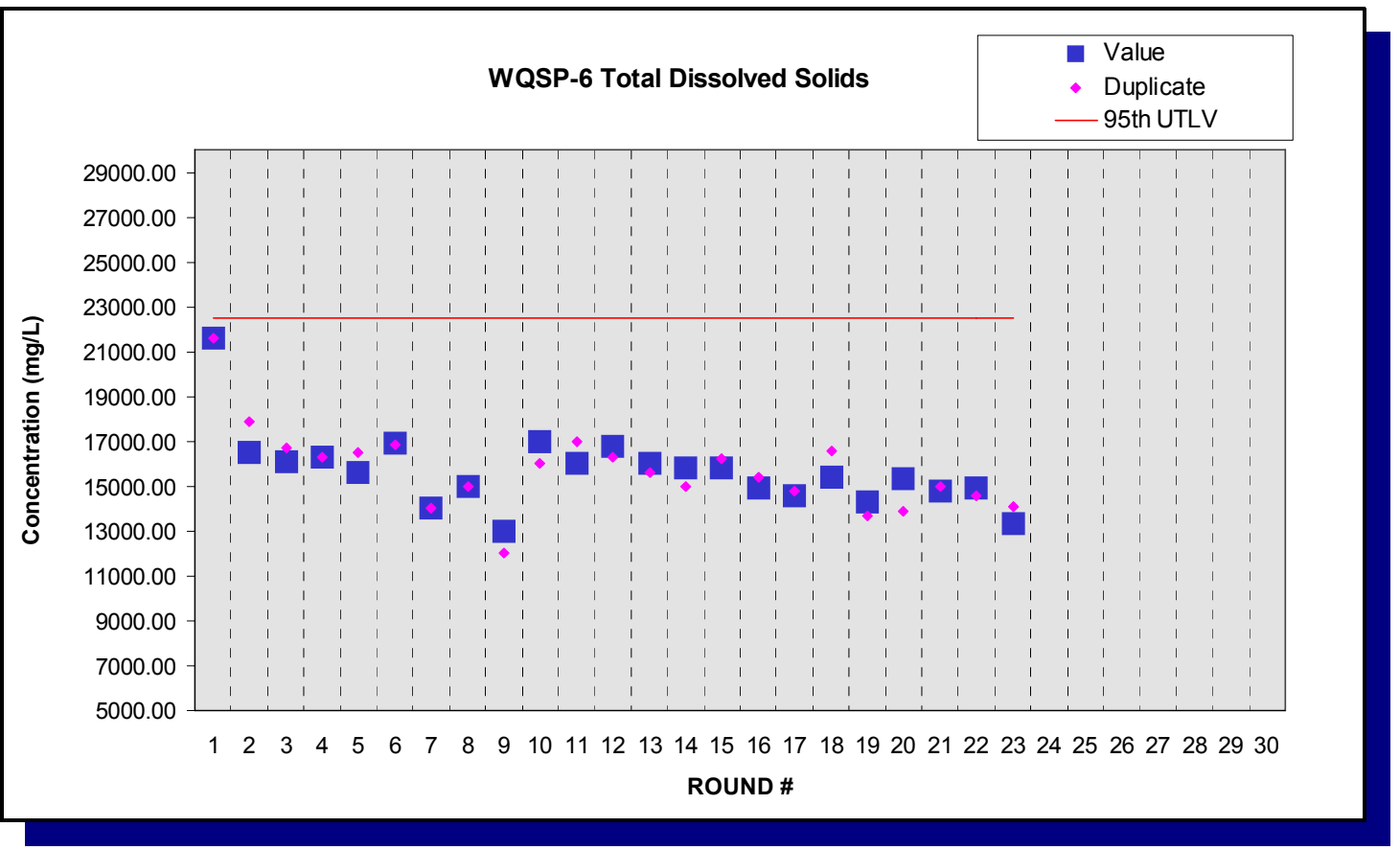

Figure E.81 - Time Trend Plot for Total Dissolved Solids in WQSP-6

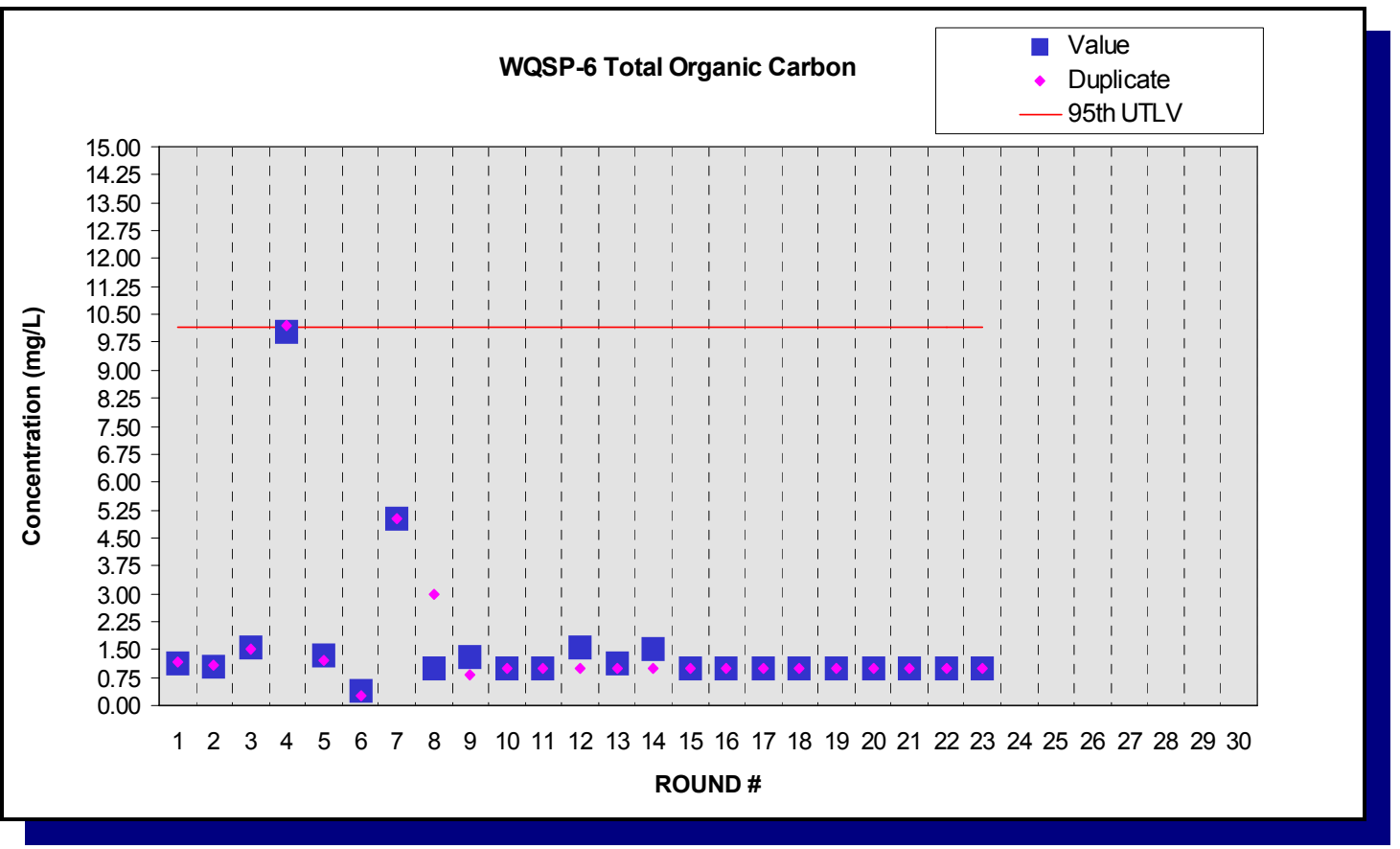

Figure E.82 - Time Trend Plot for Total Organic Carbon in WQSP-6 


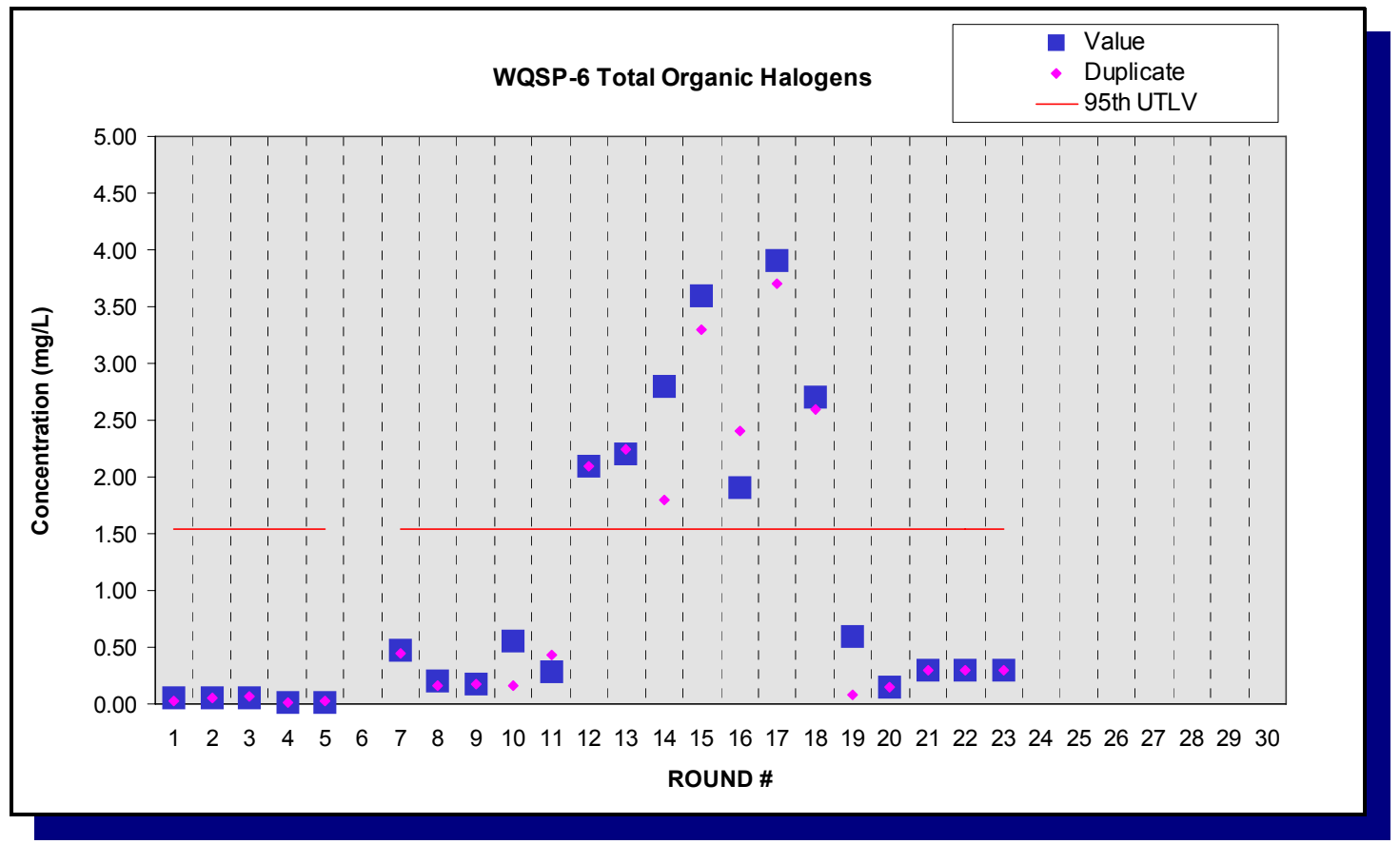

Figure E.83 - Time Trend Plot for Total Organic Halogens at WQSP-6

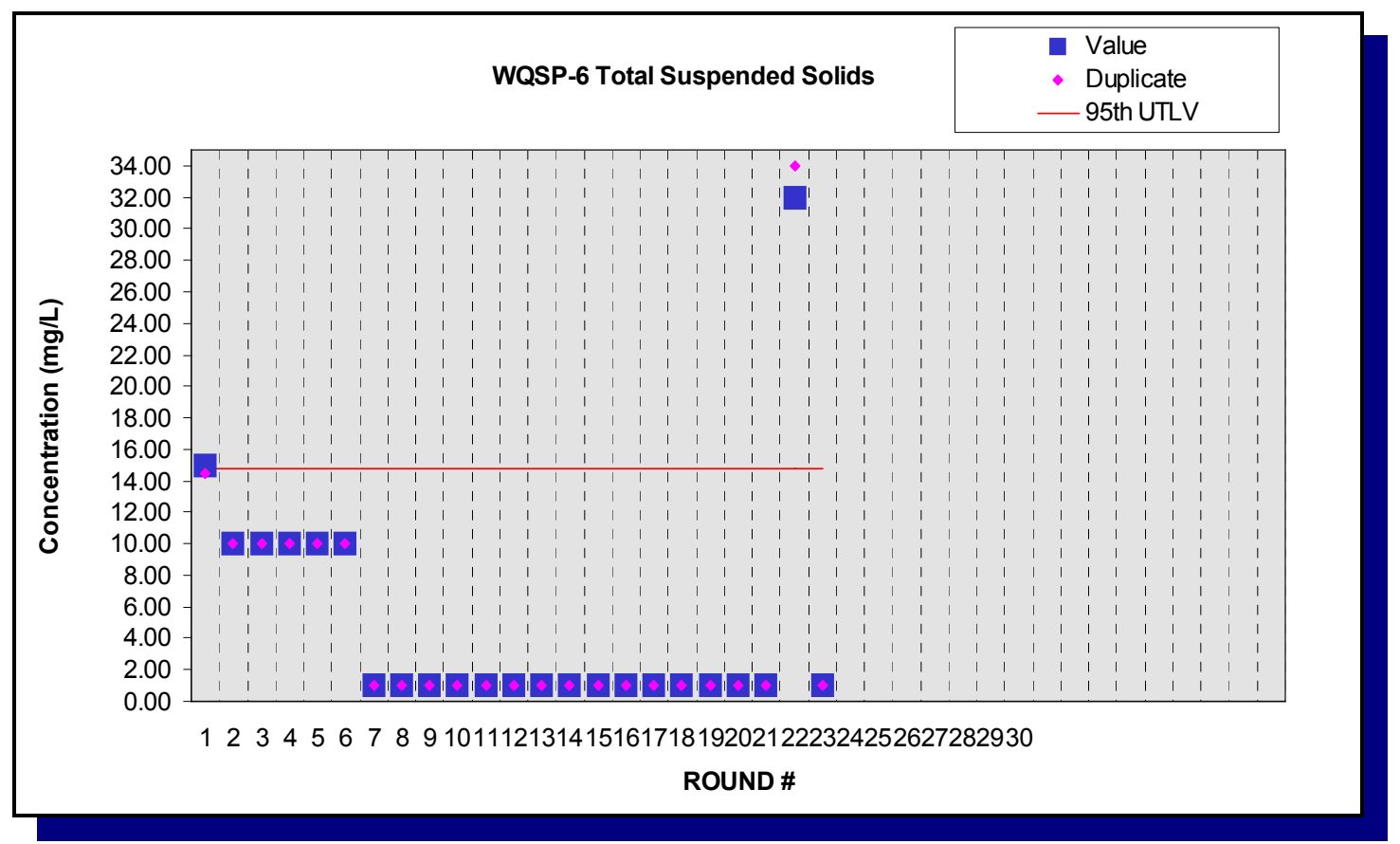

Figure E.84 - Time Trend Plot for Total Suspended Solids in WQSP-6 


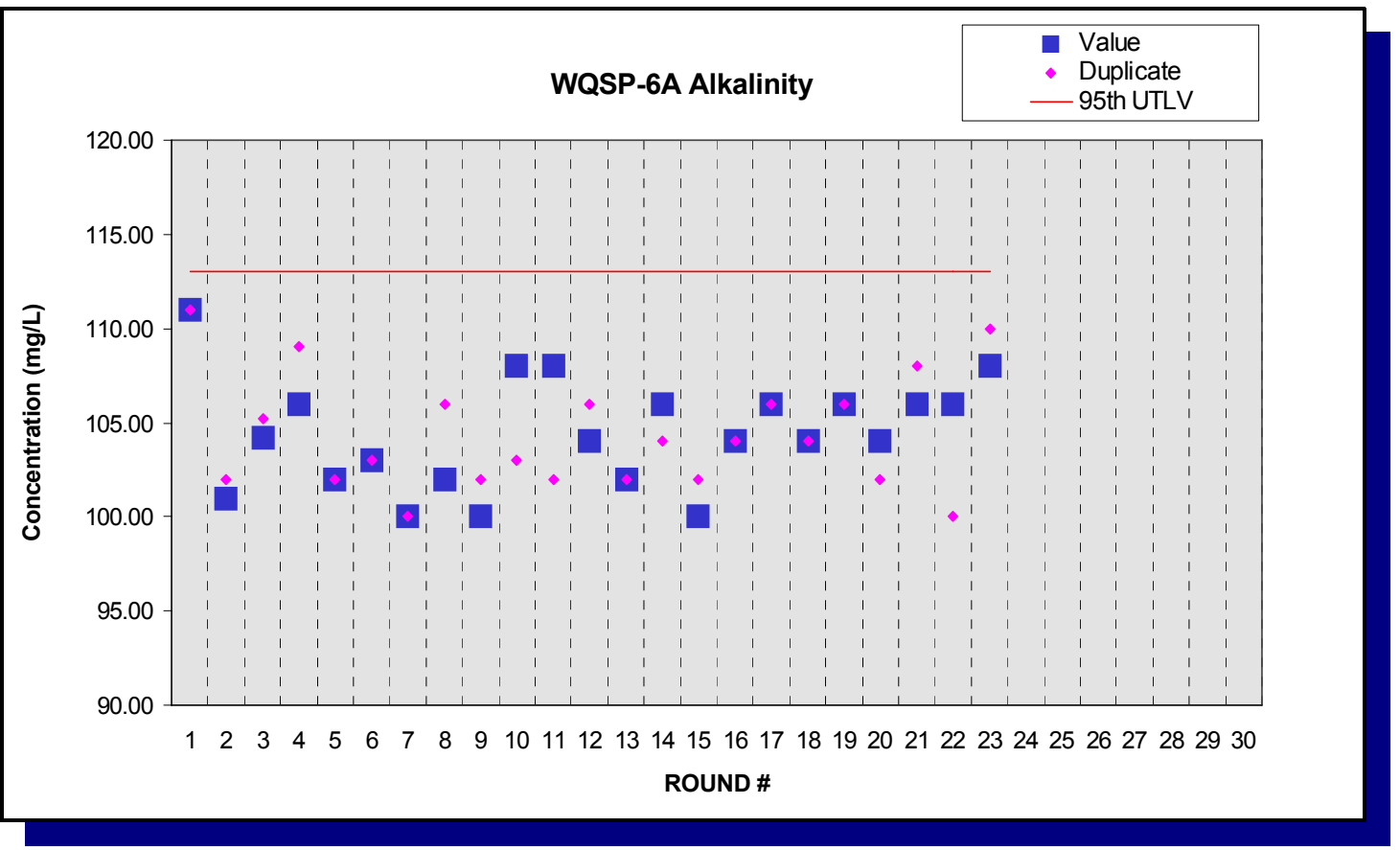

Figure E.85 - Time Trend Plot for Alkalinity at WQSP-6A

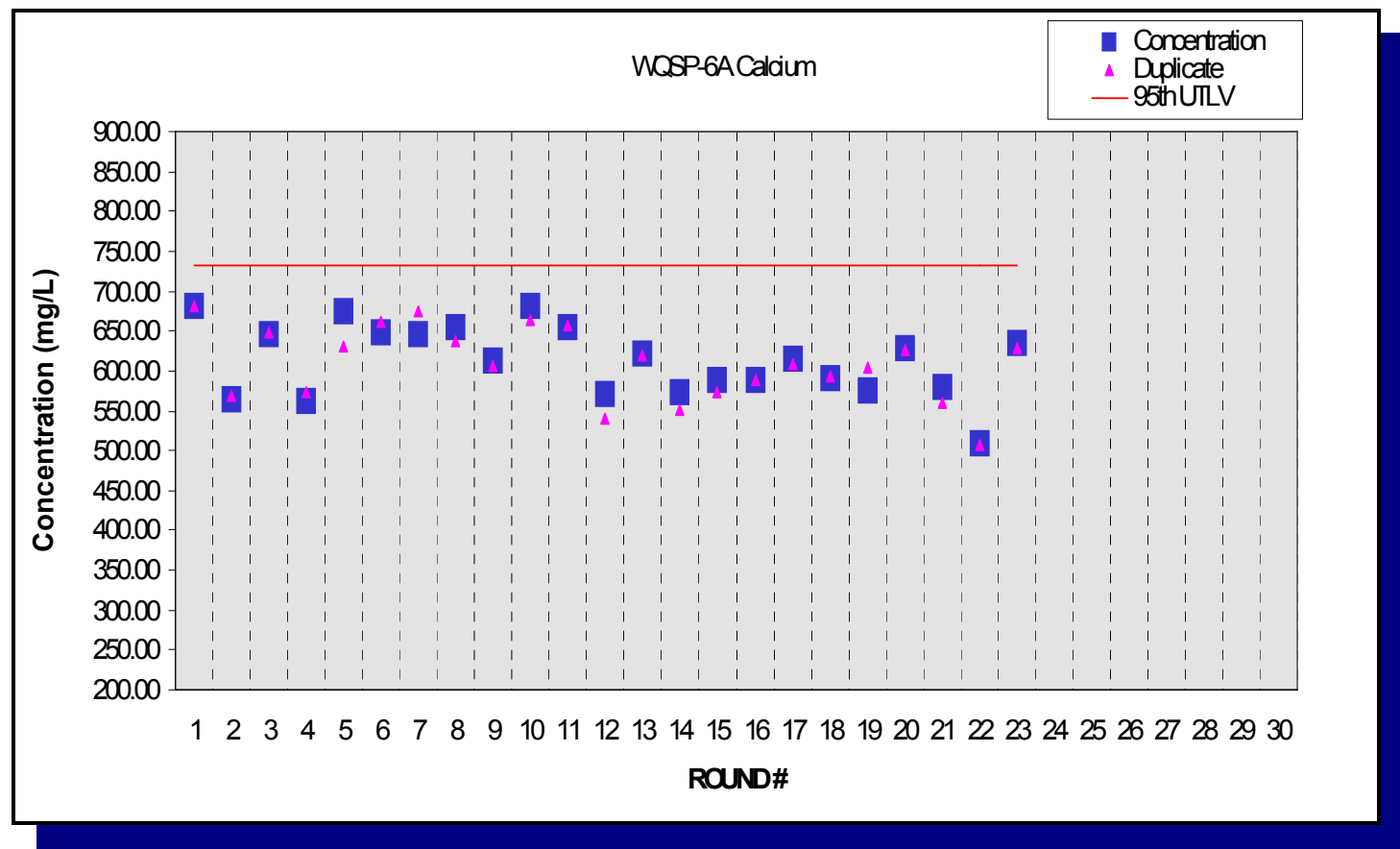

Figure E.86 - Time Trend Plot for Calcium at WQSP-6A 


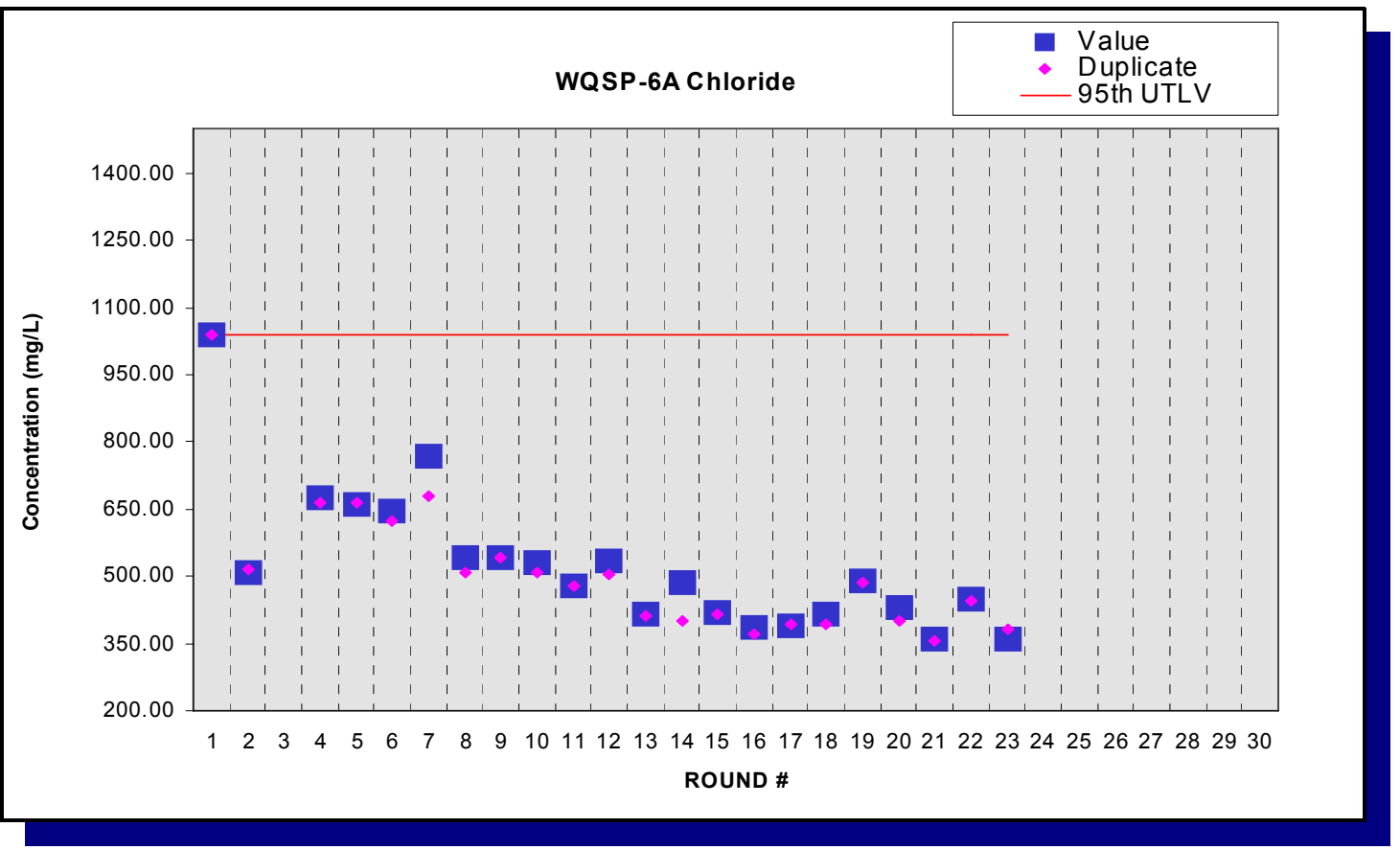

Figure E.87 - Time Trend Plot for Chloride at WQSP-6A

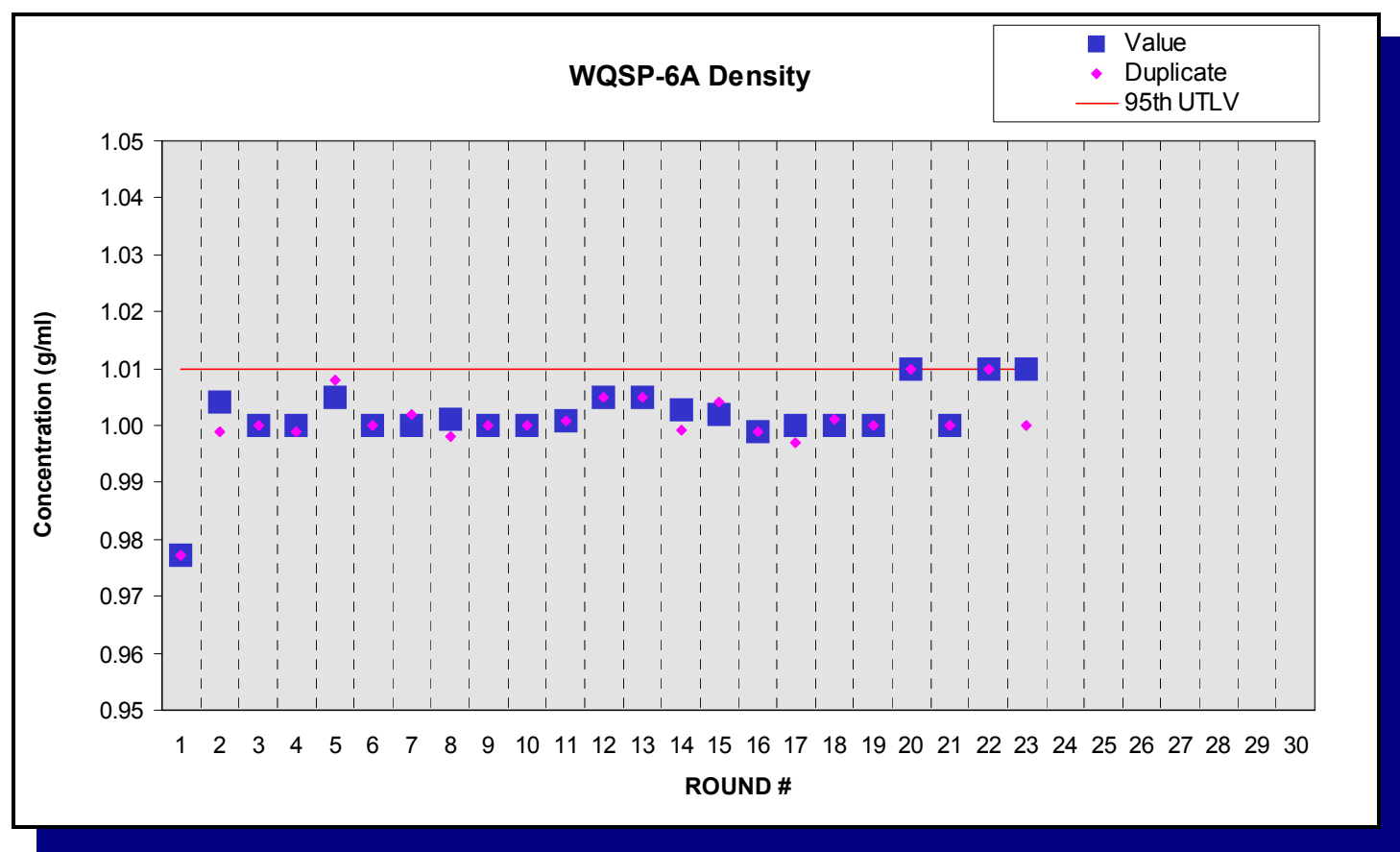

Figure E.88 - Time Trend Plot for Density at WQSP-6A 


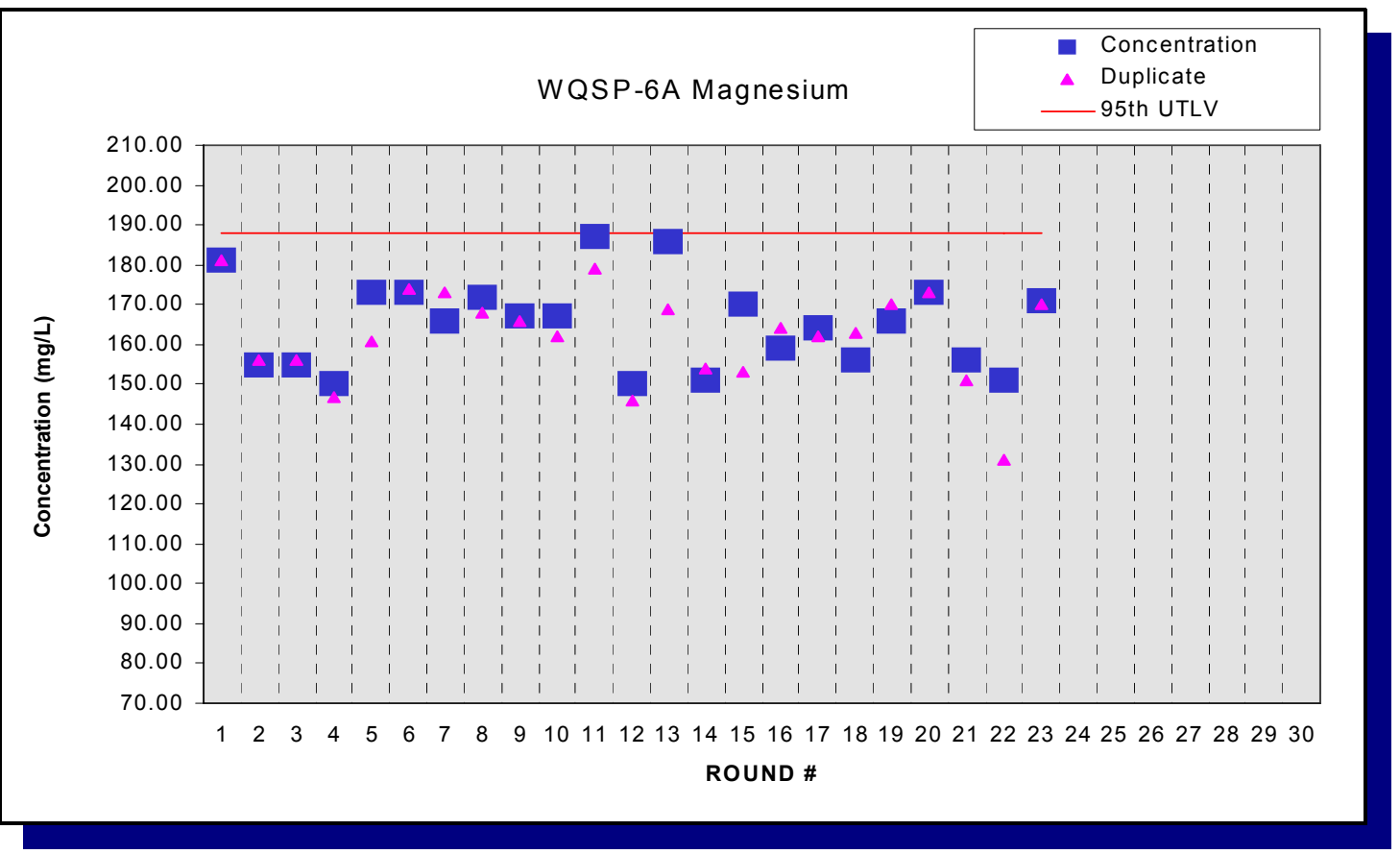

Figure E.89 - Time Trend Plot for Magnesium at WQSP-6A

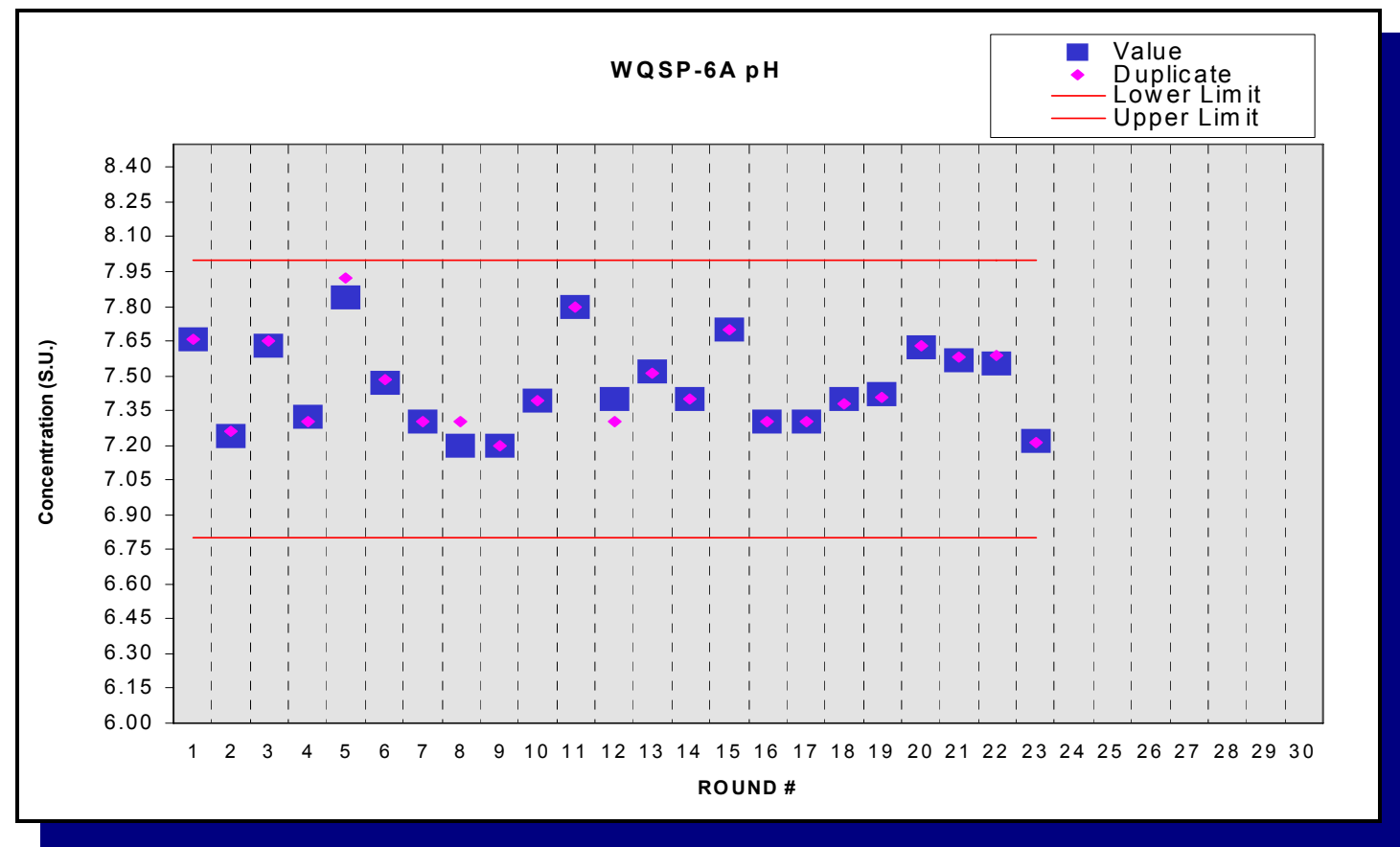

Figure E.90 - Time Trend Plot for pH at WQSP-6A 


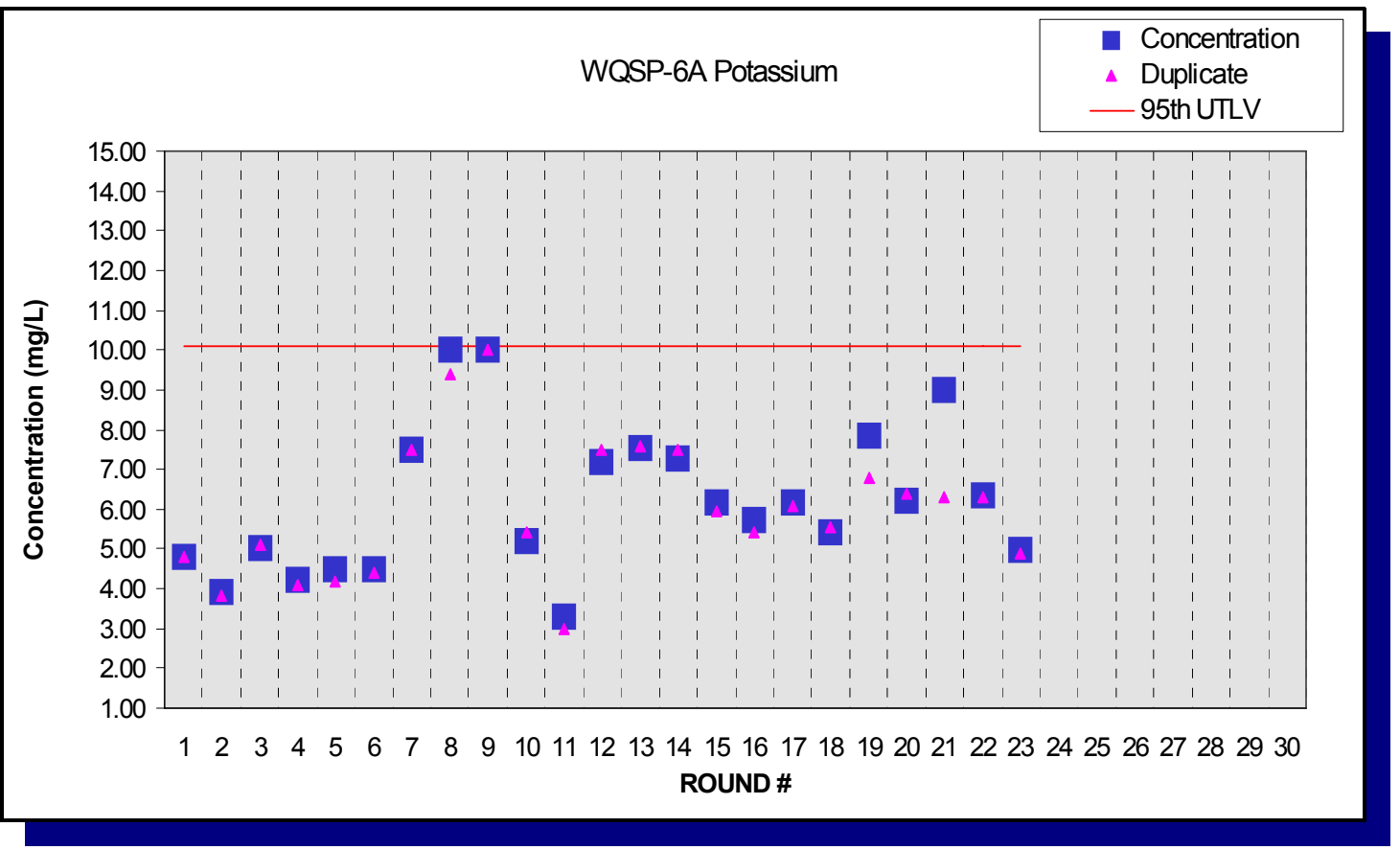

Figure E.91 - Time Trend Plot for Potassium at WQSP-6A

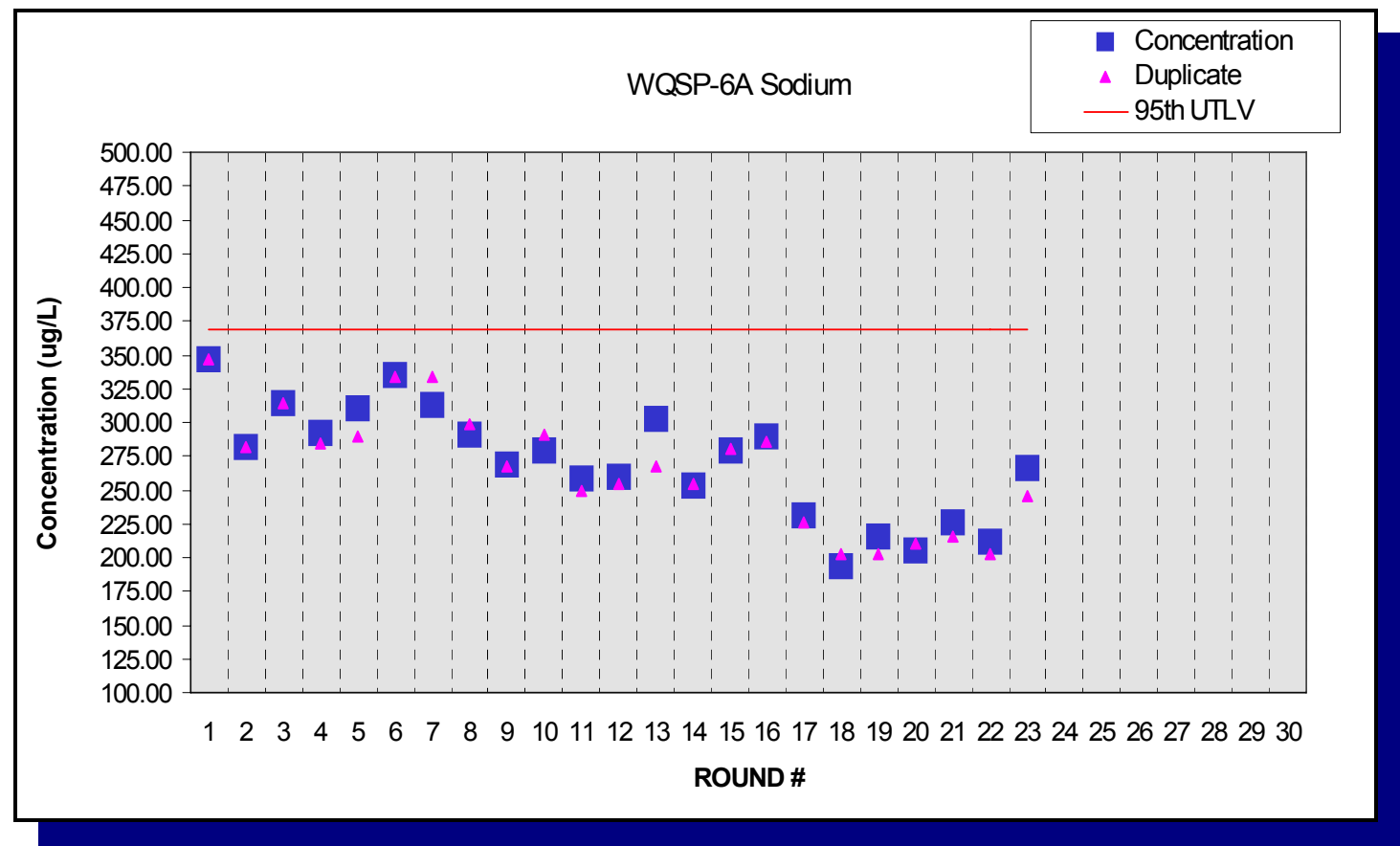

Figure E.92 - Time Trend Plot for Sodium at WQSP-6A 


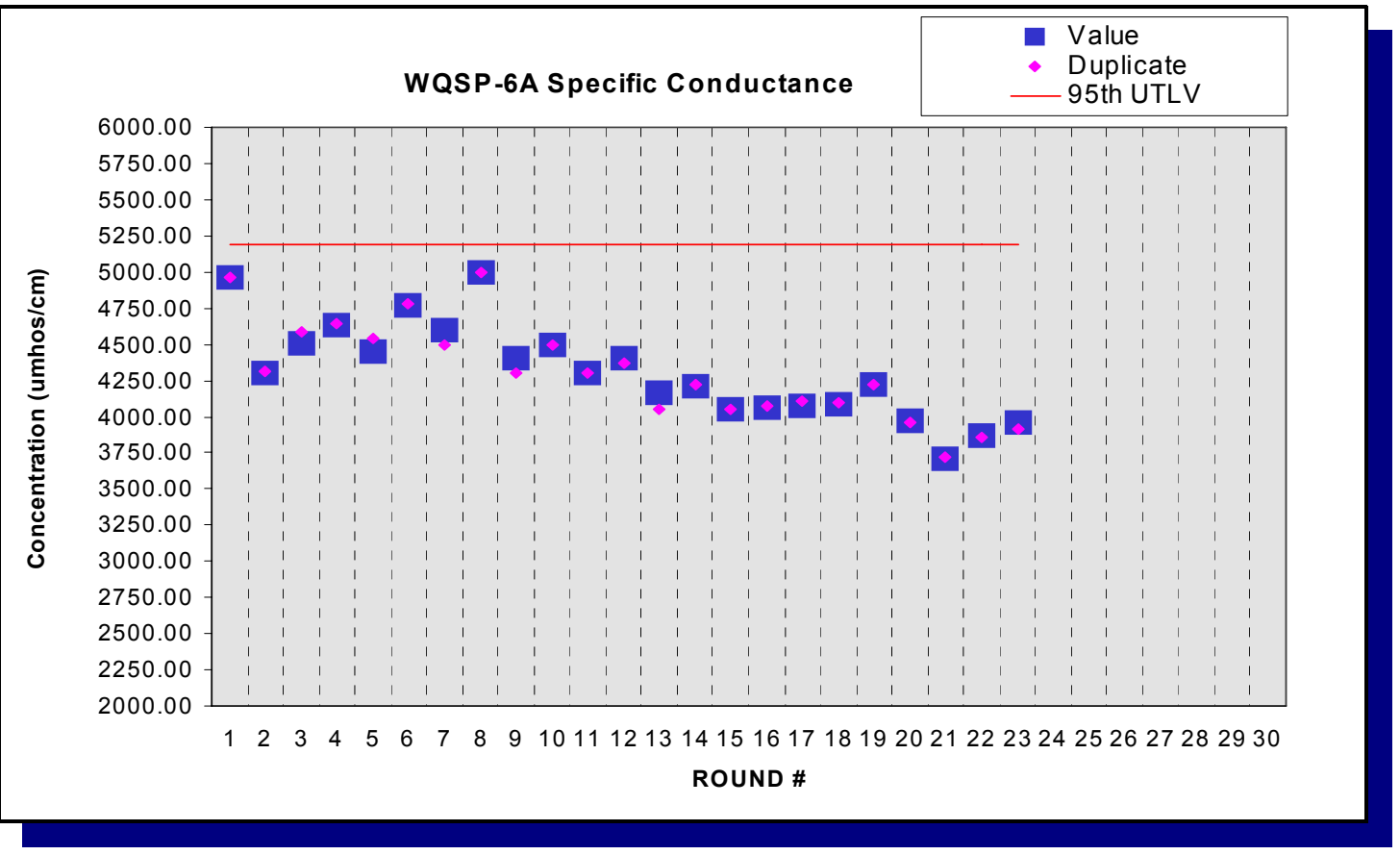

Figure E.93 - Time Trend Plot for Specific Conductance at WQSP-6A

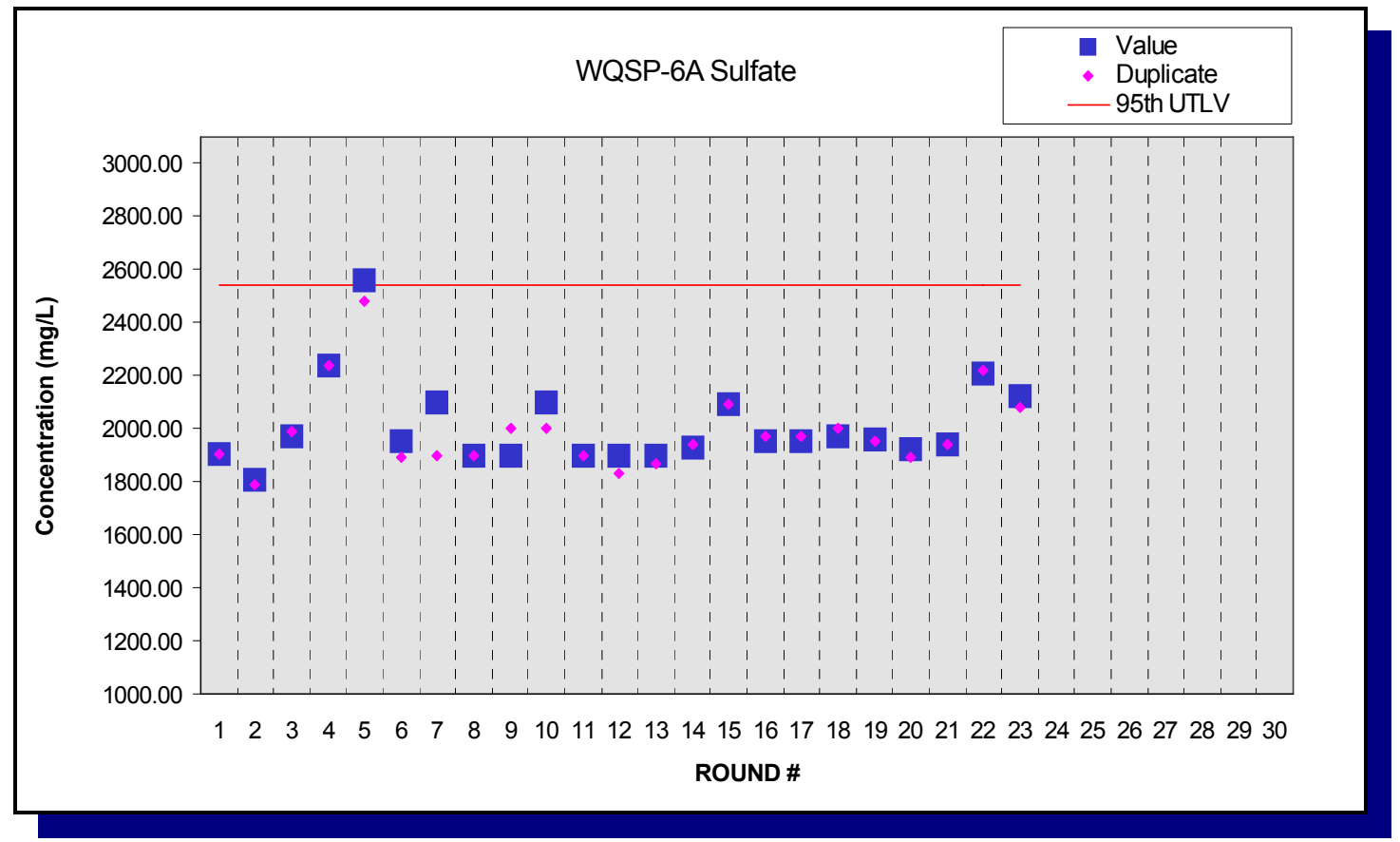

Figure E.94 - Time Trend Plot for Sulfate at WQSP-6A 


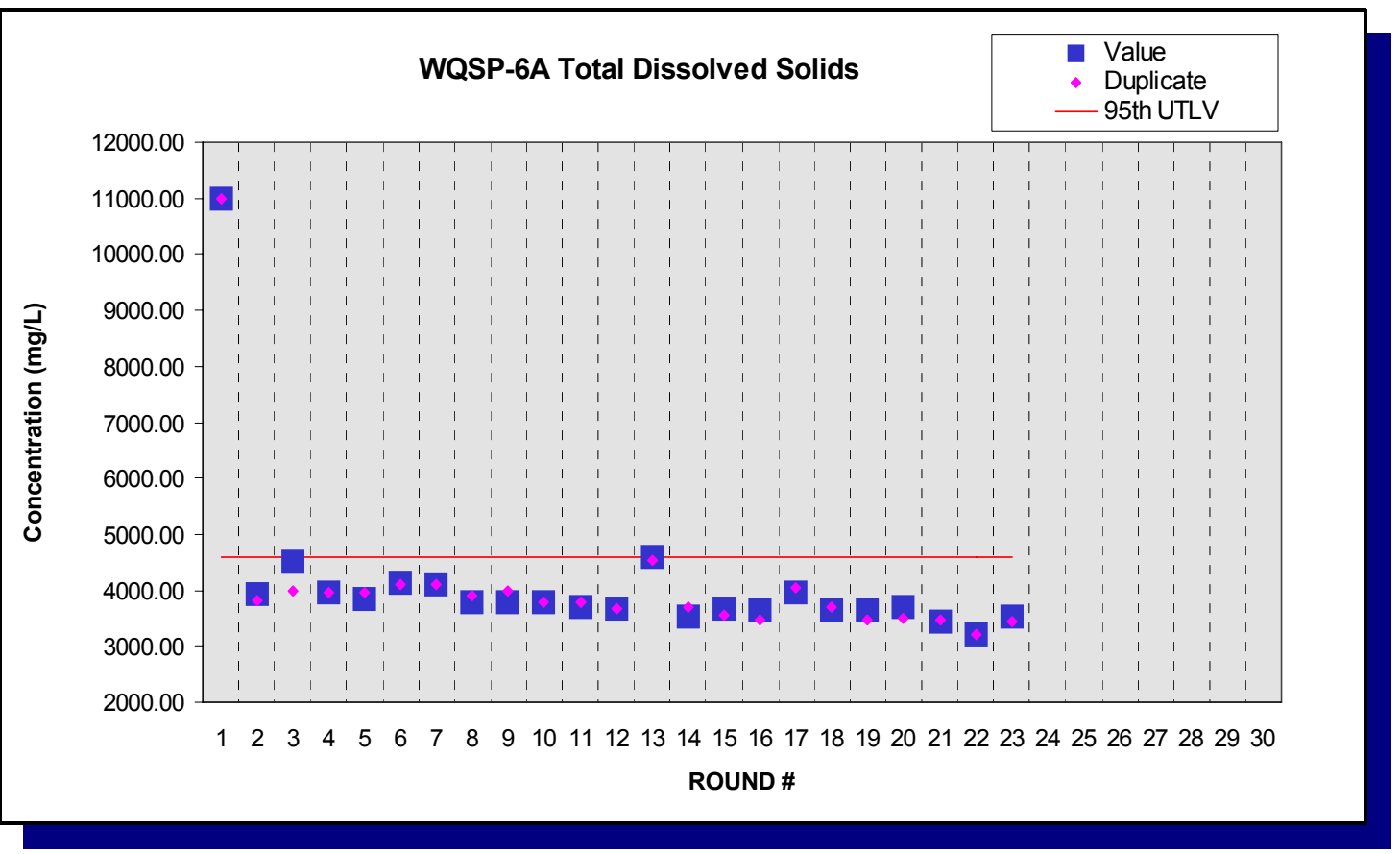

Figure E.95 - Time Trend Plot for Total Dissolved Solids at WQSP-6A

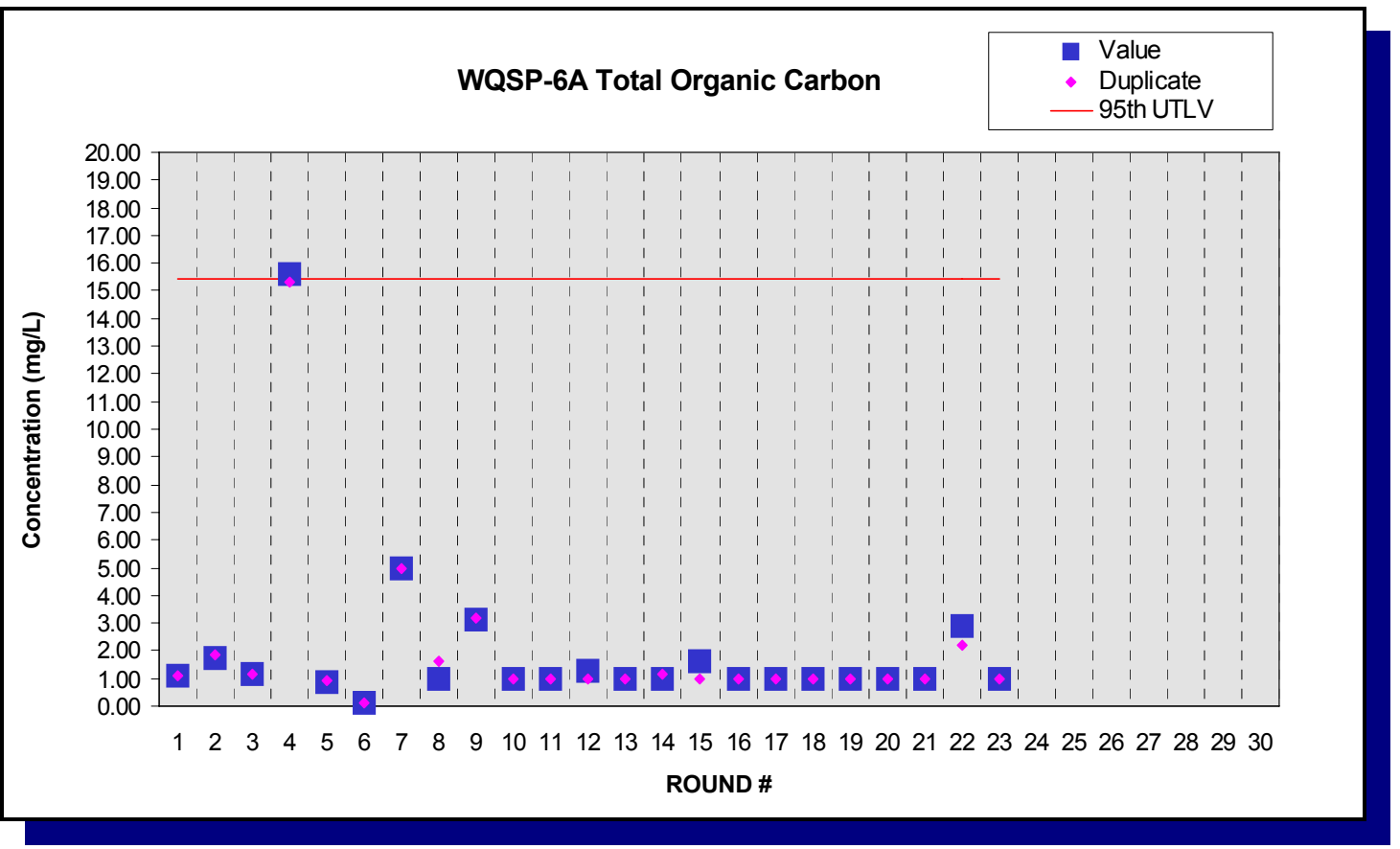

Figure E.96 - Time Trend Plot for Total Organic Carbon at WQSP-6A 


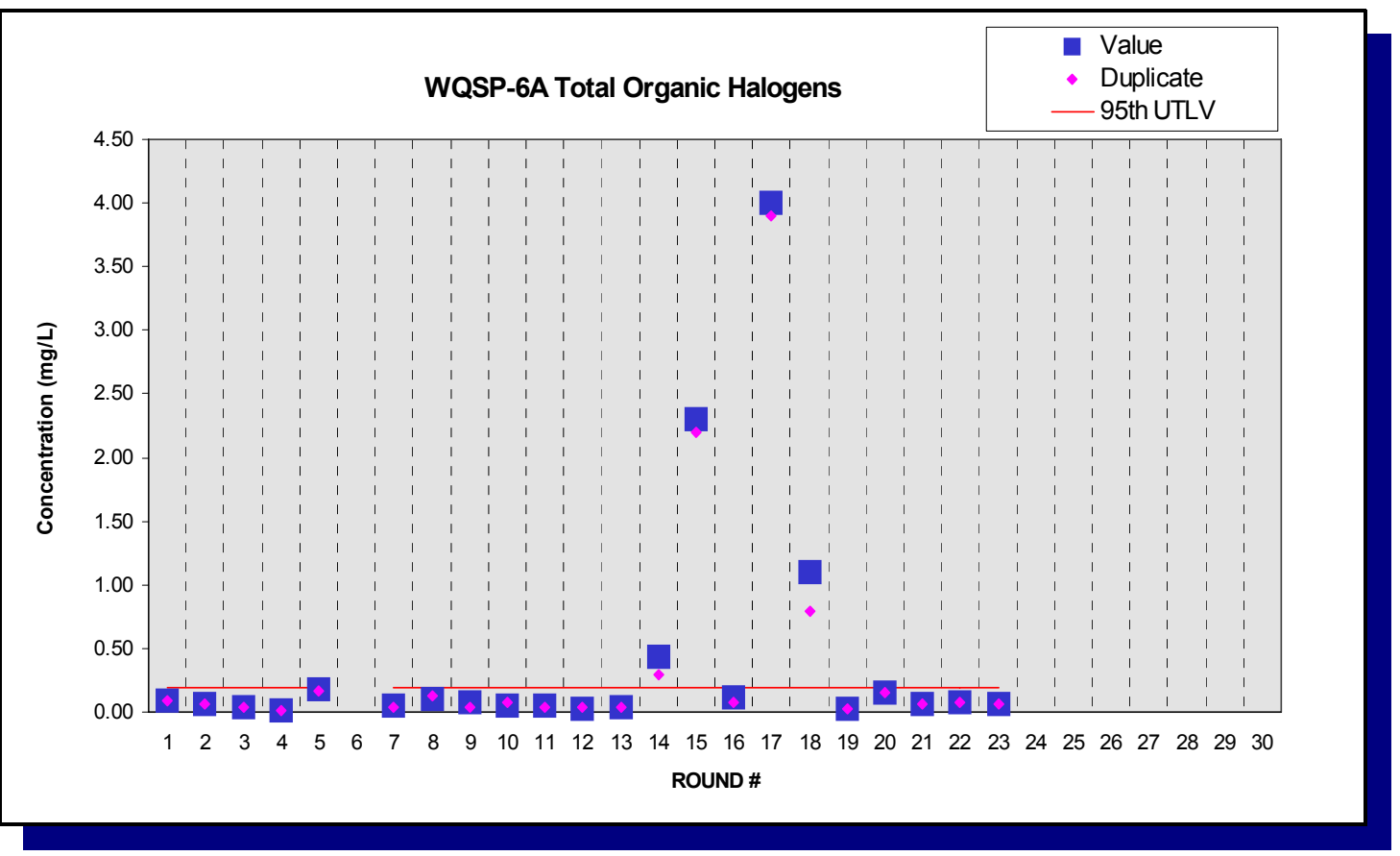

Figure E.97 - Time Trend Plot for Total Organic Halogens at WQSP-6A

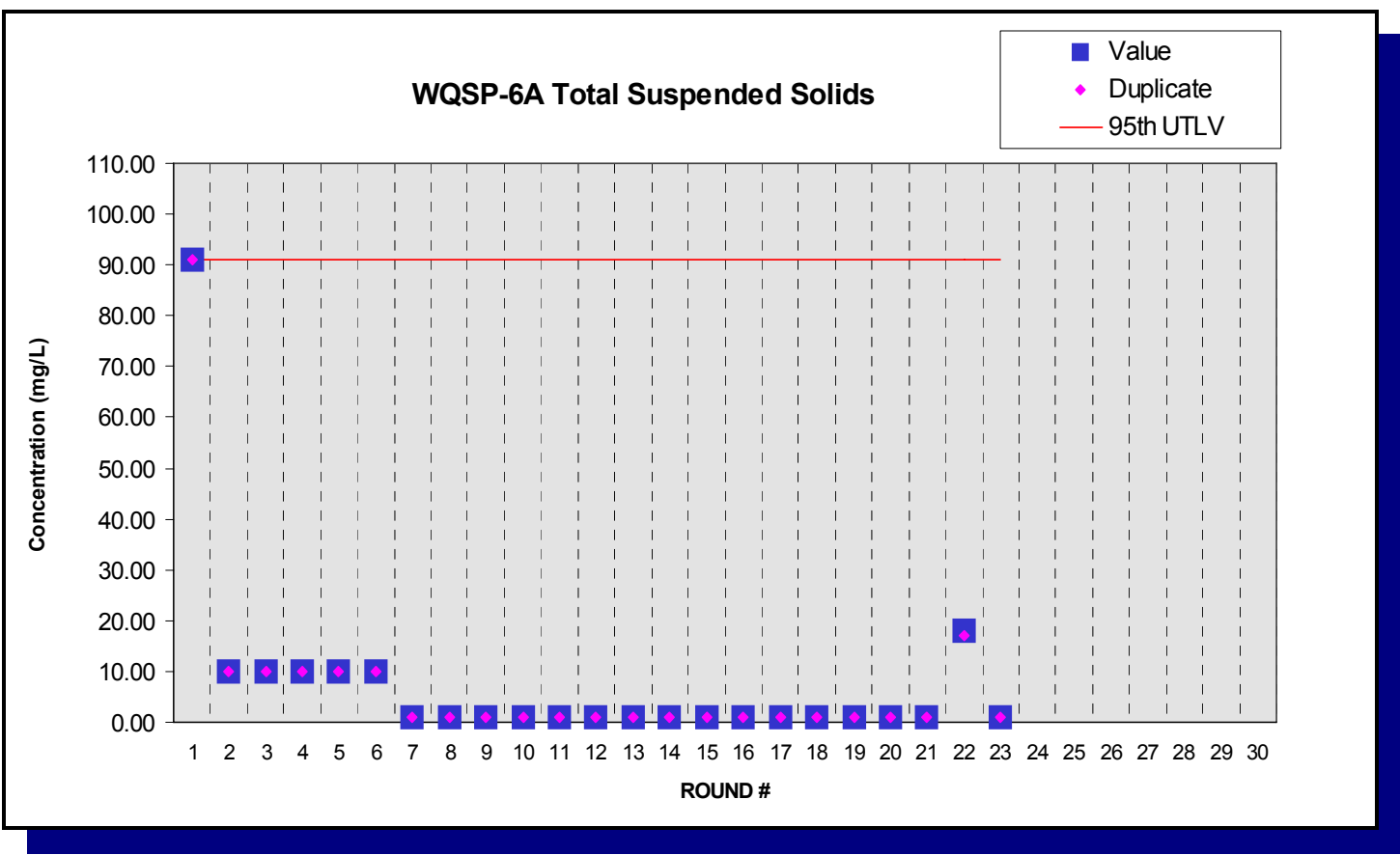

Figure E.98 - Time Trend Plot for Total Suspended Solids at WQSP-6A 
Waste Isolation Pilot Plant Annual Site Environmental Report for 2006

DOE/WIPP-07-2225

This page intentionally left blank 


\section{Appendix $F$ \\ Groundwater Data Tables}

\begin{tabular}{|c|c|c|c|c|c|c|c|c|}
\hline \multirow[b]{3}{*}{ Parameter } & \multicolumn{4}{|c|}{ Concentration } & \multirow[b]{3}{*}{ Units } & \multirow{2}{*}{\multicolumn{2}{|c|}{ Reporting Limit }} & \multirow[b]{3}{*}{$\begin{array}{l}95^{\text {th }} \\
\text { UTLV }^{\text {a }}\end{array}$} \\
\hline & \multicolumn{2}{|c|}{ Round 22} & \multicolumn{2}{|c|}{ Round 23} & & & & \\
\hline & Sample & Dup. & Sample & Dup. & & $\begin{array}{c}\text { Round } \\
22\end{array}$ & $\begin{array}{c}\text { Round } \\
23\end{array}$ & \\
\hline 1,1,1-Trichloroethane & $<1$ & $<1$ & $<1$ & $<1$ & $\mu \mathrm{g} / \mathrm{L}$ & 1 & 1 & $<\mathrm{RL}^{\mathrm{b}}$ \\
\hline 1,1,2,2-Tetrachloroethane & $<1$ & $<1$ & $<1$ & $<1$ & $\mu g / L$ & 1 & 1 & $<\mathrm{RL}$ \\
\hline 1,1,2-Trichloroethane & $<1$ & $<1$ & $<1$ & $<1$ & $\mu \mathrm{g} / \mathrm{L}$ & 1 & 1 & $<\mathrm{RL}$ \\
\hline 1,1-Dichloroethane & $<1$ & $<1$ & $<1$ & $<1$ & $\mu \mathrm{g} / \mathrm{L}$ & 1 & 1 & $<\mathrm{RL}$ \\
\hline 1,1-Dichloroethylene & $<1$ & $<1$ & $<1$ & $<1$ & $\mu g / L$ & 1 & 1 & $<\mathrm{RL}$ \\
\hline 1,2-Dichloroethane & $<1$ & $<1$ & $<1$ & $<1$ & $\mu g / L$ & 1 & 1 & $<\mathrm{RL}$ \\
\hline Carbon tetrachloride & $<1$ & $<1$ & $<1$ & $<1$ & $\mu g / L$ & 1 & 1 & $<\mathrm{RL}$ \\
\hline Chlorobenzene & $<1$ & $<1$ & $<1$ & $<1$ & $\mu \mathrm{g} / \mathrm{L}$ & 1 & 1 & $<\mathrm{RL}$ \\
\hline Chloroform & $<1$ & $<1$ & $<1$ & $<1$ & $\mu \mathrm{g} / \mathrm{L}$ & 1 & 1 & $<\mathrm{RL}$ \\
\hline cis-1,2-Dichloroethylene & $<1$ & $<1$ & $<1$ & $<1$ & $\mu g / L$ & 1 & 1 & $<\mathrm{RL}$ \\
\hline trans-1, 2-Dichloroethylene & $<1$ & $<1$ & $<1$ & $<1$ & $\mu \mathrm{g} / \mathrm{L}$ & 1 & 1 & $<\mathrm{RL}$ \\
\hline Methyl ethyl ketone & $<5$ & $<5$ & $<5$ & $<5$ & $\mu \mathrm{g} / \mathrm{L}$ & 5 & 5 & $<\mathrm{RL}$ \\
\hline Methylene chloride & $<5$ & $<5$ & $<5$ & $<5$ & $\mu g / L$ & 5 & 5 & $<\mathrm{RL}$ \\
\hline Tetrachloroethylene & $<1$ & $<1$ & $<1$ & $<1$ & $\mu \mathrm{g} / \mathrm{L}$ & 1 & 1 & $<\mathrm{RL}$ \\
\hline Toluene & $<1$ & $<1$ & $<1$ & $<1$ & $\mu g / L$ & 1 & 1 & $<\mathrm{RL}$ \\
\hline Trichloroethylene & $<1$ & $<1$ & $<1$ & $<1$ & $\mu g / L$ & 1 & 1 & $<\mathrm{RL}$ \\
\hline Trichlorofluoromethane & $<1$ & $<1$ & $<1$ & $<1$ & $\mu \mathrm{g} / \mathrm{L}$ & 1 & 1 & $<\mathrm{RL}$ \\
\hline Vinyl chloride & $<1$ & $<1$ & $<1$ & $<1$ & $\mu \mathrm{g} / \mathrm{L}$ & 1 & 1 & $<\mathrm{RL}$ \\
\hline Xylene & $<1$ & $<1$ & $<1$ & $<1$ & $\mu \mathrm{g} / \mathrm{L}$ & 1 & 1 & $<\mathrm{RL}$ \\
\hline 1,2-Dichlorobenzene & $<5$ & $<5$ & $<5$ & $<5$ & $\mu g / L$ & 5 & 5 & $<\mathrm{RL}$ \\
\hline 1,4-Dichlorobenzene & $<5$ & $<5$ & $<5$ & $<5$ & $\mu \mathrm{g} / \mathrm{L}$ & 5 & 5 & $<\mathrm{RL}$ \\
\hline 2,4-Dinitrophenol & $<20$ & $<20$ & $<20$ & $<20$ & $\mu \mathrm{g} / \mathrm{L}$ & 20 & 20 & $<\mathrm{RL}$ \\
\hline 2,4-Dinitrotoluene & $<20$ & $<20$ & $<5$ & $<5$ & $\mu \mathrm{g} / \mathrm{L}$ & 20 & 5 & $<\mathrm{RL}$ \\
\hline 2-Methylphenol & $<5$ & $<5$ & $<5$ & $<5$ & $\mu \mathrm{g} / \mathrm{L}$ & 5 & 5 & $<\mathrm{RL}$ \\
\hline $\begin{array}{l}\text { 3-Methylphenol/ } \\
\text { 4-Methylphenol }\end{array}$ & $<5$ & $<5$ & $<5$ & $<5$ & $\mu g / L$ & 5 & 5 & $<\mathrm{RL}$ \\
\hline Hexachlorobenzene & $<5$ & $<5$ & $<5$ & $<5$ & $\mu g / L$ & 5 & 5 & $<\mathrm{RL}$ \\
\hline Hexachloroethane & $<5$ & $<5$ & $<5$ & $<5$ & $\mu \mathrm{g} / \mathrm{L}$ & 5 & 5 & $<\mathrm{RL}$ \\
\hline Nitrobenzene & $<5$ & $<5$ & $<5$ & $<5$ & $\mu \mathrm{g} / \mathrm{L}$ & 5 & 5 & $<\mathrm{RL}$ \\
\hline Pentachlorophenol & $<20$ & $<20$ & $<5$ & $<5$ & $\mu \mathrm{g} / \mathrm{L}$ & 20 & 5 & $<\mathrm{RL}$ \\
\hline Pyridine & $<5$ & $<5$ & $<5$ & $<5$ & $\mu \mathrm{g} / \mathrm{L}$ & 5 & 5 & $<\mathrm{RL}$ \\
\hline Isobutanol & $<5$ & $<5$ & $<5$ & $<5$ & $\mu g / L$ & 5 & 5 & $<\mathrm{RL}$ \\
\hline Alkalinity & 50 & 44 & 50 & 48 & $\mathrm{mg} / \mathrm{L}$ & 4 & 4 & 55.7 \\
\hline Chloride & 38,500 & 35,000 & 39,200 & 44,200 & $\mathrm{mg} / \mathrm{L}$ & 2 & 2 & 40,472 \\
\hline Density & 1.05 & 1.04 & 1.04 & 1.05 & $\mathrm{~g} / \mathrm{ml}$ & $N / A^{d}$ & $N / A^{d}$ & 1.072 \\
\hline Nitrate (as N) & $<0.10$ & $<0.10$ & $<0.10$ & $<0.10$ & $\mathrm{mg} / \mathrm{L}$ & 0.1 & 0.1 & $<10$ \\
\hline $\mathrm{pH}$ & 7.56 & 7.70 & 7.01 & 7.03 & $S U^{c}$ & $N / A^{d}$ & $N / A^{d}$ & $6.89-7.65$ \\
\hline Specific conductance & 85,800 & 87,300 & 88,400 & 88,400 & $\mu \mathrm{mhos} / \mathrm{cm}$ & $\mathrm{N} / \mathrm{A}$ & $N / A$ & 175,000 \\
\hline Sulfate & 4,780 & 4,560 & 5,580 & 5,490 & $\mathrm{mg} / \mathrm{L}$ & 2 & 2 & 5,757 \\
\hline Total dissolved solids & 64,200 & 64,200 & 61,900 & 69,600 & $\mathrm{mg} / \mathrm{L}$ & 10 & 10 & 80,700 \\
\hline Total organic carbon & $<1.0$ & $<1.0$ & $<1.0$ & $<1.0$ & $\mathrm{mg} / \mathrm{L}$ & 1 & 1 & 5 \\
\hline
\end{tabular}


Waste Isolation Pilot Plant Annual Site Environmental Report for 2006 DOE/WIPP-07-2225

\begin{tabular}{|c|c|c|c|c|c|c|c|c|}
\hline \multirow[b]{3}{*}{ Parameter } & \multicolumn{4}{|c|}{ Concentration } & \multirow[b]{3}{*}{ Units } & & & \multirow[b]{3}{*}{$\begin{array}{c}9^{\text {th }} \\
\text { UTLV }\end{array}$} \\
\hline & \multicolumn{2}{|c|}{ Round 22} & \multicolumn{2}{|c|}{ Round 23} & & \multicolumn{2}{|c|}{ Reporting Limit } & \\
\hline & Sample & Dup. & Sample & Dup. & & $\begin{array}{c}\text { Round } \\
22\end{array}$ & $\begin{array}{c}\text { Round } \\
23\end{array}$ & \\
\hline Total organic halogen & $<0.30$ & $<0.30$ & $<0.30$ & $<0.03$ & $\mathrm{mg} / \mathrm{L}$ & 0.30 & 0.30 & 14.6 \\
\hline Total suspended solids & $<1.0$ & $<1.0$ & $<1.0$ & $<1.0$ & $\mathrm{mg} / \mathrm{L}$ & 1 & 1 & 33.5 \\
\hline Antimony & $<0.025$ & $<0.025$ & $<0.025$ & $<0.025$ & $\mathrm{mg} / \mathrm{L}$ & 0.025 & 0.025 & 0.33 \\
\hline Arsenic & $<0.05$ & $<0.05$ & $<0.05$ & $<0.05$ & $\mathrm{mg} / \mathrm{L}$ & 0.05 & 0.05 & $<0.1$ \\
\hline Barium & $<0.02$ & $<0.02$ & $<0.02$ & $<0.02$ & $\mathrm{mg} / \mathrm{L}$ & 0.02 & 0.02 & $<1.0$ \\
\hline Beryllium & $<0.01$ & $<0.01$ & $<0.01$ & $<0.01$ & $\mathrm{mg} / \mathrm{L}$ & 0.01 & 0.01 & $<0.02$ \\
\hline Cadmium & $<0.01$ & $<0.01$ & $<0.01$ & $<0.01$ & $\mathrm{mg} / \mathrm{L}$ & 0.01 & 0.01 & $<0.2$ \\
\hline Calcium & 1,780 & 1,800 & 1,890 & 2,110 & $\mathrm{mg} / \mathrm{L}$ & 0.50 & 0.50 & 2,087 \\
\hline Chromium & $<0.025$ & $<0.025$ & $<0.025$ & $<0.025$ & $\mathrm{mg} / \mathrm{L}$ & 0.025 & 0.025 & $<0.50$ \\
\hline Iron & $<0.50$ & $<0.50$ & $<0.50$ & $<0.50$ & $\mathrm{mg} / \mathrm{L}$ & 0.50 & 0.50 & 1.32 \\
\hline Lead & $<0.02$ & $<0.02$ & $<0.02$ & $<0.02$ & $\mathrm{mg} / \mathrm{L}$ & 0.02 & 0.02 & 0.105 \\
\hline Magnesium & 1,230 & 1,240 & 1,220 & 1,350 & $\mathrm{mg} / \mathrm{L}$ & 0.50 & 0.50 & 1,247 \\
\hline Mercury & $<0.0002$ & $<0.0002$ & $<0.0002$ & $<0.0002$ & $\mathrm{mg} / \mathrm{L}$ & 0 & 0 & $<0.002$ \\
\hline Nickel & $<0.025$ & $<0.025$ & $<0.025$ & $<0.025$ & $\mathrm{mg} / \mathrm{L}$ & 0.025 & 0.025 & 0.490 \\
\hline Potassium & 1,050 & 950 & 598 & 612 & $\mathrm{mg} / \mathrm{L}$ & 0.50 & 0.50 & 799 \\
\hline Selenium & $<0.025$ & $<0.025$ & $<0.025$ & $<0.025$ & $\mathrm{mg} / \mathrm{L}$ & 0.025 & 0.025 & 0.15 \\
\hline Silver & $<0.013$ & $<0.013$ & $<0.013$ & $<0.013$ & $\mathrm{mg} / \mathrm{L}$ & 0.013 & 0.013 & $<0.50$ \\
\hline Sodium & 17,500 & 17,600 & 25,700 & 28,400 & $\mathrm{mg} / \mathrm{L}$ & 0.50 & 0.50 & 22,090 \\
\hline Thallium & $<0.025$ & $<0.025$ & $<0.025$ & $<0.025$ & $\mathrm{mg} / \mathrm{L}$ & 0.025 & 0.025 & 0.980 \\
\hline Vanadium & $<0.025$ & $<0.025$ & $<0.025$ & $<0.025$ & $\mathrm{mg} / \mathrm{L}$ & 0.025 & 0.025 & $<0.1$ \\
\hline
\end{tabular}

Table F.2 - Analytical Results for Groundwater Sampled from Well WQSP-2

\begin{tabular}{|c|c|c|c|c|c|c|c|c|}
\hline \multirow[b]{3}{*}{ Parameter } & \multicolumn{4}{|c|}{ Concentration } & \multirow[b]{3}{*}{ Units } & & & \multirow[b]{3}{*}{$\begin{array}{c}95^{\text {th }} \\
\text { UTLV }^{\mathrm{a}}\end{array}$} \\
\hline & \multicolumn{2}{|c|}{ Round 22} & \multicolumn{2}{|c|}{ Round 23} & & \multicolumn{2}{|c|}{ Reporting Limit } & \\
\hline & Sample & Dup. & Sample & Dup. & & $\begin{array}{c}\text { Round } \\
22\end{array}$ & $\begin{array}{c}\text { Round } \\
23\end{array}$ & \\
\hline 1,1,1-Trichloroethane & $<1$ & $<1$ & $<1$ & $<1$ & $\mu \mathrm{g} / \mathrm{L}$ & 1 & 1 & $<R^{b}$ \\
\hline 1,1,2,2-Tetrachloroethane & $<1$ & $<1$ & $<1$ & $<1$ & $\mu \mathrm{g} / \mathrm{L}$ & 1 & 1 & $<\mathrm{RL}$ \\
\hline 1,1,2-Trichloroethane & $<1$ & $<1$ & $<1$ & $<1$ & $\mu \mathrm{g} / \mathrm{L}$ & 1 & 1 & $<R L$ \\
\hline 1,1-Dichloroethane & $<1$ & $<1$ & $<1$ & $<1$ & $\mu g / L$ & 1 & 1 & $<R L$ \\
\hline 1,1-Dichloroethylene & $<1$ & $<1$ & $<1$ & $<1$ & $\mu \mathrm{g} / \mathrm{L}$ & 1 & 1 & $<R L$ \\
\hline 1,2-Dichloroethane & $<1$ & $<1$ & $<1$ & $<1$ & $\mu \mathrm{g} / \mathrm{L}$ & 1 & 1 & $<R L$ \\
\hline Carbon tetrachloride & $<1$ & $<1$ & $<1$ & $<1$ & $\mu \mathrm{g} / \mathrm{L}$ & 1 & 1 & $<R L$ \\
\hline Chlorobenzene & $<1$ & $<1$ & $<1$ & $<1$ & $\mu \mathrm{g} / \mathrm{L}$ & 1 & 1 & $<R L$ \\
\hline Chloroform & $<1$ & $<1$ & $<1$ & $<1$ & $\mu \mathrm{g} / \mathrm{L}$ & 1 & 1 & $<\mathrm{RL}$ \\
\hline cis-1,2-Dichloroethylene & $<1$ & $<1$ & $<1$ & $<1$ & $\mu \mathrm{g} / \mathrm{L}$ & 1 & 1 & $<R L$ \\
\hline trans-1,2-Dichloroethylene & $<1$ & $<1$ & $<1$ & $<1$ & $\mu \mathrm{g} / \mathrm{L}$ & 1 & 1 & $<\mathrm{RL}$ \\
\hline Methyl ethyl ketone & $<5$ & $<5$ & $<5$ & $<5$ & $\mu \mathrm{g} / \mathrm{L}$ & 5 & 5 & $<R L$ \\
\hline Methylene chloride & $<5$ & $<5$ & $<5$ & $<5$ & $\mu g / L$ & 5 & 5 & $<R L$ \\
\hline Tetrachloroethylene & $<1$ & $<1$ & $<1$ & $<1$ & $\mu \mathrm{g} / \mathrm{L}$ & 1 & 1 & $<R L$ \\
\hline
\end{tabular}




\begin{tabular}{|c|c|c|c|c|c|c|c|c|}
\hline \multirow[b]{3}{*}{ Parameter } & \multicolumn{4}{|c|}{ Concentration } & \multirow[b]{3}{*}{ Units } & \multirow{2}{*}{\multicolumn{2}{|c|}{ Reporting Limit }} & \multirow[b]{3}{*}{$\begin{array}{l}95^{\text {th }} \\
\text { UTLV }^{\text {a }}\end{array}$} \\
\hline & \multicolumn{2}{|c|}{ Round 22} & \multicolumn{2}{|c|}{ Round 23} & & & & \\
\hline & Sample & Dup. & Sample & Dup. & & $\begin{array}{c}\text { Round } \\
22\end{array}$ & $\begin{array}{c}\text { Round } \\
23\end{array}$ & \\
\hline Toluene & $<1$ & $<1$ & $<1$ & $<1$ & $\mu \mathrm{g} / \mathrm{L}$ & 1 & 1 & $<\mathrm{RL}$ \\
\hline Trichloroethylene & $<1$ & $<1$ & $<1$ & $<1$ & $\mu \mathrm{g} / \mathrm{L}$ & 1 & 1 & $<\mathrm{RL}$ \\
\hline Trichlorofluoromethane & $<1$ & $<1$ & $<1$ & $<1$ & $\mu g / L$ & 1 & 1 & $<\mathrm{RL}$ \\
\hline Vinyl chloride & $<1$ & $<1$ & $<1$ & $<1$ & $\mu g / L$ & 1 & 1 & $<\mathrm{RL}$ \\
\hline Xylene & $<1$ & $<1$ & $<1$ & $<1$ & $\mu g / L$ & 1 & 1 & $<\mathrm{RL}$ \\
\hline 1,2-Dichlorobenzene & $<5$ & $<5$ & $<5$ & $<5$ & $\mu g / L$ & 5 & 5 & $<\mathrm{RL}$ \\
\hline 1,4-Dichlorobenzene & $<5$ & $<5$ & $<5$ & $<5$ & $\mu g / L$ & 5 & 5 & $<\mathrm{RL}$ \\
\hline 2,4-Dinitrophenol & $<20$ & $<20$ & $<20$ & $<20$ & $\mu g / L$ & 20 & 20 & $<\mathrm{RL}$ \\
\hline 2,4-Dinitrotoluene & $<20$ & $<20$ & $<5$ & $<5$ & $\mu \mathrm{g} / \mathrm{L}$ & 20 & 5 & $<\mathrm{RL}$ \\
\hline 2-Methylphenol & $<5$ & $<5$ & $<5$ & $<5$ & $\mu \mathrm{g} / \mathrm{L}$ & 5 & 5 & $<\mathrm{RL}$ \\
\hline $\begin{array}{l}\text { 3-Methylphenol/ } \\
\text { 4-Methylphenol }\end{array}$ & $<5$ & $<5$ & $<5$ & $<5$ & $\mu g / L$ & 5 & 5 & $<\mathrm{RL}$ \\
\hline Hexachlorobenzene & $<5$ & $<5$ & $<5$ & $<5$ & $\mu g / L$ & 5 & 5 & $<R L$ \\
\hline Hexachloroethane & $<5$ & $<5$ & $<5$ & $<5$ & $\mu \mathrm{g} / \mathrm{L}$ & 5 & 5 & $<R L$ \\
\hline Nitrobenzene & $<5$ & $<5$ & $<5$ & $<5$ & $\mu g / L$ & 5 & 5 & $<\mathrm{RL}$ \\
\hline Pentachlorophenol & $<20$ & $<20$ & $<5$ & $<5$ & $\mu g / L$ & 20 & 5 & $<\mathrm{RL}$ \\
\hline Pyridine & $<5$ & $<5$ & $<5$ & $<5$ & $\mu g / L$ & 5 & 5 & $<\mathrm{RL}$ \\
\hline Isobutanol & $<5$ & $<5$ & $<5$ & $<5$ & $\mu g / L$ & 5 & 5 & $<\mathrm{RL}$ \\
\hline Alkalinity & 52 & 50 & 40 & 50 & $\mathrm{mg} / \mathrm{L}$ & 4 & 4 & 70.3 \\
\hline Chloride & 37,500 & 38,000 & 40,600 & 41,100 & $\mathrm{mg} / \mathrm{L}$ & 2 & 2 & 39,670 \\
\hline Density & 1.03 & 1.03 & 1.04 & 1.05 & $\mathrm{~g} / \mathrm{ml}$ & $N / A^{c}$ & $N / A^{c}$ & 1.06 \\
\hline Nitrate (as N) & $<0.1$ & $<0.1$ & $<0.1$ & $<0.1$ & $\mathrm{mg} / \mathrm{L}$ & 0.1 & 0.1 & $<10$ \\
\hline $\mathrm{pH}$ & 7.42 & 7.46 & 7.12 & 7.12 & $S U^{d}$ & $N / A^{c}$ & $N / A^{c}$ & $7.00-7.60$ \\
\hline Specific conductance & 83,900 & 83,100 & 81,000 & 80,300 & $\mu \mathrm{mhos} / \mathrm{cm}$ & $N / A^{c}$ & $N / A^{c}$ & 124,000 \\
\hline Sulfate & 6,300 & 5,880 & 6,220 & 6,220 & $\mathrm{mg} / \mathrm{L}$ & 2 & 2 & 6,590 \\
\hline Total dissolved solids & 67,500 & 62,000 & 71,100 & 69,800 & $\mathrm{mg} / \mathrm{L}$ & 10 & 10 & 80,500 \\
\hline Total organic carbon & $<1.0$ & $<1.0$ & 1.8 & $<1.0$ & $\mathrm{mg} / \mathrm{L}$ & 1 & 1 & 7.97 \\
\hline Total organic halogen & $<0.30$ & $<0.30$ & $<0.30$ & $<0.30$ & $\mathrm{mg} / \mathrm{L}$ & 0.30 & 0.30 & 63.8 \\
\hline Total suspended solids & $<1.0$ & $<1.0$ & 1.5 & $<1.0$ & $\mathrm{mg} / \mathrm{L}$ & 1 & 1 & 43 \\
\hline Antimony & $<0.025$ & $<0.025$ & $<0.025$ & $<0.025$ & $\mathrm{mg} / \mathrm{L}$ & 0.025 & 0.025 & $<0.50$ \\
\hline Arsenic & $<0.05$ & $<0.05$ & $<0.05$ & $<0.05$ & $\mathrm{mg} / \mathrm{L}$ & 0.05 & 0.05 & 0.062 \\
\hline Barium & $<0.05$ & $<0.05$ & $<0.05$ & $<0.05$ & $\mathrm{mg} / \mathrm{L}$ & 0.05 & 0.05 & $<1.0$ \\
\hline Beryllium & $<0.01$ & $<0.01$ & $<0.01$ & $<0.01$ & $\mathrm{mg} / \mathrm{L}$ & 0.01 & 0.01 & $<1.0$ \\
\hline Cadmium & $<0.01$ & $<0.01$ & $<0.01$ & $<0.01$ & $\mathrm{mg} / \mathrm{L}$ & 0.01 & 0.01 & $<0.50$ \\
\hline Calcium & 1,520 & 1,480 & 1,540 & 1,580 & $\mathrm{mg} / \mathrm{L}$ & 0.50 & 0.50 & 1,827 \\
\hline Chromium & $<0.05$ & $<0.05$ & $<0.05$ & $<0.05$ & $\mathrm{mg} / \mathrm{L}$ & 0.05 & 0.05 & $<0.50$ \\
\hline Iron & $<0.50$ & $<0.50$ & $<0.50$ & $<0.50$ & $\mathrm{mg} / \mathrm{L}$ & 0.50 & 0.50 & 1.32 \\
\hline Lead & $<0.05$ & $<0.05$ & $<0.05$ & $<0.05$ & $\mathrm{mg} / \mathrm{L}$ & 0.05 & 0.05 & 0.163 \\
\hline Magnesium & 1,060 & 1,060 & 1,040 & 1,050 & $\mathrm{mg} / \mathrm{L}$ & 0.50 & 0.50 & 1,244 \\
\hline Mercury & $<0.0002$ & $<0.0002$ & $<0.0002$ & $<0.0002$ & $\mathrm{mg} / \mathrm{L}$ & 0 & 0 & $<0.002$ \\
\hline Nickel & $<0.05$ & $<0.05$ & $<0.05$ & $<0.05$ & $\mathrm{mg} / \mathrm{L}$ & 0.05 & 0.05 & 0.490 \\
\hline Potassium & 992 & 995 & 594 & 561 & $\mathrm{mg} / \mathrm{L}$ & 0.50 & 0.50 & 845 \\
\hline Selenium & $<0.025$ & $<0.025$ & $<0.025$ & $<0.025$ & $\mathrm{mg} / \mathrm{L}$ & 0.025 & 0.025 & 0.150 \\
\hline Silver & $<0.025$ & $<0.025$ & $<0.025$ & $<0.025$ & $\mathrm{mg} / \mathrm{L}$ & 0.025 & 0.025 & $<0.50$ \\
\hline
\end{tabular}


Table F.2 - Analytical Results for Groundwater Sampled from Well WQSP-2

Concentration

\begin{tabular}{|c|c|c|c|c|c|c|c|c|}
\hline \multirow[b]{2}{*}{ Parameter } & \multicolumn{2}{|c|}{ Round 22} & \multicolumn{2}{|c|}{ Round 23} & \multirow[b]{2}{*}{ Units } & \multicolumn{2}{|c|}{ Reporting Limit } & \multirow[b]{2}{*}{$\begin{array}{l}9^{\text {th }} \\
\text { UTLV }^{\mathrm{a}}\end{array}$} \\
\hline & Sample & Dup. & Sample & Dup. & & $\begin{array}{c}\text { Round } \\
22\end{array}$ & $\begin{array}{c}\text { Round } \\
23\end{array}$ & \\
\hline Sodium & 17,000 & 17,000 & 25,100 & 25,200 & $\mathrm{mg} / \mathrm{L}$ & 0.50 & 0.50 & 21,900 \\
\hline Thallium & $<0.025$ & $<0.025$ & $<0.025$ & $<0.025$ & $\mathrm{mg} / \mathrm{L}$ & 0.025 & 0.025 & 0.98 \\
\hline Vanadium & $<0.025$ & $<0.025$ & $<0.025$ & $<0.025$ & $\mathrm{mg} / \mathrm{L}$ & 0.025 & 0.025 & $<0.1$ \\
\hline $\begin{array}{l}{ }^{\mathrm{A}} 95^{\text {th }} \text { Upper tolerance I } \\
{ }^{\mathrm{b}} \text { Reporting limit } \\
{ }^{\mathrm{c}} \text { Not applicable } \\
{ }^{\mathrm{d}} \text { Standard unit }\end{array}$ & , equivale & th to $95 \%$ & fidence limi & & & & & \\
\hline
\end{tabular}

Table F.3 - Analytical Results for Groundwater Sampled from Well WQSP-3

\begin{tabular}{|c|c|c|c|c|c|c|c|c|}
\hline \multirow[b]{3}{*}{ Parameter } & \multicolumn{4}{|c|}{ Concentration } & \multirow[b]{3}{*}{ Units } & \multirow{2}{*}{\multicolumn{2}{|c|}{ Reporting Limit }} & \multirow[b]{3}{*}{$\begin{array}{l}9^{\text {th }} \\
\text { UTLV }^{\mathrm{a}}\end{array}$} \\
\hline & \multicolumn{2}{|c|}{ Round 22} & \multicolumn{2}{|c|}{ Round 23} & & & & \\
\hline & Sample & Dup. & Sample & Dup. & & $\begin{array}{c}\text { Round } \\
22\end{array}$ & $\begin{array}{c}\text { Round } \\
23\end{array}$ & \\
\hline 1,1,1-Trichloroethane & $<1$ & $<1$ & $<1$ & $<1$ & $\mu \mathrm{g} / \mathrm{L}$ & 1 & 1 & $<\mathrm{RL}^{\mathrm{b}}$ \\
\hline 1,1,2,2-Tetrachloroethane & $<1$ & $<1$ & $<1$ & $<1$ & $\mu \mathrm{g} / \mathrm{L}$ & 1 & 1 & $<\mathrm{RL}$ \\
\hline 1,1,2-Trichloroethane & $<1$ & $<1$ & $<1$ & $<1$ & $\mu g / L$ & 1 & 1 & $<\mathrm{RL}$ \\
\hline 1,1-Dichloroethane & $<1$ & $<1$ & $<1$ & $<1$ & $\mu g / L$ & 1 & 1 & $<R L$ \\
\hline 1,1-Dichloroethylene & $<1$ & $<1$ & $<1$ & $<1$ & $\mu \mathrm{g} / \mathrm{L}$ & 1 & 1 & $<\mathrm{RL}$ \\
\hline 1,2-Dichloroethane & $<1$ & $<1$ & $<1$ & $<1$ & $\mu \mathrm{g} / \mathrm{L}$ & 1 & 1 & $<\mathrm{RL}$ \\
\hline Carbon tetrachloride & $<1$ & $<1$ & $<1$ & $<1$ & $\mu \mathrm{g} / \mathrm{L}$ & 1 & 1 & $<\mathrm{RL}$ \\
\hline Chlorobenzene & $<1$ & $<1$ & $<1$ & $<1$ & $\mu \mathrm{g} / \mathrm{L}$ & 1 & 1 & $<\mathrm{RL}$ \\
\hline Chloroform & $<1$ & $<1$ & $<1$ & $<1$ & $\mu g / L$ & 1 & 1 & $<\mathrm{RL}$ \\
\hline cis-1,2-Dichloroethylene & $<1$ & $<1$ & $<1$ & $<1$ & $\mu g / L$ & 1 & 1 & $<\mathrm{RL}$ \\
\hline trans-1,2-Dichloroethylene & $<1$ & $<1$ & $<1$ & $<1$ & $\mu \mathrm{g} / \mathrm{L}$ & 1 & 1 & $<\mathrm{RL}$ \\
\hline Methyl ethyl ketone & $<5$ & $<5$ & $<5$ & $<5$ & $\mu \mathrm{g} / \mathrm{L}$ & 5 & 5 & $<\mathrm{RL}$ \\
\hline Methylene chloride & $<5$ & $<5$ & $<5$ & $<5$ & $\mu g / L$ & 5 & 5 & $<\mathrm{RL}$ \\
\hline Tetrachloroethylene & $<1$ & $<1$ & $<1$ & $<1$ & $\mu g / L$ & 1 & 1 & $<\mathrm{RL}$ \\
\hline Toluene & $<1$ & $<1$ & $<1$ & $<1$ & $\mu g / L$ & 1 & 1 & $<\mathrm{RL}$ \\
\hline Trichloroethylene & $<1$ & $<1$ & $<1$ & $<1$ & $\mu g / L$ & 1 & 1 & $<R L$ \\
\hline Trichlorofluoromethane & $<1$ & $<1$ & $<1$ & $<1$ & $\mu g / L$ & 1 & 1 & $<\mathrm{RL}$ \\
\hline Vinyl chloride & $<1$ & $<1$ & $<1$ & $<1$ & $\mu g / L$ & 1 & 1 & $<\mathrm{RL}$ \\
\hline Xylene & $<1$ & $<1$ & $<1$ & $<1$ & $\mu \mathrm{g} / \mathrm{L}$ & 1 & 1 & $<\mathrm{RL}$ \\
\hline 1,2-Dichlorobenzene & $<5$ & $<5$ & $<5$ & $<5$ & $\mu g / L$ & 5 & 5 & $<\mathrm{RL}$ \\
\hline 1,4-Dichlorobenzene & $<5$ & $<5$ & $<5$ & $<5$ & $\mu g / L$ & 5 & 5 & $<R L$ \\
\hline 2,4-Dinitrophenol & $<20$ & $<20$ & $<20$ & $<20$ & $\mu \mathrm{g} / \mathrm{L}$ & 20 & 20 & $<\mathrm{RL}$ \\
\hline 2,4-Dinitrotoluene & $<5$ & $<5$ & $<5$ & $<5$ & $\mu g / L$ & 5 & 5 & $<\mathrm{RL}$ \\
\hline 2-Methylphenol & $<5$ & $<5$ & $<5$ & $<5$ & $\mu \mathrm{g} / \mathrm{L}$ & 5 & 5 & $<\mathrm{RL}$ \\
\hline $\begin{array}{l}\text { 3-Methylphenol/ } \\
\text { 4-Methylphenol }\end{array}$ & $<5$ & $<5$ & $<5$ & $<5$ & $\mu \mathrm{g} / \mathrm{L}$ & 5 & 5 & $<\mathrm{RL}$ \\
\hline Hexachlorobenzene & $<5$ & $<5$ & $<5$ & $<5$ & $\mu g / L$ & 5 & 5 & $<\mathrm{RL}$ \\
\hline Hexachloroethane & $<5$ & $<5$ & $<5$ & $<5$ & $\mu \mathrm{g} / \mathrm{L}$ & 5 & 5 & $<\mathrm{RL}$ \\
\hline Nitrobenzene & $<5$ & $<5$ & $<5$ & $<5$ & $\mu g / L$ & 5 & 5 & $<\mathrm{RL}$ \\
\hline Pentachlorophenol & $<20$ & $<20$ & $<5$ & $<5$ & $\mu g / L$ & 20 & 5 & $<R L$ \\
\hline Pyridine & $<5$ & $<5$ & $<5$ & $<5$ & $\mu \mathrm{g} / \mathrm{L}$ & 5 & 5 & $<\mathrm{RL}$ \\
\hline Isobutanol & $<5$ & $<5$ & $<5$ & $<5$ & $\mu g / L$ & 5 & 5 & $<\mathrm{RL}$ \\
\hline
\end{tabular}


Waste Isolation Pilot Plant Annual Site Environmental Report for 2006 DOE/WIPP-07-2225

\begin{tabular}{|c|c|c|c|c|c|c|c|c|}
\hline \multicolumn{9}{|c|}{ Table F.3 - Analytical Results for Groundwater Sampled from Well WQSP-3 } \\
\hline \multirow[b]{3}{*}{ Parameter } & \multicolumn{4}{|c|}{ Concentration } & \multirow[b]{3}{*}{ Units } & & & \multirow[b]{3}{*}{$\begin{array}{c}95^{\text {th }} \\
\text { UTLV }^{\mathrm{a}}\end{array}$} \\
\hline & \multicolumn{2}{|c|}{ Round 22} & \multicolumn{2}{|c|}{ Round 23} & & \multicolumn{2}{|c|}{ Reporting Limit } & \\
\hline & Sample & Dup. & Sample & Dup. & & $\begin{array}{c}\text { Round } \\
22\end{array}$ & $\begin{array}{c}\text { Round } \\
23\end{array}$ & \\
\hline Alkalinity & 34 & 40 & 35 & 41 & $\mathrm{mg} / \mathrm{L}$ & 4 & 4 & 54.5 \\
\hline Chloride & 140,000 & 144,000 & 156,000 & 181,000 & $\mathrm{mg} / \mathrm{L}$ & 2 & 2 & 149,100 \\
\hline Density & 1.15 & 1.14 & 1.14 & 1.14 & $\mathrm{~g} / \mathrm{ml}$ & $N / A^{c}$ & $N / A^{c}$ & 1.17 \\
\hline Nitrate (as N) & $<0.10$ & $<0.10$ & $<0.10$ & $<0.10$ & $\mathrm{mg} / \mathrm{L}$ & 0.1 & 0.1 & 12 \\
\hline $\mathrm{pH}$ & 7.03 & 7.06 & 6.71 & 6.72 & $S U^{d}$ & $N / A^{c}$ & $N / A^{c}$ & $6.6-7.2$ \\
\hline Specific conductance & 210,000 & 210,000 & 182,000 & 184,000 & $\mu \mathrm{mhos} / \mathrm{cm}$ & $N / A^{c}$ & $N / A^{c}$ & 517,000 \\
\hline Sulfate & 8,780 & 9,050 & 9,520 & 9,610 & $\mathrm{mg} / \mathrm{L}$ & 1 & 1 & 8,015 \\
\hline Total dissolved solids & 200,000 & 200,000 & 225,000 & 205,500 & $\mathrm{mg} / \mathrm{L}$ & 10 & 10 & 261,000 \\
\hline Total organic carbon & $<1.0$ & $<1.0$ & $<1.0$ & $<1.0$ & $\mathrm{mg} / \mathrm{L}$ & 1 & 1 & 5 \\
\hline Total organic halogen & $<0.50$ & $<0.50$ & $<0.3$ & $<0.3$ & $\mathrm{mg} / \mathrm{L}$ & 0.30 & 0.30 & 55 \\
\hline Total suspended solids & $<1.0$ & $<1.0$ & $<1.0$ & $<1.0$ & $\mathrm{mg} / \mathrm{L}$ & 1 & 1 & 107 \\
\hline Antimony & $<0.250$ & $<0.250$ & $<0.250$ & $<0.250$ & $\mathrm{mg} / \mathrm{L}$ & 0.25 & 0.25 & $<1.0$ \\
\hline Arsenic & $<0.250$ & $<0.250$ & $<0.250$ & $<0.250$ & $\mathrm{mg} / \mathrm{L}$ & 0.25 & 0.25 & 0.207 \\
\hline Barium & $<0.02$ & $<0.02$ & $<0.02$ & $<0.02$ & $\mathrm{mg} / \mathrm{L}$ & 0.02 & 0.02 & $<1.0$ \\
\hline Beryllium & $<0.01$ & $<0.01$ & $<0.01$ & $<0.01$ & $\mathrm{mg} / \mathrm{L}$ & 0.01 & 0.01 & $<0.1$ \\
\hline Cadmium & $<0.025$ & $<0.025$ & $<0.025$ & $<0.025$ & $\mathrm{mg} / \mathrm{L}$ & 0.025 & 0.025 & $<0.50$ \\
\hline Calcium & 1,340 & 1,690 & 1,390 & 1,370 & $\mathrm{mg} / \mathrm{L}$ & 0.50 & 0.50 & 1,680 \\
\hline Chromium & $<0.025$ & $<0.025$ & $<0.025$ & $<0.025$ & $\mathrm{mg} / \mathrm{L}$ & 0.025 & 0.025 & $<2.0$ \\
\hline Iron & $<0.50$ & $<0.50$ & $<0.50$ & $<0.50$ & $\mathrm{mg} / \mathrm{L}$ & 0.50 & 0.50 & $<1.0$ \\
\hline Lead & $<0.10$ & $<0.10$ & $<0.10$ & $<0.10$ & $\mathrm{mg} / \mathrm{L}$ & 0.10 & 0.10 & 0.80 \\
\hline Magnesium & 2,280 & 2,590 & 2,200 & 2,160 & $\mathrm{mg} / \mathrm{L}$ & 0.50 & 0.50 & 2,625 \\
\hline Mercury & $<0.0002$ & $<0.0002$ & $<0.0002$ & $<0.0002$ & $\mathrm{mg} / \mathrm{L}$ & 0 & 0 & $<0.002$ \\
\hline Nickel & $<0.05$ & $<0.05$ & $<0.05$ & $<0.05$ & $\mathrm{mg} / \mathrm{L}$ & 0.05 & 0.05 & $<5.00$ \\
\hline Potassium & 2,870 & 2,910 & 1,640 & 1,580 & $\mathrm{mg} / \mathrm{L}$ & 0.50 & 0.50 & 3,438 \\
\hline Selenium & $<0.25$ & $<0.25$ & $<0.25$ & $<0.25$ & $\mathrm{mg} / \mathrm{L}$ & 0.25 & 0.25 & $<2.00$ \\
\hline Silver & $<0.013$ & $<0.013$ & $<0.013$ & $<0.013$ & $\mathrm{mg} / \mathrm{L}$ & 0.013 & 0.013 & 0.31 \\
\hline Sodium & 62,400 & 65,000 & 96,400 & 96,100 & $\mathrm{mg} / \mathrm{L}$ & 0.50 & 0.50 & 140,400 \\
\hline Thallium & $<0.025$ & $<0.025$ & $<0.025$ & $<0.025$ & $\mathrm{mg} / \mathrm{L}$ & 0.025 & 0.025 & 5.800 \\
\hline Vanadium & $<0.05$ & $<0.05$ & $<0.05$ & $<0.05$ & $\mathrm{mg} / \mathrm{L}$ & 0.05 & 0.05 & $<5.00$ \\
\hline
\end{tabular}




\section{Waste Isolation Pilot Plant Annual Site Environmental Report for 2006 DOE/WIPP-07-2225}

\begin{tabular}{|c|c|c|c|c|c|c|c|c|}
\hline \multirow[b]{3}{*}{ Parameter } & \multicolumn{4}{|c|}{ Concentration } & \multirow[b]{3}{*}{ Units } & \multirow{2}{*}{\multicolumn{2}{|c|}{ Reporting Limit }} & \multirow[b]{3}{*}{$\begin{array}{l}9^{\text {th }} \\
\text { UTLV }^{\text {a }}\end{array}$} \\
\hline & \multicolumn{2}{|c|}{ Round 22} & \multicolumn{2}{|c|}{ Round 23} & & & & \\
\hline & Sample & Dup. & Sample & Dup. & & $\begin{array}{c}\text { Round } \\
22\end{array}$ & $\begin{array}{l}\text { Round } \\
23\end{array}$ & \\
\hline 1,1,1-Trichloroethane & $<1$ & $<1$ & $<1$ & $<1$ & $\mu \mathrm{g} / \mathrm{L}$ & 1 & 1 & $<\mathrm{RL}^{\mathrm{b}}$ \\
\hline 1,1,2,2-Tetrachloroethane & $<1$ & $<1$ & $<1$ & $<1$ & $\mu \mathrm{g} / \mathrm{L}$ & 1 & 1 & $<\mathrm{RL}$ \\
\hline 1,1,2-Trichloroethane & $<1$ & $<1$ & $<1$ & $<1$ & $\mu \mathrm{g} / \mathrm{L}$ & 1 & 1 & $<R L$ \\
\hline 1,1-Dichloroethane & $<1$ & $<1$ & $<1$ & $<1$ & $\mu \mathrm{g} / \mathrm{L}$ & 1 & 1 & $<R L$ \\
\hline 1,1-Dichloroethylene & $<1$ & $<1$ & $<1$ & $<1$ & $\mu \mathrm{g} / \mathrm{L}$ & 1 & 1 & $<R L$ \\
\hline 1,2-Dichloroethane & $<1$ & $<1$ & $<1$ & $<1$ & $\mu \mathrm{g} / \mathrm{L}$ & 1 & 1 & $<\mathrm{RL}$ \\
\hline Carbon tetrachloride & $<1$ & $<1$ & $<1$ & $<1$ & $\mu \mathrm{g} / \mathrm{L}$ & 1 & 1 & $<\mathrm{RL}$ \\
\hline Chlorobenzene & $<1$ & $<1$ & $<1$ & $<1$ & $\mu \mathrm{g} / \mathrm{L}$ & 1 & 1 & $<R L$ \\
\hline Chloroform & $<1$ & $<1$ & $<1$ & $<1$ & $\mu \mathrm{g} / \mathrm{L}$ & 1 & 1 & $<\mathrm{RL}$ \\
\hline cis-1,2-Dichloroethylene & $<1$ & $<1$ & $<1$ & $<1$ & $\mu \mathrm{g} / \mathrm{L}$ & 1 & 1 & $<\mathrm{RL}$ \\
\hline trans-1,2-Dichloroethylene & $<1$ & $<1$ & $<1$ & $<1$ & $\mu \mathrm{g} / \mathrm{L}$ & 1 & 1 & $<R L$ \\
\hline Methyl ethyl ketone & $<5$ & $<5$ & $<5$ & $<5$ & $\mu \mathrm{g} / \mathrm{L}$ & 5 & 5 & $<R L$ \\
\hline Methylene chloride & $<5$ & $<5$ & $<5$ & $<5$ & $\mu \mathrm{g} / \mathrm{L}$ & 5 & 5 & $<\mathrm{RL}$ \\
\hline Tetrachloroethylene & $<1$ & $<1$ & $<1$ & $<1$ & $\mu \mathrm{g} / \mathrm{L}$ & 1 & 1 & $<R L$ \\
\hline Toluene & $<1$ & $<1$ & $<1$ & $<1$ & $\mu g / L$ & 1 & 1 & $<R L$ \\
\hline Trichloroethylene & $<1$ & $<1$ & $<1$ & $<1$ & $\mu \mathrm{g} / \mathrm{L}$ & 1 & 1 & $<R L$ \\
\hline Trichlorofluoromethane & $<1$ & $<1$ & $<1$ & $<1$ & $\mu \mathrm{g} / \mathrm{L}$ & 1 & 1 & $<\mathrm{RL}$ \\
\hline Vinyl chloride & $<1$ & $<1$ & $<1$ & $<1$ & $\mu g / L$ & 1 & 1 & $<R L$ \\
\hline Xylene & $<1$ & $<1$ & $<1$ & $<1$ & $\mu \mathrm{g} / \mathrm{L}$ & 1 & 1 & $<\mathrm{RL}$ \\
\hline 1,2-Dichlorobenzene & $<5$ & $<5$ & $<5$ & $<5$ & $\mu \mathrm{g} / \mathrm{L}$ & 5 & 5 & $<\mathrm{RL}$ \\
\hline 1,4-Dichlorobenzene & $<5$ & $<5$ & $<5$ & $<5$ & $\mu \mathrm{g} / \mathrm{L}$ & 5 & 5 & $<R L$ \\
\hline 2,4-Dinitrophenol & $<20$ & $<20$ & $<20$ & $<20$ & $\mu \mathrm{g} / \mathrm{L}$ & 20 & 20 & $<\mathrm{RL}$ \\
\hline 2,4-Dinitrotoluene & $<5$ & $<5$ & $<5$ & $<5$ & $\mu \mathrm{g} / \mathrm{L}$ & 5 & 5 & $<\mathrm{RL}$ \\
\hline 2-Methylphenol & $<5$ & $<5$ & $<5$ & $<5$ & $\mu g / L$ & 5 & 5 & $<R L$ \\
\hline $\begin{array}{l}\text { 3-Methylphenol/ } \\
\text { 4-Methylphenol }\end{array}$ & $<5$ & $<5$ & $<5$ & $<5$ & $\mu g / L$ & 5 & 5 & $<R L$ \\
\hline Hexachlorobenzene & $<5$ & $<5$ & $<5$ & $<5$ & $\mu \mathrm{g} / \mathrm{L}$ & 5 & 5 & $<\mathrm{RL}$ \\
\hline Hexachloroethane & $<5$ & $<5$ & $<5$ & $<5$ & $\mu \mathrm{g} / \mathrm{L}$ & 5 & 5 & $<\mathrm{RL}$ \\
\hline Nitrobenzene & $<5$ & $<5$ & $<5$ & $<5$ & $\mu \mathrm{g} / \mathrm{L}$ & 5 & 5 & $<\mathrm{RL}$ \\
\hline Pentachlorophenol & $<5$ & $<5$ & $<5$ & $<5$ & $\mu \mathrm{g} / \mathrm{L}$ & 5 & 5 & $<R L$ \\
\hline Pyridine & $<5$ & $<5$ & $<5$ & $<5$ & $\mu \mathrm{g} / \mathrm{L}$ & 5 & 5 & $<\mathrm{RL}$ \\
\hline Isobutanol & $<5$ & $<5$ & $<5$ & $<5$ & $\mu g / L$ & 5 & 5 & $<R L$ \\
\hline Alkalinity & 42 & 42 & 42 & 42 & $\mathrm{mg} / \mathrm{L}$ & 4 & 4 & 47.1 \\
\hline Chloride & 66,500 & 66,700 & 75,700 & 64,200 & $\mathrm{mg} / \mathrm{L}$ & 2 & 2 & 63,960 \\
\hline Density & 1.09 & 1.09 & 1.07 & 1.07 & $\mathrm{~g} / \mathrm{ml}$ & $N / A^{c}$ & $N / A^{c}$ & 1.1 \\
\hline Nitrate (as N) & $<0.10$ & $<0.10$ & $<0.10$ & $<0.10$ & $\mathrm{mg} / \mathrm{L}$ & 0.1 & 0.1 & 10 \\
\hline $\mathrm{pH}$ & 7.36 & 7.36 & 7.06 & 7.08 & $S U^{d}$ & $N / A^{c}$ & $N / A^{c}$ & $6.80-7.61$ \\
\hline Specific conductance & 128,000 & 128,000 & 123,000 & 123,000 & $\mu \mathrm{mhos} / \mathrm{cm}$ & $N / A^{c}$ & $N / A^{c}$ & 319,800 \\
\hline Sulfate & 7,920 & 8,370 & 7,390 & 7,420 & $\mathrm{mg} / \mathrm{L}$ & 2 & 2 & 7,927 \\
\hline Total dissolved solids & 127,00 & 108,000 & 112,000 & 114,000 & $\mathrm{mg} / \mathrm{L}$ & 10 & 10 & 123,500 \\
\hline Total organic carbon & $<1.0$ & $<1.0$ & $<1.0$ & $<1.0$ & $\mathrm{mg} / \mathrm{L}$ & 1 & 1 & 5 \\
\hline Total organic halogen & $<0.30$ & $<0.30$ & $<0.30$ & $<0.30$ & $\mathrm{mg} / \mathrm{L}$ & 0.30 & 0.30 & 17 \\
\hline Total suspended solids & 4.0 & 3.0 & $<1.0$ & $<1.0$ & $\mathrm{mg} / \mathrm{L}$ & 1 & 1 & 57 \\
\hline Antimony & 0.075 & 0.062 & $<0.05$ & $<0.05$ & $\mathrm{mg} / \mathrm{L}$ & 0.05 & 0.05 & 0.8 \\
\hline
\end{tabular}




\begin{tabular}{|c|c|c|c|c|c|c|c|c|}
\hline \multirow[b]{3}{*}{ Parameter } & \multicolumn{4}{|c|}{ Concentration } & \multirow[b]{3}{*}{ Units } & \multirow{2}{*}{\multicolumn{2}{|c|}{ Reporting Limit }} & \multirow[b]{3}{*}{$\begin{array}{l}9^{\text {th }} \\
\text { UTLV }^{\mathrm{a}}\end{array}$} \\
\hline & \multicolumn{2}{|c|}{ Round 22} & \multicolumn{2}{|c|}{ Round 23} & & & & \\
\hline & Sample & Dup. & Sample & Dup. & & $\begin{array}{c}\text { Round } \\
22\end{array}$ & $\begin{array}{c}\text { Round } \\
23\end{array}$ & \\
\hline Arsenic & $<0.05$ & $<0.05$ & $<0.05$ & $<0.05$ & $\mathrm{mg} / \mathrm{L}$ & 0.05 & 0.05 & $<0.50$ \\
\hline Barium & 0.071 & 0.072 & $<0.02$ & $<0.02$ & $\mathrm{mg} / \mathrm{L}$ & 0.02 & 0.02 & $<1.0$ \\
\hline Beryllium & 0.013 & 0.013 & $<0.01$ & $<0.01$ & $\mathrm{mg} / \mathrm{L}$ & 0.01 & 0.01 & 0.25 \\
\hline Cadmium & $<0.01$ & $<0.01$ & $<0.01$ & $<0.01$ & $\mathrm{mg} / \mathrm{L}$ & 0.01 & 0.01 & $<0.50$ \\
\hline Calcium & 1,870 & 1,900 & 1,770 & 1,720 & $\mathrm{mg} / \mathrm{L}$ & 0.50 & 0.50 & 1,834 \\
\hline Chromium & $<0.10$ & $<0.10$ & $<0.10$ & $<0.10$ & $\mathrm{mg} / \mathrm{L}$ & 0.10 & 0.10 & $<2.0$ \\
\hline Iron & 1.44 & 1.25 & $<0.50$ & $<0.50$ & $\mathrm{mg} / \mathrm{L}$ & 0.50 & 0.50 & $<4.0$ \\
\hline Lead & $<0.05$ & $<0.05$ & $<0.05$ & $<0.05$ & $\mathrm{mg} / \mathrm{L}$ & 0.05 & 0.05 & 0.525 \\
\hline Magnesium & 1,400 & 1,460 & 1,310 & 1,280 & $\mathrm{mg} / \mathrm{L}$ & 0.50 & 0.50 & 1,472 \\
\hline Mercury & $<0.0002$ & $<0.0002$ & $<0.0002$ & $<0.0002$ & $\mathrm{mg} / \mathrm{L}$ & 0.0002 & 0.0002 & $<0.002$ \\
\hline Nickel & $<0.025$ & $<0.025$ & $<0.025$ & $<0.025$ & $\mathrm{mg} / \mathrm{L}$ & 0.025 & 0.025 & $<5.00$ \\
\hline Potassium & 1,570 & 1,500 & 896 & 897 & $\mathrm{mg} / \mathrm{L}$ & 0.50 & 0.50 & 1,648 \\
\hline Selenium & $<0.10$ & $<0.10$ & $<0.01$ & $<0.01$ & $\mathrm{mg} / \mathrm{L}$ & 0.01 & 0.01 & 2.009 \\
\hline Silver & $<0.05$ & $<0.05$ & $<0.05$ & $<0.05$ & $\mathrm{mg} / \mathrm{L}$ & 0.05 & 0.05 & 0.519 \\
\hline Sodium & 29,500 & 28,800 & 38,400 & 37,900 & $\mathrm{mg} / \mathrm{L}$ & 0.50 & 0.50 & 38,790 \\
\hline Thallium & 0.093 & 0.078 & $<0.05$ & $<0.05$ & $\mathrm{mg} / \mathrm{L}$ & 0.05 & 0.05 & 1.00 \\
\hline Vanadium & 0.034 & 0.033 & $<0.025$ & $<0.025$ & $\mathrm{mg} / \mathrm{L}$ & 0.05 & 0.025 & $<5.00$ \\
\hline
\end{tabular}

Table F.5 - Analytical Results for Groundwater Sampled from Well WQSP-5

\begin{tabular}{|c|c|c|c|c|c|c|c|c|}
\hline \multirow[b]{3}{*}{ Parameter } & \multicolumn{4}{|c|}{ Concentration } & \multirow[b]{3}{*}{ Units } & & & \multirow[b]{3}{*}{$\begin{array}{c}9^{\text {th }} \\
\text { UTLV }^{\mathrm{a}}\end{array}$} \\
\hline & \multicolumn{2}{|c|}{ Round 22} & \multicolumn{2}{|c|}{ Round 23} & & \multicolumn{2}{|c|}{ Reporting Limit } & \\
\hline & Sample & Dup. & Sample & Dup. & & $\begin{array}{c}\text { Round } \\
22\end{array}$ & $\begin{array}{c}\text { Round } \\
23\end{array}$ & \\
\hline 1,1,1-Trichloroethane & $<1$ & $<1$ & $<1$ & $<1$ & $\mu g / L$ & 1 & 1 & $<R L^{b}$ \\
\hline 1,1,2,2-Tetrachloroethane & $<1$ & $<1$ & $<1$ & $<1$ & $\mu g / L$ & 1 & 1 & $<R L$ \\
\hline 1,1,2-Trichloroethane & $<1$ & $<1$ & $<1$ & $<1$ & $\mu g / L$ & 1 & 1 & $<\mathrm{RL}$ \\
\hline 1,1-Dichloroethane & $<1$ & $<1$ & $<1$ & $<1$ & $\mu g / L$ & 1 & 1 & $<R L$ \\
\hline 1,1-Dichloroethylene & $<1$ & $<1$ & $<1$ & $<1$ & $\mu \mathrm{g} / \mathrm{L}$ & 1 & 1 & $<\mathrm{RL}$ \\
\hline 1,2-Dichloroethane & $<1$ & $<1$ & $<1$ & $<1$ & $\mu g / L$ & 1 & 1 & $<\mathrm{RL}$ \\
\hline Carbon tetrachloride & $<1$ & $<1$ & $<1$ & $<1$ & $\mu g / L$ & 1 & 1 & $<\mathrm{RL}$ \\
\hline Chlorobenzene & $<1$ & $<1$ & $<1$ & $<1$ & $\mu g / L$ & 1 & 1 & $<\mathrm{RL}$ \\
\hline Chloroform & $<1$ & $<1$ & $<1$ & $<1$ & $\mu g / L$ & 1 & 1 & $<\mathrm{RL}$ \\
\hline cis-1,2-Dichloroethylene & $<1$ & $<1$ & $<1$ & $<1$ & $\mu g / L$ & 1 & 1 & $<\mathrm{RL}$ \\
\hline trans-1,2-Dichloroethylene & $<1$ & $<1$ & $<1$ & $<1$ & $\mu g / L$ & 1 & 1 & $<\mathrm{RL}$ \\
\hline Methyl ethyl ketone & $<5$ & $<5$ & $<5$ & $<5$ & $\mu g / L$ & 5 & 5 & $<\mathrm{RL}$ \\
\hline Methylene chloride & $<5$ & $<5$ & $<5$ & $<5$ & $\mu g / L$ & 5 & 5 & $<R L$ \\
\hline Tetrachloroethylene & $<1$ & $<1$ & $<1$ & $<1$ & $\mu g / L$ & 1 & 1 & $<R L$ \\
\hline Toluene & $<1$ & $<1$ & $<1$ & $<1$ & $\mu g / L$ & 1 & 1 & $<R L$ \\
\hline Trichloroethylene & $<1$ & $<1$ & $<1$ & $<1$ & $\mu g / L$ & 1 & 1 & $<R L$ \\
\hline Trichlorofluoromethane & $<1$ & $<1$ & $<1$ & $<1$ & $\mu g / L$ & 1 & 1 & $<\mathrm{RL}$ \\
\hline
\end{tabular}




\begin{tabular}{|c|c|c|c|c|c|c|c|c|}
\hline \multirow[b]{3}{*}{ Parameter } & \multicolumn{4}{|c|}{ Concentration } & \multirow[b]{3}{*}{ Units } & & & \multirow[b]{3}{*}{$\begin{array}{c}9^{\text {th }} \\
\text { UTLV }^{\mathrm{a}}\end{array}$} \\
\hline & \multicolumn{2}{|c|}{ Round 22} & \multicolumn{2}{|c|}{ Round 23} & & \multicolumn{2}{|c|}{ Reporting Limit } & \\
\hline & Sample & Dup. & Sample & Dup. & & $\begin{array}{c}\text { Round } \\
22\end{array}$ & $\begin{array}{c}\text { Round } \\
23\end{array}$ & \\
\hline Vinyl chloride & $<1$ & $<1$ & $<1$ & $<1$ & $\mu \mathrm{g} / \mathrm{L}$ & 1 & 1 & $<\mathrm{RL}$ \\
\hline Xylene & $<1$ & $<1$ & $<1$ & $<1$ & $\mu \mathrm{g} / \mathrm{L}$ & 1 & 1 & $<R L$ \\
\hline 1,2-Dichlorobenzene & $<5$ & $<5$ & $<5$ & $<5$ & $\mu g / L$ & 5 & 5 & $<R L$ \\
\hline 1,4-Dichlorobenzene & $<5$ & $<5$ & $<5$ & $<5$ & $\mu g / L$ & 5 & 5 & $<\mathrm{RL}$ \\
\hline 2,4-Dinitrophenol & $<20$ & $<20$ & $<20$ & $<20$ & $\mu \mathrm{g} / \mathrm{L}$ & 20 & 20 & $<\mathrm{RL}$ \\
\hline 2,4-Dinitrotoluene & $<5$ & $<5$ & $<5$ & $<5$ & $\mu \mathrm{g} / \mathrm{L}$ & 5 & 5 & $<R L$ \\
\hline 2-Methylphenol & $<5$ & $<5$ & $<5$ & $<5$ & $\mu \mathrm{g} / \mathrm{L}$ & 5 & 5 & $<\mathrm{RL}$ \\
\hline $\begin{array}{l}\text { 3-Methylphenol/ } \\
\text { 4-Methylphenol }\end{array}$ & $<5$ & $<5$ & $<5$ & $<5$ & $\mu \mathrm{g} / \mathrm{L}$ & 5 & 5 & $<\mathrm{RL}$ \\
\hline Hexachlorobenzene & $<5$ & $<5$ & $<5$ & $<5$ & $\mu \mathrm{g} / \mathrm{L}$ & 5 & 5 & $<\mathrm{RL}$ \\
\hline Hexachloroethane & $<5$ & $<5$ & $<5$ & $<5$ & $\mu g / L$ & 5 & 5 & $<R L$ \\
\hline Nitrobenzene & $<5$ & $<5$ & $<5$ & $<5$ & $\mu \mathrm{g} / \mathrm{L}$ & 5 & 5 & $<\mathrm{RL}$ \\
\hline Pentachlorophenol & $<5$ & $<5$ & $<5$ & $<5$ & $\mu \mathrm{g} / \mathrm{L}$ & 5 & 5 & $<\mathrm{RL}$ \\
\hline Pyridine & $<5$ & $<5$ & $<5$ & $<5$ & $\mu g / L$ & 5 & 5 & $<R L$ \\
\hline Isobutanol & $<5$ & $<5$ & $<5$ & $<5$ & $\mu g / L$ & 5 & 5 & $<\mathrm{RL}$ \\
\hline Alkalinity & 48 & 52 & 46 & 46 & $\mathrm{mg} / \mathrm{L}$ & 4 & 4 & 56 \\
\hline Chloride & 15,900 & 16,600 & 17,400 & 17,600 & $\mathrm{mg} / \mathrm{L}$ & 2 & 2 & 18,100 \\
\hline Density & 1.03 & 1.02 & 1.03 & 1.02 & $\mathrm{~g} / \mathrm{ml}$ & $N / A^{c}$ & $N / A^{c}$ & 1.04 \\
\hline Nitrate (as N) & $<0.10$ & $<0.10$ & $<0.10$ & $<0.10$ & $\mathrm{mg} / \mathrm{L}$ & 0.1 & 0.1 & 10 \\
\hline $\mathrm{pH}$ & 7.65 & 7.67 & 7.53 & 7.51 & $S U^{d}$ & $N / A^{c}$ & $N / A^{c}$ & $7.40-7.90$ \\
\hline Specific conductance & 42,400 & 42,300 & 43,529 & 43,277 & $\mu \mathrm{mhos} / \mathrm{cm}$ & $N / A^{c}$ & $\mathrm{~N} / \mathrm{A}^{\mathrm{c}}$ & 67,700 \\
\hline Sulfate & 5,280 & 5,630 & 6,430 & 6,320 & $\mathrm{mg} / \mathrm{L}$ & 2 & 2 & 6,129 \\
\hline Total dissolved solids & 30,000 & 31,600 & 32,550 & 33,450 & $\mathrm{mg} / \mathrm{L}$ & 10 & 10 & 43,950 \\
\hline Total organic carbon & $<1.0$ & $<1.0$ & $<1.0$ & $<1.0$ & $\mathrm{mg} / \mathrm{L}$ & 1 & 1 & 5 \\
\hline Total organic halogen & $<0.30$ & 0.30 & $<0.30$ & $<0.30$ & $\mathrm{mg} / \mathrm{L}$ & 0.30 & 0.30 & 8.37 \\
\hline Total suspended solids & $<1.0$ & $<1.0$ & $<1.0$ & $<1.0$ & $\mathrm{mg} / \mathrm{L}$ & 1 & 1 & 10 \\
\hline Antimony & $<0.05$ & $<0.05$ & $<0.05$ & $<0.05$ & $\mathrm{mg} / \mathrm{L}$ & 0.05 & 0.05 & 0.073 \\
\hline Arsenic & $<0.10$ & $<0.10$ & $<0.10$ & $<0.10$ & $\mathrm{mg} / \mathrm{L}$ & 0.10 & 0.10 & 0.50 \\
\hline Barium & $<0.02$ & $<0.02$ & $<0.02$ & $<0.02$ & $\mathrm{mg} / \mathrm{L}$ & 0.02 & 0.02 & 1 \\
\hline Beryllium & $<0.025$ & $<0.025$ & $<0.025$ & $<0.025$ & $\mathrm{mg} / \mathrm{L}$ & 0.025 & 0.025 & 0.02 \\
\hline Cadmium & $<0.01$ & $<0.01$ & $<0.01$ & $<0.01$ & $\mathrm{mg} / \mathrm{L}$ & 0.01 & 0.01 & 0.05 \\
\hline Calcium & 1,050 & 1,120 & 1,030 & 1,000 & $\mathrm{mg} / \mathrm{L}$ & 0.50 & 0.50 & 1,303 \\
\hline Chromium & $<0.025$ & $<0.025$ & $<0.250$ & $<0.250$ & $\mathrm{mg} / \mathrm{L}$ & 0.025 & 0.025 & 0.50 \\
\hline Iron & $<0.50$ & $<0.50$ & $<0.50$ & $<0.50$ & $\mathrm{mg} / \mathrm{L}$ & 0.50 & 0.50 & 0.795 \\
\hline Lead & $<0.05$ & $<0.05$ & $<0.05$ & $<0.05$ & $\mathrm{mg} / \mathrm{L}$ & 0.05 & 0.05 & 0.05 \\
\hline Magnesium & 489 & 533 & 460 & 426 & $\mathrm{mg} / \mathrm{L}$ & 0.50 & 0.50 & 547.0 \\
\hline Mercury & $<0.0002$ & $<0.0002$ & $<0.0002$ & $<0.0002$ & $\mathrm{mg} / \mathrm{L}$ & 0 & 0 & 0.002 \\
\hline Nickel & $<0.025$ & $<0.025$ & $<0.025$ & $<0.025$ & $\mathrm{mg} / \mathrm{L}$ & 0.025 & 0.025 & 0.10 \\
\hline Potassium & 568 & 635 & 337 & 317 & $\mathrm{mg} / \mathrm{L}$ & 0.50 & 0.50 & 622.0 \\
\hline Selenium & $<0.05$ & $<0.05$ & $<0.05$ & $<0.05$ & $\mathrm{mg} / \mathrm{L}$ & 0.05 & 0.05 & 0.10 \\
\hline Silver & $<0.013$ & $<0.013$ & $<0.013$ & $<0.013$ & $\mathrm{mg} / \mathrm{L}$ & 0.013 & 0.013 & 0.50 \\
\hline
\end{tabular}




\begin{tabular}{|c|c|c|c|c|c|c|c|c|}
\hline \multirow[b]{3}{*}{ Parameter } & \multicolumn{4}{|c|}{ Concentration } & \multirow[b]{3}{*}{ Units } & & & \multirow[b]{3}{*}{$\begin{array}{c}9^{\text {th }} \\
\text { UTLV }^{\mathrm{a}}\end{array}$} \\
\hline & \multicolumn{2}{|c|}{ Round 22} & \multicolumn{2}{|c|}{ Round 23} & & \multicolumn{2}{|c|}{ Reporting Limit } & \\
\hline & Sample & Dup. & Sample & Dup. & & $\begin{array}{c}\text { Round } \\
22\end{array}$ & $\begin{array}{c}\text { Round } \\
23\end{array}$ & \\
\hline Sodium & 8,180 & 8,130 & 10,800 & 10,400 & $\mathrm{mg} / \mathrm{L}$ & 0.50 & 0.50 & 11,190 \\
\hline Thallium & $<0.10$ & $<0.10$ & $<0.10$ & $<0.10$ & $\mathrm{mg} / \mathrm{L}$ & 0.10 & 0.10 & 0.209 \\
\hline Vanadium & $<0.025$ & $<0.025$ & $<0.025$ & $<0.025$ & $\mathrm{mg} / \mathrm{L}$ & 0.025 & 0.025 & 2.70 \\
\hline
\end{tabular}

Table F.6 - Analytical Results for Groundwater Sampled from Well WQSP-6

\section{Concentration}

\begin{tabular}{|c|c|c|c|c|c|c|c|c|}
\hline \multirow[b]{2}{*}{ Parameter } & \multicolumn{2}{|c|}{ Round 22} & \multicolumn{2}{|c|}{ Round 23} & \multirow[b]{2}{*}{ Units } & \multicolumn{2}{|c|}{ Reporting LIMIT } & \multirow[b]{2}{*}{$\begin{array}{l}95^{\text {th }} \\
\text { UTLV }\end{array}$} \\
\hline & Sample & Dup. & Sample & Dup. & & $\begin{array}{c}\text { Round } \\
22\end{array}$ & $\begin{array}{c}\text { Round } \\
23\end{array}$ & \\
\hline 1,1,1-Trichloroethane & $<1$ & $<1$ & $<1$ & $<1$ & $\mu \mathrm{g} / \mathrm{L}$ & 1 & 1 & $<\mathrm{RL}^{\mathrm{b}}$ \\
\hline 1,1,2,2-Tetrachloroethane & $<1$ & $<1$ & $<1$ & $<1$ & $\mu g / L$ & 1 & 1 & $<R L$ \\
\hline 1,1,2-Trichloroethane & $<1$ & $<1$ & $<1$ & $<1$ & $\mu g / L$ & 1 & 1 & $<R L$ \\
\hline 1,1-Dichloroethane & $<1$ & $<1$ & $<1$ & $<1$ & $\mu g / L$ & 1 & 1 & $<R L$ \\
\hline 1,1-Dichloroethylene & $<1$ & $<1$ & $<1$ & $<1$ & $\mu g / L$ & 1 & 1 & $<\mathrm{RL}$ \\
\hline 1,2-Dichloroethane & $<1$ & $<1$ & $<1$ & $<1$ & $\mu g / L$ & 1 & 1 & $<R L$ \\
\hline Carbon tetrachloride & $<1$ & $<1$ & $<1$ & $<1$ & $\mu g / L$ & 1 & 1 & $<R L$ \\
\hline Chlorobenzene & $<1$ & $<1$ & $<1$ & $<1$ & $\mu g / L$ & 1 & 1 & $<\mathrm{RL}$ \\
\hline Chloroform & $<1$ & $<1$ & $<1$ & $<1$ & $\mu \mathrm{g} / \mathrm{L}$ & 1 & 1 & $<\mathrm{RL}$ \\
\hline cis-1,2-Dichloroethylene & $<1$ & $<1$ & $<1$ & $<1$ & $\mu \mathrm{g} / \mathrm{L}$ & 1 & 1 & $<\mathrm{RL}$ \\
\hline trans-1,2-Dichloroethylene & $<1$ & $<1$ & $<1$ & $<1$ & $\mu g / L$ & 1 & 1 & $<R L$ \\
\hline Methyl ethyl ketone & $<5$ & $<5$ & $<5$ & $<5$ & $\mu g / L$ & 5 & 5 & $<R L$ \\
\hline Methylene chloride & $<5$ & $<5$ & $<5$ & $<5$ & $\mu g / L$ & 5 & 5 & $<R L$ \\
\hline Tetrachloroethylene & $<1$ & $<1$ & $<1$ & $<1$ & $\mu g / L$ & 1 & 1 & $<R L$ \\
\hline Toluene & $<1$ & $<1$ & $<1$ & $<1$ & $\mu g / L$ & 1 & 1 & $<R L$ \\
\hline Trichloroethylene & $<1$ & $<1$ & $<1$ & $<1$ & $\mu g / L$ & 1 & 1 & $<\mathrm{RL}$ \\
\hline Trichlorofluoromethane & $<1$ & $<1$ & $<1$ & $<1$ & $\mu g / L$ & 1 & 1 & $<\mathrm{RL}$ \\
\hline Vinyl chloride & $<1$ & $<1$ & $<1$ & $<1$ & $\mu g / L$ & 1 & 1 & $<\mathrm{RL}$ \\
\hline Xylene & $<1$ & $<1$ & $<1$ & $<1$ & $\mu \mathrm{g} / \mathrm{L}$ & 1 & 1 & $<R L$ \\
\hline 1,2-Dichlorobenzene & $<5$ & $<5$ & $<5$ & $<5$ & $\mu g / L$ & 5 & 5 & $<R L$ \\
\hline 1,4-Dichlorobenzene & $<5$ & $<5$ & $<5$ & $<5$ & $\mu g / L$ & 5 & 5 & $<R L$ \\
\hline 2,4-Dinitrophenol & $<20$ & $<20$ & $<20$ & $<20$ & $\mu \mathrm{g} / \mathrm{L}$ & 20 & 20 & $<\mathrm{RL}$ \\
\hline 2,4-Dinitrotoluene & $<5$ & $<5$ & $<5$ & $<5$ & $\mu g / L$ & 5 & 5 & $<R L$ \\
\hline 2-Methylphenol & $<5$ & $<5$ & $<5$ & $<5$ & $\mu g / L$ & 5 & 5 & $<R L$ \\
\hline $\begin{array}{l}\text { 3-Methylphenol } \\
\text { 4-Methylphenol }\end{array}$ & $<5$ & $<5$ & $<5$ & $<5$ & $\mu g / L$ & 5 & 5 & $<R L$ \\
\hline Hexachlorobenzene & $<5$ & $<5$ & $<5$ & $<5$ & $\mu g / L$ & 5 & 5 & $<\mathrm{RL}$ \\
\hline Hexachloroethane & $<5$ & $<5$ & $<5$ & $<5$ & $\mu g / L$ & 5 & 5 & $<R L$ \\
\hline Nitrobenzene & $<5$ & $<5$ & $<5$ & $<5$ & $\mu g / L$ & 5 & 5 & $<R L$ \\
\hline Pentachlorophenol & $<20$ & $<20$ & $<20$ & $<20$ & $\mu g / L$ & 5 & 5 & $<\mathrm{RL}$ \\
\hline Pyridine & $<5$ & $<5$ & $<5$ & $<5$ & $\mu g / L$ & 5 & 5 & $<R L$ \\
\hline
\end{tabular}


Waste Isolation Pilot Plant Annual Site Environmental Report for 2006 DOE/WIPP-07-2225

\begin{tabular}{|c|c|c|c|c|c|c|c|c|}
\hline \multirow[b]{3}{*}{ Parameter } & \multicolumn{4}{|c|}{ Concentration } & \multirow[b]{3}{*}{ Units } & & & \multirow[b]{3}{*}{$\begin{array}{l}95^{\text {th }} \\
\text { UTLV }^{\mathrm{a}}\end{array}$} \\
\hline & \multicolumn{2}{|c|}{ Round 22} & \multicolumn{2}{|c|}{ Round 23} & & \multicolumn{2}{|c|}{ Reporting LIMIT } & \\
\hline & Sample & Dup. & Sample & Dup. & & $\begin{array}{c}\text { Round } \\
22\end{array}$ & $\begin{array}{c}\text { Round } \\
23\end{array}$ & \\
\hline Sobutanol & $<5$ & $<5$ & $<5$ & $<5$ & $\mu \mathrm{g} / \mathrm{L}$ & 5 & 5 & $<R L$ \\
\hline Alkalinity & 52 & 54 & 48 & 48 & $\mathrm{mg} / \mathrm{L}$ & 4 & 4 & 55.8 \\
\hline Chloride & 6,250 & 5,990 & 6,410 & 6,250 & $\mathrm{mg} / \mathrm{L}$ & 2 & 2 & 6,200 \\
\hline Density & 1.01 & 1.02 & 1.02 & 1.01 & $\mathrm{~g} / \mathrm{ml}$ & $N / A^{c}$ & $N / A^{c}$ & 1.02 \\
\hline Nitrate (as N) & $<0.10$ & $<0.10$ & $<0.10$ & $<0.10$ & $\mathrm{mg} / \mathrm{L}$ & 0.1 & 0.1 & 7.45 \\
\hline $\mathrm{pH}$ & 7.79 & 7.82 & 7.68 & 7.71 & $S U^{d}$ & $N / A^{c}$ & $N / A^{c}$ & $7.50-7.90$ \\
\hline Specific conductance & 20,100 & 20,200 & 20,800 & 20,700 & $\mu \mathrm{mhos} / \mathrm{cm}$ & $N / A^{c}$ & $N / A^{c}$ & 27,660 \\
\hline Sulfate & 5,800 & 5,500 & 4,930 & 4,650 & $\mathrm{mg} / \mathrm{L}$ & 2 & 2 & 5,557 \\
\hline Total dissolved solids & 14,900 & 14,600 & 13,360 & 14,060 & $\mathrm{mg} / \mathrm{L}$ & 10 & 10 & 22,500 \\
\hline Total organic carbon & $<1.0$ & $<1.0$ & $<1.0$ & $<1.0$ & $\mathrm{mg} / \mathrm{L}$ & 1 & 1 & 10.14 \\
\hline Total organic halogen & $<0.30$ & $<0.30$ & $<0.30$ & $<0.30$ & $\mathrm{mg} / \mathrm{L}$ & 0.30 & 0.30 & 1.54 \\
\hline Total suspended solids & 32 & 34 & $<1.0$ & $<1.0$ & $\mathrm{mg} / \mathrm{L}$ & 1 & 1 & 14.8 \\
\hline Antimony & $<0.025$ & $<0.025$ & $<0.025$ & $<0.025$ & $\mathrm{mg} / \mathrm{L}$ & 0.025 & 0.025 & 0.14 \\
\hline Arsenic & $<0.10$ & $<0.10$ & $<0.10$ & $<0.10$ & $\mathrm{mg} / \mathrm{L}$ & 0.10 & 0.10 & $<0.50$ \\
\hline Barium & $<0.02$ & $<0.02$ & $<0.02$ & $<0.02$ & $\mathrm{mg} / \mathrm{L}$ & 0.02 & 0.02 & $<1.0$ \\
\hline Beryllium & $<0.01$ & $<0.01$ & $<0.01$ & $<0.01$ & $\mathrm{mg} / \mathrm{L}$ & 0.01 & 0.01 & $<0.020$ \\
\hline Cadmium & $<0.01$ & $<0.01$ & $<0.01$ & $<0.01$ & $\mathrm{mg} / \mathrm{L}$ & 0.01 & 0.01 & $<0.050$ \\
\hline Calcium & 766 & 785 & 675 & 721 & $\mathrm{mg} / \mathrm{L}$ & 0.50 & 0.50 & 796 \\
\hline Chromium & $<0.025$ & $<0.025$ & $<0.025$ & $<0.025$ & $\mathrm{mg} / \mathrm{L}$ & 0.025 & 0.025 & $<0.50$ \\
\hline Iron & $<0.50$ & $<0.50$ & $<0.50$ & $<0.50$ & $\mathrm{mg} / \mathrm{L}$ & 0.50 & 0.50 & 3.105 \\
\hline Lead & $<0.02$ & $<0.02$ & $<0.02$ & $<0.02$ & $\mathrm{mg} / \mathrm{L}$ & 0.02 & 0.02 & 0.150 \\
\hline Magnesium & 237 & 244 & 201 & 215 & $\mathrm{mg} / \mathrm{L}$ & 0.50 & 0.50 & 255 \\
\hline Mercury & $<0.0002$ & $<0.0002$ & $<0.0002$ & $<0.0002$ & $\mathrm{mg} / \mathrm{L}$ & 0 & 0 & $<0.002$ \\
\hline Nickel & $<0.025$ & $<0.03$ & $<0.03$ & $<0.03$ & $\mathrm{mg} / \mathrm{L}$ & 0.025 & 0.03 & $<0.50$ \\
\hline Potassium & 288 & 292 & 153 & 163 & $\mathrm{mg} / \mathrm{L}$ & 0.50 & 0.50 & 270 \\
\hline Selenium & $<0.025$ & $<0.025$ & $<0.025$ & $<0.025$ & $\mathrm{mg} / \mathrm{L}$ & 0.025 & 0.025 & $<0.10$ \\
\hline Silver & $<0.013$ & $<0.013$ & $<0.013$ & $<0.013$ & $\mathrm{mg} / \mathrm{L}$ & 0.013 & 0.013 & $<0.50$ \\
\hline Sodium & 3,470 & 3,650 & 4,400 & 4,660 & $\mathrm{mg} / \mathrm{L}$ & 0.50 & 0.50 & 6,290 \\
\hline Thallium & $<0.075$ & $<0.075$ & $<0.075$ & $<0.075$ & $\mathrm{mg} / \mathrm{L}$ & 0.075 & 0.075 & 0.560 \\
\hline Vanadium & $<0.025$ & $<0.025$ & $<0.025$ & $<0.025$ & $\mathrm{mg} / \mathrm{L}$ & 0.025 & 0.025 & $<0.10$ \\
\hline
\end{tabular}

${ }^{\mathrm{A}} 95^{\text {th }}$ Upper tolerance limit value, equivalent to $95 \%$ confidence limit

${ }^{\mathrm{b}}$ Reporting limit

${ }^{\mathrm{c}}$ Not applicable

${ }^{\mathrm{d}}$ Standard unit 
Table F.7 - Analytical Results for Groundwater Sampled from Well WQSP-6A

Concentration

\begin{tabular}{|c|c|c|c|c|c|c|c|c|}
\hline \multirow[b]{2}{*}{ Parameter } & \multicolumn{2}{|c|}{ Round 22} & \multicolumn{2}{|c|}{ Round 23} & \multirow[b]{2}{*}{ Units } & \multicolumn{2}{|c|}{ Reporting LIMIT } & \multirow[b]{2}{*}{$\begin{array}{l}95^{\text {th }} \\
\text { UTLV }\end{array}$} \\
\hline & Sample & Dup. & Sample & Dup. & & $\begin{array}{c}\text { Round } \\
22\end{array}$ & $\begin{array}{c}\text { Round } \\
23\end{array}$ & \\
\hline 1,1,1-Trichloroethane & $<1$ & $<1$ & $<1$ & $<1$ & $\mu \mathrm{g} / \mathrm{L}$ & 1 & 1 & $<\mathrm{RL}^{\mathrm{b}}$ \\
\hline 1,1,2,2-Tetrachloroethane & $<1$ & $<1$ & $<1$ & $<1$ & $\mu \mathrm{g} / \mathrm{L}$ & 1 & 1 & $<R L$ \\
\hline 1,1,2-Trichloroethane & $<1$ & $<1$ & $<1$ & $<1$ & $\mu \mathrm{g} / \mathrm{L}$ & 1 & 1 & $<\mathrm{RL}$ \\
\hline 1,1-Dichloroethane & $<1$ & $<1$ & $<1$ & $<1$ & $\mu \mathrm{g} / \mathrm{L}$ & 1 & 1 & $<\mathrm{RL}$ \\
\hline 1,1-Dichloroethylene & $<1$ & $<1$ & $<1$ & $<1$ & $\mu \mathrm{g} / \mathrm{L}$ & 1 & 1 & $<\mathrm{RL}$ \\
\hline 1,2-Dichloroethane & $<1$ & $<1$ & $<1$ & $<1$ & $\mu \mathrm{g} / \mathrm{L}$ & 1 & 1 & $<\mathrm{RL}$ \\
\hline Carbon tetrachloride & $<1$ & $<1$ & $<1$ & $<1$ & $\mu \mathrm{g} / \mathrm{L}$ & 1 & 1 & $<\mathrm{RL}$ \\
\hline Chlorobenzene & $<1$ & $<1$ & $<1$ & $<1$ & $\mu \mathrm{g} / \mathrm{L}$ & 1 & 1 & $<\mathrm{RL}$ \\
\hline Chloroform & $<1$ & $<1$ & $<1$ & $<1$ & $\mu \mathrm{g} / \mathrm{L}$ & 1 & 1 & $<\mathrm{RL}$ \\
\hline cis-1,2-Dichloroethylene & $<1$ & $<1$ & $<1$ & $<1$ & $\mu \mathrm{g} / \mathrm{L}$ & 1 & 1 & $<\mathrm{RL}$ \\
\hline trans-1,2-Dichloroethylene & $<1$ & $<1$ & $<1$ & $<1$ & $\mu \mathrm{g} / \mathrm{L}$ & 1 & 1 & $<\mathrm{RL}$ \\
\hline Methyl ethyl ketone & $<5$ & $<5$ & $<5$ & $<5$ & $\mu \mathrm{g} / \mathrm{L}$ & 5 & 5 & $<R L$ \\
\hline Methylene chloride & $<5$ & $<5$ & $<5$ & $<5$ & $\mu \mathrm{g} / \mathrm{L}$ & 5 & 5 & $<\mathrm{RL}$ \\
\hline Tetrachloroethylene & $<1$ & $<1$ & $<1$ & $<1$ & $\mu \mathrm{g} / \mathrm{L}$ & 1 & 1 & $<\mathrm{RL}$ \\
\hline Toluene & $<1$ & $<1$ & $<1$ & $<1$ & $\mu \mathrm{g} / \mathrm{L}$ & 1 & 1 & $<\mathrm{RL}$ \\
\hline Trichloroethylene & $<1$ & $<1$ & $<1$ & $<1$ & $\mu \mathrm{g} / \mathrm{L}$ & 1 & 1 & $<\mathrm{RL}$ \\
\hline Trichlorofluoromethane & $<1$ & $<1$ & $<1$ & $<1$ & $\mu \mathrm{g} / \mathrm{L}$ & 1 & 1 & $<R L$ \\
\hline Vinyl chloride & $<1$ & $<1$ & $<1$ & $<1$ & $\mu \mathrm{g} / \mathrm{L}$ & 1 & 1 & $<R L$ \\
\hline Xylene & $<1$ & $<1$ & $<1$ & $<1$ & $\mu \mathrm{g} / \mathrm{L}$ & 1 & 1 & $<\mathrm{RL}$ \\
\hline 1,2-Dichlorobenzene & $<5$ & $<5$ & $<5$ & $<5$ & $\mu \mathrm{g} / \mathrm{L}$ & 5 & 5 & $<R L$ \\
\hline 1,4-Dichlorobenzene & $<5$ & $<5$ & $<5$ & $<5$ & $\mu \mathrm{g} / \mathrm{L}$ & 5 & 5 & $<\mathrm{RL}$ \\
\hline 2,4-Dinitrophenol & $<20$ & $<20$ & $<20$ & $<20$ & $\mu \mathrm{g} / \mathrm{L}$ & 20 & 20 & $<\mathrm{RL}$ \\
\hline 2,4-Dinitrotoluene & $<5$ & $<5$ & $<5$ & $<5$ & $\mu \mathrm{g} / \mathrm{L}$ & 5 & 5 & $<R L$ \\
\hline 2-Methylphenol & $<5$ & $<5$ & $<5$ & $<5$ & $\mu \mathrm{g} / \mathrm{L}$ & 5 & 5 & $<\mathrm{RL}$ \\
\hline $\begin{array}{l}\text { 3-Methylphenol/ } \\
\text { 4-Methylphenol }\end{array}$ & $<5$ & $<5$ & $<5$ & $<5$ & $\mu \mathrm{g} / \mathrm{L}$ & 5 & 5 & $<\mathrm{RL}$ \\
\hline Hexachlorobenzene & $<5$ & $<5$ & $<5$ & $<5$ & $\mu \mathrm{g} / \mathrm{L}$ & 5 & 5 & $<\mathrm{RL}$ \\
\hline Hexachloroethane & $<5$ & $<5$ & $<5$ & $<5$ & $\mu \mathrm{g} / \mathrm{L}$ & 5 & 5 & $<R L$ \\
\hline Nitrobenzene & $<5$ & $<5$ & $<5$ & $<5$ & $\mu \mathrm{g} / \mathrm{L}$ & 5 & 5 & $<\mathrm{RL}$ \\
\hline Pentachlorophenol & $<20$ & $<20$ & $<5$ & $<5$ & $\mu \mathrm{g} / \mathrm{L}$ & 20 & 5 & $<\mathrm{RL}$ \\
\hline Pyridine & $<5$ & $<5$ & $<5$ & $<5$ & $\mu \mathrm{g} / \mathrm{L}$ & 5 & 5 & $<R L$ \\
\hline Isobutanol & $<5$ & $<5$ & $<5$ & $<5$ & $\mathrm{mg} / \mathrm{L}$ & 5 & 5 & $<R L$ \\
\hline Alkalinity & 106 & 100 & 108 & 110 & $\mathrm{mg} / \mathrm{L}$ & 4 & 4 & 113 \\
\hline Chloride & 450 & 446 & 360 & 381 & $\mathrm{mg} / \mathrm{L}$ & 2 & 2 & 1040 \\
\hline Density & 1.01 & 1.01 & 1.01 & 1.00 & $\mathrm{~g} / \mathrm{ml}$ & $N / A^{c}$ & $N / A^{c}$ & 1.01 \\
\hline Nitrate (as N) & 2.50 & 2.37 & 6.00 & 6.26 & $\mathrm{mg} / \mathrm{L}$ & 0.1 & 0.01 & 12.2 \\
\hline $\mathrm{pH}$ & 7.55 & 7.59 & 7.22 & 7.21 & $S U^{d}$ & $N / A^{c}$ & $N / A^{c}$ & $6.80-8.00$ \\
\hline Specific conductance & 3,870 & 3,860 & 3,960 & 3,920 & $\mu \mathrm{mhos} / \mathrm{cm}$ & $N / A^{c}$ & $N / A^{c}$ & 5,192 \\
\hline Sulfate & 2,210 & 2,220 & 2,120 & 2,080 & $\mathrm{mg} / \mathrm{L}$ & 2 & 2 & 2,543 \\
\hline Total dissolved solids & 3,200 & 3,200 & 3,515 & 3,435 & $\mathrm{mg} / \mathrm{L}$ & 10 & 10 & 4,600 \\
\hline Total organic carbon & 2.9 & 2.2 & $<1.0$ & $<1.0$ & $\mathrm{mg} / \mathrm{L}$ & 1 & 1 & 15.45 \\
\hline Total organic halogen & $<0.077$ & $<0.077$ & $<0.06$ & $<0.06$ & $\mathrm{mg} / \mathrm{L}$ & 0.03 & 0.03 & 0.19 \\
\hline Total suspended solids & 18 & 17 & $<1.0$ & $<1.0$ & $\mathrm{mg} / \mathrm{L}$ & 1.0 & 1.0 & 91 \\
\hline
\end{tabular}


Waste Isolation Pilot Plant Annual Site Environmental Report for 2006 DOE/WIPP-07-2225

\section{Table F.7 - Analytical Results for Groundwater Sampled from Well WQSP-6A}

\begin{tabular}{|c|c|c|c|c|c|c|c|c|}
\hline \multirow[b]{3}{*}{ Parameter } & \multicolumn{4}{|c|}{ Concentration } & \multirow[b]{3}{*}{ Units } & & & \multirow[b]{3}{*}{$\begin{array}{l}95^{\text {th }} \\
\text { UTLV }\end{array}$} \\
\hline & \multicolumn{2}{|c|}{ Round 22} & \multicolumn{2}{|c|}{ Round 23} & & \multicolumn{2}{|c|}{ Reporting LIMIT } & \\
\hline & Sample & Dup. & Sample & Dup. & & $\begin{array}{c}\text { Round } \\
22 \\
\end{array}$ & $\begin{array}{c}\text { Round } \\
23\end{array}$ & \\
\hline Antimony & $<0.013$ & $<0.013$ & $<0.013$ & $<0.013$ & $\mathrm{mg} / \mathrm{L}$ & 0.013 & 0.013 & 0.48 \\
\hline Arsenic & $<0.10$ & $<0.10$ & $<0.10$ & $<0.10$ & $\mathrm{mg} / \mathrm{L}$ & 0.1 & 0.1 & $<0.50$ \\
\hline Barium & $<0.02$ & $<0.02$ & $<0.02$ & $<0.02$ & $\mathrm{mg} / \mathrm{L}$ & 0.02 & 0.02 & $<0.10$ \\
\hline Beryllium & $<0.01$ & $<0.01$ & $<0.01$ & $<0.01$ & $\mathrm{mg} / \mathrm{L}$ & 0.01 & 0.01 & $<0.01$ \\
\hline Cadmium & $<0.01$ & $<0.01$ & $<0.01$ & $<0.01$ & $\mathrm{mg} / \mathrm{L}$ & 0.01 & 0.01 & $<0.05$ \\
\hline Calcium & 510 & 507 & 635 & 628 & $\mathrm{mg} / \mathrm{L}$ & 0.50 & 0.50 & 733 \\
\hline Chromium & $<0.025$ & $<0.025$ & $<0.025$ & $<0.025$ & $\mathrm{mg} / \mathrm{L}$ & 0.025 & 0.025 & $<0.50$ \\
\hline Iron & $<0.50$ & $<0.50$ & $<0.50$ & $<0.50$ & $\mathrm{mg} / \mathrm{L}$ & 0.50 & 0.50 & $<1.0$ \\
\hline Lead & $<0.02$ & $<0.02$ & $<0.02$ & $<0.02$ & $\mathrm{mg} / \mathrm{L}$ & 0.02 & 0.02 & $<0.05$ \\
\hline Magnesium & 151 & 131 & 171 & 170 & $\mathrm{mg} / \mathrm{L}$ & 0.50 & 0.50 & 188 \\
\hline Mercury & $<0.0002$ & $<0.0002$ & $<0.0002$ & $<0.0002$ & $\mathrm{mg} / \mathrm{L}$ & 0 & 0 & $<0.002$ \\
\hline Nickel & $<0.025$ & $<0.025$ & $<0.025$ & $<0.025$ & $\mathrm{mg} / \mathrm{L}$ & 0.025 & 0.025 & 0.284 \\
\hline Potassium & 6.35 & 6.32 & 4.98 & 4.90 & $\mathrm{mg} / \mathrm{L}$ & 0.50 & 0.50 & 10.1 \\
\hline Selenium & $<0.025$ & $<0.025$ & $<0.025$ & $<0.025$ & $\mathrm{mg} / \mathrm{L}$ & 0.025 & 0.025 & 0.220 \\
\hline Silver & $<0.013$ & $<0.013$ & $<0.013$ & $<0.013$ & $\mathrm{mg} / \mathrm{L}$ & 0.013 & 0.013 & $<0.50$ \\
\hline Sodium & 212 & 202 & 266 & 246 & $\mathrm{mg} / \mathrm{L}$ & 0.50 & 0.50 & 369.0 \\
\hline Thallium & $<0.025$ & $<0.025$ & $<0.025$ & $<0.025$ & $\mathrm{mg} / \mathrm{L}$ & 0.025 & 0.025 & 0.058 \\
\hline Vanadium & $<0.05$ & $<0.05$ & 0.056 & 0.058 & $\mathrm{mg} / \mathrm{L}$ & 0.05 & 0.05 & $<0.50$ \\
\hline
\end{tabular}

Table F.8 - Groundwater Level Measurement Results for 2006

\begin{tabular}{|c|l|l|r|r|r|r|r|}
\hline Well Number & Zone & Date & $\begin{array}{c}\text { Measured } \\
\text { Depth } \\
\text { from Top } \\
\text { of Casing }\end{array}$ & $\begin{array}{c}\text { Measured } \\
\text { Depth in } \\
\text { Meters }\end{array}$ & $\begin{array}{c}\text { Elevation } \\
\text { in Feet } \\
\text { AMSL }\end{array}$ & $\begin{array}{c}\text { Elevation } \\
\text { in Meters }\end{array}$ & $\begin{array}{c}\text { Feet AMSL, } \\
\text { if Adjusted } \\
\text { to } \\
\text { Equivalent } \\
\text { Freshwater } \\
\text { Head }\end{array}$ \\
\hline AEC-7 & CUL & $01 / 17 / 06$ & 485.38 & 147.94 & $3,171.91$ & 966.80 & $3,206.50$ \\
\hline AEC-7 & CUL & $02 / 14 / 06$ & 478.10 & 145.72 & $3,179.19$ & 969.02 & $3,214.43$ \\
\hline AEC-7 & CUL & $03 / 08 / 06$ & 473.07 & 144.19 & $3,184.22$ & 970.55 & $3,219.91$ \\
\hline AEC-7 & CUL & $04 / 11 / 06$ & 465.71 & 141.95 & $3,191.58$ & 972.79 & $3,227.92$ \\
\hline AEC-7 & CUL & $05 / 08 / 06$ & 460.28 & 140.29 & $3,197.01$ & 974.45 & $3,233.84$ \\
\hline AEC-7 & CUL & $06 / 14 / 06$ & 452.98 & 138.07 & $3,204.31$ & 976.67 & $3,241.79$ \\
\hline AEC-7 & CUL & $07 / 12 / 06$ & 447.36 & 136.36 & $3,209.93$ & 978.39 & $3,247.91$ \\
\hline AEC-7 & CUL & $08 / 14 / 06$ & 441.68 & 134.62 & $3,215.61$ & 980.12 & $3,254.09$ \\
\hline AEC-7 & CUL & $09 / 12 / 06$ & 437.93 & 133.48 & $3,219.36$ & 981.26 & $3,258.18$ \\
\hline AEC-7 & CUL & $10 / 09 / 06$ & 430.45 & 131.20 & $3,226.84$ & 983.54 & $3,266.32$ \\
\hline AEC-7 & CUL & $11 / 06 / 06$ & 426.83 & 130.10 & $3,230.46$ & 984.64 & $3,270.27$ \\
\hline
\end{tabular}


Waste Isolation Pilot Plant Annual Site Environmental Report for 2006 DOE/WIPP-07-2225

\begin{tabular}{|c|c|c|c|c|c|c|c|}
\hline Well Number & Zone & Date & $\begin{array}{l}\text { Measured } \\
\text { Depth } \\
\text { from Top } \\
\text { of Casing }\end{array}$ & $\begin{array}{c}\text { Measured } \\
\text { Depth in } \\
\text { Meters }\end{array}$ & $\begin{array}{c}\text { Elevation } \\
\text { in Feet } \\
\text { AMSL }\end{array}$ & $\begin{array}{l}\text { Elevation } \\
\text { in Meters }\end{array}$ & $\begin{array}{c}\text { Elevation in } \\
\text { Feet AMSL, } \\
\text { if Adjusted } \\
\text { to } \\
\text { Equivalent } \\
\text { Freshwater } \\
\text { Head }\end{array}$ \\
\hline AEC-7 & $\overline{\text { CUL }}$ & $12 / 04 / 06$ & 422.64 & 128.82 & $3,234.65$ & 985.92 & $3,274.83$ \\
\hline C-2505 & SR/D & $03 / 09 / 06$ & 43.13 & 13.15 & $3,369.92$ & 1027.15 & $\mathrm{~N} / \mathrm{A}$ \\
\hline C-2505 & $\mathrm{SR} / \mathrm{D}$ & $06 / 14 / 06$ & 43.50 & 13.26 & $3,369.55$ & 1027.04 & $\mathrm{~N} / \mathrm{A}$ \\
\hline C-2505 & SR/D & $09 / 14 / 06$ & 43.83 & 13.36 & $3,369.22$ & 1026.94 & $\mathrm{~N} / \mathrm{A}$ \\
\hline C-2505 & $\mathrm{SR} / \mathrm{D}$ & $12 / 07 / 06$ & 43.81 & 13.35 & $3,369.24$ & 1026.94 & $\mathrm{~N} / \mathrm{A}$ \\
\hline C-2506 & SR/D & $03 / 09 / 06$ & 42.53 & 12.96 & $3,370.34$ & 1027.28 & $\bar{N} / \mathrm{A}$ \\
\hline C-2506 & SR/D & $06 / 14 / 06$ & 42.93 & 13.09 & $3,369.94$ & 1027.16 & $\mathrm{~N} / \mathrm{A}$ \\
\hline C-2506 & SR/D & $09 / 14 / 06$ & 43.18 & 13.16 & $3,369.69$ & 1027.08 & $\mathrm{~N} / \mathrm{A}$ \\
\hline C-2506 & SR/D & $12 / 07 / 06$ & 42.22 & 12.87 & $3,370.65$ & 1027.37 & $\mathrm{~N} / \mathrm{A}$ \\
\hline C-2507 & SR/D & $03 / 09 / 06$ & 43.07 & 13.13 & $3,366.94$ & 1026.24 & $\bar{N} / \mathrm{A}$ \\
\hline C-2507 & $\mathrm{SR} / \mathrm{D}$ & $06 / 14 / 06$ & 43.51 & 13.26 & $3,366.50$ & 1026.11 & $\mathrm{~N} / \mathrm{A}$ \\
\hline C-2507 & SR/D & $09 / 14 / 06$ & 43.81 & 13.35 & $3,366.20$ & 1026.02 & $\mathrm{~N} / \mathrm{A}$ \\
\hline C-2507 & SR/D & $12 / 07 / 06$ & 43.95 & 13.40 & $3,366.06$ & 1025.98 & $\mathrm{~N} / \mathrm{A}$ \\
\hline C-2737 (PIP) & CUL & $01 / 18 / 06$ & 389.81 & 118.81 & $3,009.49$ & 917.29 & $3,012.48$ \\
\hline C-2737 (PIP) & CUL & $02 / 13 / 06$ & 389.24 & 118.64 & $3,010.06$ & 917.47 & $3,013.06$ \\
\hline C-2737 (PIP) & $\overline{C U L}$ & $03 / 09 / 06$ & 388.60 & 118.45 & $3,010.70$ & 917.66 & $3,013.71$ \\
\hline C-2737 (PIP) & $\overline{\text { CUL }}$ & $04 / 12 / 06$ & 388.50 & 118.41 & $3,010.80$ & 917.69 & $3,013.81$ \\
\hline C-2737 (PIP) & CUL & $05 / 08 / 06$ & 387.87 & 118.22 & $3,011.43$ & 917.88 & $3,014.44$ \\
\hline C-2737 (PIP) & CUL & $06 / 14 / 06$ & 387.52 & 118.12 & $3,011.78$ & 917.99 & $3,014.80$ \\
\hline C-2737 (PIP) & CUL & $07 / 12 / 06$ & 387.26 & 118.04 & $3,012.04$ & 918.07 & $3,015.06$ \\
\hline C-2737 (PIP) & CUL & $08 / 16 / 06$ & 387.02 & 117.96 & $3,012.28$ & 918.14 & $3,015.30$ \\
\hline C-2737 (PIP) & $\overline{\text { CUL }}$ & $09 / 13 / 06$ & 387.12 & 117.99 & $3,012.18$ & 918.11 & $3,015.20$ \\
\hline C-2737 (PIP) & $\overline{\text { CUL }}$ & $10 / 11 / 06$ & 386.88 & 117.92 & $3,012.42$ & 918.19 & $3,015.44$ \\
\hline C-2737 (PIP) & CUL & $11 / 09 / 06$ & 386.61 & 117.84 & $3,012.69$ & 918.27 & $3,015.72$ \\
\hline C-2737 (PIP) & CUL & $12 / 07 / 06$ & 387.00 & 117.96 & $3,012.30$ & 918.15 & $3,015.32$ \\
\hline C-2737 (ANNULUS) & MAG & $01 / 18 / 06$ & 255.42 & 77.85 & $3,143.88$ & 958.25 & $\mathrm{~N} / \mathrm{A}$ \\
\hline C-2737 (ANNULUS) & MAG & $02 / 13 / 06$ & 255.51 & 77.88 & $3,143.79$ & 958.23 & $\mathrm{~N} / \mathrm{A}$ \\
\hline C-2737 (ANNULUS) & MAG & $03 / 09 / 06$ & 255.15 & 77.77 & $3,144.15$ & 958.34 & $\mathrm{~N} / \mathrm{A}$ \\
\hline C-2737 (ANNULUS) & MAG & $04 / 12 / 06$ & 255.31 & 77.82 & $3,143.99$ & 958.29 & $\mathrm{~N} / \mathrm{A}$ \\
\hline C-2737 (ANNULUS) & MAG & $05 / 08 / 06$ & 255.15 & 77.77 & $3,144.15$ & 958.34 & $\mathrm{~N} / \mathrm{A}$ \\
\hline C-2737 (ANNULUS) & MAG & $06 / 14 / 06$ & 255.23 & 77.79 & $3,144.07$ & 958.31 & $\mathrm{~N} / \mathrm{A}$ \\
\hline C-2737 (ANNULUS) & MAG & $07 / 12 / 06$ & 255.29 & 77.81 & $3,144.01$ & 958.29 & $\mathrm{~N} / \mathrm{A}$ \\
\hline C-2737 (ANNULUS) & MAG & $08 / 16 / 06$ & 255.23 & 77.79 & $3,144.07$ & 958.31 & $\mathrm{~N} / \mathrm{A}$ \\
\hline C-2737 (ANNULUS) & MAG & $09 / 13 / 06$ & 256.46 & 78.17 & $3,142.84$ & 957.94 & $\mathrm{~N} / \mathrm{A}$ \\
\hline C-2737 (ANNULUS) & MAG & $10 / 11 / 06$ & 255.05 & 77.74 & $3,144.25$ & 958.37 & $\mathrm{~N} / \mathrm{A}$ \\
\hline C-2737 (ANNULUS) & MAG & $11 / 09 / 06$ & 254.82 & 77.67 & $3,144.48$ & 958.44 & $\mathrm{~N} / \mathrm{A}$ \\
\hline C-2737 (ANNULUS) & MAG & $12 / 07 / 06$ & 255.12 & 77.76 & $3,144.18$ & 958.35 & $\mathrm{~N} / \mathrm{A}$ \\
\hline C-2811 & SR/D & $03 / 09 / 06$ & 53.82 & 16.40 & $3,345.10$ & 1019.59 & $\mathrm{~N} / \mathrm{A}$ \\
\hline C-2811 & SR/D & $06 / 14 / 06$ & 54.38 & 16.58 & $3,344.54$ & 1019.42 & $\mathrm{~N} / \mathrm{A}$ \\
\hline C-2811 & SR/D & $09 / 14 / 06$ & 54.65 & 16.66 & $3,344.27$ & 1019.33 & $\mathrm{~N} / \mathrm{A}$ \\
\hline C-2811 & $\mathrm{SR} / \mathrm{D}$ & $12 / 07 / 06$ & 54.00 & 16.46 & $3,344.92$ & 1019.53 & $\mathrm{~N} / \mathrm{A}$ \\
\hline
\end{tabular}


Waste Isolation Pilot Plant Annual Site Environmental Report for 2006 DOE/WIPP-07-2225

Table F.8 - Groundwater Level Measurement Results for 2006

\begin{tabular}{|c|c|c|c|c|c|c|c|}
\hline Well Number & Zone & Date & $\begin{array}{c}\text { Measured } \\
\text { Depth } \\
\text { from Top } \\
\text { of Casing }\end{array}$ & $\begin{array}{c}\text { Measured } \\
\text { Depth in } \\
\text { Meters }\end{array}$ & $\begin{array}{c}\text { Elevation } \\
\text { in Feet } \\
\text { AMSL }\end{array}$ & $\begin{array}{l}\text { Elevation } \\
\text { in Meters }\end{array}$ & $\begin{array}{c}\text { Elevation in } \\
\text { Feet AMSL, } \\
\text { if Adjusted } \\
\text { to } \\
\text { Equivalent } \\
\text { Freshwater } \\
\text { Head }\end{array}$ \\
\hline CB-1(PIP) & $\mathrm{B} / \mathrm{C}$ & $01 / 18 / 06$ & 601.49 & 183.33 & $2,727.38$ & 831.31 & $\mathrm{~N} / \mathrm{A}$ \\
\hline CB-1(PIP) & $\mathrm{B} / \mathrm{C}$ & $02 / 15 / 06$ & 601.17 & 183.24 & $2,727.70$ & 831.40 & $\mathrm{~N} / \mathrm{A}$ \\
\hline CB-1(PIP) & $\mathrm{B} / \mathrm{C}$ & $03 / 08 / 06$ & 599.96 & 182.87 & $2,728.91$ & 831.77 & $\mathrm{~N} / \mathrm{A}$ \\
\hline CB-1(PIP) & $\mathrm{B} / \mathrm{C}$ & $04 / 11 / 06$ & 600.75 & 183.11 & $2,728.12$ & 831.53 & $\mathrm{~N} / \mathrm{A}$ \\
\hline CB-1(PIP) & $\mathrm{B} / \mathrm{C}$ & $05 / 09 / 06$ & 600.31 & 182.97 & $2,728.56$ & 831.67 & $\mathrm{~N} / \mathrm{A}$ \\
\hline CB-1(PIP) & $\mathrm{B} / \mathrm{C}$ & $06 / 13 / 06$ & 600.14 & 182.92 & $2,728.73$ & 831.72 & $\mathrm{~N} / \mathrm{A}$ \\
\hline CB-1(PIP) & $\mathrm{B} / \mathrm{C}$ & $07 / 10 / 06$ & 599.94 & 182.86 & $2,728.93$ & 831.78 & $\mathrm{~N} / \mathrm{A}$ \\
\hline CB-1(PIP) & $\mathrm{B} / \mathrm{C}$ & $08 / 16 / 06$ & 599.72 & 182.79 & $2,729.15$ & 831.84 & $\mathrm{~N} / \mathrm{A}$ \\
\hline CB-1(PIP) & $\mathrm{B} / \mathrm{C}$ & $09 / 11 / 06$ & 599.39 & 182.69 & $2,729.48$ & 831.95 & $\mathrm{~N} / \mathrm{A}$ \\
\hline CB-1 (PIP) & $\mathrm{B} / \mathrm{C}$ & $10 / 12 / 06$ & 599.19 & 182.63 & $2,729.68$ & 832.01 & $\mathrm{~N} / \mathrm{A}$ \\
\hline CB-1 (PIP) & $B / C$ & $11 / 09 / 06$ & 598.88 & 182.54 & $2,729.99$ & 832.10 & $\mathrm{~N} / \mathrm{A}$ \\
\hline CB-1 (PIP) & $B / C$ & $12 / 06 / 06$ & 598.91 & 182.55 & $2,729.96$ & 832.09 & $\mathrm{~N} / \mathrm{A}$ \\
\hline DOE-1 & CUL & $01 / 18 / 06$ & 474.55 & 144.64 & $2,991.49$ & 911.81 & $3,026.92$ \\
\hline DOE-1 & CUL & $02 / 14 / 06$ & 473.57 & 144.34 & $2,992.47$ & 912.10 & $3,028.00$ \\
\hline DOE-1 & CUL & 03/09/06 & 472.82 & 144.12 & $2,993.22$ & 912.33 & $3,028.82$ \\
\hline DOE-1 & CUL & $04 / 11 / 06$ & 471.81 & 143.81 & $2,994.23$ & 912.64 & $3,029.93$ \\
\hline DOE-1 & CUL & $05 / 08 / 06$ & 471.03 & 143.57 & $2,995.01$ & 912.88 & $3,030.79$ \\
\hline DOE-1 & CUL & $06 / 12 / 06$ & 470.51 & 143.41 & $2,995.53$ & 913.04 & $3,031.36$ \\
\hline DOE-1 & CUL & $07 / 10 / 06$ & 470.18 & 143.31 & $2,995.86$ & 913.14 & $3,031.72$ \\
\hline DOE-1 & CUL & $08 / 16 / 06$ & 470.07 & 143.28 & $2,995.97$ & 913.17 & $3,031.85$ \\
\hline DOE-2 & $\mathrm{B} / \mathrm{C}$ & $01 / 17 / 06$ & 734.62 & 223.91 & $2,684.34$ & 818.19 & $\mathrm{~N} / \mathrm{A}$ \\
\hline DOE-2 & $B / C$ & $02 / 13 / 06$ & 734.15 & 223.77 & $2,684.81$ & 818.33 & $\mathrm{~N} / \mathrm{A}$ \\
\hline DOE-2 & $\mathrm{B} / \mathrm{C}$ & $03 / 06 / 06$ & 733.83 & 223.67 & $2,685.13$ & 818.43 & $\mathrm{~N} / \mathrm{A}$ \\
\hline DOE-2 & $\mathrm{B} / \mathrm{C}$ & $04 / 10 / 06$ & 733.31 & 223.51 & $2,685.65$ & 818.59 & $\mathrm{~N} / \mathrm{A}$ \\
\hline DOE-2 & $B / C$ & $05 / 09 / 06$ & 732.67 & 223.32 & $2,686.29$ & 818.78 & $\mathrm{~N} / \mathrm{A}$ \\
\hline DOE-2 & $B / C$ & $06 / 12 / 06$ & 732.20 & 223.17 & $2,686.76$ & 818.92 & $\mathrm{~N} / \mathrm{A}$ \\
\hline DOE-2 & $\mathrm{B} / \mathrm{C}$ & $07 / 11 / 06$ & 731.77 & 223.04 & $2,687.19$ & 819.06 & $\mathrm{~N} / \mathrm{A}$ \\
\hline DOE-2 & $B / C$ & $08 / 15 / 06$ & 731.24 & 222.88 & $2,687.72$ & 819.22 & $\mathrm{~N} / \mathrm{A}$ \\
\hline DOE-2 & $B / C$ & $09 / 13 / 06$ & 730.86 & 222.77 & $2,688.10$ & 819.33 & $\mathrm{~N} / \mathrm{A}$ \\
\hline DOE-2 & $\mathrm{B} / \mathrm{C}$ & $10 / 10 / 06$ & 730.48 & 222.65 & $2,688.48$ & 819.45 & $\mathrm{~N} / \mathrm{A}$ \\
\hline DOE-2 & $B / C$ & $11 / 08 / 06$ & 730.05 & 222.52 & $2,688.91$ & 819.58 & $\mathrm{~N} / \mathrm{A}$ \\
\hline DOE-2 & $B / C$ & $12 / 04 / 06$ & 729.73 & 222.42 & $2,689.23$ & 819.68 & $\mathrm{~N} / \mathrm{A}$ \\
\hline ERDA-9 & CUL & $01 / 18 / 06$ & 400.47 & 122.06 & $3,009.63$ & 917.34 & $3,030.82$ \\
\hline ERDA-9 & CUL & $02 / 14 / 06$ & 400.10 & 121.95 & $3,010.00$ & 917.45 & $3,031.22$ \\
\hline ERDA-9 & CUL & $03 / 07 / 06$ & 399.75 & 121.84 & $3,010.35$ & 917.55 & $3,031.59$ \\
\hline ERDA-9 & CUL & $04 / 12 / 06$ & 399.23 & 121.69 & $3,010.87$ & 917.71 & $3,032.15$ \\
\hline ERDA-9 & CUL & $05 / 09 / 06$ & 398.68 & 121.52 & $3,011.42$ & 917.88 & $3,032.73$ \\
\hline ERDA-9 & CUL & $06 / 14 / 06$ & 398.35 & 121.42 & $3,011.75$ & 917.98 & $3,033.09$ \\
\hline ERDA-9 & CUL & $07 / 11 / 06$ & 398.15 & 121.36 & $3,011.95$ & 918.04 & $3,033.30$ \\
\hline ERDA-9 & CUL & $08 / 16 / 06$ & 397.89 & 121.28 & $3,012.21$ & 918.12 & $3,033.58$ \\
\hline ERDA-9 & CUL & $09 / 13 / 06$ & 397.90 & 121.28 & $3,012.20$ & 918.12 & $3,033.57$ \\
\hline
\end{tabular}


Waste Isolation Pilot Plant Annual Site Environmental Report for 2006 DOE/WIPP-07-2225

Table F.8 - Groundwater Level Measurement Results for 2006

\begin{tabular}{|c|c|c|c|c|c|c|c|}
\hline Well Number & Zone & Date & $\begin{array}{l}\text { Measured } \\
\text { Depth } \\
\text { from Top } \\
\text { of Casing }\end{array}$ & $\begin{array}{c}\text { Measured } \\
\text { Depth in } \\
\text { Meters }\end{array}$ & $\begin{array}{c}\text { Elevation } \\
\text { in Feet } \\
\text { AMSL }\end{array}$ & $\begin{array}{l}\text { Elevation } \\
\text { in Meters }\end{array}$ & \begin{tabular}{|c|}
$\begin{array}{c}\text { Elevation in } \\
\text { Feet AMSL, } \\
\text { if Adjusted } \\
\text { to } \\
\text { Equivalent } \\
\text { Freshwater } \\
\text { Head }\end{array}$ \\
\end{tabular} \\
\hline ERDA-9 & CUL & $10 / 11 / 06$ & 397.70 & 121.22 & $3,012.40$ & 918.18 & $3,033.78$ \\
\hline ERDA-9 & CUL & $11 / 09 / 06$ & 397.54 & 121.17 & $3,012.56$ & 918.23 & $3,033.95$ \\
\hline ERDA-9 & CUL & $12 / 07 / 06$ & 397.66 & 121.21 & $3,012.44$ & 918.19 & $3,033.82$ \\
\hline $\mathrm{H}-02 \mathrm{~B} 1$ & MAG & $01 / 17 / 06$ & 278.04 & 84.75 & $3,100.43$ & 945.01 & $\mathrm{~N} / \mathrm{A}$ \\
\hline $\mathrm{H}-02 \mathrm{~B} 1$ & MAG & $02 / 13 / 06$ & 267.47 & 81.52 & $3,111.00$ & 948.23 & $\mathrm{~N} / \mathrm{A}$ \\
\hline $\mathrm{H}-02 \mathrm{~B} 1$ & MAG & $03 / 07 / 06$ & 261.17 & 79.60 & $3,117.30$ & 950.15 & $\mathrm{~N} / \mathrm{A}$ \\
\hline $\mathrm{H}-02 \mathrm{~B} 1$ & MAG & $04 / 10 / 06$ & 253.72 & 77.33 & $3,124.75$ & 952.42 & $\mathrm{~N} / \mathrm{A}$ \\
\hline $\mathrm{H}-02 \mathrm{~B} 1$ & MAG & $05 / 09 / 06$ & 249.16 & 75.94 & $3,129.31$ & 953.81 & $\mathrm{~N} / \mathrm{A}$ \\
\hline $\mathrm{H}-02 \mathrm{~B} 1$ & MAG & $06 / 13 / 06$ & 245.33 & 74.78 & $3,133.14$ & 954.98 & $\mathrm{~N} / \mathrm{A}$ \\
\hline $\mathrm{H}-02 \mathrm{~B} 1$ & MAG & $07 / 11 / 06$ & 243.12 & 74.10 & $3,135.35$ & 955.65 & $\mathrm{~N} / \mathrm{A}$ \\
\hline $\mathrm{H}-02 \mathrm{~B} 1$ & MAG & $08 / 14 / 06$ & 241.19 & 73.51 & $3,137.28$ & 956.24 & $\mathrm{~N} / \mathrm{A}$ \\
\hline $\mathrm{H}-02 \mathrm{~B} 1$ & MAG & $09 / 13 / 06$ & 239.85 & 73.11 & $3,138.62$ & 956.65 & $\mathrm{~N} / \mathrm{A}$ \\
\hline $\mathrm{H}-02 \mathrm{~B} 1$ & MAG & $10 / 11 / 06$ & 238.94 & 72.83 & $3,139.53$ & 956.93 & $\mathrm{~N} / \mathrm{A}$ \\
\hline $\mathrm{H}-02 \mathrm{~B} 1$ & MAG & $11 / 09 / 06$ & 238.14 & 72.59 & $3,140.33$ & 957.17 & $\mathrm{~N} / \mathrm{A}$ \\
\hline $\mathrm{H}-02 \mathrm{~B} 1$ & MAG & $12 / 07 / 06$ & 237.63 & 72.43 & $3,140.84$ & 957.33 & $\mathrm{~N} / \mathrm{A}$ \\
\hline $\mathrm{H}-02 \mathrm{~B} 2$ & CUL & $01 / 17 / 06$ & 335.71 & 102.32 & $3,042.60$ & 927.38 & $3,046.49$ \\
\hline $\mathrm{H}-02 \mathrm{~B} 2$ & CUL & $02 / 13 / 06$ & 335.45 & 102.25 & $3,042.86$ & 927.46 & $3,046.75$ \\
\hline $\mathrm{H}-02 \mathrm{~B} 2$ & CUL & $03 / 07 / 06$ & 335.11 & 102.14 & $3,043.20$ & 927.57 & $3,047.09$ \\
\hline $\mathrm{H}-02 \mathrm{~B} 2$ & CUL & $04 / 10 / 06$ & 334.75 & 102.03 & $3,043.56$ & 927.68 & $3,047.46$ \\
\hline $\mathrm{H}-02 \mathrm{~B} 2$ & CUL & $05 / 09 / 06$ & 334.41 & 101.93 & $3,043.90$ & 927.78 & $3,047.80$ \\
\hline $\mathrm{H}-02 \mathrm{~B} 2$ & CUL & $06 / 13 / 06$ & 334.36 & 101.91 & $3,043.95$ & 927.80 & $3,047.85$ \\
\hline $\mathrm{H}-02 \mathrm{~B} 2$ & CUL & $07 / 11 / 06$ & 334.11 & 101.84 & $3,044.20$ & 927.87 & $3,048.11$ \\
\hline $\mathrm{H}-02 \mathrm{~B} 2$ & CUL & $08 / 14 / 06$ & 334.00 & 101.80 & $3,044.31$ & 927.91 & $3,048.22$ \\
\hline $\mathrm{H}-02 \mathrm{~B} 2$ & CUL & $09 / 13 / 06$ & 333.62 & 101.69 & $3,044.69$ & 928.02 & $3,048.60$ \\
\hline $\mathrm{H}-02 \mathrm{~B} 2$ & CUL & $10 / 11 / 06$ & 333.42 & 101.63 & $3,044.89$ & 928.08 & $3,048.81$ \\
\hline $\mathrm{H}-02 \mathrm{~B} 2$ & CUL & $11 / 09 / 06$ & 332.98 & 101.49 & $3,045.33$ & 928.22 & $3,049.25$ \\
\hline $\mathrm{H}-02 \mathrm{~B} 2$ & CUL & $12 / 07 / 06$ & 333.34 & 101.60 & $3,044.97$ & 928.11 & $3,048.89$ \\
\hline $\mathrm{H}-03 \mathrm{~B} 1$ & MAG & $01 / 18 / 06$ & 244.29 & 74.46 & $3,146.39$ & 959.02 & $\mathrm{~N} / \mathrm{A}$ \\
\hline $\mathrm{H}-03 \mathrm{~B} 1$ & MAG & $02 / 15 / 06$ & 244.23 & 74.44 & $3,146.45$ & 959.04 & $\mathrm{~N} / \mathrm{A}$ \\
\hline $\mathrm{H}-03 \mathrm{~B} 1$ & MAG & $03 / 07 / 06$ & 244.20 & 74.43 & $3,146.48$ & 959.05 & $\mathrm{~N} / \mathrm{A}$ \\
\hline $\mathrm{H}-03 \mathrm{~B} 1$ & MAG & $04 / 12 / 06$ & 244.12 & 74.41 & $3,146.56$ & 959.07 & $\mathrm{~N} / \mathrm{A}$ \\
\hline $\mathrm{H}-03 \mathrm{~B} 1$ & MAG & $05 / 09 / 06$ & 243.92 & 74.35 & $3,146.76$ & 959.13 & $\mathrm{~N} / \mathrm{A}$ \\
\hline $\mathrm{H}-03 \mathrm{~B} 1$ & MAG & $06 / 14 / 06$ & 244.04 & 74.38 & $3,146.64$ & 959.10 & $\mathrm{~N} / \mathrm{A}$ \\
\hline $\mathrm{H}-03 \mathrm{~B} 1$ & MAG & $07 / 11 / 06$ & 244.44 & 74.51 & $3,146.24$ & 958.97 & $\mathrm{~N} / \mathrm{A}$ \\
\hline $\mathrm{H}-03 \mathrm{~B} 1$ & MAG & $08 / 16 / 06$ & 244.20 & 74.43 & $3,146.48$ & 959.05 & $\mathrm{~N} / \mathrm{A}$ \\
\hline $\mathrm{H}-03 \mathrm{~B} 1$ & MAG & $09 / 13 / 06$ & 243.96 & 74.36 & $3,146.72$ & 959.12 & $\mathrm{~N} / \mathrm{A}$ \\
\hline $\mathrm{H}-03 \mathrm{~B} 1$ & MAG & $10 / 11 / 06$ & 243.95 & 74.36 & $3,146.73$ & 959.12 & $\mathrm{~N} / \mathrm{A}$ \\
\hline $\mathrm{H}-03 \mathrm{~B} 1$ & MAG & $11 / 09 / 06$ & 243.78 & 74.30 & $3,146.90$ & 959.18 & $\mathrm{~N} / \mathrm{A}$ \\
\hline $\mathrm{H}-03 \mathrm{~B} 1$ & MAG & $12 / 07 / 06$ & 244.03 & 74.38 & $3,146.65$ & 959.10 & $\mathrm{~N} / \mathrm{A}$ \\
\hline $\mathrm{H}-03 \mathrm{~B} 2$ & CUL & $01 / 18 / 06$ & 391.44 & 119.31 & $2,998.59$ & 913.97 & $3,009.33$ \\
\hline $\mathrm{H}-03 \mathrm{~B} 2$ & CUL & $02 / 15 / 06$ & 390.66 & 119.07 & $2,999.37$ & 914.21 & $3,010.14$ \\
\hline
\end{tabular}


Waste Isolation Pilot Plant Annual Site Environmental Report for 2006 DOE/WIPP-07-2225

Table F.8 - Groundwater Level Measurement Results for 2006

\begin{tabular}{|c|c|c|c|c|c|c|c|}
\hline Well Number & Zone & Date & $\begin{array}{c}\text { Measured } \\
\text { Depth } \\
\text { from Top } \\
\text { of Casing }\end{array}$ & $\begin{array}{c}\text { Measured } \\
\text { Depth in } \\
\text { Meters }\end{array}$ & $\begin{array}{c}\text { Elevation } \\
\text { in Feet } \\
\text { AMSL }\end{array}$ & $\begin{array}{l}\text { Elevation } \\
\text { in Meters }\end{array}$ & \begin{tabular}{|c|} 
Elevation in \\
Feet AMSL, \\
if Adjusted \\
to \\
Equivalent \\
Freshwater \\
Head
\end{tabular} \\
\hline $\mathrm{H}-03 \mathrm{~B} 2$ & CUL & $03 / 07 / 06$ & 390.34 & 118.98 & $2,999.69$ & 914.31 & $3,010.47$ \\
\hline $\mathrm{H}-03 \mathrm{~B} 2$ & CUL & $04 / 12 / 06$ & 390.36 & 118.98 & $2,999.67$ & 914.30 & $3,010.45$ \\
\hline $\mathrm{H}-03 \mathrm{~B} 2$ & $\overline{\text { CUL }}$ & $05 / 09 / 06$ & 389.54 & 118.73 & $3,000.49$ & 914.55 & $3,011.30$ \\
\hline $\mathrm{H}-03 \mathrm{~B} 2$ & CUL & $06 / 14 / 06$ & 389.19 & 118.63 & $3,000.84$ & 914.66 & $3,011.66$ \\
\hline $\mathrm{H}-03 \mathrm{~B} 2$ & CUL & $07 / 11 / 06$ & 388.88 & 118.53 & $3,001.15$ & 914.75 & $3,011.98$ \\
\hline $\mathrm{H}-03 \mathrm{~B} 2$ & $\overline{C U L}$ & $08 / 16 / 06$ & 388.75 & 118.49 & $3,001.28$ & 914.79 & $3,012.11$ \\
\hline $\mathrm{H}-03 \mathrm{~B} 2$ & $\overline{\text { CUL }}$ & $09 / 13 / 06$ & 389.29 & 118.66 & $3,000.74$ & 914.63 & $3,011.55$ \\
\hline $\mathrm{H}-03 \mathrm{~B} 2$ & CUL & $10 / 11 / 06$ & 389.02 & 118.57 & $3,001.01$ & 914.71 & $3,011.83$ \\
\hline $\mathrm{H}-03 \mathrm{~B} 2$ & CUL & $11 / 09 / 06$ & 389.61 & 118.75 & $3,000.42$ & 914.53 & $3,011.22$ \\
\hline $\mathrm{H}-03 \mathrm{~B} 2$ & $\overline{\text { CUL }}$ & $12 / 07 / 06$ & 388.91 & 118.54 & $3,001.12$ & 914.74 & $3,011.95$ \\
\hline $\mathrm{H}-04 \mathrm{~B}$ & $\overline{\text { CUL }}$ & $01 / 17 / 06$ & 329.93 & |100.56 & $3,003.42$ & 915.44 & $3,005.32$ \\
\hline $\mathrm{H}-04 \mathrm{~B}$ & CUL & $02 / 15 / 06$ & 329.52 & 100.44 & $3,003.83$ & 915.57 & $3,005.74$ \\
\hline $\mathrm{H}-04 \mathrm{~B}$ & CUL & $03 / 07 / 06$ & 329.50 & 100.43 & $3,003.85$ & 915.57 & $3,005.76$ \\
\hline $\mathrm{H}-04 \mathrm{~B}$ & CUL & $04 / 11 / 06$ & 329.44 & 100.41 & $3,003.91$ & 915.59 & $3,005.82$ \\
\hline $\mathrm{H}-04 \mathrm{~B}$ & CUL & $05 / 09 / 06$ & 329.21 & 100.34 & $3,004.14$ & 915.66 & $3,006.05$ \\
\hline $\mathrm{H}-04 \mathrm{~B}$ & CUL & $06 / 13 / 06$ & 329.29 & 100.37 & $3,004.06$ & 915.64 & $3,005.97$ \\
\hline $\mathrm{H}-04 \mathrm{~B}$ & CUL & $07 / 11 / 06$ & 329.25 & 100.36 & $3,004.10$ & 915.65 & $3,006.01$ \\
\hline $\mathrm{H}-04 \mathrm{~B}$ & CUL & $08 / 14 / 06$ & 329.52 & 100.44 & $3,003.83$ & 915.57 & $3,005.74$ \\
\hline $\mathrm{H}-04 \mathrm{~B}$ & CUL & $09 / 11 / 06$ & 329.50 & 100.43 & $3,003.85$ & 915.57 & $3,005.76$ \\
\hline $\mathrm{H}-04 \mathrm{~B}$ & CUL & $10 / 11 / 06$ & 329.79 & 100.52 & $3,003.56$ & 915.49 & $3,005.47$ \\
\hline $\mathrm{H}-04 \mathrm{~B}$ & CUL & $11 / 08 / 06$ & 329.58 & 100.46 & $3,003.77$ & 915.55 & $3,005.68$ \\
\hline $\mathrm{H}-04 \mathrm{~B}$ & CUL & $12 / 06 / 06$ & 329.96 & 100.57 & $3,003.39$ & 915.43 & $3,005.29$ \\
\hline $\mathrm{H}-04 \mathrm{C}$ & MAG & $01 / 17 / 06$ & 187.74 & 57.22 & $3,146.35$ & 959.01 & $\mathrm{~N} / \mathrm{A}$ \\
\hline $\mathrm{H}-04 \mathrm{C}$ & MAG & $02 / 15 / 06$ & 187.73 & 57.22 & $3,146.36$ & 959.01 & $\mathrm{~N} / \mathrm{A}$ \\
\hline $\mathrm{H}-04 \mathrm{C}$ & MAG & $03 / 07 / 06$ & 187.71 & 57.21 & $3,146.38$ & 959.02 & $\mathrm{~N} / \mathrm{A}$ \\
\hline $\mathrm{H}-04 \mathrm{C}$ & MAG & $04 / 11 / 06$ & 187.59 & 57.18 & $3,146.50$ & 959.05 & $\mathrm{~N} / \mathrm{A}$ \\
\hline $\mathrm{H}-04 \mathrm{C}$ & MAG & $05 / 09 / 06$ & 187.47 & 57.14 & $3,146.62$ & 959.09 & $\mathrm{~N} / \mathrm{A}$ \\
\hline $\mathrm{H}-04 \mathrm{C}$ & MAG & $06 / 13 / 06$ & 187.50 & 57.15 & $3,146.59$ & 959.08 & $\mathrm{~N} / \mathrm{A}$ \\
\hline $\mathrm{H}-04 \mathrm{C}$ & MAG & $07 / 11 / 06$ & 187.60 & 57.18 & $3,146.49$ & 959.05 & $\mathrm{~N} / \mathrm{A}$ \\
\hline $\mathrm{H}-04 \mathrm{C}$ & MAG & $08 / 14 / 06$ & 187.58 & 57.17 & $3,146.51$ & 959.06 & $\mathrm{~N} / \mathrm{A}$ \\
\hline $\mathrm{H}-04 \mathrm{C}$ & MAG & $09 / 11 / 06$ & 187.42 & 57.13 & $3,146.67$ & 959.11 & $\mathrm{~N} / \mathrm{A}$ \\
\hline $\mathrm{H}-04 \mathrm{C}$ & MAG & $10 / 11 / 06$ & 187.49 & 57.15 & $3,146.60$ & 959.08 & $\mathrm{~N} / \mathrm{A}$ \\
\hline $\mathrm{H}-04 \mathrm{C}$ & MAG & $11 / 08 / 06$ & 187.49 & 57.15 & $3,146.60$ & 959.08 & $\mathrm{~N} / \mathrm{A}$ \\
\hline $\mathrm{H}-04 \mathrm{C}$ & MAG & $12 / 06 / 06$ & 187.65 & 57.20 & $3,146.44$ & 959.03 & $\mathrm{~N} / \mathrm{A}$ \\
\hline $\mathrm{H}-05 \mathrm{~B}$ & CUL & $01 / 17 / 06$ & 469.56 & 143.12 & $3,036.48$ & 925.52 & $3,080.00$ \\
\hline $\mathrm{H}-05 \mathrm{~B}$ & $\overline{C U L}$ & $02 / 14 / 06$ & 469.51 & 143.11 & $3,036.53$ & 925.53 & $3,080.06$ \\
\hline $\mathrm{H}-05 \mathrm{~B}$ & CUL & $03 / 08 / 06$ & 469.10 & 142.98 & $3,036.94$ & 925.66 & $3,080.51$ \\
\hline $\mathrm{H}-05 \mathrm{~B}$ & CUL & $04 / 11 / 06$ & 468.98 & 142.95 & $3,037.06$ & 925.70 & $3,080.64$ \\
\hline $\mathrm{H}-05 \mathrm{~B}$ & CUL & $05 / 08 / 06$ & 468.70 & 142.86 & $3,037.34$ & 925.78 & $3,080.95$ \\
\hline $\mathrm{H}-05 \mathrm{~B}$ & CUL & $06 / 12 / 06$ & 468.60 & 142.83 & $3,037.44$ & 925.81 & $3,081.06$ \\
\hline $\mathrm{H}-05 \mathrm{~B}$ & CUL & $07 / 12 / 06$ & 468.60 & 142.83 & $3,037.44$ & 925.81 & $3,081.06$ \\
\hline
\end{tabular}


Waste Isolation Pilot Plant Annual Site Environmental Report for 2006 DOE/WIPP-07-2225

Table F.8 - Groundwater Level Measurement Results for 2006

\begin{tabular}{|c|c|c|c|c|c|c|c|}
\hline Well Number & Zone & Date & $\begin{array}{c}\text { Measured } \\
\text { Depth } \\
\text { from Top } \\
\text { of Casing }\end{array}$ & $\begin{array}{c}\text { Measured } \\
\text { Depth in } \\
\text { Meters }\end{array}$ & $\begin{array}{c}\text { Elevation } \\
\text { in Feet } \\
\text { AMSL }\end{array}$ & $\begin{array}{l}\text { Elevation } \\
\text { in Meters }\end{array}$ & $\begin{array}{c}\text { Elevation in } \\
\text { Feet AMSL, } \\
\text { if Adjusted } \\
\text { to } \\
\text { Equivalent } \\
\text { Freshwater } \\
\text { Head }\end{array}$ \\
\hline $\mathrm{H}-05 \mathrm{~B}$ & CUL & $08 / 14 / 06$ & 468.56 & 142.82 & $3,037.48$ & 925.82 & $3,081.10$ \\
\hline $\mathrm{H}-05 \mathrm{~B}$ & CUL & $09 / 12 / 06$ & 468.34 & 142.75 & $3,037.70$ & 925.89 & $3,081.34$ \\
\hline $\mathrm{H}-05 \mathrm{~B}$ & $\overline{\text { CUL }}$ & $10 / 10 / 06$ & 468.34 & 142.75 & $3,037.70$ & 925.89 & $3,081.34$ \\
\hline $\mathrm{H}-05 \mathrm{~B}$ & CUL & $11 / 06 / 06$ & 468.20 & 142.71 & $3,037.84$ & 925.93 & $3,081.50$ \\
\hline $\mathrm{H}-05 \mathrm{~B}$ & CUL & $12 / 04 / 06$ & 468.37 & 142.76 & $3,037.67$ & 925.88 & $3,081.31$ \\
\hline $\mathrm{H}-06 \mathrm{~B}$ & CUL & $01 / 16 / 06$ & 289.50 & 88.24 & $3,058.75$ & 932.31 & $3,072.14$ \\
\hline $\mathrm{H}-06 \mathrm{~B}$ & $\overline{\text { CUL }}$ & $02 / 13 / 06$ & 289.56 & 88.26 & $3,058.69$ & 932.29 & $3,072.08$ \\
\hline $\mathrm{H}-06 \mathrm{~B}$ & CUL & $03 / 06 / 06$ & 289.38 & 88.20 & $3,058.87$ & 932.34 & $3,072.27$ \\
\hline $\mathrm{H}-06 \mathrm{~B}$ & CUL & $04 / 10 / 06$ & 289.06 & 88.11 & $3,059.19$ & 932.44 & $3,072.60$ \\
\hline $\mathrm{H}-06 \mathrm{~B}$ & $\overline{\text { CUL }}$ & $05 / 08 / 06$ & 288.91 & 88.06 & $3,059.34$ & 932.49 & $3,072.76$ \\
\hline $\mathrm{H}-06 \mathrm{~B}$ & $\overline{\text { CUL }}$ & $06 / 12 / 06$ & 289.03 & 88.10 & $3,059.22$ & 932.45 & $3,072.63$ \\
\hline $\mathrm{H}-06 \mathrm{~B}$ & CUL & $07 / 11 / 06$ & 288.95 & 88.07 & $3,059.30$ & 932.47 & $3,072.72$ \\
\hline $\mathrm{H}-06 \mathrm{~B}$ & CUL & $08 / 15 / 06$ & 288.82 & 88.03 & $3,059.43$ & 932.51 & $3,072.85$ \\
\hline $\mathrm{H}-06 \mathrm{~B}$ & CUL & $09 / 13 / 06$ & 287.21 & 87.54 & $3,061.04$ & 933.00 & $3,074.53$ \\
\hline $\mathrm{H}-06 \mathrm{~B}$ & CUL & $10 / 11 / 06$ & 287.40 & 87.60 & $3,060.85$ & 932.95 & $3,074.33$ \\
\hline $\mathrm{H}-06 \mathrm{~B}$ & CUL & $11 / 06 / 06$ & 287.52 & 87.64 & $3,060.73$ & 932.91 & $3,074.21$ \\
\hline $\mathrm{H}-06 \mathrm{~B}$ & CUL & $12 / 05 / 06$ & 287.85 & 87.74 & $3,060.40$ & 932.81 & $3,073.86$ \\
\hline $\mathrm{H}-06 \mathrm{C}$ & MAG & $01 / 16 / 06$ & 280.87 & 85.61 & $3,067.65$ & 935.02 & $\mathrm{~N}, / \mathrm{A}$ \\
\hline $\mathrm{H}-06 \mathrm{C}$ & MAG & $02 / 13 / 06$ & 281.10 & 85.68 & $3,067.42$ & 934.95 & $\mathrm{~N} / \mathrm{A}$ \\
\hline $\mathrm{H}-06 \mathrm{C}$ & MAG & $03 / 06 / 06$ & 280.95 & 85.63 & $3,067.57$ & 935.00 & $\mathrm{~N} / \mathrm{A}$ \\
\hline $\mathrm{H}-06 \mathrm{C}$ & MAG & $04 / 10 / 06$ & 280.68 & 85.55 & $3,067.84$ & 935.08 & $\mathrm{~N} / \mathrm{A}$ \\
\hline $\mathrm{H}-06 \mathrm{C}$ & MAG & $05 / 08 / 06$ & 280.52 & 85.50 & $3,068.00$ & 935.13 & $\mathrm{~N} / \mathrm{A}$ \\
\hline $\mathrm{H}-06 \mathrm{C}$ & MAG & $06 / 12 / 06$ & 280.48 & 85.49 & $3,068.04$ & 935.14 & $\mathrm{~N} / \mathrm{A}$ \\
\hline $\mathrm{H}-06 \mathrm{C}$ & MAG & $07 / 12 / 06$ & 280.46 & 85.48 & $3,068.06$ & 935.14 & $\mathrm{~N} / \mathrm{A}$ \\
\hline $\mathrm{H}-06 \mathrm{C}$ & MAG & $08 / 15 / 06$ & 280.38 & 85.46 & $3,068.14$ & 935.17 & $\mathrm{~N} / \mathrm{A}$ \\
\hline $\mathrm{H}-06 \mathrm{C}$ & MAG & $09 / 13 / 06$ & 280.12 & 85.38 & $3,068.40$ & 935.25 & $\mathrm{~N} / \mathrm{A}$ \\
\hline $\mathrm{H}-06 \mathrm{C}$ & MAG & $10 / 11 / 06$ & 279.97 & 85.33 & $3,068.55$ & 935.29 & $\mathrm{~N} / \mathrm{A}$ \\
\hline $\mathrm{H}-06 \mathrm{C}$ & MAG & $11 / 06 / 06$ & 279.98 & 85.34 & $3,068.54$ & 935.29 & $\mathrm{~N} / \mathrm{A}$ \\
\hline $\mathrm{H}-06 \mathrm{C}$ & MAG & $12 / 05 / 06$ & 280.05 & 85.36 & $3,068.47$ & 935.27 & $\mathrm{~N} / \mathrm{A}$ \\
\hline $\mathrm{H}-07 \mathrm{~B} 1$ & CUL & $01 / 16 / 06$ & 163.28 & 49.77 & $3,000.89$ & 914.67 & $3,001.08$ \\
\hline $\mathrm{H}-07 \mathrm{~B} 1$ & CUL & $02 / 13 / 06$ & 163.71 & 49.90 & $3,000.46$ & 914.54 & $3,000.64$ \\
\hline $\mathrm{H}-07 \mathrm{~B} 1$ & CUL & $03 / 06 / 06$ & 163.82 & 49.93 & $3,000.35$ & 914.51 & $3,000.53$ \\
\hline $\mathrm{H}-07 \mathrm{~B} 1$ & CUL & $04 / 10 / 06$ & 163.75 & 49.91 & $3,000.42$ & 914.53 & $3,000.60$ \\
\hline $\mathrm{H}-07 \mathrm{~B} 1$ & CUL & $05 / 08 / 06$ & 163.85 & 49.94 & $3,000.32$ & 914.50 & $3,000.50$ \\
\hline $\mathrm{H}-07 \mathrm{~B} 1$ & CUL & $06 / 12 / 06$ & 164.14 & 50.03 & $3,000.03$ & 914.41 & $3,000.21$ \\
\hline H-07B1 & $\overline{C U L}$ & $07 / 11 / 06$ & 164.29 & 50.08 & $2,999.88$ & 914.36 & $3,000.06$ \\
\hline $\mathrm{H}-07 \mathrm{~B} 1$ & CUL & $08 / 15 / 06$ & 164.56 & 50.16 & $2,999.61$ & 914.28 & $2,999.79$ \\
\hline $\mathrm{H}-07 \mathrm{~B} 1$ & CUL & $09 / 12 / 06$ & 164.48 & 50.13 & $2,999.69$ & 914.31 & $2,999.87$ \\
\hline $\mathrm{H}-07 \mathrm{~B} 1$ & CUL & $10 / 09 / 06$ & 163.97 & 49.98 & $3,000.20$ & 914.46 & $3,000.38$ \\
\hline $\mathrm{H}-07 \mathrm{~B} 1$ & CUL & $11 / 08 / 06$ & 163.28 & 49.77 & $3,000.89$ & 914.67 & $3,001.08$ \\
\hline $\mathrm{H}-07 \mathrm{~B} 1$ & CUL & $12 / 07 / 06$ & 163.80 & 49.93 & $3,000.37$ & 914.51 & $3,000.55$ \\
\hline
\end{tabular}


Waste Isolation Pilot Plant Annual Site Environmental Report for 2006 DOE/WIPP-07-2225

\begin{tabular}{|c|c|c|c|c|c|c|c|}
\hline Well Number & Zone & Date & $\begin{array}{l}\text { Measured } \\
\text { Depth } \\
\text { from Top } \\
\text { of Casing }\end{array}$ & $\begin{array}{l}\text { Measured } \\
\text { Depth in } \\
\text { Meters }\end{array}$ & $\begin{array}{c}\text { Elevation } \\
\text { in Feet } \\
\text { AMSL }\end{array}$ & $\begin{array}{l}\text { Elevation } \\
\text { in Meters }\end{array}$ & \begin{tabular}{|c|} 
Elevation in \\
Feet AMSL, \\
if Adjusted \\
to \\
Equivalent \\
Freshwater \\
Head
\end{tabular} \\
\hline $\mathrm{H}-08 \mathrm{~A}$ & MAG & $01 / 18 / 06$ & 405.95 & 123.73 & $3,027.04$ & 922.64 & $\mathrm{~N} / \mathrm{A}$ \\
\hline $\mathrm{H}-08 \mathrm{~A}$ & MAG & $02 / 14 / 06$ & 405.93 & 123.73 & $3,027.06$ & 922.65 & $\mathrm{~N} / \mathrm{A}$ \\
\hline $\mathrm{H}-08 \mathrm{~A}$ & MAG & $03 / 08 / 06$ & 406.03 & 123.76 & $3,026.96$ & 922.62 & $\mathrm{~N} / \mathrm{A}$ \\
\hline $\mathrm{H}-08 \mathrm{~A}$ & MAG & $04 / 11 / 06$ & 406.00 & 123.75 & $3,026.99$ & 922.63 & $\mathrm{~N} / \mathrm{A}$ \\
\hline $\mathrm{H}-08 \mathrm{~A}$ & MAG & $05 / 09 / 06$ & 405.80 & 123.69 & $3,027.19$ & 922.69 & $\mathrm{~N} / \mathrm{A}$ \\
\hline $\mathrm{H}-08 \mathrm{~A}$ & MAG & $06 / 13 / 06$ & 405.80 & 123.69 & $3,027.19$ & 922.69 & $\bar{N} / \mathrm{A}$ \\
\hline $\mathrm{H}-08 \mathrm{~A}$ & MAG & $07 / 10 / 06$ & 405.83 & 123.70 & $3,027.16$ & 922.68 & $\mathrm{~N} / \mathrm{A}$ \\
\hline $\mathrm{H}-08 \mathrm{~A}$ & MAG & $08 / 14 / 06$ & 405.88 & 123.71 & $3,027.11$ & 922.66 & $\mathrm{~N} / \mathrm{A}$ \\
\hline $\mathrm{H}-08 \mathrm{~A}$ & MAG & $09 / 11 / 06$ & 405.79 & 123.68 & $3,027.20$ & 922.69 & $\mathrm{~N} / \mathrm{A}$ \\
\hline $\mathrm{H}-08 \mathrm{~A}$ & MAG & $10 / 10 / 06$ & 405.71 & 123.66 & $3,027.28$ & 922.71 & $\bar{N} / \mathrm{A}$ \\
\hline $\mathrm{H}-08 \mathrm{~A}$ & MAG & $11 / 09 / 06$ & 405.67 & 123.65 & $3,027.32$ & 922.73 & $\mathrm{~N} / \mathrm{A}$ \\
\hline $\mathrm{H}-08 \mathrm{~A}$ & MAG & $12 / 05 / 06$ & 405.78 & 123.68 & $3,027.21$ & 922.69 & $\mathrm{~N} / \mathrm{A}$ \\
\hline $\mathrm{H}-09 \mathrm{C}$ (PIP) & $\overline{\text { CUL }}$ & $01 / 18 / 06$ & 410.31 & 125.06 & $2,996.99$ & 913.48 & $2,998.25$ \\
\hline $\mathrm{H}-09 \mathrm{C}$ (PIP) & $\overline{\text { CUL }}$ & $02 / 14 / 06$ & 410.23 & 125.04 & $2,997.07$ & 913.51 & $2,998.33$ \\
\hline $\mathrm{H}-09 \mathrm{C}$ (PIP) & CUL & $03 / 08 / 06$ & 410.12 & 125.00 & $2,997.18$ & 913.54 & $2,998.44$ \\
\hline $\mathrm{H}-09 \mathrm{C}$ (PIP) & CUL & $04 / 11 / 06$ & 410.23 & 125.04 & $2,997.07$ & 913.51 & $2,998.33$ \\
\hline $\mathrm{H}-09 \mathrm{C}$ (PIP) & $\overline{\text { CUL }}$ & $05 / 09 / 06$ & 409.92 & 124.94 & $2,997.38$ & 913.60 & $2,998.64$ \\
\hline $\mathrm{H}-09 \mathrm{C}(\mathrm{PIP})$ & CUL & $06 / 13 / 06$ & 410.42 & 125.10 & $2,996.88$ & 913.45 & $2,998.14$ \\
\hline $\mathrm{H}-09 \mathrm{C}$ (PIP) & CUL & $07 / 10 / 06$ & 410.91 & 125.25 & $2,996.39$ & 913.30 & $2,997.65$ \\
\hline $\mathrm{H}-09 \mathrm{C}$ (PIP) & CUL & $08 / 14 / 06$ & 411.95 & 125.56 & $2,995.35$ & 912.98 & $2,996.60$ \\
\hline $\mathrm{H}-09 \mathrm{C}$ (PIP) & CUL & $09 / 11 / 06$ & 412.00 & 125.58 & $2,995.30$ & 912.97 & $2,996.55$ \\
\hline $\mathrm{H}-09 \mathrm{C}(\mathrm{PIP})$ & $\overline{\text { CUL }}$ & $10 / 10 / 06$ & 412.67 & 125.78 & $2,994.63$ & 912.76 & $2,995.88$ \\
\hline $\mathrm{H}-09 \mathrm{C}$ (PIP) & $\overline{\text { CUL }}$ & $11 / 08 / 06$ & 413.28 & 125.97 & $2,994.02$ & 912.58 & $2,995.27$ \\
\hline $\mathrm{H}-09 \mathrm{C}$ (PIP) & CUL & $12 / 05 / 06$ & 416.17 & 126.85 & $2,991.13$ & 911.70 & $2,992.36$ \\
\hline H-09C (ANNULUS) & MAG & $01 / 18 / 06$ & 271.39 & 82.72 & $3,135.91$ & 955.83 & $\mathrm{~N} / \mathrm{A}$ \\
\hline H-09C (ANNULUS) & MAG & $02 / 14 / 06$ & 271.32 & 82.70 & $3,135.98$ & 955.85 & $\mathrm{~N} / \mathrm{A}$ \\
\hline H-09C (ANNULUS) & MAG & $03 / 08 / 06$ & 271.17 & 82.65 & $3,136.13$ & 955.89 & $\mathrm{~N} / \mathrm{A}$ \\
\hline H-09C (ANNULUS) & MAG & $04 / 11 / 06$ & 271.26 & 82.68 & $3,136.04$ & 955.86 & $\mathrm{~N} / \mathrm{A}$ \\
\hline $\mathrm{H}-09 \mathrm{C}$ (ANNULUS) & MAG & $05 / 09 / 06$ & 271.13 & 82.64 & $3,136.17$ & 955.90 & $\mathrm{~N} / \mathrm{A}$ \\
\hline H-09C (ANNULUS) & MAG & $06 / 13 / 06$ & 271.00 & 82.60 & $3,136.30$ & 955.94 & $\mathrm{~N} / \mathrm{A}$ \\
\hline $\mathrm{H}-09 \mathrm{C}$ (ANNULUS) & MAG & $07 / 10 / 06$ & 271.07 & 82.62 & $3,136.23$ & 955.92 & $\mathrm{~N} / \mathrm{A}$ \\
\hline H-09C (ANNULUS) & MAG & $08 / 14 / 06$ & 271.13 & 82.64 & $3,136.17$ & 955.90 & $\mathrm{~N} / \mathrm{A}$ \\
\hline $\mathrm{H}-09 \mathrm{C}$ (ANNULUS) & MAG & $09 / 11 / 06$ & 271.01 & 82.60 & $3,136.29$ & 955.94 & $\mathrm{~N} / \mathrm{A}$ \\
\hline $\mathrm{H}-09 \mathrm{C}$ (ANNULUS) & MAG & $10 / 10 / 06$ & 271.02 & 82.61 & $3,136.28$ & 955.94 & $\mathrm{~N} / \mathrm{A}$ \\
\hline H-09C (ANNULUS) & MAG & $11 / 08 / 06$ & 270.80 & 82.54 & $3,136.50$ & 956.01 & $\mathrm{~N} / \mathrm{A}$ \\
\hline H-09C (ANNULUS) & MAG & $12 / 05 / 06$ & 271.07 & 82.62 & $3,136.23$ & 955.92 & $\mathrm{~N} / \mathrm{A}$ \\
\hline $\mathrm{H}-10 \mathrm{~A}$ & MAG & $01 / 17 / 06$ & 463.47 & 141.27 & $3,225.20$ & 983.04 & $\mathrm{~N} / \mathrm{A}$ \\
\hline $\mathrm{H}-10 \mathrm{~A}$ & MAG & $02 / 14 / 06$ & 464.02 & 141.43 & $3,224.65$ & 982.87 & $\mathrm{~N} / \mathrm{A}$ \\
\hline $\mathrm{H}-10 \mathrm{~A}$ & MAG & $03 / 08 / 06$ & 464.43 & 141.56 & $3,224.24$ & 982.75 & $\mathrm{~N} / \mathrm{A}$ \\
\hline $\mathrm{H}-10 \mathrm{~A}$ & MAG & $04 / 11 / 06$ & 464.83 & 141.68 & $3,223.84$ & 982.63 & $\mathrm{~N} / \mathrm{A}$ \\
\hline $\mathrm{H}-10 \mathrm{~A}$ & MAG & $05 / 09 / 06$ & 464.98 & 141.73 & $3,223.69$ & 982.58 & $\mathrm{~N} / \mathrm{A}$ \\
\hline
\end{tabular}


Waste Isolation Pilot Plant Annual Site Environmental Report for 2006 DOE/WIPP-07-2225

Table F.8 - Groundwater Level Measurement Results for 2006

\begin{tabular}{|c|c|c|c|c|c|c|c|}
\hline Well Number & Zone & Date & $\begin{array}{l}\text { Measured } \\
\text { Depth } \\
\text { from Top } \\
\text { of Casing }\end{array}$ & $\begin{array}{c}\text { Measured } \\
\text { Depth in } \\
\text { Meters }\end{array}$ & $\begin{array}{c}\text { Elevation } \\
\text { in Feet } \\
\text { AMSL }\end{array}$ & $\begin{array}{l}\text { Elevation } \\
\text { in Meters }\end{array}$ & \begin{tabular}{|c} 
Elevation in \\
Feet AMSL, \\
if Adjusted \\
to \\
Equivalent \\
Freshwater \\
Head \\
\end{tabular} \\
\hline $\mathrm{H}-10 \mathrm{~A}$ & MAG & 06/13/06 & 465.36 & 141.84 & $3,223.31$ & 982.46 & N/A \\
\hline $\mathrm{H}-10 \mathrm{~A}$ & MAG & $07 / 10 / 06$ & 465.65 & 141.93 & $3,223.02$ & 982.38 & $\mathrm{~N} / \mathrm{A}$ \\
\hline $\mathrm{H}-10 \mathrm{~A}$ & MAG & $08 / 14 / 06$ & 465.89 & 142.00 & $3,222.78$ & 982.30 & $\mathrm{~N} / \mathrm{A}$ \\
\hline $\mathrm{H}-10 \mathrm{~A}$ & MAG & 09/11/06 & 465.88 & 142.00 & $3,222.79$ & 982.31 & $\mathrm{~N} / \mathrm{A}$ \\
\hline $\mathrm{H}-10 \mathrm{~A}$ & MAG & $10 / 10 / 06$ & 465.56 & 141.90 & $3,223.11$ & 982.40 & $\mathrm{~N} / \mathrm{A}$ \\
\hline $\mathrm{H}-10 \mathrm{~A}$ & MAG & $11 / 09 / 06$ & 465.09 & 141.76 & $3,223.58$ & 982.55 & $\mathrm{~N} / \mathrm{A}$ \\
\hline $\mathrm{H}-10 \mathrm{~A}$ & MAG & $12 / 06 / 06$ & 465.04 & 141.74 & $3,223.63$ & 982.56 & $\mathrm{~N} / \mathrm{A}$ \\
\hline $\mathrm{H}-10 \mathrm{C}$ & CUL & $01 / 17 / 06$ & 662.50 & 201.93 & $3,026.14$ & 922.37 & $3,032.56$ \\
\hline $\mathrm{H}-10 \mathrm{C}$ & CUL & $02 / 14 / 06$ & 663.43 & 202.21 & $3,025.21$ & 922.08 & $3,031.62$ \\
\hline $\mathrm{H}-10 \mathrm{C}$ & CUL & $03 / 08 / 06$ & 663.64 & 202.28 & $3,025.00$ & 922.02 & $3,031.41$ \\
\hline $\mathrm{H}-10 \mathrm{C}$ & CUL & $04 / 11 / 06$ & 663.97 & 202.38 & $3,024.67$ & 921.92 & $3,031.08$ \\
\hline $\mathrm{H}-10 \mathrm{C}$ & CUL & 05/09/06 & 663.90 & 202.36 & $3,024.74$ & 921.94 & $3,031.15$ \\
\hline $\mathrm{H}-10 \mathrm{C}$ & CUL & $06 / 13 / 06$ & 664.21 & 202.45 & $3,024.43$ & 921.85 & $3,030.84$ \\
\hline $\mathrm{H}-10 \mathrm{C}$ & CUL & $07 / 10 / 06$ & 664.35 & 202.49 & $3,024.29$ & 921.80 & $3,030.69$ \\
\hline $\mathrm{H}-10 \mathrm{C}$ & CUL & $08 / 14 / 06$ & 664.44 & 202.52 & $3,024.20$ & 921.78 & $3,030.60$ \\
\hline $\mathrm{H}-10 \mathrm{C}$ & CUL & $09 / 11 / 06$ & 663.66 & 202.28 & $3,024.98$ & 922.01 & $3,031.39$ \\
\hline $\mathrm{H}-10 \mathrm{C}$ & CUL & $10 / 10 / 06$ & 662.16 & 201.83 & $3,026.48$ & 922.47 & $3,032.90$ \\
\hline $\mathrm{H}-10 \mathrm{C}$ & CUL & $11 / 09 / 06$ & 662.70 & 201.99 & $3,025.94$ & 922.31 & $3,032.36$ \\
\hline $\mathrm{H}-10 \mathrm{C}$ & CUL & $12 / 06 / 06$ & 663.40 & 202.20 & $3,025.24$ & 922.09 & $3,031.65$ \\
\hline $\mathrm{H}-11 \mathrm{~B} 2$ & MAG & $01 / 18 / 06$ & 273.71 & 83.43 & $3,138.20$ & 956.52 & $\mathrm{~N} / \mathrm{A}$ \\
\hline $\mathrm{H}-11 \mathrm{~B} 2$ & MAG & $02 / 15 / 06$ & 273.61 & 83.40 & $3,138.30$ & 956.55 & $\mathrm{~N} / \mathrm{A}$ \\
\hline $\mathrm{H}-11 \mathrm{~B} 2$ & MAG & $03 / 08 / 06$ & 273.50 & 83.36 & $3,138.41$ & 956.59 & $\mathrm{~N} / \mathrm{A}$ \\
\hline $\mathrm{H}-11 \mathrm{~B} 2$ & MAG & $04 / 11 / 06$ & 273.50 & 83.36 & $3,138.41$ & 956.59 & $\mathrm{~N} / \mathrm{A}$ \\
\hline $\mathrm{H}-11 \mathrm{~B} 2$ & MAG & 05/09/06 & 273.34 & 83.31 & $3,138.57$ & 956.64 & $\mathrm{~N} / \mathrm{A}$ \\
\hline $\mathrm{H}-11 \mathrm{~B} 2$ & MAG & $06 / 13 / 06$ & 273.47 & 83.35 & $3,138.44$ & 956.60 & $\mathrm{~N} / \mathrm{A}$ \\
\hline $\mathrm{H}-11 \mathrm{~B} 2$ & MAG & 07/10/06 & 273.48 & 83.36 & $3,138.43$ & 956.59 & $\mathrm{~N} / \mathrm{A}$ \\
\hline $\mathrm{H}-11 \mathrm{~B} 2$ & MAG & $08 / 16 / 06$ & 273.50 & 83.36 & $3,138.41$ & 956.59 & $\mathrm{~N} / \mathrm{A}$ \\
\hline $\mathrm{H}-11 \mathrm{~B} 2$ & MAG & $09 / 11 / 06$ & 273.27 & 83.29 & $3,138.64$ & 956.66 & $\mathrm{~N} / \mathrm{A}$ \\
\hline $\mathrm{H}-11 \mathrm{~B} 2$ & MAG & $10 / 12 / 06$ & 273.30 & 83.30 & $3,138.61$ & 956.65 & $\mathrm{~N} / \mathrm{A}$ \\
\hline $\mathrm{H}-11 \mathrm{~B} 2$ & MAG & $11 / 09 / 06$ & 273.21 & 83.27 & $3,138.70$ & 956.68 & $\mathrm{~N} / \mathrm{A}$ \\
\hline $\mathrm{H}-11 \mathrm{~B} 2$ & MAG & $12 / 06 / 06$ & 273.46 & 83.35 & $3,138.45$ & 956.60 & $\mathrm{~N} / \mathrm{A}$ \\
\hline $\mathrm{H}-11 \mathrm{~B} 4$ & CUL & $01 / 18 / 06$ & 425.25 & 129.62 & $2,985.64$ & 910.02 & $3,005.50$ \\
\hline $\mathrm{H}-11 \mathrm{~B} 4$ & CUL & $02 / 15 / 06$ & 424.70 & 129.45 & $2,986.19$ & 910.19 & $3,006.08$ \\
\hline $\mathrm{H}-11 \mathrm{~B} 4$ & CUL & 03/08/06 & 424.33 & 129.34 & $2,986.56$ & 910.30 & $3,006.48$ \\
\hline $\mathrm{H}-11 \mathrm{~B} 4$ & CUL & $04 / 11 / 06$ & 424.31 & 129.33 & $2,986.58$ & 910.31 & $3,006.50$ \\
\hline $\mathrm{H}-11 \mathrm{~B} 4$ & CUL & $05 / 09 / 06$ & 423.90 & 129.20 & $2,986.99$ & 910.43 & $3,006.93$ \\
\hline $\mathrm{H}-11 \mathrm{~B} 4$ & CUL & $06 / 13 / 06$ & 423.88 & 129.20 & $2,987.01$ & 910.44 & $3,006.96$ \\
\hline $\mathrm{H}-11 \mathrm{~B} 4$ & CUL & 07/10/06 & 423.79 & 129.17 & $2,987.10$ & 910.47 & $3,007.05$ \\
\hline $\mathrm{H}-11 \mathrm{~B} 4$ & CUL & $08 / 16 / 06$ & 423.89 & 129.20 & $2,987.00$ & 910.44 & $3,006.95$ \\
\hline $\mathrm{H}-11 \mathrm{~B} 4$ & CUL & 09/11/06 & 423.58 & 129.11 & $2,987.31$ & 910.53 & $3,007.28$ \\
\hline $\mathrm{H}-11 \mathrm{~B} 4$ & CUL & $10 / 12 / 06$ & 424.07 & 129.26 & $2,986.82$ & 910.38 & $3,006.75$ \\
\hline
\end{tabular}


Waste Isolation Pilot Plant Annual Site Environmental Report for 2006 DOE/WIPP-07-2225

Table F.8 - Groundwater Level Measurement Results for 2006

\begin{tabular}{|c|c|c|c|c|c|c|c|}
\hline Well Number & Zone & Date & $\begin{array}{c}\text { Measured } \\
\text { Depth } \\
\text { from Top } \\
\text { of Casing }\end{array}$ & $\begin{array}{c}\text { Measured } \\
\text { Depth in } \\
\text { Meters }\end{array}$ & $\begin{array}{c}\text { Elevation } \\
\text { in Feet } \\
\text { AMSL }\end{array}$ & $\begin{array}{l}\text { Elevation } \\
\text { in Meters }\end{array}$ & \begin{tabular}{|c|} 
Elevation in \\
Feet AMSL, \\
if Adjusted \\
to \\
Equivalent \\
Freshwater \\
Head
\end{tabular} \\
\hline $\mathrm{H}-11 \mathrm{~B} 4$ & CUL & $11 / 09 / 06$ & 423.88 & 129.20 & $2,987.01$ & 910.44 & $3,006.96$ \\
\hline $\mathrm{H}-11 \mathrm{~B} 4$ & CUL & $12 / 06 / 06$ & 424.23 & 129.31 & $2,986.66$ & 910.33 & $3,006.58$ \\
\hline $\mathrm{H}-12$ & CUL & $01 / 17 / 06$ & 458.18 & 139.65 & $2,969.01$ & 904.95 & $3,000.51$ \\
\hline $\mathrm{H}-12$ & CUL & $02 / 14 / 06$ & 458.07 & 139.62 & $2,969.12$ & 904.99 & $3,000.63$ \\
\hline $\mathrm{H}-12$ & CUL & $03 / 08 / 06$ & 457.75 & 139.52 & $2,969.44$ & 905.09 & $3,000.98$ \\
\hline $\mathrm{H}-12$ & CUL & $04 / 11 / 06$ & 457.60 & 139.48 & $2,969.59$ & 905.13 & $3,001.14$ \\
\hline $\mathrm{H}-12$ & CUL & $05 / 09 / 06$ & 457.22 & 139.36 & $2,969.97$ & 905.25 & $3,001.55$ \\
\hline $\mathrm{H}-12$ & CUL & $06 / 13 / 06$ & 457.23 & 139.36 & $2,969.96$ & 905.24 & $3,001.54$ \\
\hline $\mathrm{H}-12$ & CUL & $07 / 10 / 06$ & 457.21 & 139.36 & $2,969.98$ & 905.25 & $3,001.56$ \\
\hline $\mathrm{H}-12$ & CUL & $08 / 14 / 06$ & 457.13 & 139.33 & $2,970.06$ & 905.27 & $3,001.65$ \\
\hline $\mathrm{H}-12$ & CUL & $09 / 11 / 06$ & 457.06 & 139.31 & $2,970.13$ & 905.30 & $3,001.72$ \\
\hline $\mathrm{H}-12$ & CUL & $10 / 10 / 06$ & 457.16 & 139.34 & $2,970.03$ & 905.27 & $3,001.62$ \\
\hline $\mathrm{H}-12$ & CUL & $11 / 09 / 06$ & 457.04 & 139.31 & $2,970.15$ & 905.30 & $3,001.75$ \\
\hline $\mathrm{H}-12$ & CUL & $12 / 06 / 06$ & 457.44 & 139.43 & $2,969.75$ & 905.18 & $3,001.31$ \\
\hline $\mathrm{H}-14$ & MAG & $01 / 17 / 06$ & 244.92 & 74.65 & $3,102.21$ & 945.55 & $\mathrm{~N} / \mathrm{A}$ \\
\hline $\mathrm{H}-14$ & MAG & $02 / 13 / 06$ & 238.56 & 72.71 & $3,108.57$ & 947.49 & $\mathrm{~N} / \mathrm{A}$ \\
\hline $\mathrm{H}-14$ & MAG & $03 / 06 / 06$ & 235.09 & 71.66 & $3,112.04$ & 948.55 & $\mathrm{~N} / \mathrm{A}$ \\
\hline $\mathrm{H}-14$ & MAG & $04 / 10 / 06$ & 229.51 & 69.95 & $3,117.62$ & 950.25 & $\mathrm{~N} / \mathrm{A}$ \\
\hline $\mathrm{H}-14$ & MAG & $05 / 08 / 06$ & 226.03 & 68.89 & $3,121.10$ & 951.31 & $\mathrm{~N} / \mathrm{A}$ \\
\hline $\mathrm{H}-14$ & MAG & $06 / 13 / 06$ & 222.43 & 67.80 & $3,124.70$ & 952.41 & $\mathrm{~N} / \mathrm{A}$ \\
\hline $\mathrm{H}-14$ & MAG & $07 / 12 / 06$ & 220.14 & 67.10 & $3,126.99$ & 953.11 & $\mathrm{~N} / \mathrm{A}$ \\
\hline $\mathrm{H}-14$ & MAG & $08 / 14 / 06$ & 218.06 & 66.46 & $3,129.07$ & 953.74 & $\mathrm{~N} / \mathrm{A}$ \\
\hline $\mathrm{H}-14$ & MAG & $09 / 13 / 06$ & 216.47 & 65.98 & $3,130.66$ & 954.23 & $\mathrm{~N} / \mathrm{A}$ \\
\hline $\mathrm{H}-14$ & MAG & $10 / 10 / 06$ & 215.26 & 65.61 & $3,131.87$ & 954.59 & $\mathrm{~N} / \mathrm{A}$ \\
\hline $\mathrm{H}-14$ & MAG & $11 / 09 / 06$ & 214.13 & 65.27 & $3,133.00$ & 954.94 & $\mathrm{~N} / \mathrm{A}$ \\
\hline $\mathrm{H}-14$ & MAG & $12 / 05 / 06$ & 213.33 & 65.02 & $3,133.80$ & 955.18 & $\mathrm{~N} / \mathrm{A}$ \\
\hline $\mathrm{H}-15$ & $\overline{C U L}$ & $01 / 18 / 06$ & 493.37 & 150.38 & $2,988.26$ & 910.82 & $3,024.99$ \\
\hline $\mathrm{H}-15$ & CUL & $02 / 15 / 06$ & 492.57 & 150.14 & $2,989.06$ & 911.07 & $3,025.87$ \\
\hline $\mathrm{H}-15$ & CUL & $03 / 07 / 06$ & 492.25 & 150.04 & $2,989.38$ & 911.16 & $3,026.22$ \\
\hline $\mathrm{H}-15$ & MAG & $03 / 07 / 06$ & 357.50 & 108.97 & $3,124.13$ & 952.23 & $\mathrm{~N} / \mathrm{A}$ \\
\hline $\mathrm{H}-17$ & CUL & $01 / 18 / 06$ & 420.76 & 128.25 & $2,964.55$ & 903.59 & $3,005.23$ \\
\hline $\mathrm{H}-17$ & CUL & $02 / 15 / 06$ & 420.18 & 128.07 & $2,965.13$ & 903.77 & $3,005.89$ \\
\hline $\mathrm{H}-17$ & CUL & $03 / 08 / 06$ & 419.87 & 127.98 & $2,965.44$ & 903.87 & $3,006.24$ \\
\hline $\mathrm{H}-17$ & CUL & $04 / 11 / 06$ & 419.60 & 127.89 & $2,965.71$ & 903.95 & $3,006.55$ \\
\hline $\mathrm{H}-17$ & CUL & $05 / 09 / 06$ & 419.21 & |127.78 & $2,966.10$ & 904.07 & $3,006.99$ \\
\hline $\mathrm{H}-17$ & CUL & $06 / 13 / 06$ & 419.12 & 127.75 & $2,966.19$ & 904.09 & $3,007.09$ \\
\hline $\mathrm{H}-17$ & CUL & $07 / 10 / 06$ & 419.05 & 127.73 & $2,966.26$ & 904.12 & $3,007.17$ \\
\hline $\mathrm{H}-17$ & CUL & $08 / 16 / 06$ & 419.10 & 127.74 & $2,966.21$ & 904.10 & $3,007.12$ \\
\hline $\mathrm{H}-17$ & CUL & $09 / 11 / 06$ & 418.92 & 127.69 & $2,966.39$ & 904.16 & $3,007.32$ \\
\hline $\mathrm{H}-17$ & CUL & $10 / 12 / 06$ & 419.20 & 127.77 & $2,966.11$ & 904.07 & $3,007.00$ \\
\hline $\mathrm{H}-17$ & CUL & $11 / 09 / 06$ & 419.14 & 127.75 & $2,966.17$ & 904.09 & $3,007.07$ \\
\hline
\end{tabular}


Waste Isolation Pilot Plant Annual Site Environmental Report for 2006 DOE/WIPP-07-2225

Table F.8 - Groundwater Level Measurement Results for 2006

\begin{tabular}{|c|c|c|c|c|c|c|c|}
\hline Well Number & Zone & Date & $\begin{array}{l}\text { Measured } \\
\text { Depth } \\
\text { from Top } \\
\text { of Casing }\end{array}$ & $\begin{array}{c}\text { Measured } \\
\text { Depth in } \\
\text { Meters }\end{array}$ & $\begin{array}{c}\text { Elevation } \\
\text { in Feet } \\
\text { AMSL }\end{array}$ & $\begin{array}{l}\text { Elevation } \\
\text { in Meters }\end{array}$ & \begin{tabular}{|c} 
Elevation in \\
Feet AMSL, \\
if Adjusted \\
to \\
Equivalent \\
Freshwater \\
Head
\end{tabular} \\
\hline $\mathrm{H}-17$ & CUL & $12 / 06 / 06$ & 419.46 & 127.85 & $2,965.85$ & 903.99 & $3,006.71$ \\
\hline $\mathrm{H}-18$ & MAG & $01 / 16 / 06$ & 281.03 & 85.66 & $3,133.18$ & 954.99 & N/A \\
\hline $\mathrm{H}-18$ & MAG & $02 / 13 / 06$ & 280.14 & 85.39 & $3,134.07$ & 955.26 & $\mathrm{~N} / \mathrm{A}$ \\
\hline $\mathrm{H}-18$ & MAG & $03 / 06 / 06$ & 279.36 & 85.15 & $3,134.85$ & 955.50 & $\mathrm{~N} / \mathrm{A}$ \\
\hline $\mathrm{H}-18$ & MAG & $04 / 10 / 06$ & 278.09 & 84.76 & $3,136.12$ & 955.89 & $\mathrm{~N} / \mathrm{A}$ \\
\hline $\mathrm{H}-18$ & MAG & $05 / 08 / 06$ & 277.16 & 84.48 & $3,137.05$ & 956.17 & $\mathrm{~N} / \mathrm{A}$ \\
\hline $\mathrm{H}-18$ & MAG & $06 / 12 / 06$ & 276.26 & 84.20 & $3,137.95$ & 956.45 & $\mathrm{~N} / \mathrm{A}$ \\
\hline $\mathrm{H}-18$ & MAG & $07 / 11 / 06$ & 275.58 & 84.00 & $3,138.63$ & 956.65 & $\mathrm{~N} / \mathrm{A}$ \\
\hline $\mathrm{H}-18$ & MAG & $08 / 15 / 06$ & 274.84 & 83.77 & $3,139.37$ & 956.88 & $\mathrm{~N} / \mathrm{A}$ \\
\hline $\mathrm{H}-18$ & MAG & $09 / 13 / 06$ & 274.08 & 83.54 & $3,140.13$ & 957.11 & $\mathrm{~N} / \mathrm{A}$ \\
\hline $\mathrm{H}-18$ & MAG & $10 / 11 / 06$ & 273.41 & 83.34 & $3,140.80$ & 957.32 & $\mathrm{~N} / \mathrm{A}$ \\
\hline $\mathrm{H}-18$ & MAG & $11 / 08 / 06$ & 272.82 & 83.16 & $3,141.39$ & 957.50 & $\mathrm{~N} / \mathrm{A}$ \\
\hline $\mathrm{H}-18$ & MAG & $12 / 05 / 06$ & 272.60 & 83.09 & $3,141.61$ & 957.56 & $\mathrm{~N} / \mathrm{A}$ \\
\hline $\mathrm{H}-19 \mathrm{~B} 0$ & CUL & $01 / 17 / 06$ & 428.75 & 130.68 & $2,989.63$ & 911.24 & $3,011.39$ \\
\hline $\mathrm{H}-19 \mathrm{~B} 0$ & CUL & $02 / 15 / 06$ & 427.90 & 130.42 & $2,990.48$ & 911.50 & $3,012.30$ \\
\hline $\mathrm{H}-19 \mathrm{~B} 0$ & CUL & $03 / 07 / 06$ & 427.58 & 130.33 & $2,990.80$ & 911.60 & $3,012.64$ \\
\hline $\mathrm{H}-19 \mathrm{~B} 0$ & CUL & $04 / 11 / 06$ & 427.49 & 130.30 & $2,990.89$ & 911.62 & $3,012.73$ \\
\hline $\mathrm{H}-19 \mathrm{~B} 0$ & CUL & $05 / 08 / 06$ & 426.80 & 130.09 & $2,991.58$ & 911.83 & $3,013.47$ \\
\hline $\mathrm{H}-19 \mathrm{~B} 0$ & CUL & $06 / 14 / 06$ & 426.51 & 130.00 & $2,991.87$ & 911.92 & $3,013.78$ \\
\hline $\mathrm{H}-19 \mathrm{~B} 0$ & CUL & $07 / 11 / 06$ & 426.23 & 129.91 & $2,992.15$ & 912.01 & $3,014.08$ \\
\hline $\mathrm{H}-19 \mathrm{~B} 0$ & CUL & 08/15/06 & 426.20 & 129.91 & $2,992.18$ & 912.02 & $3,014.11$ \\
\hline $\mathrm{H}-19 \mathrm{~B} 0$ & CUL & $09 / 11 / 06$ & 426.83 & 130.10 & $2,991.55$ & 911.82 & $3,013.44$ \\
\hline $\mathrm{H}-19 \mathrm{~B} 0$ & CUL & $10 / 11 / 06$ & 426.34 & 129.95 & $2,992.04$ & 911.97 & $3,013.96$ \\
\hline $\mathrm{H}-19 \mathrm{~B} 0$ & CUL & $11 / 08 / 06$ & 426.17 & 129.90 & $2,992.21$ & 912.03 & $3,014.14$ \\
\hline $\mathrm{H}-19 \mathrm{~B} 0$ & CUL & $12 / 06 / 06$ & 426.18 & 129.90 & $2,992.20$ & 912.02 & $3,014.13$ \\
\hline $\mathrm{H}-19 \mathrm{~B} 2$ & CUL & $03 / 07 / 06$ & 428.93 & 130.74 & $2,990.08$ & 911.38 & $3,011.97$ \\
\hline $\mathrm{H}-19 \mathrm{~B} 2$ & CUL & $06 / 14 / 06$ & 427.86 & 130.41 & $2,991.15$ & 911.70 & $3,013.12$ \\
\hline $\mathrm{H}-19 \mathrm{~B} 2$ & CUL & $09 / 11 / 06$ & 428.16 & 130.50 & $2,990.85$ & 911.61 & $3,012.80$ \\
\hline $\mathrm{H}-19 \mathrm{~B} 2$ & CUL & $12 / 06 / 06$ & 427.52 & 130.31 & $2,991.49$ & 911.81 & $3,013.48$ \\
\hline $\mathrm{H}-19 \mathrm{~B} 3$ & CUL & $03 / 07 / 06$ & 428.14 & 130.50 & $2,990.95$ & 911.64 & $3,012.80$ \\
\hline $\mathrm{H}-19 \mathrm{~B} 3$ & CUL & $06 / 14 / 06$ & 428.09 & 130.48 & $2,991.00$ & 911.66 & $3,012.86$ \\
\hline $\mathrm{H}-19 \mathrm{~B} 3$ & CUL & $09 / 11 / 06$ & 428.38 & 130.57 & $2,990.71$ & 911.57 & $3,012.55$ \\
\hline $\mathrm{H}-19 \mathrm{~B} 3$ & CUL & $12 / 06 / 06$ & 427.75 & 130.38 & $2,991.34$ & 911.76 & $3,013.22$ \\
\hline $\mathrm{H}-19 \mathrm{~B} 4$ & CUL & $03 / 07 / 06$ & 428.40 & 130.58 & $2,990.63$ & 911.54 & $3,012.31$ \\
\hline $\mathrm{H}-19 \mathrm{~B} 4$ & CUL & $06 / 14 / 06$ & 427.32 & 130.25 & $2,991.71$ & 911.87 & $3,013.46$ \\
\hline $\mathrm{H}-19 \mathrm{~B} 4$ & CUL & $09 / 11 / 06$ & 427.64 & 130.34 & $2,991.39$ & 911.78 & $3,013.12$ \\
\hline $\mathrm{H}-19 \mathrm{~B} 4$ & CUL & $12 / 06 / 06$ & 427.00 & 130.15 & $2,992.03$ & 911.97 & $3,013.80$ \\
\hline $\mathrm{H}-19 \mathrm{~B} 5$ & CUL & 03/07/06 & 428.44 & 130.59 & $2,990.19$ & 911.41 & $3,011.78$ \\
\hline $\mathrm{H}-19 \mathrm{~B} 5$ & CUL & $06 / 14 / 06$ & 427.37 & 130.26 & $2,991.26$ & 911.74 & $3,012.92$ \\
\hline H-19B5 & CUL & 09/11/06 & 427.68 & 130.36 & $2,990.95$ & 911.64 & $3,012.59$ \\
\hline $\mathrm{H}-19 \mathrm{~B} 5$ & CUL & $12 / 06 / 06$ & 427.01 & 130.15 & $2,991.62$ & 911.85 & $3,013.31$ \\
\hline
\end{tabular}


Waste Isolation Pilot Plant Annual Site Environmental Report for 2006 DOE/WIPP-07-2225

Table F.8 - Groundwater Level Measurement Results for 2006

\begin{tabular}{|c|c|c|c|c|c|c|c|}
\hline Well Number & Zone & Date & $\begin{array}{c}\text { Measured } \\
\text { Depth } \\
\text { from Top } \\
\text { of Casing }\end{array}$ & $\begin{array}{c}\text { Measured } \\
\text { Depth in } \\
\text { Meters }\end{array}$ & $\begin{array}{c}\text { Elevation } \\
\text { in Feet } \\
\text { AMSL }\end{array}$ & $\begin{array}{l}\text { Elevation } \\
\text { in Meters }\end{array}$ & \begin{tabular}{|c|} 
Elevation in \\
Feet AMSL, \\
if Adjusted \\
to \\
Equivalent \\
Freshwater \\
Head
\end{tabular} \\
\hline $\mathrm{H}-19 \mathrm{~B} 6$ & CUL & $03 / 07 / 06$ & 429.06 & 130.78 & $2,990.01$ & 911.36 & $3,011.73$ \\
\hline $\mathrm{H}-19 \mathrm{~B} 6$ & CUL & $06 / 14 / 06$ & 428.00 & 130.45 & $2,991.07$ & 911.68 & $3,012.86$ \\
\hline $\mathrm{H}-19 \mathrm{~B} 6$ & CUL & $09 / 11 / 06$ & 428.29 & 130.54 & $2,990.78$ & 911.59 & $3,012.55$ \\
\hline $\mathrm{H}-19 \mathrm{~B} 6$ & CUL & $12 / 06 / 06$ & 427.66 & 130.35 & $2,991.41$ & 911.78 & $3,013.23$ \\
\hline $\mathrm{H}-19 \mathrm{~B} 7$ & CUL & $03 / 07 / 06$ & 429.15 & 130.80 & $2,989.84$ & 911.30 & $3,011.59$ \\
\hline $\mathrm{H}-19 \mathrm{~B} 7$ & CUL & $06 / 14 / 06$ & 428.07 & 130.48 & $2,990.92$ & 911.63 & $3,012.75$ \\
\hline $\mathrm{H}-19 \mathrm{~B} 7$ & CUL & $09 / 11 / 06$ & 428.35 & 130.56 & $2,990.64$ & 911.55 & $3,012.45$ \\
\hline $\mathrm{H}-19 \mathrm{~B} 7$ & CUL & $12 / 06 / 06$ & 427.72 & 130.37 & $2,991.27$ & 911.74 & $3,013.12$ \\
\hline |-461 & CUL & $01 / 16 / 06$ & 237.42 & 72.37 & $3,052.06$ & 930.27 & $3,052.62$ \\
\hline $1-461$ & CUL & $02 / 13 / 06$ & 237.66 & 72.44 & $3,051.82$ & 930.19 & $3,052.37$ \\
\hline $1-461$ & CUL & $03 / 06 / 06$ & 237.57 & 72.41 & $3,051.91$ & 930.22 & $3,052.46$ \\
\hline |-461 & CUL & $04 / 10 / 06$ & 237.33 & 72.34 & $3,052.15$ & 930.30 & $3,052.71$ \\
\hline $\mid-461$ & CUL & $05 / 08 / 06$ & 237.34 & 72.34 & $3,052.14$ & 930.29 & $3,052.70$ \\
\hline $\mid-461$ & CUL & $06 / 12 / 06$ & 237.51 & 72.39 & $3,051.97$ & 930.24 & $3,052.52$ \\
\hline |-461 & CUL & $07 / 11 / 06$ & 237.54 & 72.40 & $3,051.94$ & 930.23 & $3,052.49$ \\
\hline $\mid-461$ & CUL & $08 / 15 / 06$ & 238.18 & 72.60 & $3,051.30$ & 930.04 & $3,051.85$ \\
\hline |-461 & CUL & $09 / 13 / 06$ & 234.82 & 71.57 & $3,054.66$ & 931.06 & $3,055.23$ \\
\hline $1-461$ & CUL & $10 / 11 / 06$ & 234.92 & 71.60 & $3,054.56$ & 931.03 & $3,055.13$ \\
\hline |-461 & CUL & $11 / 06 / 06$ & 235.30 & 71.72 & $3,054.18$ & 930.91 & $3,054.74$ \\
\hline |-461 & CUL & $12 / 05 / 06$ & 235.88 & $\overline{71.90}$ & $3,053.60$ & 930.74 & $3,054.16$ \\
\hline $\mathrm{P}-17$ & CUL & $01 / 18 / 06$ & 347.88 & 106.03 & $2,989.36$ & 911.16 & $3,004.82$ \\
\hline $\mathrm{P}-17$ & CUL & $02 / 15 / 06$ & 347.32 & 105.86 & $2,989.92$ & 911.33 & $3,005.42$ \\
\hline $\mathrm{P}-17$ & CUL & $03 / 08 / 06$ & 347.06 & 105.78 & $2,990.18$ & 911.41 & $3,005.70$ \\
\hline $\mathrm{P}-17$ & CUL & $04 / 11 / 06$ & 346.90 & 105.74 & $2,990.34$ & 911.46 & $3,005.87$ \\
\hline P-17 & CUL & $05 / 09 / 06$ & 346.59 & 105.64 & $2,990.65$ & 911.55 & $3,006.20$ \\
\hline $\mathrm{P}-17$ & CUL & $06 / 13 / 06$ & 346.62 & 105.65 & $2,990.62$ & 911.54 & $3,006.17$ \\
\hline $\mathrm{P}-17$ & CUL & $07 / 10 / 06$ & 346.57 & 105.63 & $2,990.67$ & 911.56 & $3,006.22$ \\
\hline SNL-01 & CUL & $01 / 17 / 06$ & 434.70 & 132.50 & $3,078.14$ & 938.22 & $3,083.13$ \\
\hline SNL-01 & CUL & $02 / 13 / 06$ & 434.81 & 132.53 & $3,078.03$ & 938.18 & $3,083.02$ \\
\hline SNL-01 & CUL & $03 / 07 / 06$ & 434.68 & 132.49 & $3,078.16$ & 938.22 & $3,083.15$ \\
\hline SNL-01 & CUL & $04 / 10 / 06$ & 434.92 & 132.56 & $3,077.92$ & 938.15 & $3,082.91$ \\
\hline SNL-01 & CUL & $05 / 08 / 06$ & 434.92 & 132.56 & $3,077.92$ & 938.15 & $3,082.91$ \\
\hline SNL-01 & CUL & $06 / 12 / 06$ & 435.13 & 132.63 & $3,077.71$ & 938.09 & $3,082.69$ \\
\hline SNL-01 & CUL & $07 / 12 / 06$ & 435.02 & 132.59 & $3,077.82$ & 938.12 & $3,082.80$ \\
\hline SNL-01 & CUL & $08 / 14 / 06$ & 434.32 & 132.38 & $3,078.52$ & 938.33 & $3,083.52$ \\
\hline SNL-01 & CUL & $09 / 12 / 06$ & 433.74 & 132.20 & $3,079.10$ & 938.51 & $3,084.12$ \\
\hline SNL-01 & CUL & $10 / 09 / 06$ & 431.04 & 131.38 & $3,081.80$ & 939.33 & $3,086.89$ \\
\hline SNL-01 & CUL & $11 / 06 / 06$ & 430.06 & 131.08 & $3,082.78$ & 939.63 & $3,087.90$ \\
\hline SNL-01 & CUL & $12 / 04 / 06$ & 429.86 & 131.02 & $3,082.98$ & 939.69 & $3,088.11$ \\
\hline SNL-02 & CUL & $01 / 16 / 06$ & 249.04 & 75.91 & $3,073.99$ & 936.95 & $3,076.20$ \\
\hline SNL-02 & CUL & $02 / 13 / 06$ & 248.85 & 75.85 & $3,074.18$ & 937.01 & $3,076.40$ \\
\hline
\end{tabular}


Waste Isolation Pilot Plant Annual Site Environmental Report for 2006 DOE/WIPP-07-2225

Table F.8 - Groundwater Level Measurement Results for 2006

\begin{tabular}{|c|c|c|c|c|c|c|c|}
\hline Well Number & Zone & Date & $\begin{array}{c}\text { Measured } \\
\text { Depth } \\
\text { from Top } \\
\text { of Casing }\end{array}$ & $\begin{array}{c}\text { Measured } \\
\text { Depth in } \\
\text { Meters }\end{array}$ & $\begin{array}{c}\text { Elevation } \\
\text { in Feet } \\
\text { AMSL }\end{array}$ & $\begin{array}{l}\text { Elevation } \\
\text { in Meters }\end{array}$ & \begin{tabular}{|c|} 
Elevation in \\
Feet AMSL, \\
if Adjusted \\
to \\
Equivalent \\
Freshwater \\
Head
\end{tabular} \\
\hline SNL-02 & CUL & $03 / 06 / 06$ & 248.54 & 75.75 & $3,074.49$ & 937.10 & $3,076.71$ \\
\hline SNL-02 & CUL & $04 / 10 / 06$ & 248.02 & 75.60 & $3,075.01$ & 937.26 & $3,077.23$ \\
\hline SNL-02 & CUL & $05 / 08 / 06$ & 247.93 & 75.57 & $3,075.10$ & 937.29 & $3,077.33$ \\
\hline SNL-02 & CUL & $06 / 12 / 06$ & 248.13 & 75.63 & $3,074.90$ & 937.23 & $3,077.12$ \\
\hline SNL-02 & CUL & $07 / 11 / 06$ & 247.96 & 75.58 & $3,075.07$ & 937.28 & $3,077.30$ \\
\hline SNL-02 & CUL & $08 / 15 / 06$ & 247.67 & 75.49 & $3,075.36$ & 937.37 & $3,077.59$ \\
\hline SNL-02 & CUL & $09 / 12 / 06$ & 245.68 & 74.88 & $3,077.35$ & 937.98 & $3,079.60$ \\
\hline SNL-02 & CUL & $10 / 09 / 06$ & 246.34 & 75.08 & $3,076.69$ & 937.78 & $3,078.93$ \\
\hline SNL-02 & CUL & $11 / 06 / 06$ & 247.18 & 75.34 & $3,075.85$ & 937.52 & $3,078.08$ \\
\hline SNL-02 & CUL & $12 / 04 / 06$ & 248.20 & 75.65 & $3,074.83$ & 937.21 & $3,077.05$ \\
\hline SNL-03 & CUL & $01 / 16 / 06$ & 418.78 & 127.64 & $3,071.56$ & 936.21 & $3,083.75$ \\
\hline SNL-03 & CUL & $02 / 13 / 06$ & 418.90 & 127.68 & $3,071.44$ & 936.17 & $3,083.62$ \\
\hline SNL-03 & CUL & $03 / 06 / 06$ & 418.83 & 127.66 & $3,071.51$ & 936.20 & $3,083.70$ \\
\hline SNL-03 & CUL & $04 / 10 / 06$ & 418.72 & 127.63 & $3,071.62$ & 936.23 & $3,083.81$ \\
\hline SNL-03 & CUL & $05 / 08 / 06$ & 418.60 & 127.59 & $3,071.74$ & 936.27 & $3,083.93$ \\
\hline SNL-03 & CUL & $06 / 12 / 06$ & 418.75 & 127.64 & $3,071.59$ & 936.22 & $3,083.78$ \\
\hline SNL-03 & CUL & $07 / 12 / 06$ & 418.63 & 127.60 & $3,071.71$ & 936.26 & $3,083.90$ \\
\hline SNL-03 & CUL & $08 / 14 / 06$ & 418.63 & 127.60 & $3,071.71$ & 936.26 & $3,083.90$ \\
\hline SNL-03 & CUL & $09 / 12 / 06$ & 417.87 & 127.37 & $3,072.47$ & 936.49 & $3,084.69$ \\
\hline SNL-03 & CUL & $10 / 09 / 06$ & 416.88 & 127.07 & $3,073.46$ & 936.79 & $3,085.71$ \\
\hline SNL-03 & CUL & $11 / 06 / 06$ & 416.16 & 126.85 & $3,074.18$ & 937.01 & $3,086.46$ \\
\hline SNL-03 & CUL & $12 / 04 / 06$ & 415.99 & 126.79 & $3,074.35$ & 937.06 & $3,086.64$ \\
\hline SNL-05 & CUL & $01 / 16 / 06$ & 306.61 & 93.45 & $3,075.27$ & 937.34 & $3,079.05$ \\
\hline SNL-05 & CUL & $02 / 13 / 06$ & 306.69 & 93.48 & $3,075.19$ & 937.32 & $3,078.97$ \\
\hline SNL-05 & CUL & $03 / 06 / 06$ & 306.61 & 93.45 & $3,075.27$ & 937.34 & $3,079.05$ \\
\hline SNL-05 & CUL & $04 / 10 / 06$ & 306.53 & 93.43 & $3,075.35$ & 937.37 & $3,079.13$ \\
\hline SNL-05 & CUL & $05 / 08 / 06$ & 306.30 & 93.36 & $3,075.58$ & 937.44 & $3,079.37$ \\
\hline SNL-05 & CUL & $06 / 12 / 06$ & 306.44 & 93.40 & $3,075.44$ & 937.39 & $3,079.22$ \\
\hline SNL-05 & CUL & $07 / 12 / 06$ & 306.41 & 93.39 & $3,075.47$ & 937.40 & $3,079.25$ \\
\hline SNL-05 & CUL & $08 / 15 / 06$ & 306.29 & 93.36 & $3,075.59$ & 937.44 & $3,079.38$ \\
\hline SNL-05 & CUL & $09 / 12 / 06$ & 305.51 & 93.12 & $3,076.37$ & 937.68 & $3,080.16$ \\
\hline SNL-05 & CUL & $10 / 09 / 06$ & 304.55 & 92.83 & $3,077.33$ & 937.97 & $3,081.14$ \\
\hline SNL-05 & CUL & $11 / 06 / 06$ & 303.98 & 92.65 & $3,077.90$ & 938.14 & $3,081.71$ \\
\hline SNL-05 & CUL & $12 / 04 / 06$ & 304.17 & 92.71 & $3,077.71$ & 938.09 & $3,081.52$ \\
\hline SNL-08 & CUL & $02 / 14 / 06$ & 526.34 & 160.43 & $3,029.45$ & 923.38 & $3,054.24$ \\
\hline SNL-08 & CUL & $03 / 08 / 06$ & 526.15 & 160.37 & $3,029.64$ & 923.43 & $3,054.44$ \\
\hline SNL-08 & CUL & $04 / 11 / 06$ & 526.22 & 160.39 & $3,029.57$ & 923.41 & $3,054.37$ \\
\hline SNL-08 & CUL & $05 / 08 / 06$ & 526.03 & 160.33 & $3,029.76$ & 923.47 & $3,054.57$ \\
\hline SNL-08 & CUL & $06 / 12 / 06$ & 526.04 & 160.34 & $3,029.75$ & 923.47 & $3,054.56$ \\
\hline SNL-08 & CUL & $07 / 12 / 06$ & 526.03 & 160.33 & $3,029.76$ & 923.47 & $3,054.57$ \\
\hline SNL-08 & CUL & $08 / 14 / 06$ & 526.08 & 160.35 & $3,029.71$ & 923.46 & $3,054.52$ \\
\hline
\end{tabular}


Waste Isolation Pilot Plant Annual Site Environmental Report for 2006 DOE/WIPP-07-2225

Table F.8 - Groundwater Level Measurement Results for 2006

\begin{tabular}{|c|c|c|c|c|c|c|c|}
\hline Well Number & Zone & Date & $\begin{array}{c}\text { Measured } \\
\text { Depth } \\
\text { from Top } \\
\text { of Casing }\end{array}$ & $\begin{array}{c}\text { Measured } \\
\text { Depth in } \\
\text { Meters }\end{array}$ & $\begin{array}{c}\text { Elevation } \\
\text { in Feet } \\
\text { AMSL }\end{array}$ & $\begin{array}{l}\text { Elevation } \\
\text { in Meters }\end{array}$ & \begin{tabular}{|c|} 
Elevation in \\
Feet AMSL, \\
if Adjusted \\
to \\
Equivalent \\
Freshwater \\
Head
\end{tabular} \\
\hline SNL-08 & CUL & $09 / 11 / 06$ & 525.87 & 160.29 & $3,029.92$ & 923.52 & $3,054.74$ \\
\hline SNL-08 & CUL & $10 / 10 / 06$ & 525.93 & 160.30 & $3,029.86$ & 923.50 & $3,054.67$ \\
\hline SNL-08 & $\overline{\text { CUL }}$ & $11 / 06 / 06$ & 525.90 & 160.29 & $3,029.89$ & 923.51 & $3,054.71$ \\
\hline$\overline{\text { SNL-08 }}$ & CUL & $12 / 04 / 06$ & 526.21 & 160.39 & $3,029.58$ & 923.42 & $3,054.38$ \\
\hline SNL-09 & CUL & $01 / 16 / 06$ & 309.54 & 94.35 & $3,051.41$ & 930.07 & $3,057.02$ \\
\hline SNL-09 & CUL & $02 / 13 / 06$ & 309.73 & 94.41 & $3,051.22$ & 930.01 & $3,056.82$ \\
\hline SNL-09 & CUL & $03 / 06 / 06$ & 309.52 & 94.34 & $3,051.43$ & 930.08 & $3,057.04$ \\
\hline SNL-09 & $\overline{\text { CUL }}$ & $04 / 10 / 06$ & 309.27 & 94.27 & $3,051.68$ & 930.15 & $3,057.29$ \\
\hline SNL-09 & CUL & $05 / 09 / 06$ & 308.98 & 94.18 & $3,051.97$ & 930.24 & $3,057.59$ \\
\hline SNL-09 & CUL & $06 / 12 / 06$ & 309.15 & 94.23 & $3,051.80$ & 930.19 & $3,057.41$ \\
\hline SNL-09 & CUL & $07 / 11 / 06$ & 309.14 & 94.23 & $3,051.81$ & 930.19 & $3,057.42$ \\
\hline SNL-09 & CUL & $08 / 15 / 06$ & 309.03 & 94.19 & $3,051.92$ & 930.23 & $3,057.54$ \\
\hline SNL-09 & CUL & $09 / 13 / 06$ & 307.99 & 93.88 & $3,052.96$ & 930.54 & $3,058.60$ \\
\hline SNL-09 & CUL & $10 / 10 / 06$ & 307.44 & 93.71 & $3,053.51$ & 930.71 & $3,059.16$ \\
\hline SNL-09 & CUL & $11 / 06 / 06$ & 307.79 & 93.81 & $3,053.16$ & 930.60 & $3,058.80$ \\
\hline SNL-09 & CUL & $12 / 05 / 06$ & 308.36 & 93.99 & $3,052.59$ & 930.43 & $3,058.22$ \\
\hline SNL-10 & CUL & $09 / 14 / 06$ & 323.24 & 98.52 & $3,054.35$ & 930.97 & $3,054.64$ \\
\hline SNL-10 & CUL & $10 / 10 / 06$ & 322.75 & 98.37 & $3,054.84$ & 931.12 & $3,055.13$ \\
\hline SNL-12 & CUL & $01 / 18 / 06$ & 337.40 & 102.84 & $3,002.04$ & 915.02 & $3,002.97$ \\
\hline SNL-12 & CUL & $02 / 14 / 06$ & 337.16 & 102.77 & $3,002.28$ & 915.09 & $3,003.21$ \\
\hline SNL-12 & CUL & $03 / 08 / 06$ & 336.95 & 102.70 & $3,002.49$ & 915.16 & $3,003.42$ \\
\hline SNL-12 & CUL & $04 / 11 / 06$ & 337.03 & 102.73 & $3,002.41$ & 915.13 & $3,003.34$ \\
\hline SNL-12 & CUL & $05 / 09 / 06$ & 336.78 & 102.65 & $3,002.66$ & 915.21 & $3,003.59$ \\
\hline SNL-12 & CUL & $06 / 13 / 06$ & 337.02 & 102.72 & $3,002.42$ & 915.14 & $3,003.35$ \\
\hline SNL-12 & CUL & $07 / 10 / 06$ & 337.03 & 102.73 & $3,002.41$ & 915.13 & $3,003.34$ \\
\hline SNL-12 & CUL & $08 / 14 / 06$ & 337.43 & 102.85 & $3,002.01$ & 915.01 & $3,002.94$ \\
\hline SNL-12 & CUL & $09 / 11 / 06$ & 337.52 & 102.88 & $3,001.92$ & 914.99 & $3,002.85$ \\
\hline SNL-12 & CUL & $10 / 10 / 06$ & 337.94 & 103.00 & $3,001.50$ & 914.86 & $3,002.42$ \\
\hline SNL-12 & CUL & $11 / 06 / 06$ & 337.95 & 103.01 & $3,001.49$ & 914.85 & $3,002.41$ \\
\hline SNL-12 & CUL & $12 / 05 / 06$ & 338.50 & 103.17 & $3,000.94$ & 914.69 & $3,001.86$ \\
\hline SNL-13 & CUL & $01 / 17 / 06$ & 286.68 & 87.38 & $3,007.55$ & 916.70 & $3,013.81$ \\
\hline SNL-13 & CUL & $04 / 10 / 06$ & 286.40 & 87.29 & $3,007.83$ & 916.79 & $3,014.11$ \\
\hline SNL-13 & CUL & $05 / 08 / 06$ & 286.25 & 87.25 & $3,007.98$ & 916.83 & $3,014.26$ \\
\hline SNL-13 & CUL & $06 / 13 / 06$ & 286.36 & 87.28 & $3,007.87$ & 916.80 & $3,014.15$ \\
\hline SNL-13 & CUL & $07 / 11 / 06$ & 286.30 & 87.26 & $3,007.93$ & 916.82 & $3,014.21$ \\
\hline SNL-13 & CUL & $08 / 14 / 06$ & 286.00 & 87.17 & $3,008.23$ & 916.91 & $3,014.53$ \\
\hline SNL-13 & CUL & $09 / 11 / 06$ & 285.51 & 87.02 & $3,008.72$ & 917.06 & $3,015.04$ \\
\hline SNL-13 & CUL & $10 / 09 / 06$ & 285.58 & 87.04 & $3,008.65$ & 917.04 & $3,014.97$ \\
\hline SNL-13 & CUL & $11 / 06 / 06$ & 285.52 & 87.03 & $3,008.71$ & 917.05 & $3,015.03$ \\
\hline SNL-13 & CUL & $12 / 05 / 06$ & 285.68 & 87.08 & $3,008.55$ & 917.01 & $3,014.86$ \\
\hline SNL-14 & CUL & $01 / 18 / 06$ & 376.72 & 114.82 & $2,991.66$ & 911.86 & $3,009.61$ \\
\hline
\end{tabular}


Waste Isolation Pilot Plant Annual Site Environmental Report for 2006 DOE/WIPP-07-2225

Table F.8 - Groundwater Level Measurement Results for 2006

\begin{tabular}{|c|c|c|c|c|c|c|c|}
\hline Well Number & Zone & Date & $\begin{array}{l}\text { Measured } \\
\text { Depth } \\
\text { from Top } \\
\text { of Casing }\end{array}$ & $\begin{array}{c}\text { Measured } \\
\text { Depth in } \\
\text { Meters }\end{array}$ & $\begin{array}{c}\text { Elevation } \\
\text { in Feet } \\
\text { AMSL }\end{array}$ & $\begin{array}{l}\text { Elevation } \\
\text { in Meters }\end{array}$ & \begin{tabular}{|c} 
Elevation in \\
Feet AMSL, \\
if Adjusted \\
to \\
Equivalent \\
Freshwater \\
Head
\end{tabular} \\
\hline SNL-14 & CUL & $02 / 15 / 06$ & 376.34 & 114.71 & $2,992.04$ & 911.97 & $3,010.01$ \\
\hline SNL-14 & CUL & $03 / 08 / 06$ & 376.10 & 114.64 & $2,992.28$ & 912.05 & $3,010.26$ \\
\hline SNL-14 & CUL & $04 / 11 / 06$ & 376.22 & 114.67 & $2,992.16$ & 912.01 & $3,010.14$ \\
\hline SNL-14 & CUL & $05 / 09 / 06$ & 375.91 & 114.58 & $2,992.47$ & 912.10 & $3,010.47$ \\
\hline SNL-14 & CUL & $06 / 13 / 06$ & 376.02 & 114.61 & $2,992.36$ & 912.07 & $3,010.35$ \\
\hline SNL-14 & CUL & $07 / 10 / 06$ & 376.01 & 114.61 & $2,992.37$ & 912.07 & $3,010.36$ \\
\hline SNL-14 & CUL & $08 / 16 / 06$ & 376.26 & 114.68 & $2,992.12$ & 912.00 & $3,010.09$ \\
\hline SNL-14 & CUL & $09 / 11 / 06$ & 376.20 & 114.67 & $2,992.18$ & 912.02 & $3,010.16$ \\
\hline SNL-15 & CUL & $04 / 11 / 06$ & 692.65 & 211.12 & $2,788.58$ & 849.96 & $2,840.64$ \\
\hline SNL-15 & CUL & $05 / 08 / 06$ & 686.26 & 209.17 & $2,794.97$ & 851.91 & $2,848.50$ \\
\hline SNL-15 & CUL & $07 / 10 / 06$ & 676.09 & 206.07 & $2,805.14$ & 855.01 & $2,861.01$ \\
\hline SNL-15 & CUL & $08 / 14 / 06$ & 670.96 & 204.51 & $2,810.27$ & 856.57 & $2,867.32$ \\
\hline SNL-15 & CUL & $09 / 11 / 06$ & 667.02 & 203.31 & $2,814.21$ & 857.77 & $2,872.17$ \\
\hline SNL-15 & CUL & $10 / 10 / 06$ & 663.09 & 202.11 & $2,818.14$ & 858.97 & $2,877.00$ \\
\hline SNL-15 & CUL & $11 / 09 / 06$ & 659.80 & 201.11 & $2,821.43$ & 859.97 & $2,881.05$ \\
\hline SNL-15 & CUL & $12 / 06 / 06$ & 656.42 & 200.08 & $2,824.81$ & 861.00 & $2,885.21$ \\
\hline SNL-16 & CUL & $09 / 12 / 06$ & 121.10 & 36.91 & $3,011.93$ & 918.04 & $3,013.14$ \\
\hline SNL-16 & CUL & $10 / 09 / 06$ & 120.81 & 36.82 & $3,012.22$ & 918.12 & $3,013.44$ \\
\hline SNL-16 & CUL & $11 / 08 / 06$ & 120.64 & 36.77 & $3,012.39$ & 918.18 & $3,013.61$ \\
\hline SNL-16 & CUL & $12 / 07 / 06$ & 121.48 & 37.03 & $3,011.55$ & 917.92 & $3,012.76$ \\
\hline SNL-17 & CUL & $11 / 06 / 06$ & 231.07 & 70.43 & $3,006.99$ & 916.53 & $3,007.10$ \\
\hline SNL-17 & CUL & $12 / 05 / 06$ & 231.12 & 70.45 & $3,006.94$ & 916.52 & $3,007.05$ \\
\hline SNL-18 & CUL & $09 / 12 / 06$ & 300.44 & 91.57 & $3,073.76$ & 936.88 & $3,077.49$ \\
\hline SNL-18 & CUL & $10 / 09 / 06$ & 299.45 & 91.27 & $3,074.75$ & 937.18 & $3,078.49$ \\
\hline SNL-18 & CUL & $11 / 06 / 06$ & 298.98 & 91.13 & $3,075.22$ & 937.33 & $3,078.97$ \\
\hline SNL-18 & CUL & $12 / 04 / 06$ & 299.06 & 91.15 & $3,075.14$ & 937.30 & $3,078.89$ \\
\hline SNL-19 & CUL & $09 / 12 / 06$ & 144.38 & 44.01 & $3,078.28$ & 938.26 & $3,079.75$ \\
\hline SNL-19 & CUL & $10 / 09 / 06$ & 145.57 & 44.37 & $3,077.09$ & 937.90 & $3,078.55$ \\
\hline SNL-19 & CUL & $11 / 06 / 06$ & 146.12 & 44.54 & $3,076.54$ & 937.73 & $3,078.00$ \\
\hline SNL-19 & CUL & $12 / 04 / 06$ & 146.93 & 44.78 & $3,075.73$ & 937.48 & $3,077.18$ \\
\hline PZ-01 & SR/D & $03 / 09 / 06$ & 40.00 & 12.19 & $3,373.41$ & $1,028.22$ & $\mathrm{~N} / \mathrm{A}$ \\
\hline PZ-01 & SR/D & $06 / 14 / 06$ & 40.15 & 12.24 & $3,373.26$ & $1,028.17$ & $\mathrm{~N} / \mathrm{A}$ \\
\hline PZ-01 & SR/D & $09 / 14 / 06$ & 40.30 & 12.28 & $3,373.11$ & $1,028.12$ & $\mathrm{~N} / \mathrm{A}$ \\
\hline PZ-01 & $\mathrm{SR} / \mathrm{D}$ & $12 / 07 / 06$ & 40.60 & 12.37 & $3,372.81$ & $1,028.03$ & $\mathrm{~N} / \mathrm{A}$ \\
\hline PZ-02 & SR/D & $03 / 09 / 06$ & 40.18 & 12.25 & $3,373.24$ & $1,028.16$ & $\mathrm{~N} / \mathrm{A}$ \\
\hline PZ-02 & SR/D & $06 / 14 / 06$ & 40.63 & 12.38 & $3,372.79$ & $1,028.03$ & $\mathrm{~N} / \mathrm{A}$ \\
\hline PZ-02 & SR/D & $09 / 14 / 06$ & 40.78 & 12.43 & $3,372.64$ & $1,027.98$ & $\mathrm{~N} / \mathrm{A}$ \\
\hline PZ-02 & $\mathrm{SR} / \mathrm{D}$ & $12 / 07 / 06$ & 41.11 & 12.53 & $3,372.31$ & $1,027.88$ & $\mathrm{~N} / \mathrm{A}$ \\
\hline PZ-03 & SR/D & $03 / 09 / 06$ & 41.74 & 12.72 & $3,374.41$ & $1,028.52$ & $\mathrm{~N} / \mathrm{A}$ \\
\hline PZ-03 & SR/D & $06 / 14 / 06$ & 41.96 & 12.79 & $3,374.19$ & $1,028.45$ & $\mathrm{~N} / \mathrm{A}$ \\
\hline PZ-03 & SR/D & 09/14/06 & 41.97 & 12.79 & $3,374.18$ & $1,028.45$ & $\mathrm{~N} / \mathrm{A}$ \\
\hline
\end{tabular}


Waste Isolation Pilot Plant Annual Site Environmental Report for 2006 DOE/WIPP-07-2225

Table F.8 - Groundwater Level Measurement Results for 2006

\begin{tabular}{|c|c|c|c|c|c|c|c|}
\hline Well Number & Zone & Date & $\begin{array}{c}\text { Measured } \\
\text { Depth } \\
\text { from Top } \\
\text { of Casing }\end{array}$ & $\begin{array}{c}\text { Measured } \\
\text { Depth in } \\
\text { Meters }\end{array}$ & $\begin{array}{c}\text { Elevation } \\
\text { in Feet } \\
\text { AMSL }\end{array}$ & $\begin{array}{l}\text { Elevation } \\
\text { in Meters }\end{array}$ & \begin{tabular}{|c|} 
Elevation in \\
Feet AMSL, \\
if Adjusted \\
to \\
Equivalent \\
$\begin{array}{c}\text { Freshwater } \\
\text { Head }\end{array}$ \\
\end{tabular} \\
\hline PZ-03 & SR/D & $12 / 07 / 06$ & 42.30 & 12.89 & $3,373.85$ & $1,028.35$ & $\mathrm{~N} / \mathrm{A}$ \\
\hline PZ-04 & SR/D & $03 / 09 / 06$ & 43.81 & 13.35 & $3,368.29$ & $1,026.65$ & $\mathrm{~N} / \mathrm{A}$ \\
\hline PZ-04 & SR/D & $06 / 14 / 06$ & 44.13 & 13.45 & $3,367.97$ & $1,026.56$ & $\mathrm{~N} / \mathrm{A}$ \\
\hline PZ-04 & SR/D & $09 / 14 / 06$ & 44.34 & 13.51 & $3,367.76$ & $1,026.49$ & $\mathrm{~N} / \mathrm{A}$ \\
\hline PZ-04 & SR/D & $12 / 07 / 06$ & 44.54 & 13.58 & $3,367.56$ & $1,026.43$ & $\mathrm{~N} / \mathrm{A}$ \\
\hline PZ-05 & SR/D & $03 / 09 / 06$ & 39.37 & 12.00 & $3,375.94$ & $1,028.99$ & $\mathrm{~N} / \mathrm{A}$ \\
\hline PZ-05 & SR/D & $06 / 14 / 06$ & 39.76 & 12.12 & $3,375.55$ & $1,028.87$ & $\mathrm{~N} / \mathrm{A}$ \\
\hline PZ-05 & SR/D & $09 / 14 / 06$ & 39.95 & 12.18 & $3,375.36$ & $1,028.81$ & $\mathrm{~N} / \mathrm{A}$ \\
\hline PZ-05 & SR/D & $12 / 07 / 06$ & 40.28 & 12.28 & $3,375.03$ & $1,028.71$ & $\mathrm{~N} / \mathrm{A}$ \\
\hline PZ-06 & SR/D & $03 / 09 / 06$ & 41.29 & 12.59 & $3,372.20$ & $1,027.85$ & $\mathrm{~N} / \mathrm{A}$ \\
\hline PZ-06 & SR/D & $06 / 14 / 06$ & 41.66 & 12.70 & $3,371.83$ & $1,027.73$ & $\mathrm{~N} / \mathrm{A}$ \\
\hline PZ-06 & SR/D & $09 / 14 / 06$ & 41.84 & $\mid 12.75$ & $3,371.65$ & $1,027.68$ & $\mathrm{~N} / \mathrm{A}$ \\
\hline PZ-06 & SR/D & $12 / 07 / 06$ & 41.84 & 12.75 & $3,371.65$ & $1,027.68$ & $\mathrm{~N} / \mathrm{A}$ \\
\hline PZ-07 & SR/D & $03 / 09 / 06$ & 34.93 & 10.65 & $3,379.06$ & $1,029.94$ & $\mathrm{~N} / \mathrm{A}$ \\
\hline PZ-07 & SR/D & $06 / 14 / 06$ & 35.50 & 10.82 & $3,378.49$ & $1,029.76$ & $\mathrm{~N} / \mathrm{A}$ \\
\hline PZ-07 & SR/D & $09 / 14 / 06$ & 35.51 & 10.82 & $3,378.48$ & $1,029.76$ & $\mathrm{~N} / \mathrm{A}$ \\
\hline PZ-07 & SR/D & $12 / 07 / 06$ & 35.97 & 10.96 & $3,378.02$ & $1,029.62$ & $\mathrm{~N} / \mathrm{A}$ \\
\hline PZ-08 & SR/D & Dry all year & & & & & $\mathrm{N} / \mathrm{A}$ \\
\hline PZ-09 & SR/D & 03/09/06 & 55.02 & 16.77 & $3,366.19$ & $1,026.01$ & N/A \\
\hline PZ-09 & SR/D & $06 / 14 / 06$ & 55.59 & 16.94 & $3,365.62$ & $1,025.84$ & $\mathrm{~N} / \mathrm{A}$ \\
\hline PZ-09 & SR/D & $09 / 14 / 06$ & 55.72 & 16.98 & $3,365.49$ & $1,025.80$ & $\mathrm{~N} / \mathrm{A}$ \\
\hline PZ-09 & SR/D & $12 / 07 / 06$ & 56.46 & 17.21 & $3,364.75$ & $1,025.58$ & $\mathrm{~N} / \mathrm{A}$ \\
\hline PZ-10 & SR/D & $03 / 09 / 06$ & 34.23 & 10.43 & $3,371.57$ & $1,027.65$ & N/A \\
\hline $\mathrm{PZ}-10$ & SR/D & $06 / 14 / 06$ & 35.10 & 10.70 & $3,370.70$ & $1,027.39$ & $\mathrm{~N} / \mathrm{A}$ \\
\hline PZ-10 & SR/D & $09 / 14 / 06$ & 35.51 & 10.82 & $3,370.29$ & $1,027.26$ & $\mathrm{~N} / \mathrm{A}$ \\
\hline PZ-10 & SR/D & $12 / 07 / 06$ & 34.59 & 10.54 & $3,371.21$ & $1,027.54$ & $\mathrm{~N} / \mathrm{A}$ \\
\hline PZ-11 & SR/D & $03 / 09 / 06$ & 43.12 & 13.14 & $3,375.83$ & $1,028.95$ & $\mathrm{~N} / \mathrm{A}$ \\
\hline $\mathrm{PZ}-11$ & $\mathrm{SR} / \mathrm{D}$ & $06 / 14 / 06$ & 43.49 & 13.26 & $3,375.46$ & $1,028.84$ & $\mathrm{~N} / \mathrm{A}$ \\
\hline PZ-11 & SR/D & $09 / 14 / 06$ & 43.43 & 13.24 & $3,375.52$ & $1,028.86$ & $\mathrm{~N} / \mathrm{A}$ \\
\hline PZ-11 & SR/D & $12 / 07 / 06$ & 44.05 & 13.43 & $3,374.90$ & $1,028.67$ & $\mathrm{~N} / \mathrm{A}$ \\
\hline PZ-12 & SR/D & $03 / 09 / 06$ & 49.68 & 15.14 & $3,359.31$ & $1,023.92$ & $\mathrm{~N} / \mathrm{A}$ \\
\hline PZ-12 & SR/D & $06 / 14 / 06$ & 50.46 & 15.38 & $3,358.53$ & $1,023.68$ & $\mathrm{~N} / \mathrm{A}$ \\
\hline$P Z-12$ & $\mathrm{SR} / \mathrm{D}$ & $09 / 14 / 06$ & 50.68 & 15.45 & $3,358.31$ & $1,023.61$ & $\mathrm{~N} / \mathrm{A}$ \\
\hline PZ-12 & SR/D & $12 / 07 / 06$ & 50.55 & 15.41 & $3,358.44$ & $1,023.65$ & $\mathrm{~N} / \mathrm{A}$ \\
\hline WIPP-11 & CUL & $01 / 16 / 06$ & 363.50 & 110.79 & $3,067.03$ & 934.83 & $3,085.89$ \\
\hline WIPP-11 & $\overline{C U L}$ & $02 / 13 / 06$ & 363.52 & 110.80 & $3,067.01$ & 934.82 & $3,085.87$ \\
\hline WIPP-11 & CUL & $03 / 06 / 06$ & 363.44 & 110.78 & $3,067.09$ & 934.85 & $3,085.96$ \\
\hline WIPP-11 & CUL & $04 / 10 / 06$ & 363.24 & 110.72 & $3,067.29$ & 934.91 & $3,086.16$ \\
\hline WIPP-11 & CUL & $05 / 08 / 06$ & 363.07 & 110.66 & $3,067.46$ & 934.96 & $3,086.34$ \\
\hline WIPP-11 & CUL & $06 / 12 / 06$ & 363.10 & 110.67 & $3,067.43$ & 934.95 & $3,086.31$ \\
\hline WIPP-11 & CUL & $07 / 12 / 06$ & 363.05 & 110.66 & $3,067.48$ & 934.97 & $3,086.36$ \\
\hline
\end{tabular}


Waste Isolation Pilot Plant Annual Site Environmental Report for 2006 DOE/WIPP-07-2225

Table F.8 - Groundwater Level Measurement Results for 2006

\begin{tabular}{|c|c|c|c|c|c|c|c|}
\hline Well Number & Zone & Date & $\begin{array}{l}\text { Measured } \\
\text { Depth } \\
\text { from Top } \\
\text { of Casing }\end{array}$ & $\begin{array}{c}\text { Measured } \\
\text { Depth in } \\
\text { Meters }\end{array}$ & $\begin{array}{c}\text { Elevation } \\
\text { in Feet } \\
\text { AMSL }\end{array}$ & $\begin{array}{l}\text { Elevation } \\
\text { in Meters }\end{array}$ & \begin{tabular}{|c} 
Elevation in \\
Feet AMSL, \\
if Adjusted \\
to \\
Equivalent \\
Freshwater \\
Head \\
\end{tabular} \\
\hline WIPP-11 & CUL & $08 / 14 / 06$ & 363.00 & 110.64 & $3,067.53$ & 934.98 & $3,086.41$ \\
\hline WIPP-11 & CUL & $09 / 12 / 06$ & 362.39 & 110.46 & $3,068.14$ & 935.17 & $3,087.05$ \\
\hline WIPP-11 & CUL & $10 / 09 / 06$ & 361.53 & 110.19 & $3,069.00$ & 935.43 & $3,087.94$ \\
\hline WIPP-11 & CUL & $11 / 09 / 06$ & 360.65 & 109.93 & $3,069.88$ & 935.70 & $3,088.85$ \\
\hline WIPP-11 & CUL & $12 / 04 / 06$ & 360.97 & 110.02 & $3,069.56$ & 935.60 & $3,088.52$ \\
\hline WIPP-13 & CUL & $01 / 16 / 06$ & 344.30 & 104.94 & $3,061.41$ & 933.12 & $3,079.84$ \\
\hline WIPP-13 & CUL & $02 / 13 / 06$ & 344.30 & 104.94 & $3,061.41$ & 933.12 & $3,079.84$ \\
\hline WIPP-13 & CUL & $03 / 06 / 06$ & 344.28 & 104.94 & $3,061.43$ & 933.12 & $3,079.86$ \\
\hline WIPP-13 & CUL & 04/10/06 & 344.04 & 104.86 & $3,061.67$ & 933.20 & $3,080.11$ \\
\hline WIPP-13 & CUL & $05 / 08 / 06$ & 343.92 & 104.83 & $3,061.79$ & 933.23 & $3,080.24$ \\
\hline WIPP-13 & CUL & $06 / 12 / 06$ & 344.08 & 104.88 & $3,061.63$ & 933.18 & $3,080.07$ \\
\hline WIPP-13 & CUL & 07/11/06 & 343.90 & 104.82 & $3,061.81$ & 933.24 & $3,080.26$ \\
\hline WIPP-13 & CUL & $08 / 15 / 06$ & 344.01 & 104.85 & $3,061.70$ & 933.21 & $3,080.14$ \\
\hline WIPP-13 & CUL & $09 / 13 / 06$ & 343.43 & 104.68 & $3,062.28$ & 933.38 & $3,080.75$ \\
\hline WIPP-13 & CUL & $10 / 10 / 06$ & 342.58 & 104.42 & $3,063.13$ & 933.64 & $3,081.64$ \\
\hline WIPP-13 & CUL & $11 / 08 / 06$ & 341.92 & 104.22 & $3,063.79$ & 933.84 & $3,082.34$ \\
\hline WIPP-13 & CUL & $12 / 04 / 06$ & 342.11 & 104.28 & $3,063.60$ & 933.79 & $3,082.14$ \\
\hline WIPP-18 & MAG & $01 / 18 / 06$ & 309.02 & 94.19 & $3,148.72$ & 959.73 & $\mathrm{~N} / \mathrm{A}$ \\
\hline WIPP-18 & MAG & $02 / 23 / 06$ & 308.90 & 94.15 & $3,148.84$ & 959.77 & N/A \\
\hline WIPP-18 & MAG & $03 / 07 / 06$ & 308.95 & 94.17 & $3,148.79$ & 959.75 & $\mathrm{~N} / \mathrm{A}$ \\
\hline WIPP-18 & MAG & $04 / 10 / 06$ & 308.77 & 94.11 & $3,148.97$ & 959.81 & $\mathrm{~N} / \mathrm{A}$ \\
\hline WIPP-18 & MAG & $05 / 09 / 06$ & 308.59 & 94.06 & $3,149.15$ & 959.86 & $\mathrm{~N} / \mathrm{A}$ \\
\hline WIPP-18 & MAG & $06 / 13 / 06$ & 308.64 & 94.07 & $3,149.10$ & 959.85 & $\mathrm{~N} / \mathrm{A}$ \\
\hline WIPP-18 & MAG & $07 / 11 / 06$ & 308.68 & 94.09 & $3,149.06$ & 959.83 & $\mathrm{~N} / \mathrm{A}$ \\
\hline WIPP-18 & MAG & 08/15/06 & 308.59 & 94.06 & $3,149.15$ & 959.86 & $\mathrm{~N} / \mathrm{A}$ \\
\hline WIPP-18 & MAG & 09/13/06 & 308.42 & 94.01 & $3,149.32$ & 959.91 & $\mathrm{~N} / \mathrm{A}$ \\
\hline WIPP-18 & MAG & $10 / 11 / 06$ & 308.38 & 93.99 & $3,149.36$ & 959.92 & $\mathrm{~N} / \mathrm{A}$ \\
\hline WIPP-18 & MAG & $11 / 08 / 06$ & 308.30 & 93.97 & $3,149.44$ & 959.95 & $\mathrm{~N} / \mathrm{A}$ \\
\hline WIPP-18 & MAG & $12 / 04 / 06$ & 308.38 & 93.99 & $3,149.36$ & 959.92 & $\mathrm{~N} / \mathrm{A}$ \\
\hline WIPP-19 & CUL & $01 / 18 / 06$ & 391.87 & 119.44 & $3,043.27$ & 927.59 & $3,065.93$ \\
\hline WIPP-19 & CUL & $02 / 23 / 06$ & 391.56 & 119.35 & $3,043.58$ & 927.68 & $3,066.26$ \\
\hline WIPP-19 & CUL & $03 / 07 / 06$ & 391.36 & 119.29 & $3,043.78$ & 927.74 & $3,066.47$ \\
\hline WIPP-19 & CUL & $04 / 10 / 06$ & 391.00 & 119.18 & $3,044.14$ & 927.85 & $3,066.85$ \\
\hline WIPP-19 & CUL & 05/09/06 & 390.60 & 119.05 & $3,044.54$ & 927.98 & $3,067.27$ \\
\hline WIPP-19 & CUL & $06 / 13 / 06$ & 390.65 & 119.07 & $3,044.49$ & 927.96 & $3,067.22$ \\
\hline WIPP-19 & CUL & $07 / 11 / 06$ & 390.44 & 119.01 & $3,044.70$ & 928.02 & $3,067.44$ \\
\hline WIPP-19 & CUL & 08/15/06 & 390.42 & 119.00 & $3,044.72$ & 928.03 & $3,067.47$ \\
\hline WIPP-19 & CUL & 09/13/06 & 390.13 & 118.91 & $3,045.01$ & 928.12 & $3,067.77$ \\
\hline WIPP-19 & CUL & $10 / 11 / 06$ & 389.62 & 118.76 & $3,045.52$ & 928.27 & $3,068.31$ \\
\hline WIPP-19 & CUL & $11 / 08 / 06$ & 389.18 & 118.62 & $3,045.96$ & 928.41 & $3,068.78$ \\
\hline WIPP-19 & CUL & $12 / 04 / 06$ & 389.32 & 118.66 & $3,045.82$ & 928.37 & $3,068.63$ \\
\hline
\end{tabular}


Waste Isolation Pilot Plant Annual Site Environmental Report for 2006 DOE/WIPP-07-2225

\begin{tabular}{|c|c|c|c|c|c|c|c|}
\hline Well Number & Zone & Date & $\begin{array}{c}\text { Measured } \\
\text { Depth } \\
\text { from Top } \\
\text { of Casing }\end{array}$ & $\begin{array}{c}\text { Measured } \\
\text { Depth in } \\
\text { Meters }\end{array}$ & $\begin{array}{c}\text { Elevation } \\
\text { in Feet } \\
\text { AMSL }\end{array}$ & $\begin{array}{l}\text { Elevation } \\
\text { in Meters }\end{array}$ & \begin{tabular}{|c|} 
Elevation in \\
Feet AMSL, \\
if Adjusted \\
to \\
Equivalent \\
Freshwater \\
Head
\end{tabular} \\
\hline WIPP-25 (ANNULUS) & MAG & $01 / 16 / 06$ & 150.11 & 45.75 & $3,064.28$ & 933.99 & $\mathrm{~N} / \mathrm{A}$ \\
\hline WIPP-25 (PIP) & $\overline{\text { CUL }}$ & $01 / 16 / 06$ & 145.55 & 44.36 & $3,068.84$ & 935.38 & $3,075.79$ \\
\hline WIPP-26 & CUL & $01 / 16 / 06$ & 127.58 & 38.89 & $3,025.62$ & 922.21 & $3,026.98$ \\
\hline WIPP-26 & CUL & $02 / 13 / 06$ & 127.96 & 39.00 & $3,025.24$ & 922.09 & $3,026.59$ \\
\hline WIPP-26 & $\overline{\text { CUL }}$ & $03 / 06 / 06$ & 128.04 & 39.03 & $3,025.16$ & 922.07 & $3,026.51$ \\
\hline WIPP-26 & CUL & $04 / 10 / 06$ & 127.93 & 38.99 & $3,025.27$ & 922.10 & $3,026.62$ \\
\hline WIPP-26 & $\overline{\text { CUL }}$ & $05 / 08 / 06$ & 128.02 & 39.02 & $3,025.18$ & 922.07 & $3,026.53$ \\
\hline WIPP-26 & $\overline{\text { CUL }}$ & $06 / 12 / 06$ & 128.26 & 39.09 & $3,024.94$ & 922.00 & $3,026.28$ \\
\hline WIPP-26 & CUL & $07 / 11 / 06$ & 128.31 & 39.11 & $3,024.89$ & 921.99 & $3,026.23$ \\
\hline WIPP-26 & CUL & $08 / 15 / 06$ & 129.06 & 39.34 & $3,024.14$ & 921.76 & $3,025.47$ \\
\hline WIPP-30 (ANNULUS) & MAG & $01 / 16 / 06$ & 350.09 & 106.71 & $3,078.96$ & 938.47 & $\mathrm{~N} / \mathrm{A}$ \\
\hline WIPP-30 (ANNULUS) & MAG & $02 / 13 / 06$ & 350.16 & 106.73 & $3,078.89$ & 938.45 & $\mathrm{~N} / \mathrm{A}$ \\
\hline WIPP-30 (ANNULUS) & MAG & $03 / 06 / 06$ & 350.17 & 106.73 & $3,078.88$ & 938.44 & $\mathrm{~N} / \mathrm{A}$ \\
\hline WIPP-30 (ANNULUS) & MAG & $04 / 10 / 06$ & 350.06 & 106.70 & $3,078.99$ & 938.48 & $\mathrm{~N} / \mathrm{A}$ \\
\hline WIPP-30 (ANNULUS) & MAG & $05 / 08 / 06$ & 307.33 & 93.67 & $3,121.72$ & 951.50 & $\mathrm{~N} / \mathrm{A}$ \\
\hline WIPP-30 (ANNULUS) & MAG & $06 / 14 / 06$ & 309.17 & 94.24 & $3,119.88$ & 950.94 & $\mathrm{~N} / \mathrm{A}$ \\
\hline WIPP-30 (ANNULUS) & MAG & $07 / 12 / 06$ & 308.50 & 94.03 & $3,120.55$ & 951.14 & $\mathrm{~N} / \mathrm{A}$ \\
\hline WIPP-30 (ANNULUS) & MAG & $08 / 16 / 06$ & 308.17 & 93.93 & $3,120.88$ & 951.24 & $\mathrm{~N} / \mathrm{A}$ \\
\hline WIPP-30 (ANNULUS) & MAG & $09 / 12 / 06$ & 306.86 & 93.53 & $3,122.19$ & 951.64 & $\mathrm{~N} / \mathrm{A}$ \\
\hline WIPP-30 (ANNULUS) & MAG & $10 / 09 / 06$ & 306.78 & 93.51 & $3,122.27$ & 951.67 & $\mathrm{~N} / \mathrm{A}$ \\
\hline WIPP-30 (ANNULUS) & MAG & $11 / 06 / 06$ & 306.37 & 93.38 & $3,122.68$ & 951.79 & $\mathrm{~N} / \mathrm{A}$ \\
\hline WIPP-30 (ANNULUS) & MAG & $12 / 04 / 06$ & 306.09 & 93.30 & $3,122.96$ & 951.88 & $\mathrm{~N} / \mathrm{A}$ \\
\hline WIPP-30 (PIP) & CUL & $01 / 16 / 06$ & 349.37 & 106.49 & $3,079.68$ & 938.69 & $3,087.04$ \\
\hline WIPP-30 (PIP) & CUL & $02 / 13 / 06$ & 349.52 & 106.53 & $3,079.53$ & 938.64 & $3,086.88$ \\
\hline WIPP-30 (PIP) & $\overline{\text { CUL }}$ & $03 / 06 / 06$ & 349.42 & 106.50 & $3,079.63$ & 938.67 & $3,086.98$ \\
\hline WIPP-30 (PIP) & CUL & 04/10/06 & 349.32 & 106.47 & $3,079.73$ & 938.70 & $3,087.09$ \\
\hline WIPP-30 (PIP) & CUL & $05 / 08 / 06$ & 350.51 & 106.84 & $3,078.54$ & 938.34 & $3,085.87$ \\
\hline WIPP-30 (PIP) & $\overline{C U L}$ & $06 / 12 / 06$ & 351.12 & 107.02 & $3,077.93$ & 938.15 & $3,085.24$ \\
\hline WIPP-30 (PIP) & $\overline{\text { CUL }}$ & $07 / 12 / 06$ & 350.88 & 106.95 & $3,078.17$ & 938.23 & $3,085.49$ \\
\hline WIPP-30 (PIP) & $\overline{\text { CUL }}$ & $08 / 16 / 06$ & 350.85 & 106.94 & $3,078.20$ & 938.24 & $3,085.52$ \\
\hline WIPP-30 (PIP) & $\overline{\text { CUL }}$ & $09 / 12 / 06$ & 351.37 & 107.10 & $3,077.68$ & 938.08 & $3,084.99$ \\
\hline WIPP-30 (PIP) & CUL & $10 / 09 / 06$ & 349.24 & 106.45 & $3,079.81$ & 938.73 & $3,087.17$ \\
\hline WIPP-30 (PIP) & $\overline{C U L}$ & $11 / 06 / 06$ & 348.58 & 106.25 & $3,080.47$ & 938.93 & $3,087.84$ \\
\hline WIPP-30 (PIP) & $\overline{\text { CUL }}$ & $12 / 04 / 06$ & 348.15 & 106.12 & $3,080.90$ & 939.06 & $3,088.29$ \\
\hline WQSP-1 & $\overline{\text { CUL }}$ & $01 / 17 / 06$ & 359.88 & 109.69 & $3,059.32$ & 932.48 & $3,073.45$ \\
\hline WQSP-1 & $\overline{\text { CUL }}$ & $02 / 15 / 06$ & 359.44 & 109.56 & $3,059.76$ & 932.61 & $3,073.91$ \\
\hline WQSP-1 & CUL & $03 / 07 / 06$ & 359.43 & 109.55 & $3,059.77$ & 932.62 & $3,073.92$ \\
\hline WQSP-1 & $\overline{C U L}$ & $04 / 10 / 06$ & 359.24 & 109.50 & $3,059.96$ & 932.68 & $3,074.11$ \\
\hline WQSP-1 & $\overline{\text { CUL }}$ & $05 / 09 / 06$ & 359.04 & 109.44 & $3,060.16$ & 932.74 & $3,074.32$ \\
\hline WQSP-1 & $\overline{\text { CUL }}$ & $06 / 13 / 06$ & 359.35 & 109.53 & $3,059.85$ & 932.64 & $3,074.00$ \\
\hline WQSP-1 & CUL & $07 / 11 / 06$ & 359.09 & 109.45 & $3,060.11$ & 932.72 & $3,074.27$ \\
\hline
\end{tabular}


Waste Isolation Pilot Plant Annual Site Environmental Report for 2006 DOE/WIPP-07-2225

Table F.8 - Groundwater Level Measurement Results for 2006

\begin{tabular}{|c|c|c|c|c|c|c|c|}
\hline Well Number & Zone & Date & $\begin{array}{c}\text { Measured } \\
\text { Depth } \\
\text { from Top } \\
\text { of Casing }\end{array}$ & $\begin{array}{c}\text { Measured } \\
\text { Depth in } \\
\text { Meters }\end{array}$ & $\begin{array}{c}\text { Elevation } \\
\text { in Feet } \\
\text { AMSL }\end{array}$ & $\begin{array}{l}\text { Elevation } \\
\text { in Meters }\end{array}$ & \begin{tabular}{|c|} 
Elevation in \\
Feet AMSL, \\
if Adjusted \\
to \\
Equivalent \\
Freshwater \\
Head
\end{tabular} \\
\hline WQSP-1 & CUL & $08 / 15 / 06$ & 359.20 & 109.48 & $3,060.00$ & 932.69 & $3,074.16$ \\
\hline WQSP-1 & CUL & $09 / 13 / 06$ & 358.56 & 109.29 & $3,060.64$ & 932.88 & $3,074.82$ \\
\hline WQSP-1 & CUL & $10 / 11 / 06$ & 357.56 & 108.98 & $3,061.64$ & 933.19 & $3,075.86$ \\
\hline WQSP-1 & CUL & $11 / 08 / 06$ & 357.07 & 108.83 & $3,062.13$ & 933.34 & $3,076.37$ \\
\hline WQSP-1 & CUL & $12 / 06 / 06$ & 357.10 & 108.84 & $3,062.10$ & 933.33 & $3,076.34$ \\
\hline WQSP-2 & CUL & $01 / 17 / 06$ & 399.42 & 121.74 & $3,064.48$ & 934.05 & $3,081.48$ \\
\hline WQSP-2 & CUL & $02 / 15 / 06$ & 398.97 & 121.61 & $3,064.93$ & 934.19 & $3,081.95$ \\
\hline WQSP-2 & CUL & $03 / 07 / 06$ & 398.99 & 121.61 & $3,064.91$ & 934.18 & $3,081.93$ \\
\hline WQSP-2 & CUL & $04 / 10 / 06$ & 399.14 & 121.66 & $3,064.76$ & 934.14 & $3,081.77$ \\
\hline WQSP-2 & CUL & $05 / 09 / 06$ & 398.73 & 121.53 & $3,065.17$ & 934.26 & $3,082.20$ \\
\hline WQSP-2 & CUL & $06 / 13 / 06$ & 398.99 & 121.61 & $3,064.91$ & 934.18 & $3,081.93$ \\
\hline WQSP-2 & CUL & $07 / 11 / 06$ & 398.71 & 121.53 & $3,065.19$ & 934.27 & $3,082.22$ \\
\hline WQSP-2 & CUL & $08 / 15 / 06$ & 398.79 & 121.55 & $3,065.11$ & 934.25 & $3,082.14$ \\
\hline WQSP-2 & CUL & $09 / 13 / 06$ & 398.14 & 121.35 & $3,065.76$ & 934.44 & $3,082.81$ \\
\hline WQSP-2 & CUL & $10 / 11 / 06$ & 397.07 & 121.03 & $3,066.83$ & 934.77 & $3,083.93$ \\
\hline WQSP-2 & CUL & $11 / 08 / 06$ & 396.57 & 120.87 & $3,067.33$ & 934.92 & $3,084.45$ \\
\hline WQSP-2 & CUL & $12 / 06 / 06$ & 396.56 & 120.87 & $3,067.34$ & 934.93 & $3,084.46$ \\
\hline WQSP-3 & CUL & $01 / 17 / 06$ & 465.00 & 141.73 & $3,015.30$ & 919.06 & $3,070.57$ \\
\hline WQSP-3 & CUL & $02 / 23 / 06$ & 464.54 & 141.59 & $3,015.76$ & 919.20 & $3,071.10$ \\
\hline WQSP-3 & CUL & $03 / 07 / 06$ & 464.34 & 141.53 & $3,015.96$ & 919.26 & $3,071.32$ \\
\hline WQSP-3 & CUL & $04 / 10 / 06$ & 464.00 & 141.43 & $3,016.30$ & 919.37 & $3,071.71$ \\
\hline WQSP-3 & CUL & $05 / 09 / 06$ & 463.59 & 141.30 & $3,016.71$ & 919.49 & $3,072.18$ \\
\hline WQSP-3 & CUL & $06 / 13 / 06$ & 464.66 & 141.63 & $3,015.64$ & 919.17 & $3,070.96$ \\
\hline WQSP-3 & CUL & $07 / 11 / 06$ & 464.03 & 141.44 & $3,016.27$ & 919.36 & $3,071.68$ \\
\hline WQSP-3 & CUL & $08 / 15 / 06$ & 463.58 & 141.30 & $3,016.72$ & 919.50 & $3,072.19$ \\
\hline WQSP-3 & CUL & $09 / 13 / 06$ & 463.48 & 141.27 & $3,016.82$ & 919.53 & $3,072.30$ \\
\hline WQSP-3 & CUL & $10 / 11 / 06$ & 462.94 & 141.10 & $3,017.36$ & 919.69 & $3,072.92$ \\
\hline WQSP-3 & CUL & $11 / 08 / 06$ & 463.75 & 141.35 & $3,016.55$ & 919.44 & $3,072.00$ \\
\hline WQSP-3 & CUL & $12 / 06 / 06$ & 462.77 & 141.05 & $3,017.53$ & 919.74 & $3,073.11$ \\
\hline WQSP-4 & CUL & $01 / 17 / 06$ & 445.95 & 135.93 & $2,987.05$ & 910.45 & $3,006.99$ \\
\hline WQSP-4 & CUL & $02 / 15 / 06$ & 445.17 & 135.69 & $2,987.83$ & 910.69 & $3,007.81$ \\
\hline WQSP-4 & CUL & $03 / 07 / 06$ & 444.81 & 135.58 & $2,988.19$ & 910.80 & $3,008.19$ \\
\hline WQSP-4 & CUL & $04 / 11 / 06$ & 444.67 & 135.54 & $2,988.33$ & 910.84 & $3,008.34$ \\
\hline WQSP-4 & CUL & $05 / 09 / 06$ & 444.05 & 135.35 & $2,988.95$ & 911.03 & $3,009.00$ \\
\hline WQSP-4 & CUL & $06 / 13 / 06$ & 443.81 & 135.27 & $2,989.19$ & 911.11 & $3,009.25$ \\
\hline WQSP-4 & CUL & $07 / 11 / 06$ & 443.47 & 135.17 & $2,989.53$ & 911.21 & $3,009.61$ \\
\hline WQSP-4 & CUL & $08 / 15 / 06$ & 443.50 & 135.18 & $2,989.50$ & 911.20 & $3,009.58$ \\
\hline WQSP-4 & CUL & $09 / 13 / 06$ & 443.88 & 135.29 & $2,989.12$ & 911.08 & $3,009.18$ \\
\hline WQSP-4 & CUL & $10 / 11 / 06$ & 443.62 & 135.22 & $2,989.38$ & 911.16 & $3,009.45$ \\
\hline WQSP-4 & CUL & $11 / 08 / 06$ & 443.35 & 135.13 & $2,989.65$ & 911.25 & $3,009.74$ \\
\hline WQSP-4 & CUL & $12 / 06 / 06$ & 444.46 & 135.47 & $2,988.54$ & 910.91 & $3,008.56$ \\
\hline
\end{tabular}


Waste Isolation Pilot Plant Annual Site Environmental Report for 2006 DOE/WIPP-07-2225

\begin{tabular}{|c|c|c|c|c|c|c|c|}
\hline Well Number & Zone & Date & $\begin{array}{c}\text { Measured } \\
\text { Depth } \\
\text { from Top } \\
\text { of Casing }\end{array}$ & $\begin{array}{c}\text { Measured } \\
\text { Depth in } \\
\text { Meters }\end{array}$ & $\begin{array}{c}\text { Elevation } \\
\text { in Feet } \\
\text { AMSL }\end{array}$ & $\begin{array}{l}\text { Elevation } \\
\text { in Meters }\end{array}$ & \begin{tabular}{|c|} 
Elevation in \\
Feet AMSL, \\
if Adjusted \\
to \\
Equivalent \\
Freshwater \\
Head
\end{tabular} \\
\hline WQSP-5 & CUL & $01 / 17 / 06$ & 382.18 & 116.49 & $3,002.22$ & 915.08 & $3,007.85$ \\
\hline WQSP-5 & CUL & $02 / 15 / 06$ & 381.28 & 116.21 & $3,003.12$ & 915.35 & $3,008.77$ \\
\hline WQSP-5 & CUL & $03 / 07 / 06$ & 380.95 & 116.11 & $3,003.45$ & 915.45 & $3,009.11$ \\
\hline WQSP-5 & CUL & $04 / 11 / 06$ & 381.20 & 116.19 & $3,003.20$ & 915.38 & $3,008.85$ \\
\hline WQSP-5 & CUL & $05 / 09 / 06$ & 380.10 & 115.85 & $3,004.30$ & 915.71 & $3,009.97$ \\
\hline WQSP-5 & CUL & $06 / 13 / 06$ & 379.87 & 115.78 & $3,004.53$ & 915.78 & $3,010.21$ \\
\hline WQSP-5 & CUL & $07 / 11 / 06$ & 379.52 & 115.68 & $3,004.88$ & 915.89 & $3,010.57$ \\
\hline WQSP-5 & CUL & $08 / 15 / 06$ & 379.38 & 115.64 & $3,005.02$ & 915.93 & $3,010.71$ \\
\hline WQSP-5 & CUL & $09 / 13 / 06$ & 379.69 & 115.73 & $3,004.71$ & 915.84 & $3,010.39$ \\
\hline WQSP-5 & CUL & $10 / 11 / 06$ & 379.77 & 115.75 & $3,004.63$ & 915.81 & $3,010.31$ \\
\hline WQSP-5 & $\overline{C U L}$ & $11 / 08 / 06$ & 379.15 & 115.56 & $3,005.25$ & 916.00 & $3,010.94$ \\
\hline WQSP-5 & CUL & $12 / 06 / 06$ & 379.23 & 115.59 & $3,005.17$ & 915.98 & $3,010.86$ \\
\hline WQSP-6 & CUL & $01 / 17 / 06$ & 346.34 & 105.56 & $3,018.36$ & 920.00 & $3,020.87$ \\
\hline WQSP-6 & CUL & $02 / 15 / 06$ & 345.83 & 105.41 & $3,018.87$ & 920.15 & $3,021.39$ \\
\hline WQSP-6 & CUL & $03 / 07 / 06$ & 345.68 & 105.36 & $3,019.02$ & 920.20 & $3,021.54$ \\
\hline WQSP-6 & CUL & $04 / 11 / 06$ & 345.37 & 105.27 & $3,019.33$ & 920.29 & $3,021.85$ \\
\hline WQSP-6 & CUL & $05 / 09 / 06$ & 345.52 & 105.31 & $3,019.18$ & 920.25 & $3,021.70$ \\
\hline WQSP-6 & CUL & $06 / 13 / 06$ & 345.07 & 105.18 & $3,019.63$ & 920.38 & $3,022.15$ \\
\hline WQSP-6 & CUL & $07 / 11 / 06$ & 344.67 & 105.06 & $3,020.03$ & 920.51 & $3,022.56$ \\
\hline WQSP-6 & CUL & $08 / 15 / 06$ & 344.62 & 105.04 & $3,020.08$ & 920.52 & $3,022.61$ \\
\hline WQSP-6 & CUL & $09 / 13 / 06$ & 415.52 & 126.65 & $2,949.18$ & 898.91 & $2,951.00$ \\
\hline WQSP-6 & CUL & $10 / 11 / 06$ & 344.52 & 105.01 & $3,020.18$ & 920.55 & $3,022.71$ \\
\hline WQSP-6 & CUL & $11 / 08 / 06$ & 344.02 & 104.86 & $3,020.68$ & 920.70 & $3,023.21$ \\
\hline WQSP-6 & CUL & $12 / 06 / 06$ & 344.06 & 104.87 & $3,020.64$ & 920.69 & $3,023.17$ \\
\hline WQSP-6A & $\mathrm{DL}$ & $01 / 17 / 06$ & 166.96 & 50.89 & $3,196.84$ & 974.40 & $\mathrm{~N} / \mathrm{A}$ \\
\hline WQSP-6A & $\mathrm{DL}$ & $02 / 15 / 06$ & 166.60 & 50.78 & $3,197.20$ & 974.51 & $\mathrm{~N} / \mathrm{A}$ \\
\hline WQSP-6A & $\mathrm{DL}$ & $03 / 07 / 06$ & 166.74 & 50.82 & $3,197.06$ & 974.46 & $\mathrm{~N} / \mathrm{A}$ \\
\hline WQSP-6A & $\mathrm{DL}$ & $04 / 11 / 06$ & 166.83 & 50.85 & $3,196.97$ & 974.44 & $\mathrm{~N} / \mathrm{A}$ \\
\hline WQSP-6A & $\mathrm{DL}$ & $05 / 09 / 06$ & 166.71 & 50.81 & $3,197.09$ & 974.47 & $\mathrm{~N} / \mathrm{A}$ \\
\hline WQSP-6A & $\mathrm{DL}$ & $06 / 13 / 06$ & 166.96 & 50.89 & $3,196.84$ & 974.40 & $\mathrm{~N} / \mathrm{A}$ \\
\hline WQSP-6A & $\mathrm{DL}$ & $07 / 11 / 06$ & 166.75 & 50.83 & $3,197.05$ & 974.46 & $\mathrm{~N} / \mathrm{A}$ \\
\hline WQSP-6A & $\mathrm{DL}$ & $08 / 15 / 06$ & 166.90 & 50.87 & $3,196.90$ & 974.42 & $\mathrm{~N} / \mathrm{A}$ \\
\hline WQSP-6A & $\mathrm{DL}$ & $09 / 13 / 06$ & 166.88 & 50.87 & $3,196.92$ & 974.42 & $\mathrm{~N} / \mathrm{A}$ \\
\hline WQSP-6A & $\mathrm{DL}$ & $10 / 11 / 06$ & 166.81 & 50.84 & $3,196.99$ & 974.44 & $\mathrm{~N} / \mathrm{A}$ \\
\hline WQSP-6A & $\mathrm{DL}$ & $11 / 08 / 06$ & $166.61 \mid$ & 50.78 & $3,197.19$ & 974.50 & $\mathrm{~N} / \mathrm{A}$ \\
\hline WQSP-6A & $\mathrm{DL}$ & $12 / 06 / 06$ & 166.89 & 50.87 & $3,196.91$ & 974.42 & $\mathrm{~N} / \mathrm{A}$ \\
\hline
\end{tabular}


Waste Isolation Pilot Plant Annual Site Environmental Report for 2006 DOE/WIPP-07-2225

\begin{tabular}{|c|c|c|c|c|c|c|c|}
\hline \multicolumn{4}{|c|}{ Sorted By Active Wells at Year-End } & \multicolumn{4}{|c|}{$\begin{array}{c}\text { Sorted By Formation for Wells Measured at Least } \\
\text { Once in } 2006\end{array}$} \\
\hline Count & $\begin{array}{c}\text { Well } \\
\text { Number }\end{array}$ & Zone & Notes & Count & $\begin{array}{c}\text { Well } \\
\text { Number }\end{array}$ & Zone & $\begin{array}{c}\text { Reason Not Assessed } \\
\text { for Long-Term Water } \\
\text { Level Trend }\end{array}$ \\
\hline 1 & AEC-7 & CUL & & 1 & CB-1(PIP) & $\mathrm{B} / \mathrm{C}$ & \\
\hline 2 & C-2505 & $S R / D$ & & 2 & DOE-2 & $\mathrm{B} / \mathrm{C}$ & \\
\hline 3 & C-2506 & $S R / D$ & & 3 & AEC-7 & CUL & Not reflective of Culebra \\
\hline 4 & C-2507 & $S R / D$ & & 4 & DOE-1 & CUL & \\
\hline 5 & C-2737 & MAG/CUL & & 5 & ERDA-9 & CUL & \\
\hline 6 & C-2811 & $S R / D$ & & 6 & $\mathrm{H}-02 \mathrm{~B} 2$ & CUL & \\
\hline 7 & CB-1 (PIP) & $\mathrm{B} / \mathrm{C}$ & & 7 & $\mathrm{H}-03 \mathrm{~B} 2$ & CUL & \\
\hline 8 & DOE-2 & $\mathrm{B} / \mathrm{C}$ & & 8 & $\mathrm{H}-04 \mathrm{~B}$ & CUL & \\
\hline 9 & ERDA-9 & CUL & & 9 & $\mathrm{H}-05 \mathrm{~B}$ & CUL & \\
\hline 10 & $\mathrm{H}-02 \mathrm{~B} 1$ & MAG & & 10 & $\mathrm{H}-06 \mathrm{~B}$ & CUL & \\
\hline 11 & $\mathrm{H}-02 \mathrm{~B} 2$ & CUL & & 11 & H-07B1 & CUL & \\
\hline 12 & $\mathrm{H}-03 \mathrm{~B} 1$ & MAG & & 12 & $\mathrm{H}-10 \mathrm{C}$ & CUL & \\
\hline 13 & $\mathrm{H}-03 \mathrm{~B} 2$ & CUL & & 13 & $\mathrm{H}-11 \mathrm{~B} 4$ & CUL & \\
\hline 14 & $\mathrm{H}-03 \mathrm{D}$ & SR/D & $\begin{array}{l}\text { Dry; not regularly } \\
\text { measured in } 2006\end{array}$ & 14 & $\mathrm{H}-12$ & CUL & \\
\hline 15 & $\mathrm{H}-04 \mathrm{~B}$ & CUL & & 15 & $\mathrm{H}-17$ & CUL & \\
\hline 16 & $\mathrm{H}-04 \mathrm{C}$ & MAG & & 16 & $\mathrm{H}-19 \mathrm{~B} 0$ & CUL & \\
\hline 17 & $\mathrm{H}-05 \mathrm{~B}$ & CUL & & 17 & $\mathrm{H}-19 \mathrm{~B} 2$ & CUL & Redundant to $\mathrm{H}-19 \mathrm{~B} 0$ \\
\hline 18 & $\mathrm{H}-06 \mathrm{~B}$ & CUL & & 18 & $\mathrm{H}-19 \mathrm{~B} 3$ & CUL & Redundant to $\mathrm{H}-19 \mathrm{~B} 0$ \\
\hline 19 & $\mathrm{H}-06 \mathrm{C}$ & MAG & & 19 & $\mathrm{H}-19 \mathrm{~B} 4$ & CUL & Redundant to $\mathrm{H}-19 \mathrm{~B} 0$ \\
\hline 20 & $\mathrm{H}-07 \mathrm{~B} 1$ & CUL & & 20 & $\mathrm{H}-19 \mathrm{~B} 5$ & CUL & Redundant to $\mathrm{H}-19 \mathrm{~B} 0$ \\
\hline 21 & $\mathrm{H}-08 \mathrm{~A}$ & MAG & & 21 & $\mathrm{H}-19 \mathrm{~B} 6$ & CUL & Redundant to $\mathrm{H}-19 \mathrm{~B} 0$ \\
\hline 22 & $\mathrm{H}-09 \mathrm{C}$ & MAG/CUL & & 22 & $\mathrm{H}-19 \mathrm{~B} 7$ & CUL & Redundant to $\mathrm{H}-19 \mathrm{~B} 0$ \\
\hline 23 & $\mathrm{H}-10 \mathrm{~A}$ & MAG & & 23 & I-461 & CUL & \\
\hline 24 & $\mathrm{H}-10 \mathrm{C}$ & CUL & & 24 & $\mathrm{P}-17$ & CUL & \\
\hline 25 & $\mathrm{H}-11 \mathrm{~B} 2$ & MAG & & 25 & SNL-01 & CUL & \\
\hline 26 & $\mathrm{H}-11 \mathrm{~B} 4$ & CUL & & 26 & SNL-02 & CUL & \\
\hline 27 & $\mathrm{H}-12$ & CUL & & 27 & SNL-03 & CUL & \\
\hline 28 & $\mathrm{H}-14$ & MAG & & 28 & SNL-05 & CUL & \\
\hline 29 & $\mathrm{H}-15$ & MAG/CUL & & 29 & SNL-06 & CUL & $1000-\mathrm{ft}$ probe; no levels \\
\hline 30 & $\mathrm{H}-16$ & MULTIPLE & $\begin{array}{l}\text { Complex multi-packer } \\
\text { system; not in WLMP }\end{array}$ & 30 & SNL-08 & CUL & \\
\hline 31 & $\mathrm{H}-17$ & CUL & & 31 & SNL-09 & CUL & \\
\hline 32 & $\mathrm{H}-18$ & MAG & & 32 & SNL-10 & CUL & Short period of record \\
\hline 33 & $\mathrm{H}-19 \mathrm{~B} 0$ & CUL & & 33 & SNL-12 & CUL & \\
\hline 34 & $\mathrm{H}-19 \mathrm{~B} 2$ & CUL & & 34 & SNL-13 & CUL & \\
\hline 35 & $\mathrm{H}-19 \mathrm{~B} 3$ & CUL & & 35 & SNL-14 & CUL & \\
\hline
\end{tabular}


Waste Isolation Pilot Plant Annual Site Environmental Report for 2006 DOE/WIPP-07-2225

\begin{tabular}{|c|c|c|c|c|c|c|c|}
\hline \multicolumn{8}{|c|}{ Table F.9 - WIPP Well Inventory for 2006} \\
\hline \multicolumn{4}{|c|}{ Sorted By Active Wells at Year-End } & \multicolumn{4}{|c|}{$\begin{array}{l}\text { Sorted By Formation for Wells Measured at Least } \\
\text { Once in } 2006\end{array}$} \\
\hline Count & $\begin{array}{c}\text { Well } \\
\text { Number }\end{array}$ & Zone & Notes & Count & $\begin{array}{c}\text { Well } \\
\text { Number }\end{array}$ & Zone & $\begin{array}{c}\text { Reason Not Assessed } \\
\text { for Long-Term Water } \\
\text { Level Trend }\end{array}$ \\
\hline 36 & $\mathrm{H}-19 \mathrm{~B} 4$ & CUL & & 36 & SNL-15 & CUL & $\begin{array}{l}\text { Rose over } 40 \text { feet, not in } \\
\text { equilibrium }\end{array}$ \\
\hline 37 & H-19B5 & CUL & & 37 & SNL-16 & CUL & Short period of record \\
\hline 38 & $\mathrm{H}-19 \mathrm{~B} 6$ & CUL & & 38 & SNL-17 & CUL & Short period of record \\
\hline 39 & $\mathrm{H}-19 \mathrm{~B} 7$ & CUL & & 39 & SNL-18 & CUL & Short period of record \\
\hline 40 & I-461 & CUL & & 40 & SNL-19 & CUL & Short period of record \\
\hline 41 & SNL-01 & CUL & & 41 & WIPP-11 & CUL & \\
\hline 42 & SNL-02 & CUL & & 42 & WIPP-13 & CUL & \\
\hline 43 & SNL-03 & CUL & & 43 & WIPP-19 & CUL & \\
\hline 44 & SNL-05 & CUL & & 44 & WIPP-26 & CUL & \\
\hline 45 & SNL-06 & CUL & & 45 & WQSP-1 & CUL & \\
\hline 46 & SNL-08 & CUL & & 46 & WQSP-2 & CUL & \\
\hline 47 & SNL-09 & CUL & & 47 & WQSP-3 & CUL & \\
\hline 48 & SNL-10 & CUL & & 48 & WQSP-4 & CUL & \\
\hline 49 & SNL-12 & CUL & & 49 & WQSP-5 & CUL & \\
\hline 50 & SNL-13 & CUL & & 50 & WQSP-6 & CUL & \\
\hline 51 & SNL-14 & CUL & & 51 & WQSP-6A & $\mathrm{DL}$ & \\
\hline 52 & SNL-15 & CUL & & 52 & $\mathrm{H}-02 \mathrm{~B} 1$ & MAG & \\
\hline 53 & SNL-16 & CUL & & 53 & $\mathrm{H}-03 \mathrm{~B} 1$ & MAG & \\
\hline 54 & SNL-17 & CUL & & 54 & $\mathrm{H}-04 \mathrm{C}$ & MAG & \\
\hline 55 & SNL-18 & CUL & & 55 & $\mathrm{H}-06 \mathrm{C}$ & MAG & \\
\hline 56 & SNL-19 & CUL & & 56 & $\mathrm{H}-08 \mathrm{~A}$ & MAG & \\
\hline 57 & PZ-01 & SR/D & & 57 & $\mathrm{H}-10 \mathrm{~A}$ & MAG & \\
\hline 58 & PZ-02 & $S R / D$ & & 58 & $\mathrm{H}-11 \mathrm{~B} 2$ & MAG & \\
\hline 59 & PZ-03 & $S R / D$ & & 59 & $\mathrm{H}-14$ & MAG & \\
\hline 60 & PZ-04 & $S R / D$ & & 60 & $\mathrm{H}-18$ & MAG & \\
\hline 61 & PZ-05 & $S R / D$ & & 61 & WIPP-18 & MAG & \\
\hline 62 & PZ-06 & $S R / D$ & & 62 & C-2737 & MAG/CUL & \\
\hline 63 & PZ-07 & SR/D & & 63 & $\mathrm{H}-09 \mathrm{C}$ & MAG/CUL & \\
\hline 64 & PZ-08 & $S R / D$ & & 64 & $\mathrm{H}-15$ & MAG/CUL & \\
\hline 65 & PZ-09 & $S R / D$ & & 65 & WIPP-25 & MAG/CUL & \\
\hline 66 & $P Z-10$ & $S R / D$ & & 66 & WIPP-30 & MAG/CUL & \\
\hline 67 & PZ-11 & $S R / D$ & & 67 & C-2505 & $S R / D$ & \\
\hline 68 & PZ-12 & $S R / D$ & & 68 & C-2506 & $S R / D$ & \\
\hline 69 & WIPP-11 & CUL & & 69 & C-2507 & $S R / D$ & \\
\hline 70 & WIPP-13 & CUL & & 70 & C-2811 & $S R / D$ & \\
\hline 71 & WIPP-18 & MAG & & 71 & PZ-01 & $S R / D$ & \\
\hline 72 & WIPP-19 & CUL & & 72 & PZ-02 & $S R / D$ & \\
\hline 73 & WIPP-25 & MAG/CUL & & 73 & PZ-03 & SR/D & \\
\hline
\end{tabular}


Waste Isolation Pilot Plant Annual Site Environmental Report for 2006 DOE/WIPP-07-2225

Table F.9 - WIPP Well Inventory for 2006

\begin{tabular}{clll|cccc}
\hline \multicolumn{2}{c|}{ Sorted By Active Wells at Year-End } & \multicolumn{3}{|c}{ Sorted By Formation for Wells Measured at Least } \\
Once in 2006
\end{tabular}


Waste Isolation Pilot Plant Annual Site Environmental Report for 2006

DOE/WIPP-07-2225

This page intentionally left blank 


\section{Appendix G \\ Air Sampling Data: Concentrations of Radionuclides}

\begin{tabular}{|c|c|c|c|c|c|c|c|c|c|c|}
\hline \multirow[t]{2}{*}{ Location } & Qtr. & [RN] & $2 \times$ TPU & MDC & {$[\mathrm{RN}]$} & $2 \times$ TPU & MDC & [RN] & $2 \times$ TPU & MDC \\
\hline & & & ${ }^{241} \mathrm{Am}$ & & & ${ }^{238} \mathrm{Pu}$ & & & ${ }^{239+240} \mathrm{Pu}$ & \\
\hline \multirow[t]{4}{*}{ CBD } & 1 & $2.58 \mathrm{E}-08$ & $5.10 \mathrm{E}-08$ & $3.47 \mathrm{E}-04$ & $1.20 \mathrm{E}-08$ & $4.34 \mathrm{E}-08$ & $1.24 \mathrm{E}-04$ & $8.61 \mathrm{E}-08$ & $8.62 \mathrm{E}-08$ & $1.11 \mathrm{E}-04$ \\
\hline & 2 & $2.62 \mathrm{E}-08$ & 4.46E-08 & $6.19 \mathrm{E}-05$ & $1.02 \mathrm{E}-09$ & $5.74 \mathrm{E}-08$ & $1.11 \mathrm{E}-04$ & $1.51 \mathrm{E}-09$ & 3.97E-08 & $6.19 \mathrm{E}-05$ \\
\hline & 3 & $-1.77 \mathrm{E}-08$ & 3.43E-08 & $1.98 \mathrm{E}-04$ & $-6.10 \mathrm{E}-08$ & $1.18 \mathrm{E}-07$ & $1.01 \mathrm{E}-05$ & $-3.03 E-08$ & $8.28 \mathrm{E}-08$ & $1.09 \mathrm{E}-04$ \\
\hline & 4 & $-9.98 E-09$ & 2.40E-08 & 2.10E-04 & $-6.59 \mathrm{E}-10$ & $5.42 \mathrm{E}-08$ & $2.48 \mathrm{E}-05$ & $-1.27 \mathrm{E}-08$ & 3.07E-08 & $1.24 \mathrm{E}-04$ \\
\hline \multirow[t]{4}{*}{ MLR } & 1 & 7.04E-08 & $7.59 \mathrm{E}-08$ & 3.47E-04 & $-2.16 \mathrm{E}-08$ & 4.73E-08 & $1.24 \mathrm{E}-04$ & $-5.37 \mathrm{E}-09$ & 2.35E-08 & $1.11 \mathrm{E}-04$ \\
\hline & 2 & $-1.26 \mathrm{E}-08$ & 2.66E-08 & $6.19 \mathrm{E}-05$ & 1.37E-08 & $6.79 \mathrm{E}-08$ & $1.11 \mathrm{E}-04$ & $3.94 \mathrm{E}-08$ & $5.53 \mathrm{E}-08$ & $6.19 \mathrm{E}-05$ \\
\hline & 3 & $8.61 \mathrm{E}-09$ & $6.56 \mathrm{E}-08$ & $1.98 \mathrm{E}-04$ & $2.74 \mathrm{E}-08$ & 7.92E-08 & $9.95 \mathrm{E}-06$ & $-9.11 \mathrm{E}-09$ & 2.57E-08 & 1.09E-04 \\
\hline & 4 & $4.98 \mathrm{E}-08$ & $6.03 \mathrm{E}-08$ & 2.10E-04 & $-6.41 \mathrm{E}-09$ & $5.58 \mathrm{E}-08$ & $2.48 \mathrm{E}-05$ & $-1.02 \mathrm{E}-08$ & $2.70 \mathrm{E}-08$ & $1.24 \mathrm{E}-04$ \\
\hline \multirow[t]{4}{*}{ SEC } & 1 & $5.24 \mathrm{E}-09$ & 3.83E-08 & 3.47E-04 & $7.25 \mathrm{E}-09$ & $3.48 \mathrm{E}-08$ & 1.24E-04 & 5.30E-08 & $5.90 \mathrm{E}-08$ & $1.11 \mathrm{E}-04$ \\
\hline & 2 & $-1.84 \mathrm{E}-08$ & $5.71 \mathrm{E}-08$ & $6.20 \mathrm{E}-05$ & $-4.12 \mathrm{E}-09$ & $4.42 \mathrm{E}-08$ & $1.11 \mathrm{E}-04$ & $-6.15 E-09$ & $1.87 \mathrm{E}-08$ & $6.19 \mathrm{E}-05$ \\
\hline & 3 & $8.14 \mathrm{E}-08$ & $8.48 \mathrm{E}-08$ & $1.98 \mathrm{E}-04$ & $-7.25 \mathrm{E}-09$ & $1.98 \mathrm{E}-08$ & $=-06$ & $3.66 \mathrm{E}-08$ & $5.04 \mathrm{E}-08$ & $1.09 \mathrm{E}-04$ \\
\hline & 4 & 7.30E-09 & 3.50E-08 & $2.10 \mathrm{E}-04$ & 8.39E-09 & $4.20 \mathrm{E}-08$ & $2.48 \mathrm{E}-05$ & $-6.57 E-09$ & 2.09E-08 & $1.24 \mathrm{E}-04$ \\
\hline \multirow[t]{4}{*}{ SMR } & 1 & $2.88 \mathrm{E}-08$ & $5.76 \mathrm{E}-08$ & 3.47E-04 & $1.61 \mathrm{E}-08$ & 4.33E-08 & 1.24E-04 & $-1.00 \mathrm{E}-08$ & $2.79 \mathrm{E}-08$ & $1.11 \mathrm{E}-04$ \\
\hline & 2 & 3.23E-08 & $5.01 \mathrm{E}-08$ & $6.19 \mathrm{E}-05$ & $1.54 \mathrm{E}-09$ & $5.80 \mathrm{E}-08$ & $1.11 \mathrm{E}-04$ & $6.18 \mathrm{E}-09$ & $3.68 \mathrm{E}-08$ & $6.19 \mathrm{E}-05$ \\
\hline & 3 & $-5.91 E-10$ & 4.86E-08 & $1.98 \mathrm{E}-04$ & 3.55E-08 & 7.27E-08 & $9.95 \mathrm{E}-06$ & $3.22 \mathrm{E}-08$ & 5.37E-08 & 1.09E-04 \\
\hline & 4 & $-1.09 \mathrm{E}-08$ & 2.55E-08 & 2.10E-04 & $-1.23 \mathrm{E}-09$ & $5.04 \mathrm{E}-08$ & $2.48 \mathrm{E}-05$ & $-4.92 \mathrm{E}-09$ & $1.84 \mathrm{E}-08$ & $1.24 \mathrm{E}-04$ \\
\hline \multirow[t]{4}{*}{ WEE } & 1 & $2.30 \mathrm{E}-08$ & $5.96 \mathrm{E}-08$ & $E-04$ & $-5.92 \mathrm{E}-09$ & $=-08$ & 1.2 & E-09 & 2.53E-08 & $1.11 \mathrm{E}-04$ \\
\hline & 2 & 1.67E-09 & 4.3 & -05 & 3.62E-08 & $=-08$ & & $-1.36 \mathrm{E}-08$ & 2.81E-08 & $6.19 \mathrm{E}-05$ \\
\hline & 3 & 2.84E-08 & 5.83E-08 & $1.98 \mathrm{E}-04$ & 2.29E-08 & 8.43E-08 & 9.97E-06 & 1.18E-08 & $5.90 \mathrm{E}-08$ & 1.09E-04 \\
\hline & 4 & $-4.44 \mathrm{E}-09$ & $1.59 \mathrm{E}-08$ & 2.10E-04 & $3.81 \mathrm{E}-08$ & 7.81E-08 & $2.48 \mathrm{E}-05$ & 8.83E-08 & $9.08 \mathrm{E}-08$ & $1.24 \mathrm{E}-04$ \\
\hline \multirow[t]{4}{*}{ WFF } & 1 & 4.23E-08 & $6.27 \mathrm{E}-08$ & $1.73 \mathrm{E}-04$ & $1.08 \mathrm{E}-08$ & 4.45E-08 & 1.24E-04 & 6.30E-09 & $4.79 \mathrm{E}-08$ & $1.11 \mathrm{E}-04$ \\
\hline & 2 & $1.64 \mathrm{E}-08$ & $5.58 \mathrm{E}-08$ & $6.19 \mathrm{E}-05$ & $-1.34 \mathrm{E}-08$ & 7.27E-08 & $1.11 \mathrm{E}-04$ & 4.36E-08 & 7.69E-08 & $6.19 \mathrm{E}-05$ \\
\hline & 3 & 4.07E-08 & 7.53E-08 & $1.98 \mathrm{E}-04$ & 3.47E-08 & $9 \mathrm{E}-07$ & & 2E-08 & 8.05E-08 & 1.09E-04 \\
\hline & 4 & 4.07E-09 & 3.9 & -04 & $1.22 \mathrm{E}-09$ & -08 & 2.4 & E-07 & 9.53E-08 & $1.24 \mathrm{E}-04$ \\
\hline \multirow[t]{4}{*}{ WSS } & 1 & 2.85E-08 & $7.58 \mathrm{E}-08$ & 3.47E-04 & $1.14 \mathrm{E}-08$ & $6.46 \mathrm{E}-08$ & 1.24E-04 & $-1.31 \mathrm{E}-08$ & 3.64E-08 & $1.11 \mathrm{E}-04$ \\
\hline & 2 & 3.52E-08 & $6.22 \mathrm{E}-08$ & $6.19 \mathrm{E}-05$ & 6.06E-08 & 8.87E-08 & $1.11 \mathrm{E}-04$ & $2.28 \mathrm{E}-08$ & 4.94E-08 & $6.19 \mathrm{E}-05$ \\
\hline & 3 & $5.28 \mathrm{E}-08$ & $8.24 \mathrm{E}-08$ & $1.98 \mathrm{E}-04$ & 3.27E-08 & 7.01E-08 & $9.95 \mathrm{E}-06$ & $3.02 \mathrm{E}-08$ & 7.10E-08 & 1.09E-04 \\
\hline & 4 & 9.83E-09 & 3.56E-08 & $2.10 \mathrm{E}-04$ & 1.49E-08 & $5.99 \mathrm{E}-08$ & $2.48 \mathrm{E}-05$ & $-2.13 E-08$ & 3.76E-08 & $1.24 \mathrm{E}-04$ \\
\hline \multirow{7}{*}{ WAB } & 1 & 3.56E-04 & $5.21 \mathrm{E}-04$ & $6.68 \mathrm{E}-04$ & $6.08 \mathrm{E}-05$ & 2.92E-04 & 4.54E-04 & 6.46E-05 & $2.88 \mathrm{E}-04$ & 4.40E-04 \\
\hline & 2 & 7.07E-05 & 2.26E-04 & 3.36E-04 & $-1.31 \mathrm{E}-04$ & 2.30E-04 & 3.97E-04 & $1.99 \mathrm{E}-04$ & 4.17E-04 & 3.46E-04 \\
\hline & 3 & $5.31 \mathrm{E}-04$ & $5.76 \mathrm{E}-04$ & $5.29 \mathrm{E}-04$ & $-8.80 \mathrm{E}-05$ & $2.08 \mathrm{E}-04$ & 3.55E-04 & $2.10 \mathrm{E}-04$ & 3.81E-04 & 4.53E-04 \\
\hline & 4 & 7.90E-05 & 2.53E-04 & $5.16 \mathrm{E}-04$ & $-7.26 \mathrm{E}-05$ & $1.76 \mathrm{E}-04$ & 3.25E-04 & 1.83E-04 & $3.32 \mathrm{E}-04$ & 4.23E-04 \\
\hline & imum & $-1.84 \mathrm{E}-08$ & $5.71 \mathrm{E}-08$ & $6.20 \mathrm{E}-05$ & $-6.10 \mathrm{E}-08$ & $1.18 \mathrm{E}-07$ & $1.01 \mathrm{E}-05$ & $-3.03 E-08$ & $8.28 \mathrm{E}-08$ & 1.09E-04 \\
\hline & kimum & $8.14 \mathrm{E}-08$ & $8.48 \mathrm{E}-08$ & $1.98 \mathrm{E}-04$ & $6.06 \mathrm{E}-08$ & 8.87E-08 & $1.11 \mathrm{E}-04$ & 1.13E-07 & $9.53 \mathrm{E}-08$ & $1.24 \mathrm{E}-04$ \\
\hline & Mean & $1.94 \mathrm{E}-08$ & 5.16E-08 & $1.98 \mathrm{E}-04$ & $9.46 \mathrm{E}-09$ & $6.07 \mathrm{E}-08$ & 6.74E-05 & $1.54 \mathrm{E}-08$ & 4.84E-08 & $1.01 \mathrm{E}-04$ \\
\hline
\end{tabular}

\begin{tabular}{|c|c|c|c|c|c|c|c|c|c|c|}
\hline Location & Qtr. & [RN] & $2 \times$ TPU & MDC & [RN] & X TPU & MDC & [RN] & $2 \times$ TPU & MDC \\
\hline & & & ${ }^{234} U$ & & & ${ }^{235} U$ & & & ${ }^{238} U$ & \\
\hline \multirow[t]{4}{*}{ CBD } & 1 & $3.08 \mathrm{E}-06$ & 4.87E-07 & $9.78 \mathrm{E}-04$ & 1.87E-07 & $1.33 \mathrm{E}-07$ & $\overline{1.61 E-04}$ & $2.95 \mathrm{E}-06$ & $4.76 \mathrm{E}-07$ & $\overline{5.94 E-04}$ \\
\hline & 2 & 3.37E-06 & 1.87E-06 & 1.37E-03 & 4.65E-08 & $1.60 \mathrm{E}-07$ & 1.24E-04 & 2.66E-06 & $1.51 \mathrm{E}-06$ & 5.82E-04 \\
\hline & 3 & 1.63E-06 & 5.62E-07 & $1.40 \mathrm{E}-03$ & 5.95E-08 & 8.88E-08 & 1.73E-04 & $1.68 \mathrm{E}-06$ & $5.76 \mathrm{E}-07$ & 6.93E-04 \\
\hline & 4 & $9.06 \mathrm{E}-07$ & 2.82E-07 & 1.37E-03 & 4.97E-08 & $6.21 \mathrm{E}-08$ & 1.61E-04 & $9.06 \mathrm{E}-07$ & 2.81E-07 & 6.93E-04 \\
\hline \multirow[t]{4}{*}{ MLR } & 1 & 2.95E-06 & 4.30E-07 & $9.78 \mathrm{E}-04$ & $1.09 \mathrm{E}-07$ & $9.20 \mathrm{E}-08$ & $1.61 \mathrm{E}-04$ & 2.71E-06 & 4.11E-07 & 5.94E-04 \\
\hline & 2 & $2.45 \mathrm{E}-06$ & $1.45 \mathrm{E}-06$ & 1.37E-03 & 2.49E-07 & $2.56 \mathrm{E}-07$ & 1.24E-04 & $2.48 \mathrm{E}-06$ & 1.46E-06 & 5.82E-04 \\
\hline & 3 & 1.70E-06 & 4.96E-07 & $1.40 \mathrm{E}-03$ & $9.13 \mathrm{E}-08$ & $9.54 \mathrm{E}-08$ & 1.73E-04 & 1.35E-06 & 4.16E-07 & 6.93E-04 \\
\hline & 4 & 8.57E-07 & 2.64E-07 & 1.37E-03 & 1.07E-08 & $3.72 \mathrm{E}-08$ & 1.61E-04 & $7.86 \mathrm{E}-07$ & 2.49E-07 & 6.93E-04 \\
\hline \multirow[t]{2}{*}{ SEC } & 1 & 2.06E-06 & 3.55E-07 & 9.78E-04 & 4.96E-08 & $6.82 \mathrm{E}-08$ & $1.61 \mathrm{E}-04$ & 1.70E-06 & $3.21 \mathrm{E}-07$ & $5.94 \mathrm{E}-04$ \\
\hline & 2 & 2.52E-06 & 1.45E-06 & 1.37E-03 & -8.27E-09 & 3.93E-08 & 1.24E-04 & 1.93E-06 & 1.14E-06 & $5.82 \mathrm{E}-04$ \\
\hline
\end{tabular}


Waste Isolation Pilot Plant Annual Site Environmental Report for 2006 DOE/WIPP-07-2225

\begin{tabular}{|c|c|c|c|c|c|c|c|c|c|c|}
\hline \multirow[t]{2}{*}{ Table } & G.1 - & \multicolumn{9}{|c|}{$\begin{array}{l}\text { Radionuclide Concentrations }\left(\mathrm{Bq} / \mathrm{m}^{3}\right) \text { in Quarterly Composite Air Filters Collected from } \\
\text { Locations Surrounding the WIPP Site. See Appendix C for the sampling location codes. }\end{array}$} \\
\hline & 3 & 1.36E-06 & 3.95E-07 & $1.40 \mathrm{E}-03$ & 5.52E-08 & $6.79 \mathrm{E}-08$ & 1.73E-04 & $1.13 \mathrm{E}-06$ & $3.46 \mathrm{E}-07$ & $6.93 \mathrm{E}-04$ \\
\hline & 4 & 9.03E-07 & 2.81E-07 & 1.37E-03 & 8.43E-08 & $7.79 \mathrm{E}-08$ & 1.61E-04 & 8.17E-07 & 2.62E-07 & 6.93E-04 \\
\hline \multirow[t]{4}{*}{ SMR } & 1 & 3.13E-06 & $4.52 \mathrm{E}-07$ & $9.78 \mathrm{E}-04$ & 2.31E-07 & 1.34E-07 & 1.61E-04 & 2.90E-06 & 4.33E-07 & $5.94 \mathrm{E}-04$ \\
\hline & 2 & 2.79E-06 & 9.95E-07 & 1.37E-03 & 2.01E-07 & 1.67E-07 & $1.24 \mathrm{E}-04$ & 2.35E-06 & 8.58E-07 & $5.82 \mathrm{E}-04$ \\
\hline & 3 & 1.51E-06 & 4.71E-07 & 1.40E-03 & 1.12E-07 & 1.08E-07 & 1.73E-04 & 1.62E-06 & 4.95E-07 & 6.93E-04 \\
\hline & 4 & $1.04 \mathrm{E}-06$ & 3.10E-07 & 1.37E-03 & 6.33E-08 & 7.00E-08 & 1.61E-04 & 1.13E-06 & 3.29E-07 & $6.93 \mathrm{E}-04$ \\
\hline \multirow[t]{4}{*}{ WEE } & 1 & $2.50 \mathrm{E}-06$ & 3.88E-07 & $9.78 \mathrm{E}-04$ & 1.20E-07 & 9.64E-08 & 1.61E-04 & 2.31E-06 & 3.71E-07 & 5.94E-04 \\
\hline & 2 & 2.57E-06 & $9.43 \mathrm{E}-07$ & 1.37E-03 & 2.14E-07 & 1.72E-07 & $1.24 \mathrm{E}-04$ & 2.36E-06 & 8.77E-07 & 5.82E-04 \\
\hline & 3 & $1.48 \mathrm{E}-06$ & 5.08E-07 & $1.40 \mathrm{E}-03$ & $9.64 \mathrm{E}-08$ & 9.77E-08 & 1.73E-04 & $1.42 \mathrm{E}-06$ & 4.91E-07 & 6.93E-04 \\
\hline & 4 & 1.14E-06 & 3.53E-07 & 1.37E-03 & $3.26 \mathrm{E}-08$ & 5.49E-08 & 1.61E-04 & $1.00 \mathrm{E}-06$ & 3.21E-07 & $6.93 \mathrm{E}-04$ \\
\hline \multirow[t]{4}{*}{ WFF } & 1 & $2.50 \mathrm{E}-06$ & 4.00E-07 & $9.78 \mathrm{E}-04$ & $1.50 \mathrm{E}-07$ & 1.09E-07 & 1.61E-04 & 2.34E-06 & 3.85E-07 & 5.94E-04 \\
\hline & 2 & 2.93E-06 & 1.75E-06 & 1.37E-03 & $9.99 \mathrm{E}-08$ & 1.49E-07 & $1.24 \mathrm{E}-04$ & $2.42 \mathrm{E}-06$ & 1.46E-06 & $5.82 \mathrm{E}-04$ \\
\hline & 3 & 1.49E-06 & 4.19E-07 & $1.40 \mathrm{E}-03$ & $7.29 \mathrm{E}-08$ & 7.30E-08 & 1.73E-04 & 1.10E-06 & 3.35E-07 & $6.93 \mathrm{E}-04$ \\
\hline & 4 & $1.02 \mathrm{E}-06$ & 3.09E-07 & 1.37E-03 & 6.63E-08 & 7.62E-08 & 1.61E-04 & 1.10E-06 & 3.26E-07 & 6.93E-04 \\
\hline \multirow[t]{4}{*}{ WSS } & 1 & 2.98E-06 & 4.41E-07 & $9.78 \mathrm{E}-04$ & 1.34E-07 & 1.04E-07 & 1.61E-04 & 2.39E-06 & 3.93E-07 & $5.94 \mathrm{E}-04$ \\
\hline & 2 & 2.61E-06 & 1.86E-06 & 1.37E-03 & 5.05E-07 & 4.81E-07 & $1.24 \mathrm{E}-04$ & 2.60E-06 & 1.84E-06 & $5.82 \mathrm{E}-04$ \\
\hline & 3 & 1.14E-06 & $3.52 \mathrm{E}-07$ & $1.40 \mathrm{E}-03$ & 3.36E-08 & 5.69E-08 & 1.73E-04 & 1.23E-06 & $3.72 \mathrm{E}-07$ & 6.93E-04 \\
\hline & 4 & 9.61E-07 & 3.00E-07 & 1.37E-03 & $6.55 \mathrm{E}-08$ & 7.72E-08 & 1.61E-04 & $9.25 \mathrm{E}-07$ & 2.93E-07 & 6.93E-04 \\
\hline \multirow[t]{7}{*}{ WAB } & 1 & $1.54 \mathrm{E}-02$ & $3.88 \mathrm{E}-03$ & 1.63E-03 & 8.55E-04 & 1.04E-03 & $9.71 \mathrm{E}-04$ & 1.87E-02 & 4.27E-03 & $1.25 \mathrm{E}-03$ \\
\hline & 2 & $1.20 \mathrm{E}-02$ & 4.75E-03 & $1.88 \mathrm{E}-03$ & 1.07E-03 & 1.10E-03 & 7.50E-04 & 1.03E-02 & 4.21E-03 & $1.09 \mathrm{E}-03$ \\
\hline & 3 & $8.12 \mathrm{E}-03$ & 2.59E-03 & 1.73E-03 & $2.40 \mathrm{E}-04$ & 4.64E-04 & 5.83E-04 & 6.64E-03 & $2.25 \mathrm{E}-03$ & $1.02 \mathrm{E}-03$ \\
\hline & 4 & 4.92E-03 & 1.73E-03 & 1.67E-03 & 3.80E-04 & 4.83E-04 & 5.30E-04 & 4.69E-03 & $1.68 \mathrm{E}-03$ & 9.91E-04 \\
\hline & Minimum & $8.57 \mathrm{E}-07$ & 2.64E-07 & 1.37E-03 & $-8.27 \mathrm{E}-09$ & 3.93E-08 & $1.24 \mathrm{E}-04$ & $7.86 \mathrm{E}-07$ & $2.49 \mathrm{E}-07$ & $6.93 \mathrm{E}-04$ \\
\hline & Maximum & 3.37E-06 & 1.87E-06 & 1.37E-03 & 5.05E-07 & 4.81E-07 & 1.24E-04 & $2.95 \mathrm{E}-06$ & 4.76E-07 & $5.94 \mathrm{E}-04$ \\
\hline & Mean & 1.98E-06 & 6.63E-07 & $1.28 \mathrm{E}-03$ & 1.14E-07 & 1.14E-07 & 1.55E-04 & 1.80E-06 & $6.08 \mathrm{E}-07$ & $6.40 \mathrm{E}-04$ \\
\hline
\end{tabular}

\begin{tabular}{|c|c|c|c|c|c|c|c|c|c|c|}
\hline Location & 2 tr. & [RN] & X TPU & MDC & [RN] & X TPU & MDC & [RN] & $2 \times$ TPU & MDC \\
\hline & & & ${ }^{40} \mathrm{~K}$ & & & ${ }^{60} \mathrm{Co}$ & & & ${ }^{137} \mathrm{Cs}$ & \\
\hline \multirow[t]{4}{*}{ CBD } & 1 & $2.26 \mathrm{E}-04$ & 1.15E-04 & $1.61 \mathrm{E}-04$ & $2.17 \mathrm{E}-05$ & 2.35E-05 & $2.86 \mathrm{E}-05$ & $-2.77 \mathrm{E}-05$ & $2.11 \mathrm{E}-05$ & $2.15 \mathrm{E}-05$ \\
\hline & 2 & 2.93E-04 & $2.55 \mathrm{E}-04$ & 4.03E-04 & $1.50 \mathrm{E}-05$ & 3.59E-05 & 4.04E-05 & $-4.02 \mathrm{E}-05$ & $3.90 \mathrm{E}-05$ & 4.07E-05 \\
\hline & 3 & 2.10E-04 & $2.53 \mathrm{E}-04$ & 4.07E-04 & $1.45 \mathrm{E}-05$ & 3.70E-05 & 4.15E-05 & $-5.28 \mathrm{E}-06$ & $3.40 \mathrm{E}-05$ & 4.14E-05 \\
\hline & 4 & 3.17E-04 & 3.60E-04 & 4.47E-04 & 3.82E-05 & 3.52E-05 & 4.46E-05 & 9.37E-06 & 2.81E-05 & 3.39E-05 \\
\hline \multirow[t]{4}{*}{ MLR } & 1 & 2.07E-04 & 1.13E-04 & 1.61E-04 & -7.32E-06 & $2.40 \mathrm{E}-05$ & 2.62E-05 & $-2.42 \mathrm{E}-06$ & $1.86 \mathrm{E}-05$ & 2.16E-05 \\
\hline & 2 & 3.44E-04 & $3.45 \mathrm{E}-04$ & 3.95E-04 & 3.57E-05 & 3.57E-05 & 4.10E-05 & $-1.39 \mathrm{E}-05$ & 3.71E-05 & 4.07E-05 \\
\hline & 3 & ${ }^{*} 6.95 \mathrm{E}-04$ & 3.56E-04 & 4.16E-04 & 2.34E-05 & 3.70E-05 & 4.18E-05 & $-1.12 \mathrm{E}-05$ & $3.25 \mathrm{E}-05$ & 4.15E-05 \\
\hline & 4 & *1.04E-03 & $6.78 \mathrm{E}-04$ & 7.90E-04 & 2.22E-05 & 7.37E-05 & 8.23E-05 & -7.36E-05 & 7.05E-05 & $8.14 \mathrm{E}-05$ \\
\hline \multirow[t]{4}{*}{ SEC } & 1 & ${ }^{*} 6.96 \mathrm{E}-04$ & 3.47E-04 & 4.06E-04 & -5.91E-06 & 3.54E-05 & 3.91E-05 & $-3.54 \mathrm{E}-05$ & 3.82E-05 & 4.02E-05 \\
\hline & 2 & *3.05E-04 & 1.76E-04 & 2.33E-04 & 7.65E-06 & 1.91E-05 & 2.27E-05 & -1.07E-05 & $1.51 \mathrm{E}-05$ & 1.65E-05 \\
\hline & 3 & *3.09E-04 & 1.76E-04 & 2.34E-04 & 1.14E-05 & $1.88 \mathrm{E}-05$ & 2.28E-05 & $-8.84 \mathrm{E}-06$ & $1.52 \mathrm{E}-05$ & $1.68 \mathrm{E}-05$ \\
\hline & 4 & *1.47E-03 & $6.98 \mathrm{E}-04$ & 8.19E-04 & 4.12E-05 & 7.11E-05 & 8.04E-05 & -7.92E-05 & 7.80E-05 & 8.17E-05 \\
\hline \multirow[t]{4}{*}{ SMR } & 1 & *4.99E-04 & 3.37E-04 & 3.91E-04 & -9.07E-06 & 3.62E-05 & 3.97E-05 & -1.77E-05 & 3.70E-05 & 4.02E-05 \\
\hline & 2 & ${ }^{*} 2.35 \mathrm{E}-04$ & $1.78 \mathrm{E}-04$ & 2.29E-04 & 1.19E-05 & 1.78E-05 & 2.18E-05 & 5.01E-06 & $1.46 \mathrm{E}-05$ & 1.75E-05 \\
\hline & 3 & $1.55 \mathrm{E}-04$ & 1.57E-04 & 2.50 & $1.01 \mathrm{E}-05$ & 2.17 & 2.58E-05 & $3.42 \mathrm{E}-06$ & $1.50 \mathrm{E}-05$ & 1.8 \\
\hline & 4 & *1.14E-03 & 7.06E-04 & 8.20E-04 & $-2.12 E-05$ & 7.48E-05 & 8.05E-05 & $-8.75 E-05$ & 7.82E-05 & 8.12E-05 \\
\hline \multirow[t]{4}{*}{ WEE } & 1 & $2.81 \mathrm{E}-04$ & $1.20 \mathrm{E}-04$ & 1.61 & $-2.75 E-07$ & 2.19E-05 & 2.51E-05 & $-3.55 E-05$ & 2.02E-05 & 1.96E-05 \\
\hline & 2 & 2.89E-04 & 2.64E-04 & 4.18E-04 & $-1.55 \mathrm{E}-05$ & 3.89E-05 & 4.15E-05 & $-4.05 E-05$ & 3.98E-05 & 4.17E-05 \\
\hline & 3 & $9.55 \mathrm{E}-05$ & $1.90 \mathrm{E}-04$ & 2.27E-04 & -1.39E-05 & 2.16E-05 & 2.24E-05 & $-3.65 E-06$ & $1.45 \mathrm{E}-05$ & 1.67E-05 \\
\hline & 4 & 4.08E-04 & 5.07E-04 & 8.18E-04 & 4.38E-05 & 7.04E-05 & 7.96E-05 & $-4.70 \mathrm{E}-05$ & 7.30E-05 & 7.86E-05 \\
\hline \multirow[t]{4}{*}{ WFF } & 1 & $-1.23 \mathrm{E}-04$ & 1.40E-04 & 2.67E-04 & -1.82E-05 & 2.38E-05 & 2.43E-05 & $-3.00 \mathrm{E}-05$ & 2.01E-05 & $2.03 \mathrm{E}-05$ \\
\hline & 2 & 3.68E-04 & $3.51 \mathrm{E}-04$ & 4.02E-04 & 7.40E-06 & 3.73E-05 & 4.15E-05 & $-5.53 E-05$ & $3.94 \mathrm{E}-05$ & $3.99 \mathrm{E}-05$ \\
\hline & 3 & 1.23E-04 & 1.92E-04 & 2.32E-04 & 7.29E-06 & $1.84 \mathrm{E}-05$ & $2.20 \mathrm{E}-05$ & -8.07E-06 & $1.53 \mathrm{E}-05$ & $1.68 \mathrm{E}-05$ \\
\hline & 4 & *3.63E-01 & $3.45 \mathrm{E}-04$ & 4.37E-04 & 1.49E-05 & 3.67E-05 & 4.35E-05 & $2.68 \mathrm{E}-05$ & $2.74 \mathrm{E}-05$ & $3.42 \mathrm{E}-05$ \\
\hline \multirow[t]{3}{*}{ WSS } & 1 & *4.55E-04 & 3.49E-04 & 4.03E-04 & 2.41E-05 & $3.48 \mathrm{E}-05$ & 4.01E-05 & $-1.49 \mathrm{E}-05$ & $3.80 \mathrm{E}-05$ & 4.17E-05 \\
\hline & 2 & $1.58 \mathrm{E}-04$ & 1.39E-04 & 2.17E-04 & 5.93E-08 & 1.98E-05 & 2.25E-05 & $-6.13 E-06$ & $1.54 \mathrm{E}-05$ & $1.75 \mathrm{E}-05$ \\
\hline & 3 & *5.12E-04 & 3.56E-04 & 4.11E-04 & 3.51E-05 & $3.65 \mathrm{E}-05$ & 4.18E-05 & $-2.29 \mathrm{E}-07$ & 2.44E-05 & $4.21 \mathrm{E}-05$ \\
\hline
\end{tabular}


Waste Isolation Pilot Plant Annual Site Environmental Report for 2006 DOE/WIPP-07-2225

\begin{tabular}{|c|c|c|c|c|}
\hline \multicolumn{2}{|c|}{ Table G.1 - } & \multicolumn{3}{|c|}{$\begin{array}{l}\text { Radionuclide Concentrations (Bq/r } \\
\text { Locations Surrounding the WIPP S }\end{array}$} \\
\hline & 4 & 2.04E-04 & 3.82E-04 & 4.57E-04 \\
\hline \multirow[t]{7}{*}{ WAB } & 1 & $1.19 \mathrm{E}+00$ & 7.46E-01 & $1.09 \mathrm{E}+00$ \\
\hline & 2 & *3.37E+00 & $2.66 \mathrm{E}+00$ & $3.06 \mathrm{E}+00$ \\
\hline & 3 & *5.81E+00 & $2.59 \mathrm{E}+00$ & $3.05 E+00$ \\
\hline & 4 & $2.06 \mathrm{E}+00$ & $2.71 \mathrm{E}+00$ & $3.33 \mathrm{E}+00$ \\
\hline & imum & $-1.23 \mathrm{E}-04$ & $1.40 \mathrm{E}-04$ & $2.67 \mathrm{E}-04$ \\
\hline & imum & 3.63E-01 & 3.54E-04 & 4.37E-04 \\
\hline & Mean & 1.34E-02 & 3.07E-04 & 3.93E-04 \\
\hline \multirow[t]{2}{*}{ Location } & Qtr. & [RN] & $2 \times$ TPU & MDC \\
\hline & & & ${ }^{90} \mathrm{Sr}$ & \\
\hline \multirow[t]{4}{*}{ CBD } & 1 & $2.21 \mathrm{E}-06$ & 4.93E-06 & $3.10 \mathrm{E}-04$ \\
\hline & 2 & $2.47 \mathrm{E}-07$ & $3.71 \mathrm{E}-06$ & $2.25 \mathrm{E}-03$ \\
\hline & 3 & $-3.88 E-06$ & 6.74E-06 & $2.85 \mathrm{E}-03$ \\
\hline & 4 & 1.93E-07 & 5.55E-06 & $2.57 \mathrm{E}-03$ \\
\hline \multirow[t]{4}{*}{ MLR } & 1 & $2.80 \mathrm{E}-06$ & 4.97E-06 & $3.10 \mathrm{E}-04$ \\
\hline & 2 & 4.54E-07 & 3.66E-06 & $2.25 \mathrm{E}-03$ \\
\hline & 3 & $-9.11 \mathrm{E}-08$ & 7.07E-06 & 2.85E-03 \\
\hline & 4 & 2.96E-06 & $6.13 \mathrm{E}-06$ & 2.57E-03 \\
\hline \multirow[t]{4}{*}{ SEC } & 1 & $-1.83 \mathrm{E}-07$ & $4.58 \mathrm{E}-06$ & 3.10E-04 \\
\hline & 2 & $1.86 \mathrm{E}-06$ & 3.63E-06 & $2.25 \mathrm{E}-03$ \\
\hline & 3 & 3.07E-06 & $6.95 \mathrm{E}-06$ & 2.85E-03 \\
\hline & 4 & 4.04E-06 & 5.93E-06 & 2.57E-03 \\
\hline \multirow[t]{4}{*}{ SMR } & 1 & $-6.06 \mathrm{E}-07$ & $4.55 \mathrm{E}-06$ & 3.10E-04 \\
\hline & 2 & 3.30E-07 & 3.69E-06 & $2.25 \mathrm{E}-03$ \\
\hline & 3 & 7.09E-07 & 7.74E-06 & $2.85 \mathrm{E}-03$ \\
\hline & 4 & $1.22 \mathrm{E}-06$ & 5.75E-06 & 2.57E-03 \\
\hline \multirow[t]{4}{*}{ WEE } & 1 & 1.71E-06 & $4.81 \mathrm{E}-06$ & 3.10E-04 \\
\hline & 2 & $-1.26 \mathrm{E}-06$ & 3.63E-06 & $2.25 \mathrm{E}-03$ \\
\hline & 3 & $-3.21 \mathrm{E}-06$ & 7.16E-06 & $2.85 \mathrm{E}-03$ \\
\hline & 4 & 5.55E-06 & 5.78E-06 & 2.57E-03 \\
\hline \multirow[t]{4}{*}{ WFF } & 1 & $5.98 \mathrm{E}-08$ & 4.95E-06 & $3.10 \mathrm{E}-04$ \\
\hline & 2 & 4.70E-07 & 3.69E-06 & $2.25 \mathrm{E}-03$ \\
\hline & 3 & $-3.92 \mathrm{E}-07$ & 7.01E-06 & $2.85 \mathrm{E}-03$ \\
\hline & 4 & 6.01E-07 & $5.45 \mathrm{E}-06$ & 2.57E-03 \\
\hline \multirow[t]{4}{*}{ WSS } & 1 & 1.93E-06 & $5.00 \mathrm{E}-06$ & $3.10 \mathrm{E}-04$ \\
\hline & 2 & $1.23 \mathrm{E}-06$ & 3.82E-06 & $2.25 \mathrm{E}-03$ \\
\hline & 3 & $9.42 \mathrm{E}-08$ & 6.95E-06 & 2.85E-03 \\
\hline & 4 & 2.38E-06 & 5.86E-06 & 2.57E-03 \\
\hline \multirow[t]{7}{*}{ WAB } & 1 & $5.78 \mathrm{E}-03$ & 3.47E-02 & 2.47E-03 \\
\hline & 2 & $-7.90 \mathrm{E}-03$ & 2.67E-02 & 3.99E-03 \\
\hline & 3 & $-3.07 E-02$ & 5.05E-02 & 5.92E-03 \\
\hline & 4 & $1.28 \mathrm{E}-02$ & 4.21E-02 & 5.61E-03 \\
\hline & imum & $-3.88 \mathrm{E}-06$ & $6.74 \mathrm{E}-06$ & $2.85 \mathrm{E}-03$ \\
\hline & imum & 5.55E-06 & 5.78E-06 & 2.57E-03 \\
\hline & Mean & 8.75E-07 & 5.35E-06 & $2.00 \mathrm{E}-03$ \\
\hline
\end{tabular}

*Gamma spectroscopy samples with confidence levels greater than 90 percent - not considered "detects." 
Waste Isolation Pilot Plant Annual Site Environmental Report for 2006

DOE/WIPP-07-2225

This page intentionally left blank 


\section{Appendix $\mathrm{H}$ \\ Comparison of Detected Radionuclides to the Radiological Baseline}

The figures in this appendix show the highest detected radionuclides from 2006 environmental monitoring sample analysis results compared to the 99 percent confidence interval radiological baseline values established for these isotopes (DOE/WIPP 92-037). Figures address air filter composite, groundwater, surface water, sediment, soil, and vegetation results. Note, all results with the exception of vegetation and were compared to the baseline upper 99 percentile probability value. The baseline did not include probability distributions for these, therefore these sample results are compared to the baseline mean values. In 2006 there were no radionuclides detected in animal samples. A detailed discussion of environmental monitoring radionuclide sample results is contained in Chapter 4 .

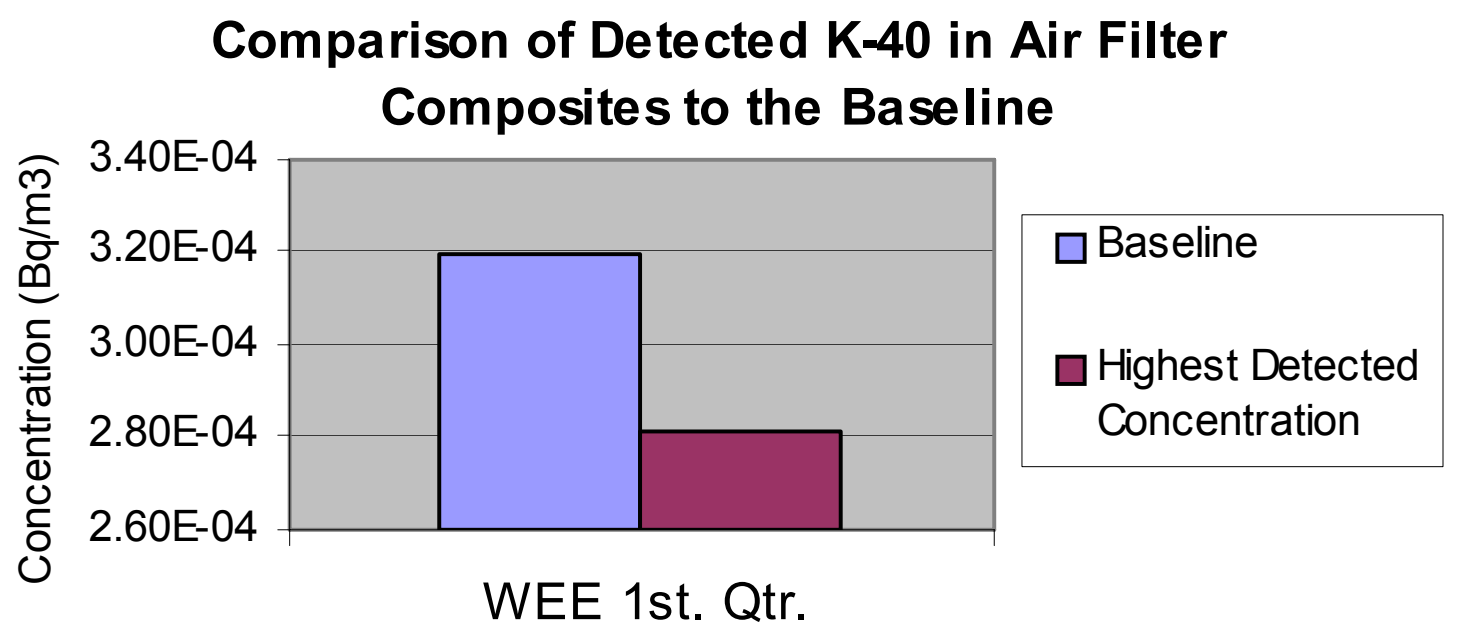




\section{Comparison of Detected U-234 in}

Groundwater to the Baseline
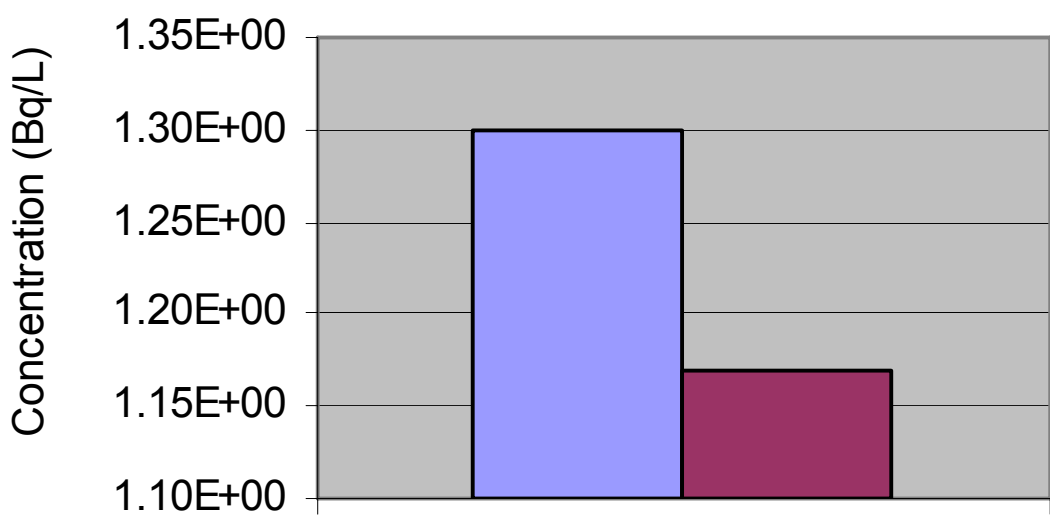

$\square$ Baseline

$\square$ Highest Detected Concentration

WQSP-2 Round 22

Comparison of Detected U-235 in

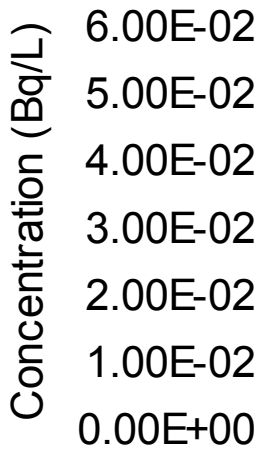
Groundwater to the Baseline

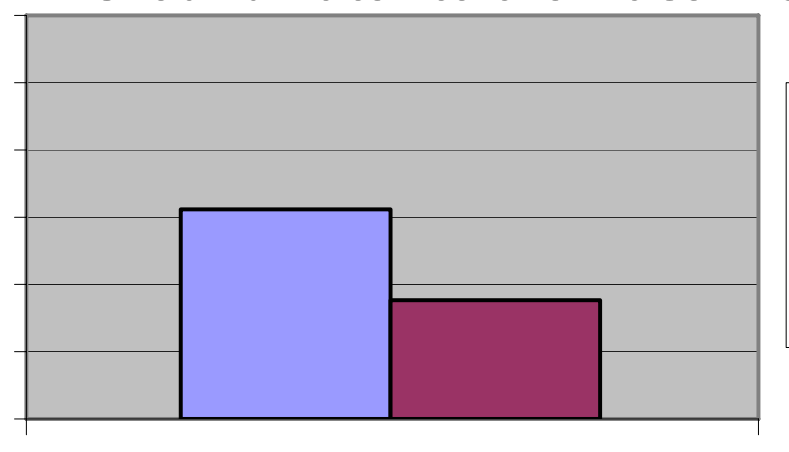

Baseline

Highest Detected Concentration

WQSP-2 Round 22 


\section{Comparison of Detected U-238 in}

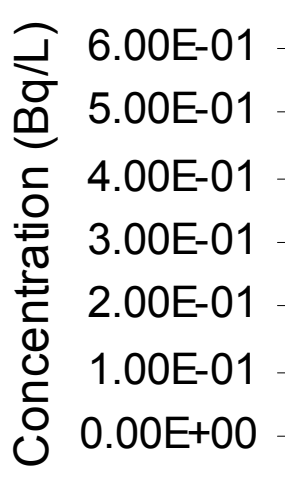

\section{Groundwater to the Baseline}

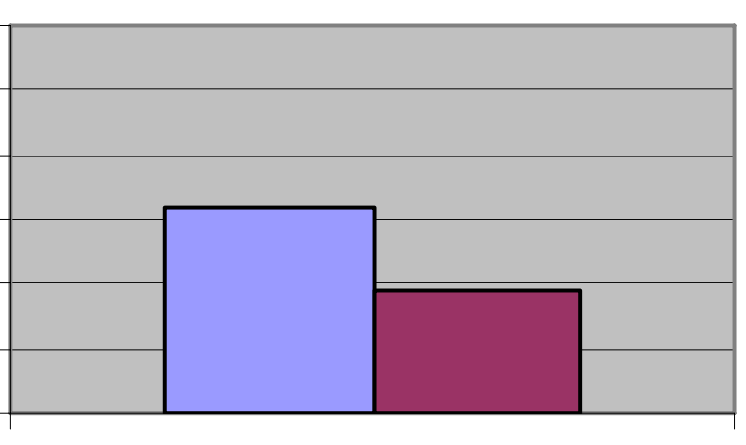

Baseline

Highest Detected Concentration

WQSP 1 Round 22

Comparison of Detected K-40 in

\section{Groundwater to the Baseline}

$6.40 \mathrm{E}+01$

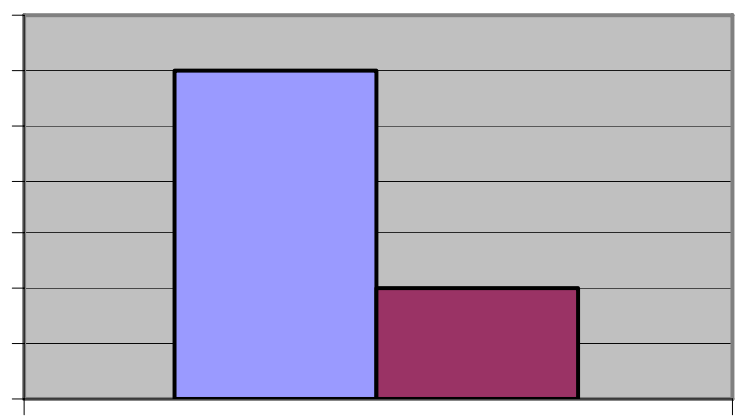

Baseline

$6.20 \mathrm{E}+01$

$6.10 \mathrm{E}+01$

$6.00 \mathrm{E}+01$

$5.90 \mathrm{E}+01$

$5.80 \mathrm{E}+01$

$5.70 \mathrm{E}+01$

WQSP-3 Round 23 


\section{Comparison of Detected U-234 in Surface}

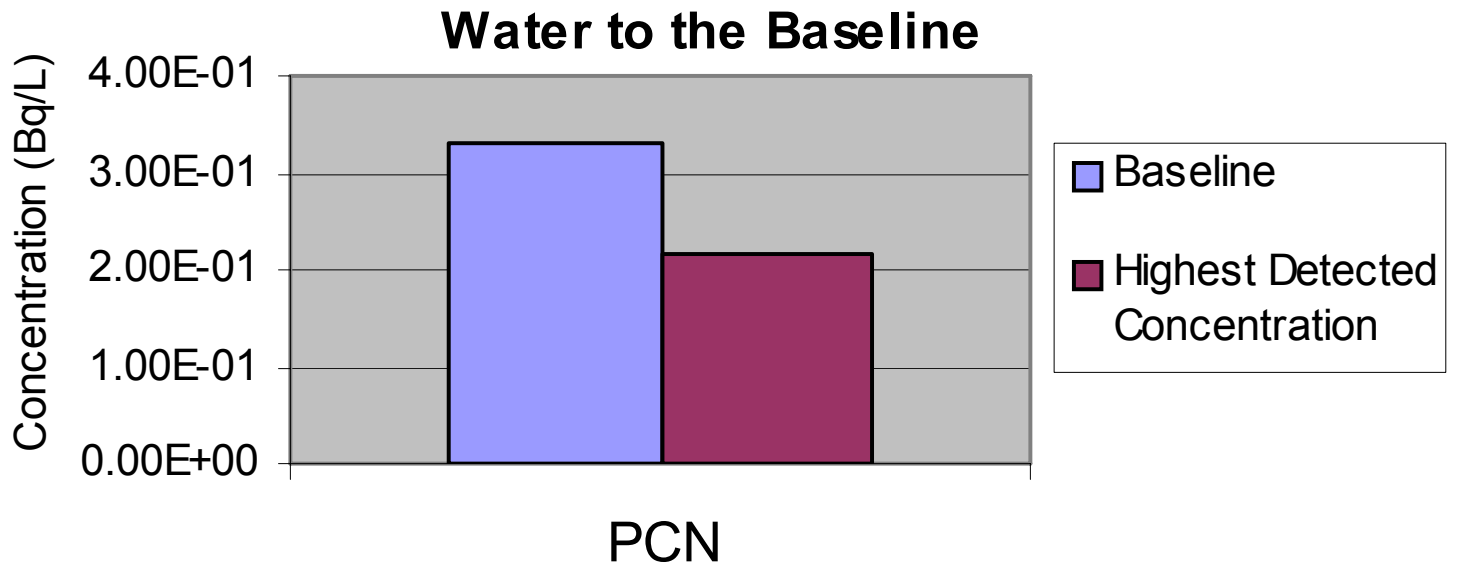

Comparison of Detected U-235 in Surface Water to the Baseline
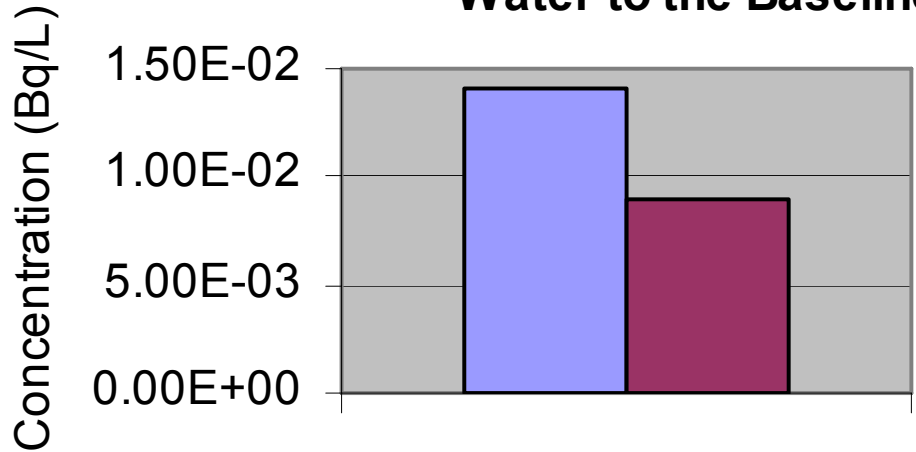

$\square$ Baseline

$\square$ Highest Detected Concentration

\section{PCN}


Comparison of Detected U-238 in Surface Water to the Baseline
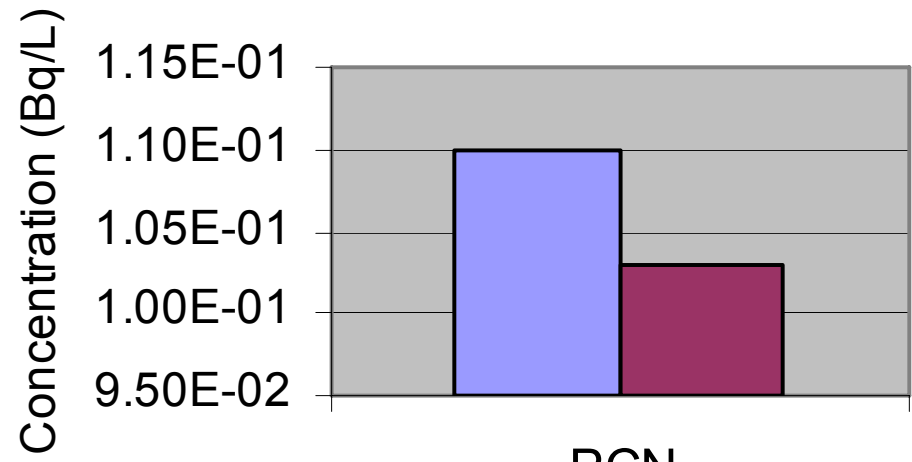

$\square$ Baseline

$\square$ Highest Detected Concentration

PCN

\section{Comparison of Detected K-40 in Surface Water to the Baseline}
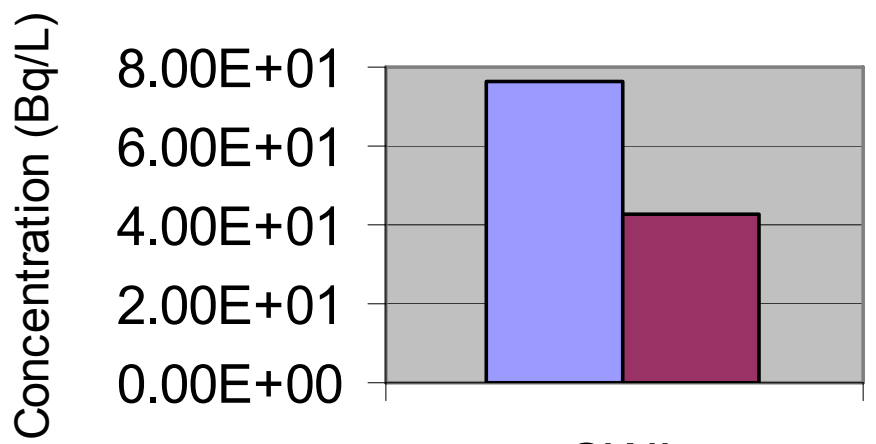

$\square$ Baseline
$\square$ Highest Detected
Concentration

SWL 


\section{Comparison of Detected U-234 in Sediment to} the Baseline

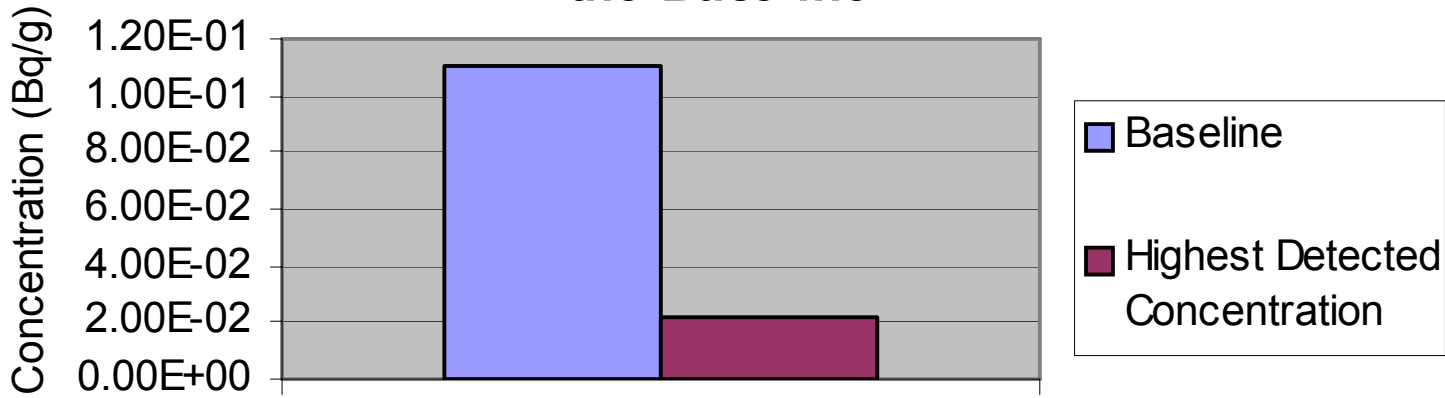

CBD

Comparison of Detected U-235 in Sediment to the Baseline

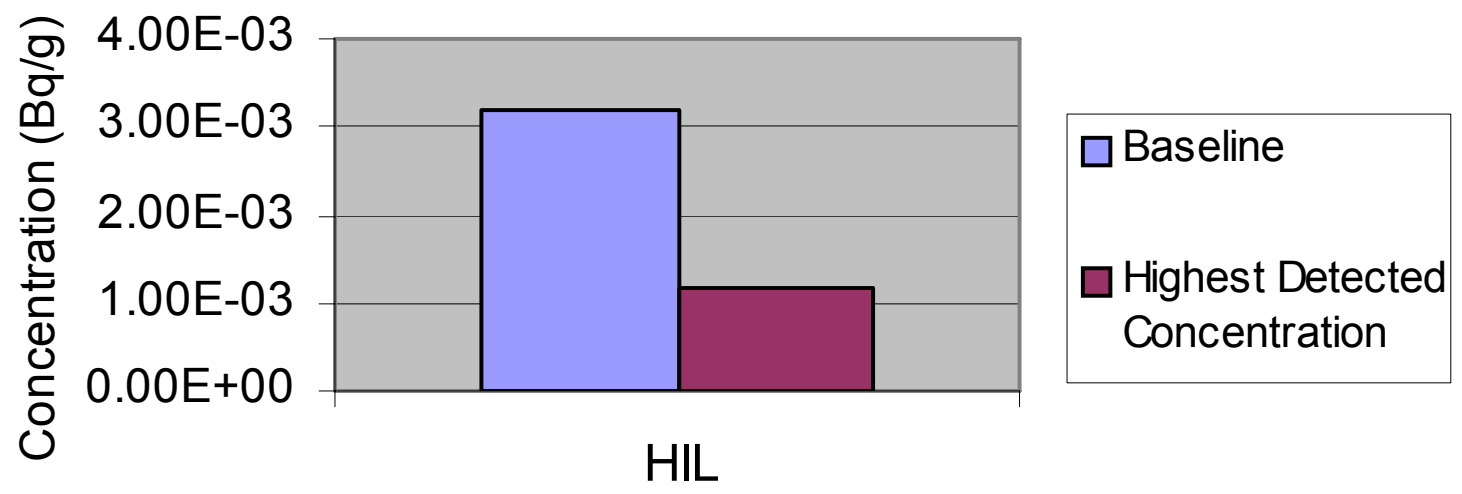




\section{Comparison of Detected U-238 in Sediment to} the Baseline
6.00E-02
$5.00 \mathrm{E}-02$
4.00E-02
$3.00 \mathrm{E}-02$
$2.00 \mathrm{E}-02$
$1.00 \mathrm{E}-02$
$0.00 \mathrm{E}+00$

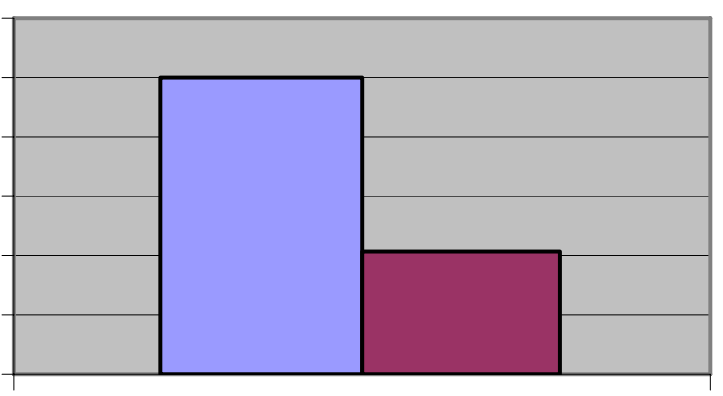

Baseline

Highest Detected

Concentration

\section{TUT}

Comparison of Detected Pu-239+240 in Sediment to the Baseline

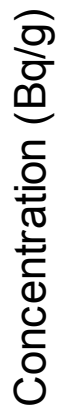

$2.00 \mathrm{E}-03$
$1.50 \mathrm{E}-03$
$1.00 \mathrm{E}-03$
$5.00 \mathrm{E}-04$
$0.00 \mathrm{E}+00$

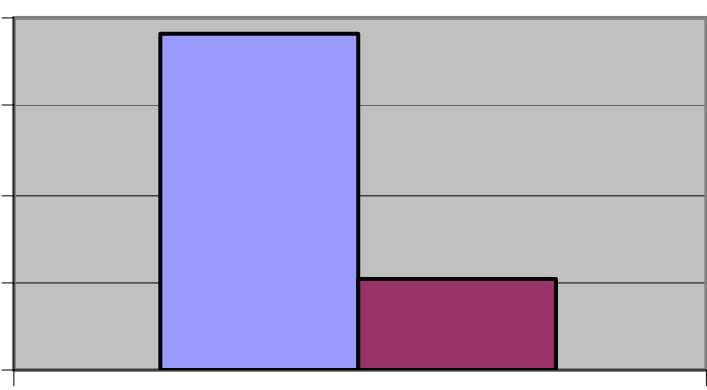

Baseline

$\square$ Highest Detected Concentration

\section{$\mathrm{BHT}$}


Comparison of Detected K-40 in Sediment to

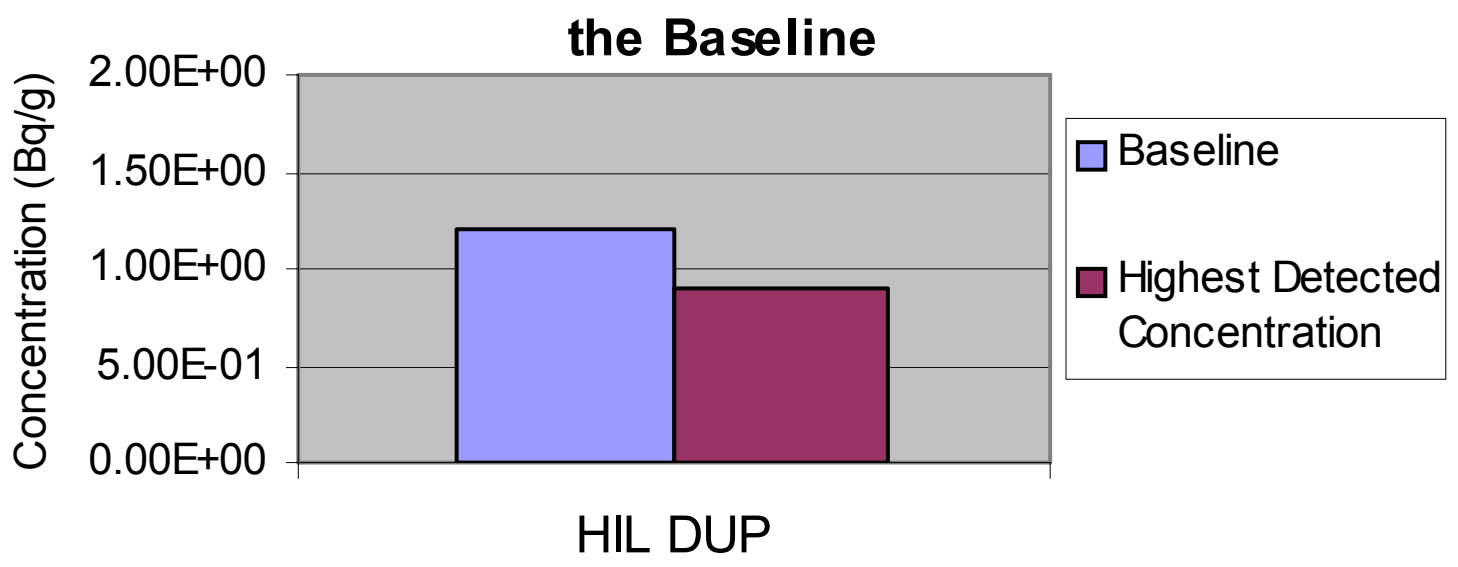

Comparison of Detected Co-60 in Sediment to the Baseline

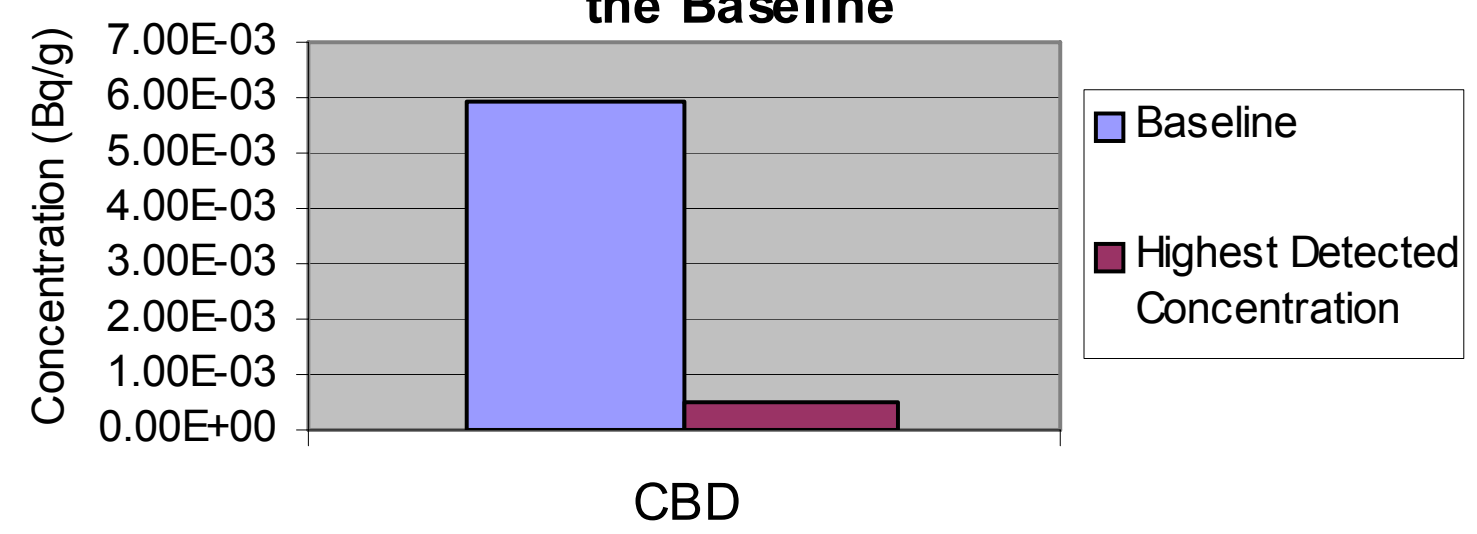


Comparison of Detected Cs-137 in Sediment to the Baseline

Baseline

$\square$ Highest Detected Concentration

\section{$\mathrm{BHT}$}

Comparison of Detected U-234 in Soil to the Baseline

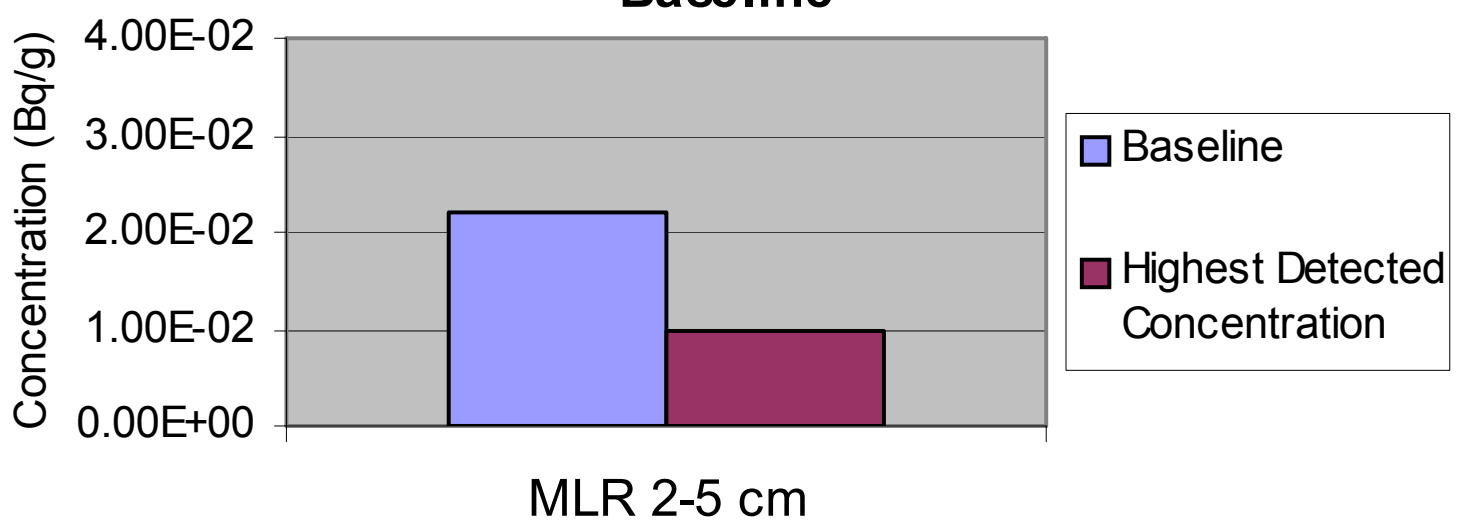


Comparison of Detected U-235 in Soil to the Baseline

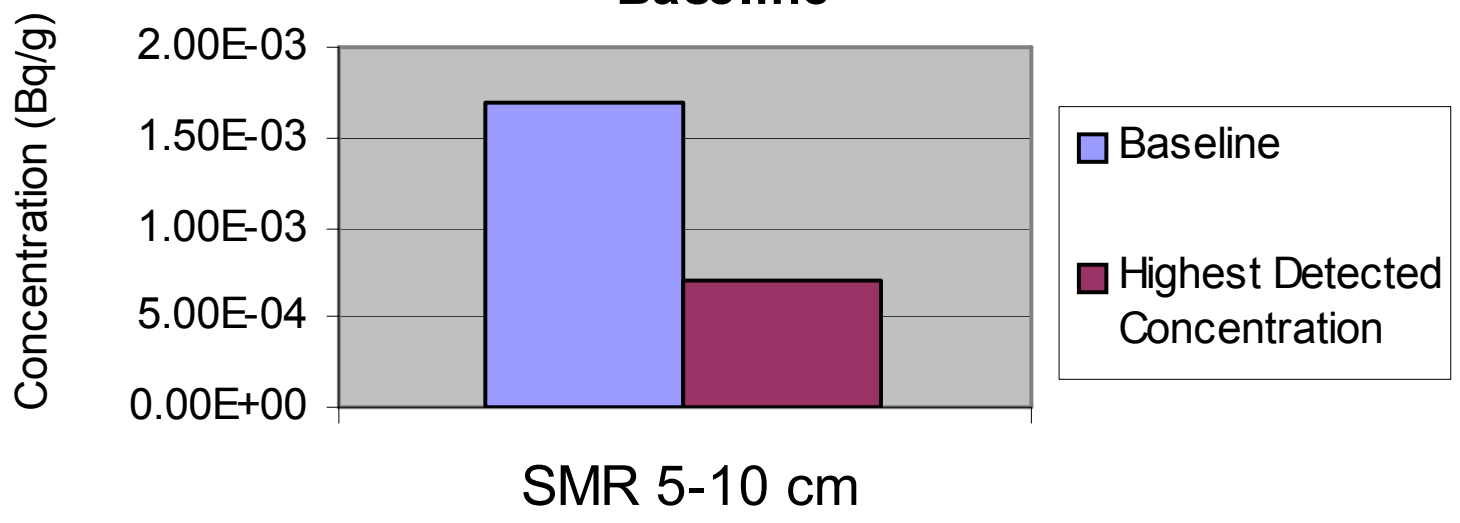

Comparison of Detected U-238 in Soil to the Baseline

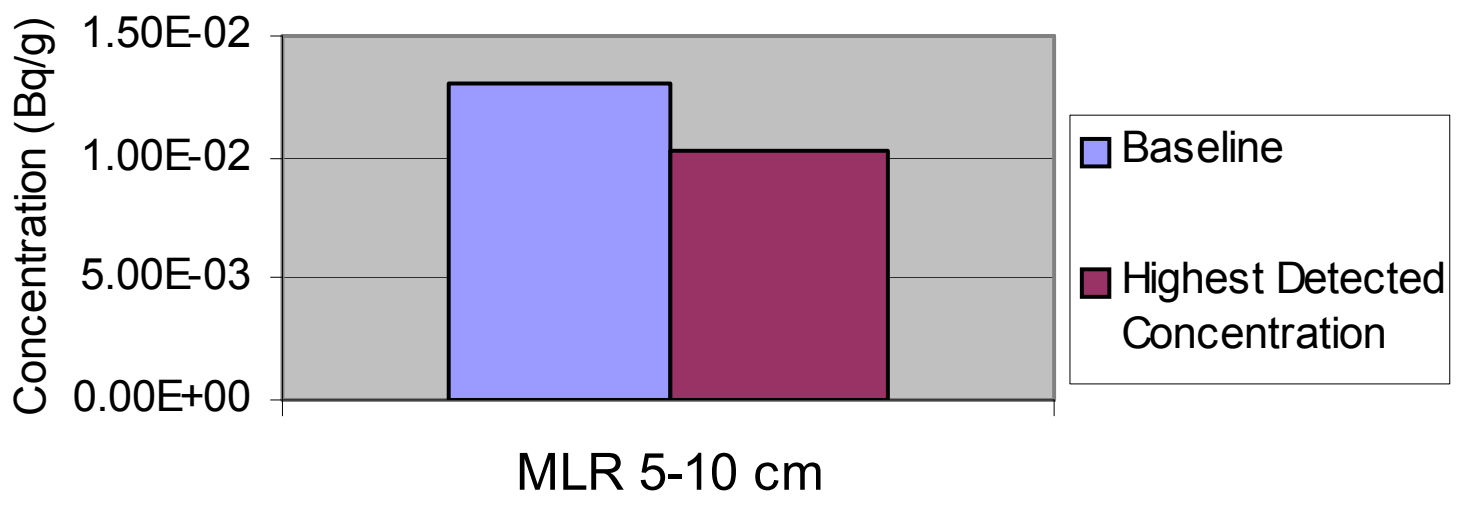


Comparison of Detected Am-241 in Soil to the

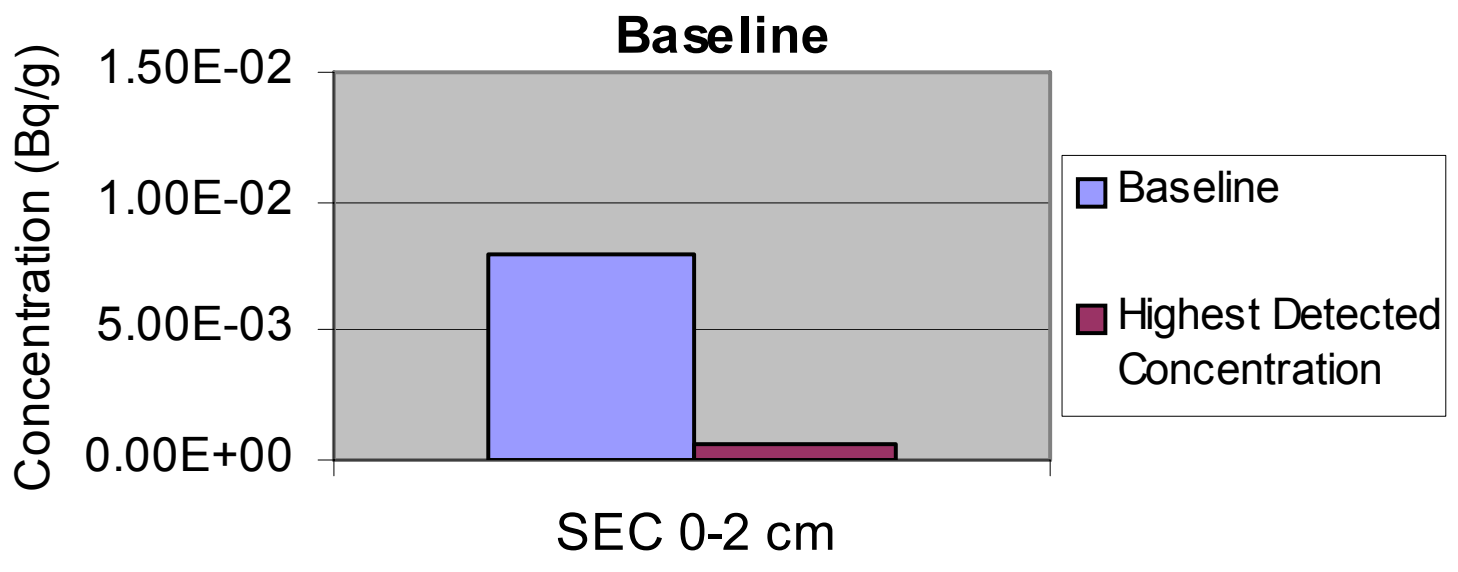

Comparison of Detected Pu-238 in Soil to the

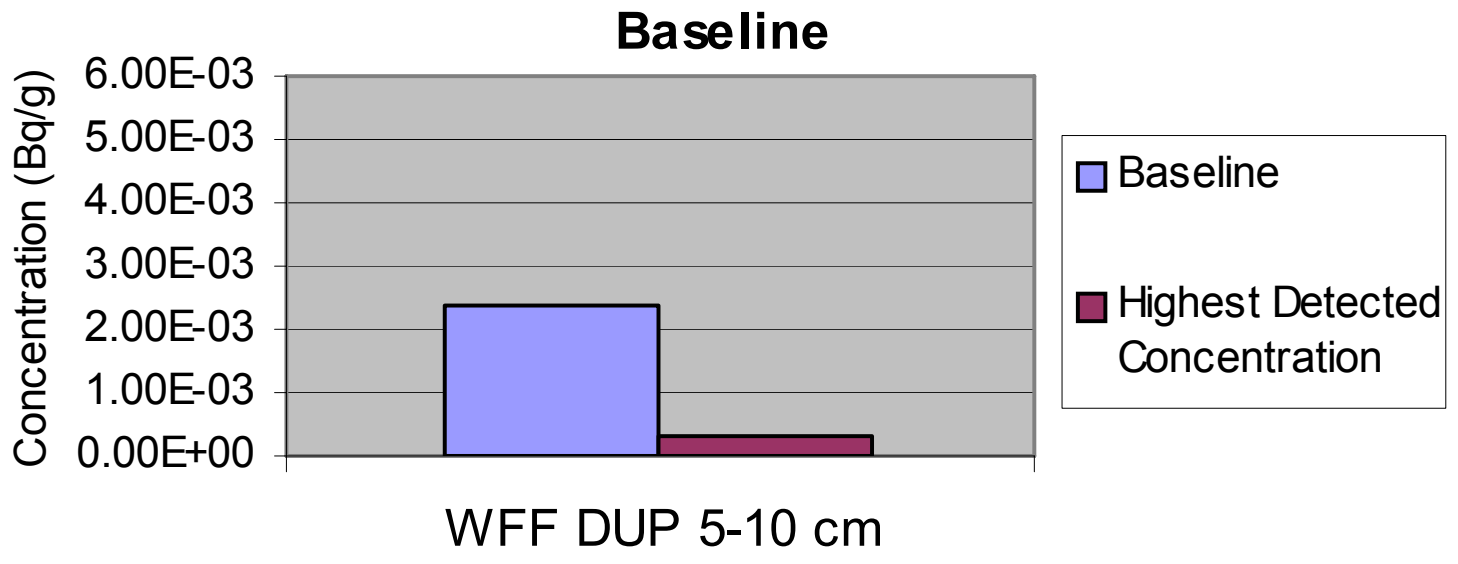


Comparison of Detected Pu-239+240 in Soil to

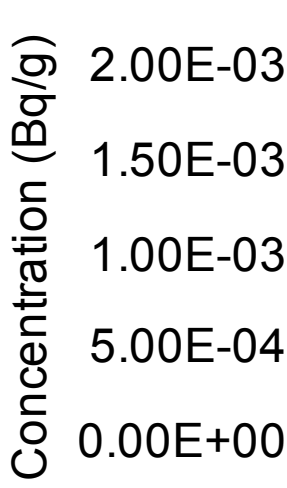
the Baseline

SEC 0-2 cm

Comparison of Detected K-40 in Soil to the Baseline
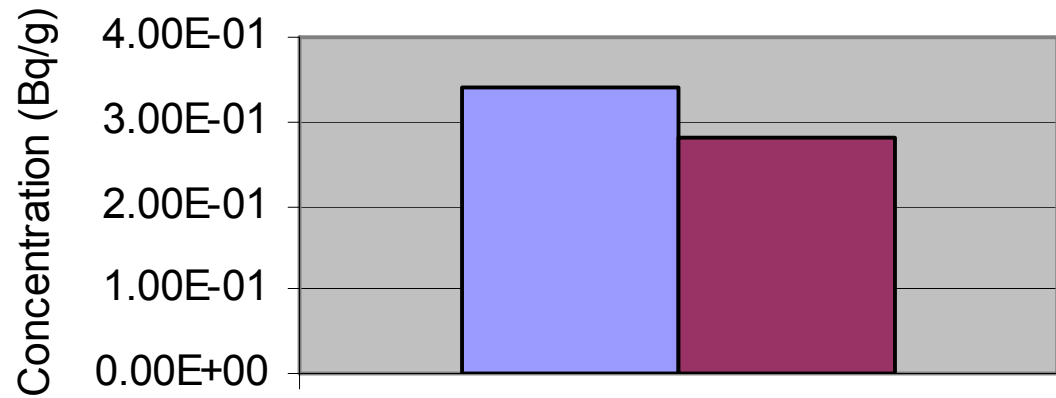

Baseline

Highest Detected Concentration

MLR 5-10 cm 


\section{Comparison of Detected Cs-137 in Soil to the} Baseline

के
$\overline{0}$
9
$\overline{0}$
$\frac{0}{0}$
$\stackrel{0}{0}$
$\overline{0}$
0
0
0

$5.00 \mathrm{E}-02$
$4.00 \mathrm{E}-02$
$3.00 \mathrm{E}-02$
$2.00 \mathrm{E}-02$
$1.00 \mathrm{E}-02$
$0.00 \mathrm{E}+00$

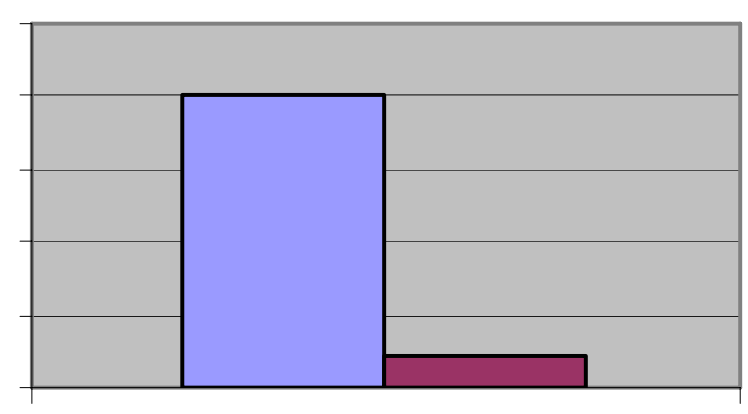

$\square$ Baseline

$\square$ Highest Detected Concentration

SEC $5-10 \mathrm{~cm}$

Comparison of Detected U-238 in Vegetation to the Baseline

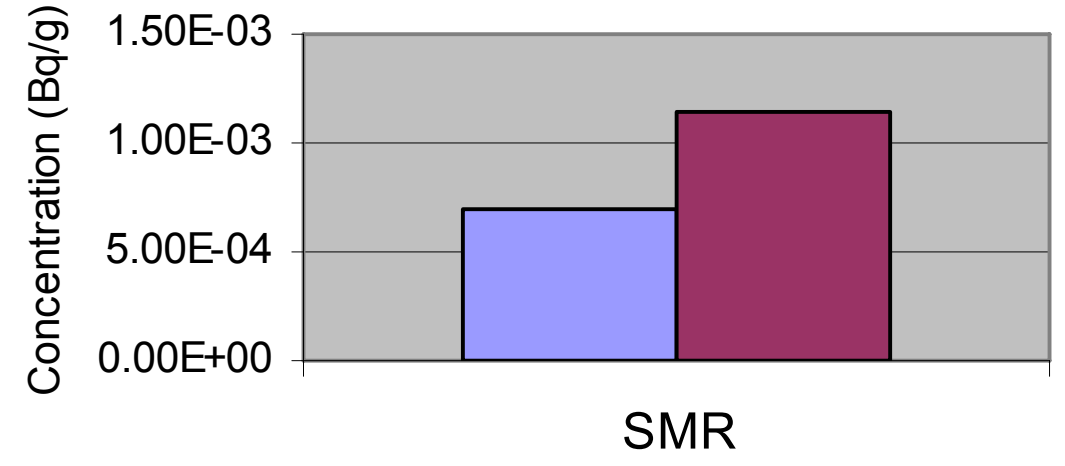

$\square$ Baseline (Mean)

Highest Detected Concentration 


\section{Comparison of Detected K-40 in}

\section{Vegetation to the Baseline}

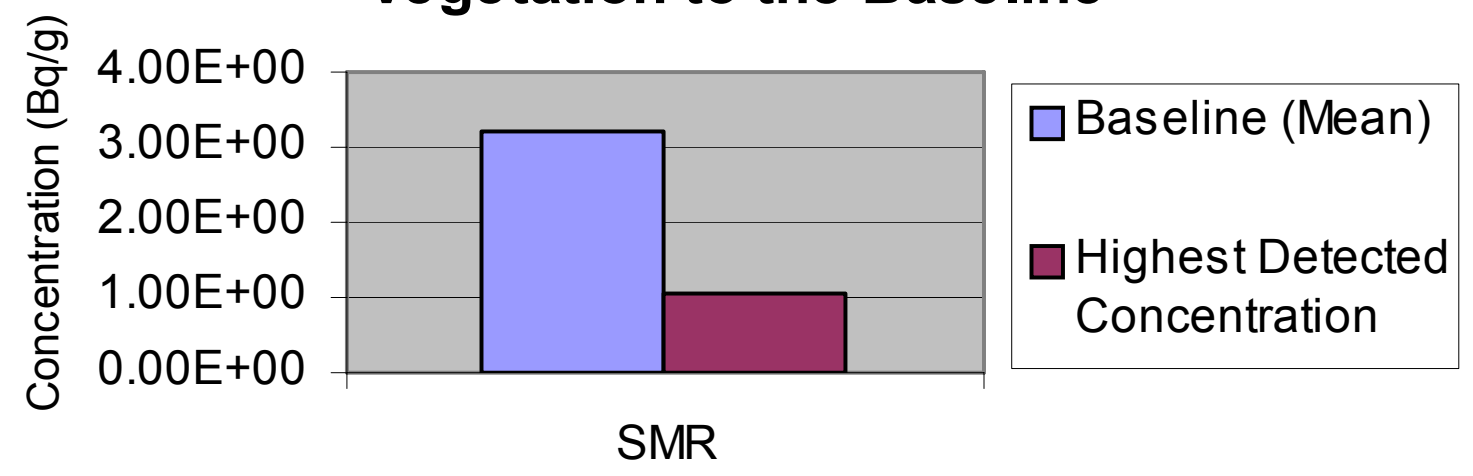

